\title{
Subterranean copepods (Crustacea, Copepoda) from the Pilbara region in Western Australia
}

\author{
T. Karanovic \\ Western Australian Museum, Locked Bag 49, Welshpool DC, WA 6986, Australia
}

\begin{abstract}
Subterranean copepods have been studied from 160 samples (from around 150 different localities) in the Pilbara region, collected by the Department of Conservation and Land Management, Western Australian Museum, mining companies and environmental consultants between 1997 and 2003. A rich and interesting copepod fauna was found in this arid area, comprising 41 species and subspecies classified into 24 genera, seven families and two orders (Cyclopoida and Harpacticoida). The following five genera are new to science: Australoeucyclops (Eucyclopinae), Orbuscyclops (Cyclopinae), Biameiropsis (Ameiridae), Archinitocrella (Ameiridae), and Abnitocrella (Ameiridae). Two new subgenera are also described: Rochacyclops (in the genus Halicyclops Norman, 1903) and Pilbaracyclops (in the genus Fierscyclops Karanovic, 2004). Only 11 species were previously known from the region, so an additional 30 species and subspecies of copepods are reported for the first time in the Pilbara in this monograph. Of them, 23 species and subspecies are described as new to science and ascribed to the following 15 genera: Halicyclops Norman, 1903 (one new species); Australoeucyclops gen. nov. (one species), Mesocyclops Sars, 1914 (one), Orbuscyclops gen. nov. (one), Diacyclops Kiefer, 1927 (four), Fierscyclops Karanovic, 2004 (two), Pseudectinosoma Kunz, 1935 (one), Schizopera Sars, 1905 (two), Parapseudoleptomesochra Lang, 1965 (one), Biameiropsis gen. nov. (one), Archinitocrella gen. nov. (one), Abnitocrella gen. nov. (two), Stygonitocrella Reid, Hunt and Stanley, 2003 (three), Parastenocatis Kessler, 1913 (one), and Elaphoidella Chappuis, 1929 (one new species).

Keys to species worldwide are provided for the genera Stygonitocrella and Australoeucyclops, as well as for the Australian species of Halicyclops, Diacyclops, and Schizopera. Ameiropsis abbreviata Sars, 1911 is transferred into the newly established genus Biameiropsis, and the following four species are transferred into Australoeucyclops: Paracyclops eucyclopoides Kiefer, 1927, P. timmsi Kiefer, 1969, P. waiariki Lewis, 1974, and Eucyclops linderi Lindberg, 1948. Thermocyclops operculifer aberrans Lindberg, 1952 is elevated to specific status and recorded for the first time in Australia. Phyllopodopsyllus thiebaudi Petkovski, 1955 is also reported for the first time from Australia, as are the genera Pseudectinosoma and Stygonitocrella. The small cyclopoid genus Orbuscyclops is one of the exceptions in the family, showing that a reduction in body size is not necessarily closely followed by reductions in the segmentation of thoracic appendages.

Of the 41 species and subspecies five have a cosmopolitan or almost cosmopolitan distribution, another five have a relatively wide distribution (three of them being Australian endemics), while 31 species and subspecies $(76 \%)$ are endemic to the Pilbara region. A very long process of accumulation is likely to be one of the main reasons for such a rich fauna of subterranean copepods, as this part of Australia has been emergent, and hence a freshwater system, since the Precambrian. Representatives of the genera Allocyclops Kiefer, 1931 and Parastenocaris may have invaded the subterranean waters of the Pilbara as early as the Jurassic, because these cosmopolitan genera have no marine relatives and no modern pathways between different continents, making it likely their present distribution is the result of continental drift. Although the majority of species from the Pilbara have a clear freshwater origin, no less than 16 species $(39 \%)$ are marine derived, with their close relatives still flourishing in the marine environment. Some of them are quite recent colonisers, like the representatives of the genera Halicyclops, Schizopera, and Phyllopodopsyllus T. Scott, 1906. The Tethyan connection is clearly recognisable for many taxa and the characters of the first Australian representative of the genus Pseudectinosoma strongly suggests a Tethyan origin of this genus as well. A prominent zoogeographical feature of the Pilbara copepods with a freshwater origin is the Eastern Gondwana connection.
\end{abstract}


Results of this survey are compared with those from the neighbouring Murchison region and some striking differences are revealed. Not a single species endemic to the Murchison was found in the Pilbara and those that occur in both regions are widespread Australian or cosmopolitan species. There are also surprising differences in the copepod genera of the Pilbara and Murchison and similar differences were also observed and reported in fauna other than copepods. The only real connection between these two neighbouring Western Australian regions seems to be the genus Schizopera. A "pulsating desert hypothesis" has been tentatively proposed, that may account for some of the observed differences between the Pilbara and Murchison stygofaunas. During the past episodes of very severe aridity in Australia the real desert would spread westwards from the central part of the continent, perhaps-wiping-out-most-of the stygofauna and forcing the rest to retreat, first towards the coast and then either northwards or southwards of the Tropic of Capricorn. It is noted that the diversity of the three main freshwater harpacticoid families is quite different in Australian subterranean waters from elsewhere. This is explained as a reflection of a different colonisation history of the subterranean freshwater habitats in parts of the former Gondwana and in the Northern Hemisphere.

\section{INTRODUCTION}

In 2002, the Western Australian Department of Conservation and Land Management (CALM) began surveying the biodiversity of terrestrial, aquatic and groundwater habitats of the Pilbara region. This large regional survey was intended to provide an overview of biodiversity in the Pilbara and a context for assessing the significance of localised occurrences of surface and groundwater species. Stygofauna has not previously been included in broadscale biological survey programs in Western Australia (Burbidge et al. 2000) but the lack of information about stygofauna and its distribution in the Pilbara was making it difficult to assess the likely environmental impacts of economically important natural resource development projects. While identifying copepods collected during this survey, I have also taken the opportunity to review all samples of unidentified copepods collected previously by the Western Australian Museum, mining companies and environmental consultants from the region. The total number of samples available to me was 160 , collected between 1997 and 2003 from all over the Pilbara. This is very similar to the number of samples (164) I had previously studied from the neighbouring Murchison region of Western Australia (Karanovic 2004a). I have compared results from the Pilbara with those from the Murchison, even though the biological survey in the former is far from complete. Nevertheless, I believe a significant proportion of the subterranean copepod diversity (at least on generic level) from the region has now been documented, because collecting has occurred across the region and all major calcrete bodies have been sampled. Surface water habitats are scheduled for sampling later during the biological survey and descriptions of new surface water copepods may be presented in the future.

Bordered by the Indian Ocean to the west, the
Ashburton River to the south and sandy deserts to the east and north, the Pilbara natural region (Figure 116) has a total area of almost $185,000 \mathrm{~km}^{2}$. It is also recognised as one of the regions of the Eremaean Botanical Province and sometimes is called the Fortescue Botanical District (Beard 1975). For the purpose of this study the entire Ashburton River catchment was included with the Pilbara, as well as the area to the east around Lake Disappointment (which is the only part of the area investigated with internal drainage). Geologically, the Pilbara region is situated on the Pilbara Craton, which together with Yilgarn Craton forms the Western Shield (Beard 1998), an area that has been emergent since the Precambrian. The Pilbara Craton is part of the oldest non-marine landscape on Earth (Bird and Chivas 1988), and consists mostly of Proterozoic and Archaean rocks (with the exception of some minor superficial sediments). It lies between two sedimentary basins: the Canning Basin to the northeast and the Carnavon Basin to the southwest (Beard 1975). The region is everywhere arid, with average rainfall varying from 180 to 300 $\mathrm{mm}$ per annum. The highest rainfall is around the mountain massif of the Hamersley Range, where many summits exceed $900 \mathrm{~m}$ in altitude and one (Mt Meharry) reaches $1235 \mathrm{~m}$ to be the highest peak in Western Australia. Climatic conditions in the Pilbara are dominated to a greater degree than in any other part of Western Australia by tropical cyclones during summer months and predominantly from January to March (Beard 1975). The drainages of most major rivers were formed during the Late Cretaceous to Early Tertiary and are very well preserved because of the tectonic stability of the area and because a change from a humid to an arid climate during the Tertiary slowed down erosion and sedimentation (Van de Graaff et al. 1977). This Early Tertiary climatic change was probably due to changes in oceanic circulation caused by the drifting apart of Australia and Antarctica. 
The Pilbara region can be physiographically divided into four major types: 1 ) the coastal plains; 2) the moderately elevated interior; 3) the broad valleys of the larger rivers (e.g. the De Grey, Fortescue and Ashburton); and 4) sandstone islands (namely the Montebello Group, Barrow Island, Dampier Archipelago and their satellites) (Storr 1984). Because of the low rainfall and brief wet season, watercourses flow for only short periods but surface water is fairly plentiful (for an arid zone) owing to the frequency of river pools and waterholes. In this dry region there is frequently very little soil in the ordinary sense, and in the explanatory notes to the soil maps there is a common expression "extensive areas in this unit without soil cover". Groundwater and soil calcrete (terrestrial limestone) is a habitat for stygofauna in the Pilbara (Humphreys 1999, 2001), just as it is in the neighbouring Murchison region (Karanovic 2004a) but the narrow coastal strip of sandstone (soft dune limestone) and alluvium are also very important. In Aboriginal times the region, except for offshore islands that were uninhabited, was thinly populated (Beard 1975), with very reduced intensity of occupation during the Last Glacial Maximum (Marwick 2002). European settlers gradually occupied the region with flocks of sheep and cattle and to mine minerals from the 1860 s onwards but the area has remained sparsely populated and only about 40,000 people $(39,676$ estimated by the Australian Bureau of Statistics for 2000/2001) live in the Pilbara. Today, large areas have been protected in three major national parks: Millstream-Chichester, Karijini and Rudall River.

The Pilbara was recognised as one of the major Australian centres of biological endemism (Cracraft 1991, Crisp et al. 1999), even before the investigation of stygofauna in Western Australia started. It was not until the last decade or so that Australian subterranean waters started to be investigated systematically (Humphreys 1993). Now, the Western Australian arid zone is recognised to include one of the world's more diverse and notable subterranean faunas, including a number of higher order taxa variously new to science (e.g. Wilson and Ponder 1992, Poore and Humphreys 1992, 1998, Yager and Humphreys 1996, Danielopol et al. 2000, Jaume and Humphreys 2001, Jaume et al. 2001). Also, a number of stygal copepods have been described from ancient freshwater as well as from anchialine waters (see Karanovic 2004a). The first published records of the Pilbara copepods are those by Pesce et al. (1996a), who described Metacyclops mortoni and Mesocyclops brooksi as new species from the Ashburton River catchment and also reported Microcyclops varicans (Sars, 1863) from the same area. At the same time Pesce and De Laurentiis
(1996) described Diacyclops humphreysi from a number of localities near Exmouth (Cape Range region) and also from two localities near Onslow in the Pilbara. Subsequently the same authors (De Laurentiis et al. 1999) described one species of the genus Halicyclops Norman, 1903 ( $H$. rochai) and two species of the genus Diacyclops Kiefer, 1927 (D. reidae and $D$. einslei). They also emended and corrected the description of Diacyclops humphreysi Pesce and De Laurentiis, 1996, based on wider collecting in the Pilbara, and reported Microcyclops varicans, Metacyclops mortoni Pesce, De Laurentiis and Humphreys, 1996 and Mesocyclops brooksi from some additional localities in the region. Lee and Huys (2002) reported the first harpacticoid from the Pilbara, as a new genus and new species in the family Ameiridae Monard, 1927 (Inermipes humphreysi), from Barrow Island. The same island yielded the first representative of the genus Allocyclops Kiefer, 1932 from Australia, which I described (Karanovic 2003) as a new species, $A$. (Psammocyclops) consensus. Holyńska and Brown (2003) reported Mesocyclops brooksi and two previously unrecorded species of Mesocyclops Sars, 1914 (M. notius Kiefer, 1981 and $M$. darwini Dussart and Fernando, 1988) for this region - from the Fortescue Marsh, a very large, episodically flooded water body. Halse et al. (2002b) listed several copepod taxa from five springs in the Pilbara, mostly identified to the generic level. Finally, one new species of the genus Metacyclops (M. pilbaricus) was described by Karanovic (2004b) from the Newman Borefield. Altogether 11 species of copepods are known from the Pilbara, 10 of which are cyclopoids and only one a harpacticoid. All these species are listed in this monograph, some are redescribed and some reported from new localities.

The fragmentary preliminary research suggested a very rich copepod stygofauna in the Pilbara, and stygofauna in general, and this was one of the main reasons for CALM undertaking the current regional biological survey. Results to date from the additional sampling confirm early impressions and additional 31 species of copepods are reported for the Pilbara in this monograph, most of them new to science. Five new genera and two new subgenera are also described.

\section{MATERIAL AND METHODS}

The approximate surface of the area investigated is $185,000 \mathrm{~km}^{2}$, which is only slightly more than the area of the Murchison region, presented in my previous monograph (Karanovic 2004a). In total 160 samples containing copepods, from around 150 different localities, were studied. Locality data and number of specimens are listed and numbered for every species separately and all the material is 
deposited in the Western Australian Museum, Perth. Localities are only mentioned by their number from the list in the Discussion section for each species (for example: "one female from locality 8 has ...").

Samples were collected with haul-nets (mesh size $50,150,250$ or $350 \mu \mathrm{m}$ ) from bores and wells. Bores are holes mainly made by mining companies in the purpose of water monitoring and abstractions or mineral exploration. They are usually 10 to $20 \mathrm{~cm}$ in diameter and-ma-y-be-lined entirely,-or in part, by PVC tubing (the casing). This tubing may be open only at the bottom, or it may be pierced at one or more levels by holes of various sizes ("slots"). The top may be securely capped or entirely open to the elements. Some bores record the water pressure at a given level in the aquifer (piezometers), while others, together with hand dug wells (ca. $1 \times 1.5 \mathrm{~m}$ ) equipped with windmills, provide water for pastoral use. Many of these features are derelict. Haul-nets are actually simple plankton nets of a different size suitable for the bore; collar can range from 30 to $200 \mathrm{~mm}$ in diameter and is made of stainless steel. Weighed nets (using simple fishing leads, or more complicated brass intermediate collars) were lowered down into the bore with one bottle screwed on its distal part then hauled through the water column, usually a number of times. The Bou-Rouch pump and KaramanChappuis methods were used for sampling stygofauna from the interstitial habitats (mostly near permanent springs). Water chemistry was analysed both in the field (using Yeo-Kal 611 water quality analyser) and in the laboratory (using many different techniques) and will be presented elsewhere, after completion of the survey. The samples were sorted live under a dissecting microscope and the copepods picked out and fixed in $70 \%$ or $100 \%$ ethanol and assigned a field number (Prefix BES for the Museum samples). Many bores established for hydrogeological work, mineral exploration and water monitoring have prefixes or suffixes of relevance only to that drilling program. These codes are cited in the examined material for each species to aid specification of the location.

Specimens were dissected and mounted on microscope slides in Faure's medium, which was prepared following the procedure discussed by Stock and Vaupel Klein (1996), and dissected appendages were then covered by a coverslip. For the urosome or the entire animal two human hairs were mounted between the slide and coverslip, so the parts could not be compressed. By manipulating the coverslip carefully by hand, the whole animal or a particular appendage could be positioned in different aspects, making possible the observation of morphological details. During the examination water slowly evaporated and appendages eventually remained in completely dry Faure's medium, ready for a long term depositing. All drawings were prepared using a drawing tube attached to a Leica-DMLS brighfield compound microscope, with C-PLAN achromatic objectives. Specimens that were not drawn were examined in a mixture of equal parts of distilled water and glycerol and, after examination, were again preserved in $70 \%$ ethanol.

Morphological terminology follows Huys and Boxshall (1991), except for small differences in the spelling of some appendages (antennula, mandibula, maxillula instead of antennule, mandible, maxillule), as an attempt to standardise the terminology for homologue appendages in different crustacean groups. Also, for the armature formula of swimming legs a much simplified version is used. The only reason for this is that there are a number of transitional forms between spine and seta in copepods. To avoid possible confusion in some descriptions I sometimes use the term "armature element" (or just "element") instead of spine or seta. When a particular appendage or a structure is not mentioned in the description (usually paragnaths) it means it was not observed, but when a drawing is missing and the appendage is described in the text it means that it was observed but it was not drawn, either because it was very badly mounted or it is almost identical to the same appendage of another species from the same genus in the monograph. Biospeleological terminology follows Humphreys (2000b).

\section{SYSTEMATICS}

Order Cyclopoida Sars, 1886

Family Cyclopidae Burmeister, 1834

Subfamily Halicyclopinae Kiefer, 1927

Genus Halicyclops Norman, 1903

Subgenus Rochacyclops subgen. nov.

\section{Diagnosis}

Moderately large Halicyclopinae, with robust habitus and greatest width near posterior end of cephalothorax. First pedigerous somite completely incorporated into cephalothorax. Hyaline fringes of prosomites narrow and smooth, and somites without pronounced lateral expansions. Genital double somite in female without ventrolateral cuticular windows or recesses, with sharply or bluntly serrated hyaline fringe; copulatory pore small and seminal receptacle very small, heart shaped. Abdominal somites (except anal one) with serrated hyaline fringe, both in female and male; pseudoperculum not well developed. Caudal rami short, 0.7 to 1.3 times as long as wide; innermost apical seta well developed, considerably longer 
than ramus; lateral seta arising from proximal part of ramus. Antennula six-segmented in female and 12- or 13-segmented in male. Antenna foursegmented, with or without short seta representing exopod and with five lateral elements on second endopodal segment, one of which extremely long. Mandibula with palp reduced to small protuberance, which bears two setae; distal seta much longer than proximal. Maxillula composed of well developed praecoxa and twosegmented palp (endopod sometimes partly or completely fused). Maxilla four-segmented, not prehensile. Maxilliped two segmented; armed with three setae on protopod and five setae on endopod. All swimming legs with threesegmented exopod and endopod; third exopodal segment spine formula 3.4.4.3 or 3.4.3.3; second endopodal segment of first leg with one inner seta and on other legs with two inner setae; all armature elements on third endopodal segment of fourth leg spiniform, inner apical spine somewhat longer than outer. Sexual dimorphism in armature of swimming legs not unusual. Seta at inner-distal corner of coxa of fourth leg much smaller than same seta on other swimming legs. Fifth leg with basis and endopod fused to somite; exopod onesegmented and armed with three strong spines and one apical seta in female, three spines and three setae (two additional setae along inner margin) in male. Sixth leg in male armed with three or two elements.

\section{Type species}

Halicyclops rochai De Laurentiis, Pesce and Humphreys, 1999

\section{Other species}

Halicyclops caridophilus Humes, 1947, Halicyclops tetracanthus Rocha, 1995, Halicyclops cenoticola Rocha, Iliffe, Reid and Suarez-Morales, 1998 and Halicyclops calm sp. nov.

\section{Etymology}

The subgenus is named in honour of Dr Carlos Eduardo Falavinga da Rocha, from the University of São Paulo, in recognition of his numerous recent contributions to the knowledge of the halicyclopinae copepods. His family name is prefixed to the existing generic name Cyclops. Gender masculine.

\section{Halicyclops (Rochacyclops) rochai De Laurentiis, Pesce and Humphreys, 1999 Figures 1-4}

\section{Synonymy}

Halicyclops rochai sp. nov. - De Laurentiis et al., 1999: 245, Figures 1-21.

\section{Material Examined}

1) Australia, Pilbara, Little George River, bore NWCHSLK1180, 15 November 2002, leg. J. Cocking and M. Scanlon (CALM), 20 58'14"S 117 05'30"E: two males + one female in alcohol (WAM C25060)

2) Australia, Pilbara, Eramura Creek, bore NWCHSLK1033, 13 November 2002, leg. J. Cocking and M. Scanlon (CALM), 21 ${ }^{\circ} 03^{\prime} 31^{\prime \prime S} 116^{\circ} 15^{\prime} 42 \mathrm{E}$ : one male + one copepodid in alcohol (WAM C25061)

3) Australia, Pilbara, Barrow Island, bore L8, 11 August 2002, leg. G. Humphreys (BIOTA) $20^{\circ} 49^{\prime} 04^{\prime \prime} \mathrm{S} 115^{\circ} 23^{\prime} 35^{\prime \prime} \mathrm{E}$ : one female. (CY 308) dissected by Jane McRae on one slide (WAM C25062)

4) Australia, Pilbara, Robe River, bore G70730101, 17 June 2003, leg. J. Cocking and M. Scanlon (CALM), 2134'32"S 115052'58"E: one copepodid in alcohol (WAM C25063)

5) Australia, Pilbara, Barrow Island, bore L8, 22 October 1998, leg. W.F. Humphreys and S.M.

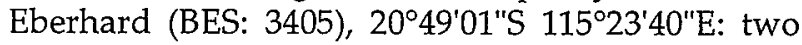
females in alcohol (WAM C25064)

6) Australia, Pilbara, Barrow Island, bore L8 (taken at midpoint, old water supply well, $150 \mathrm{~mm}$ casing), 13 January 1999, leg. K. Hallett (BES: 6971), $20^{\circ} 49^{\prime} 02^{\prime \prime S} 115^{\circ} 23^{\prime} 42^{\prime \prime} \mathrm{E}$ : one female in alcohol (WAM C25065)

7) Australia, Pilbara, Barrow Island, Bore M5N (taken at midpoint, new unused well, $100 \mathrm{~mm}$ casing), 13 January 1999, leg. K. Hallett (BES: 6997), $20^{\circ} 48^{\prime} 37^{\prime \prime S} 115^{\circ} 24^{\prime} 36^{\prime \prime} \mathrm{E}$ : one male + one copepodid in alcohol (WAM C25066)

8) Australia, Pilbara, Barrow Island, bore C65 (deep south), 24 October 1998, leg. W.F. Humphreys and S.M. Eberhard (BES: 3447), 20 $52^{\circ} 56^{\prime \prime} S$ $115^{\circ} 23^{\prime} 06^{\prime \prime} \mathrm{E}$ : one male dissected on one slide (WAM C25067) + one female dissected on two slides (WAM C25068)

9) Australia, Pilbara, Barrow Island, bore C77J, 24 October 1998, leg. W.F. Humphreys and S.M.

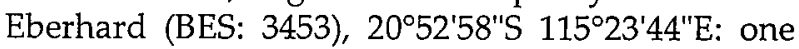
female dissected on two slides (WAM C25069)

10) Australia, Pilbara, Robe River, bore G70730103, 14 November 2002, leg. J. Cocking and M. Scanlon (CALM), 2132'59"S 115'51'50"E: three females in alcohol (WAM C25070)

11) Australia, Pilbara, Robe River, bore G70730104, post-purge, 14 November 2002, leg. J. Cocking and M. Scanlon (CALM), 21 ${ }^{\circ} 34^{\prime} 53^{\prime \prime} S$ 115'52'14"E: two males + three females + one copepodid in alcohol (WAM C25071)

12) Australia, Pilbara, Robe River, bore G70730104, pre-purge, 14 November 2002, leg. J. Cocking and M. Scanlon (CALM), 21 ${ }^{\circ} 34^{\prime} 53^{\prime \prime} S$ $114^{\circ} 52^{\prime} 14^{\prime \prime} \mathrm{E}$ : two males + one female + one copepodid in alcohol (WAM C25072)

13) Australia, Pilbara, Robe River, bore G70730104, post-purge II, 14 November 2002, leg. J. Cocking and M. Scanlon (CALM), 21⒊ $34^{\prime} 53^{\prime \prime S}$ 
$114^{\circ} 52^{\prime} 14^{\prime \prime} \mathrm{E}$ : one male + three females in alcohol (WAM C25073)

14) Australia, Pilbara, Ord Ranges, bore GNHSLK1664, 17 November 2002, leg. J. Cocking and M. Scanlon (CALM), 20'20'20"S 119 07'26"E: 16 males +14 females + eight copepodids in alcohol (WAM C25074)

15) Australia, Pilbara, Robe River, bore G70730101, 14 November 2002, leg. J. Cocking and M. Scanlon (CALM), 21⒊'32"S 115 52'58"E: one female in_alcohol(WAM_25075)

16) Australia, Pilbara, Barrow Island, bore MW17, 10 August 2002, leg. G. Humphreys (BIOTA) $20^{\circ} 46^{\prime} \mathrm{S} 115^{\circ} 28^{\prime} \mathrm{E}$ : one copepodid (CY 306) dissected on one slide by Jane McRae (WAM C25076)

17) Australia, Pilbara, Barrow Island, bore AMW20, 10 August 2002, leg. G. Humphreys (BIOTA): one female (CY 307) dissected on one slide by Jane McRae (WAM C 28635)

18) Australia, Pilbara, Robe River, bore G70730101，4 April 2003, leg. J. Cocking and M. Scanlon (CALM), 21⒊'32"S 115'52'58"E: one male + one female in alcohol (WAM C 28636)

19) Australia, Pilbara, Robe River, Yarraloola Station, bore PANNASLK4, 5 April 2003, leg. J. Cocking and M. Scanlon (CALM), 21 ${ }^{\circ} 37^{\prime} 59^{\prime \prime} S$ $115^{\circ} 57^{\prime} 41$ "E: two copepodids in alcohol (WAM C 28637)

20) Australia, Pilbara, Barrow Island, bore F11, 25 October 1998, leg. W.F. Humphreys and S.M. Eberhard (BES: 3463), 2050'46"S 115²2'23"E: one male dissected on two slides (WAM C 28638)

\section{Redescription}

Female. Habitus robust (Figure 1A), with prosome/urosome ratio 1.72 and greatest width at $2 / 3$ of cephalothorax length. Body length/width ratio about two; cephalothorax about three times as wide as genital double somite. Free pedigerous somites without pronounced lateral expansions. Colour of preserved specimen yellowish. Nauplius eye not visible. Rostrum well developed, membranous, broadly rounded and furnished with two large sensilla.

Cephalothorax 0.9 times as long as its greatest width; represents $46 \%$ of total body length. Surface of cephalic shield with few large sensilla; no other ornamentation visible. Hyaline fringe of prosomites narrow and smooth. Fifth pedigerous somite with two large dorsal sensilla and with smooth fringe dorsally and ventrally (Figure 1B).

Genital double somite (Figure 1B, E) 0.9 times as long as wide, ornamented with four large sensilla dorsally (two at middle, two near posterior margin). Hyaline fringe of genital double and two subsequent somites frilled and bluntly serrated. No cuticular recesses ventrolaterally on posterior half of genital double somite or spiniform processes laterally. Copulatory pore small; copulatory duct narrow and short, rigidly sclerotized. Seminal receptacle very small, heart-shaped (Figure $1 \mathrm{E}$ ). Ovipores situated dorsolaterally, covered by reduced sixth legs, bearing two minute spines and one smooth seta (Figure 1B). Third urosomite with pair of dorsal sensilla near posterior margin. Fourth urosomite without ornamentation. Anal somite with smooth, broad and almost straight anal operculum, which represents $57 \%$ of somite's width; ornamented with two large sensilla dorsally and transverse row of spinules on posterior margin.

Anal sinus widely opened, ornamented with two diagonal rows of minute spinules (Figure 1B).

Caudal rami (Figure 1B and 2G) 1.3 times as long as wide, parallel, with space between them about one half of ramus' width. Distal margin ventrally with small protuberance medially, which seems to be a cuticular tube pore. One arched row of large spinules present ventrolaterally near posterior margin; another row of somewhat smaller spinules dorsally, at base of dorsal seta (Figure 1B). Dorsal seta very long, about six times as long as ramus, inserted on protuberance overreaching border of ramus, uniarticulate at base and plumose distally. Lateral seta arising at distal end of proximal fourth, positioned dorsolaterally, uniplumose and shorter than ramus. Outermost apical seta slender, about 1.7 times as long as ramus, pinnate distally. Innermost apical seta also slender, about 1.2 times as long as outermost apical one, pinnate along inner margin. Principal apical setae with breaking plane; inner seta about 1.9 times as long as outer one, and 0.68 times as long as body.

Antennula (Figure 2D) slightly shorter than cephalothorax length, six-segmented, with slender aesthetascs on fourth and sixth segments and setal formula: 8.12.5.6.2.9. One stout seta at distal outer corner of first segment and one on sixth segment articulating on basal part; no setae with breaking plane and all setae slender (no spiniform or very short setae). Most setae smooth, only nine setae (21\%) plumose or pinnate at their distal parts. Length ratio of antennular segments, from proximal end and along caudal margins, $1: 1.3: 0.7: 2.2: 1.3: 1.8$.

Antenna (Figure $2 \mathrm{C}$ ) four-segmented, comprising very reduced and unarmed coxa (mostly fused with basis), basis and two-segmented endopod. Basis ornamented with short row of spinules at proximal inner part; armed with two pinnate setae at distal inner corner and with smooth seta representing exopod; exopodal seta just over half the length of basis, while other two setae only slightly shorter than basis. First endopodal segment armed with one pinnate seta at middle. Second endopodal segment about twice as long as first, ornamented with two longitudinal rows of spinules along caudal surface (some very long) and armed with five lateral and seven apical setae; one lateral seta extremely long, about 1.4 times as long as segment. 


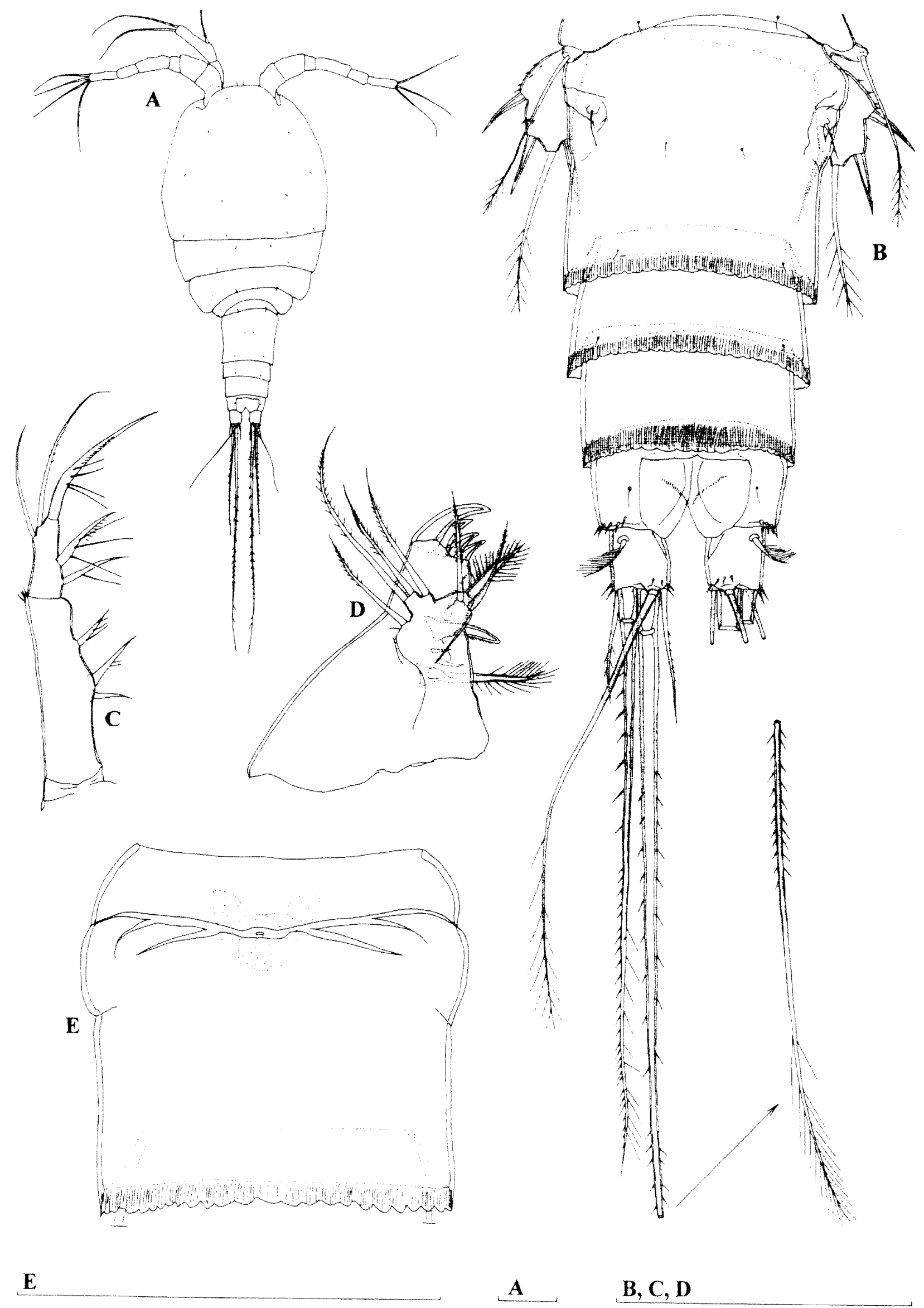

Figure 1 Halicyclops (Rochacyclops) rochai De Laurentiis, Pesce and Humphreys, 1999, female $(0.558 \mathrm{~mm})$ from locality 8 (WAM C25068): A, habitus, dorsal view; B, urosome, dorsal view; C, maxilliped; D, maxillula; E, genital double somite, ventral view. Scales $=0.1 \mathrm{~mm}$. 


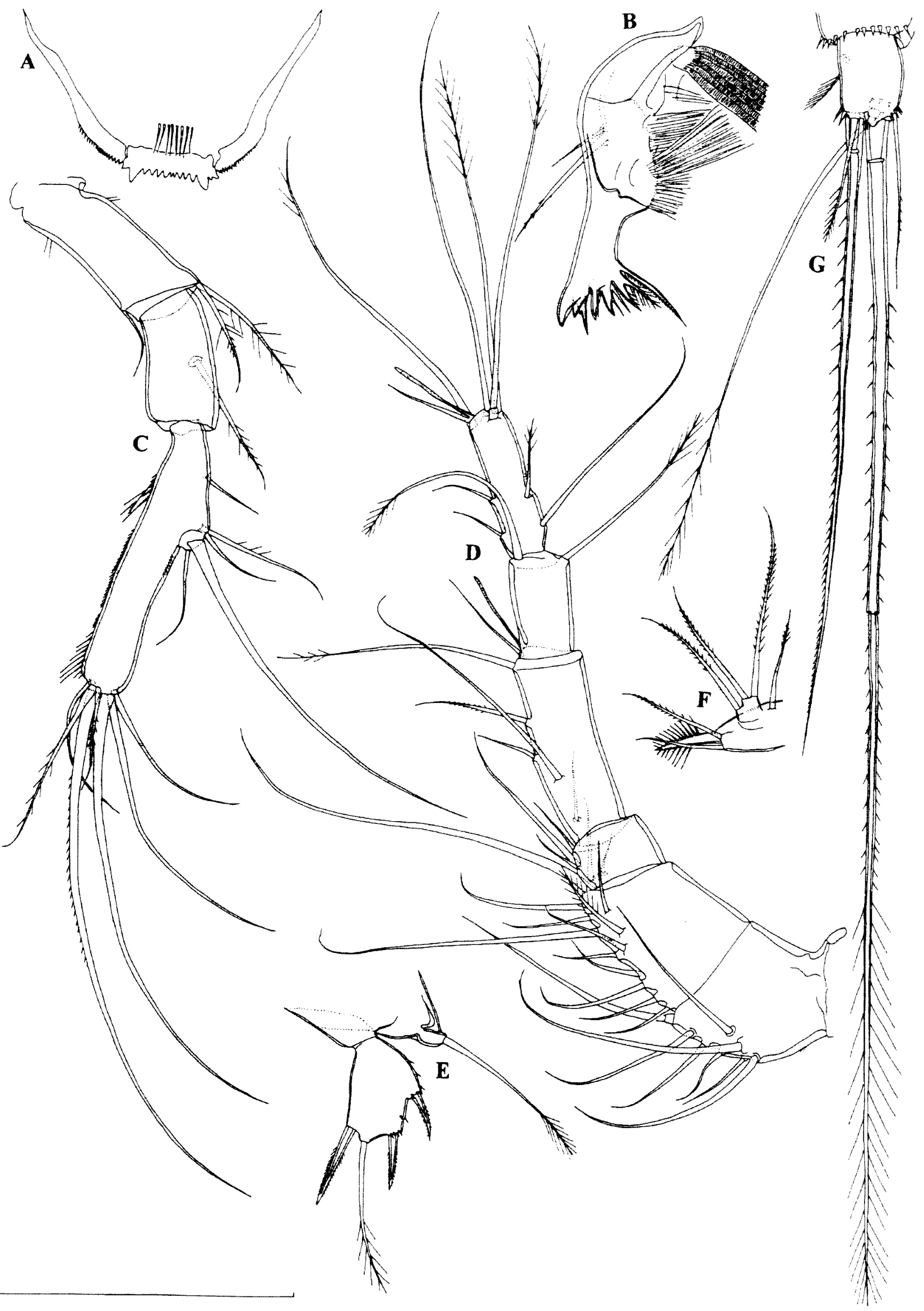

Figure 2 Halicyclops (Rochacyclops) rochai De Laurentiis, Pesce and Humphreys, 1999, A-F, female $(0.558 \mathrm{~mm})$ from locality 8 (WAM C25068); G, female (0.608 mm) from locality 9 (WAM C25069): A, labrum; B, mandibula; C, antenna; D, antennula; $E$, fifth leg; F, maxillular palp; $G$, right caudal ramus, ventral view. Scale $=0.1 \mathrm{~mm}$. 
Labrum (Figure 2A) trapezoidal, omamented with short row of eight long, slender spinules on ventral surface, with short row of minute spinules along lateral sides and with finely serrated distolateral margin. Cutting edge slightly concave, with 13 blunt teeth. No other ornamentation visible.

Mandibula (Figure $2 \mathrm{~B}$ ) with palp reduced to small protuberance, which bears two setae; distal seta pinnate distally, almost 2.2 times as long as proximal smooth seta but not reaching gnathobasal teeth. Coxal gnathobase cutting edge clearly divided into three regions: inner group of four complex smooth teeth, innermost tooth strongest, outermost sharpest; middle group of four simple smooth teeth and two spinules; outer group of two strongly pinnate teeth and outermost pinnate seta. Gnathobasal seta about 1.4 times as long as proximal seta on reduced palp.

Maxillula (Figure $1 \mathrm{D}$ and $2 \mathrm{~F}$ ) composed of well developed praecoxa and one-segmented palp. Arthrite of praecoxa with four apical, strong, short and smooth spines. Praecoxa armed with seven armature elements along inner margin, longest one plumose. Palp with completely or only partly fused endopod, bearing two apical and one lateral pinnate setae; armed laterally with one exopodal pinnate seta and apically with two slender, pinnate setae and one robust, strongly bipinnate spine

Maxilla (Figure 3F) four-segmented but praecoxa fused to coxa on posterior surface. Proximal endite of praecoxa armed with two setae (one plumose, other pinnate distally); distal endite very small, unarmed. Proximal endite of coxa with one short pinnate seta; distal endite highly mobile and bearing one proximal, completely fused and very stout seta and one distal, smaller seta. Seta fused to endite ornamented with three elongated spinules. Basis expanded into spinulose claw and armed with two setae; strong seta longer than claw. Endopod armed with two spinulose and two smooth setae. Longer endopodal spinulose seta about as long as strong seta on basis; shorter endopodal spinulose seta about 2.2 times as long as longer endopodal smooth seta. Both endopodal spinulose setae, as well as claw and strong seta on basis, with most proximal spinules longer than subsequent spinules in row.

Maxilliped (Figure 1C) two-segmented, armed with three setae on protopod and five setae on endopod, and ornamented with bunch of spinules near distal margin of protopod. Proximal protopodal seta smooth; middle seta strong, pinnate and about 1.5 times as long as proximal one; distal protopodal seta about as long as proximal one, ornamented with three long spinules. Two lateral and innermost apical endopodal setae very stout and with several very long spinules. Middle apical seta longest one, pinnate, and about 1.4 times as long as outermost, smooth, apical seta. Protopod about 2.3 times as long as endopod.

All swimming legs with three-segmented exopod and endopod (Figure 3A, B, C, D). Armature formula (legend: inner/outer spine or seta; inner/ terminal/outer):

\begin{tabular}{lcccccc} 
& \multicolumn{3}{c}{ Exopod } & \multicolumn{3}{c}{ Endopod } \\
Segments & 1 & 2 & 3 & 1 & 2 & 3 \\
First leg & $1 / 1$ & $1 / 1$ & $3 / 2 / 3$ & $1 / 0$ & $1 / 0$ & $3 / 2 / 1$ \\
Second leg & $1 / 1$ & $1 / 1$ & $4 / 2 / 3$ & $1 / 0$ & $2 / 0$ & $3 / 2 / 1$ \\
Third leg & $1 / 1$ & $1 / 1$ & $4 / 2 / 3$ & $1 / 0$ & $2 / 0$ & $3 / 2 / 1$ \\
Fourth leg & $1 / 1$ & $1 / 1$ & $4 / 2 / 2$ & $1 / 0$ & $2 / 0$ & $2 / 2 / 1$
\end{tabular}

Third exopodal segment spine formula: 3.4 .4 .3 . Intercoxal sclerite of first swimming leg with two bunches of delicate hairs; all other intercoxal sclerites without visible ornamentation. Coxae unornamented (except on first leg, where coxa bears short row of spinules along posterior margin) but armed with pinnate seta at inner distal corner; pinnate seta very short on fourth leg (Figure 3D). Spine inserted at inner, protruded corner of basis of first leg reaching halfway of second endopodal segment (Figure $3 \mathrm{~A}$ ). All setae slender and plumose, except for two modified setae on fourth leg endopod. Third endopodal segment of fourth swimming leg about 2.5 times as long as wide; inner apical spine about 1.3 times as long as outer one; two inner setae spiniform, bipinnate and with three very long spinules proximally (Figure 3D).

Fifth leg (Figures $2 \mathrm{E}$ and $3 \mathrm{E}$ ) with basis and endopod completely fused to somite; outer basal seta inserted on elongate basal protuberance (about twice as long as wide) and pinnate distally. Exopod about 1.5 times as long as wide, with smooth inner margin and a few small spinules along outer margin; several small spinules present at base of outer spines. Armature consists of three strong spines and one apical seta; inner apical spine slightly shorter than segment, about 1.5 times as long as outer apical spine and 1.6 times as long as outer proximal spine. Exopodal apical seta plumose at distal end, about 1.5 times as long as segment and 0.9 times as long as basal seta.

Sixth leg indistinct triangular plate, armed with two almost equal, smooth spines fused to plate, and one smooth, much longer seta.

Male. Habitus robust, with prosome/urosome ratio 1.9 and greatest width at posterior end of cephalothorax. Body length/width ratio about 2.3; cephalothorax about 2.5 times as wide as genital somite.

Cephalothorax as long as its greatest width. Ornamentation of prosomites, colour and nauplius eve similar to those of female. Fifth pedigerous somite ornamented with five sensilla dorsally (Figure $4 B$ ). Hyaline fringe of fifth pedigerous somite smooth; that of genital somite bluntly serrated and frilled dorsally; those of other urosomites (except anal one) bluntly serrated and 


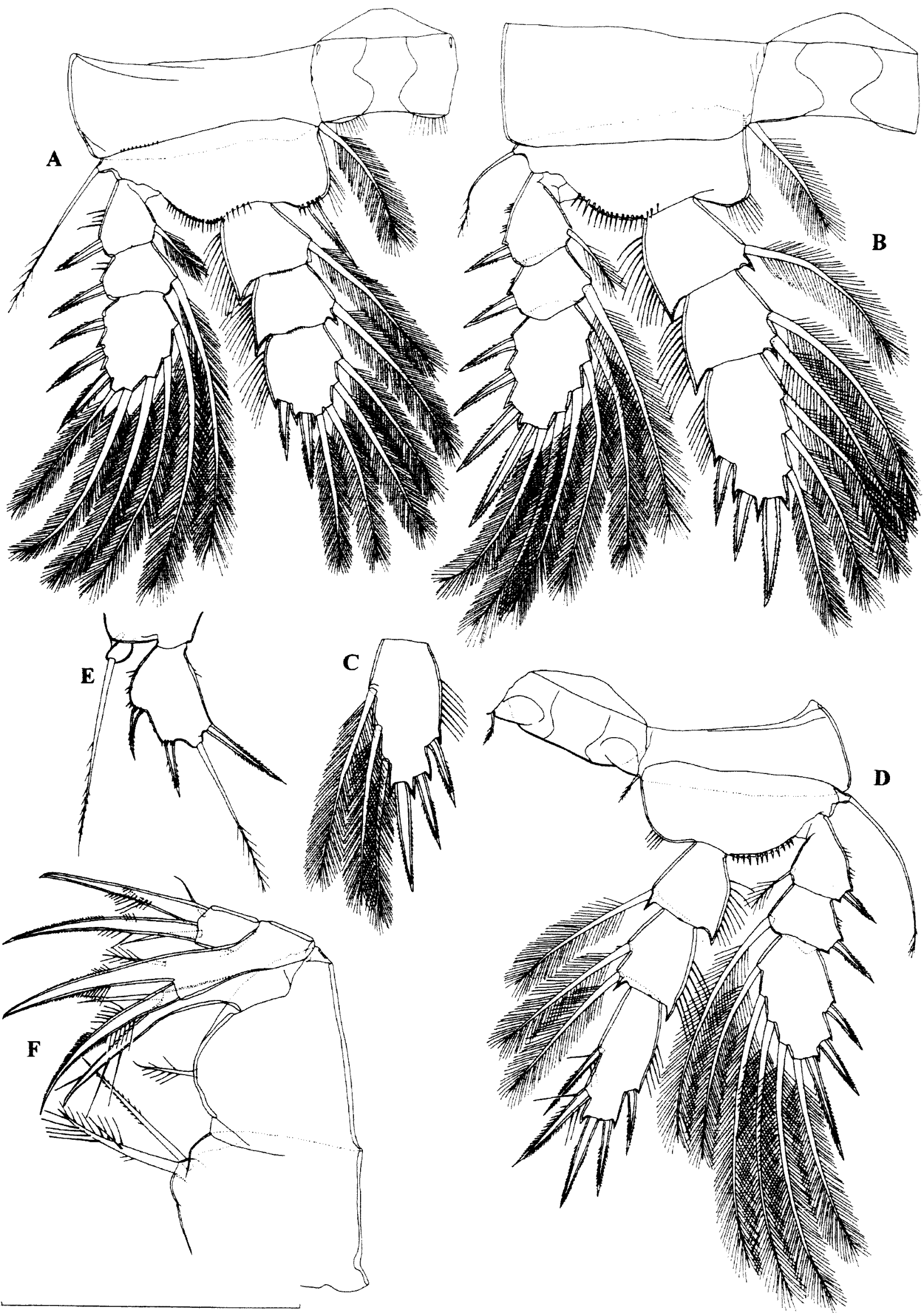

Figure 3 Halicyclops (Rochacyclops) rochai De Laurentiis, Pesce and Humphreys, 1999, A-D and F, female (0.558 $\mathrm{mm}$ ) from locality 8 (WAM C25068); E, female $(0.608 \mathrm{~mm}$ ) from locality 9 (WAM C25069): A, first swimming leg; B, second swimming leg; C, third endopodal segment of third swimming leg; D, fourth swimming leg; $E$, fifth leg; F, maxilla. Scale $=0.1 \mathrm{~mm}$. 


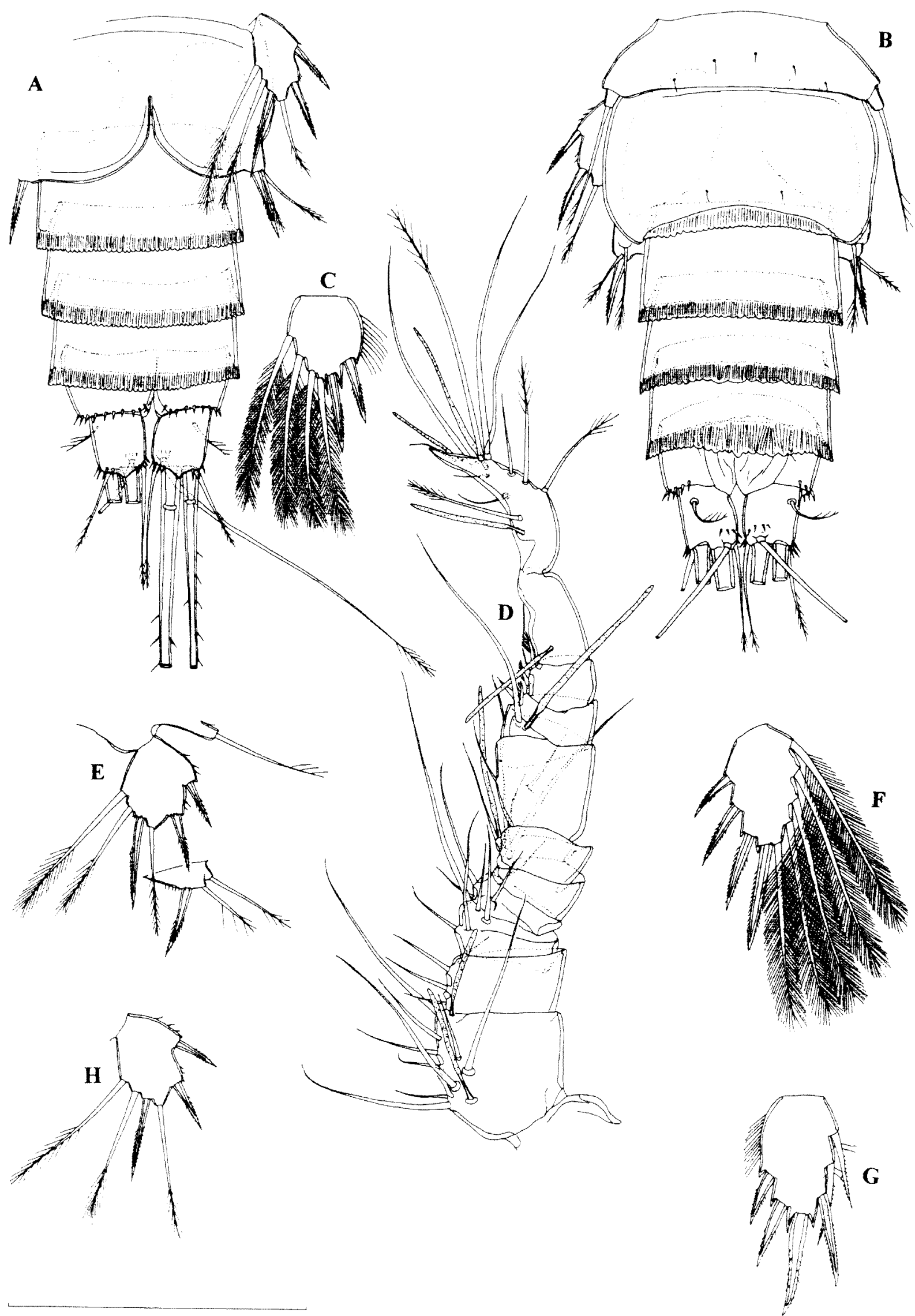

Figure 4 Halicyclops (Rochacyclops) rochai De Laurentiis, Pesce and Humphreys, 1999, A, B and D-F, male (0.467 $\mathrm{mm}$ ) from locality 20 (WAM C28638); C, male $(0.538 \mathrm{~mm}$ ) from locality 7 (WAM C25066); G and $\mathrm{H}$, male $(0.463 \mathrm{~mm}$ ) from locality 8 (WAM C25067): A, urosome, ventral view; B, urosome, dorsal view; C, third endopodal segment of first swimming leg; D, antennula; $E$, fifth and sixth legs; $F$, third exopodal segment of third swimming leg; $G$, third endopodal segment of second swimming leg; $H$, fifth leg. Scale $=0.1 \mathrm{~mm}$. 
frilled both dorsally and ventrally. Dorsal hyaline fringe of preanal somite slightly produced posteriorly in form of pseudo-operculum, and more strongly serrated (Figure 4B).

Genital somite ornamented with two dorsal sensilla; third urosomite without any ornamentation; fourth urosomite with two dorsal sensilla; fifth somite unornamented. Anal somite with smooth, somewhat concave and very broad anal operculum, which represents $54 \%$ of somite's width; ornamented with two sensilla dorsally and transverse row of spinules on posterior margin. Anal sinus widely opened, without surface ornamentation.

Caudal rami (Figure 4A, B) about 1.2 times as long as wide, almost parallel, with little space between them. Armature and ornamentation similar to female.

Antennula (Figure 4D) of almost equal length to cephalothorax, 12-segmented, geniculate, with geniculation between eleventh and twelfth segments. Aesthetasc formula: 2.0.0.0.0.1.0.1.0.0.1.3. All aesthetascs slender and long. Setal formula: 9.4.5.4.2.2.2.2.2.2.0.11. Setae on ninth and tenth segments characteristically modified, spiniform. Only seven setae pinnate distally (four on twelfth segment and three of the spiniform setae), and only five setae on twelfth segment articulating on basal part.

Antenna, labrum, mandibula, maxillula, maxilla, maxilliped and swimming legs (Figure 4C, F) similar to female.

Fifth leg (Figure 4E, H) exopod about 1.2 times as long as wide, ornamented with two short rows of small spinules on outer margin, and with several small spinules at base of spines. Armature consists of three spines and three setae. Inner apical spine as long as segment, about 1.5 times as long as outer apical spine and 1.8 times as long as outer proximal spine. Exopodal proximal inner seta about 1.2 times as long as distal inner seta, which is slightly longer or as long as exopodal apical seta. Exopodal apical seta about as long as basal one. All setae pinnate.

Sixth leg (Figure 4A, E) distinct large plate, armed with one spine and two pinnate setae; ornamented with short row of spinules at base of spine. Outer seta 1.4 times as long as inner seta and about 1.3 times as long as spine.

\section{Variability}

Body length of females ranges from $0.51 \mathrm{~mm}$ to $0.808 \mathrm{~mm}(0.629 \mathrm{~mm}$ average; $\mathrm{n}=12)$, while in males it ranges from $0.463 \mathrm{~mm}$ to $0.538 \mathrm{~mm}(0.489$ $\mathrm{mm}$ average; $\mathrm{n}=7$ ). Innermost spine on the female fifth leg can be somewhat longer or shorter (Figure $2 \mathrm{E}$ and $3 \mathrm{E}$ ), as can the innermost apical seta on the caudal rami (Figure $1 B$ and $2 \mathrm{G}$ ). One male from locality 8 has all armature elements on the outer margin of the third endopodal segment of second leg spiniform (Figure $4 G$ ) and the fifth leg with less ornamentation than usual (Figure 4H). No other type of variability was observed.

\section{Discussion}

The subfamily Halicyclopinae Kiefer, 1927 currently encompasses more than 90 valid species and subspecies, classified into six genera (Boxshall and Halsey 2004; Karanovic 2004a). They mostly inhabit interstitial water of beaches, anchialine caves, coastal lagoons and estuaries (Rocha et al 2000), although some are known to be comensal on lobsters (Humes 1947) or to inhabit inland waters with increased salinity (Karanovic 2004a). The subfamily is clearly divided into two groups: one encompassing the genera Neocyclops Gurney, 1927 and Troglocyclops Rocha and Iliffe, 1994 and the other encompassing the genera Halicyclops Norman, 1903, Colpocyclops Monchenko, 1977, Smirnoviella Monchenko, 1977 and Prehendocyclops Rocha, Iliffe, Reid and SuárezMorales, 2000. The first group is characterised by a number of symplesiomorphies, including the first pedigerous somite partly distinct, the female antennula composed of more than six segments, the antenna five-segmented, the maxilliped four- or five-segmented, the fifth leg of the female threesegmented and the lateral seta on caudal rami arising distally on the ramus. The genus Troglocyclops is represented by a single species, described from an anchialine cave in the Bahamas (Rocha and Iliffe 1994) and is the most primitive genus of Halicyclopinae. Petkovski (1986b) divided the genus Neocyclops into two subgenera, on the base of the segmentation of male fifth leg alone. His new subgenus, Protoneocyclops Petkovski, 1986, encompasses seven species with four-segmented male fifth legs, while Neocyclops s. str. has six species with the same appendage three-segmented. However, three species of Neocyclops remain unascribed to either of the two subgenera, because their males are unknown (De Laurentiis et al. 1997, Rocha et al. 2000). It should be mentioned here that the armature of the male fifth leg is exactly the same in both Neocyclops s. I. subgenera.

The other four Halicyclopinae genera are more derived and very closely related. For example, they all have exactly the same shape of the female fifth leg. Halicyclops is a cosmopolitan genus, with more than 70 species and subspecies described (Karanovic 2004a), and is the most primitive of the four. Prehendocyclops, with three species, is nowadays apparently confined to Mexican cenotes (Rocha et al. 2000) and it can be distinguished from Halicyclops by modifications of antenna and mouth parts, as well as by differently shaped caudal rami. Modifications of antenna and mouth parts are the only characters that separate Smirnoviella and Colpocyclops from Halicyclops. These two genera, 
with two species each (Monchenko 1974, 1997a, b, 1978, 1982), probably evolved from one or two Halicrclops-like ancestral forms in estuaries connected to the Caspian and Black Sea. However, because the original descriptions of many Halicyclops species are very basic and lack details of mouth parts or/and antenna, one should not be surprised if detailed redescription of some species reveal their close relationship with Smimoviella or Colpocyclops. Even Monchenko (1978) admitted that he left Colpocyclops longispinosus (Monchenko, 1974) for some time in the genus Halicyclops, because he believed that the maxillipeds were lost and maxillae deformed during the dissection of the type material. Prehendocyclops and Colpocyclops both have male fifth legs with one additional seta on the inner margin (compared with the female), as do the majority of Halicyclops species (males of Smirnoviella are yet to be found). The seta is reduced in some species of Halicyclops, so their fifth legs lack sexual dimorphism. However, several Halicyclops species have two setae on the inner margin of the male fifth leg, a plesiomorphy shared only with the genus Troglocyclops, the most primitive Halicyclopinae genus (Rocha and Iliffe, 1994). The Tethyan character of this group with two inner setae was recognised both by Rocha et al. (1998) and De Laurentiis at al. (1999) and it is even named the "caridophilus"-group by the latter authors. Both Halicyclops species presented in this monograph belong to this group and a detailed study of their morphology leads into the recognition of Rochacyclops subgen. nov. I believe it deserves generic status; certainly no less than Colpocyclops or Smirnoviella do. Unfortunately, incomplete original descriptions of many Halicyclops species and undiscovered males in quite a few representatives are the main reasons why I elevated this group only to the subgeneric rank of the genus Halicyclops.

Although the character that easiest distinguishes Rochacyclops subgen. nov. from Halicyclops s. str. (armature of the male fifth leg) is a plesiomorphy, several other characters may prove to be apomorphic and useful in further separating the two, including sexual dimorphism in the armature of the swimming legs, length of the innermost apical seta on the caudal rami and presence or absence of ventrolateral cuticular recesses on the urosome. For example, very short innermost apical setae on the caudal rami and cuticular recesses on the genital double somite of Halicyclops longiturcatus Pesce, De Laurentiis and Humphreys, 1996 strongly suggest that this species does not belong to the subgenus Rochacyclops, although males of this Australian representative are yet to be discovered (Pesce et al. 1996b).

I here redescribe the relatively well described
Halicyclops (R.) rochai De Laurentiis, Pesce and Humphreys, 1999 only to point out some characters, including the habitus and ornamentation of urosomites, that can be used to distinguish it from the new species described below. De Laurentiis et al. (1999) described H. (R.) rochai from three bores at Yarraloola Station (Robe River catchment) and two localities (one bore and one well) at Mardie Station (Fortescue River catchment). I have found this species in 20 samples from the Pilbara, which makes it the second most commonly found groundwater cyclopoid in this region.

\section{Halicyclops (Rochacyclops) calm sp. nov. Figures 5-8 and 109A-C}

\section{Material Examined}

\section{Holotype}

Female (WAM C28639), Australia, Pilbara, De Grey Station, bore GNHSLK1696, 17 November 2002, leg. J. Cocking and M. Scanlon (CALM), $20^{\circ} 18^{\prime} 59^{\prime \prime} \mathrm{S} 119^{\circ} 25^{\prime} 35^{\prime \prime} \mathrm{E}$ : dissected on two slides.

\section{Allotype}

Male (WAM C28640), Australia, Pilbara, De Grey Station, bore GNHSLK1696, 17 November 2002, leg. I. Cocking and M. Scanlon (CALM), 20 18'59"S $119^{\circ} 25^{\prime} 35^{\prime \prime} \mathrm{E}$ : dissected on two slides.

\section{Paratypes}

Australia, Pilbara, De Grey Station, bore GNHSLK1696, 17 November 2002, leg. J. Cocking and M. Scanlon (CALM), 20'18'59'S 119'25'35"E: 18 males +22 females (one ovigerous) + 16 copepodids (one male (WAM C28640) and two females (WAM C 28641 and 28642) dissected on one slide each; others in alcohol (WAM C28643))

\section{Other material}

Australia, Pilbara, Six Mile Well, 4 August 1996, leg. W.F. Humphreys (BES: 4946), 21 49'S 116 19'E: one male + one ovigerous female in alcohol (WAM C28644)

\section{Description}

Female (holotype). Body length, excluding caudal setae, $0.652 \mathrm{~mm}$. Habitus robust (Figure 5C) but much less than in previous species, with prosome/ urosome ratio 1.6 and greatest width at $2 / 3$ of cephalothorax length. Body length/width ratio about 2.6; cephalothorax about 3.3 times as wide as genital double somite. Free pedigerous somites without pronounced lateral expansions. Colour of preserved specimen yellowish. Nauplius eye not visible. Rostrum well developed, membranous, broadly rounded and furnished with two large sensilla. 


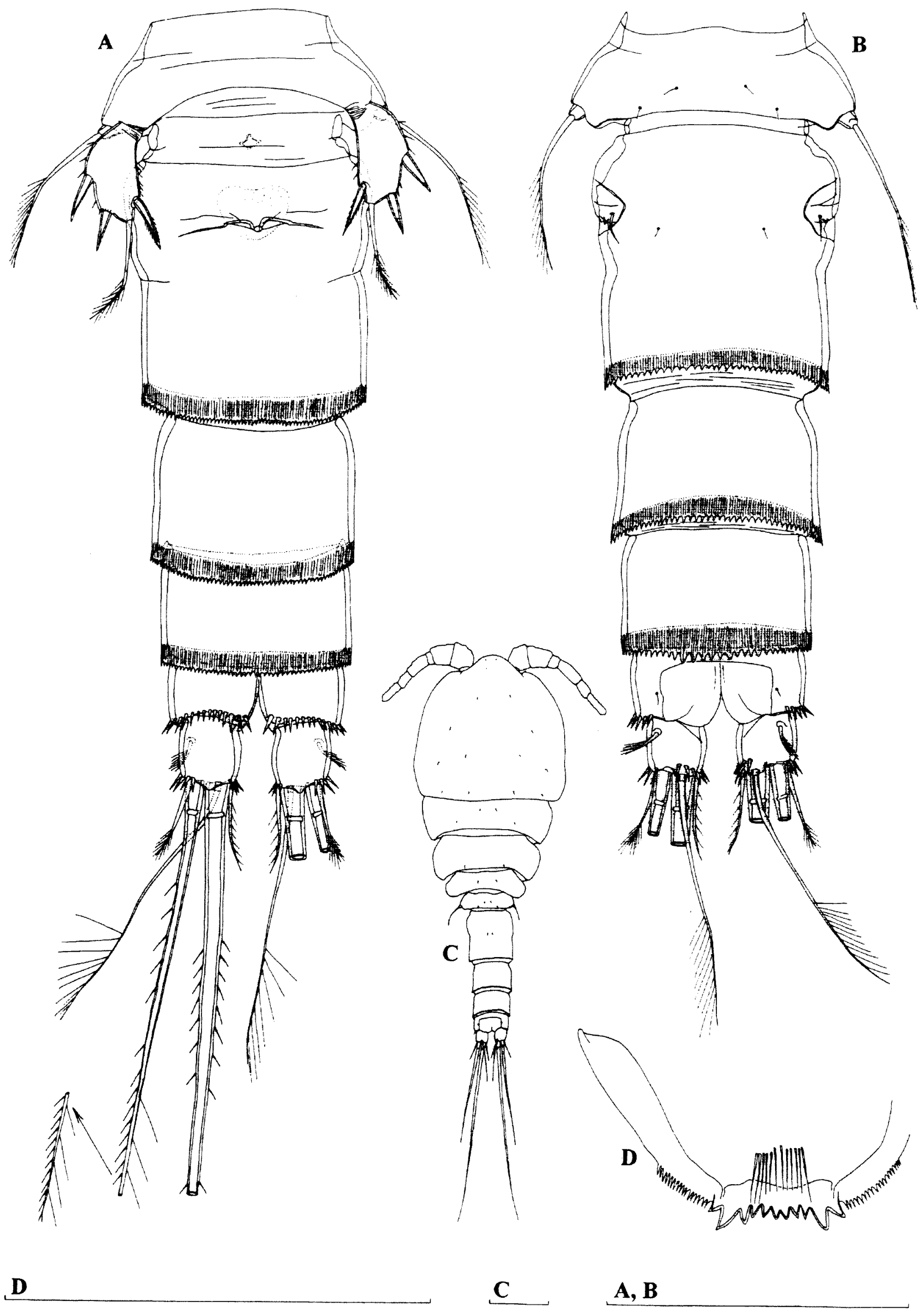

Figure 5 Halicyclops (Rochacyclops) calm sp. nov., holotype (female): A, urosome, ventral view; B, urosome, dorsal view; C, habitus, dorsal view; $D$, labrum. Scales $=0.1 \mathrm{~mm}$. 
Cephalothorax almost as long as its greatest width; represents $38 \%$ of total body length. Surface of cephalic shield with few large sensilla; no other ornamentation visible. Hyaline fringe of prosomites narrow and smooth. Fifth pedigerous somite with four large dorsal sensilla and with smooth fringe dorsally and ventrally (Figure $5 \mathrm{~B}$ ).

Genital double somite (Figure 5A, B) 1.1 times as long as wide, ornamented with two large sensilla dorsally in middle. Hyaline fringe of genital double and two subsequent somites frilled and sharply serrated. No cuticular recesses ventrolaterally in posterior half of genital double somite or spiniform processes laterally. Copulatory pore small; copulatory duct narrow and short, rigidly sclerotized. Seminal receptacle very small, heartshaped (Figure 5A). Ovipores situated dorsolaterally, covered by reduced sixth legs, bearing two minute spines and one smooth seta (Figure 5B). Third and fourth urosomites without ornamentation. Dorsal hyaline fringe of fourth somite slightly produced posteriorly in form of pseudo-operculum, and more strongly serrated. Anal somite with smooth, broad and slightly concave anal operculum, which represents $65 \%$ of somite's width; ornamented with two large sensilla dorsally and transverse row of spinules on posterior margin. Anal sinus widely opened, smooth (Figure 5B).

Caudal rami (Figure 5A, B) 1.2 times as long as wide, parallel, with space between them about one half of ramus' width. Distal margin ventrally with small protuberance medially, which seems to be cuticular tube pore (Figure 5A). One arched row of large spinules present ventrolaterally near posterior margin; one row along posterior margin laterally; other row of few large spinules dorsally, at base of dorsal seta. Dorsal seta very long, about four times as long as ramus, inserted on protuberance overreaching border of ramus, uniarticulate at base and plumose distally. Lateral seta arising at $1 / 4$, positioned dorsolaterally, uniplumose and shorter than ramus. Outermost apical seta slender, about 1.2 times as long as ramus, pinnate distally. Innermost apical seta also slender, about as long as outermost apical one, pinnate along inner margin. Principal apical setae with breaking planes; inner seta about 1.7 times as long as outer one and 0.46 times as long as body.

Antennula (Figure $6 \mathrm{~A}$ ) reaching just beyond middle of cephalothorax, six-segmented, with slender aesthetascs on fourth and sixth segments and setal formula: 8.12.5.6.2.10. One stout seta on distal outer corner of first segment and one on second segment articulating on basal part; one seta on second segment, one on fifth and two setae on sixth segment with breaking planes; one seta on distal outer corner of third segment spiniform and short. Most setae smooth, only 13 setae $(30 \%)$ plumose or pinnate at their distal parts. Length ratio of antennular segments, from proximal end and along caudal margins, $1: 1.8: 1.1: 3.2: 1.9: 2.8$.

Antenna (Figure 6D) four-segmented, comprising very reduced and unarmed coxa (mostly fused with next segment), basis and two-segmented endopod. Basis ornamented with short row of spinules at proximal inner part and few spinules along proximal part of outer margin; armed with two pinnate setae at distal inner corner and with smooth seta representing exopod; all setae about as long as basis. First endopodal segment armed with one smooth seta at middle. Second endopodal segment almost twice as long as first one, ornamented with two longitudinal rows of spinules along caudal surface (some very long), and armed with five lateral and seven apical setae; one lateral seta long and strong, although shorter than segment.

Labrum (Figure 5D) trapezoidal, ornamented with short row of 12 long and slender spinules on ventral surface and with finely serrated distolateral margin. Cutting edge slightly concave, with 11 more or less sharp teeth. No other ornamentation visible.

Mandibula (Figure $7 G$ ) with palp reduced to small protuberance, which bears two setae; distal seta pinnate distally, almost four times as long as proximal smooth seta but not reaching gnathobasal teeth. Coxal gnathobase cutting edge clearly divided into three regions: inner group of four complex smooth teeth, innermost tooth strongest, outermost sharpest; middle group of two simple smooth teeth and three spinules; outer group of two strongly pinnate teeth and outermost pinnate seta. Gnathobasal seta about 1.3 times as long as proximal seta on reduced palp.

Maxillula composed of well developed praecoxa and two-segmented palp (Figure $7 \mathrm{H}$ ). Arthrite of praecoxa with four apical, strong, short and smooth spines. Praecoxa armed with seven armature elements along inner margin, longest one plumose. Palp with completely divided endopod, which bears two apical and one lateral pinnate setae, and armed laterally with one exopodal pinnate seta and apically with two slender and pinnate setae and one robust, strongly bipinnate spine.

Maxilla (Figure 6C) four-segmented but praecoxa fused to coxa on posterior surface. Proximal endite of praecoxa armed with two setae (one plumose, other pinnate distally); distal endite very small, unarmed. Proximal endite of coxa with one short pinnate seta; distal endite highly mobile and bearing one proximal, completely fused and very stout seta and one distal, smaller seta. Seta fused to endite ornamented with four elongated spinules. Basis expanded into spinulose claw and armed with two setae; strong seta slightly longer than claw. Endopod armed with two spinulose and three smooth setae. Longer endopodal spinulose seta 


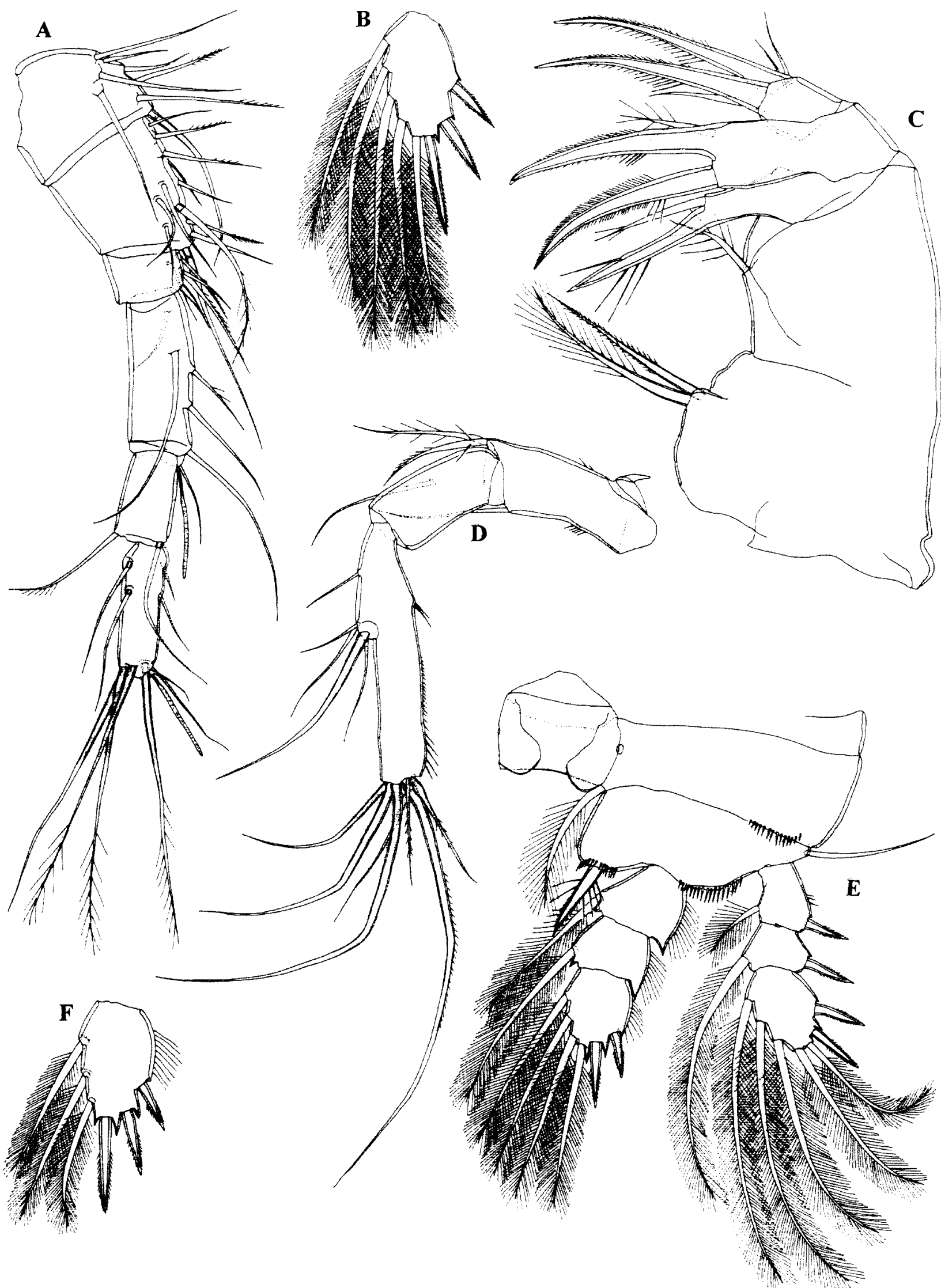

C

A, B, D, E, F

Figure 6 Halicyclops (Rochacyclops) calm sp. nov., holotype (female): A, antennula; B, third exopodal segment of third swimming leg; $C$, maxilla; $D$, antenna; $E$, first swimming leg; $F$, third endopodal segment of third swimming leg. Scales $=0.1 \mathrm{~mm}$. 


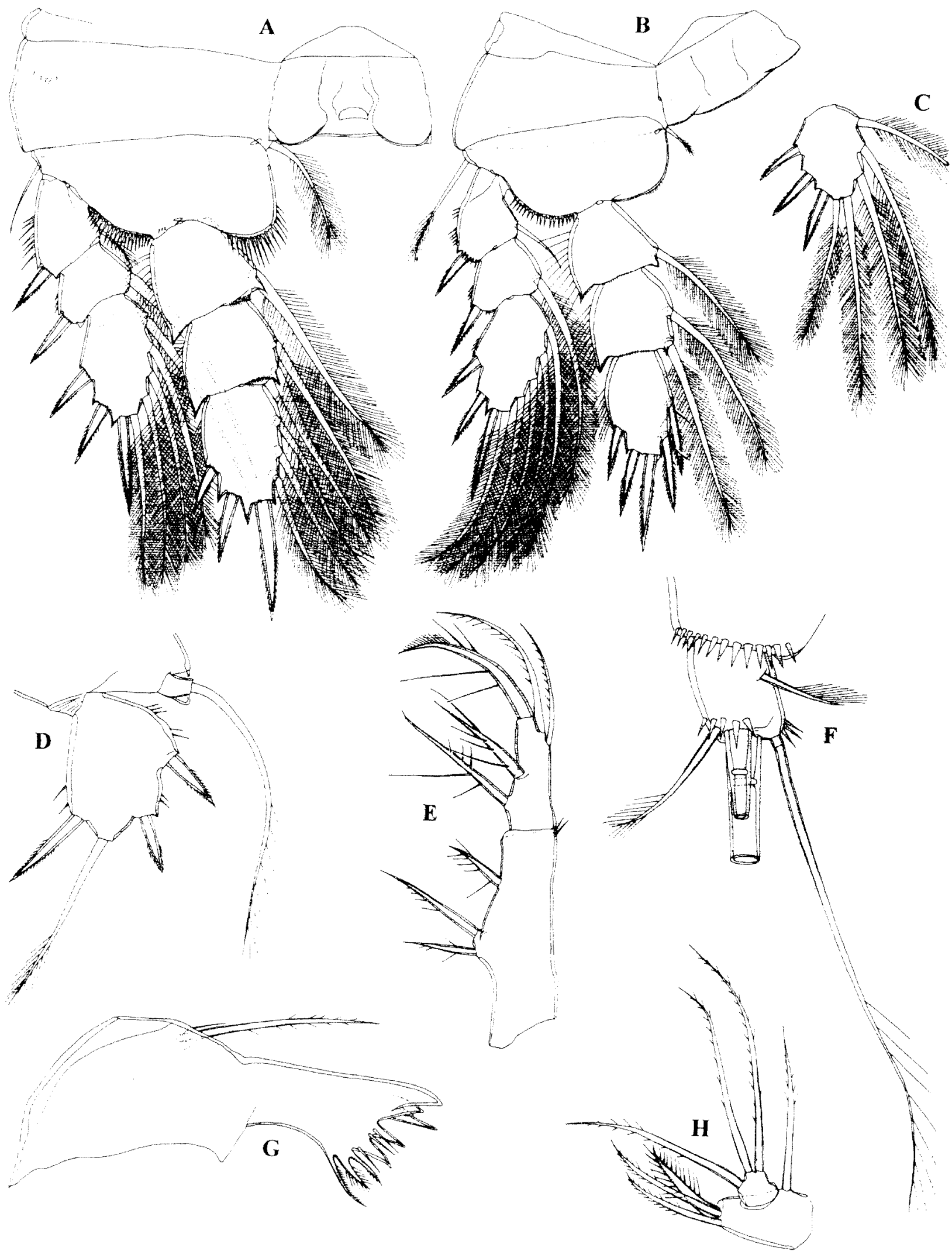

\section{D, E, F, G, H}

$\mathrm{A}, \mathrm{B}, \mathrm{C}$

Figure 7 Halicyclops (Rochacyclops) calm sp. nov., holotype (female): A, second swimming leg; B, fourth swimming leg; C, third exopodal segment of first swimming leg; D, fifth leg; E, maxilliped; F, left caudal ramus, lateral view; $G$, mandibula; $H$, maxillular palp. Scales $=0.1 \mathrm{~mm}$. 
about 1.2 times as long as strong seta on basis; shorter endopodal spinulose seta about twice as long as longest endopodal smooth seta. Both endopodal spinulose setae, as well as claw and strong seta on basis, with most proximal spinules longer than subsequent spinules in row.

Maxilliped (Figure 7E) two-segmented, armed with three setae on protopod and five setae on endopod, and ornamented with bunch of spinules near distal margin of protopod. Proximal protopodal seta bipinnate; middle seta strong, unipinnate and about 1.5 times as long as proximal one; distal protopodal seta somewhat shorter than proximal one, ornamented with several long spinules. Two lateral and innermost apical endopodal setae very stout and with several very long spinules. Middle apical seta longest one, unipinnate, and about 1.3 times as long as outermost, also unipinnate, apical seta. Protopod about 1.9 times as long as endopod.

All swimming legs with three-segmented exopod and endopod (Figure 6B, E, F and 7A, B, C). Armature formula of swimming legs as follows (legend: inner/outer spine or seta; inner/terminal/ outer):

\begin{tabular}{|c|c|c|c|c|c|c|}
\hline \multirow[b]{2}{*}{ Segments } & \multicolumn{3}{|c|}{ Exopod } & \multicolumn{3}{|c|}{ Endopod } \\
\hline & 1 & 2 & 3 & 1 & 2 & 3 \\
\hline First leg & $1 / 1$ & $1 / 1$ & $3 / 2 /(2) 3$ & $1 / 0$ & $1 / 0$ & $3 / 21$ \\
\hline Second leg & $1 / 1$ & $1 / 1$ & $4 / 2 / 2$ & $1 / 0$ & $2 / 0$ & $3 / 2 /$ \\
\hline This & $1 / 1$ & $1 / 1$ & $4 / 2 / 2$ & $1 / 0$ & $2 / 0$ & $3 / 2 / 1$ \\
\hline Fourth leg & $1 / 1$ & $1 / 1$ & $4 / 2 / 2$ & $1 / 0$ & $2 / 0$ & $2 / 2 /$ \\
\hline
\end{tabular}

Third exopodal segment spine formula: $3(2) .3 .3 .3$. All intercoxal sclerites without ornamentation and with rounded protrusions at both sides of distal margin. Coxae unornamented, except for coxa of first leg, which bears short row of spinules along posterior margin, and several spinules on coxa of second leg; armed with pinnate seta at inner distal corner; this seta very short on fourth leg (Figure 7B). Spine inserted at inner, protruded corner of basis of first leg reaching halfway of second endopodal segment (Figure 6E). All setae slender and plumose, except for two modified setae on fourth leg endopod. Third endopodal segment of fourth swimming leg about 1.5 times as long as wide; inner apical spine about 1.4 times as long as outer one; two inner setae spiniform, bipinnate and with two very long spinules proximally (Figure $7 \mathrm{~B}$ ).

Fifth leg (Figure 5A and 7D) with basis and endopod completely fused to somite; outer basal seta inserted on short basal protuberance (which about as long as wide) and pinnate distally. Exopod about 1.4 times as long as wide, ornamented with several large spinules along both outer and inner margins. Armature consists of three strong spines and one apical seta; inner apical (or subapical) spine 0.6 times as long as segment, about 1.6 times as long as outer apical spine and 1.4 times as long as outer proximal spine. Exopodal apical seta plumose at distal end, about 1.3 times as long as segment and 0.6 times as long as basal seta.

Sixth leg indistinct triangular plate, armed with two almost equal, smooth spines, which are fused to plate, and one smooth, much longer seta.

Male (allotype). Body length, excluding caudal setae, $0.523 \mathrm{~mm}$. Habitus (Figure $8 \mathrm{~A}$ ) robust, with prosome/urosome ratio 1.6 and greatest width at posterior end of cephalothorax. Body length/width ratio about 2.8 ; cephalothorax about 2.6 times as wide as genital somite.

Cephalothorax as long as its greatest width. Ornamentation of prosomites, colour and nauplius eye similar to those of female. Fifth pedigerous somite ornamented with four sensilla dorsally (Figure $8 \mathrm{E}$ ). Hyaline fringe of fifth pedigerous somite smooth; that of genital somite sharply serrated and frilled dorsally; those of other urosomites (except anal one) sharply serrated and frilled both dorsally and ventrally (Figure $8 \mathrm{E}, \mathrm{F}$ ).

Genital somite ornamented with two dorsal sensilla; third urosomite without any ornamentation; fourth urosomite with two dorsal sensilla; fifth somite unornamented. Anal somite with smooth, almost straight and very broad anal operculum, which represents $56 \%$ of somite's width; ornamented with two sensilla dorsally and transverse row of spinules on posterior margin. Anal sinus widely opened, ornamented with two diagonal rows of minute spinules (Figure $8 \mathrm{E}$ ).

Caudal rami (Figure $8 \mathrm{E}, \mathrm{F}$ ) about as long as wide, almost parallel, with space between them about half of ramus' width. Armature and ornamentation similar to female.

Antennula (Figure 8B) of almost equal length to cephalothorax, 13-segmented, geniculate, with geniculation between eleventh and twelfth segments. Aesthetasc formula: 2.0.1.0.0.0.0.1.0.0.1.1.2. All aesthetascs slender and long. Setal formula: 9.4.5.4.1.1.2.2.2.3.0.1.10. Setae on ninth and tenth segments characteristically modified, spiniform. Only three spiniform setae pinnate at their distal ends and only four setae on thirteenth segment articulating on basal part.

Antenna, labrum, mandibula, maxillula, maxilla, maxilliped and swimming legs similar to female.

Third endopodal segment of second swimming leg with most distal inner seta spiniform (Figure 8D).

Fifth leg (Figure 8G) exopod about 1.2 times as long as wide, ornamented with two short rows of spinules on outer margin, and with several small spinules at base of spines. Armature consists of three spines and three setae. Inner apical spine almost as long as segment, about 1.4 times as long as outer apical spine and 1.6 times as long as outer proximal spine. Exopodal inner setae of about same length and only slightly longer than exopodal apical seta. Exopodal apical seta about 0.8 times as long as basal one. All setae plumose. 


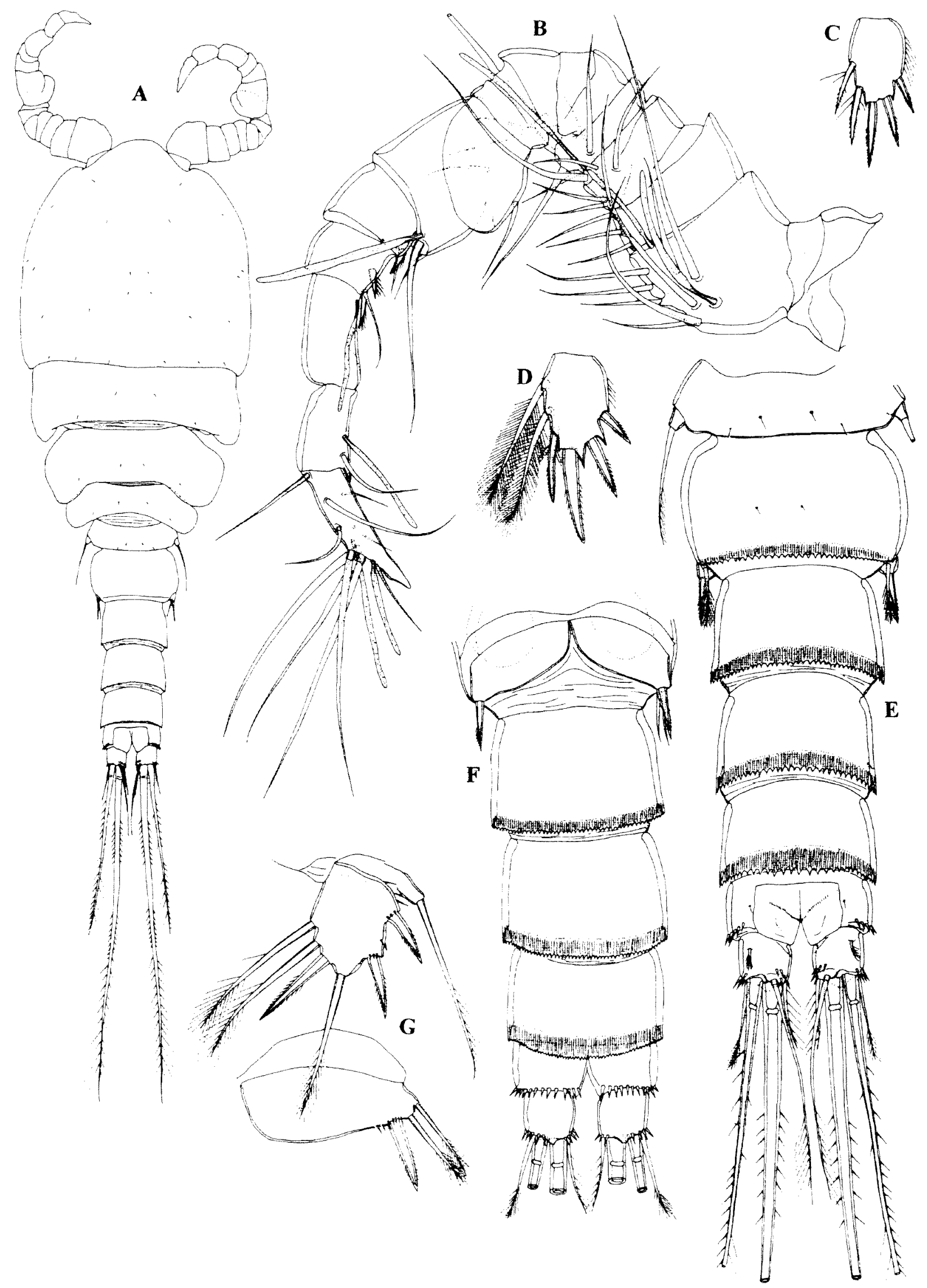

B, G

A

C, D, E, F

Figure 8 Halicyclops (Rochacyclops) calm sp. nov, allotype (male): A, habitus, dorsal view; B, antennula; C, third endopodal segment of fourth swimming leg; D, third endopodal segment of second swimming leg; E, urosome, dorsal view; $F$, abdomen, ventral view; $G$, fifth and sixth legs. Scales $=0.1 \mathrm{~mm}$. 
Sixth leg (Figure 8F, G) distinct large plate, armed with one spine and two pinnate setae; ornamented with short row of spinules at base of spine. Both setae plumose, of about same length and 1.2 times as long as spine.

\section{Variability}

Body length of females ranges from $0.544 \mathrm{~mm}$ to $0.652 \mathrm{~mm}(0.6 \mathrm{~mm}$ average; $\mathrm{n}=9)$, while in males it ranges from $0.45 \mathrm{~mm}$ to $0.523 \mathrm{~mm}(0.477 \mathrm{~mm}$ average; $n=7$ ). No other type of variability was observed.

\section{Etymology}

The species name is the official acronym for the Department of Conservation and Land Management (CALM), a Western Australian Government organisation that funded the two years of taxonomic research on which this monograph is based. The name should be treated as a noun in apposition.

\section{Discussion}

The two inner setae on the male fifth leg clearly put Halicyclops (R.) calm sp. nov. into the subgenus Rochacyclops. The long innermost apical setae of the caudal rami and the absence of cuticular recesses on the urosome further support its close relationship with other members of the newly established subgenus. At present four other species are included in the subgenus Rochacyclops: Halicyclops (R.) caridophilus Humes, 1947 from the gill chambers of a lobster from Borneo (Humes 1947), H. (R.) tetracanthus Rocha, 1995 from an estuary in Belize (Rocha 1995), H. (R.) cenoticola Rocha, Illife, Reid and Suárez-Morales, 1998 from cenotes of the Yucatan Peninsula (Rocha et al. 1998) and $H$. (R.) rochai De Laurentiis, Pesce and Humphreys, 1999 from numerous bores and wells from the Pilbara (De Laurentiis et al. 1999, and this monograph). Unfortunately, the description of $H$. (R.) caridophilus is quite short and the drawings are pretty schematic but it may be easily distinguished from the new species by a different armature of the swimming legs (its spine formula is 3.4.4.3) and by the presence of only one seta on the mandibular palp. It seems that Humes (1947) was not quite able to distinguish dorsal from innermost apical setae on the caudal rami of $H$. (R.) caridophilus, as it appears that this species has somewhat shorter innermost setae than the other members of the subgenus. A complete redescription of this species would certainly be very welcome, as would be redescriptions of many Halicyclops species. My very limited time for this project did not allow for anything like that, unfortunately. Halicyclops (R.) tetracanthus differs from $H$. (R.) calm by much shorter caudal rami, more robust habitus, different armature of the swimming legs (its spine formula is 3.4.3.3), absence of the seta representing the exopod on the antenna, as well as by many other microcharacters, especially regarding ornamentation of some appendages or armature elements (see Rocha 1995). A number of characters may also be used to distinguish $H$. (R.) cenoticola from the new species, including the relative length of the caudal rami armature $(H$. (R.) cenoticola has much longer outermost apical and dorsal setae), different armature of the swimming legs (spine formula 3.4.4.3) and only two armature elements on the male sixth leg (Rocha et al. 1998). Halicyclops (R.) rochai is probably the closest relative of $H$. (R.) calm, as it is morphologically the most similar. However, they can be readily distinguished by the different spine formulae of the swimming legs. Halicyclops (R.) calm has also much more slender habitus than $H$. (R.) rochai, shorter third endopodal segment of the fourth swimming leg, sharply serrated hyaline fringe of the abdominal somites, more rounded exopod of the fifth leg, endopod of the maxilla armed with five elements, and clearly divided last two segments of the male antennula. As these differences are actually a mixture of plesiomorphies and apomorphies, it seems that $H$. (R.) rochai and $H$. (R.) calm originated from a common ancestor, rather than one from the other. Halicyclops (R.) calm appears to be much less common than $H$. (R.) rochai, and to date has been found at two localities in the Pilbara.

All other Australian representatives of the genus Halicyclops belong to the nominotypical subgenus. Below is a key to aid in their identification:

1. Innermost apical seta on caudal rami very short; cuticular recesses on urosome present; fifth leg in male with single inner seta

3

- Innermost apical seta longer than caudal rami; cuticular recesses on urosome absent; fifth leg in male with two inner setae

2

2. Third exopodal segment of second and third leg with four outer spines...

H. (R.) rochai De Laurentiis et al., 1999

- Same segment with three outer spines $H$. $(R)$ calm sp. nov.

3. Genital double somite without spiniform processes laterally ......................................... 4

- Same somite with spiniform processes ................. H. (H.) spinifer Kiefer, 1935

4. Caudal rami not more than two times as long as wide 5

- Rami more than four times as long as wide H. (H.) longifurcatus Pesce et al., 1996 
5. Cuticular tube on caudal ramus present ...........6 6

- That tube absent ................................................ 7

6. Integumental window on cephalothorax absent; caudal rami less than 1.5 times as long as wide H. (H.) ambiguus Kiefer, 1967

- Integumental window on cephalothorax present; caudal rami about 1.7 times as long as wide ... H. (H.) pescei Karanovic, 2004

7. Caudal rami very short, about 1.2 times as long as wide H. (H) eberhardi Laurentiis et al., 2001

- Caudal rami almost twice as long as wide

H. (H.) kieferi Karanovic, 2004

Subfamily Eucyclopinae Kiefer, 1927

Genus Tropocyclops Kiefer, 1927

Tropocyclops prasinus (Fischer, 1860)

Figures $109 \mathrm{D}$ and E

\section{Synonymy}

Cyclops prasinus n.sp. - Fischer, 1860: 652, plate 20, Figures 19-26a (fide Kiefer, 1929a).

Cyclops prasinus Fischer - Marsh, 1910: 1097, plate 78 , Figures $1-3$ and 10

Eucyclops prasinus (Fischer) - Wilson, 1932: 339, Figure 202.

Cyclops (Eucyclops - Tropocyclops) prasinus Fischer - Pesta, 1928: 111, Figure 93.

Cyclops (Tropocyclops) prasinus Fischer Stephanides, 1948: 38, plate 15, Figures 141-144.

Eucyclops (Tropocyclops) prasinus (Fischer) Kiefer, 1929a: 39, Figure 13; Kiefer, 1931: 506, Figures 1-2; Kiefer, 1933: 559.

Tropocyclops prasinus (Fischer) - Rylov, 1948: 151, Figure 26; Kiefer, 1948; 69, Figures 3-6; ŠrámekHušek, 1953: 36, Figures 62-65; Ito, 1954: 383, Figures 42-47; Kiefer, 1956: 246, Figures 30-34; Šrámek-Hušek, 1957: 159, Figures 1-8; Kiefer, 1960a: 36, Figures 85-86; Dussart, 1968: 130, Figures 1a, b, c; Dussart, 1969: 52, Figure 17; Monchenko, 1974: 107, Figures 45-46; Kiefer, 1978: 214; Kiefer and Fryer, 1978: 167, Figure 78; Dussart and Defaye, 1985: 42; Defaye, 1988: 128, Figures 70-72.

Tropocyclops prasinus prasinus (Jurine) - DamianGeorgescu, 1963: 88, Figure 47.

Tropocyclops prasinus prasinus (Fischer) - Plesa, 1956: 364, Figs1-7; Kiefer, 1962: 319, Figures 1-3; Shen et al., 1979: 333, Figure 190; Dussart, 1982: 319, Figure 3A; Reid, 1985: 102, Figures 89-91.

Tropocyclops of. prasinus (Fischer) - Kiefer, 1938b: 277, Figures 10-17.
Tropocyclops prasinus (Fischer) s. lat. - Reid, 1991b: 6, Figures 5-12; Ueda et al., 1996: 53, Figures 42 52.

Tropocyclops sp. 1, sp. 2 and sp. 3-Ishida, 2002b: 49, Figure 15.

Leptocaris viridis n.sp. - Henry, 1919: 40.

Leptocaris viridis Henry - Henry, 1923: 564.

\section{Material Examined}

1) Australia, Pilbara, Mulga Downs Station, Pipally Well, 3 September 2000, leg. W.F. Humphreys (BES: 8459), 22 $14^{\prime} 07^{\prime \prime} \mathrm{S} 118^{\circ} 36^{\prime} 52^{\prime \prime} \mathrm{E}$ : eight males + seven females (two ovigerous) + one copepodid in alcohol (WAM C28645)

2) Australia, Pilbara, Newman Borefield, bore WB23/1, 22 July 1997, leg. W.F. Humphreys and S.M. Eberhard (BES: 4803), 2319'30'S 11950'51"E: one female in alcohol (WAM C28646)

\section{Discussion}

Tropocyclops prasinus (Fischer, 1860) is one of those cosmopolitan species that has been reported or described countless times, either as a new species, subspecies, variety or a form. The synonymy presented here is far from complete and for a more comprehensive list one should consult Dussart and Defaye (1985). Besides the material presented in this monograph, I had an opportunity to examine a few samples containing $T$. prasinus from New South Wales, provided by Jane Gough (NSW National Parks and Wildlife Service), and I could not find any significant morphological difference between it and $T$. prasinus from my European samples (unpublished data). Additionally, I have nine specimens of this species from the Kimberley region in Western Australia and it appears to be widely distributed in Australia. I also have to agree with Lindberg (1953) that Leptocaris viridis, described from New South Wales by Henry (1919) and additionally mentioned in Henry (1923), probably is Tropocyclops prasinus. In the Pilbara, $T$. prasinus is probably a stygophile.

\section{Genus Ectocyclops Brady, 1904}

\section{Ectocyclops phaleratus (Koch, 1838)}

\section{Synonymy}

Cyclops phaleratus n.sp. - Koch, 1838: 21, Figure 9 (fide Wilson, 1932).

Cyclops phaleratus Koch - Fedchenko, 1875: 38, plate 9, Figures 1-5; Sars, 1896: 76; Marsh, 1910: 1099, plate 79, Figure 9 and plate 80, Figures 1 6. 
Platycyclops phaleratus (Koch) - Sars, 1914: 78, Figure 48; Henry, 1919: 41; Henry, 1923: 565 , plate 58, Figures 1-2.

Cyclops (Paracyclops) phaleratus Koch - Pesta, 1928: 113, Figure 95.

Cyclops (Ectocyclops) phaleratus Koch Stephanides, 1948: 42, plate 16, Figures 158-160.

Ectocyclops phaleratus (Koch) - Kiefer, 1929a: 43, Figure 15; Wilson, 1932: 341, Figure 203; Rylov, 1948: 163, Figure 31; Comita, 1951: 371, plate 1, Figures 12-13; Lindberg, 1953: 5; Šrámek-Hušek, 1953: 38, Figures 66-69; Kiefer, 1960a: 37, Figure 90; Damian-Georgescu, 1963: 101, Figure 54; Dussart, 1969: 62, Figure 22; Monchenko, 1974: 132, Figures 54-55; Kiefer, 1978: 214; Shen et al., 1979: 349, Figures 202-203; Yeatman, 1983: 72, Figures 10a-10d; Dussart and Defaye, 1985: 52; Reid, 1985: 100, Figures 81-83; Defaye, 1988: 130, Figure 85; Gaviria, 1994: 379, Figure 71F; Ishida, 2002b: 51, Figures 18a-18e.

Ectocyclops rubescens Brady - Morton, 1990: 670, Figures $7 \mathrm{a}-7 \mathrm{~h}$.

\section{Material Examined}

Australia, Pilbara, Hamersley Range, Munjina Creek, 5 September 2000, leg. W.F. Humphreys (BES: 8473 and 8479): one copepodid in alcohol (WAM C28647)

\section{Discussion}

The cosmopolitan Ectocyclops phaleratus (Koch, 1838) was first reported in Australia by Sars (1896) from a collection made at Centennial Park, Sydney. Marsh $(1919,1923)$ found it at four other locations in New South Wales, Brehm (1953) reported it from Tasmania and Morton (1990) reported this species (although as $E$. rubescens) from numerous locations from all Australian states, except Western Australia. It was reported from Western Australia by Halse et al. (2000a) from the Mooka Ruin Spring in the Carnavon Basin (also as E. rubescens) and from several springs from the Pilbara by Halse et al. (2002b).

\section{Genus Australoeucyclops gen. nov.}

\section{Diagnosis}

Moderately large Eucyclopinae, with relatively slender habitus and not markedly flattened dorsoventrally. Cephalothorax longer than wide; surface of caphalothoracic shield with several large sensilla and no other ornamentation. Free pedigerous somites without pronounced lateral expansions, with narrow and smooth hyaline fringe. Fourth and fifth pedigerous somites with strong fringes of elongate setules laterally. Genital double somite and two subsequent somites sharply serrated ventrally and only wavy or finely serrated dorsally; ornamentated with few sensilla and/or small cuticular pores. Seminal receptacle with two subequal expansions. Caudal rami parallel, with smooth outer margins; lateral seta slightly longer than ramus width; outermost apical seta stout, spiniform; few spinules at base of lateral and outermost apical setae but not extending any further. Female antennula 12 -segmented, slender and long, usually reaching beyond $3 / 4$ of cephalothorax. Male antennula 16-segmented, digeniculate; most aesthetascs with bunch of hairs apically. All swimming legs with three-segmented exopods and endopods; third exopodal segment spine formula 3.4.3.3; inner spine on basis of first leg longer than first two endopodal segments; first exopodal segment of fourth leg without inner seta. Fifth leg simple trapeziform cuticular plate, armed with three elements, all on the same plane and each on its own small protuberance; innermost spine strong and significantly longer than segment. Spine on male sixth leg longer than middle seta.

\section{Type species}

Australoeucyclops karaytugi sp. nov.

\section{Other species}

Paracyclops eucyclopoides Kiefer, 1927; Eucyclops linderi Lindberg, 1948; Paracyclops timmsi Kiefer, 1969; Paracyclops waiariki Lewis, 1974.

\section{Etymology}

The generic name is composed of the Latin adjective "australis", meaning "southern", and the existing generic name Eucyclops. Gender masculine.

\section{Australoeucyclops karaytugi sp. nov. Figures 9-12}

\section{Material Examined}

\section{Holotype}

Female (WAM C28648), Australia, Pilbara, Weeli Wolli Spring, surface pool, 16 November 1998, leg. S.M. Eberhard (BES: 3601 and 3608), 22 $55^{\circ}$ 'S $119^{\circ} 11^{\prime} \mathrm{E}$ : dissected on 2 slides.

\section{Allotype}

Male (WAM C28649), Australia, Pilbara, Weeli Wolli Spring, surface pool, 16 November 1998, leg. S.M. Eberhard (BES: 3601 and 3608), 22 ${ }^{\circ} 55^{\prime}$ S $119^{\circ} 11^{\prime} \mathrm{E}$ : dissected on 2 slides.

\section{Paratypes}

Australia, Pilbara, Weeli Wolli Spring, surface pool, 16 November 1998, leg. S.M. Eberhard (BES: 
3601 and 3608), 2255' 119 11 E: one female + one copepodid in alcohol (WAM C28650)

\section{Description}

Female (holotype). Body length, excluding caudal setae, $0.552 \mathrm{~mm}$. Habitus (Figure 9A) not very robust, with prosome/urosome ratio 1.5 and greatest width at posterior end of cephalothorax. Body length/width ratio about 3.2 ; cephalothorax about 2.6 times as wide as genital double somite. Free pedigerous somites without pronounced lateral expansions, except in fifth pedigerous somite, which has lateral corner slightly protruded. Colour of preserved specimen yellowish. Nauplius eye not visible. Rostrum well developed, membranous, broadly rounded and furnished with two large sensilla.

Cephalothorax 1.2 times as long as its greatest width; represents $38 \%$ of total body length. Surface of cephalic shield with few large sensilla; no other ormamentation visible. Hyaline fringe of prosomites narrow and smooth. Second and third pedigerous somites (first and second free prosomites) ornamented with few large sensilla. Fourth pedigerous somite with two large dorsal sensilla and with strong fringes of elongate setules at posterior margin laterally (Figure 9A). Fifth pedigerous somite with two large dorsal sensilla, with smooth fringe dorsally and ventrally, and two rows of elongate setules on lateral protrusions (Figure 10A and 11E).

Genital double somite (Figure 9B, 10A and 11E) as long as wide (ventral view), ornamented with two large sensilla dorsally in middle and with four cuticular pores laterally at each side (Figure 10A). Hyaline fringe of genital double and two subsequent somites sharply serrated ventrally and only wavy (not serrated) dorsally. Copulatory pore large, ovoid; copulatory duct short, rigidly sclerotized. Seminal receptacle relatively small, representing $52 \%$ of double somite width and $36 \%$ of its length; anterior expansion about 1.5 times as long as posterior one (Figure 9B). Parts of oviducts rigidly sclerotized. Ovipores situated dorsolaterally, covered by reduced sixth legs, bearing two minute spines and one pinnate seta (Figure 10A and 11E). Third urosomite ornamented with two ventral cuticular pores; fourth somite with dorsal row of minute spinules posteriorly. Anal somite with smooth, broad and convex anal operculum, which represents $70 \%$ of somite's width; ornamented with two large sensilla dorsally and transverse row of spinules on posterior margin ventrally (Figure $9 B$ and 10A). Anal sinus widely opened, ornamented with two long diagonal rows of long spinules.

Caudal rami (Figure $9 \mathrm{~B}$ and 10A) 3.8 times as long as wide, parallel, with space between them about one fourth of ramus' width. Distal margin ventrally with small protuberance medially, which seems to be cuticular tube pore (Figure 9B). Ornamentation consists of two dorsal cuticular pores (one proximal, one distal) and several spinules at base of lateral and outermost apical setae. Dorsal seta about 0.9 times as long as ramus, inserted at $7 / 8$ of ramus length, uniarticulate at base and plumose distally. Lateral seta arising at $3 / 4$ of ramus length, positioned somewhat dorsolaterally, uniplumose and longer than ramus width. Outermost apical seta stout, spiniform, about 0.9 times as long as ramus, pinnate; spinules along inner margin hair-like, those along outer margin stronger. Innermost apical seta slender, plumose and about 0.8 times as long as outermost apical one. Principal apical setae with breaking planes; inner seta about 1.6 times as long as outer one and half as long as body.

Antennula (Figure $9 \mathrm{C}$ ) reaching just beyond $3 / 4$ of cephalothorax, 12-segmented, with one slender aesthetasc on ninth, eleventh and twelfth segments each and setal formula: 8.4.2.6.4.2.2.3.2.2.2.7. No setae with breaking planes or articulating on basal part; one seta at distal outer corner of sixth segment spiniform and very short. Most setae smooth, only 13 setae $(30 \%)$ plumose or pinnate at their distal parts. Length ratio of antennular segments, from proximal end and along caudal margins, $1: 0.5: 0.3$ $: 0.6: 0.6: 0.3: 0.7: 1.1: 1: 0.8: 0.9: 1.5$. First segment with transverse row of large spinules; eleventh and twelfth segments with one smooth and narrow longitudinal cuticular frill each; other segments without visible ornamentation.

Antenna (Figure 11C) four-segmented, comprising short coxobasis and three-segmented endopod; all segments of about same length. Coxobasis about 1.6 times as long as wide, ornamented with row of spinules along external margin and with two additional arched rows on caudal surface, armed with two smooth setae at distal inner corner and with pinnate seta representing exopod, slightly reaching beyond tip of appendage. First endopodal segment armed with one smooth seta and ornamented with longitudinal row of spinules along external margin. Second endopodal segment about 1.6 times as long as wide, ornamented with longitudinal row of spinules and armed with nine smooth setae (seven lateral, two subapical; one subapical seta longer and much stronger than any other seta on that segment ). Third endopodal segment 1.9 times as long as wide, armed with seven apical setae (strongest one with several pinnules; others smooth) and ornamented as previous segment.

Labrum trapezoidal, ornamented with two bunches of 10 long and slender spinules on ventral surface. Cutting edge slightly concave, with 16 more or less blunt teeth between produced serrated lateral comers. No other ornamentation visible.

Mandibula with small but distinct palp, armed with two very long, finely plumed setae and one 


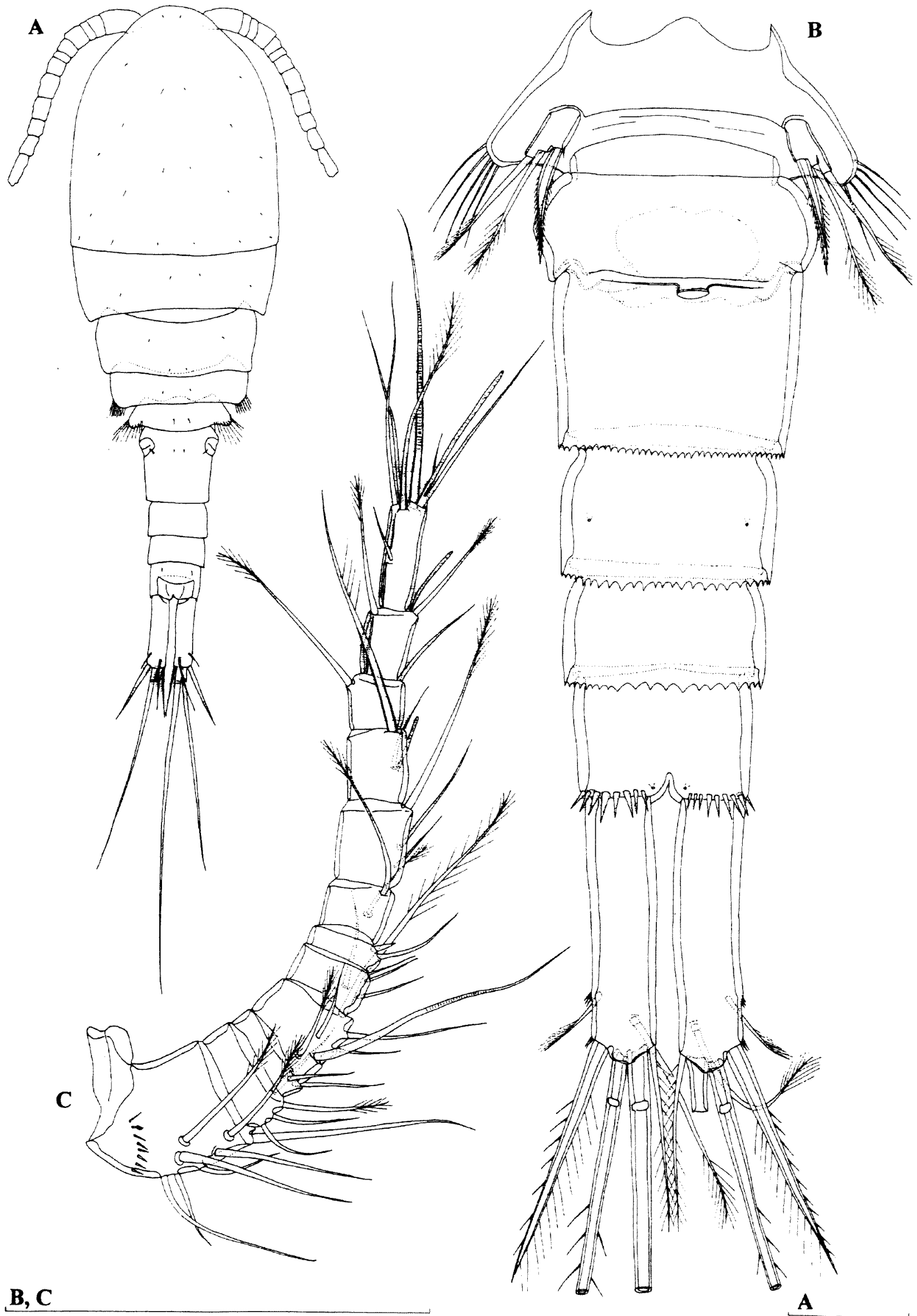

Figure 9 Australoeucyclops karaytugi gen. et sp. nov., holotype (female): A, habitus dorsal view; B, urosome, ventral view; $C$, antennula. Scales $=0.1 \mathrm{~mm}$. 


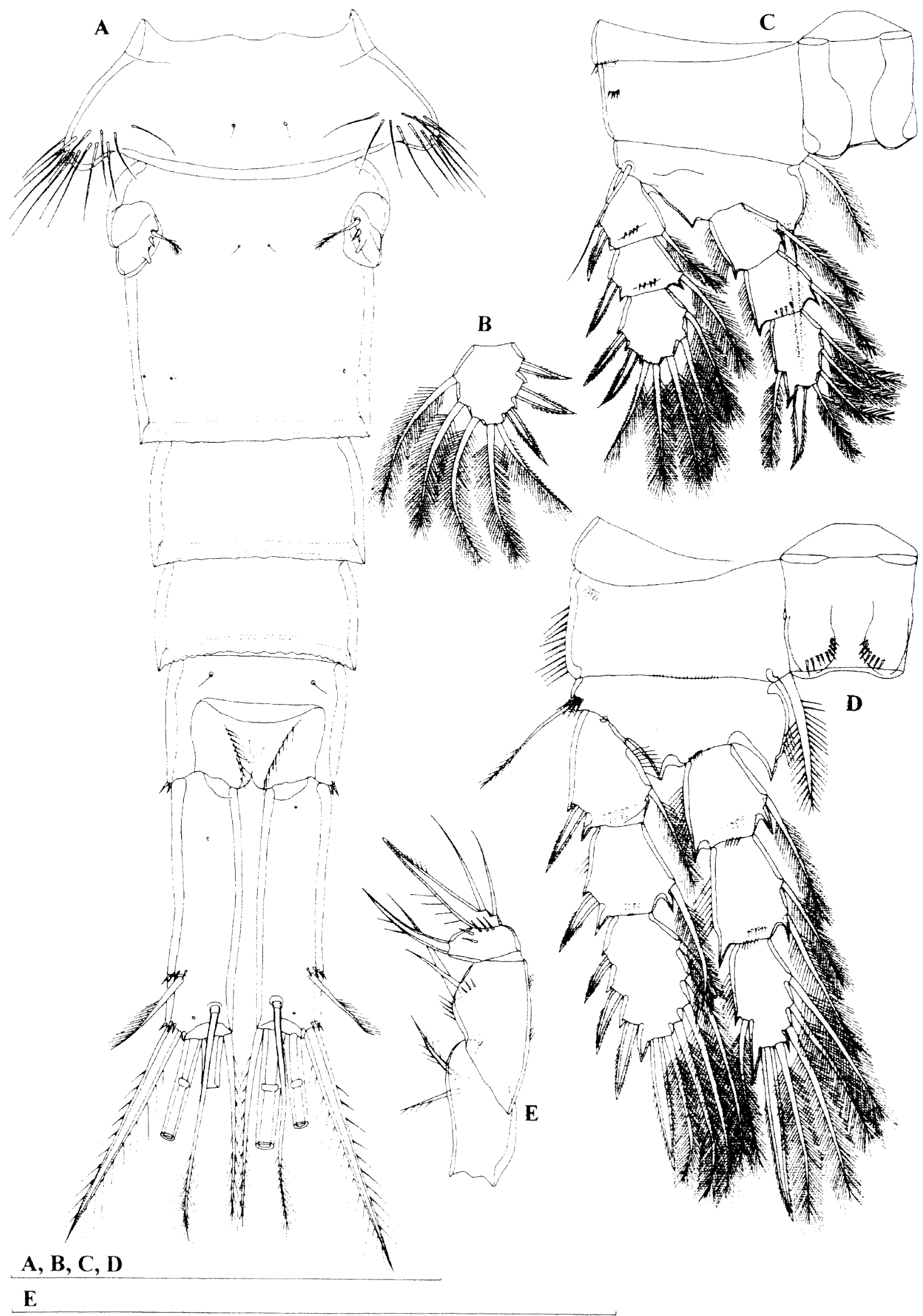

Figure 10 Australoeucvelops karavtugi gen et $\mathrm{sp}$. now., holotype (female): A, urosome, dorsal view; B, third exopodal segment of first swimming leg; C, first swimming leg; D, second swimming leg; E, maxilliped. Scales $=0.1$ $\mathrm{mm}$. 
short, smooth, seta on distal end. Coxal gnathobase cutting edge with very strong teeth and outermost pinnate seta, longer than short seta on palp.

Maxillula composed of well developed praecoxa and two-segmented palp. Arthrite of praecoxa with four strong apical spines; only one distinct and ornamented with two setules; others smooth and completely fused to praecoxa. Praecoxa armed with seven armature elements along inner margin, longest one plumose. Palp with distinct endopod, which bearing three apical setae (outermost strongest, longest and unipinnate; other two smooth), and armed laterally with one exopodal plumose seta and apically with two slender and pinnate setae and one robust, strongly bipinnate, spine. Palp somewhat shorter than arthrite of praecoxa.

Maxilla (Figure 11F) five-segmented but praecoxa fused to coxa on posterior surface and also partly on anterior surface. No other ornamentation visible. Proximal endite of praecoxa elongate, robust, armed with two pinnate seta, distal endite small, unarmed. Proximal endite of coxa with one strong, bipinnate seta; distal endite highly mobile, elongate and armed apically with proximal strong and pinnate setae and distal smooth, slender and shorter one. Basis expanded into robust claw, ornamented with longitudinal row of strong spinules along concave margin (most proximal spinules shortest) and armed with two setae; strong seta as long as claw, pinnate. Endopod two-segmented; proximal segment armed with two robust setae; distal segment with one robust apical seta and two slender subapical setae; only one seta on first segment pinnate, all other setae on endopod smooth. Longest seta on distal endopodal segment about 1.1 times as long as strong seta on basis.

Maxilliped (Figure 10E) four-segmented, composed of syncoxa, basis and two-segmented endopod. Syncoxa unornamented but armed with three pinnate setae of subequal length. Basis almost twice as long as wide, ornamented with several short rows of spinules and armed with two smooth setae; proximal seta almost twice as long as distal one. First endopodal segment ornamented with one arched row of strong spinules and armed with one strong, unipinnate seta. Second endopodal segment very small, unornamented but armed with two smooth and one bipinnate seta; bipinnate seta basaly completely fused to segment.

All swimming legs with three-segmented exopod and endopod (Figure 10B, C, D and 11A, B, D). Armature formula of swimming legs as follows (legend: inner/outer spine or seta; inner/terminal/ outer):

\begin{tabular}{lcccccc} 
& \multicolumn{3}{c}{ Exopod } & \multicolumn{3}{c}{ Endopod } \\
Segments & 1 & 2 & 3 & 1 & 2 & 3 \\
First leg & $1 / 1$ & $1 / 1$ & $3 / 2 /(2) 3$ & $1 / 0$ & $1 / 0$ & $3 / 2 / 1$ \\
Second leg & $1 / 1$ & $1 / 1$ & $4 / 2 / 3$ & $1 / 0$ & $2 / 0$ & $3 / 2 / 1$
\end{tabular}

$\begin{array}{lllllll}\text { Third leg } & 1 / 1 & 1 / 1 & 4 / 2 / 2 & 1 / 0 & 2 / 0 & 3 / 2 / 1 \\ \text { Fourth leg } & 0 / 1 & 1 / 1 & 4 / 2 / 2 & 1 / 0 & 2 / 0 & 2 / 2 / 1\end{array}$

Third exopodal segment spine formula: $3(2) .4 .3 .3$. Intercoxal sclerite of first leg without ornamentation and with rounded protrusion at each side of distal margin; sclerites of other swimming legs armed with arched rows of spinules. All coxae ornamented with several rows of spinules and armed with one pinnate seta at inner distal corner; this seta very robust, almost spiniform, in fourth leg (Figure 11B). Spine inserted at inner, protruded corner of basis of first leg reaching halfway of third endopodal segment (Figure 10C). All setae slender and plumose. First and second segment of both exopod and endopod of each leg with short row of spinules along distal margin, sometimes on both sides. Third endopodal segment of fourth swimming leg about 1.8 times as long as wide; inner apical spine about 2.5 times as long as outer one and about 1.9 times as long as segment (Figure 11B).

Fifth leg (Figure 9B and 11E) simple quadrate (or slightly trapeziform) small cuticular plate, without any ornamentation and armed with three elements, all on the same plane and each on its own small protuberance. Outermost seta (probably ancestral basal one) unipinnate along outer margin, about 2.5 times as long as segment. Middle seta plumose at distal end, about as long as outermost one. Innermost spine very strong, about 0.8 times as long as middle seta and twice as long as segment.

Sixth leg (Figure 11E) distinct, more or less oval, cuticular plate, armed with two almost equally long minute smooth spines and one bipinnate and much longer seta; median spine distinct, other one completely fused to leg.

Male (allotype). Body length, excluding caudal setae, $0.478 \mathrm{~mm}$. Habitus (Figure 12D) relatively slender, with prosome/urosome ratio 1.4 and greatest width at posterior end of cephalothorax. Body length/width ratio about 3.3 ; cephalothorax about 2.8 times as wide as genital somite.

Cephalothorax 1.2 times as long as its greatest width. Ornamentation of prosomites, colour and nauplius eye similar to those of female. Fourth and fifth pedigerous somites lack elongated setules on lateral margins and fifth somite also with less protruded lateral corners than in female. Hyaline fringe of fifth pedigerous somite smooth; that of genital somite sharply serrated and frilled dorsally; that of other urosomites (except anal one) sharply serrated and frilled both dorsally and ventrally (Figure 12A).

Genital somite ornamented with two dorsal sensilla; third urosomite without any ornamentation; fourth and fifth urosomites with two cuticular pores ventrally each (Figure 12A). Anal somite with smooth, concave and very broad anal operculum, which represents $62 \%$ of somite's width; ornamented with two sensilla dorsally, 


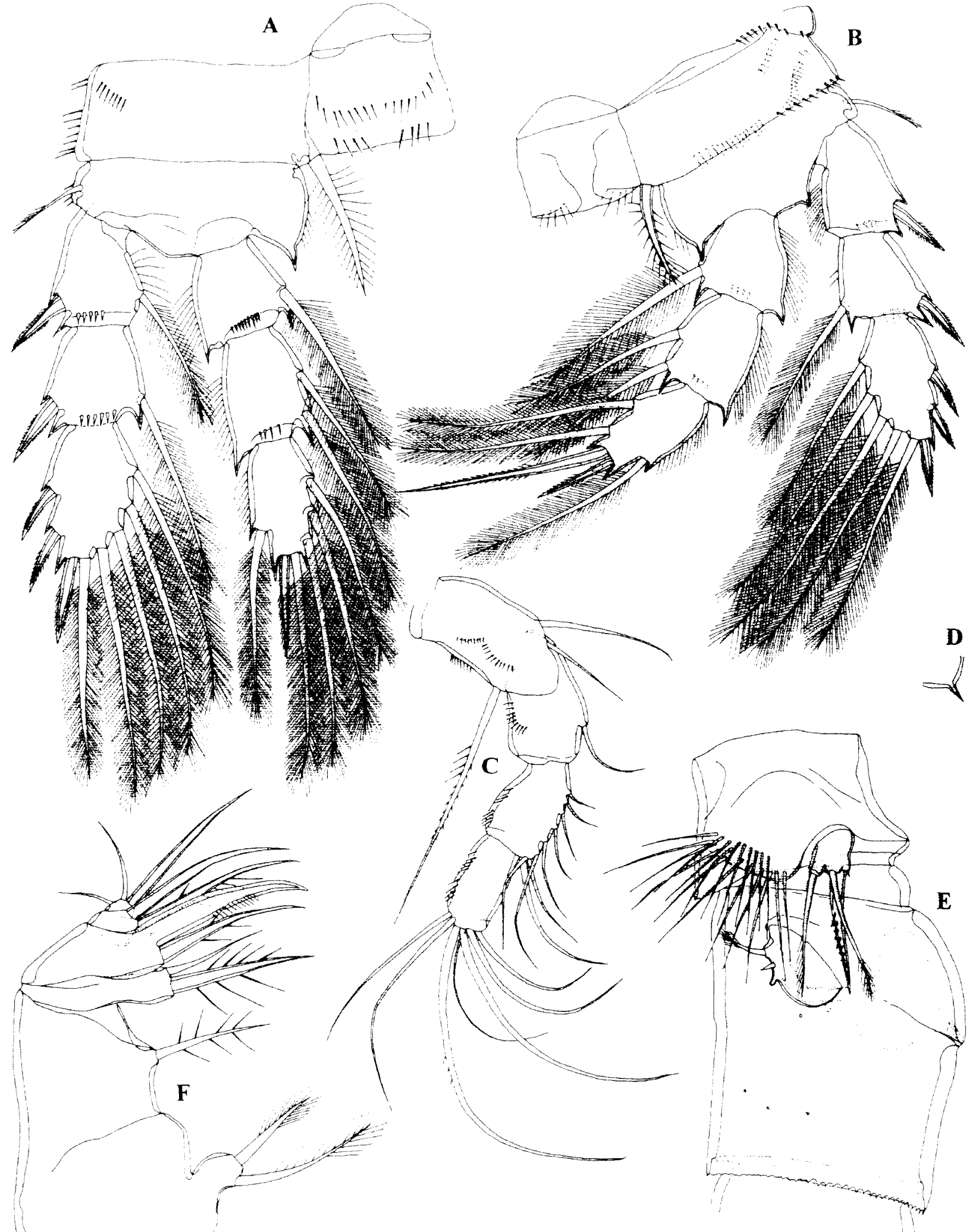

A, B, C, D, E

$\mathbf{F}$

Figure 11 Australoencrclops karaytugigen. et sp. nov, holotype (female): A, third swimming leg; B, fourth swimming leg; $C$, antenna; D, inner distal corner of basis of fourth swimming leg; $E$, first urosomite and genital double somite, lateral view; $\mathrm{F}$, maxilla. Scales $=0.1 \mathrm{~mm}$. 
transverse row of spinules on posterior margin ventrally and two cuticular pores ventrally. Anal sinus widely opened, ornamented with two diagonal rows of minute spinules.

Caudal rami (Figure 12A) about three times as long as wide, parallel, with very small space between them. Armature and ornamentation similar to female, except innermost apical setae almost as long as outermost ones.

Antennula (Figure 12B) of almost equal length as cephalothorax, 16-segmented, digeniculate, with geniculations between ninth and tenth and between fourteenth and fifteenth segments. First segment with short, diagonal row of spinules; other segments without ornamentation. Fourteenth and fifteenth segments with characteristic cuticular structures (geniculation blades). Aesthetasc formula: 2.1.1.1.1.1.1.0.1.0.0.0.0.0.0.1. All aesthetascs slender and all, except that on sixteenth segment, with bunch of hairs apically. Setal formula: 6.3.1.1.1.1.1.2.2.2.3.1.1.0.1.11. Setae on eleventh, twelfth and thirteenth segments characteristically modified, spiniform. Only three spiniform setae and single seta on fifteenth segment pinnate at their distal ends and only two setae (one on fifteenth and one on sixteenth segments) articulating on basal part.

Antenna, labrum, mandibula, maxillula, maxilla, maxilliped and swimming legs (Figure 12E) similar to female.

Fifth leg (Figure 12A, C) also similar to female, except innermost spine slightly less robust.

Sixth leg (Figure 12A, C) distinct large plate, armed with one spine and two pinnate setae; ornamented with one cuticular pore proximally and with short row of spinules at base of spine. Outermost seta about as long as spine and 1.5 times as long as middle seta. Spine on sixth leg longer and more robust than that on fifth leg.

\section{Variability}

Unfortunately, besides the holotype and allotype, only one paratype adult female was collected and studied, although not dissected. It was somewhat shorter $(0.508 \mathrm{~mm})$ than the holotype but no other type of variability was observed.

\section{Etymology}

The species is named in honour of Dr Süphan Karaytug from the Balikesir University (Turkey), in recognition of his numerous recent contributions to the knowledge of the eucyclopinid copepods and especially the genus Paracyclops. The name is a noun in the genitive singular.

\section{Discussion}

The subfamily Eucyclopinae Kiefer, 1927 presently encompasses about 185 species and subspecies, which are mostly benthic in freshwater habitats and classified into nine valid genera (Dussart and Defaye 1985, Pospisil and Stoch 1997). Among other characters, Kiefer (1927) defined this subfamily by the possession of three armature elements on the terminal (or only) segment of the fifth leg. However, he (Kiefer 1930a, 1933) recognised Eucyclops teras (Graeter, 1907) (later redescribed and transferred into a separate subgenus Stygocyclops by Plesa, 1971) and Thaumasiocyclops insulanus Kiefer, 1930 also as members of the subfamily Eucyclopinae, although they have only two armature elements on the fifth leg. Heberer and Kiefer (1932) even reported one aberrant female of Eucyclops serrulatus (Fishcher, 1851) with only two armature elements on the fifth leg. There are only two other species of Eucyclopinae with fewer than three armature elements on the fifth leg. The first one is Austriocyclops vindobonae Kiefer, 1964, which was recently rediscovered, redescribed and transferred from Cyclopinae to Eucyclopinae by Pospisil and Stoch (1997). It has a completely reduced fifth leg, with only one or two setae as its remnants. It should be said that the genus Ectocyclops Brady, 1904 also has a completely reduced fifth leg but in this genus all 17 species and subspecies have retained complete armature. Tropocyclops jamaicensis Reid and Janetzky, 1996 constitutes the fifth known case (including the earlier mentioned aberrant specimen of Eucyclops serrulatus) of reduction of the number of fifth leg setae in Eucyclopinae. It was described from phytotelmata in leaf axils of Jamaican bromeliads (Reid and Janetzky 1996) and, in my opinion, represents a separate genus. It seems to me that Reid and Janetzky (1996) went to unnecessary trouble trying to widen the generic diagnosis of Tropocyclops Kiefer, 1927 but, perhaps, things will be easier to comprehend when more species are described from tropical phytotelmata or other habitats. The genera Thaumasiocyclops, Austriocyclops and the subgenus Stygocyclops are also still monospecific.

The genus Macrocyclops Claus, 1893 is the only one in the subfamily with a two-segmented fifth leg. Its nine species and subspecies have an isolated position within the Eucyclopinae also because of the nature of the outermost armature element on the apical segment (spine in Macrocyclops; outer basal seta in other genera) and probably deserves a separate subfamily status. Unfortunately, that is well beyond the scope of this monograph and a proper revision of the subfamily Eucyclopinae, not based solely on morphology, is certainly needed.

Australoeucyclops gen. nov. has an onesegmented fifth leg, with three armature elements (innermost spine and two setae), like the majority of Eucyclopinae, which are classified into the following five genera: Afrocyclops Sars, 1927 (with 


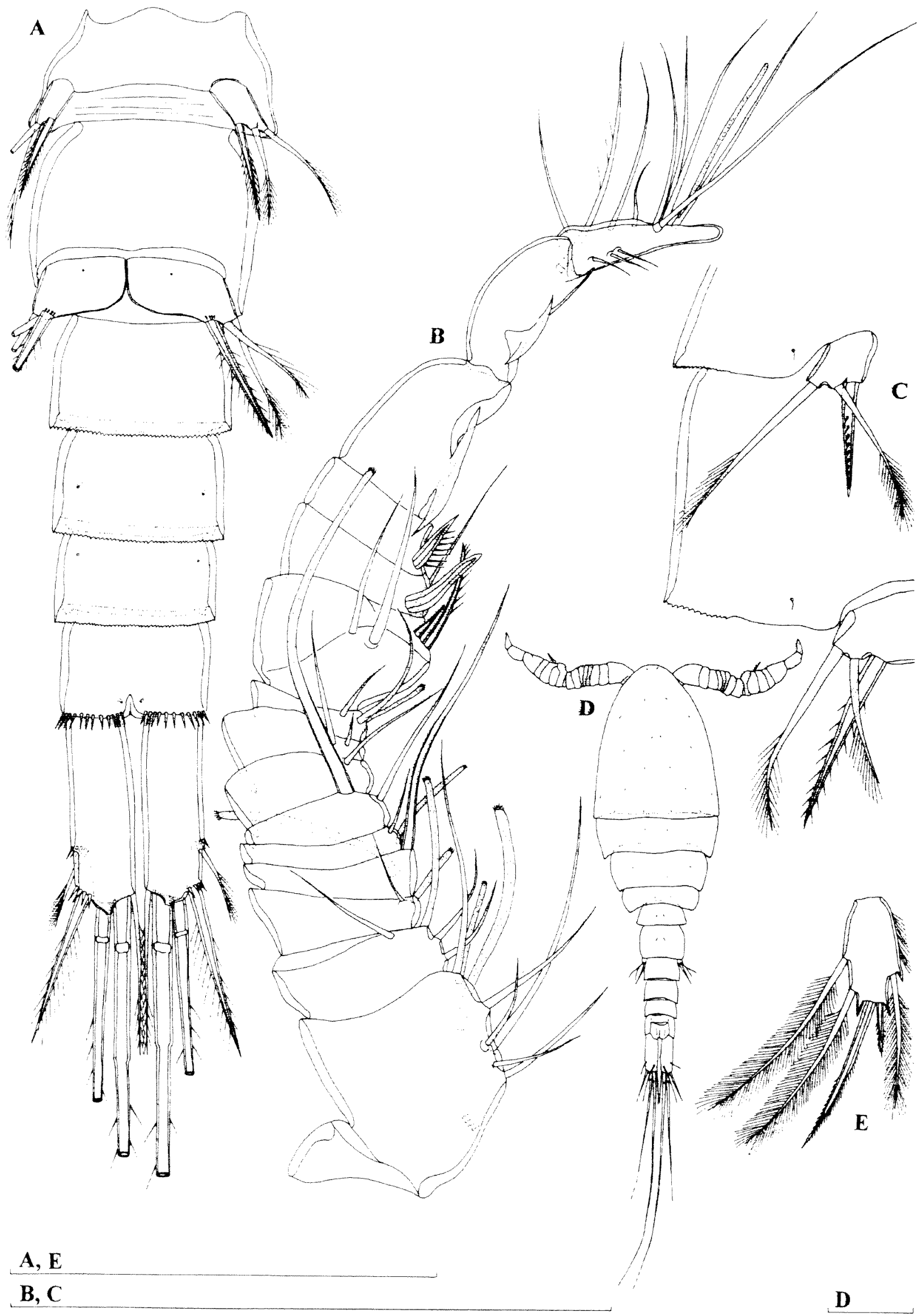

Figure 12 Australoeucyclops karaytugi gen. et sp. nov, allotype (male): A, urosome, ventral view; B, antennula; C, fifth anf sixth legs; D, habitus, dorsal view; E, third endopodal segment of fourth swimming leg. Scales $=0.1$ mm. 
11 species and subspecies), Eucyclops Claus, 1893 (over 80 species), Ochridacyclops Kiefer, 1937 (four described species and one subspecies), Paracyclops Claus, 1893 (with nearly 30 taxa) and Tropocyclops Kiefer, 1927 (containing around 30 species and subspecies). Afrocyclops is an endemic African (including Madagascar) genus ( $A$. gibsoni abbreviatus (Kiefer, 1933) is found additionally in Java and Bali). It is close to Eucyclops but clearly distinguished by the position of a lateral seta on the terminal segment of the female antennula, an exceptionally long spine on the sixth leg in male, a smooth outer margin of the caudal rami and the spine formula of the swimming legs 2(3).3.3.3 (see Einsle 1971). Tropocyclops is the only genus in the subfamily without characteristic aesthetascs on the male antennulae (they are smooth, like in Cyclopinae); it also has a very characteristic seminal receptacle and an exceptionally long inner apical spine on the third endopodal segment of the fourth swimming leg.

Ochridacyclops was described from a freshwater sponge from Lake Ohrid (Macedonia) by Kiefer (1937). Petkovski (1954) described a separate subspecies of the type species from another sponge from Lake Prespa (also Macedonia) and another new species was later described from streams in Kwangtung (China) by Shen and Tai (1964) (see also Shen et al. 1979). Two species described from Japan by Karaytug et al. (1996) and Ishida (2002a) in the genus Ochridacyclops are obvious members of Eucyclops, from which the former can be distinguished by the 11-segmented female antennulae. A few species of Eucyclops have also been reported with 11-segmented antennulae but they are most probably aberrant specimens (or they had partly fused segments). My examination of $E$. inarmatus Kiefer, 1932 from Montenegro (unpublished data) showed clearly 12-segmented antennulae, unlike those in the original description (see Kiefer, 1932), although all specimens had a very characteristic enormous transformed seta on the fourth segment.

Australoeucyclops gen. nov. is most closely related to the genera Eucyclops and Paracyclops. Australoeucyclops karaytugi sp. nov. is chosen as the type species, because it has the most complete description, but the oldest known species is Paracyclops eucyclopoides Kiefer, 1929. The latter species was described from Lombok (near Java) by Kiefer (1929c) and later reported and redescribed from Sumatra, Java and Bali (Heberer and Kiefer 1932, Kiefer, 1933). Heberer and Kiefer (1932) and Kiefer (1933) noted mixed characters of Paracyclops and Eucyclops in this species (a factor reflected also in Kiefer's (1929c) choice of specific name) but it was not until much later (Kiefer 1969) that its spine formula was corrected (3.4.3.3 instead of 3.4.4.3). The second species, now in my new genus, was described from South Australia by Lindberg (1948), as Eucyclops linderi, and included with the same name in his list of Australian cyclopoids (Lindberg 1953). Morton (1990) formally transferred this species into the genus Paracyclops, which also reflects its quite unsettled position. The third species included in the genus Australoeucyclops was described from New South Wales as Paracyclops timmsi by Kiefer (1969), who also noted its very close relationship with $P$. eucyclopoides but failed to recognise its similarity with Lindberg's Eucyclops linderi. Finally, Lewis (1974) described Paracyclops waiariki from New Zealand and noted that "it does not conform precisely to the generic description". This species was redescribed in detail by Karaytug and Boxshall (1998a), although without any mention of its questionable position in the genus Paracyclops. In addition to Australoeucyclops karaytugi sp. nov. I have examined another new species from this genus from the Margaret River region of Western Australia, which will be published elsewhere.

The genus Paracyclops was recently partly revised (Karaytug and Boxshall 1998a, b) and studied extensively (Karaytug and Boxshall 1996, 1998c, 1999, Karaytug et al. 1998). Although Karaytug and Boxshall (1998b) redescribed the type species and designated a neotype, they failed to revise the generic diagnosis and its relationships with the other Eucyclopinae. In fact, not a single species was synonymized for the first time in this revision nor was its taxonomic status within the genus questioned. Consequently, species described in other genera (like Eucyclops linderi) were not discussed or transferred into Paracyclops. Karaytug and Boxshall (1998b) merely found it "interesting to note" that a $0.5 \mathrm{~m}$ deep puddle near St Petersburg (Russia) contained three almost indistinguishable "species" (something that would be very surprising even in tropical rainforest), which they redescribed without questioning their validity. However, the abovementioned publications by Karaytug and Boxshall have made an enormous contribution to the knowledge of the Eucyclopinae, especially through very detailed redescriptions and drawings of many species. Besides Paracyclops waiariki, which is now included in the genus Australoeucyclops, Karaytug and Boxshall (1998a) redescribed two other species with 12-segmented antennulae, neither of which I would include into the new genus: Paracyclops yeatmani Daggett and Davis, 1974 is either a member of Eucyclops or a new genus; and P. smileyi Strayer, 1988 is only partly redescribed and has a different spine formula, much shorter antennula and caudal rami, as well as some other reductions of the mouth parts and swimming legs.

The genus Australoeucyclops is well defined by its slender habitus, caudal rami shape, 12- 
segmented antennulae, spine formula, absence of inner seta on the first exopodal segment of the fourth leg and its fifth leg shape. Although, it combines characteristics of Paracyclops and Eucyclops this is not to suggest a need for fusion of these two genera, since the type species of each genus is associated with a large flock of morphologically and ecologically very similar species. Australoeucyclops is also very well defined zoogeographically, containing species from only Australia, New Zealand and Indonesia. As I already have one new species in preparation (other than $A$. karaytugi), I suspect many more species will be described from the Australian and New Zealand subterranean and surface waters. Also many Western Australian species preliminary identified as "Paracyclops sp.", by Jane McRae and Stuart Halse from the CALM may prove to be members of this genus. As Australoencyclops already numbers five described species, it is reasonable to present below a key to aid in their identification.

1. Innemost apical seta on caudal rami longer than outermost one ..... .. 2

- Innermost seta shorter. Australoeucyclops karaytugi sp. nov.

2. Caudal rami with smooth surface..... 3

- Caudal rami ornamented with numerous minute spinules both ventrally and dorsally .... Australoeucyclops waiariki (Lewis, 1974) comb. nov.

3. Inner apical spine on third endopodal segment of fourth leg longer than semgent

Same spine about as long as segment Australoeucyclops lingeri (Lindberg, 1948) comb. nov.

4. Spine on fifth leg about as long as two setae.... .... Australoeucyclops eucyclopoides (Kiefer, 1929) com. nov.

- Same spine much shorter.... Australoeucyclops timmsi (Kiefer, 1969) comb. nov.

\section{Subfamily Cyclopinae Kiefer, 1927}

Genus Thermocyclops Kiefer, 1937

Thermocyclops aberrans Lindberg, 1952 Figures 13-15

\section{Synonymy}

Thermocyclops operculatus aberrans subsp. nov. Lindberg, 1952: 12, Figures 3a-d.

Thermocvclops operculifer aberrans Lindberg Lindberg, 1954: 6; Dussart and Defaye, 1985: 130; Herbst, 1986: 173 .

Thermocyclops cf. schmeili (Poppe and Mrázek) Fernando and Ponvi, 1981: 119, Figures 17-21.
Thermocyclops operculifer Kiefer - Defaye et al., 1987: 3150, Figures 35-42.

[non] Mesocyclops (Thermocyclops) operculifer n.sp. - Kiefer, 1930b: 187, Figures 6-10.

[non] Mesocyclops (Thermocyclops) operculifer Kiefer - Heberer and Kiefer, 1932: 252, Figures 35-38.

[non] Thermocyclops operculifer (Kiefer) Lindberg, 1954: 6, Figure 2; Dussart and Defaye, 1985: 130; Herbst, 1986: 173.

\section{Material Examined}

1) Australia, Pilbara, Ore Body 23, about $4.5 \mathrm{~km}$ north of Ophthalmia Dam, bore W004, sample 58.1, February 2001, leg. G. Humphreys, J. Bradbury and K. Armstrong (BES: 5595), 2320'16"S 119 50'11"E: four females + one copepodid (one female dissected on two slides (WAM C34227); one female dissected on one slide (WAM C28651); others in alcohol (WAM C28652))

2) Australia, Pilbara, Mulga Downs Station, Salt Well, 5 September 2000, leg. W.F. Humphreys (BES: $8477), 22^{\circ} 17^{\prime} 42^{\prime \prime} \mathrm{S} 118^{\circ} 47^{\prime} 22^{\prime \prime} \mathrm{E}$ : one copepodid in alcohol (WAM C 28653)

\section{Redescription of female}

Body length, excluding caudal setae, $0.85 \mathrm{~mm}$. Habitus (Figure 13A) robust, with prosome/ urosome ratio 1.3 and greatest width at posterior end of cephalothorax. Body length/width ratio about 2.7; cephalothorax 2.7 times as wide as genital double somite. Free pedigerous somites without pronounced lateral expansions, except in fourth pedigerous somites, which lateral corner slightly protruded. Colour of preserved specimen yellowish. Nauplius eye not visible. Rostrum well developed, membranous, very broad and furnished with two large sensilla.

Cephalothorax slightly shorter than its greatest width; represents $36 \%$ of total body length. Surface of cephalic shield with large sensilla; no other ornamentation visible. Hyaline fringe of prosomites narrow and smooth. All free pedigerous somites ornamented dorsally with four sensilla. Fifth pedigerous somite with smooth fringe dorsally and ventrally (Figure 13A, B).

Genital double somite (Figure 13B) about as long as wide, ornamented with two large sensilla dorsally at middle and with two sensilla and two cuticular pores ventrally near posterior end. Hyaline fringe of genital double and two subsequent somites sharply serrated both ventrally and dorsally. Copulatory pore small, ovoid; copulatory duct short, rigidly sclerotized. Seminal receptacle relatively large, representing $77 \%$ of double somite width and $51 \%$ of its length; anterior expansion about 0.4 times as long as posterior one but much broader and arched in ventral vew; 

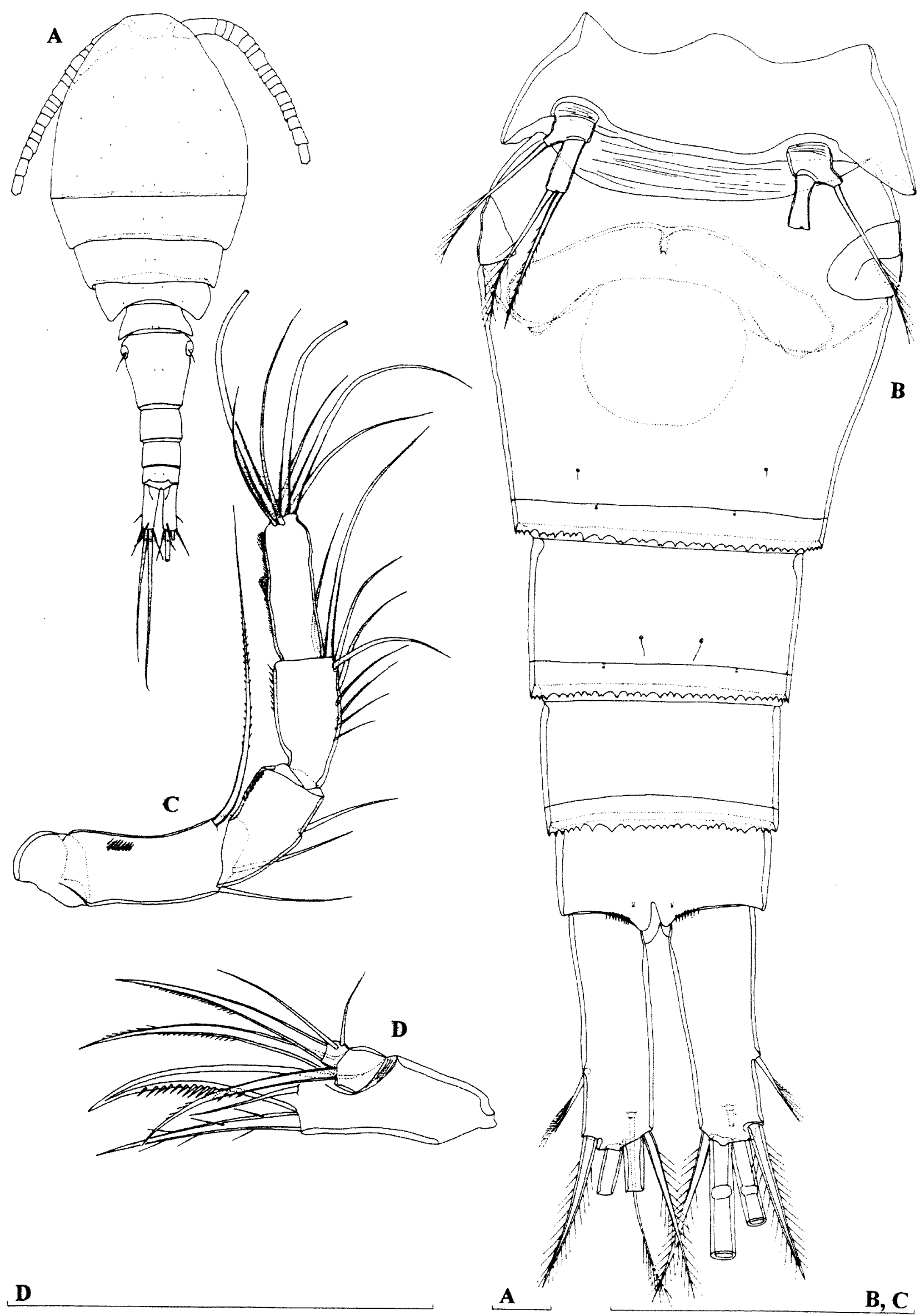

\section{D}

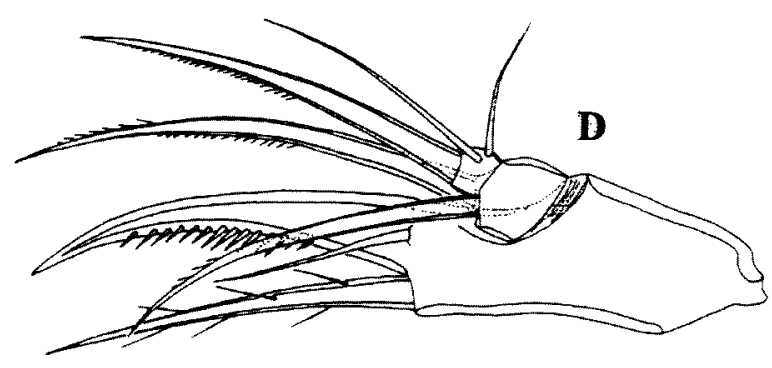

Figure 13 Thermocyclops aberrans Lindberg, 1952, female: A, habitus, dorsal view; B, urosome, ventral view; C, antenna; D, basis and endopod of maxilla. Scales $=0.1 \mathrm{~mm}$. 
posterior expansion ovoid (Figure 13B). Parts of oviducts rigidly sclerotized. Ovipores situated dorsolaterally, covered by reduced sixth legs, bearing two minute spines and one pinnate seta. Third urosomite ornamented with two ventral cuticular pores and two sensilla; fourth somite without any ornamentation. Anal somite with smooth, broad, short and slightly convex anal operculum, which represents $52 \%$ of somite's width and not extending beyond posterior margin of somite (Figure 14C); ornamented with two large sensilla dorsally and very short transverse row of spinules on posterior margin ventrally and two cuticular pores also ventrally (Figure 13B). Anal sinus not widely opened, without visible ornamentation.

Caudal rami (Figure 13B and 14C) 3.1 times as long as wide, slightly divergent, without any visible ornamentation, with space between them about one third of ramus' width. Dorsal seta about 0.7 times as long as ramus, inserted at $6 / 7$ of ramus length, uniarticulate at base and uniplumose distally. Lateral seta arising at $2 / 3$ of ramus length, uniplumose and longer than ramus width. Outermost apical seta stout, spiniform, about 0.7 times as long as ramus, bipinnate. Innermost apical seta also bipinnate and stout but not as much as outermost apical one, and only slightly longer than outermost apical or dorsal. Principal apical setae with breaking planes; inner seta about 1.2 times as long as outer one and 0.3 times as long as body.

Antennula (Figure 14D) reaching posterior margin of cephalothorax, 17-segmented, with one slender aesthetasc on twelfth and seventeenth segments each and setal formula: 8.4.2.6.3.1.1.1.1.0.1.1.0.1.2.2.7. No setae with breaking planes or articulating on basal part. All setae slender and most setae smooth, only 7 setae $(17 \%)$ plumose or pinnate at their distal parts. Ornamentation consists of short transverse row of spinules and three rows of cuticular pits on first segment, one row of cuticular pits on fourth segment and several minute spinules at base of seta on eleventh segment. Length ratio of antennular segments, from proximal end and along caudal margins, $1: 0.3: 0.2: 0.5: 0.3: 0.2: 0.6: 0.3: 0.3: 0.3$ $: 0.3: 0.4: 0.2: 0.3: 0.4: 0.6: 0.7$

Antenna (Figure 13C) five-segmented, comprising short coxa, basis and three-segmented endopod. Coxa partly fused to basis on frontal surface. Basis about three times as long as wide, ornamented with short longitudinal row of spinules on frontal surface; armed with two smooth setae at distal inner comer and with pinnate seta representing exopod, which slightly reaches beyond tip of appendage. First endopodal segment armed with one smooth seta, ornamented with longitudinal row of spinules along external margin. Second endopodal segment about twice as long as wide, also omamented with longitudinal row of spinules, armed with nine smooth setae (seven lateral, two subapical; one subapical seta much stronger than any other seta on that segment and about twice as long as segment). Third endopodal segment 3.2 times as long as wide, armed with seven apical setae (strongest one with several pinnules; others smooth) and ornamented as previous segment.

Labrum (Figure 14A) trapezoidal, ornamented with two bunches of 11 long and slender spinules on ventral surface. Cutting edge slightly concave, with 11 sharp teeth between produced and serrated lateral corners. No other ornamentation visible.

Mandibula with small but distinct palp, armed with two very long, finely plumed setae and one short, smooth, seta on distal end (Figure 15D). Coxal gnathobase cutting edge with very strong teeth and outermost pinnate seta, which longer than short seta on palp.

Maxillula composed of well developed praecoxa and two-segmented palp. Arthrite of praecoxa with four strong apical spines; only one distinct and ornamented with two setules; others smooth and completely fused to praecoxa. Praecoxa armed with seven armature elements along inner margin, longest one plumose. Palp (Figure 14B) with distinct endopod, which bearing three smooth setae (outermost longest), and armed laterally with one exopodal smooth seta and apically with two slender setae (one smooth, other unipinnate) and one robust, strongly bipinnate spine. Palp somewhat shorter than arthrite of praecoxa.

Maxilla (Figure 13D) unornamented and fivesegmented but praecoxa fused to coxa on posterior surface and also partly on anterior surface. Proximal endite of praecoxa elongate, robust, armed with two pinnate setae, distal endite small, unarmed. Proximal endite of coxa with one strong, bipinnate seta; distal endite highly mobile, elongate and armed apically with proximal strong and pinnate setae and distal smooth, slender and shorter one. Basis expanded into robust claw, ornamented with longitudinal row of strong spinules along concave margin and armed with two setae; strong seta as long as claw, bipinnate. Endopod two-segmented; proximal segment armed with two robust, pinnate setae; distal segment with one robust, pinnate, apical seta and two slender, smooth, subapical setae. Longest seta on distal endopodal segment about 1.1 times as long as strong seta on basis.

Maxilliped (Figure 15E) four-segmented, composed of syncoxa, basis and two-segmented endopod. Syncoxa unomamented but armed with three setae; middle seta strongest, bipinnate, about as long as segment and almost twice as long as most proximal, bipinnate seta or most distal, smooth one. Basis 1.3 times as long as wide, ornamented with several short rows of spinules and armed with two bipinnate setae; proximal seta 1.8 times as long as 


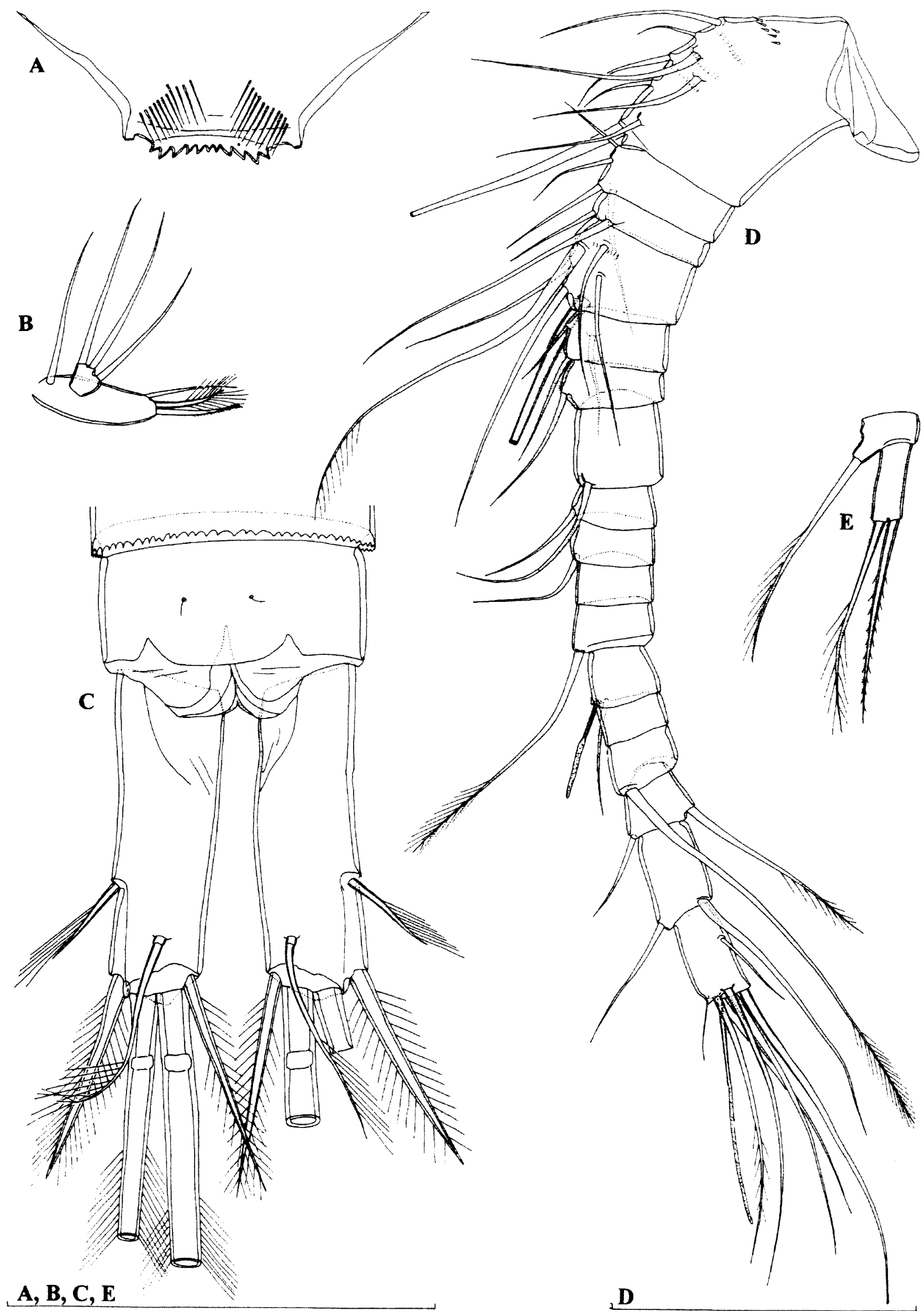

Figure 14 Thermocyclops aberrans Lindberg, 1952, female: A, labrum; B, maxillular palp; C, anal somite and caudal rami, dorsal view; $D$, antennula; $E$, fifth leg. Scales $=0.1 \mathrm{~mm}$. 


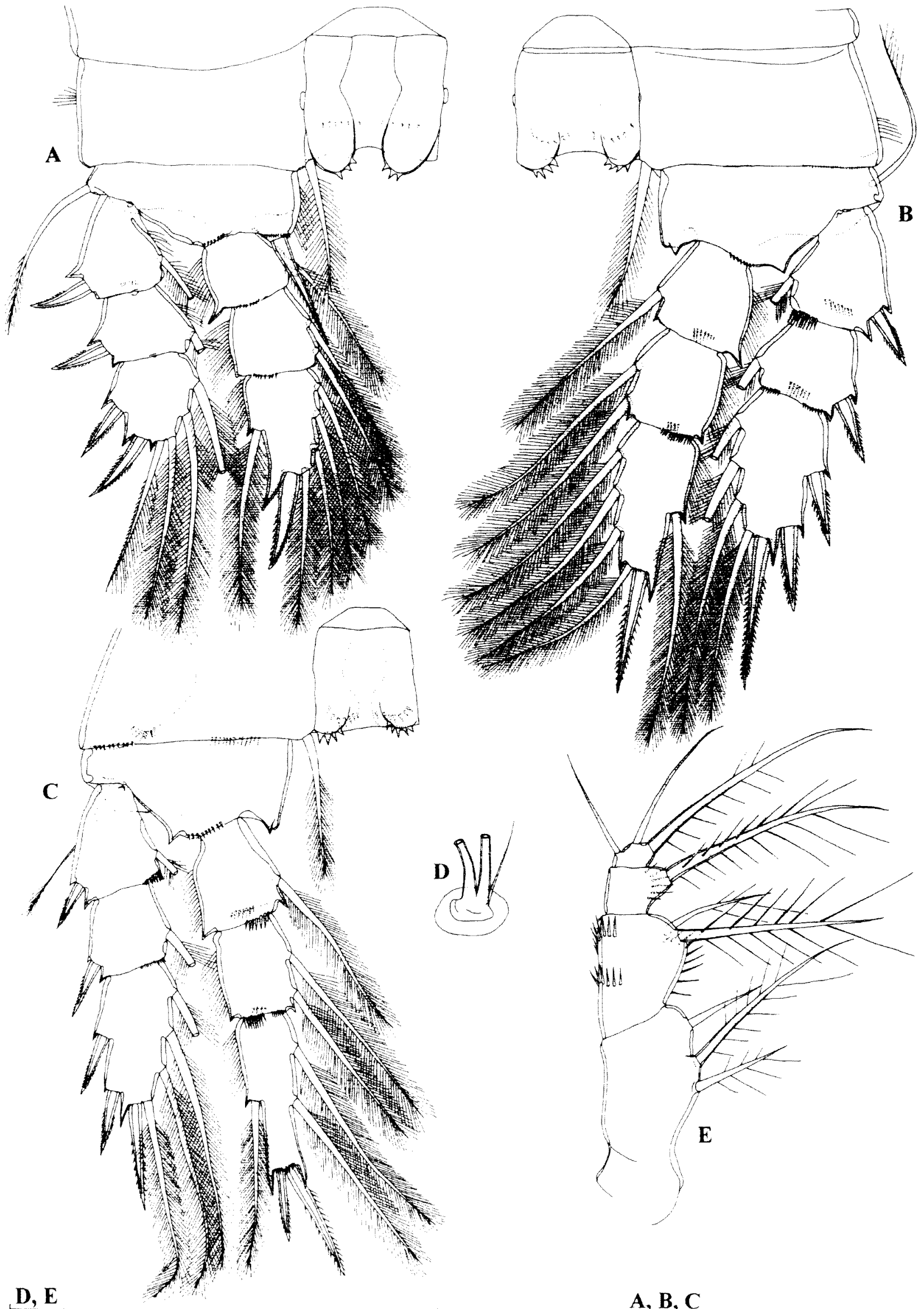

Figure 15 Thermocyclops aberrans Lindberg, 1952, female: A, first swimming leg; B, third swimming leg; C, fourth swimming leg; D, mandibular palp; E, maxilliped. Scales $=0.1 \mathrm{~mm}$. 
distal one. First endopodal segment ornamented with one arched row of strong spinules and armed with one strong, bipinnate seta. Second endopodal segment very small, unornamented but armed with two smooth and one bipinnate seta; bipinnate seta innermost, about 1.7 times as long as middle one and almost 2.3 times as outermost seta. All pinnate setae with very long pinnules.

All swimming legs with three-segmented exopod and endopod (Figure 15A, B, C). Armature formula of swimming legs as follows (legend: inner/outer spine or seta; inner/terminal/outer):

\begin{tabular}{lcccccc} 
& \multicolumn{3}{c}{ Exopod } & \multicolumn{3}{c}{ Endopod } \\
Segments & 1 & 2 & 3 & 1 & 2 & 3 \\
First leg & $1 / 1$ & $1 / 1$ & $2 / 2 / 2$ & $1 / 0$ & $2 / 0$ & $3 / 2 / 1$ \\
Second leg & $1 / 1$ & $1 / 1$ & $3 / 2 / 2$ & $1 / 0$ & $2 / 0$ & $3 / 2 / 1$ \\
Third leg & $1 / 1$ & $1 / 1$ & $3 / 2 / 2$ & $1 / 0$ & $2 / 0$ & $3 / 2 / 1$ \\
Fourth leg & $1 / 1$ & $1 / 1$ & $3 / 2 / 2$ & $1 / 0$ & $2 / 0$ & $2 / 2 / 1$
\end{tabular}

Third exopodal segment spine formula: 2.3 .3 .3 . Intercoxal sclerites of all swimming legs with sharply serrated rounded protrusions at both sides of distal margin, ornamented additionally with one interrupted row of spinules each. All coxae ornamented with several rows of spinules and armed with plumose seta at inner distal corner. Spine inserted at inner, protruded corner of basis of first leg reaching halfway of second endopodal segment (Figure 15A). All setae slender and plumose. First and second segment of both exopod and endopod of each leg with short row of spinules along distal margin, sometimes on both sides. Basis with one row of spinules at base of each endopod; basis of first leg with aditional row of spinules at base of inner spine and one row of hair-like spinules along inner margin. Third endopodal segment of fourth swimming leg about 2.6 times as long as wide; inner apical spine about 1.6 times as long as outer one and about 0.8 times as long as segment (Figure 15C).

Fifth leg (Figure 13B and 14E) two-segmented, unornamented, with membranous joint with fifth pedigerous somite. Basal segment almost twice as wide as long, armed with lateral uniplumose seta inserted on elongated setophore. Distal segment much narrower, about 2.7 times as long as wide, armed apically with inner spine and outer seta, which subequal and slightly more than 2.5 times as long as segment.

Sixth leg distinct, more or less oval, cuticular plate, armed with two almost equally long minute smooth spines and one bipinnate and much longer seta; median spine distinct, other one completely fused to leg.

\section{Variability}

Body length of females ranges from $0.792 \mathrm{~mm}$ to $0.885 \mathrm{~mm}(0.85 \mathrm{~mm}$ average; $\mathrm{n}=4)$. No other type of variability was observed.

\section{Discussion}

The genus Thermocyclops Kiefer, 1927 today comprises more than fifty valid species and subspecies (Defaye et al. 1987, Baribwegure et al. 2000, Boxshall and Halsey 2004), distributed mainly in tropical areas, with the centre of diversity in Africa south of the Sahara. Herbst (1986) reviewed world records and provided a key to females for 50 species and subspecies recognised by him at the time, none of them from Australia. So far only two widely distributed (possibly cosmopolitan) species have been reported, although not illustrated, from this continent (Tait et al. 1984, Timms and Morton 1988, Halse et al. 2000b): Thermocyclops decipiens (Kiefer, 1929) and T. crassus (Fischer, 1853). The former species was actually reported as Mesocyclops decipiens by Tait et al. (1984) and the latter one as Mesocyclops hyalinus. Timms and Morton (1988) found $T$. decipiens to be very frequent throughout tropical Australia, while $T$. crassus seemed to have a restricted distribution in the tropics but was widespread in temperate Australia. Thermocyclops aberrans Lindberg, 1952 stat. nov. is the third named Australian representative of this genus, although an undescribed species of Thermocyclops has been recorded in Western Australia by Pinder et al. (2004). The diversity of the genus seems to be constrained in Australia by a relatively long period of arid climate, even in the tropical and subtropical regions. The taxonomy of $T$. aberrans is somewhat confused, even in the light of the recent discovery, and deserves to be further discussed.

Kiefer (1930b) described one new species of Thermocyclops (in those days only a subgenus of Mesocyclops) from Lombok Island (Indonesia) as Mesocyclops (Thermocyclops) operculifer (see Synonymy). Its very unusual long anal operculum clearly separated it from other members of the genus, a fact reflected also in Kiefer's (1930b) choice of specific name. Heberer and Kiefer (1932) redescribed this species after collecting additional material, also from Lombok Island. Two decades later Lindberg (1954) found morphologically almost identical population of this species on one of the Gilbert Islands (Kiribati) and described the male for the first time. However, two years earlier (Lindberg, 1952) he had described a new subspecies of Thermocyclops operculifer from Cambodia, as $T$. operculatus aberrans. This obvious misspelling of the specific name was latter corrected (Lindberg, 1954), although he did not further discuss differences between the two subspecies. This probably encouraged Defaye et al. (1987) to believe that the differences between the two are not significant, as they described one population with a short anal operculum from Java as $T$. operculifer, although their drawings agreed completely with the description of $T$. operculifer aberrans. One of the 
possible motivations for this could be a close proximity of their population to the type locality of the nominotypical subspecies, as the subspecies aberrans was known at that time only from Cambodia. However, they (Defaye et al., 1987) failed to recognise the similarity of their material with a population from an unspecified locality in Malaysia, which Fernando and Ponyi (1981) had shortly beforehand described and illustrated and tentatively assigned as Thermocyclops cf. schmeili. Fernando and Ponyi (1981) did not compare their material with either $T$. operculifer or $T$. operculifer aberrans but they suggested that their population might represent a new species.

After examining material from the Pilbara, which is morphologically very similar to $T$. operculifer aberrans, and assessing all the abovementioned literature, I strongly believe that the two forms are actually two distinct species. Although all published descriptions and illustrations are incomplete, they are adequate enough to permit a clear distinction between these two species. Not only has $T$. aberrans a much shorter anal operculum than $T$. operculifer (which is an autapomorphy of the latter species) but they can be distinguished by at least three other morphological characters: the absence of cuticular pits on the urosomites (probably a plesiomorphy of $T$. operculifer, since $T$. aberrans has retained some cuticular pits on proximal segments of the antennula), a shorter inner apical spine on the third endopodal segment of the fourth swimming leg and a somewhat shorter inner apical seta on the caudal rami. The last two characters are also probably plesiomorphies of $T$. operculifer, since the majority of Thermocyclops species have a very long inner spine on the fourth leg endopod and also have the inner apical seta on the caudal rami significantly longer than the outermost one.

In fact, an innermost apical seta shorter than the caudal ramus is so rare in the genus Thermocyclops that only two other taxa, besides $T$. operculifer and $T$. aberrans, have been recorded with the characteristic: T. hastatus antillensis Herbst, 1986 , from Guadeloupe (West Indies) (Herbst 1986) and T. hooki Löffler, 1968, from Kenya and Uganda (Löffler 1968, Einsle 1970). It is likely the latter species does not belong to the genus Thermocyclops, since it has a 15 -segmented antennula, and may be related to the North American Mesocyclops bernardi Petkovski, 1986. Mesocyclops bernardi was transferred to the genus Diacyclops by Reid (1993a), although she admits that "this species combines morphological features of several genera". T. hastatus antillensis can be distinguished from both $T$. operculifer and $T$. aberrans by the complete absence of cuticular pits, non-serrated hyaline fringe of the abdominal somites, different ornamentation of the intercoxal sclerite of the fourth swimming leg, equally long apical spines on the third endopodal segment of the fourth leg and some other, less important, characters.

\section{Genus Mesocyclops Sars, 1914}

\section{Mesocyclops brooksi Pesce, De Laurentiis and Humphreys, 1996}

\section{Synonymy}

Mesocyclops brooksi sp. nov. - Pesce et al., 1996a: 71, Figures 16-28.

Mesocyclops brooksi Pesce, De Laurentiis and Humphreys, 1996 - De Laurentiis et al., 1999: 256; Hotyniska and Brown, 2003: 1328; Karanovic, 2004a: 58, Figures 27-29.

\section{Material Examined}

1) Australia, Pilbara, Lake Disappointment, Ilgarari Creek, Bulloo Downs Station, well (site number 31), 7 September 2000, leg. W.F.

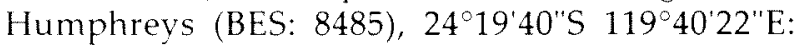
two females (one ovigerous) in alcohol (WAM C28654)

2) Australia, Pilbara, Lake Disappointment, Ilgarari Creek, Bulloo Downs Station, Old Ilgarari Well, 7 September 2000, leg. W.F. Humphreys (BES: $8489), 24^{\circ} 20^{\prime} 03^{\prime \prime} \mathrm{S} 119^{\circ} 40^{\prime} 48^{\prime \prime} \mathrm{E}$ : one female in alcohol (WAM C28655)

3) Australia, Pilbara, Mulga Downs Station, Munjong Well, 2 September 2000, leg. W.F. Humphreys (BES: 8445 ), 22 $13^{\prime} 20^{\prime \prime S} 118^{\circ} 42^{\prime} 20^{\prime \prime} \mathrm{E}$ : one female dissected on one slide (WAM C28656)

4) Australia, Pilbara, Mulga Downs Station, Silver Grass Well, 3 September 2000, leg. W.F. Humphreys (BES: 8464), 22 ${ }^{\circ} 15^{\prime} 24^{\prime \prime S} 118^{\circ} 39^{\prime} 23^{\prime \prime} \mathrm{E}$ : one female + one copepodid in alcohol (WAM C28657)

5) Australia, Pilbara, Lake Disappointment, Ilgarari Creek, Bulloo Downs Station, No 37 Government Well, 7 September 2000, leg. W.F. Humphreys (BES: 8484), 24 1849"S 11941'51"E: seven females +16 copepodids in alcohol (WAM C28658)

6) Australia, Pilbara, Newman, bore W244, 12 November 1998, leg. S.M. Eberhard (BES: 3533), $23^{\circ} 13^{\prime} \mathrm{S} 119^{\circ} \mathrm{5} 5^{\circ}$ : one copepodid in alcohol (WAM C28659)

7) Australia, Pilbara, Mulga Downs Station, Calamina Well, 3 September 2000, leg. W.F.

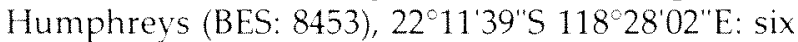
females + one copepodid in alcohol (WAM C28660)

\section{Discussion}

Mesocyclops brooksi was originally described from Bobs Well, near the Ashburton River, just south of the Pilbara region, by Pesce et al. (1996a). 
De Laurentiis et al. (1999) reported this species from another four localities in the Pilbara. Holyniska and Brown (2003) reported it from the Fortescue Marsh (in the Pilbara) but also from several localities in south-western Western Australia, based on the material of Stuart Halse and others, who have shown the species to be widely distributed through the southern half of Western Australia (Halse et al. 2000a, 2002a). There is also a single record from Townsville, Queensland (Holyńska and Brown 2003). Here, I report $M$. brooksi from another seven localities (six wells and one bore) in the Pilbara. The species is known as stygophile only from more arid parts of Western Australia but there has been little sampling of groundwater further south. In the Murchison region $M$. brooksi was found (Karanovic $2004 a)$ in 19 out of 164 samples (12\%), while in the Pilbara region I have found it only in seven out of 160 samples $(4.5 \%)$, which suggests its more scarce occurrence towards the northern part of Western Australia. The isolated (and intriguing) record from Townswille (Holyńska and Brown 2003) is the most northern and the only one from the East Coast of Australia.

\section{Mesocyclops darwini Dussart and Fernando, 1988}

\section{Synonymy}

Mesocyclops darwini nov. sp. - Dussart and Fernando, 1988: 259, Figures 71-78.

Mesocyclops darwini Dussart and Fernando Holyńska, 2000: 371, Figures 6-8 and 9C, F, G; Holyńska and Brown, 2003: 1328.

Mesocyclops rarus Kiefer - Dussart and Fernando, 1986: 291.

\section{Discussion}

I have not found any specimens of this species in subterranean waters of the Pilbara region. However, it was reported from the Fortescue Marsh in the Pilbara by Holyńska and Brown (2003), where it apparently lives sympatrically with two other congeners: $M$. brooksi Pesce, De Laurentiis and Humphreys, 1996 and M. notius Kiefer, 1981. Halse et al. (2002b) also listed this species for two springs in the Pilbara. It should be mentioned here that Moonjari Well (reported as a locality for $M$. darwini by Holyńska and Brown (2003)) is a locality (closest site) not a real well (Stuart Halse, pers. comm.).

Mesocyclops darwini is a stygoxene species, originally described by Dussart and Fernando (1988) from the inundation area of Adelaide River, near Darwin, Northern Territory. Holyńska (2000) redescribed this species and reported it from several localities from both sides of New Guinea. Unfortunately, she did not comment on small differences between the original description and her material (the length of dorsal seta on the caudal ramus, for example), although she gave very nice comparative drawings of the closely related $M$. rarus Kiefer, 1981. Holyńska and Brown (2003) additionally reported $M$. darwini from one locality in Queensland.

\section{Mesocyclops notius Kiefer, 1981}

\section{Synonymy}

Mesocyclops notius n. sp. - Kiefer, 1981: 165, Figures 5-8.

Mesocyclops notius Kiefer - Dussart and Defaye, 1985: 122; Dussart and Fernando, 1988: 259, Figures 79-85; Holyńska, 2000: 437; Holyńska and Brown, 2003: 1328

Mesocyclops leuckarti (Claus) - [partim.] Timms, 1970: 22 (fide Kiefer, 1981)

\section{Discussion}

This species was also absent from the samples I have examined but Holyńska and Brown (2003) reported it from the Fortescue Marsh in the Pilbara. Mesocyclops notius seems to be relatively rare in Western Australia and some of the early records of the species are perhaps doubtful. Confirmed records come from Lake Gregory in the southern Kimberley (Halse et al. 1998) and Fortescue Marsh (Holyńska and Brown 2003)

Kiefer (1981) described M. notius from a number of localities in New South Wales. Dussart and Fernando (1988) redescribed it from the inundation area of Adelaide River, near Darwin, Northern Territory, where it also lives sympatrically with $M$. darwini. Finally Holyńska and Brown (2003) reported $M$. notius from two localities in Queensland and two localities in Western Australia (abovementioned Fortescue Marsh and Lake Gregory). It is a stygoxene element in the copepod fauna of the Pilbara.

\section{Mesocyclops holynskae sp. nov. Figures 16-19}

\section{Material Examined}

\section{Holotype}

Female (WAM C28661), Australia, Pilbara, Weeli Wolli Spring, surface pool, 16 November 1998, leg. S.M. Eberhard (BES: 3601 and 3608), 22 ${ }^{\circ} 55^{\circ} \mathrm{S}$ $119^{\circ} 11 \mathrm{E}$ : dissected on two slides

\section{Paratypes}

Australia, Pilbara, Weeli Wolli Spring, surface pool, 16 November 1998, leg. S.M. Eberhard (BES: 3601 and 3608), $22^{\circ} 55^{\prime} \mathrm{S} 119^{\circ} 11^{\prime} \mathrm{E}$ : one female (WAM C28662) + one copepodid (WAM C28663) 


\section{Other material}

Australia, Pilbara, Mulga Downs Station, Mamamoonah Well, 2 September 2000, leg. W.F. Humphreys (BES: 8442), 22 07'28'S 118 17'16"E: one female dissected on one slide (WAM C28664)

\section{Description}

Female (holotype). Body length, excluding caudal setae, $1.13 \mathrm{~mm}$. Habitus (Figure $16 \mathrm{~B}$ ) robust, with prosome/urosome ratio 1.7 and greatest width at $2 /$ 3 of cephalothorax length. Body length/width ratio about 2.9; cephalothorax three times as wide as genital double somite. Free pedigerous somites without pronounced lateral expansions, except in fifth pedigerous somite, which lateral corner slightly protruded. Colour of preserved specimen light brown. Nauplius eye visible. Rostrum well developed, membranous, very broad and furnished with two large sensilla.

Cephalothorax about 1.2 times as long as its greatest width (Figure 16B); represents $41 \%$ of total body length. Surface of cephalic shield (Figure 19C) and tergites and pleurites of prosomites with many small sensilla and cuticular pores. Hyaline fringe of prosomites narrow and smooth. Fifth pedigerous somite with smooth fringe dorsally and ventrally, ornamented with four sensilla dorsally and without any ornamentation laterally and verntrally (Figure $16 \mathrm{C}$ and $19 \mathrm{E}$ ).

Genital double somite (Figure 16A) slightly longer than wide, ornamented with two large sensilla dorsally at middle and with two cuticular pores ventrally near posterior end. Hyaline fringe of genital double and two subsequent somites smooth both ventrally and dorsally. Copulatory pore small, ovoid; copulatory duct short, straight, rigidly sclerotized. Central part of seminal receptacle relatively large, ovoid, representing 33\% of double somite width and $58 \%$ of its length; lateral arms of receptacle very narrow, connecting in straight line with oviducts, parts of which rigidly sclerotized. Ovipores situated dorsolaterally, covered by reduced sixth legs, bearing two minute spines and one plumose seta. Third urosomite ornamented with two ventral cuticular pores; fourth somite without any ornamentation. Anal somite with smooth, narrow, very short and slightly convex anal operculum, which represents $51 \%$ of somite's width and not extending beyond anterior half of somite's length (Figure 18C); ornamented with two short sensilla dorsally and transverse row of spinules on posterior margin ventrally and two cuticular pores also ventrally (Figure 16A). Anal sinus widely opened, without visible ornamentation.

Caudal rami (Figure 16A) three times as long as wide, parallel, with little space between them; ornamented with single cuticular pore ventrally. Dorsal seta about 1.2 times as long as ramus, inserted at 6/7 of ramus length, uniarticulate at base and plumose distally. Lateral seta arising at $3 / 5$ of ramus' length, uniplumose, much longer than ramus' width and 0.6 times as long as ramus. Outermost apical seta stout, spiniform, slightly longer than ramus, bipinnate. Innermost apical seta plumose, about 2.9 times longer than outermost apical seta. Principal apical setae plumose and with breaking planes; inner seta about 1.4 times as long as outer one and 0.47 times as long as body.

Antennula (Figure $16 \mathrm{~B}$ and 19B, D) reaching beyond posterior margin of cephalothorax, 17segmented, with one slender aesthetasc on twelfth and seventeenth segments each (latter one sharing common base with one terminal seta) and setal formula: 8.4 .2 .6 .3 .2 .2 .1 .1 .0 .1 .1 .0 .1 .1 .3 .7 . No setae with breaking planes or articulating on basal part. One seta on sixth segment short, all other setae slender; one seta on sixteenth segment minute (Figure 19B). Ornamentation consists of short transverse row of spinules on first segment, and finely serrated hyaline lamella on last two segments.

Antenna (Figure 19A) four-segmented, comprising coxobasis and three-segmented endopod; all segments of about same length. Coxobasis about 2.4 times as long as wide, ornamented on frontal surface with three rows of spinules near external margin (middle row with strongest spinules) and with two diagonal rows of minute spinules proximally near internal margin; caudal surface with two longitudinal rows of spinules along external margin; additional row of minute spinules proximally along internal margin. Coxobasis armed with two smooth setae at distal inner corner and with pinnate seta representing exopod, which slightly reaches beyond tip of appendage. First endopodal segment armed with one smooth seta, ornamented with longitudinal row of spinules along external margin. Second endopodal segment about 1.8 times as long as wide, also ornamented with longitudinal row of spinules, armed with nine smooth setae (seven lateral, two subapical; one subapical seta longer and much stronger than any other seta on that segment). Third endopodal segment 2.3 times as long as wide, armed with seven apical setae and ornamented as previous segment.

Labrum (Figure 18D) trapezoidal, ornamented with two bunches of 15 long and slender spinules on ventral surface. Cutting edge short and concave, with 10 blunt teeth between produced and rounded lateral corners. No other ornamentation visible.

Mandibula (Figure 17B) ornamented with three short rows of small spinules near small but distinct palp, which armed with two very long, finely plumed setae and one short, smooth, seta on distal end. Coxal gnathobase cutting edge with eight strong smooth teeth, four long spinules at base of 


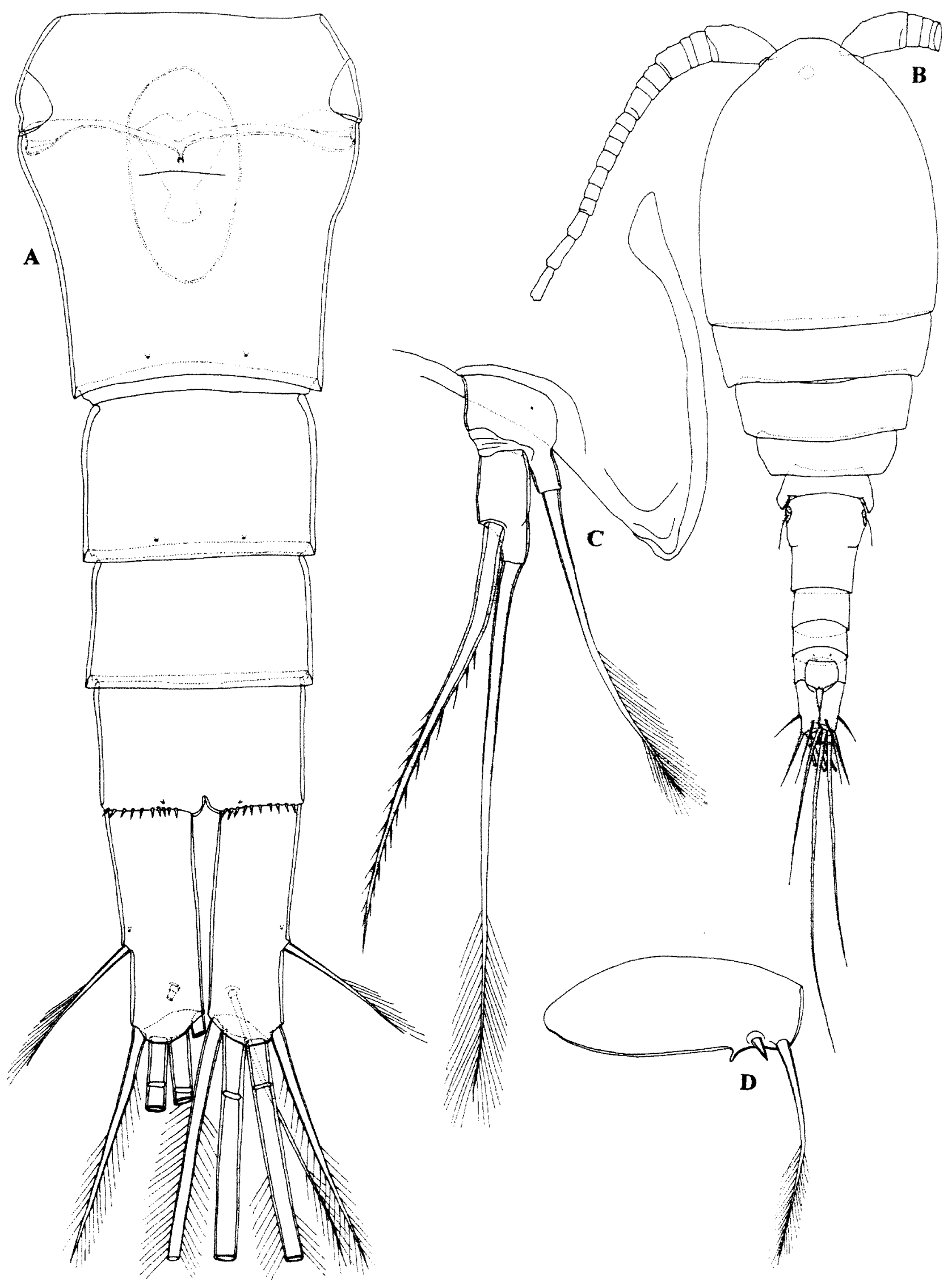

\section{C, D}

Figure 16 Mesocyclops holynskae sp. nov., holotype (female): A, abdomen, ventral view; B, habitus, dorsal view; C, fifth leg, ventral view; $D$, sixth leg. Scales $=0.1 \mathrm{~mm}$. 


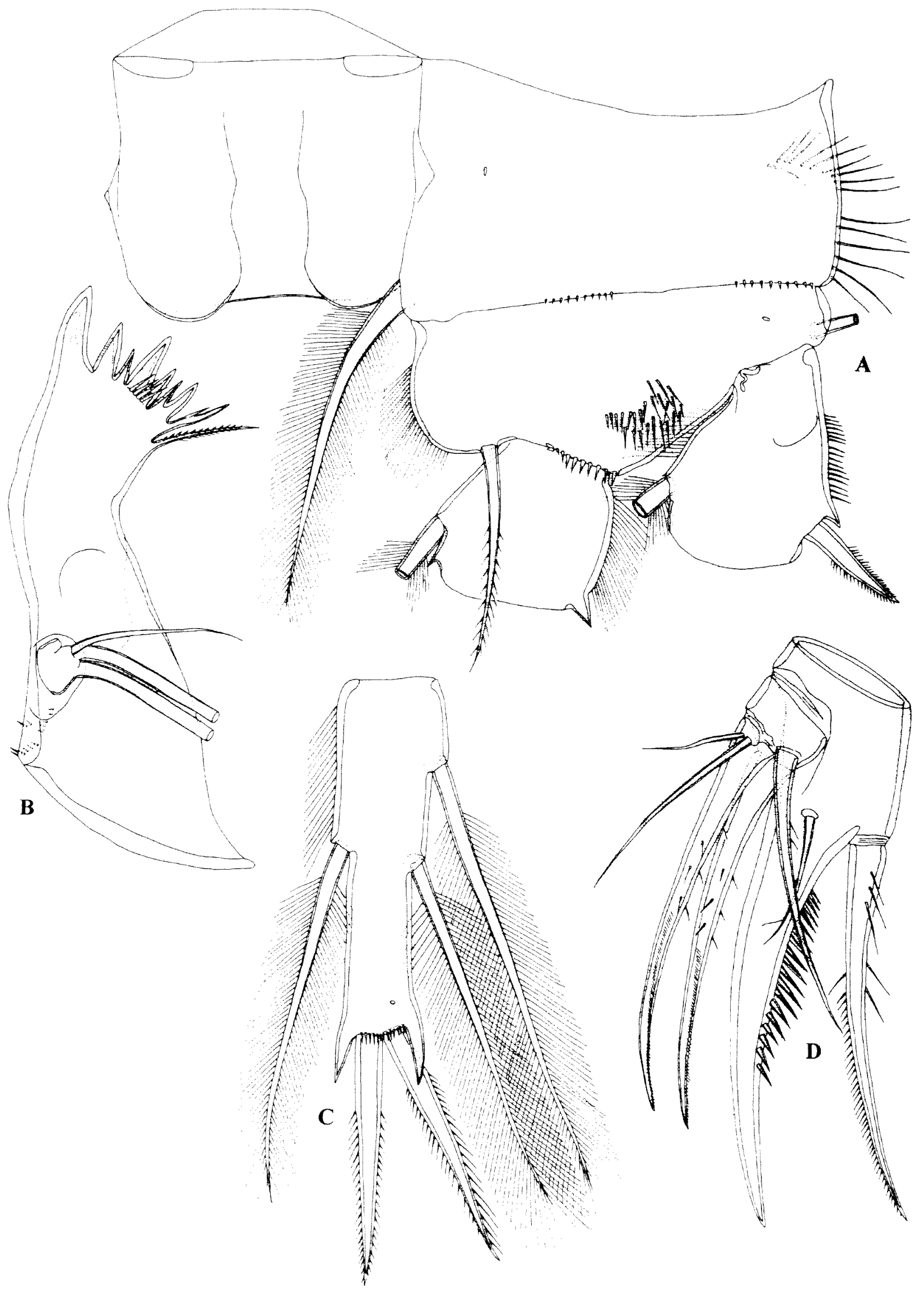

Figure 17 Mesocyclops holynskat sp. now, holotype (female): A, first swimming leg, without second and third endopodal and exopodal segments; B, mandibula; $C$, third endopodal segment of fourth swimming leg; D, basis and endopod of maxilla. Scale $=0.1 \mathrm{~mm}$. 
fourth spine, and outermost bipinnate seta, which shorter than short seta on palp. First, second, fourth and eighth spines (from inner side) complex; other four spines simple.

Maxillula composed of well developed praecoxa and two-segmented palp. Arthrite of praecoxa with four strong apical spines; praecoxa armed additionally with seven armature elements along inner margin, longest one plumose. Palp (Figure 19F) with distinct endopod, which bearing two apical and one lateral setae (outermost apical seta longest and strongest), and armed laterally with one exopodal smooth seta and apically with two slender setae (one smooth, other unipinnate) and one robust, bipinnate spine. Palp somewhat shorter than arthrite of praecoxa.

Maxilla (Figure 17D) unornamented and fivesegmented but praecoxa fused to coxa on posterior surface and also partly on anterior surface. Proximal endite of praecoxa elongate, robust, armed with two pinnate setae, distal endite small, unarmed. Proximal endite of coxa with one strong, bipinnate seta; distal endite highly mobile, elongate and armed apically with proximal strong and pinnate seta and distal smooth, slender and shorter one. Basis expanded into robust claw, ornamented with longitudinal row of strong spinules along concave margin (middle spinules strongest) and armed with two setae; strong seta as long as claw, bipinnate. Endopod two-segmented; proximal segment armed with two robust, pinnate setae; distal segment very small, with one robust, pinnate, apical seta and two slender, smooth, subapical setae; part of distal segment fused with base of apical robust seta. Longest seta on distal endopodal segment about as long as strong seta on basis.

Maxilliped (Figure 18B) four-segmented, composed of syncoxa, basis and two-segmented endopod. Syncoxa unornamented but armed with three strongly pinnate setae; middle seta strongest, about as long as segment, twice as long as most proximal one and 1.5 times as long as most distal seta. Basis 2.4 times as long as wide, ornamented with one arched row of very long spinules along inner margin and two fields of shorter spinules near outer margin; armed with two pinnate setae, proximal seta 1.4 times as long as distal one. First endopodal segment unornamented and armed with one strong, bipinnate seta. Second endopodal segment small, unornamented but armed with three setae; innermost seta bipinnate and strongest, about 1.6 times as long as middle, unipinnate seta and almost 4.2 times as outermost, smooth one. All pinnate setae with very long pinnules; that on first endopodal segment and innermost seta on second endopodal segment with additional row of short spinules along convex margin distally.

All swimming legs with three-segmented exopods and endopods. Armature formula of swimming legs as follows (legend: inner/outer spine or seta; inner/terminal/outer):

\begin{tabular}{|c|c|c|c|c|c|c|}
\hline \multirow[b]{2}{*}{ Segments } & \multicolumn{3}{|c|}{ Exopod } & \multicolumn{3}{|c|}{ Endopod } \\
\hline & 1 & 2 & 3 & 1 & 2 & 3 \\
\hline First leg & $1 / 1$ & $1 / 1$ & $2 / 2 / 2$ & $1 / 0$ & $2 / 0$ & $3 / 2 / 1$ \\
\hline Second leg & $1 / 1$ & $1 / 1$ & $3 / 2 / 2$ & $1 / 0$ & $2 / 0$ & $3 / 2 / 1$ \\
\hline Third leg & $1 / 1$ & $1 / 1$ & $3 / 2 / 2$ & $1 / 0$ & $2 / 0$ & $3 / 2 / 1$ \\
\hline Fourth leg & $1 / 1$ & $1 / 1$ & $3 / 2 / 2$ & $1 / 0$ & $2 / 0$ & $2 / 2 / 1$ \\
\hline
\end{tabular}

Third exopodal segment spine formula: 2.3.3.3. Intercoxal sclerite of first swimming leg with smooth rounded protrusion at each side of distal margin; other swimming legs with sharply pointed and very long protrusions; no other ornamentation visible. All coxae ornamented with several rows of spinules and armed with plumose seta at inner distal corner; coxa of fourth leg (Figure 18A) with only two rows of spinules on frontal surface along posterior margin, while caudal surface ornamented with five rows of spinules. Spine inserted at inner, protruded corner of basis of first leg very slender, reaching halfway of second endopodal segment (Figure 17A). All setae slender and plumose. First and second segment of both exopod and endopod of each leg with short row of spinules along distal margin, sometimes on both sides. Basis with one row of spinules at base of each endopod; basis of first leg with additional field of spinules at middle and one row of hair-like spinules along inner margin. Third endopodal segment of fourth swimming leg (Figure 17C) about 3.2 times as long as wide, with well produced latero-distal corners and ornamented with one row of spinules at base of apical spines, one row of hairs along proximal part of outer margin and one cuticular pore distally; both apical spines of almost same length, about 0.7 times as long as segment.

Fifth leg (Figure 16C and 19E) two-segmented. Basal segment wider than long, with single cuticular pore near proximal outer corner; armed with lateral plumose seta inserted on elongated setophore. Distal segment much narrower, about 2.1 times as long as wide, unornamented and armed with apical seta and lateral spine; apical seta plumose distally, about 1.2 times as long as lateral, strongly pinnate spine and more than 4.5 times as long as segment.

Sixth leg (Figure 16D) distinct, more or less oval, cuticular plate, armed with two almost equally long minute smooth spines and one plumose and much longer seta, which reaches halfway of gential double somite; median spine distinct, other one completely fused to leg.

Male. Unknown.

\section{Variability}

Body length of females ranges from $1.12 \mathrm{~mm}$ to $1.292 \mathrm{~mm}(1.18 \mathrm{~mm}$ average; $\mathrm{n}=3)$. No other type of variability was observed. 


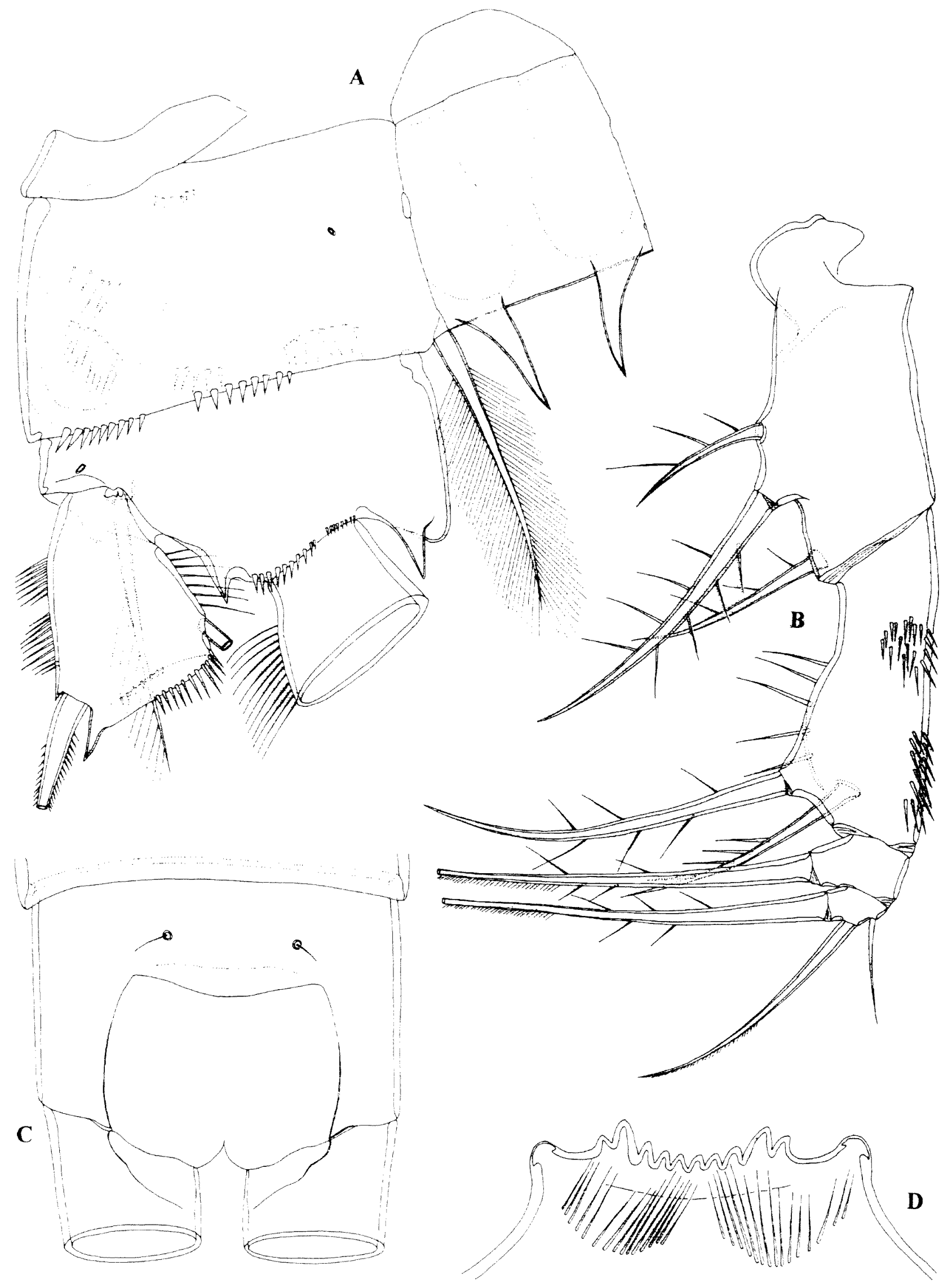

Figure 18 Mesocyclops holynskae sp. nov., holotype (female): A, fourth swimming leg, basal part; B, maxilliped; C, anal somite, dorsal view; $D$, labrum. Scale $=0.1 \mathrm{~mm}$. 


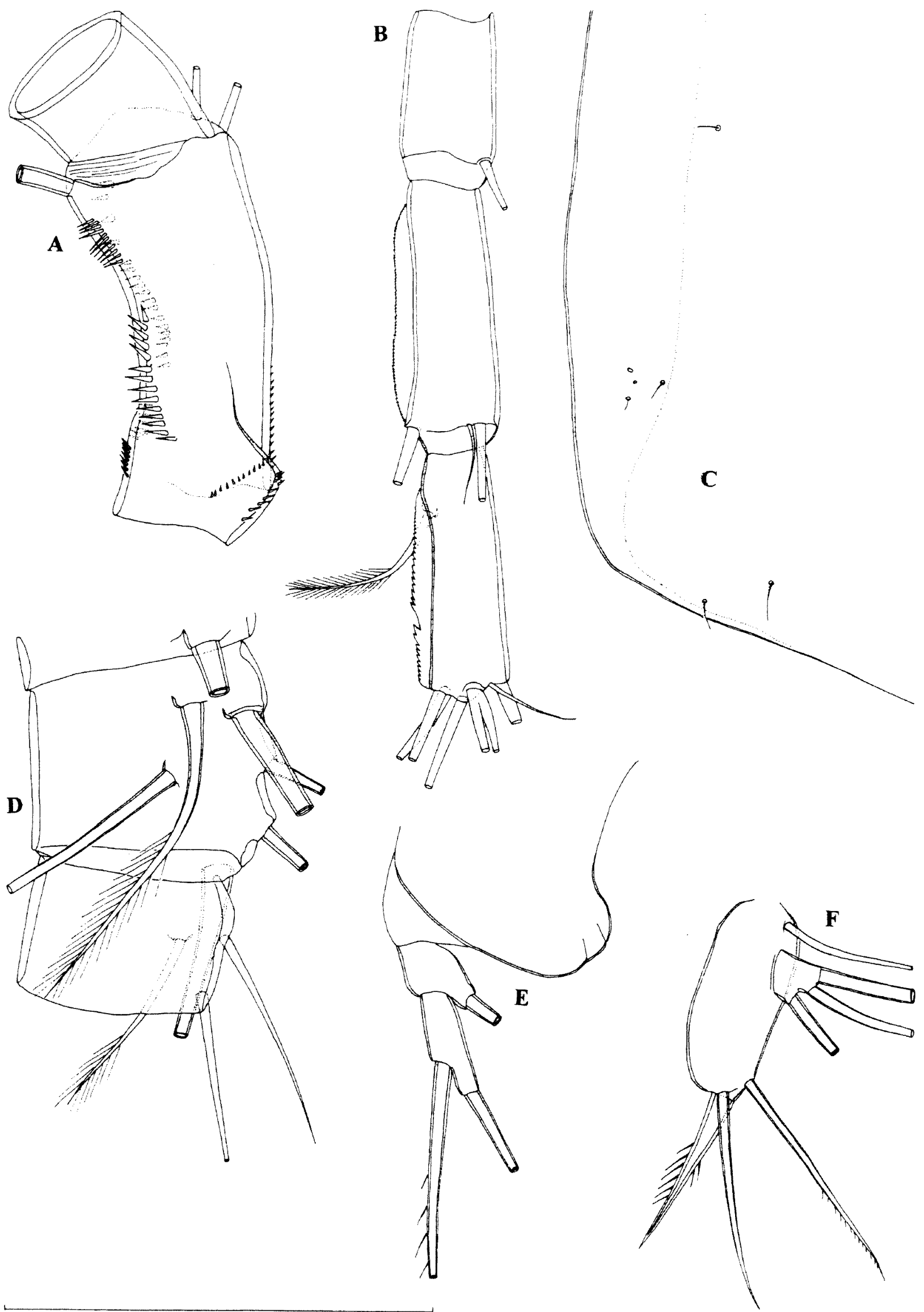

Figure 19 Mesocyclops holynskae sp. nov., holotype (female): A, basis of antenna; B, antennula, three most distal segments; C, cephalic shield, left posterior lateral corner; D, antennula, fourth and fifth segments; $E$, fifth leg, lateral view; F, maxillular palp. Scale $=0.1 \mathrm{~mm}$. 


\section{Etymology}

This species is named in honour of Dr Maria Holyriska from the Museum and Institute of Zoology in Warsaw (Poland), in recognition of her outstanding work on the Australian and Asian Mesocvclops species. The name is a noun in the genitive singular.

\section{Discussion}

In the last two decades, and relying on the pioneering studies by Kiefer (1981) and Van de Velde (1984), our knowledge about the species definitions within the genus Mesocyclops Sars, 1914 increased tremendously (Ghenne and Fiers 2000). The demonstrated diagnostic significance of several "microcharacters" paved the way for further taxonomic and zoogeographical improvements. The genus, as currently known, contains 68 species and subspecies (Holyniska 2000), the overwhelming majority of which inhabit tropical and subtropical surface freshwaters. In Australia Mesocyclops seems to be quite diverse (unlike the previously mentioned genus Thermocyclops), with 11 recorded species: M. acanthoramus Holyńska and Brown, 2003; M. aspericornis (Daday, 1906); $M$. australiensis (Sars, 1908); M. brooksi Pesce, De Laurentiis and Humphreys, 1996; M. cuttacuttae Dumont and Maas, 1985; M. darwini Dussart and Fernando, 1988; $M$. notius Kiefer, 1981; $M$. papuensis Van de Velde, 1987; M. pseudoannae Van de Velde, 1987; M. pubiventris Holyńska and Brown, 2003; and M. woutersi Van de Velde, 1987. A key to all of them, together with some other "expected" species, was provided by Holyniska and Brown (2003). Holyniska (2000) suggested that records of $M$. annae Kiefer, 1930 and $M$. pehpeiensis $\mathrm{Hu}, 1943$ on this continent (Tait et al. 1984, Dussart and Fernando 1986) are probably referable to their close Australian relatives, $M$. pseudoannae and $M$. papuensis.

Mesocyclops holynskae sp. nov. is very similar to $M$. darwini, a species already recorded in the Pilbara. Both $M$. holynskae and $M$. darwini share the following, supposedly plesiomorphic, features: seminal receptacle with narrow lateral arms (or long receptacle ducts); medial spine on the basis of first leg present; caudal spinule pattern of the basis of antenna simple; serrated hyaline membrane of ultimate segment of antennula not extending beyond medial seta (see Holyniska 2000). They also have a very similar ornamentation of coxa and basis of the first swimming leg and relatively similar fourth swimming leg. However, the shape and the relative size of the seminal receptacle are quite different in these two species: $M$. holynskae has a much smaller and almost perfectly ellipsoid receptacle and a very short duct, without posterior chitinous part. The shape of the seminal receptacle and copulatory duct are so similar in the original description of $M$. darwini by Dussart and Fernando (1988) and in the redescription of this species by Holyriska (2000), that I have to exclude the possibility of intraspecific variability. Lack of any ornamentation on the first maxillipedal segment, smooth hyaline fringe of all urosomites and only one big notch in the serrate hyaline membrane of the ultimate antennular segment further distinguish M. holynskae from M. darwini. Holyńska (2000) reported much shorter dorsal caudal setae in $M$. darwini than those in my specimens, which are more like those in the original description of $M$. darwini (see Dussart and Fernando 1988). This could be a consequence of a different angle these armature elements form with the caudal rami, leading to a false conclusion of their different length.

The perfectly ellipsoid seminal receptacle, without a posterior ridge near the copulatory pore, found in $M$. holynskae, is rare in the genus Mesocyclops. Mesocyclops reidae Petkovski, 1986 is the only species with the same shape and size of the seminal receptacle and genital area. This species was described by Petkovski (1986a) from Colombia and redescribed later by Reid (1993a) from the United States and Honduras. It differs from $M$. holynskae in a number of characters, including caudal rami shape, ornamentation of the fifth pedigerous somite and fifth leg shape. An ellipsoid seminal receptacle was also found in the South African M. tenuisaccus (Sars, 1927) by Van de Velde (1984) but the receptacle is very small in this species and the chitinized area around the copulatory pore is different from that in M. holynskae. More or less ellipsoid seminal receptacles (although with different position and shape of the area around copulatory pore) were also noted in the following four South American species: $M$. annulatus (Wierzejski, 1892); M. ellipticus Kiefer, 1936; M. intermedius Pesce, 1985; and M. meridianus (Kiefer, 1926). They all differ markedly from M. holynskae.

\section{Genus Orbuscyclops gen. nov.}

\section{Diagnosis}

Very small Cyclopinae, with slender (harpacticoidal) habitus and greatest width at midlength of cephalothorax. Cephalothorax of female about 1.5 times as wide as genital double somite. Hyaline fringe of all somites narrow and smooth. Integument not strongly chitinized, ornamented only with few sensilla on each prosomite and pair of sensilla on first, second and last (anal) urosomites. Anal operculum broad, smooth and convex, just reaching posterior margin of anal somite. Caudal rami less than twice as long as wide, parallel; dorsal seta about as long as ramus, while outermost and innermost apical setae much 
shorter. Female genital double somite with small receptacle and small copulatory pore; ovipores situated laterally, at midlength. Antennula in female short, nine segmented. Antenna foursegmented, without exopod and with setal formula: 1.1.5.7. Labrum trapezoidal, with 15 small sharp teeth. Mandibula with two long and one short seta on reduced palp. Maxillula with one-segmented palp; endopod with only two setae. Maxilla fivesegmented; proximal endite of praecoxa armed with single seta; distal endopodal segment with three setae. Maxilliped four segmented, with setal formula: 1.1.1.2. Exopod of first swimming leg twosegmented; all other exopods and endopods of swimming legs three-segmented; all legs with inner coxal seta and first leg with inner basal spine; last exopodal segment spine formula: 3.3.3.3; first exopodal segment of all legs without inner seta; third endopodal segment of fourth leg with two apical spines; intercoxal sclerites of all legs smooth. No sexual dimorphism in swimming legs. Fifth leg very small, two segmented, inserted ventrally; basal segment wider than long, with lateral seta on very short setophore; distal segment narrower, somewhat longer than wide, with two apical, equally long and plumose setae, which are almost twice as long as segment. Sixth leg in female semicircular, with two short spines and one, much longer, seta. Sixth leg in male large quadriform plate, with inner short spine and two longer setae. Antennula in male 14-segmented, digeniculate, with only two smooth aesthetascs on first segment.

\section{Type and only species}

Orbuscyclops westaustraliensis sp. nov.

\section{Etymology}

The generic name is composed of the Latin adjective "orbus" (meaning "orphan" and refering to its isolated position in the subfamily) and the existing generic name Cyclops. Gender masculine.

\section{Orbuscyclops westaustraliensis sp. nov.}

Figures 20-22

\section{Material Examined}

\section{Holotype}

Female (WAM C28665), Australia, Pilbara, Robe River, bore G70730104, post-purge, 14 November 2002, leg. J. Cocking and M. Scanlon (CALM), $21^{\circ} 34^{\prime} 53^{\prime \prime S} 115^{\circ} 52^{\prime} 14^{\prime \prime E}$ : dissected on two slides

\section{Allotype}

Male (WAM C28666), Australia, Pilbara, Robe River, bore G70730104, post-purge, 14 November 2002, leg. J. Cocking and M. Scanlon (CALM), $21^{\circ} 34^{\prime} 53^{\prime \prime} \mathrm{S} 115^{\circ} 52^{\prime} 14^{\prime \prime} \mathrm{E}$ : dissected on two slides

\section{Topotype}

Australia, Pilbara, Robe River, bore G70730104, pre-purge, 14 November 2002, leg. J. Cocking and M. Scanlon (CALM), 21 34'53'S 114'52'14'E: one male in alcohol (WAM C28667)

\section{Other material}

Australia, Pilbara, near Mount Turner, bore NWSLK248, 20 November 2002, leg. J. Cocking and M. Scanlon (CALM), 22 43'04"S 117 30'38'E: one male dissected on one slide (WAM C28668)

\section{Description}

Female (holotype). Body length, excluding caudal setae, $0.287 \mathrm{~mm}$. Habitus (Figure 20B, D) slender, with prosome/urosome ratio 1.3 and greatest width at midlength of cephalothorax. Body length/width ratio about 3.9; cephalothorax 1.5 times as wide as genital double somite. Free pedigerous somites without pronounced lateral expansions. Colour of preserved specimen yellowish. Nauplius eye not visible. Rostrum well developed, membranous, very broad and furnished with two large sensilla.

Cephalothorax (Figure 20B) almost 1.4 times as long as its greatest width; represents $35 \%$ of total body length. Surface of cephalic shield with few sensilla; no other ornamentation visible. Hyaline fringe of prosomites narrow and smooth. All free pedigerous somites ornamented dorsally with few sensilla. More or less sclerotized joint (as pseudosomite) present between prosome and urosome, as well as between fifth pedigerous somite and genital double somite. Fifth pedigerous somite with smooth fringe dorsally and ventrally, ornamented only with two dorsal sensilla.

Genital double somite (Figure 20A) about as long as wide, ornamented only with two large sensilla dorsally at middle. Hyaline fringe of genital double and two subsequent somites smooth both ventrally and dorsally. Copulatory pore small, ovoid; copulatory duct short, not sclerotized. Seminal receptacle relatively small, almost quadriform, about 2.3 times as wide as long, representing $50 \%$ of double somite width and $24 \%$ of its length; anterior expansion with somewhat convex anterior margin, about 1.5 times as long as posterior expansion, which has straight posterior margin. Parts of oviducts rigidly sclerotized. Ovipores situated laterally, at midlength of double somite, covered by reduced sixth legs, which bearing two minute spines and one pinnate seta. Third and fourth urosomites without any ornamentation visible. Anal somite with smooth, broad and convex anal operculum, which represents $56 \%$ of somite's width and reaches posterior margin of somite (Figure 21E); ornamented with two large sensilla dorsally and without transverse row of spinules on posterior margin ventrally. Anal sinus not widely opened, without visible ornamentation. 


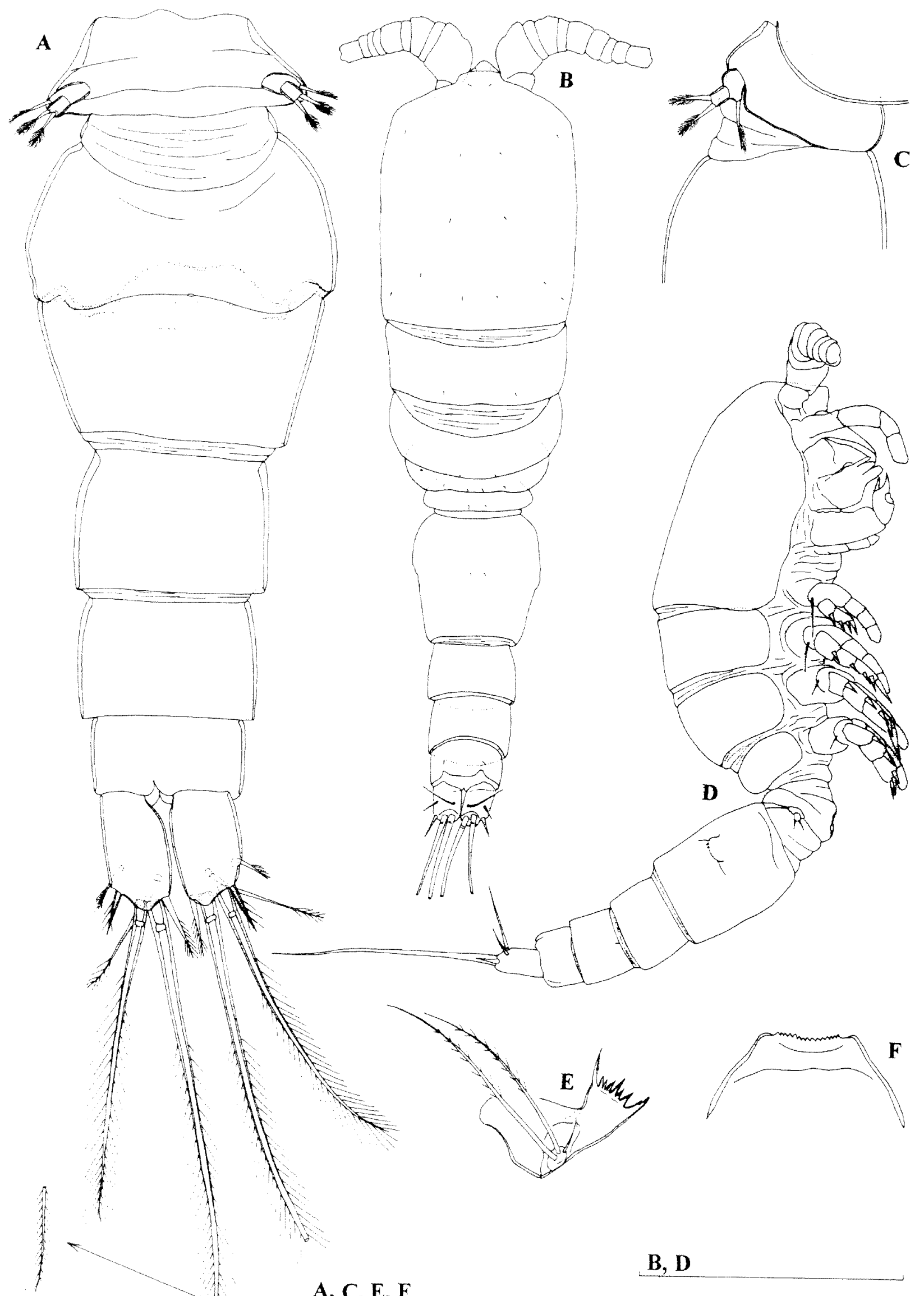

A, C, E, F

Figure 20 Orbuscyclops westaustraliensis gen. et sp. nov, holotype (female): A, urosome, ventral view; B, habitus, dorsal view; $C$, first urosomite, with fifth leg, lateral view; D, habitus, lateral view; E, mandibula; F, labrum. Scales $=0.1 \mathrm{~mm}$. 
Caudal rami (Figure 20A and 21E) 1.8 times as long as wide, parallel, with space between them about one third of ramus' width; without any visible ornamentation. Dorsal seta about 1.1 times as long as ramus, inserted at $4 / 5$ of ramus length, uniarticulate at base and bipinnate distally. Lateral seta arising somewhat dorsolaterally at $3 / 4$ of ramus length, uniplumose and shorter than ramus width. Outermost apical seta stout, spiniform, about 0.5 times as long as ramus, bipinnate. Innermost apical seta also bipinnate and stout but not as much as outermost apical one, and about 1.2 times as long as outermost apical seta. Principal apical setae plumose and with breaking planes; inner seta about 1.6 times as long as outer one and 0.3 times as long as body.

Antennula (Figure $21 \mathrm{~F}$ ) reaching to middle of cephalothorax, nine-segmented, unornamented, with one slender aesthetasc on ninth segment and setal formula: 7.3.5.2.4.2.1.2.5. No setae with breaking planes or articulating on basal part; all setae slender, smooth and relatively short. Length ratio of antennular segments, from proximal end and along caudal margins, $1: 0.3: 0.4: 0.4: 1: 0.7$ : $0.5: 0.7: 1.1$.

Antenna (Figure 21G) four-segmented, comprising short coxobasis and three-segmented endopod; all endopodal segments of about same length, coxobasis somewhat longer. Coxobasis about 2.3 times as long as wide, ornamented with short row of spinules along external margin proximally, armed with single smooth seta at distal inner corner. First endopodal segment armed with one smooth seta at middle, ornamented with short transverse row of long spinules near external margin. Second endopodal segment about 1.8 times as long as wide, ornamented with longitudinal row of spinules along external margin, armed with five smooth setae (three lateral, two subapical; one subapical seta somewhat longer and much stronger than any other seta on this segment). Third endopodal segment 1.9 times as long as wide, armed with seven smooth apical setae (four of which strong and claw-like) and ornamented as previous segment.

Labrum (Figure 20F) trapezoidal, unornamented and relatively large. Cutting edge slightly concave, with 15 small and sharp teeth between produced, rounded lateral corners.

Mandibula (Figure 20E) with small and not clearly distinct palp, armed with two very long, bipinnate setae and one short, smooth, seta on distal end. Coxal gnathobase cutting edge with eight very strong teeth (innermost strongest and complex; others simple) and outermost pinnate seta, which as long as short seta on palp.

Maxillula (Figure 21L) composed of well developed praecoxa and one-segmented palp. Arthrite of praecoxa with four strong apical spines; only one distinct and ornamented with two setules; others smooth and completely fused to praecoxa. Praecoxa armed with five armature elements along inner margin, longest one plumose. Palp with endopod basally fused to coxobasis, which bears two smooth apical setae; armed laterally with one exopodal smooth seta and apically with two smooth slender setae and one robust, strongly bipinnate spine. Palp clearly shorter than arthrite of praecoxa.

Maxilla (Figure 21H) unornamented and fivesegmented but praecoxa fused to coxa on posterior surface and also partly on anterior surface. Proximal endite of praecoxa small, armed with one bipinnate setae; distal endite small, unarmed. Proximal endite of coxa with one short, bipinnate seta; distal endite highly mobile, elongate and armed apically with two smooth setae (proximal seta about 1.7 times as long as distal one). Basis expanded into robust unornamented claw, armed with two setae; strong seta longer than claw, unipinnate; other seta minute. Endopod two-segmented; proximal segment armed with two robust, unipinnate setae; distal segment with one robust, unipinnate, apical seta and two slender, smooth, and almost equally long subapical setae. Longest seta on distal endopodal segment about as long as strong seta on basis.

Maxilliped (Figure $21 \mathrm{~K}$ ) four-segmented, composed of syncoxa, basis and two-segmented endopod. Syncoxa 1.8 times as long as wide ornamented with few spinules along outer margin, armed with single bipinnate seta, which about 0.8 times as long as segment. Basis 1.4 times as long as wide, ornamented with two short rows of spinules near outer margin and with one row of very long spinules along inner margin, armed with single bipinnate setae, which 1.2 times as long as segment. First endopodal segment unornamented and armed with one strong, unipinnate seta; this seta longest and strongest on maxilliped. Second endopodal segment very small, unornamented but armed with two setae; inner seta unipinnate, about 1.2 times as long as outer, smooth one. All pinnate setae with very long pinnules.

First swimming leg (Figure 21A) with twosegmented exopod and three-segmented endopod; all other swimming legs with three-segmented exopod and endopod (Figure 21B, C, D). Armature formula of swimming legs as follows (legend: inner/ outer spine or seta; inner/terminal/outer):

\begin{tabular}{|c|c|c|c|c|c|c|}
\hline \multirow[b]{2}{*}{ Segments } & \multicolumn{3}{|c|}{ Exopod } & \multicolumn{3}{|c|}{ Endopod } \\
\hline & 1 & 2 & 3 & 1 & 2 & 3 \\
\hline First leg & $0 / 1$ & $2 / 2 / 3$ & - & $1 / 0$ & $1 / 0$ & $2 / 1 / 1$ \\
\hline Second leg & $0 / 1$ & $1 / 1$ & $2 / 2 / 2$ & $1 / 0$ & $1 / 0$ & $1 / 2 / 1$ \\
\hline Third leg & $0 / 1$ & $1 / 1$ & $2 / 2 / 2$ & $1 / 0$ & $1 / 0$ & $2 / 2 / 1$ \\
\hline Fourth leg & $0 / 1$ & $1 / 1$ & $2 / 2 / 2$ & $1 / 0$ & $1 / 0$ & $2 / 2 / 1$ \\
\hline
\end{tabular}

Last exopodal segment spine formula: 3.3.3.3. Intercoxal sclerites of all swimming legs unornamented, with smooth and bilobate distal 


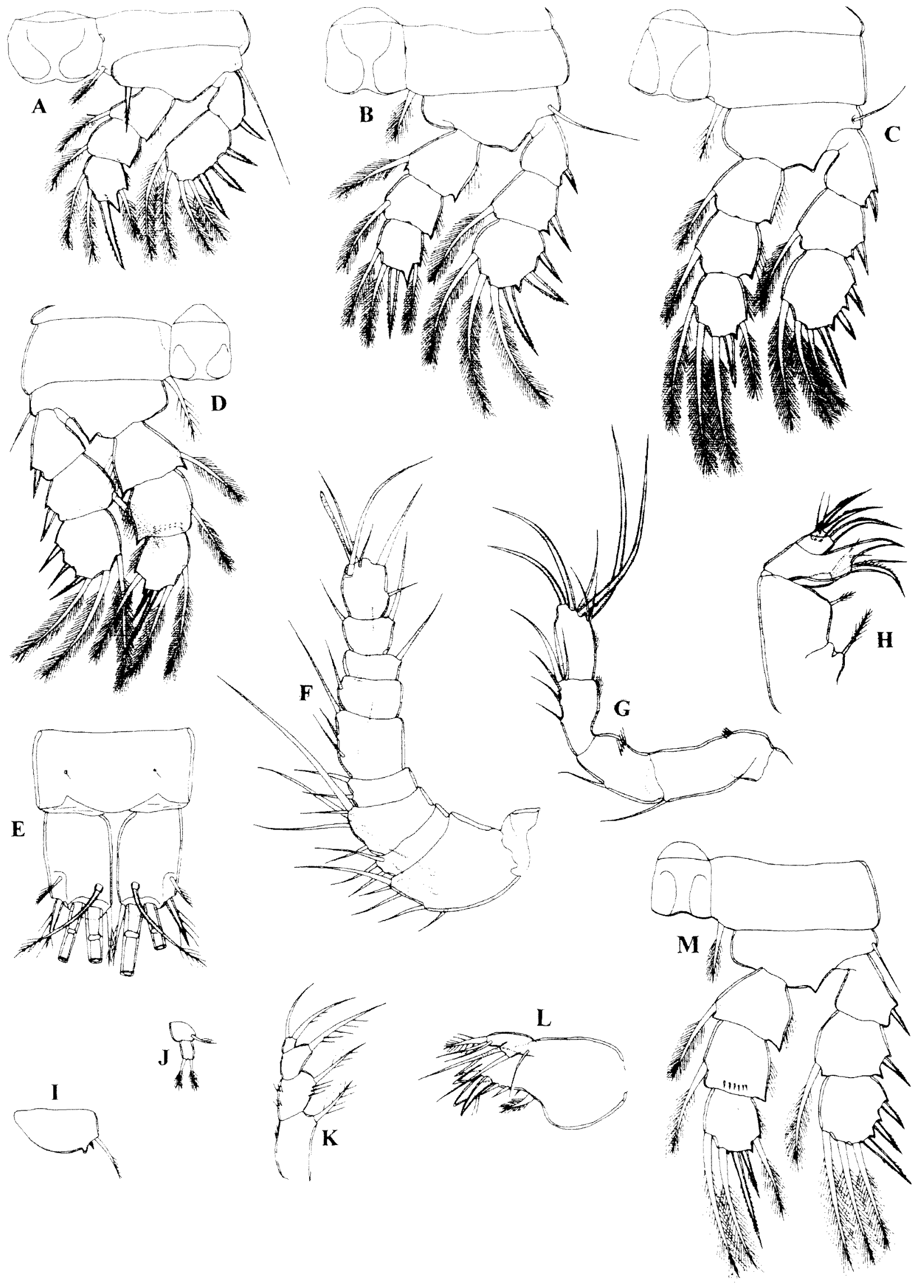

Figure 21 Orbuscrclops westaustraliensis gen. et sp. now, A-L, holotype (female); M, male (0.305 mm) from near Mount Tumer (WAM C28668): A, first swimming leg; B, second swimming leg; C, third swimming leg; D, fourth swimming leg; $E$, anal somite and caudal rami, dorsal view; $F$, antennula; $G$, antenna; $H$, maxilla; $I$, sixth leg; ], fifth leg; $K$, maxilliped; L, maxillula; $M$, fourth swimming leg. Scale $=0.1 \mathrm{~mm}$. 
margin. All coxae unornamented and armed with plumose seta at inner distal corner. Spine inserted at inner, protruded corner of basis of first leg reaching one third of second endopodal segment's length (Figure 21A). All setae slender and plumose. Second endopodal segment of fourth swimming leg with short row of spinules along distal margin, all other endopodal and exopodal segments, as well as basis of each leg, without visible ornamentation, except for hairs along outer margins of all endopods. Apical spine on third endopodal segment of first swimming leg very robust, about 1.6 times as long as segment (Figure 21A). Apical spine on third endopodal segment of third leg shorter than segment (Figure 21C). Third endopodal segment of fourth swimming leg about 1.4 times as long as wide; inner apical spine about 2.2 times as long as outer one and almost 1.2 times as long as segment (Figure 21D).

Fifth leg (Figure 20A, C and 21J) very small, twosegmented, unornamented, and inserted ventrally near posterior lateral corner. Basal segment about 1.4 times as wide as long, armed with lateral uniplumose seta inserted on very short setophore (Figure 20C). Distal segment narrower, about 1.3 times as long as wide, armed apically with two equally long and plumose setae, which 1.8 times as long as segment.

Sixth leg (Figure 21I) distinct, more or less semicircular, cuticular plate, armed with two almost equally long minute smooth spines and one unipinnate and much longer seta; median spine distinct, other one completely fused to leg.

Male (allotype). Body length, excluding caudal setae, $0.246 \mathrm{~mm}$. Habitus (Figure 22A) slender, with prosome/urosome ratio 1.25 and greatest width at posterior end of cephalothorax. Body length/width ratio about 4.2; cephalothorax about 2.1 times as wide as genital somite.

Cephalothorax 1.5 times as long as its greatest width, represents $37 \%$ of body length. Ornamentation of prosomites, colour and nauplius eye similar to those of female. Hyaline fringe of fifth pedigerous somite smooth, as well as that of other urosomites. Fifth pedigerous somite ornamented with two dorsal sensilla; genital somite as well as next three somites without any ornamentation.

Genital somite about 1.4 times as wide as long (dorsal view). Anal somite with smooth, broad and straight anal operculum, which represents $44 \%$ of somite's width, not reaching posterior margin of somite; ornamented with two sensilla dorsally, without any spinules on posterior margin. Anal sinus widely opened, unornamented.

Caudal rami (Figure 22A) about 1.5 times as long as wide, parallel, with very small space between them. Armature and ornamentation similar to female.
Antennula (Figure 22E) slightly shorter than cephalothorax, 14-segmented but fourth and fifth segments partly fused, unornamented, digeniculate, with geniculations between seventh and eighth and twelfth and thirteenth segments. Twelfth segment with characteristic cuticular structures (geniculation blades). Two aesthetascs on first, one on seventh and one on fourteenth segment. Setal formula: 7.3.2.1.2.0.0.0.1.1.1.0.1.10. Setae on tenth and eleventh segments very short, spiniform; all other setae slender and all setae smooth. Only one seta on fifth, one on thirteenth and three on fourteenth segment articulating on basal part.

Antenna, labrum, mandibula, maxillula, maxilla, maxilliped and swimming legs (Figure 22B, F) similar to female. Third endopodal segment of fourth swimming leg (Figure 22F) about 1.2 times as long as wide, with inner apical spine somewhat shorter than in female.

Fifth leg (Figure 22A) also similar to female, except inner apical seta on distal segment slightly longer than outer apical one.

Sixth leg (Figure 22D) distinct large plate, almost quadriform, unornamented and armed with one spine and two pinnate setae. Outermost seta about 2.4 times as long as spine and 1.6 times as long as middle seta. Outermost seta of sixth leg much shorter than any seta of fifth leg (Figure 22A).

\section{Variability}

Body length of males ranges from $0.246 \mathrm{~mm}$ to $0.305 \mathrm{~mm}(0.272 \mathrm{~mm}$ average; $\mathrm{n}=3)$, while only one female was collected. Male from near Mount Turner has the inner apical spine on the third endopodal segment of fourth leg (Figure 21M) considerably longer than the allotype male, as well as slightly longer innermost apical setae on the caudal rami (Figure 22B). No other type of variability was observed.

\section{Etymology}

The specific name is an adjective, derived from the Australian state where the material was collected, in apposition to the generic name.

\section{Discussion}

Orbuscyclops westaustraliensis gen. nov., sp. nov. is one of the smallest known cyclopoids, with the male being slightly smaller than presently known lowest size limit of about $0.25 \mathrm{~mm}$ (Reid and Strayer 1994). De Laurentiis et al. (2001) speculated that the cyclopoid copepod fauna inhabiting the groundwaters of Western Australia lacks true stygobitic genera. After the discovery of the first representative of Allocyclops Kiefer, 1932 on Barrow Island (Karanovic 2003) and two new species of Goniocyclops Kiefer, 1955 in the Murchison region (Karanovic 2004a), this picture 


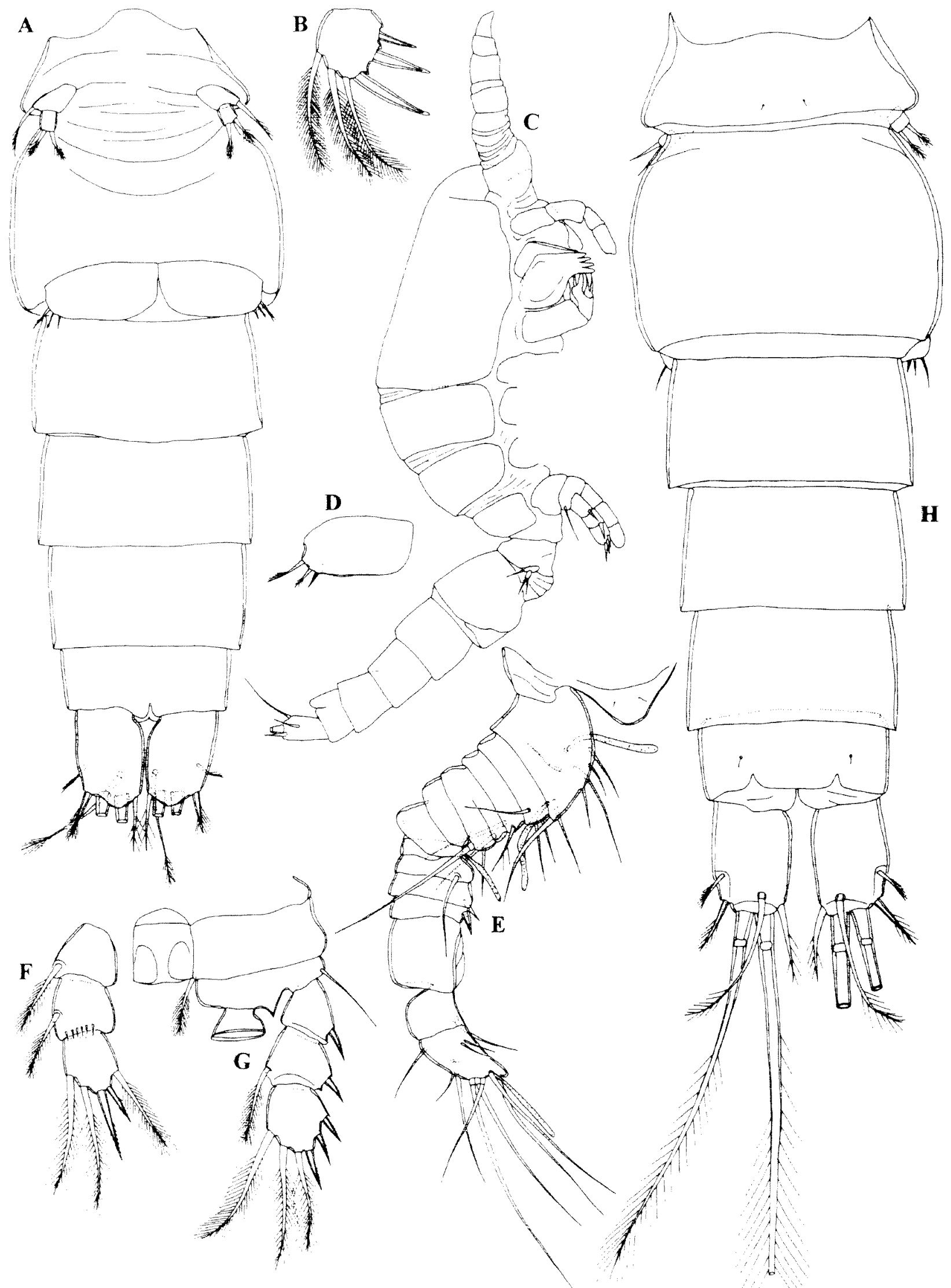

$\mathrm{A}, \mathrm{B}, \mathrm{D}, \mathrm{E}, \mathrm{F}, \mathrm{G}, \mathrm{H}$

C

Figure 22 Orbuscyclops westaustraliensis gen. et sp. nov., A-G, allotype (male); H, male (0.305 mm) from near Mount Turner (WAM C28668): A, urosome, ventral view; B, third exopodal segment of second swimming leg; C, habitus, lateral view; $D$, sixth leg; $E$, antennula; $F$, endopod of fourth swimming leg; $G$, fourth swimming leg, without endopod; $\mathrm{H}$, urosome, dorsal view, Scales $=0.1 \mathrm{~mm}$. 
has changed. The only other Australian cyclopoid that probably could qualify for this category (small subterranean cyclopoids) is Mixocyclops minutus Chappuis, 1951. Although the single female of this species was collected from mosses in Tasmania (Chappuis 1951) it could well be that its real habitat is interstitial waters, as many other subterranean copepods are occasionally found in small numbers in mosses, especially around springs. The only other representative of the genus Mixocyclops Kiefer, 1944 was described from one of the tiny Crozet Islands, in the southern Indian Ocean (Kiefer 1944). Species of the genus Goniocyclops have relatively clear Eastern Gondwana connections (Karanovic 2004a), while the genus Allocyclops has representatives on all continents except Antarctica (Karanovic 2001b, 2003, Tomikawa et al. 2005).

Orbuscyclops gen. nov. is the first endemic stygobitic cyclopoid genus in Australia and it cannot be related closely to any other known genus. Two autapomorphies distinguish it from other members of Cyclopinae: a nine-segmented antennula in female and a reduced exopod of the first swimming leg (but not the endopod). The antennula is reduced in the female of many benthic and interstitial Cyclopinae to 10-12 segments from the presumed ancestral 17 (Pesce 1996) but never to nine. The second major modification of stygobitic Cyclopinae, after reduction in body size, is shortening of the swimming legs (Reid and Stryer 1994). And indeed, the swimming legs of Orbuscyclops are very short but, amazingly, all with three-segmented endopods and all, except the first one, have three segmented exopods. Reduction of swimming legs in Cyclopidae occurs either in the endopod or in both rami, never in the exopod alone. The antenna, maxillula, maxilla and maxilliped of Orbuscyclops have some reductions in armature and ornamentation but their segmentation is plesiomorphic. The mandibula and fifth leg are also plesiomorphic but with complete armature, so that neither provides any clues about the phylogenetic relationships of the new genus. A somewhat similar fifth leg (two segmented, with two equal apical setae on the distal segment) is found in the genus Reidcyclops Karanovic, 2000 and several "Diacyclops" species from Lake Baikal (Karanovic 2000) but other morphological details do not support a close relationship with Orbuscyclops.

It was shown by Monchenko and Von Vaupel Klein (1999) that the process of oligomerization is correlated to a large extent with a decrease in body length in Cyclopinae. The new genus is one of the exceptions in the subfamily and shows that a reduction in body size is not necessarily closely followed by reductions in the segmentation of thoracic appendages.
Genus Diacyclops Kiefer, 1927

\section{Diacyclops humphreysi humphreysi Pesce and De Laurentiis, 1996 \\ Figures 23-25}

\section{Synonymy}

Diacyclops humphreysi n. sp. - Pesce and De Laurentiis, 1996: 525, Figures 1-12.

Diacyclops humphreysi Pesce and De Laurentiis, 1996 - De Laurentiis et al., 1999: 249.

\section{Material Examined}

1) Australia, Pilbara, Newman Borefield, bore WB23/4, 23 July 1997, leg. W.F. Humphreys and S.M. Eberhard (BES: 4823 and 4829), 23'19'03'S $119^{\circ} 51^{\prime} 02^{\prime \prime} \mathrm{E}$ : one male + one female + one copepodid (male (WAM C28669) and female (WAM C28670) dissected on two slides each; copepodid in alcohol (WAM C28671))

2) Australia, Pilbara, Newman Borefield, bore WB23/4, 22 July 1997, leg. W.F. Humphreys and

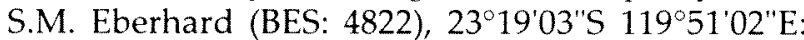
one female in alcohol (WAM C28672)

3) Australia, Pilbara, Newman Borefield, monitoring bore for pump K27, 23 July 1997, leg. W.F. Humphreys and S.M. Eberhard (BES: 4825), $23^{\circ} 19^{\prime} 45^{\prime \prime} \mathrm{S} 119^{\circ} 51^{\prime} 27^{\prime \prime} \mathrm{E}$ : one male + three females + two copepodids in alcohol (WAM C28673)

4) Australia, Pilbara, Newman Borefield, bore W236, 22 July 1997, leg. W.F. Humphreys and S.M.

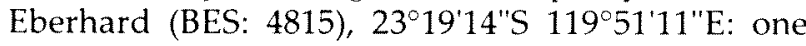
male + two females in alcohol (WAM C28674)

5) Australia, Pilbara, Marillana Creek, bore MCYM105, 25 November 2002, leg. J. Cocking and M. Scanlon (CALM), 22 $43^{\prime} 42^{\prime \prime S} 119^{\circ} 00^{\prime} 40^{\prime \prime} \mathrm{E}$ : four males + two females in alcohol (WAM C28675)

6) Australia, Pilbara, Marillana Creek, bore MCYM109, 25 November 2002, leg. J. Cocking and M. Scanlon (CALM), 22 $45^{\prime} 06^{\prime \prime S} 119^{\circ} 06^{\prime} 43^{\prime \prime} \mathrm{E}$ : two males +10 females + seven copepodids in alcohol (WAM C28676)

7) Australia, Pilbara, Marillana Creek, bore MCYM110, 25 November 2002, leg. J. Cocking and M. Scanlon (CALM), 22 ${ }^{\circ} 45^{\prime} 34^{\prime \prime S} 11^{\circ} 07^{\prime} 21^{\prime \prime} \mathrm{E}$ : one male + one female in alcohol (WAM C28677)

8) Australia, Pilbara, Marillana Creek, bore MCYM112, 25 November 2002, leg. J. Cocking and M. Scanlon (CALM), 22 $46^{\circ} 37^{\prime \prime S} 119^{\circ} 07^{\prime} 48^{\prime \prime} \mathrm{E}$ : four males + three females + five copepodids in alcohol (WAM C28678)

9) Australia, Pilbara, Millstream, Palm Springs, bore P1, 31 July 1997, leg. W.F. Humphreys and S.M. Eberhard (BES: 4891), 21 $34^{\prime} 24^{\prime \prime S} 116^{\circ} 57^{\prime} 59^{\prime \prime} \mathrm{E}$. one female dissected on one slide (WAM C28679)

10) Australia, Pilbara, Rocklea, bore PSPRSLK36, 21 November 2002, leg. J. Cocking and M. Scanlon (CALM), 23 $07^{\prime} 42^{\prime \prime S} 117^{\circ} 36^{\prime} 38^{\prime \prime} \mathrm{E}$ : two females + two copepodids (one female 
dissected on one slide (WAM C28680); others in alcohol (WAM C28681))

11) Australia, Pilbara, Ratty Springs, bore $99 \mathrm{RSO2}$, 22 November 2002, leg. J. Cocking and M. Scanlon (CALM), 23 12'21'S 117 32'19"E: two males + 27 females +15 copepodids in alcohol (WAM C28682)

12) Australia, Pilbara, Yandi, bore WBO4, 5 October 2002, leg. J. Cocking and M. Scanlon (CALM), 22 47'37'S 119 17'54'F: one female + one copepodid in alcohol + one female (CY 315) dissected by Jane McRae on one slide (WAM C28683)

13) Australia, Pilbara, Weeli Wolli Spring, bore BH17D, 5 October 2002, leg. J. Cocking and M.

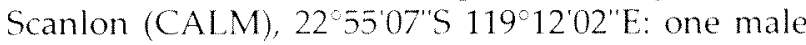
+ one female in alcohol (WAM C28684) + one female (CY 313) dissected on one slide by Jane McRae (WAM C28685)

14) Australia, Pilbara, Railway near $O B 25$, bore W13, 10 April 2003, leg. J. Cocking and M. Scanlon

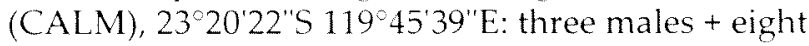
females + three copepodids in alcohol (WAM C28686)

15) Australia, Pilbara, Palm Creek, bore PLUVIOP.8, 12 April 2003, leg. J. Cocking and M. Scanlon (CALM), 21 3455'S 116 58 $03^{\prime \prime} \mathrm{E}$ : one male + four females + three copepodids (one female dissected on one slide (WAM C28687); others in alcohol (WAM C28688))

16) Australia, Pilbara, Palm Creek, bore PLUVIOP.6A, 12 April 2003, leg. J. Cocking and M. Scanlon (CALM), 21 34'47'S 116 57'53"E: two females in alcohol (WAM C28689)

17) Australia, Pilbara, Turee Creek, bore PFO10-3, 8 April 2003, leg. J. Cocking and M. Scanlon (CALM), 23 $22^{\prime} 17^{\prime \prime S} 117^{\circ} 50^{\prime} 54^{\prime \prime} \mathrm{E}$ : three females in alcohol (WAM C28690)

18) Australia, Pilbara, Paraburdoo Town Borefield, bore PTO-6B, 22 November 2002, leg. J. Cocking and M. Scanlon (CALM), 23 10'57"S $117^{\circ} 42^{\prime} 18^{\prime \prime} \mathrm{E}$ : four females + one copepodid in alcohol (WAM C28691)

19) Australia, Pilbara, Fortescue River, bore G70830106, 14 November 2002, leg. J. Cocking and M. Scanlon (CALM), 21'11'25"S 116'01'13"E: one male in alcohol (WAM C28692)

20) Australia, Pilbara, Newman, bore W29, 19 November 1998, leg. S.M. Eberhard (BES: 5498), $2324^{\prime} \mathrm{S} 119^{\circ} 47^{\prime} \mathrm{E}$ : five males + six females in alcohol (WAM C28693)

21) Australia, Pilbara, Newman, bore WP116, 11 November 1998, leg. S.M. Eberhard (BES: 3520), 2314'S 119054'E: three females + one copepodid (one female dissected on one slide (WAM C28694); others in alcohol (WAM C28695))

22) Australia, Pilbara, Newman, bore W226, 11 November 1998, leg. S.M. Eberhard (BES: 3523), $2315 \mathrm{~S} 11954 \mathrm{E}$ : nine males + 23 females + two copepodids in alcohol (WAM C28696)
23) Australia, Pilbara, Newman, bore W152, 11 November 1998, leg. S.M. Eberhard (BES: 3517), $23^{\circ} 16^{\mathrm{S}} 119^{\circ} 53^{\prime} \mathrm{E}$ : four males + three females in alcohol (WAM C28697)

24) Australia, Pilbara, Newman, bore W229, 11 November 1998, leg. S.M. Eberhard (BES: 3511), $2312^{\prime} \mathrm{S} 119^{\circ} 51^{\prime} \mathrm{E}$ : one male in alcohol (WAM (28698)

25) Australia, Pilbara, Newman, bore near W126, 12 November 1998, leg. S.M. Eberhard (BES: 3576), $23^{\circ} 15^{\prime} \mathrm{S} 119^{\circ} 53^{\prime} \mathrm{E}$ : one female in alcohol (WAM C28699)

26) Australia, Pilbara, Newman, bore W117, 12 November 1998, leg. S.M. Eberhard (BES: 3530), $23^{\circ} 14^{\prime} \mathrm{S} 119^{\circ} 54^{\prime} \mathrm{E}$ : two females in alcohol (WAM (28700)

27) Australia, Pilbara, Newman, bore W129, 12 November 1998, leg. S.M. Eberhard (BES: 3537), 23.14'S 119 53'E: one copepodid in alcohol (WAM C28701)

28) Australia, Pilbara, Newman, bore W28, 19 November 1998, leg. S.M. Eberhard (BES: 6367), $23^{\circ} 24^{\prime} \mathrm{S} 119^{\circ} 47^{\prime} \mathrm{E}$ : one male + four females + four copepodids in alcohol (WAM C28702)

29) Australia, Pilbara, Newman, bore WP131, 11 November 1998, leg. S.M. Eberhard (BES: 3506), $23^{\circ} 13^{\prime} \mathrm{S} 119^{\circ} 54^{\prime} \mathrm{E}$ : one male + six females in alcohol (WAM C28703)

30) Australia, Pilbara, Newman, bore W230, 11 November 1996, leg. S.M. Eberhard (BES: 3466), $23^{\circ} 13^{\prime} \mathrm{S} 119^{\circ} 54^{\prime} \mathrm{E}$ : one male + 60 females + eight copepodids in alcohol (WAM C28704)

31) Australia, Pilbara, Robe River, Bou-Rouch pump, 2 August 1997, leg. W.F. Humphreys and S.M. Eberhard (BES: 1033), 21 ${ }^{\circ} 49^{\prime} 06^{\prime \prime S} 116^{\circ} 43^{\prime} 32^{\prime \prime E}$ : three females + six copepodids in alcohol (WAM C28705)

32) Australia, Pilbara, Mulga Downs Station, Yampire Bore, 3 September 2000, leg. W.F. Humphreys (BES: 8448), 22 $14{ }^{\prime} 55^{\prime \prime S} 118^{\circ} 33^{\prime} 44^{\prime \prime} \mathrm{E}$ : one female + two copepodids in alcohol (WAM C28706)

33) Australia, Pilbara, bore HI512, 23 November 2000, leg. S. Anstee (96 HDM 02): one female + one copepodid in alcohol (WAM C28706)

34) Australia, Pilbara, GNH near Newman Airport, bore W28, 10 April 2003, leg. J. Cocking and $M$. Scanlon (CALM), 23'24'12'S $119^{\circ} 47^{\prime} 45^{\prime \prime} \mathrm{E}$ : five males +11 female +24 copepodids in alcohol (WAM C28707)

35) Australia, Pilbara, Nammuldi, bore NAIM2, 7 March 2003, leg. J. Cocking and M. Scanlon

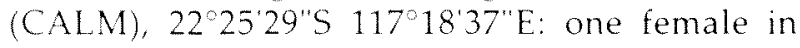
alcohol (WAM C28708)

36) Australia, Pilbara, Paraburdoo Town Borefield, bore PTP8, 9 April 2003, leg. J. Cocking and M. Scanlon (CALM), 23 10 41'S 117 42 55"E: four males + one copepodid in alcohol (WAM C28709)

37) Australia, Pilbara, Paraburdoo Town 
Borefield, bore PTO2, 9 April 2003, leg. J. Cocking and M. Scanlon (CALM), 23 11 $23^{\prime \prime} S 117^{\circ} 40^{\prime} 42^{\prime \prime} \mathrm{E}$ : two males + 14 females + one copepodid in alcohol (WAM C28710)

38) Australia, Pilbara, Fortescue River, bore G70830104, 4 April 2003, leg. J. Cocking and M. Scanlon (CALM), 21 $12^{\prime} 57^{\prime \prime S} 116^{\circ} 02^{\prime} 32^{\prime \prime} E$ : two males in alcohol (WAM C28711)

39) Australia, Pilbara, Mowstead Creek, bore HS1, 4 April 2003, leg. J. Cocking and M. Scanlon (CALM), 22 $14^{\prime} 38^{\prime \prime} S 117^{\circ} 10^{\prime 2} 23^{\prime \prime} \mathrm{E}$ : seven males +40 femles ( 3 ovigerous) + four copepodids in alcohol (WAM C28712)

40) Australia, Pilbara, Newman Borefield, bore WB23/1, 22 July 1997, leg. W.F. Humphreys and S.M. Eberhard (BES: 4803), 2319'30'S 119 50'51"E: two males +10 females + one copepodid in alcohol (WAM C28713)

41) Australia, Pilbara, Newman Borefield, bore W77, 23 July 1997, leg. W.F. Humphreys and S.M. Eberhard (BES: 4831), $23^{\circ} 19^{\prime} 30^{\prime \prime S} 119^{\circ} 50^{\prime} 51^{\prime \prime} \mathrm{E}$ : two males + two females in alcohol (WAM C28714)

42) Australia, Pilbara, Millstream, Palm Springs, bore PluvioP4, 19 November 2002, leg. J. Cocking and M. Scanlon (CALM), 21 34'39"S 116 58'12"E: one male in alcohol (WAM C28715)

43) Australia, Pilbara, Turee Creek, bore PFO9-4, 23 November 2002, leg. J. Cocking and M. Scanlon (CALM), $23^{\circ} 22^{\prime} 07^{\prime \prime S} 117^{\circ} 57^{\prime} 36^{\prime \prime} \mathrm{E}$ : one male + three females + three copepodids in alcohol (WAM C28716)

44) Australia, Pilbara, Paraburdoo Town Borefield, bore TPB2-1, 22 November 2002, leg. J. Cocking and M. Scanlon (CALM), 23 11'17"S $117^{\circ} 40^{\prime} 38^{\prime \prime} \mathrm{E}$ : two males + eight females + two copepodids (one female dissected on one slide (WAM C28717); others in alcohol (WAM C28718))

45) Australia, Pilbara, Paraburdoo Town Borefield, bore PTP-8, 22 November 2002, leg. J. Cocking and M. Scanlon (CALM), 23 10'41"S $117^{\circ} 42^{\prime} 55^{\prime \prime} \mathrm{E}$ : four males + one female in alcohol (WAM C28719)

46) Australia, Pilbara, GNH near Newman Airport, bore W28, 4 October 2002, leg. J. Cocking

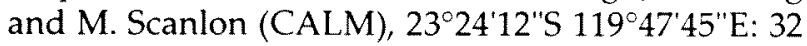
males +25 females + nine copepodids in alcohol (WAM C28720)

47) Australia, Pilbara, Fortescue $3 \mathrm{~A}$, bore $\mathrm{G}$ 70830104, 14 November 2002, leg. J. Cocking and M. Scanlon (CALM), 21 $12^{\prime} 57^{\prime \prime S} 116^{\circ} 02^{\prime} 32^{\prime \prime E}$ : one male (CY 328) dissected by Jane McRae on one slide (WAM C28721)

48) Australia, Pilbara, Weeli Wolli Spring, surface pool, 16 November 1998, leg. S.M. Eberhard (BES: 3601 and 3608$), 22^{\circ} 55^{\prime} \mathrm{S} 119^{\circ} 11^{\prime} \mathrm{E}$ : one male on one slide in toto (WAM C28722)

49) Australia, Pilbara, Paraburdoo Town Borefield, bore PTO-11, 9 April 2003, leg. J. Cocking and M. Scanlon (CALM), 23'11'18'S 117 40'03'E: three males + two females + one copepodid (one female dissected on one slide (WAM C28723); others in alcohol (WAM C28724))

50) Australia, Pilbara, SW of OB 23 (Ore Body 23, about $4.5 \mathrm{~km}$ north of Ophthalmia Dam), bore W234, 10 April 2003, leg. J. Cocking and M. Scanlon

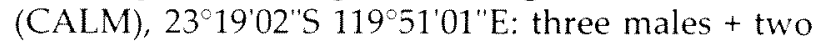
femles + one copepodid (one female dissected on one slide (WAM C28725); others in alcohol (WAM C28726))

51) Australia, Pilbara, SW of OB 23(Ore Body 23, about $4.5 \mathrm{~km}$ north of Ophthalmia Dam), bore 23-4, 4 April 2002, leg. J. Cocking and M. Scanlon (CALM), 23'19'02'S 119 51'01"E: four males + three females in alcohol (WAM C28727)

52) Australia, Pilbara, W of OB 23 (Ore Body 23, about $4.5 \mathrm{~km}$ north of Ophthalmia Dam), bore W270, 4 October 2002, leg. J. Cocking and M.

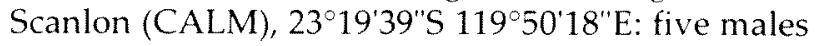
+ four females + four copepodids in alcohol (WAM C28728)

53) Australia, Pilbara, Newman, bore F3, 13 November 1998, leg. S.M. Eberhard (BES: 3583), $23^{\circ} 20^{\prime} \mathrm{S} 119^{\circ} 50^{\prime} \mathrm{E}$ : 12 males + 20 females (one female dissected on one slide (WAM C28729); others in alcohol (WAM C28730))

54) Australia, Pilbara, Newman, bore W135, 20 November 1998, leg. S.M. Eberhard (BES: 6380), $23^{\circ} 17^{\prime} \mathrm{S} 119^{\circ} 52^{\prime} \mathrm{E}: 28$ males +29 females +14 copepodids in alcohol (WAM C28731)

55) Australia, Pilbara, Newman, bore WP120, 11 November 1998, leg. S.M. Eberhard (BES: 3526), $23^{\circ} 13^{\prime} \mathrm{S} 119^{\circ} 53^{\prime} \mathrm{E}$ : one male + three femles + one copepodid (one female dissected on one slide (WAM C28732); others in alcohol (WAM C28733))

56) Australia, Pilbara, Newman, bore W222, 20 November 1998, leg. S.M. Eberhard (BES: 6391), $23^{\circ} 20^{\prime} \mathrm{S} 119^{\circ} 51^{\prime} \mathrm{E}$ : six males + 28 females + four copepodids in alcohol (WAM C28734)

57) Australia, Pilbara, Newman, bore W244, 12 November 1998, leg. S.M. Eberhard (BES: 3533), $23^{\circ} 13^{\prime} \mathrm{S} 119^{\circ} 55^{\prime} \mathrm{E}$ : one male + four females in alcohol (WAM C28735)

58) Australia, Pilbara, Old Yalleen Well, 4 August 1996, leg. W.F. Humphreys (BES: 4950), $21^{\circ} 53^{\prime} \mathrm{S}$ $116^{\circ} 24^{\prime} \mathrm{E}$ : one male + one female + one copepodid in alcohol (WAM C28736)

59) Australia, Pilbara, Mulga Downs Station, Mamamoonah Well, 2 September 2000, leg. W.F. Humphreys (BES: 8442), 22 $07^{\prime} 28^{\prime \prime} \mathrm{S} 118^{\circ} 17^{\prime} 16^{\prime \prime} \mathrm{E}$ : one male + two females + one copepodid in alcohol (WAM C28737)

60) Australia, Pilbara, Mulga Downs Station, Ebathacalby Well, 2 September 2000, leg. W.F. Humphreys (BES: 8440 ), 22 ${ }^{\circ} 14^{\prime} 58^{\prime \prime} \mathrm{S} 118^{\circ} 44^{\prime} 52^{\prime \prime} \mathrm{E}$ : one male + two females + two copepodids in alcohol (WAM C28738)

61) Australia, Pilbara, Hardey River Borefield, bore HRO28, 27 July 1997, leg. W.F. Humphreys 
and S.M. Fberhard (BES: 4851), 224301"S 1173059"E: one copepodid in alcohol (WAM (28739)

62) Australia, Pilbara, Fortescue Vallev, Ebathacalby Well, 25 July 1997, leg. W.F. Humphreys and S.M. Eberhard (BES: 4848 and 5648), 22 1459's 1184451"E: two males + one female + one copepodid in alcohol (WAM C28740)

63) Australia, Pilbara, Mount Florence Station, V15 Well, 4 September 2000 , leg. W.F. Humphrevs (BES: 8465), 220445"S $118^{\circ} 06^{\prime} 18^{\prime \prime} \mathrm{E}$ : three males + four females in alcohol (WAM C28741)

64) Australia, Pilbara, Fortescue River road bridge, Bou-Rouch pump samples 2, 9, 10, four and 6, 5 August 1997, leg. W.F. Humphreys and S.M. Eberhard (BES: 1037, 4963, 4975, 4980 and 4998), $21^{\circ} 17^{\prime} 52^{\prime \prime S} 116^{\circ} 08^{\prime} 23^{\prime \prime} \mathrm{E}$ : one female dissected on one slide (WAM C28742)

65) Australia, Pilbara, Weeli Wolli, bore HD11D (00245), 2 August 2002, leg. G. Humphrevs (BIOTA) 22 57'06"S 119 09'23"E: one female (CY 317) dissected on one slide by Jane McRae (WAM (28748)

66) Australia, Pilbara, Weeli Wolli, bore $\mathrm{BH} 32 \mathrm{~s}$ (00216), 1 August 2002, leg. G. Humphrevs (BIOTA) $22^{\circ} 5$ ' $119^{\circ} 12^{\prime} \mathrm{E}$ : one female (CY 318) dissected on one slide by Jane McRae (WAM C28749)

\section{Supplementary description}

Female. Habitus (Figure 23B) slender, with prosome/urosome ratio 1.6 and greatest width at midlength of cephalothorax. Body length/width ratio about 3.2 ; cephalothorax 2.2 times as wide as genital double somite. Free pedigerous somites without pronounced lateral expansions, except in fifth pedigerous somite, which lateral corners slightly protruded. Preserved specimen colourless. Nauplius eye not visible. Rostrum well developed, membranous, very broad and furnished with two large sensilla.

Cephalothorax (Figure 23B) about as long as its greatest width; represents $32 \%$ of total body length. Surface of cephalic shield with several large sensilla; no other ornamentation visible. Hyaline fringe of prosomites narrow and smooth. All free pedigerous somites ornamented dorsally with few sensilla. More or less sclerotized joint (as pseudosomite) present between prosome and urosome, as well as between fifth pedigerous somite and genital double somite. Fifth pedigerous somite with smooth fringe dorsally and ventrally, ormamented only with two dorsal sensilla (Figure 23A).

Genital double somite (Figure 23A, C) about as long as wide, omamented only with two large sensilla dorsally at middle. Hyaline fringe of genital double and two subsequent somites smooth both ventrally and dorsally. Copulatory pore small, Tshaped, positioned just anterior of double somite midlength; copulatory duct relatively long, rigidly sclerotized. Seminal receptacle relatively small, almost ovoid, about 1.1 times as wide as long, representing $46 \%$ of double somite width and $41 \%$ of its length; anterior expansion somewhat shorter than posterior one. Oviducts rigidly sclerotized, long and with several loops. Ovipores situated dorsolaterally, at $2 / 5$ of double somite's length, covered by reduced sixth legs, which bearing two minute spines and one pinnate seta. Third and fourth urosomite without any visible ormamentation. Anal somite with smooth, broad, very short and convex anal operculum, which represents $54 \%$ of somite's width and not reaching posterior margin of somite (Figure 23A); ornamented with two large sensilla dorsally and with transverse row of short spinules on posterior margin ventrally. Anal sinus widely opened, without visible ornamentation.

Caudal rami (Figure 23C and 24B) 2.2 times as long as wide, parallel, with space between them about one third of ramus' width; ornamented with transverse row of elongated spinules dorsally inside proximal inner recess (Figure $24 B$ ) and with several spinules at base of lateral and outermost apical setae; distal margin ventrally with small medial protuberance, which seems to be cuticular tube pore. Dorsal seta about 1.8 times as long as ramus, inserted at $6 / 7$ of ramus length, uniarticulate at base and unipinnate distally. Lateral seta arising somewhat dorsolaterally at $3 / 5$ of ramus length, uniplumose and shorter than ramus width. Outermost apical seta stout, spiniform, about 0.6 times as long as ramus, bipinnate. Innermost apical seta also bipinnate and about as long as outermost one but much more slender. Principal apical setae plumose and with breaking planes; inner seta about 1.5 times as long as outer one and almost 0.4 times as long as body.

Antennula (Figure 24A) reaching $2 / 3$ of cephalothorax in length, 12-segmented, ornamented just with short row of spinules on first segment, with one slender aesthetasc on ninth segment and setal formula: $8 \cdot 4 \cdot 2 \cdot 6 \cdot 2 \cdot 2 \cdot 2 \cdot 3 \cdot 2 \cdot 2.2 .8$. No setae with breaking planes or articulating on basal part. One seta on sixth segment spiniform and very short; all other setae slender and most setae smooth, only 8 setae $(19 \%)$ plumose or pinnate at their distal parts. Length ratio of antennular segments, from proximal end and along caudal margins, $1: 0.4: 0.3: 0.6: 0.4$ : $0.3: 0.6: 1.1: 0.9: 0.6: 0.8: 1$.

Antenna four-segmented, comprising coxobasis and three-segmented endopod; all endopodal segments of about same length, coxobasis somewhat longer. Coxobasis (Figure 23E) about 2.6 times as long as wide, ornamented with two short rows of spinules along external margin proximally, armed with two smooth setae at distal inner corner; seta representing exopod absent. First 


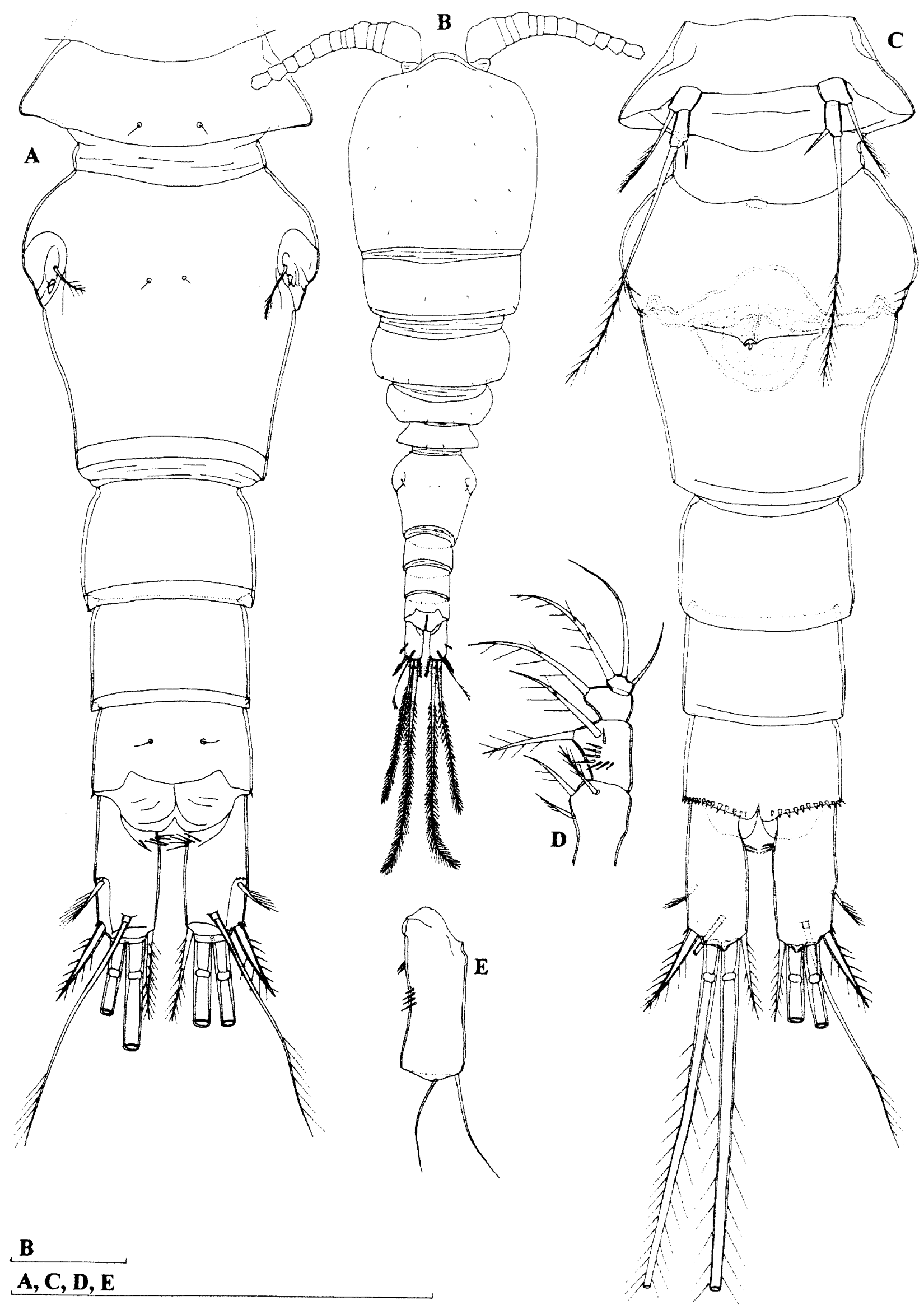

Figure 23 Diacyclops humphreysi humphreysi Pesce and De Laurentiis 1996, female $(0.485 \mathrm{~mm})$ from locality 1 (WAM C28670): A, urosome, dorsal view; B, habitus, dorsal view; C, urosome, ventral view; D, maxilliped; E, basis of antenna. Scales $=0.1 \mathrm{~mm}$. 


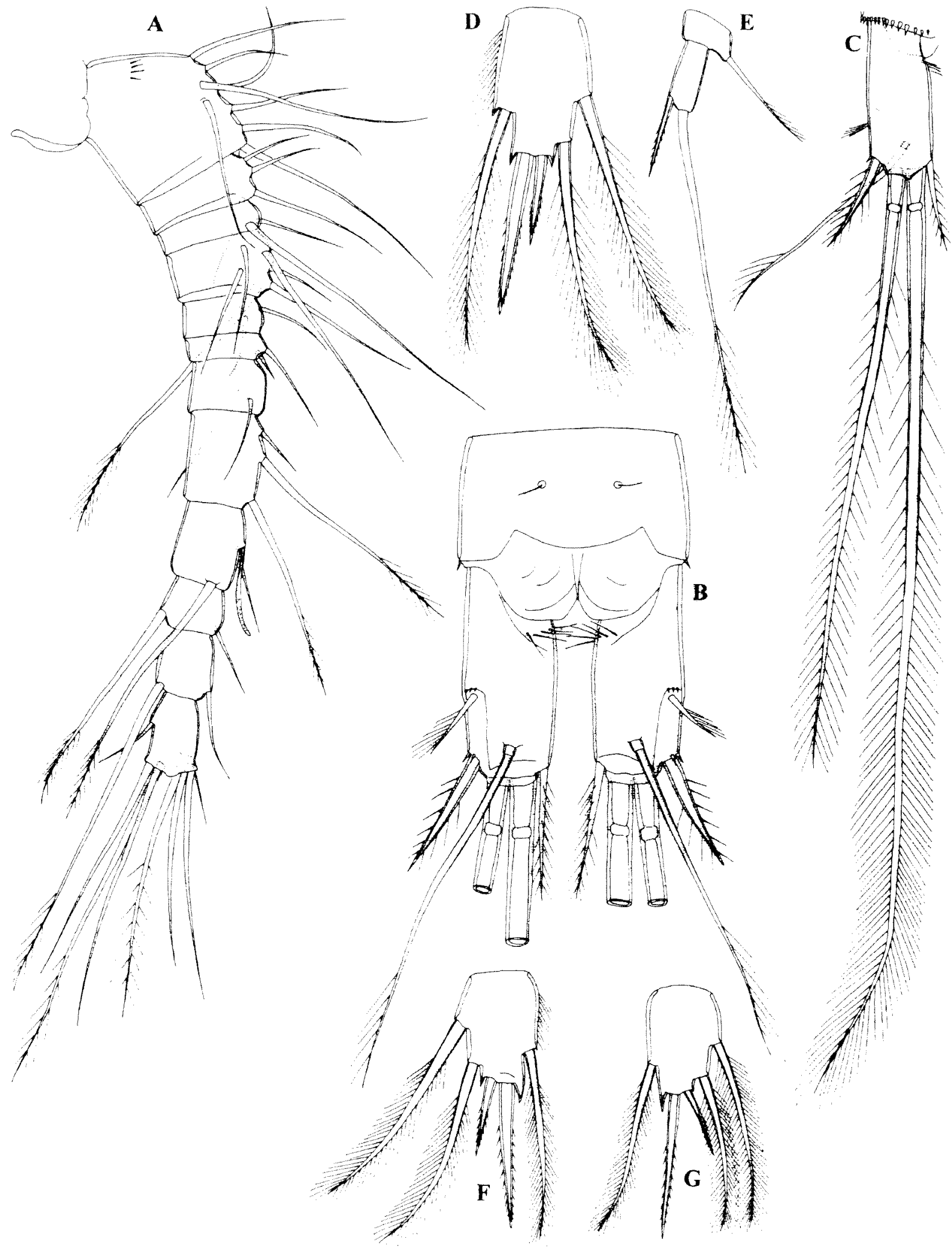

\section{$\mathrm{A}, \mathrm{C}$ \\ B, D, E, F, G}

Figure 24 Diacyclops humphreysi humphreysi Pesce and De Laurentiis 1996, A-E, female (0.485 mm) from locality 1 (WAM C28670); F, male (0.388 mm) from locality 1 (WAM C28669); G, male $(0.404 \mathrm{~mm}$ ) from locality 48 (WAM C28722): A, antennula; B, anal somite and caudal rami, dorsal view; $C$, right caudal ramus, ventral view; $D$, third endopodal segment of fourth swimming leg; $E$, fifth leg; $F$, third endopodal segment of fourth swimming leg; $G$, third endopodal segment of fourth swimming leg. Scales $=0.1 \mathrm{~mm}$ 
endopodal segment armed with one smooth seta at middle, ornamented with transverse short row of long spinules near external margin. Second endopodal segment about 1.7 times as long as wide, ornamented with longitudinal row of spinules along external margin, armed with six smooth setae (four lateral, two subapical; one subapical seta somewhat longer and much stronger than any other seta on that segment). Third endopodal segment 2.2 times as long as wide, armed with seven smooth apical setae and ornamented as previous segment.

Labrum trapezoidal, unornamented and relatively large. Cutting edge slightly concave, with 14 large and more or less blunt teeth between produced, rounded lateral corners.

Mandibula with small and not clearly distinct palp, armed with two very long, bipinnate setae and one short, smooth, seta on distal end. Coxal gnathobase cutting edge with only six very strong teeth (innermost strongest and complex) and outermost pinnate seta, which much longer than short seta on palp.

Maxillula composed of well developed praecoxa and two-segmented palp. Arthrite of praecoxa with four strong and smooth apical spines; only one distinct, others completely fused to praecoxa. Praecoxa armed with five armature elements along inner margin, longest one plumose. Palp with distinct endopod, which bearing three smooth apical setae, and armed laterally with one exopodal smooth seta and apically with two smooth slender setae and one robust, strongly bipinnate spine. Palp clearly shorter than arthrite of praecoxa.

Maxilla unornamented and five-segmented but praecoxa fused to coxa on posterior surface. Proximal endite of praecoxa well developed, about as long as wide, armed with two pinnate setae; distal endite small, unarmed. Proximal endite of coxa with one short, bipinnate seta; distal endite highly mobile, elongate and armed apically with two setae (proximal seta bipinnate and strong but equally long as distal smooth one). Basis expanded into robust bipinnate claw, armed with two setae; strong seta much longer than claw, unipinnate; other seta minute. Endopod two-segmented; proximal segment armed with one robust, pinnate seta and two smooth ones; distal segment very small, armed with one robust, pinnate, apical seta and one slender and smooth subapical seta. Longest seta on distal endopodal segment somewhat shorter than strong seta on basis.

Maxilliped (Figure 23D) four-segmented, composed of syncoxa, basis and two-segmented endopod. Syncoxa 1.5 times as long as wide, unornamented and armed with three pinnate setae; middle seta strongest, slightly longer than most distal one and about 1.4 times as long as most proximal seta. Basis 1.2 times as long as wide, ornamented with single arched row of long spinules at middle, armed with two bipinnate, subequal setae. First endopodal segment unornamented and armed with one strong, pinnate seta; this seta longest and strongest on maxilliped. Second endopodal segment very small, unornamented but armed with three setae; innermost seta bipinnate, about as long as middle, smooth one and twice as long as outermost seta. All pinnate setae with very long pinnules.

All swimming legs with three-segmented exopod and endopod (Figure 24D and 25A, B, C). Armature formula of swimming legs as follows (legend: inner/ outer spine or seta; inner/terminal/outer):

\begin{tabular}{|c|c|c|c|c|c|c|}
\hline \multirow[b]{2}{*}{ Segments } & \multicolumn{3}{|c|}{ Exopod } & \multicolumn{3}{|c|}{ Endopod } \\
\hline & 1 & 2 & 3 & 1 & 2 & 3 \\
\hline First leg & $0 / 1$ & $1 / 1$ & $2 / 2 / 2$ & $1 / 0$ & $1 / 0$ & $2 / 2 /$ \\
\hline Second leg & $0 / 1$ & $1 / 1$ & $3 / 2 / 2$ & $1 / 0$ & $1 / 0$ & $2 / 2 / 1$ \\
\hline Thi & $0 / 1$ & $1 / 1$ & $3 / 2 / 2$ & $1 / 0$ & $1 / 0$ & $2 / 2 / 1$ \\
\hline Fourth leg & $0 / 1$ & $1 / 1$ & $3 / 2 / 2$ & $1 / 0$ & $2 / 0$ & $2 / 2 /$ \\
\hline
\end{tabular}

Last exopodal segment spine formula: 2.3.3.3. Intercoxal sclerites of all swimming legs unornamented, with smooth and bilobate distal margin. All coxae unornamented (except short row of spinules on coxa of fourth leg) and armed with plumose seta at inner distal corner. Spine inserted at inner, slightly protruded corner of basis of first leg reaching one third of second endopodal segment's length (Figure 25A). All setae slender and plumose. Majority of first and second endopodal and exopodal segments with row of spinules along posterior margin; all endopodal segments with row of hairs along outer margin; hairs also present along inner margin of basis and first exopodal segment of each swimming leg. Apical spine on third endopodal segment of first swimming leg very robust, about 1.8 times as long as segment (Figure 25A). Apical spine on third endopodal segment of second and third leg about 1.4 times as long as segment (Figure 35B). Second and third leg without any significant difference. Third endopodal segment of fourth swimming leg about 1.5 times as long as wide; outer apical spine about 1.8 times as long as inner one and only slightly longer than segment (Figure 24D).

Fifth leg (Figure $23 \mathrm{C}$ and $24 \mathrm{E}$ ) relatively small, two-segmented, unornamented and inserted clearly ventrally. Basal segment about 1.7 times as wide as long, armed with lateral uniplumose seta inserted on short setophore (Figure 24E). Distal segment much narrower, about 2.4 times as long as wide, armed with apical seta and subapical, inner spine; apical seta 5.3 times as long as segment, plumose distally, reaching almost $2 / 3$ of genital double somite in length (Figure 23C); subapical spine about 1.2 times as long as segment, bipinnate (Figure 24E).

Sixth leg distinct, more or less semicircular, cuticular plate, armed with two almost equally long minute smooth spines and one bipinnate and much 


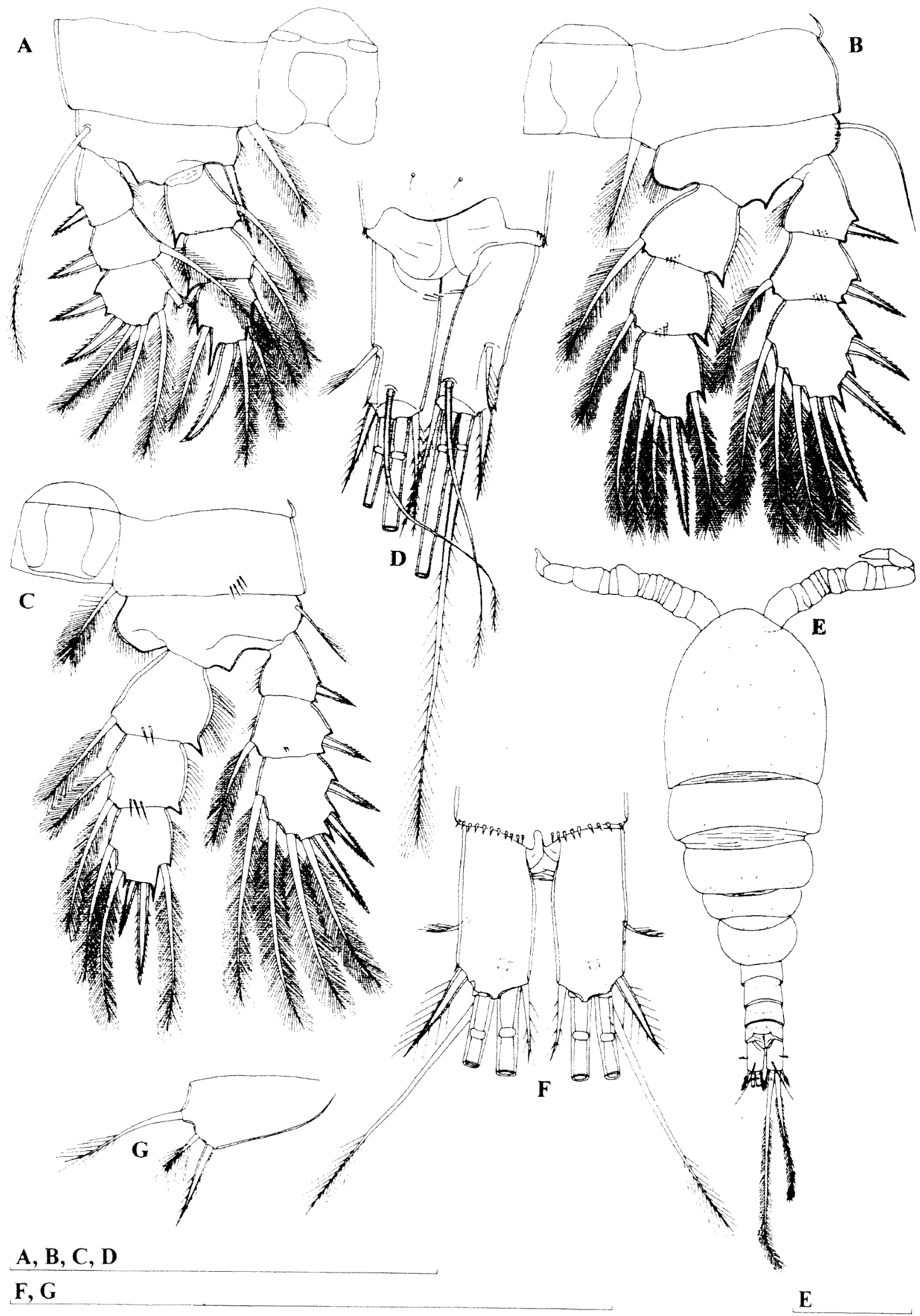

Figure 25 Diacyclops humphreysi humphreysi Pesce and De Laurentiis 1996, A-C, female (0.485 mm) from locality 1 (WAM C28670); D, female (0.44 mm) from locality 44 (WAM C28717); E and G, male $(0.388 \mathrm{~mm}$ ) from locality 1 (WAM C28669); F, male $(0.404 \mathrm{~mm}$ ) from locality 48 (WAM C28722): A, first swimming leg; B third swimming leg; $C$, fourth swimming leg; $D$, anal somite and caudal rami, dorsal view; $E$, habitus, dorsal view; $F$, caudal rami, ventral view; $G$, sixth leg. Scales $=0.1 \mathrm{~mm}$. 
longer seta; median spine distinct, other one completely fused to leg.

Male. Habitus (Figure 25E) relatively slender, with prosome/urosome ratio more than 1.9 and greatest width at $2 / 3$ of cephalothorax's length. Body length/width ratio about 2.8 ; cephalothorax about 2.1 times as wide as genital somite.

Cephalothorax about as long as its greatest width, represents $35 \%$ of body length. Ornamentation of prosomites, colour and nauplius eye similar to those of female. Hyaline fringe of fifth pedigerous somite smooth, as well as that of other urosomites. Fifth pedigerous somite, as well as genital somite, ornamented with two dorsal sensilla; next three somites without any ornamentation.

Genital somite more than twice as wide as long (dorsal view). Anal somite with smooth, broad and convex anal operculum, which represents $48 \%$ of somite's width, not reaching posterior margin of somite; ornamented with two sensilla dorsally and with row of spinules on posterior margin ventrally. Anal sinus widely opened, unornamented.

Caudal rami (Figure 25F) about 2.2 times as long as wide, parallel, with very small space between them. Armature and ornamentation similar to female.

Antennula slightly longer than cephalothorax, 15segmented, unornamented, digeniculate, with geniculations between seventh and eighth and between thirteenth and fourteenth segments. Three aesthetascs on first, one on eighth and one on twelfth segment. Setal formula: 8.3.2.2.0.1.0.1.1.1.1.1.1.1.11. Setae on ninth, tenth, eleventh and thirteenth segments very short, spiniform; all other setae slender and all setae smooth, except seta on fourteenth and one seta on fifteenth segments. Only three setae on fifteenth segment articulating on basal part.

Antenna, labrum, mandibula, maxillula, maxilla, maxilliped and swimming legs similar to female. Third endopodal segment of fourth swimming leg (Figure 24F) about 1.3 times as long as wide, with outer apical spine somewhat longer than in female. Fifth leg also very similar to female.

Sixth leg (Figure 25G) distinct large plate, almost triangular, unornamented and armed with one bipinnate spine and two plumose setae. Outermost seta about 1.4 times as long as spine and 2.4 times as long as middle seta.

\section{Variability}

Body length of females ranges from $0.36 \mathrm{~mm}$ to $0.488 \mathrm{~mm}(0.432 \mathrm{~mm}$ average; $\mathrm{n}=18)$, while in males it ranges from $0.321 \mathrm{~mm}$ to $0.404 \mathrm{~mm}(0.372$ $\mathrm{mm}$ average; $\mathrm{n}=6$ ). The relative length of apical spines on the third endopodal segment of fourth leg can be somewhat different (Figure 24D, F, G and $25 \mathrm{C}$ ), as well as that of the innermost apical seta on the caudal ramus (Figure 24B, C and 25D, F). No other type of variability was observed.
}

\section{Discussion}

The genus Diacyclops Kiefer, 1927 shows a worldwide distribution, with a few nearly cosmopolitan species. Most members are widespread in the Holarctic, few species and subspecies are known from the tropics and the temperate Southern Hemisphere (Pesce 1994). For example, only three species are known from South America (Reid 1998). The genus, as now defined, includes almost 100 species and subspecies (Monchenko and Von Vaupel Klein 1999) and is one of the most successful and diverse of the cyclopoid genera, with species living in all known types of continental epigean and subterranean habitats (Reid 1993b). The evidence from crossbreeding studies (Monchenko 2000) suggests there are a number of cryptic species in this genus.

In Australia six species have been reported so far: Diacyclops bisetosus (Rehberg, 1880); $D$. crassicaudoides (Kiefer, 1928); D. cryonastes Morton, 1985; D. einslei De Laurentiis, Pesce and Humphreys, 1999; D. humphreysi Pesce and De Laurentiis, 1996; and D. reidae De Laurentiis, Pesce and Humphreys, 1999. However, according to Morton (1985), D. crassicaudoides is a junior synonym of the widely distributed and eurytopic $D$. bisetosus; the former species was described by Kiefer (1928c) from New Zealand and reported from Tasmania by Brehm (1953). Diacyclops cryonastes is very common in Tasmania, while on the mainland it is known only from high alpine areas of the Great Dividing Range (Morton 1985). This epigean species has an 11-segmented antennula in the female and three-segmented rami in all swimming legs, which makes it an obvious member of the "michaelseni"-group (see Fiers et al. 1996). Diacyclops einslei, $D$. humphreysi and $D$. reidae are all closely related subterranean species and members of the "crassicaudis"-group. This group is characterised by a 12-segmented antennula in the female and three-segmented rami in all swimming legs. Pesce and De Laurentiis (1996) recognised 15 species and subspecies in the "crassicaudis"-group and, besides $D$. einslei and $D$. reidae, I would add two other taxa to that list: $D$. rupestris (Mazepova, 1950), from Lake Baikal (Mazepova 1950); and D. conversus Reid, 2004, from the United States (Reid 2004). However, this group is probably without phylogenetic importance and the latter species is considered by Reid (2004) as a member of the North American "nearcticus"group. On the other hand, the three abovementioned Australian species and all other species and subspecies reported in this monograph are morphologically very similar and probably phylogenetically very close. Besides a 12-segmented antennula in the female and three segmented rami in all swimming legs they also have the outer apical spine of the third endopodal segment of the fourth 
leg longer than the inner one. These characters unite them, together with D. alticola Kiefer, 1935 and $D$. longifurcus Shen and Sung, 1963, from India and China respectively (see Shen et al. 1979), into an easily recognisable, probably monophyletic and zoogeographically understandable group of species, which I name here after its oldest member the "alticola"-group. Both D. alticola and D. longifurcus can be distinguished from all Australian representatives by much longer caudal rami.

Diacyclops humphreysi was described from eight localities near Exmouth (Cape Range peninsula) and two localities near Onslow (Pilbara region) by Pesce and De Laurentiis (1996). De Laurentiis et al. (1999) slightly corrected the original description, reporting this species from 12 additional bores and one well in the Pilbara region, mostly from the Fortescue River aquifer but also from Yule and Robe Rivers. I have found $D$. humphreysi in 66 out of 160 samples from all over the Pilbara, which makes it the most frequently encountered species here. I have also found a very rich population of this species in the subterranean waters of southwest Western Australia (unpublished data), which seems to be separated from the main one, as not a single specimen was found in the intermediate Murchison region (Karanovic 2004a). Specimens from southwestern Western Australia are morphologically much closer to those from the mainland Pilbara and Cape Range than to the population on Barrow Island, which is described below as a separate subspecies. Because one new subspecies and three new species of Diacyclops are described in this monograph, and they are all morphologically very close to each other, $D$. humphreysis. str. had to be redescribed in detail. It seems that the speciation process has been very intense in this complex of species (and probably still is), with some populations achieving reproductive isolation, some being at the subspecific level and also perhaps some cryptic species yet to be revealed with the use of alternative taxonomic methods.

\section{Diacyclops humphreysi unispinosus subsp. nov.} Figures 26-29, 109F and 110

\section{Material Examined}

\section{Holotype}

Female (WAM C28743), Australia, Pilbara, Barrow Island, bore L8, 23 October 1998, leg. W.F. Humphreys and S.M. Eberhard (BES: 3423), $209^{\circ} 01^{\prime \prime} \mathrm{S} 11523^{\prime} 40^{\prime \prime} \mathrm{E}$ : dissected on two slides

\section{Allotype}

Male (WAM C28744), Australia, Pilbara, Barrow Island, bore L8, 23 October 1998, leg. W.F. Humphreys and S.M. Eberhard (BES: 3423), $20^{\circ} 49^{\circ} 01^{\prime \prime S} 115^{\circ} 23^{\prime} 40^{\prime \prime} \mathrm{E}$ : dissected on 1 slide
Paratypes

Australia, Pilbara, Barrow Island, bore L8, 23 October 1998, leg. W.F. Humphreys and S.M. Eberhard (BES: 3423 ), 20 49'01'S 115 23'40"E: three males + 13 females + five copepodids (one male and one female on one slide in toto (WAM C28745); others in alcohol (WAM C28746))

\section{Other material}

1) Australia, Pilbara, Barrow Island, bore MW 7, 11 August 2002, leg. G. Humphreys (BIOTA) $20^{\circ} 46^{\prime} 40^{\prime \prime} \mathrm{S} 115^{\circ} 27^{\prime} 57^{\prime \prime} \mathrm{E}$ : one copepodid (CY 310) dissected on one slide by Jane McRae (WAM C28747)

2) Australia, Pilbara, Barrow Island, bore MW 7, 22 October 1998, leg. W.F. Humphreys and S.M. Eberhard (BES: 3398), 20 46 40"S $115^{\circ} 27^{\prime} 56^{\prime \prime} \mathrm{E}$ : one female dissected on two slides (WAM C28750)

3) Australia, Pilbara, Barrow Island, bore L 32J, 25 October 1998, leg. W.F. Humphreys and S.M.

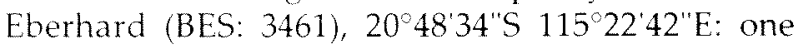
female dissected on one slide (WAM C28588)

4) Australia, Pilbara, Barrow Island, bore M62, 23 October 1998, leg. W.F. Humphreys and S.M. Eberhard (BES: 3433), 20 49'08'S 115 24'24'E: two females (one dissected on one slide (WAM C28589); other in alcohol (WAM C28590)

5) Australia, Pilbara, Barrow Island, bore F11, 25 October 1998, leg. W.F. Humphreys and S.M. Eberhard (BES: 3463), 20 50'46"S 115'22'23"E: one male dissected on one slide (WAM C28591)

\section{Description}

Female (holotype). Body length, excluding caudal setae, $0.427 \mathrm{~mm}$. Habitus (Figure 26A) slender, with prosome/urosome ratio 1.6 and greatest width at midlength of cephalothorax. Body length/width ratio about 3.2 ; cephalothorax 2.2 times as wide as genital double somite. Free pedigerous somites without pronounced lateral expansions, except in fifth pedigerous somite, which lateral corner somewhat protruded. Preserved specimen colourless. Nauplius eye not visible. Rostrum well developed, membranous, very broad and furnished with two large sensilla.

Cephalothorax (Figure 26A) about 1.1 times as long as its greatest width; represents $34 \%$ of total body length. Surface of cephalic shield with few sensilla; no other ornamentation visible. Hyaline fringe of prosomites narrow and smooth. All free pedigerous somites ornamented dorsally with two sensilla. More or less sclerotized joint (as pseudosomite) present between prosome and urosome, as well as between fifth pedigerous somite and genital double somite. Fifth pedigerous somite with smooth fringe dorsally and ventrally, ornamented only with two dorsal sensilla (Figure 26C). 


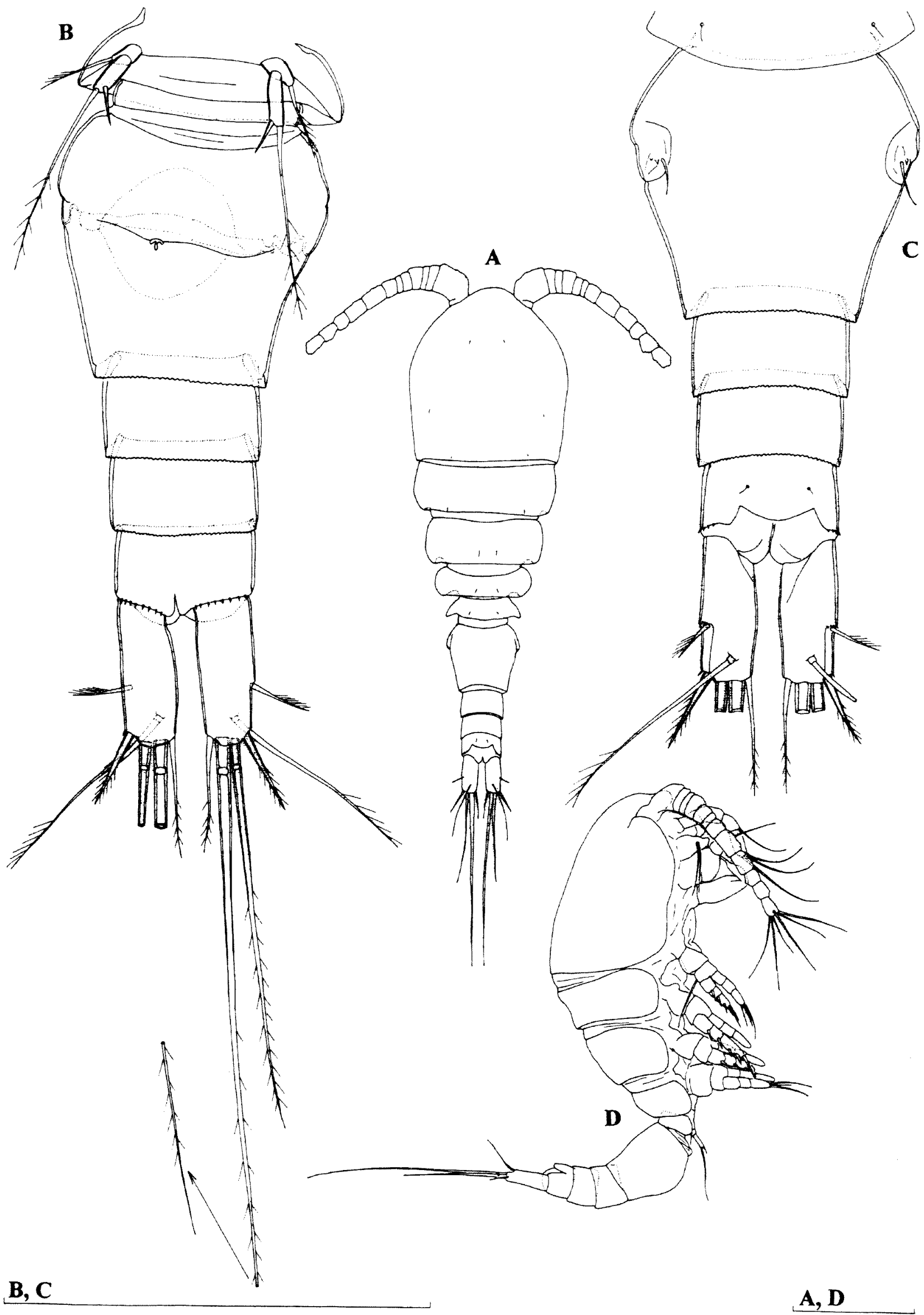

Figure 26 Diacyclops humphreysi unispinosus ssp. nov., A-C, holotype (female); D, paratype female (0.425 mm; WAM C28745): A, habitus, dorsal view; B, urosome, ventral view; C, urosome, dorsal view; D, habitus, lateral view. Scales $=0.1 \mathrm{~mm}$. 


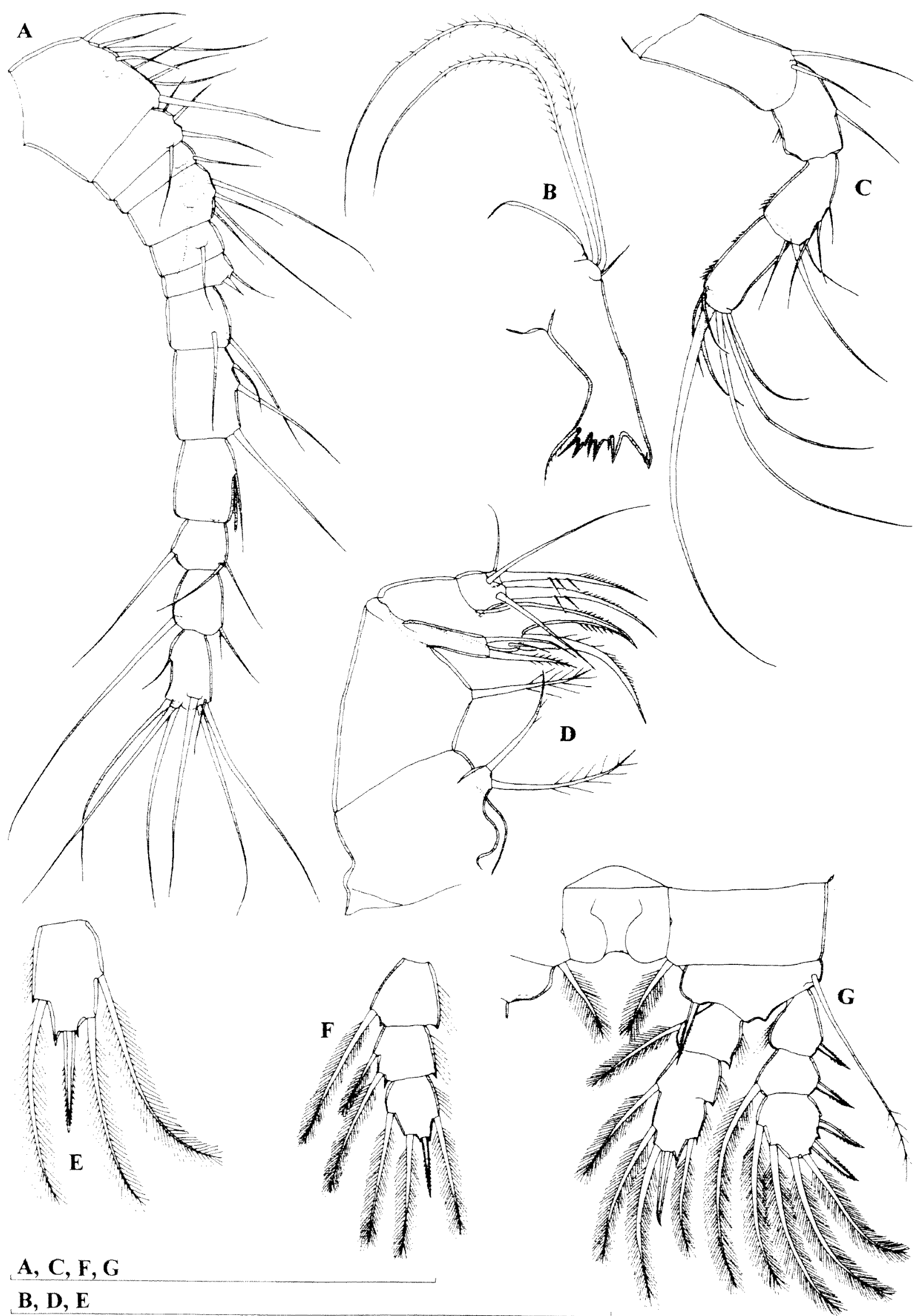

Figure 27 Diacrclops humphrevsi unispinosus ssp. nov. A-E, holotype (female); F, female (0.423 mm) from locality 4 (WAM C28589); G, female $(0.412 \mathrm{~mm}$ ) from locality 3 (WAM C28588): A, antennula; B, mandibula; C, antenma; D. maxilla; $E$, third endopodal segment of fourth swimming leg; $F$, endopod of fourth swimming leg; $G$, abnormal first swimming leg. Scales $=0.1 \mathrm{~mm}$. 
Genital double somite (Figure 26B, C) about as long as wide, unornamented. Hyaline fringe of genital double and two subsequent somites serrated both ventrally and dorsally. Copulatory pore small, T-shaped, positioned just anterior of double somite midlength; copulatory duct not rigidly sclerotized. Seminal receptacle relatively small, ovoid, about as wide as long, representing $50 \%$ of double somite width and $51 \%$ of its length; anterior expansion somewhat shorter than posterior one. Parts of oviducts rigidly sclerotized, long and with several loops. Ovipores situated dorsolaterally, at $2 / 5$ of double somite's length, covered by reduced sixth legs, which bearing two minute spines and one smooth seta. Third and fourth urosomites without any visible ornamentation. Anal somite with smooth, broad, very short and convex anal operculum, which represents $52 \%$ of somite's width and not reaching posterior margin of somite (Figure 26C); ornamented with two large sensilla dorsally and with transverse row of short spinules on posterior margin. Anal sinus widely opened, without visible ornamentation.

Caudal rami (Figure 26B, C) 2.6 times as long as wide, parallel, with space between them about one third of ramus' width; without transverse row of elongated spinules dorsally inside proximal inner recess (Figure $26 \mathrm{C}$ ), ornamented only with several spinules at base of lateral and outermost apical setae; distal margin ventrally with very small protuberance medially, which seems to be cuticular tube pore.. Dorsal seta about 1.4 times as long as ramus, inserted at $5 / 6$ of ramus length, uniarticulate at base and unipinnate distally. Lateral seta arising somewhat dorsolaterally at 3/5 of ramus length, uniplumose and slightly shorter than ramus width. Outermost apical seta stout, spiniform, about 0.6 times as long as ramus, bipinnate. Innermost apical seta also bipinnate but much more slender and about 1.4 times as long as outermost one. Principal apical setae bipinnate and with breaking planes; inner seta about 1.9 times as long as outer one, 0.34 times as long as body.

Antennula (Figure $27 \mathrm{~A}$ ) reaching $2 / 3$ of cephalothorax in length, 12-segmented, unornamented, with one slender aesthetasc on ninth segment and setal formula: 8.4.2.4.1.2.2.3.2.2.3.8. No setae with breaking planes and only one seta on twelfth segment articulating on basal part. One seta on sixth segment spiniform and very short; all other setae slender and all setae smooth. Length ratio of antennular segments, from proximal end and along caudal margins, $1: 0.4: 0.3$ $: 0.5: 0.4: 0.3: 0.7: 1.2: 1: 0.6: 0.8: 1$.

Antenna (Figure 27C) four-segmented, comprising coxobasis and three-segmented endopod; all endopodal segments of about same length, coxobasis somewhat longer. Coxobasis about 2.2 times as long as wide, unornamented but armed with two smooth setae at distal inner corner; seta representing exopod absent. First endopodal segment armed with one smooth seta at middle, ornamented with transverse short row of long spinules near external margin. Second endopodal segment about 1.7 times as long as wide, ornamented with longitudinal row of spinules along external margin, armed with six smooth setae (four lateral, two subapical; one subapical seta somewhat longer and much stronger than any other seta on that segment). Third endopodal segment 2.3 times as long as wide, armed with seven smooth apical setae and ornamented as previous segment.

Labrum trapezoidal, unornamented and relatively large. Cutting edge slightly concave, with 14 large and more or less blunt teeth between produced, rounded lateral corners.

Mandibula (Figure 27B) with small and not clearly distinct palp, armed with two very long, bipinnate setae and one short, smooth, seta on distal end. Coxal gnathobase cutting edge with only six very strong teeth (innermost strongest and complex), one cuticular spinule and outermost pinnate seta, which 1.6 times as long as short seta on palp.

Maxillula (Figure 28G, H) composed of well developed praecoxa and two-segmented palp. Arthrite of praecoxa with four strong and smooth apical spines; only one distinct, others completely fused to praecoxa. Praecoxa armed with five armature elements along inner margin, longest one plumose. Palp with distinct endopod, which bearing three smooth apical setae, and armed laterally with one exopodal smooth seta and apically with two smooth slender setae and one robust, strongly bipinnate spine. Palp clearly shorter than arthrite of praecoxa.

Maxilla (Figure 27D) unornamented and fivesegmented but praecoxa fused to coxa on posterior surface. Proximal endite of praecoxa well developed, about as long as wide, armed with two pinnate setae; distal endite small, unarmed. Proximal endite of coxa with one short, bipinnate seta; distal endite highly mobile, elongate and armed apically with two setae (proximal seta bipinnate and strong but equally long as distal smooth one). Basis expanded into robust bipinnate claw, armed with two setae; strong seta much longer than claw, unipinnate; other seta minute. Endopod two-segmented; proximal segment armed with one robust, pinnate seta and two smooth ones; distal segment very small, armed with one robust, pinnate, apical seta and one slender and smooth subapical seta. Longest seta on distal endopodal segment somewhat shorter than strong seta on basis.

Maxilliped (Figure 28C) four-segmented, composed of syncoxa, basis and two-segmented endopod. Syncoxa 1.5 times as long as wide, 

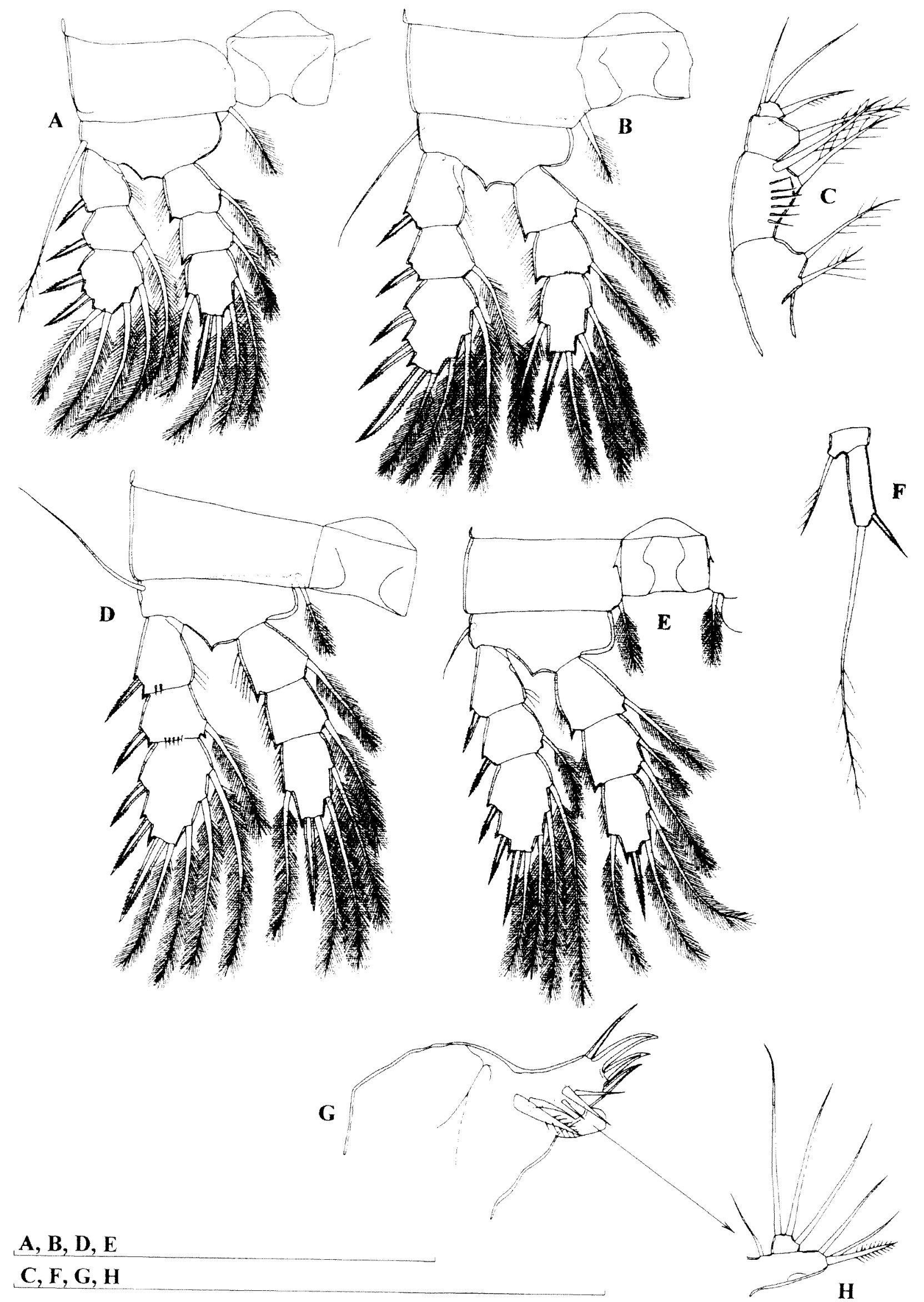

Figure 28 Diacrclops humphreysi unispinosus ssp. nov., holotype (female): A, first swimming leg; B, second swimming leg; C, maxilliped; D, third swimming leg; E, fourth swimming leg; F, fifth leg; G, maxillula; $H$, maxillular palp. Scales $=0.1 \mathrm{~mm}$. 
unornamented and armed with two pinnate setae; distal seta about 1.4 times as long as proximal one. Basis 1.4 times as long as wide, ornamented with single arched row of long spinules at middle, armed with two bipinnate, subequal setae. First endopodal segment unornamented and armed with one strong, pinnate seta; this seta as long as setae on basis. Second endopodal segment very small, unornamented but armed with three setae; innermost seta unipinnate, about 0.6 times as long as middle, smooth one and 0.8 times as long as outermost seta. All pinnate setae with long pinnules.

All swimming legs with three-segmented exopod and endopod (Figure 27E and 28A, B, D, E). Armature formula of swimming legs as follows (legend: inner/outer spine or seta; inner/terminal/ outer):

\begin{tabular}{|c|c|c|c|c|c|c|}
\hline \multirow[b]{2}{*}{ Segments } & \multicolumn{3}{|c|}{ Exopod } & \multicolumn{3}{|c|}{ Endopod } \\
\hline & 1 & 2 & 3 & 1 & 2 & 3 \\
\hline First leg & $0 / 1$ & $1 / 1$ & $2 / 2 / 2$ & $1 / 0$ & $1 / 0$ & $2 / 2 /$ \\
\hline Second leg & $0 / 1$ & $1 / 1$ & $3 / 2 / 2$ & $1 / 0$ & $1 / 0$ & $2 / 2$ \\
\hline Thi & $0 / 1$ & $1 / 1$ & $3 / 2 / 2$ & $1 / 0$ & $1 / 0$ & $2 / 2$ \\
\hline Fourth leg & $0 / 1$ & $1 / 1$ & $3 / 2 / 2$ & $1 / 0$ & $2 / 0$ & $2 / 1$ \\
\hline
\end{tabular}

Last exopodal segment spine formula: 2.3.3.3. Intercoxal sclerites of all swimming legs unornamented, with smooth and bilobate distal margin. All coxae unornamented and armed with plumose seta at inner distal corner. Basis of each leg also unornamented but armed with slender lateral seta on outer margin. Spine at inner corner of basis of first leg absent (Figure 28A). All setae slender and plumose. First and second exopodal segments of third leg and second endopodal segment of second leg with row of spinules along posterior margin; all endopodal segments with row of hairs along outer margin; hairs also present along inner margin of first exopodal segment of each swimming leg. Apical spine on third endopodal segment of first swimming leg not very robust, about 1.2 times as long as segment (Figure 28A). Apical spine on third endopodal segment of second and third leg slightly longer than segment (Figure 28B, D). Third endopodal segment of fourth swimming leg about 1.6 times as long as wide; armed apically with single spine, which only slightly shorter than segment (Figure 27E).

Fifth leg (Figure 26B and 28F) relatively small, two-segmented, unornamented and inserted clearly ventrally. Basal segment about 1.7 times as wide as long, armed with lateral uniplumose seta inserted on short setophore (Figure 28F). Distal segment much narrower, about 3.4 times as long as wide, armed with apical seta and subapical, inner spine; apical seta 3.5 times as long as segment, pinnate distally, reaching almost $2 / 3$ of genital double somite in length (Figure 26B); subapical spine about 0.7 times as long as segment, bipinnate (Figure 28F).

Sixth leg distinct, more or less semicircular, cuticular plate, armed with two almost equally long minute smooth spines and one smooth, much longer seta; median spine distinct, other one completely fused to leg.

Male (allotype). Body length, excluding caudal setae, $0.377 \mathrm{~mm}$. Habitus (Figure 29A) relatively slender, with prosome/urosome ratio more than 1.7 and greatest width near posterior end of cephalothorax. Body length/width ratio about 2.9; cephalothorax about 2.1 times as wide as genital somite.

Cephalothorax (Figure 29A) slightly longer than its greatest width, represents $37 \%$ of body length. Ornamentation of prosomites, colour and nauplius eye similar to those of female. Hyaline fringe of fifth pedigerous somite smooth, those of other urosomites serrated. Fifth pedigerous somite ornamented with two dorsal sensilla; genital somite as well as next three urosomites without any ornamentation.

Genital somite (Figure 29C) about 1.7 times as wide as long (dorsal view), with two spermatophores completely formed inside. Anal somite with smooth, not so broad and only slightly convex anal operculum, which represents $45 \%$ of somite's width, reaching middle of somite's length; ornamented with two sensilla dorsally and with row of spinules along posterior margin. Anal sinus unornamented.

Caudal rami (Figure 29C) parallel and about 2.6 times as long as wide. Armature and ornamentation similar to female.

Antennula (Figure 29E) longer than cephalothorax, 15-segmented, unornamented, digeniculate, with geniculations between seventh and eighth and thirteenth and fourteenth segments. Three aesthetascs present on first, one on eighth and one on twelfth segment. Setal formula: 8.3.2.2.0.1.0.1.1.1.1.1.1.1.11. Setae on ninth, tenth, eleventh and thirteenth segments very short, spiniform; all other setae slender and all setae, except seta one fourteenth and one seta on fifteenth segments, smooth. Just three setae on fifteenth segment articulating on basal part.

Antenna, labrum, mandibula, maxillula, maxilla, maxilliped and swimming legs similar to female. Third endopodal segment of fourth swimming leg (Figure 29D) about 1.5 times as long as wide, with single apical spine somewhat shorter than segment. Fifth leg also very similar to female.

Sixth leg (Figure 29B) distinct, almost triangular plate, unornamented and armed with one bipinnate spine and two setae. Outermost seta unipinnate, about 2.7 times as long as spine and 2.4 times as long as middle smooth seta.

\section{Variability}

Body length of females ranges from $0.326 \mathrm{~mm}$ to $0.492 \mathrm{~mm}(0.418 \mathrm{~mm}$ average; $\mathrm{n}=18)$, while in 


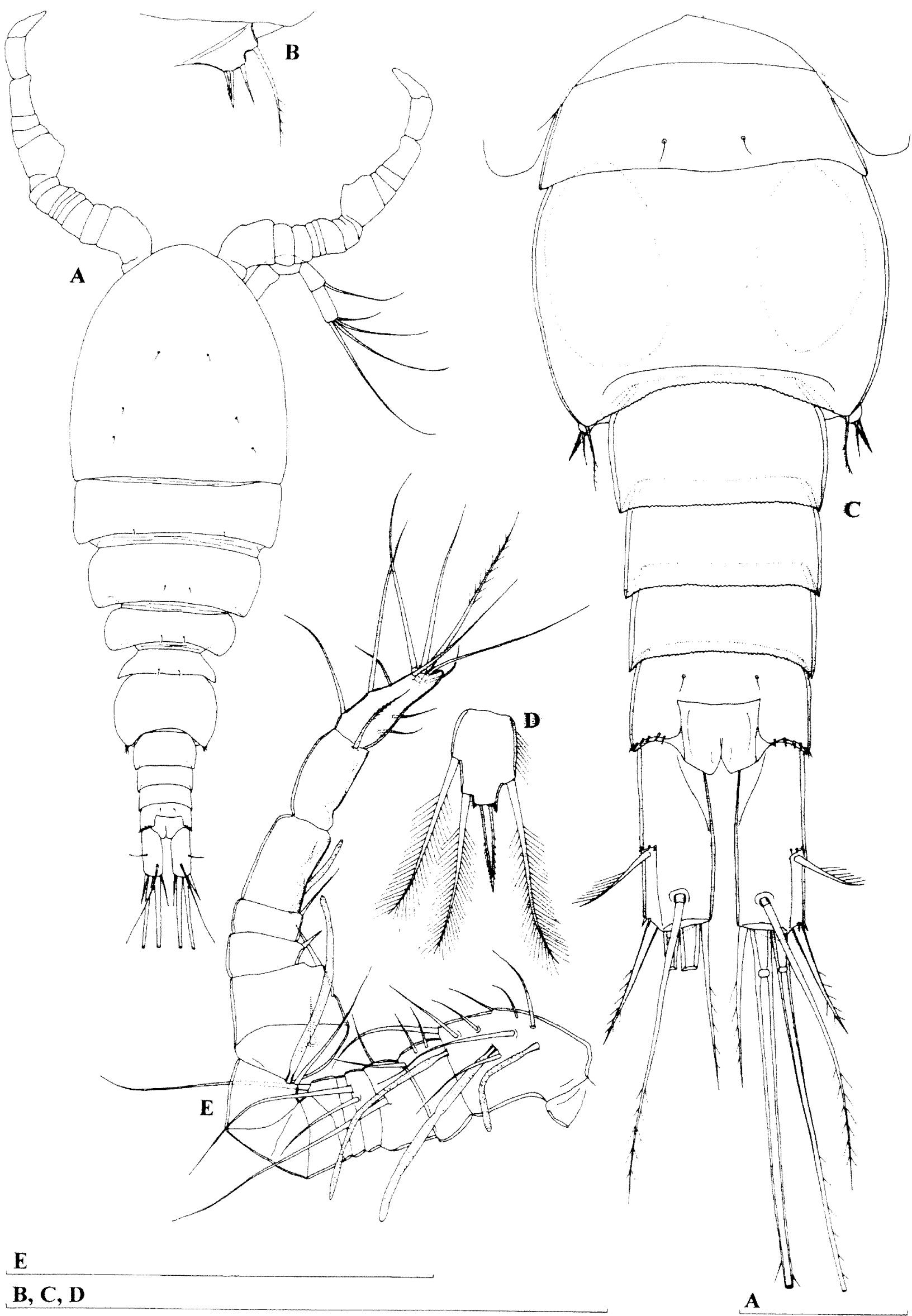

Figure 29 Diacyclops humphreysi unispinosus ssp. nov., allotype (male): A, habitus, dorsal view; B, sixth leg; C, urosome, dorsal view; D, third endopodal segment of fourth swimming leg; $E$, antennula. Scales $=0.1 \mathrm{~mm}$. 
males it ranges from $0.324 \mathrm{~mm}$ to $0.377 \mathrm{~mm}(0.352$ $\mathrm{mm}$ average; $\mathrm{n}=5$ ). One female from locality 4 has a much shorter third endopodal segment of the fourth swimming leg (Figure 27F) than the holotype and one female from locality 3 has one abnormal first leg (Figure 27G), while the opposite leg is normally built. No specimens with two apical spines on the third endopodal segment of the fourth leg were found, even as an abnormality.

\section{Etymology}

The subspecific name refers to its main morphological character: only one apical spine on the third endopodal segment of the fourth swimming leg ("unicus" L. = "only" + "spinosus" L. $=$ "thorny"). It is an adjective agreeing in gender with the masculine generic name.

\section{Discussion}

Diacyclops humphreysi unispinosus ssp. nov. differs from $D$. humphreysi s. str. by the absence of an inner basal spine on the first swimming leg (Figure 28A) and by the presence of a single apical spine on the third endopodal segment of the fourth swimming leg (Figures 27E, F, 28E and 29D). All 29 specimens from Barrow Island, to which this subspecies is restricted, were checked for these two characters and the only exception is one individual with an abnormal first swimming leg (Figure 27G) with the basal spine present (the opposite leg is normally built). Other small differences between the two subspecies include reductions in armature of the fourth antennular segment (Figure 27A) and the first maxillipedal segment (Figure 28C) in $D . h$. unispinosus, although these characters were checked only in dissected specimens. Diacyclops humphreysi s. str. has generally somewhat shorter innermost apical caudal setae than $D$. $h$. unispinosus but this is variable in the nominotypical subspecies and sometimes very similar to the condition in D. h. unispinosus (see Figure 25D).

I had the opportunity to study some of the materials of $D$. $h$. unispinosus at the beginning of my work on Australian copepods and was convinced of the subspecific (rather than specific) status of this population but decided to postpone publishing until some proof of breeding between the two could be found on the mainland (see the next section on Diacyclops humphreysi humphreysi $X$ unispinosus). Barrow Island, owing to eustatic changes, would have been part of the mainland for most of the previous several million years before about 8000 BP (Karanovic 2003). Fortunately, because of the detailed survey of the Pilbara region, interbreeding populations were found in seven localities near the coast (mostly in the Robe River aquifer), which removed any doubt about the subspecific status of the Barrow Island population.
Incidentally, the Robe River mouth is the closest one to Barrow Island.

A single apical spine on the third endopodal segment of the fourth leg has been recorded only twice in the genus Diacyclops. It is a specific character for the North American D. albus Reid, 1991 but only an abnormality in the European $D$. balearicus Gourbault and Lescher-Moutoué, 1979. Both these species are members of the "languidoides"-group, having an 11-segmented antennula and swimming legs with segmentation formula $2 / 2,3 / 2,3 / 3,3 / 3$, and have no close phylogenetic relationship with $D$. humphreysi unispinosus (see Gourbault and Lescher-Moutoué 1979, Reid 1991a).

\section{Diacyclops humphreysi humphreysi X unispinosus \\ Figure 30}

\section{Material Examined}

1) Australia, Pilbara, Harding Dam, bore HD2/81, 15 November 2002, leg. J. Cocking and M. Scanlon (CALM), $20^{\circ} 57^{\prime} 47^{\prime \prime} \mathrm{S} 117^{\circ} 05^{\prime} 55^{\prime \prime} \mathrm{E}$ : four males + 11 females +11 copepodids (one female dissected on one slide (WAM C28592); others in alcohol (WAM C28593))

2) Australia, Pilbara, Robe River, bore G70730103, 14 November 2002, leg. J. Cocking and M. Scanlon (CALM), 2132'59"S 115 51'50"E: two females + one copepodid (one female dissected on two slides (WAM C28594); others in alcohol (WAM C28595))

3) Australia, Pilbara, Robe River, bore G70730104, post-purge, 14 November 2002, leg. J. Cocking and M. Scanlon (CALM), 21 $34^{\prime} 53^{\prime \prime S} 115^{\circ} 52^{\prime} 14^{\prime \prime E}$ : four males + nine females + six copepodids (two females dissected on one slide each (WAM C28596 and C28597); others in alcohol (WAM C28598))

4) Australia, Pilbara, Robe River, bore G70730104, pre-purge, 14 November 2002, leg. J. Cocking and M. Scanlon (CALM), 21 34'53"S 114'52'14"E: four males + 12 females + five copepodids in alcohol (WAM C28599)

5) Australia, Pilbara, Robe River, bore G70730104, post-purge II, 14 November 2002, leg. J. Cocking and M. Scanlon (CALM), 21 34'53'S 114 $52^{\prime} 14^{\prime \prime} \mathrm{E}$ : two males +13 females + one copepodid in alcohol (WAM C28600)

6) Australia, Pilbara, Robe River, bore G70730102, 4 April 2003, leg. J. Cocking and M. Scanlon (CALM), 21 34'53'S 115'52'14"E: seven males + 10 females + three copepodids in alcohol (WAM C28601)

7) Australia, Pilbara, Robe River, Yarraloola Station, bore PANNASLK4, 5 April 2003, leg. J. Cocking and M. Scanlon (CALM), 21 37'59"S 115 57'41"E: three males + five females + 11 copepodids (one female dissected on one slide (WAM C28602); others in alcohol (WAM C28603)) 

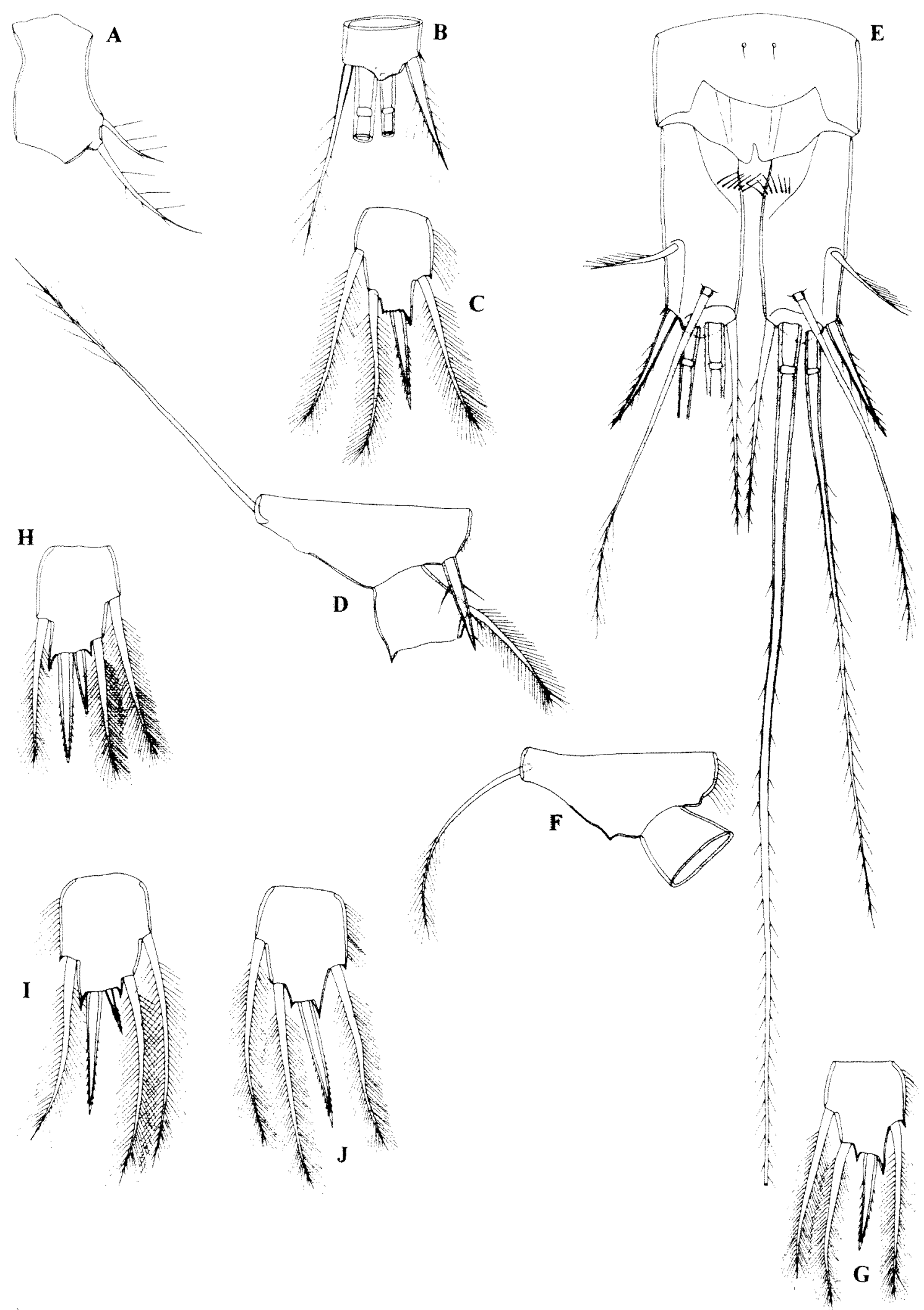

Figure 30 Diacyclops humphreysi humphreysi $X$ unispinosus, A-D, female $(0.419 \mathrm{~mm})$ from locality 2 (WAM C28594); E-G, female $(0.385 \mathrm{~mm}$ ) from locality 7 (WAM C28602); $\mathrm{H}$, female $(0.408 \mathrm{~mm}$ ) from locality 3 (WAM C28596); I and J, female (0.506) from locality 3 (WAM C28597): A, first segment of maxilliped; B, distal end of left caudal ramus, ventral view; $C$, third endopodal segment of fourth swimming leg; $D$, basis of first swimming leg; $E$, anal somite and caudal rami, dorsal view; $F$, basis of first swimming leg; $G$, third endopodal segment of fourth swimming leg; H, third endopodal segment of fourth swimming leg; I, third endopodal segment of left fourth swimming leg; J, third endopodal segment of right swimming leg. Scale = $0.1 \mathrm{~mm}$ 


\section{Variability}

Body length of females ranges from $0.377 \mathrm{~mm}$ to $0.506 \mathrm{~mm}(0.435 \mathrm{~mm}$ average; $\mathrm{n}=12)$, while in males it ranges from $0.369 \mathrm{~mm}$ to $0.404 \mathrm{~mm}(0.384$ $\mathrm{mm}$ average; $\mathrm{n}=4$ ). The third endopodal segment of the fourth swimming leg can be armed with only one apical spine (Figure $30 \mathrm{C}, \mathrm{J}, \mathrm{G}$ ), with two well developed spines (Figure $36 \mathrm{H}$ ) or the inner spine can be present but variously reduced (Figure 30I). The basis of the first swimming leg can be with or without a spine on the inner margin (Figure 30D, F). Generaly the first segment of the maxilliped bears two seate (Figure $30 \mathrm{~A}$ ) but cound not be checked on every specimen. Caudal rami (Figure 30B, E) show very little variability. Generally, in any one sample the majority of specimens have the characteristics of the nominotypical subspecies, although some specimens have characteristics of both subspecies (Figure 30I, J)

\section{Discussion}

The interbreeding population between $D$. humphreysi s. str. Pesce and De Laurentiis, 1996 and $D$. humphreysi unispinosus ssp. nov., although not a systematic category, is listed to make the presentation of members of $D$. humphreysi speciescomplex less confusing. It is restricted mainly to the Robe River aquifer and not only proves the subspecific status of $D$. h. unispinosus but also shows us that the Barrow Island population was the one to move across the newly formed land bridge and that the area of contact was fairly limited. All other populations of $D$. humphreysi on the mainland (including earlier mentioned ones from southwestern Western Australia) show no signs of interbreeding with the Barrow Island subspecies. This leads me to believe that the contact occurred during the last ice-age and that the subspecies unispinosus is not older than 100,000 years (being the offspring of the population that invaded Barrow Island during the ice-age next to last). Indirect evidence like this, that help establish an absolute age of a taxon, are very rare in copepods and extremely important, as only a few true fossils of these crustaceans have been discovered so far (Huys and Boxshall 1991).

\section{Diacyclops sobeprolatus sp. nov}

Figures 31-34

\section{Material Examined}

\section{Holotype}

Female (WAM C28604), Australia, Pilbara, Newman Borefield, large bore W78, 23 July 1997, leg. W.F. Humphreys and S.M. Eberhard (BES: $4835), 23^{\circ} 19^{\prime} 45^{\prime \prime S} 119^{\circ} 51^{\prime} 15^{\prime \prime} \mathrm{E}$ : dissected on two slides

\section{Other material}

1) Australia, Pilbara, SQ4, bore GNHSLK1508, 18 November 2002, leg. J. Cocking and M. Scanlon (CALM), $21^{\circ} 06^{\prime} 48^{\prime \prime S} 118^{\circ} 42^{\prime} 08^{\prime \prime} \mathrm{E}$ : three females (one dissected on one slide (WAM C28605); others in alcohol (WAM C28606))

2) Australia, Pilbara, Weeli Wolli Spring, bore BH17S, 5 October 2002, leg. J. Cocking and M.

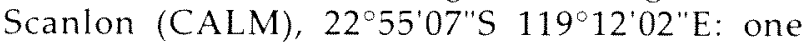
female dissected on one slide (WAM C28607)

3) Australia, Pilbara, OB 23 (Ore Body 23, about $4.5 \mathrm{~km}$ north of Ophthalmia Dam), bore W218, sample 32.2, February 2001, leg. G. Humphreys, J. Bradbury and K. Armstrong (BES: 5581), 2319'36'S $119^{\circ} 50^{\prime 2} 8^{\prime \prime} \mathrm{E}$ : one female in alcohol (WAM C34040)

4) Australia, Pilbara, near Mount Turner, bore NWSLK248, 6 April 2003, leg. J. Cocking and M. Scanlon (CALM), $22^{\circ} 43^{\prime} 04^{\prime \prime S} 117^{\circ} 30^{\prime} 38^{\prime \prime} \mathrm{E}$ : three males +20 females + three copepodids in alcohol (WAM C34041)

5) Australia, Pilbara, near Mount Turner, bore NWSLK248, 20 November 2002, leg. J. Cocking and M. Scanlon (CALM), 22 $43^{\prime} 04^{\prime \prime} S 117^{\circ} 30^{\prime} 38^{\prime \prime} \mathrm{E}$ : three males + seven females + five copepodids (one male dissected on two slides (WAM C34042); one female dissected on one slide (WAM C34043); others in alcohol (WAM C34044))

6) Australia, Pilbara, Railway near $\mathrm{OB} 25$, bore W13, 4 October 2002, leg. J. Cocking and M. Scanlon

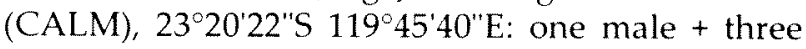
females in alcohol (WAM C34045)

7) Australia, Pilbara, Homestead Creek, bore 96HDM09, 7 April 2003, leg. J. Cocking and M. Scanlon (CALM), 22 $14^{\prime} 20^{\prime \prime S} 117^{\circ} 09^{\prime} 01^{\prime \prime} \mathrm{E}$ : two females + one copepodid in alcohol (WAM C34046)

8) Australia, Pilbara, At Production Bore K31, bore W260, 10 April 2003, leg. J. Cocking and M. Scanlon (CALM), 2317'31"S 11952'12"E: one copepodid in alcohol (WAM C34047)

9) Australia, Pilbara, At Production Bore K31, bore W260, 4 October 2002, leg. J. Cocking and M.

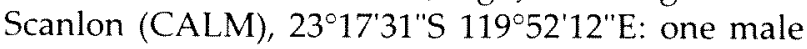
+ three females + one copepodid in alcohol (WAM C34048)

10) Australia, Pilbara, Newman, bore W135, 20 November 1998, leg. S.M. Eberhard (BES: 6380), $23^{\circ} 17^{\prime} \mathrm{S} 119^{\circ} 52^{\prime} \mathrm{E}$ : one male in alcohol (WAM C34049)

11) Australia, Pilbara, Newman, bore WP120, 11 November 1998, leg. S.M. Eberhard (BES: 3526), $23^{\circ} 13^{\prime} \mathrm{S} 119^{\circ} 53^{\prime} \mathrm{E}$ : one male + three female + one copepodid (one female dissected on one slide (WAM C34050); others in alcohol (WAM C34051))

\section{Description}

Female (holotype). Body length, excluding caudal setae, $0.715 \mathrm{~mm}$. Habitus (Figure $31 \mathrm{~B}$ ) relatively robust, with prosome/urosome ratio 1.7 and greatest width at midlength of cephalothorax. Body 


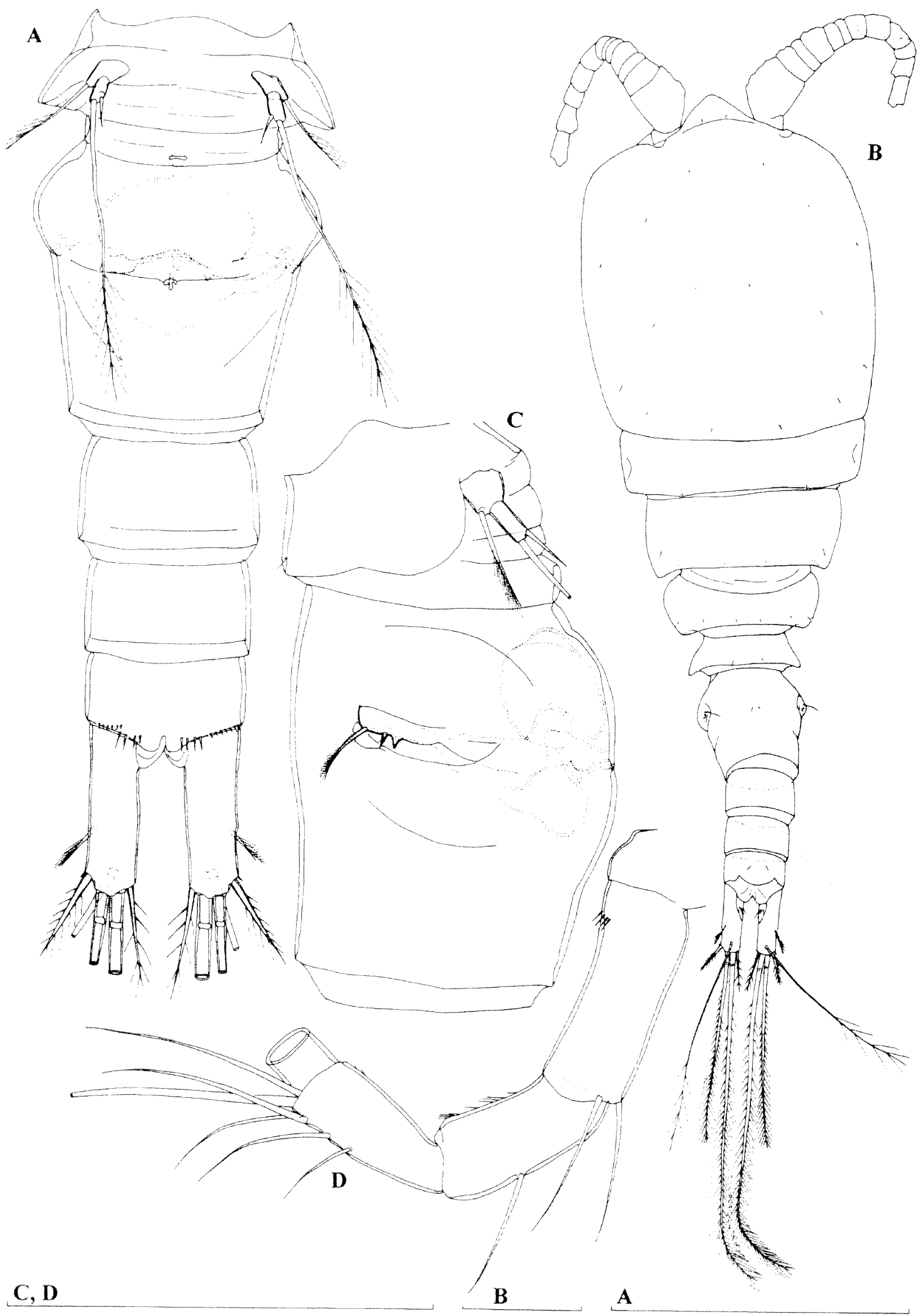

Figure 31 Diacrclops sobeprolatus sp. nov, holotype (female): A, urosome, ventral view; B, habitus, dorsal view; C, first urosomite and genital double somite, lateral view; D, antenna, without most distal segment. Scales $=0.1$ $\mathrm{mm}$. 
length/width ratio about 2.9; cephalothorax 2.8 times as wide as genital double somite. Free pedigerous somites without pronounced lateral expansions, except in fifth pedigerous somite, which lateral corners somewhat protruded. Preserved specimen colourless. Nauplius eye not visible. Rostrum well developed, membranous, almost triangular and furnished with two large sensilla.

Cephalothorax (Figure 31B) about 1.1 times as long as its greatest width; represents $37 \%$ of total body length. Surface of cephalic shield with several large sensilla; no other ornamentation visible. Hyaline fringe of prosomites narrow and smooth. All free pedigerous somites ornamented dorsally with few sensilla. More or less sclerotized joint (as pseudosomite) present between prosome and urosome, as well as between fifth pedigerous somite and genital double somite. Fifth pedigerous somite with smooth fringe dorsally and ventrally, ornamented only with two dorsal sensilla.

Genital double somite (Figure 31A, C) about as long as wide, ornamented at middle with two dorsal sensilla. Hyaline fringe of genital double and two subsequent somites smooth both ventrally and dorsally. Copulatory pore small, T-shaped, positioned just anterior of double somite midlength; copulatory duct relatively long, rigidly sclerotized. Seminal receptacle relatively large, clearly divided into anterior and posterior expansions, about as wide as long (ventral view), representing $54 \%$ of double somite width and $56 \%$ of its length; anterior expansion larger and wider than posterior one. Most lateral parts of oviducts rigidly sclerotized, with two loops; part of oviduct closer to receptacle membranous, relatively wide. Ovipores situated somewhat dorsolaterally, at 2/5 of double somite's length, covered by reduced sixth legs, which bearing two minute spines and one pinnate seta. Third and fourth urosomites without any visible ornamentation. Anal somite with smooth, broad, very short and convex anal operculum (Figure $32 \mathrm{~A}$ ), which represents $59 \%$ of somite's width and not reaching posterior margin of somite; ornamented with two large sensilla dorsally and with transverse row of spinules on posterior margin ventrally (Figure 31A). Anal sinus widely opened, without visible ornamentation.

Caudal rami (Figure $31 \mathrm{~A}$ and $32 \mathrm{~A}$ ) almost 3.3 times as long as wide, parallel, with space between them slightly less than one ramus' width; ornamented with transverse row of elongated spinules dorsally inside proximal inner recess and with several spinules at base of lateral and outermost apical setae; distal margin ventrally with very small medial protuberance, which seems to be cuticular tube pore.. Dorsal seta about 3.2 times as long as ramus and even slightly longer than outer principal apical seta, inserted at $5 / 6$ of ramus length, uniarticulate at base and plumose distally. Lateral seta arising somewhat dorsolaterally at $3 / 5$ of ramus length, uniplumose and about as long as ramus' width. Outermost apical seta stout, spiniform, about 0.5 times as long as ramus, bipinnate. Innermost apical seta also bipinnate but much more slender and about 1.3 times as long as outermost one. Principal apical setae plumose and with breaking planes; inner seta about 1.8 times as long as outer one, 0.4 times as long as body.

Antennula (Figure $32 \mathrm{~B}$ ) reaching $2 / 3$ of cephalothorax, 12-segmented, unornamented, with one slender aesthetasc on ninth segment and setal formula: 8.4.2.6.3.2.2.3.2.2.3.8. No setae with breaking planes and only one apical seta on twelfth segment articulating on basal part. One seta on sixth segment spiniform and very short; all other setae slender and most setae smooth, only four setae on twelfth and one seta on fourth segment pinnate distally. Length ratio of antennular segments, from proximal end and along caudal margins, $1: 0.4: 0.2$ $: 0.4: 0.3: 0.2: 0.5: 1: 0.8: 0.5: 0.7: 0.8$.

Antenna (Figure 31D) five-segmented, comprising very small coxa (partly fused to next segment), basis and three-segmented endopod; all endopodal segments of about same length; basis somewhat longer, about 2.4 times as long as wide, ornamented with few spinules near outer margin proximally, armed with two smooth, subequal setae at distal inner corner; seta representing exopod absent. First endopodal segment armed with one smooth seta at middle and ornamented with longitudinal row of slender spinules along external margin. Second endopodal segment about 2.3 times as long as wide, ornamented with longitudinal row of spinules along external margin distally, armed with six smooth setae (four lateral, two subapical; one subapical seta somewhat longer and much stronger than any other seta on this segment). Third endopodal segment 2.3 times as long as wide, armed with seven smooth apical setae and ornamented as previous two segments.

Labrum (Figure 33B) trapezoidal, unornamented and relatively large. Cutting edge slightly concave, with 16 large and more or less sharp teeth between produced, pointed lateral corners.

Mandibula with small and not clearly distinct palp, armed with two very long, plumose setae and one short, smooth seta on distal end. Coxal gnathobase cutting edge with six very strong teeth (innermost strongest and complex) and outermost pinnate seta, which longer than short seta on palp.

Maxillula composed of well developed praecoxa and two-segmented palp. Arthrite of praecoxa with four strong and smooth apical spines; only one distinct, others completely fused to praecoxa. Praecoxa armed with five armature elements along inner margin, longest one plumose. Palp with distinct endopod, which bearing three smooth 


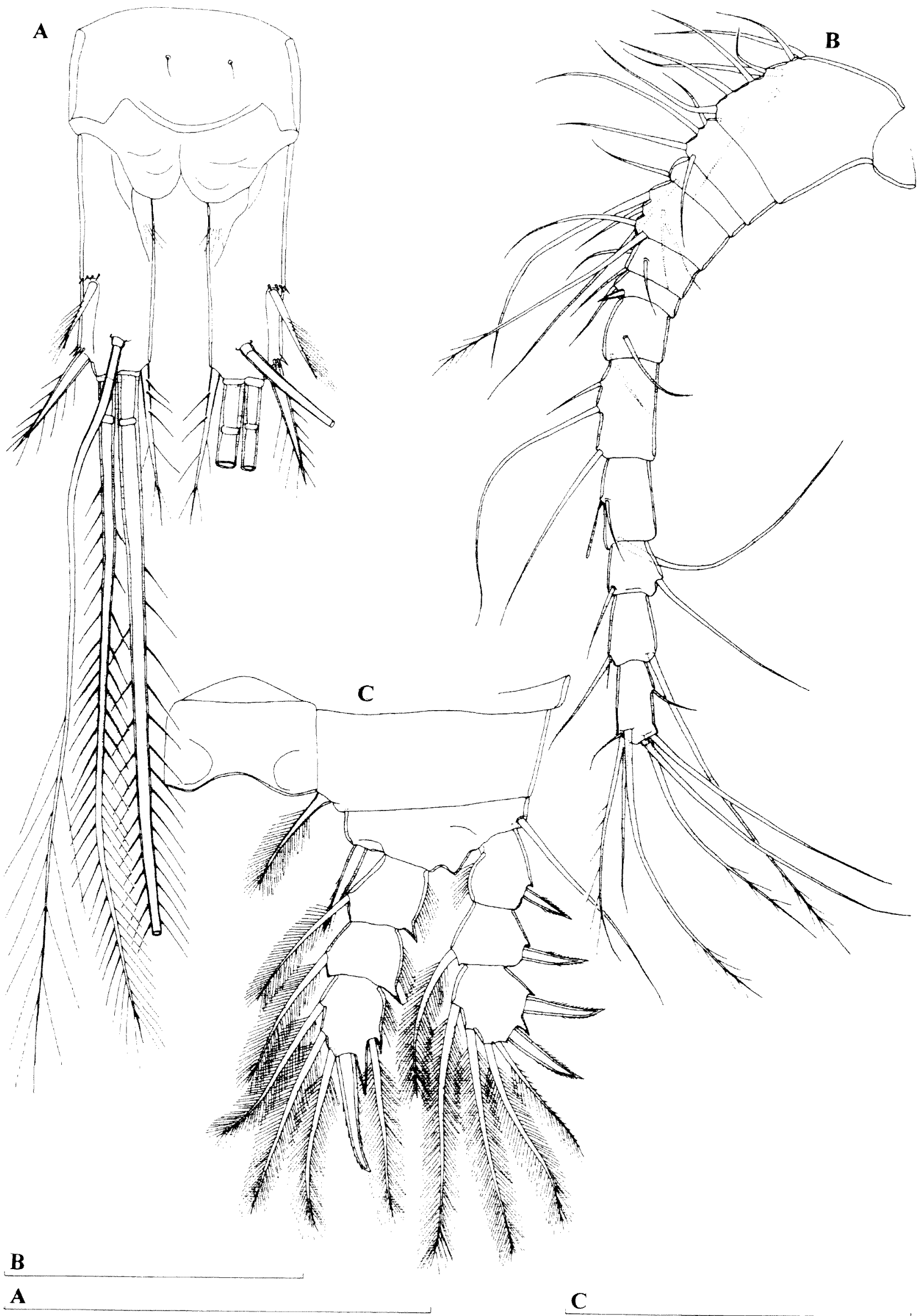

Figure 32 Diacyclops sobeprolatus sp. now, holotype (female): A, anal somite and caudal rami, dorsal view; B, antennula; $C$, first swimming leg. Scales $=0.1 \mathrm{~mm}$. 


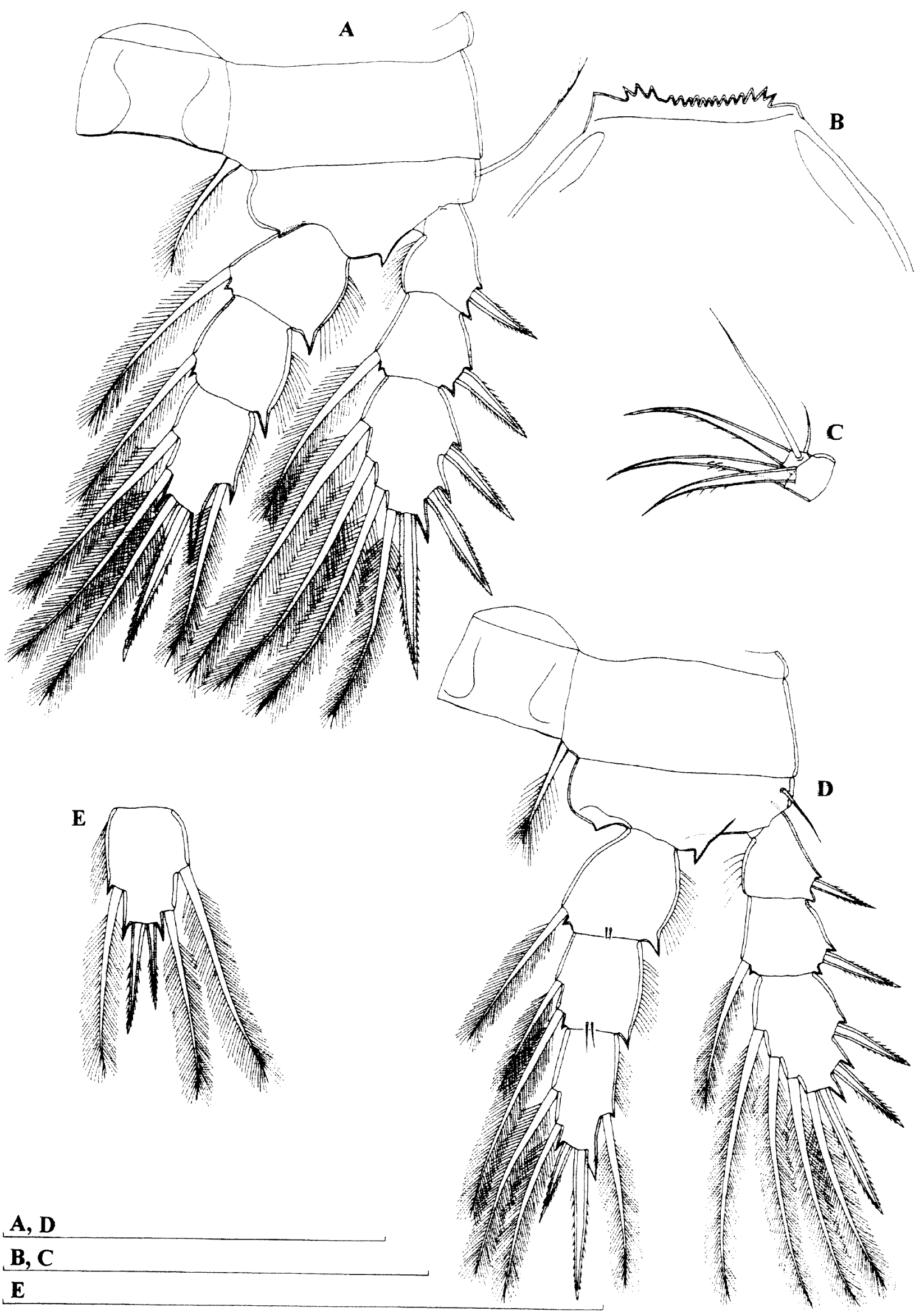

Figure 33 Diacyclops sobeprolatus sp. nov., A-D, holotype (female); E, female $(0.473 \mathrm{~mm})$ from locality 1 (WAM C28605): A, third swimming leg; B, labrum; C, endopod of maxilla; D, fourth swimming leg; E, third endopodal segment of fourth swimming leg. Scales $=0.1 \mathrm{~mm}$. 
apical setae, and armed laterally with one exopodal smooth seta and apically with two smooth slender setae and one robust, strongly bipinnate spine. Palp clearly shorter than arthrite of praecoxa.

Maxilla (Figure 33C) unornamented and fivesegmented but praecoxa fused to coxa on posterior surface. Proximal endite of praecoxa well developed, about as long as wide, armed with two pinnate setae; distal endite small, unarmed. Proximal endite of coxa with one short, bipinnate seta; distal endite highly mobile, elongate and armed apically with two setae (proximal seta bipinnate and strong but equally long as distal smooth one). Basis expanded into robust bipinnate claw, armed with two setae; strong seta much longer than claw, unipinnate; other seta minute. Endopod two-segmented; proximal segment armed with two robust, pinnate setae; distal segment very small, armed with one robust, pinnate, apical seta and two slender and smooth subapical setae. Longest seta on distal endopodal segment somewhat shorter than strong seta on basis.

Maxilliped four-segmented, composed of syncoxa, basis and two-segmented endopod. Syncoxa about 1.5 times as long as wide, unornamented and armed with three pinnate setae; middle seta strongest, slightly longer than most distal one and about 1.4 times as long as most proximal seta. Basis 1.2 times as long as wide, ornamented with single arched row of long spinules at middle, armed with two bipinnate, subequal setae. First endopodal segment unomamented and armed with one strong, pinnate seta; this seta longest and strongest on maxilliped. Second endopodal segment very small, unornamented but armed with three setae; innermost seta bipinnate, about as long as middle, smooth one and twice as long as outermost seta. All pinnate setae with very long pinnules.

All swimming legs with three-segmented exopod and endopod (Figure 32C and 33A, B). Armature formula of swimming legs as follows (legend: inner/ outer spine or seta; inner/terminal/outer):

\begin{tabular}{lcccccc} 
& \multicolumn{3}{c}{ Exopod } & \multicolumn{3}{c}{ Endopod } \\
Segments & 1 & 2 & 3 & 1 & 2 & 3 \\
First leg & $0 / 1$ & $1 / 1$ & $2 / 2 / 2$ & $1 / 0$ & $1 / 0$ & $2 / 2 / 1$ \\
Second leg & $0 / 1$ & $1 / 1$ & $3 / 2 / 2$ & $1 / 0$ & $1 / 0$ & $2 / 2 / 1$ \\
Third leg & $0 / 1$ & $1 / 1$ & $3 / 2 / 2$ & $1 / 0$ & $1 / 0$ & $2 / 2 / 1$ \\
Fourth leg & $0 / 1$ & $1 / 1$ & $3 / 2 / 2$ & $1 / 0$ & $2 / 0$ & $2 / 2 / 1$
\end{tabular}

Last exopodal segment spine formula: 2.3 .3 .3 . Intercoxal sclerites of all swimming legs unomamented, with smooth and bilobate distal margin. All coxae unornamented and armed with plumose seta at inner distal corner. Basis of each leg also unornamented but armed with slender lateral seta on outer margin. Spine at inner corner of basis of first leg stout, reaching halfway of second endopodal segment (Figure 32C). All setae slender and plumose, outer apical seta on third exopodal segment of first leg pinnate along outer margin, plumose along inner one. First and second endopodal segments of fourth leg with two spinules on posterior margin; all endopodal segments with row of hairs along outer margin; hairs also present along inner margin of first exopodal segment of each swimming leg. Apical spine on third endopodal segment of first swimming leg very robust, about 1.4 times as long as segment (Figure 32C). Apical spine on third endopodal segment of second and third leg also1.4 times longer than segment; second and third leg (Figure 33A) without any important difference. Third endopodal segment of fourth swimming leg about 1.9 times as long as wide; armed apically with two strong spines; outer apical spine about 1.8 times as long as inner one and almost 1.3 times as long as segment (Figure 33D).

Fifth leg (Figure 31A, C) relatively small, twosegmented, unornamented and inserted clearly ventrally. Basal segment about 1.7 times as wide as long, armed with lateral uniplumose seta inserted on short setophore. Distal segment much narrower, about 2.5 times as long as wide, armed with apical seta and subapical, inner spine; apical seta 9.4 times as long as segment, pinnate distally, almost reaching posterior margin of genital double somite (Figure 31A); subapical spine about 1.2 times as long as segment.

Sixth leg (Figure 31C) distinct, more or less semicircular, cuticular plate, armed with two almost equally long minute smooth spines and one smooth, much longer seta; median spine distinct, other one completely fused to leg.

Male. Habitus (Figure $34 \mathrm{~A}$ ) relatively slender, with prosome/urosome ratio more than 1.6 and greatest width at middle of cephalothorax. Body length/width ratio about 3.1 ; cephalothorax 2.2 times as wide as genital somite.

Cephalothorax (Figure 34A) somewhat longer than its greatest width, represents $37 \%$ of body length. Ornamentation of prosomites, colour and nauplius eye similar to those of female. Hyaline fringe of fifth pedigerous somite smooth, as well as that of other urosomites. Fifth pedigerous somite, as well as genital somite, ornamented with two dorsal sensilla; next three urosomites without any ornamentation.

Genital somite (Figure 34B) about 1.6 times as wide as long (dorsal view), with two spermatophores completely formed inside. Anal somite and anal sinus similar to those of female.

Caudal rami (Figure 34B) parallel and about 2.9 times as long as wide. Armature and ormamentation similar to female, although dorsal seta slightly shorter than outer principal apical seta.

Antennula longer than cephalothorax, 15 segmented, unornamented, digeniculate, with geniculations between seventh and eighth and 


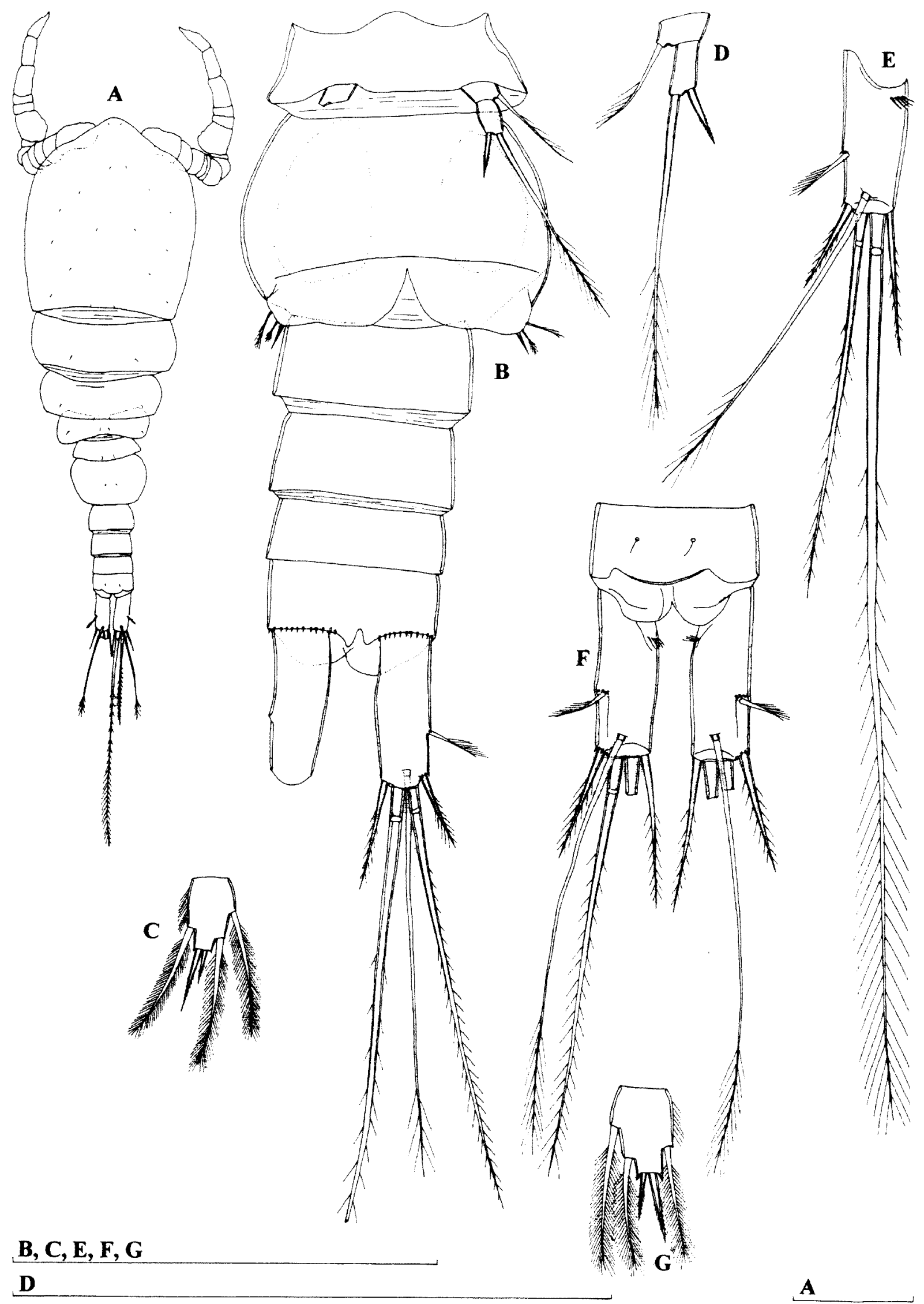

Figure 34 Diacyclops sobeprolatus sp. nov., A-C, male $(0.429 \mathrm{~mm})$ from locality 5 (WAM C34042); D and E, female $(0.473 \mathrm{~mm}$ ) from locality 1 (WAM C28605); F and G, female $(0.488 \mathrm{~mm}$ ) from locality 5 (WAM C34043): A, habitus, dorsal view; $B$, urosome, ventral view; $C$, third endopodal segment of fourth swimming leg; $D$, fifth leg; E, left caudal ramus, dorsal view; F, anal somite and caudal rami, dorsal view; $G$, third endopodal segment of fourth swimming leg. Scales $=0.1 \mathrm{~mm}$. 
thirteenth and fourteenth segments. Three aesthetascs present on first segment, one on eighth and one on twelfth segment. Setal formula: 8.3.2.2.0.1.0.1.1.1.1.1.1.1.11. Setae on ninth, tenth, eleventh and thirteenth segments very short, spiniform; all other setae slender and all setae, except for seta on fourteenth and one seta on fifteenth segments, smooth. Just three setae on fifteenth segment articulating on basal part.

Antenna, labrum, mandibula, maxillula, maxilla, maxilliped and swimming legs similar to female. Third endopodal segment of fourth swimming leg (Figure 29D) about 1.5 times as long as wide; outer apical spine 1.9 times as long as inner one and 0.9 times as long as segment. Fifth leg very similar to female.

Sixth leg (Figure 34B) distinct, large cuticular plate, unornamented and armed with one bipinnate spine and two setae. Outermost seta unipinnate, about 1.7 times as long as spine and 1.4 times as long as middle bipinnate seta. Spine on sixth leg much shorter than that on fifth leg.

\section{Variability}

Body length of females ranges from $0.423 \mathrm{~mm}$ to $0.715 \mathrm{~mm}$ (0.514 $\mathrm{mm}$ average; $\mathrm{n}=12)$, while in males it ranges from $0.388 \mathrm{~mm}$ to $0.429 \mathrm{~mm}(0.403$ $\mathrm{mm}$ average; $\mathrm{n}=5$ ). The dorsal seta on the caudal rami (Figure $34 \mathrm{E}, \mathrm{F}$ ) and the outer apical spine on the third endopodal segment of the fourth swimming leg (Figure $33 \mathrm{E}$ and $34 \mathrm{G}$ ) can be somewhat shorter than in the holotype. No other type of variability was observed.

\section{Etymology}

The specific name is composed of the Greek noun "sobe" (meaning "horse's tail") and the Latin adjective "prolatus" (meaning "elongated"). The name agrees in gender with the masculine generic name and refers to the species main distinguishing character: a very long dorsal caudal seta.

\section{Discussion}

Diacyclops sobeprolatus sp. nov. shares with $D$. humphreysi Pesce and De Laurentiis, 1996 and $D$. cockingi sp. nov. first exopodal segments of all swimming legs without an inner seta. It is readily distinguishable from both by the exceptionally long dorsal caudal setae, which are as long as the outer principal caudal setae. Additionally, $D$. sobeprolatus sp. nov, differs from $D$. humphreysi by a much more robust habitus, longer caudal rami, larger seminal receptacle and longer third endopodal segment of the fourth swimming leg. It can additionally be distinguished from $D$. cockingi by a much shorter innermost apical caudal seta, longer seminal receptacle, less ornamented antennal basis and the smooth hyaline fringe of the abdominal somites.
Similarly long dorsal caudal setae are found only in D. scanloni sp. nov., which differs from $D$. sobeprolatus by the plesiomorphic armature of the swimming legs and also by a more robust habitus, a less convex anal operculum and a shorter innermost apical caudal seta. Diacyclops sobeprolatus was twice found in the same bore as $D$. humphreysis. str. (localities 10 and 11), which strengthens the case for its specific status. Small differences between the species in the "alticola"-group are, in my opinion, the result of a relatively recent speciation and only very extensive sampling (which resulted in numerous sympatric occurrence of different species) helped me not to overlook the existence of several species.

\section{Diacyclops cockingi sp. nov. Figures 35-37}

\section{Material Examined}

\section{Holotype}

Female (WAM C34052), Australia, Pilbara, Turee Creek, bore PFO10-4, 23 November 2002, leg. J. Cocking and M. Scanlon (CALM), 23 $22^{\prime} 17^{\prime \prime S}$ $117^{\circ} 50^{\prime} 53^{\prime \prime} \mathrm{E}$ : dissected on two slides

\section{Paratype}

Australia, Pilbara, Turee Creek, bore PFO10-4, 23 November 2002, leg. J. Cocking and M. Scanlon

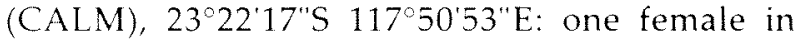
alcohol (WAM C34053)

\section{Other material}

1) Australia, Pilbara, Sherlock River, bore NWCHSLK1196, 16 November 2002, leg. J. Cocking and M. Scanlon (CALM), 20 56 $45^{\prime \prime S} 117^{\circ} 37^{\prime} 49^{\prime \prime} \mathrm{E}$ : four males + 31 females + two copepodids (one female dissected on one slide (WAM C34054); others in alcohol (WAM C34055))

2) Australia, Pilbara, Weeli Wolli Spring, BouRouch pump, 16 November 1998, leg. S.M. Eberhard (BES: 3590), 22 55'S 119 $11^{\prime} \mathrm{E}: 13$ males + 38 females +52 copepodids (one female dissected on one slide (WAM C34056); one male on slide in toto (WAM C34057); others in alcohol (WAM C34058))

3) Australia, Pilbara, Weeli Wolli Spring, bore BH32s, 16 November 1998, leg. S.M. Eberhard (BES: $5490), 22^{\circ} 55^{\circ} \mathrm{S} 119^{\circ} 11^{\prime} \mathrm{E}$ : three females in alcohol (WAM C 34059)

4) Australia, Pilbara, Weeli Wolli Spring, bore BH16s, 16 November 1998, leg. S.M. Eberhard (BES: 3586), 2255'S 119 11'E: one female in alcohol (WAM C 34060$)$

5) Australia, Pilbara, Cane River Borefield, bore CR1/82, 5 April 2003, leg. J. Cocking and M. Scanlon

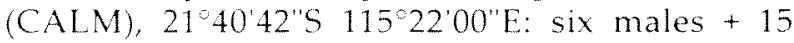


females + five copepodids (one female dissected on one slide (WAM C34061); others in alcohol (WAM C34062))

6) Australia, Pilbara, Weeli Wolli Spring, bore BH17S, 11 April 2003, leg. J. Cocking and M. Scanlon (CALM), 22 55 $07^{\prime \prime S} 119^{\circ} 12^{\prime} 02^{\prime \prime E}$ : one male + two copepodids in alcohol (WAM C34063)

7) Australia, Pilbara, Nanjigardy Pool, bore PFO14, 8 April 2003, leg. J. Cocking and M. Scanlon

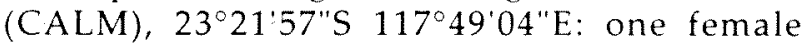
dissected on one slide (WAM C34064)

8) Australia, Pilbara, Paraburdoo Town Borefield, bore TPB2-1, 22 November 2002, leg. J. Cocking and

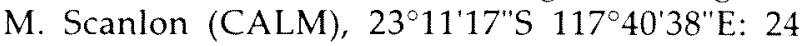
males +30 females + six copepodids (one male and one female dissected on two slides each (WAM C34065 and C34066); others in alcohol (WAM C34067))

9) Australia, Pilbara, Paraburdoo Town Borefield, bore PTP-8, 22 November 2002, leg. J. Cocking and

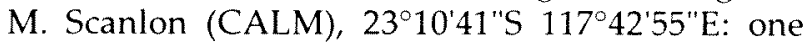
female + one copepodid in alcohol (WAM C34068)

10) Australia, Pilbara, Carlindi Creek, bore MBSLK388A, 17 November 2002, leg. J. Cocking and M. Scanlon (CALM), 20 $58^{\prime} 14^{\prime \prime S} 117^{\circ} 05^{\prime} 30^{\prime \prime} \mathrm{E}: 29$ males + 17 females + two copepodids (one female dissected on one slide (WAM C34069); others in alcohol (WAM C34070))

11) Australia, Pilbara, West Strelley, bore MBSLK400A, 17 November 2002, leg. J. Cocking and M. Scanlon (CALM), 20 36'10'S 119 07'24'E: four males + two females (one female dissected on one slide (WAM C34071); others in alcohol(WAM C34072))

12) Australia, Pilbara, Yule River, bore GNHSLK1448, 18 November 2002, leg. J. Cocking and M. Scanlon (CALM), 21 36'11"S 118 48'52"E: 12 males +24 females (one ovigerous) +22 copepodids (one female dissected on one slide (WAM C34073); others in alcohol (WAM C34074))

13) Australia, Pilbara, Tabba Tabba Creek, bore GNHSLK1648A, 16 November 2002, leg. J. Cocking and M. Scanlon (CALM), 20 22'14"S 118 $56^{\circ} 58^{\prime \prime} \mathrm{E}$ : six males + eight females + four copepodids in alcohol (WAM C34075)

14) Australia, Pilbara, OB 23 (Ore Body 23, about $4.5 \mathrm{~km}$ north of Ophthalmia Dam), bore T401, sample 25.2, February 2001, leg. G. Humphreys, J Bradbury and K. Armstrong (BES: 5580), 23⒈'01"S 119 51'42"E: 17 males +15 females +11 copepodids (one female dissected on one slide (WAM C34076); others in alcohol (WAM C34077))

15) Australia, Pilbara, Old Yalleen Well, 4 August 1996, leg. W.F. Humphreys (BES: 4950), 215'S $116^{\circ} 24^{\prime} \mathrm{E}$ : one female in alcohol (WAM C34078)

16) Australia, Pilbara, Roy Hill Station, Battle Hill Well, 8 September 2000 , leg. W.F. Humphreys (BES: 8506 and 8509 ), $22^{\circ} 44^{\prime} 28^{\prime \prime} \mathrm{S} 120^{\circ} 07^{\prime} 37^{\prime \prime} \mathrm{E}$ : three females in alcohol (WAM C34079)

\section{Description}

Female (holotype). Body length, excluding caudal setae, $0.689 \mathrm{~mm}$. Habitus (Figure $35 \mathrm{C}$ ) relatively robust, with prosome/urosome ratio 1.6 and greatest width at posterior end of cephalothorax. Body length/width ratio about 2.8; cephalothorax 2.5 times as wide as genital double somite. All free pedigerous somites, except first one, with lateral corners somewhat protruded. Preserved specimen colourless. Nauplius eye not visible. Rostrum well developed, membranous, rounded and furnished with two large sensilla.

Cephalothorax (Figure 35C) only slightly longer than its greatest width; represents $37 \%$ of total body length. Surface of cephalic shield with several large sensilla; no other ornamentation visible. Hyaline fringe of prosomites narrow and smooth. All free pedigerous somites ornamented dorsally with two sensilla. More or less sclerotized joint (as pseudosomite) present between prosome and urosome, as well as between fifth pedigerous somite and genital double somite. Fifth pedigerous somite with smooth fringe dorsally and ventrally, ornamented only with two dorsal sensilla.

Genital double somite (Figure 35A, C) about as long as wide, ornamented at middle with two dorsal sensilla. Hyaline fringe of genital double and two subsequent somites not serrated but with periodic notches both ventrally and dorsally. Copulatory pore small, $\mathrm{T}$-shaped, positioned at $2 / 5$ of double somite's length; copulatory duct relatively long and narrow, rigidly sclerotized. Seminal receptacle relatively small, about 2.2 times as wide as long (ventral view), representing $50 \%$ of double somite width and $28 \%$ of its length; anterior expansion shorter than posterior one. Oviducts rigidly sclerotized, relatively narrow, with several loops. Ovipores situated somewhat dorsolaterally, at 2/5 of double somite's length, covered by reduced sixth legs, which bear two minute spines and one short seta. Third and fourth urosomites without any visible ornamentation. Anal somite with smooth, broad, very short and convex anal operculum, which represents $55 \%$ of somite's width and not reaching posterior margin of somite; ornamented with two large sensilla dorsally and with transverse row of spinules along posterior margin. Anal sinus widely opened, without visible ornamentation.

Caudal rami (Figure 35A) almost 3.2 times as long as wide, parallel, with space between them about half one ramus' width; ornamented with transverse row of elongated spinules dorsally inside proximal inner recess and with several spinules at base of lateral and outermost apical setae; distal margin ventrally with very small medial protuberance, which seems to be cuticular tube pore.. Dorsal seta about 1.6 times as long as ramus, much shorter than outer principal apical seta, inserted at $5 / 6$ of ramus length, uniarticulate at base and plumose distally. 

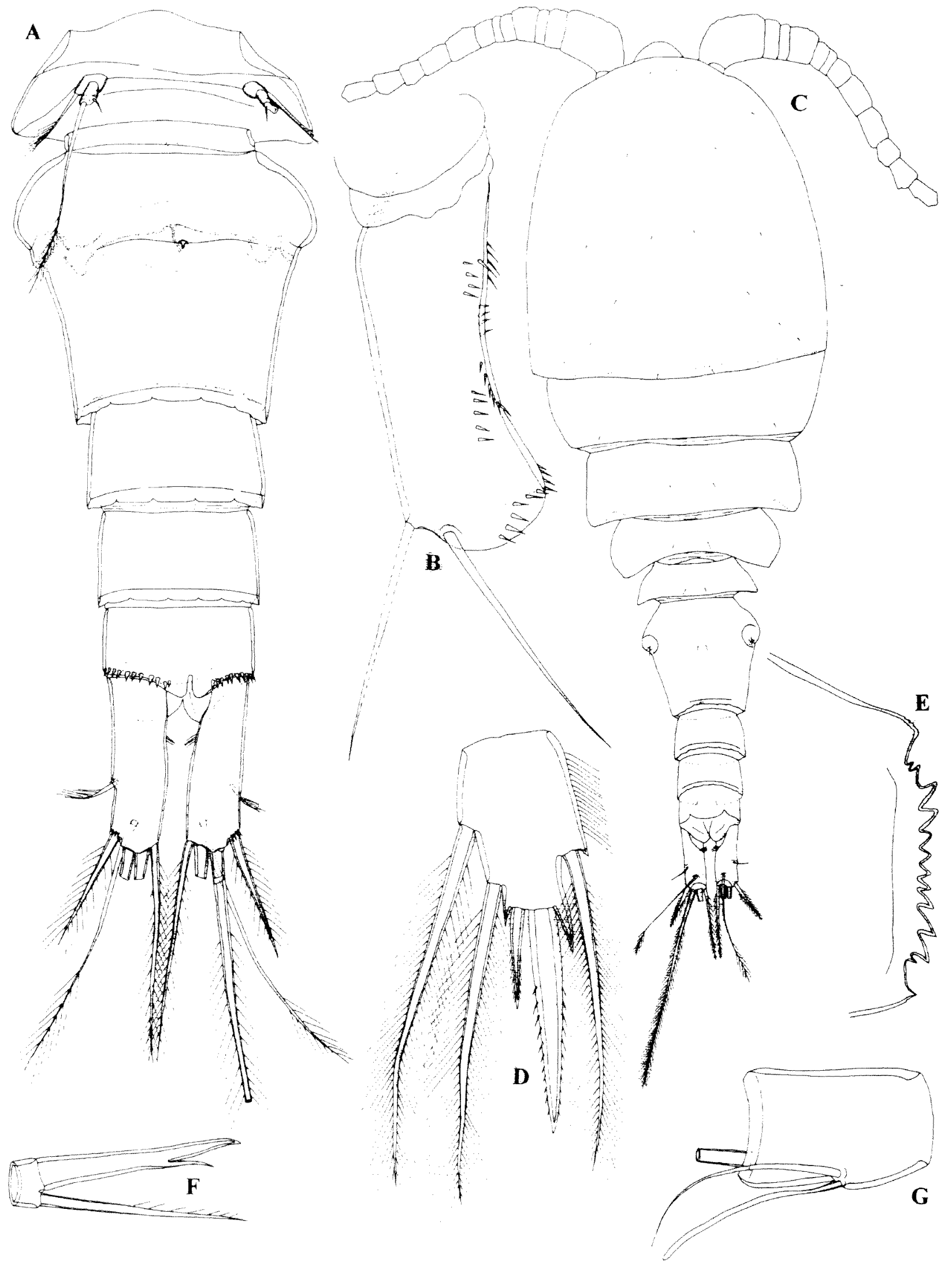

A

B, D, E, F, G

C

Figure 35 Diactclops cockingi sp. nov, holotype (female): A, urosome, ventral view; B, basis of antenna; C, habitus, dorsal view; D, third endopodal segment of fourth swimming leg; E, labrum; F, maxilla, distal part of distal endite of coxa; $G$, antennula, ninth segment. Scales $=0.1 \mathrm{~mm}$. 
Lateral seta arising somewhat dorsolaterally at $3 / 5$ of ramus length, uniplumose and about as long as ramus' width. Outermost apical seta stout, spiniform, about 0.7 times as long as ramus, bipinnate. Innermost apical seta also bipinnate but more slender, about 1.7 times as long as outermost seta and 1.3 times as long as ramus. Principal apical setae plumose and with breaking planes; inner seta about 1.7 times as long as outer one, 0.4 times as long as body.

Antennula reaching $2 / 3$ of cephalothorax, 12segmented, unornamented, with one slender aesthetasc on ninth segment and setal formula: 8.4.2.6.3.2.2.3.2.2.3.8. No setae with breaking planes and only one apical seta on twelfth segment articulating on basal part. One seta on sixth segment spiniform and very short; all other setae slender and most setae smooth. Length ratio of antennular segments, from proximal end and along caudal margins, $1: 0.3: 0.2: 0.4: 0.3: 0.2: 0.5: 1: 0.9: 0.6:$ $0.7: 0.8$.

Antenna five-segmented, comprising very small coxa (partly fused to basis), basis and threesegmented endopod; all endopodal segments of about same length. Basis (Figure 35B) somewhat longer, about 2.7 times as long as wide, ornamented with several rows of spinules all along outer margin proximally and one short row on proximal inner corner, armed with two smooth, subequal setae at distal inner corner; seta representing exopod absent. First endopodal segment armed with one smooth seta at middle, ornamented with longitudinal row of slender spinules along external margin. Second endopodal segment about 2.4 times as long as wide, ornamented with longitudinal row of spinules along external margin distally, armed with six smooth setae (four lateral, two subapical; one subapical seta somewhat longer and much stronger than any other seta on thist segment). Third endopodal segment 2.4 times as long as wide, armed with seven smooth apical setae and ornamented as previous two segments.

Labrum (Figure 35E) trapezoidal, unornamented and relatively large. Cutting edge straight, with 12 large and more or less sharp teeth between produced, pointed lateral corners.

Mandibula with small and not clearly distinct palp, armed with two very long, plumose setae and one short, smooth seta on distal end. Coxal gnathobase cutting edge with six very strong teeth (innermost strongest and complex) and outermost pinnate seta, which longer than short seta on palp.

Maxillula composed of well developed praecoxa and two-segmented palp. Arthrite of praecoxa with four strong and smooth apical spines; only one distinct, others completely fused to praecoxa. Praecoxa armed with five armature elements along inner margin, longest one plumose. Palp with distinct endopod, bearing three smooth apical setae, and armed laterally with one exopodal smooth seta and apically with two smooth slender setae and one robust, strongly bipinnate spine. Palp clearly shorter than arthrite of praecoxa.

Maxilla (Figure 35F) unornamented and fivesegmented but praecoxa fused to coxa on posterior surface. Proximal endite of praecoxa well developed, about as long as wide, armed with two pinnate setae; distal endite small, unarmed. Proximal endite of coxa with one short, bipinnate seta; distal endite highly mobile, elongate and armed apically with two equally long setae (proximal seta strong, smooth, with cleft tip; distal seta more slender and unipinnate). Basis expanded into robust smooth claw, armed with two setae; strong seta much longer than claw, unipinnate; other seta minute. Endopod two-segmented; proximal segment armed with two robust, pinnate setae; distal segment very small, armed with one robust, pinnate, apical seta and two slender and smooth subapical setae. Longest seta on distal endopodal segment somewhat shorter than strong seta on basis.

Maxilliped four-segmented, composed of syncoxa, basis and two-segmented endopod. Syncoxa about 1.5 times as long as wide, unornamented and armed with three pinnate setae; middle seta strongest, slightly longer than most distal one and about 1.4 times as long as most proximal seta. Basis 1.2 times as long as wide, ornamented with single arched row of long spinules at middle, armed with two bipinnate, subequal setae. First endopodal segment unornamented and armed with one strong, pinnate seta; this seta longest and strongest on maxilliped. Second endopodal segment very small, unornamented but armed with three setae; innermost seta bipinnate, about as long as middle, smooth one and twice as long as outermost seta. All pinnate setae with very long pinnules.

All swimming legs with three-segmented exopod and endopod (Figure 35D and 36A). Armature formula of swimming legs as follows (legend: inner/ outer spine or seta; inner/terminal/outer):

\begin{tabular}{lcccccc} 
& \multicolumn{3}{c}{ Exopod } & \multicolumn{3}{c}{ Endopod } \\
Segments & 1 & 2 & 3 & 1 & 2 & 3 \\
First leg & $0 / 1$ & $1 / 1$ & $2 / 2 / 2$ & $1 / 0$ & $1 / 0$ & $2 / 2 / 1$ \\
Second leg & $0 / 1$ & $1 / 1$ & $3 / 2 / 2$ & $1 / 0$ & $1 / 0$ & $2 / 2 / 1$ \\
Third leg & $0 / 1$ & $1 / 1$ & $3 / 2 / 2$ & $1 / 0$ & $1 / 0$ & $2 / 2 / 1$ \\
Fourth leg & $0 / 1$ & $1 / 1$ & $3 / 2 / 2$ & $1 / 0$ & $2 / 0$ & $2 / 2 / 1$
\end{tabular}

Last exopodal segment spine formula: 2.3.3.3. Intercoxal sclerites of all swimming legs unornamented, with smooth and bilobate distal margin. All coxae unornamented and armed with plumose seta at inner distal corner. Basis of each leg also unornamented but armed with slender lateral seta on outer margin. Spine at inner corner of basis of first leg stout, reaching halfway of second endopodal segment (Figure 36A). All setae slender 


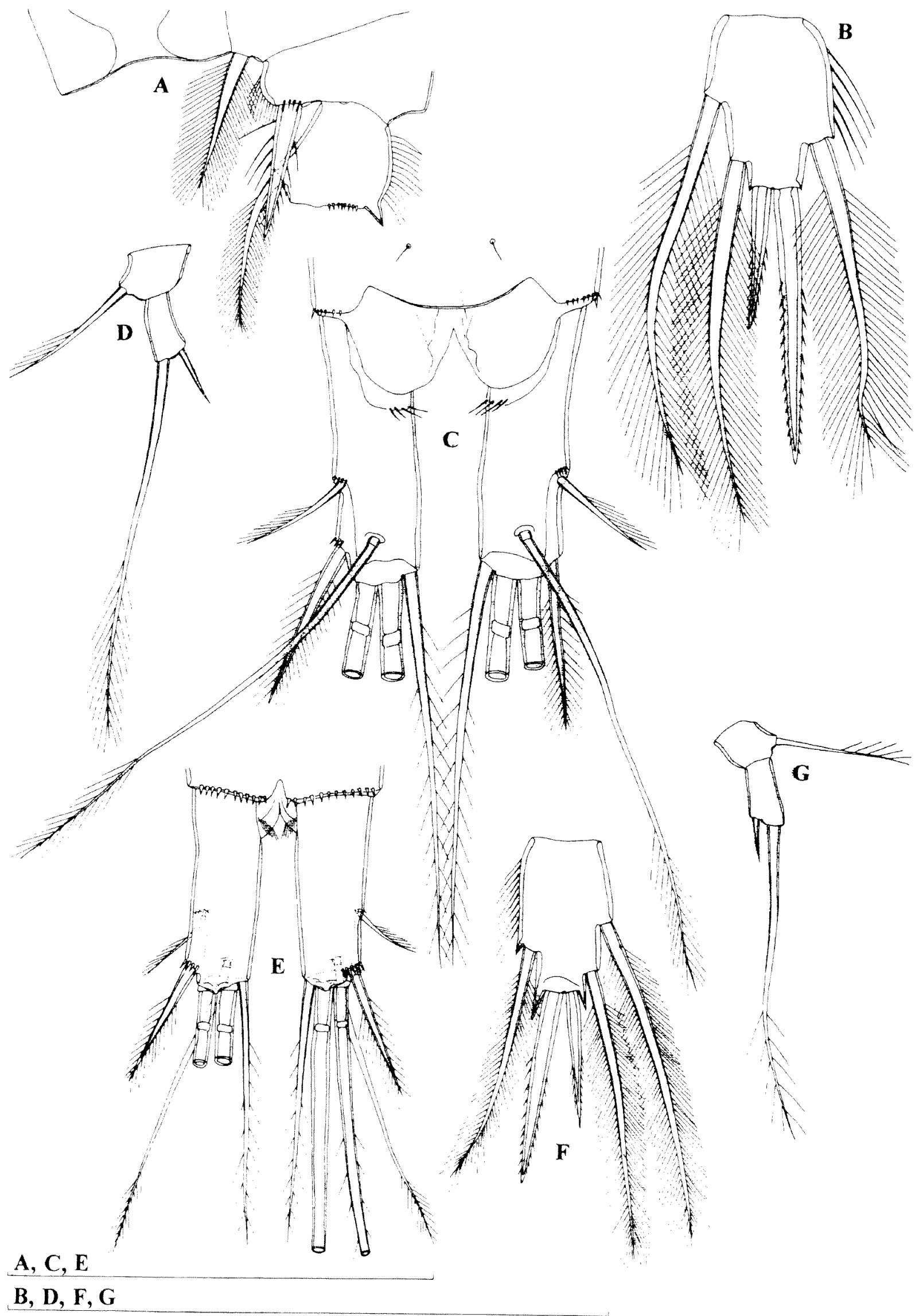

Figure 36 Diacyclops cockingi sp. nov. A, holotype (female); B-D, female $(0.781 \mathrm{~mm}$ ) from locality 8 (WAM C34066); E-G; female $(0.446 \mathrm{~mm}$ ) from locality 2 (WAM C 34056 ): A, basis of first swimming leg; B, third endopodal segment of fourth swimming leg; C, caudal rami, dorsal view; D, fifth leg; $E$, caudal rami, ventral view; $F$, third endopodal segment of fourth swimming leg; $G$, fifth leg. Scales $=0.1 \mathrm{~mm}$. 

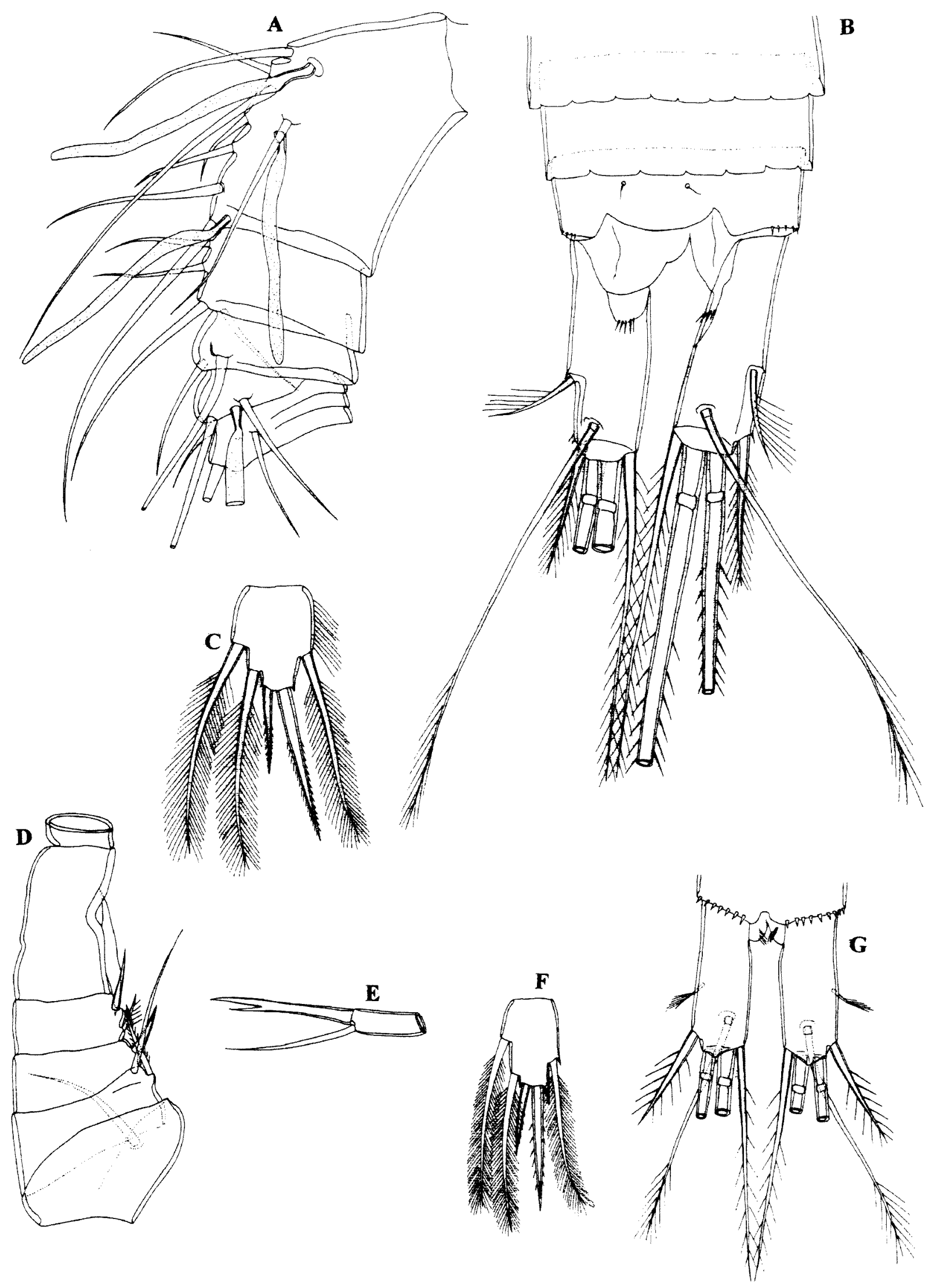

Figure 37 Diacyclops cockingi sp. nov., A-E, male $(0.531 \mathrm{~mm}$ ) from locality 8 (WAM C34065); F and G, male (0.482 $\mathrm{mm}$ ) from locality 2 (WAM C34057): A, antennula, proximal part; B, abdomen, dorsal view; $C$, third endopodal segment of fourth swimming $\operatorname{leg}$; $D$, antennula, middle part; $E$, distal part of maxillular distal endite of coxa; $F$, third endopodal segment of fourth swimming leg; $G$, caudal rami, ventral view. Scale $=0.1$ $\mathrm{mm}$. 
and plumose, outer apical seta on third exopodal segment of first leg pinnate along outer margin, plumose along inner one. All endopodal segments with row of hairs along outer margin; hairs also present along inner margin of first exopodal segment of each swimming leg. Third endopodal segment of fourth swimming leg about 1.5 times as long as wide; armed apically with two spines; outer apical spine very stout, about 2.2 times as long as inner one and almost 1.3 times as long as segment (Figure 35D).

Fifth leg relatively small, two-segmented, unornamented and inserted clearly ventrallv. Basal segment about 1.3 times as wide as long, armed with lateral uniplumose seta inserted on short setophore. Distal segment much narrower, about twice as long as wide, armed with apical seta and subapical, inner spine; apical seta 5.5 times as long as segment, pinnate distally, reaching midlength of genital double somite (Figure 35A); subapical spine slightly shorter than segment.

Sixth leg distinct, more or less semicircular, cuticular plate, armed with two almost equally long minute smooth spines and one smooth short seta; median spine distinct, other one completely fused to leg.

Male. Habitus relatively slender, with prosome/ urosome ratio more than 1.7 and greatest width at middle of cephalothorax. Body length/width ratio about 2.8; cephalothorax 1.9 times as wide as genital somite.

Cephalothorax somewhat longer than its greatest width, represents $38 \%$ of body length. Ornamentation of prosomites, colour and nauplius eye similar to those of female. Hyaline fringe of fifth pedigerous somite smooth, other urosomites with hyaline fringe similar to female (Figure 37B). Fifth pedigerous somite, as well as genital somite, ornamented with two dorsal sensilla; next three urosomites without any ornamentation.

Genital somite about 2.1 times as wide as long (dorsal view), with two spermatophores completely formed inside. Anal somite and anal sinus similar to those of female.

Caudal rami (Figure 37B, G) parallel and about 2.6 times as long as wide. Armature and ornamentation similar to female.

Antennula (Figure $37 \mathrm{~A}, \mathrm{D}$ ) longer than cephalothorax, 15-segmented, unornamented, digeniculate, with geniculations between seventh and eighth and thirteenth and fourteenth segments. Three aesthetascs present on first segment, one on fourth, one on eighth and one on twelfth segment. Setal formula: 8.4.2.3.2.1.0.1.1.2.1.2.0.1.11. Setae on ninth, tenth, eleventh and twelfth segments very short, spiniform; all other setae slender and all setae, except for seta on fourteenth and one seta on fifteenth segments, smooth. Only three setae on fifteenth segment articulating on basal part.
Thirteenth and fourteenth segments with characteristic cuticular structures (geniculation blades).

Antenna, labrum, mandibula, maxillula, maxilla, maxilliped and swimming legs similar to female. Third endopodal segment of fourth swimming leg (Figure $37 \mathrm{C}$ ) about 1.3 times as long as wide; outer apical spine 1.8 times as long as inner one and 1.5 times as long as segment. Fifth leg very similar to female

Sixth leg distinct, large cuticular plate, unornamented and armed with one bipinnate spine and two setae. Outermost seta unipinnate, about 2.3 times as long as spine and 2.5 times as long as middle bipinnate seta.

\section{Variability}

Body length of females ranges from $0.409 \mathrm{~mm}$ to $0.802 \mathrm{~mm}(0.597 \mathrm{~mm}$ average; $\mathrm{n}=30)$, while in males it ranges from $0.375 \mathrm{~mm}$ to $0.662 \mathrm{~mm}(0.514$ $m m$ average; $n=17$ ). The third endopodal segment of the fourth swimming leg can be more or less elongated, both in female (Figure 35D and 36B, F) and male (Figure $37 \mathrm{C}, \mathrm{F}$ ) and the relative length of apical spines on this segment may vary. Differences in the caudal rami shape (Figure 35A, 36C, E and $37 \mathrm{~B}, \mathrm{G})$ are surprisingly small and mostly the result of size differences between specimens.

\section{Etymology}

The species is named in honour of Jim Cocking from the Department of Conservation and Land Management (CALM), who was one of the collectors of the type material and of most of the material studied in this monograph. The name is a noun in the genitive singular.

\section{Discussion}

Diacyclops cockingi sp. nov. shares the greatest number of its morphological characters with $D$. humphreysi s. str. and can be distinguished from this species only by the more robust habitus, longer innermost apical caudal setae (which are as long as the rami), longer caudal rami and more complex ornamentation of the antennal basis. However, when these two species are present in the same sample, as they were in localities 8,9 and 15 , their different size and habitus make it difficult not to recognise them as separate species, even under a dissecting microscope. Actually, one can recognise them as different species, even before realising they belong to the genus Diacyclops. Diacyclops cockingi was also found twice sympatrically with $D$. scanloni sp. nov. (localities 11 and 16), with which it shares relatively long innermost apical caudal setae but could be distinguished by a number of characters, including the armature of swimming legs and the length of the dorsal caudal setae. 
Diacyclops einslei De Laurentiis, Pesce and Humphreys, 1999

Figures $38-41$

\section{Synonymy}

Diacyclops einslei sp. nov. - De Laurentiis et al., 1999: 253, Figures 41-50.

\section{Material Examined}

1) Australia, Pilbara, Millstream, Palm Springs, bore P5, 31 July 1997, leg. W.F. Humphreys and S.M. Eberhard (BES: 4900), 2134'S 116 ${ }^{\circ} 58^{\prime} \mathrm{E}$ : one female dissected on three slides (WAM C34080)

2) Australia, Pilbara, Millstream, Palm Springs, bore P4, 30 July 1997, leg. W.F. Humphreys and S.M. Eberhard (BES: 4879), 21 ${ }^{\circ} 34^{\prime} 44^{\prime \prime S} 116^{\circ} 58^{\prime} 07^{\prime \prime} \mathrm{E}$ : one female dissected on two slides (WAM C34081)

3) Australia, Pilbara, Palm Creek, bore PLUVIOP4, 12 April 2003, leg. J. Cocking and M. Scanlon (CALM), 21 34'39'S 116 58'12"E: one male + one female + three copepodids in alcohol (WAM C34082)

4) Australia, Pilbara, Millstream, Palm Springs, bore PLUVIOP4, 19 November 2002, leg. J. Cocking and M. Scanlon (CALM), 21 $34^{\prime} 39^{\prime \prime S} 116^{\circ} 58^{\prime} 12^{\prime \prime E}$ : two males + six females (one male dissected on two slides (WAM C34083); others in alcohol (WAM C34084))

\section{Supplementary description}

Female. Habitus (Figure 38A) robust, with prosome/urosome ratio 1.8 and greatest width at posterior end of cephalothorax. Body length/width ratio about 2.4 ; cephalothorax 2.7 times as wide as genital double somite. Free pedigerous somites without pronounced lateral expansions. Preserved specimen colourless. Nauplius eye not visible. Rostrum well developed, membranous, very broad and furnished with two large sensilla.

Cephalothorax (Figure 38A) about 1.1 times as long as its greatest width; represents $47 \%$ of total body length. Surface of cephalic shield with several large sensilla; no other ornamentation visible. Hyaline fringe of prosomites narrow and smooth. All free pedigerous somites ornamented dorsally with few sensilla. More or less sclerotized joint (as pseudosomite) present between prosome and urosome, as well as between fifth pedigerous somite and genital double somite. Fifth pedigerous somite with smooth fringe dorsally and ventrally, ornamented only with two dorsal sensilla.

Genital double somite (Figure 38B) about 0.8 times as long as wide, ornamented only with two large sensilla dorsally at middle. Hyaline fringe of genital double and two subsequent somites smooth both ventrally and dorsally. Copulatory pore small, ovoid, positioned just posterior of one third of double somite length; copulatory duct relatively short, not rigidly sclerotized. Seminal receptacle small, about 2.2 times as wide as long, representing $41 \%$ of double somite width and $23 \%$ of its length; anterior expansion larger than posterior one. Most lateral parts of oviducts rigidly sclerotized, with two loops; part of oviduct closest to receptacle membranous and relatively wide. Ovipores situated dorsolaterally, at $2 / 5$ of double somite's length, covered by reduced sixth legs, which bear two minute spines and one pinnate seta. Third and fourth urosomites without any visible ornamentation. Anal somite with smooth, broad, very short and almost straight anal operculum, which represents $56 \%$ of somite's width and not reaching posterior margin of somite (Figure 40A); ornamented with two large sensilla dorsally and with transverse row of large spinules on posterior margin. Anal sinus widely opened, without visible ornamentation.

Caudal rami (Figure 38B and 40A, E) 1.6 times as long as wide, very short, parallel, with space between them about one third of ramus' width; ornamented with transverse row of elongated spinules dorsally inside proximal inner recess (Figure 40A) and with few spinules at base of lateral and outermost apical setae; distal margin ventrally with small medial protuberance, which seems to be cuticular tube pore. Dorsal seta about 1.6 times as long as ramus, inserted at $4 / 5$ of ramus length, uniarticulate at base and pinnate distally. Lateral seta arising somewhat dorsolaterally at $3 / 5$ of ramus length, uniplumose and slightly shorter than ramus width. Outermost apical seta stout, spiniform, about 0.7 times as long as ramus, bipinnate. Innermost apical seta also bipinnate and about 2.6 times as long as outermost one but more slender. Principal apical setae plumose and with breaking plane; inner seta about 1.6 times as long as outer one and almost 0.4 times as long as body.

Antennula (Figure $38 \mathrm{D}$ ) reaching somewhat beyond middle of cephalothorax, 12-segmented, unornamented, with one slender aesthetasc on ninth segment and setal formula: 8.4.2.6.2.2.2.3.2.2.3.8. No setae with breaking planes and only one apical seta on twelfth segment articulating on basal part. One seta on sixth segment spiniform and very short; all other setae slender and most setae smooth, only four setae (9\%) pinnate at their distal part. Length ratio of antennular segments, from proximal end and along caudal margins, $1: 0.3: 0.2: 0.4: 0.3: 0.2: 0.5: 0.8: 0.8: 0.5$ $: 0.5: 0.7$.

Antenna (Figure 39F) four-segmented, comprising coxobasis and three-segmented endopod; all endopodal segments of about same length, coxobasis somewhat longer. Coxobasis about 2.2 times as long as wide, ornamented with four short rows of spinules along external margin, armed with two smooth setae at distal inner corner; seta representing exopod absent. First endopodal 


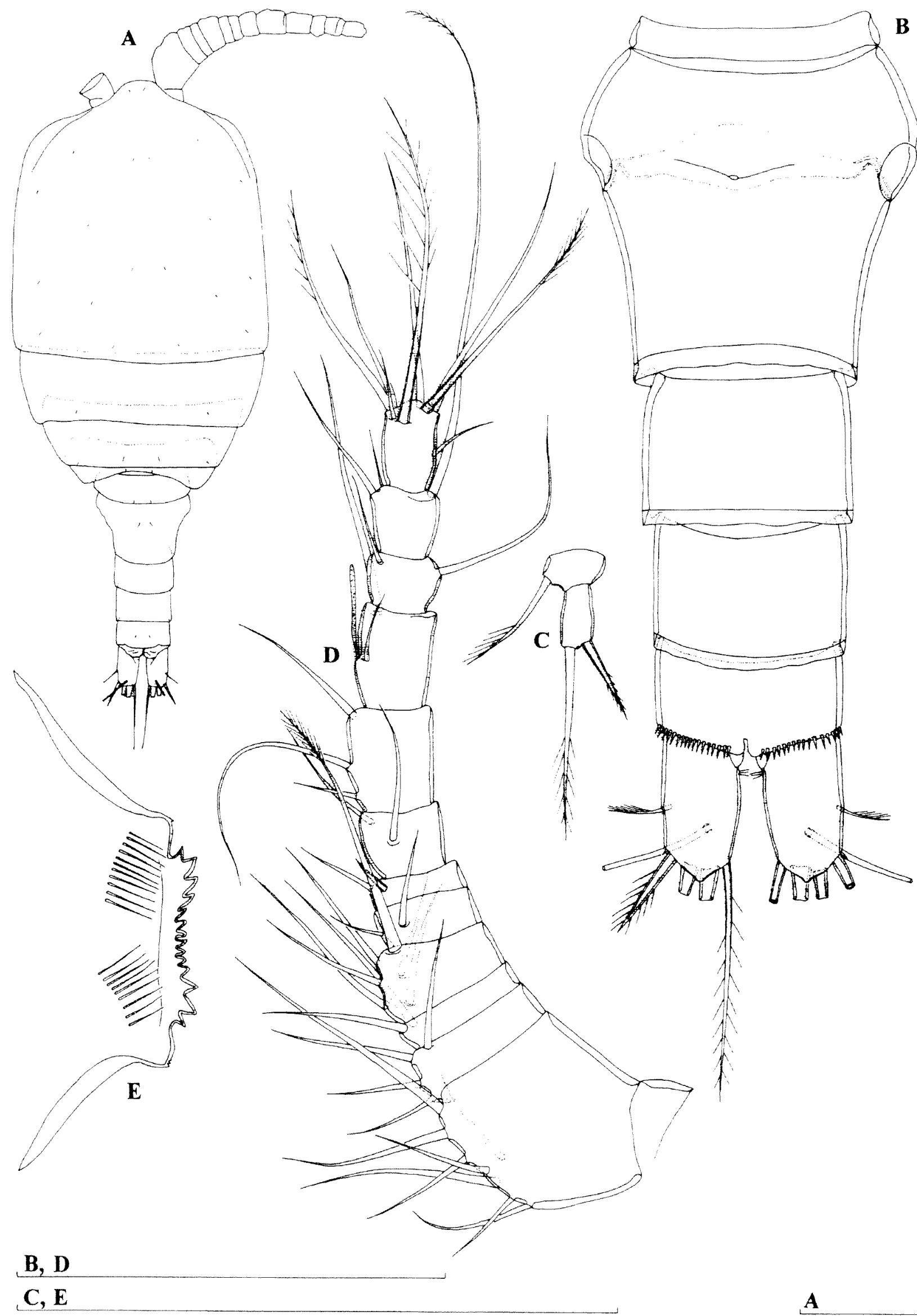

Figure 38 Diacyclops einslei De Laurentiis, Pesce and Humphreys 1999, female $(0.498 \mathrm{~mm})$ from locality 1 (WAM C34080): A, habitus, dorsal view; B, abdomen, ventral view; $C$, fifth leg; D, antennula; $E$, labrum. Scales =0.1 $\mathrm{mm}$. 


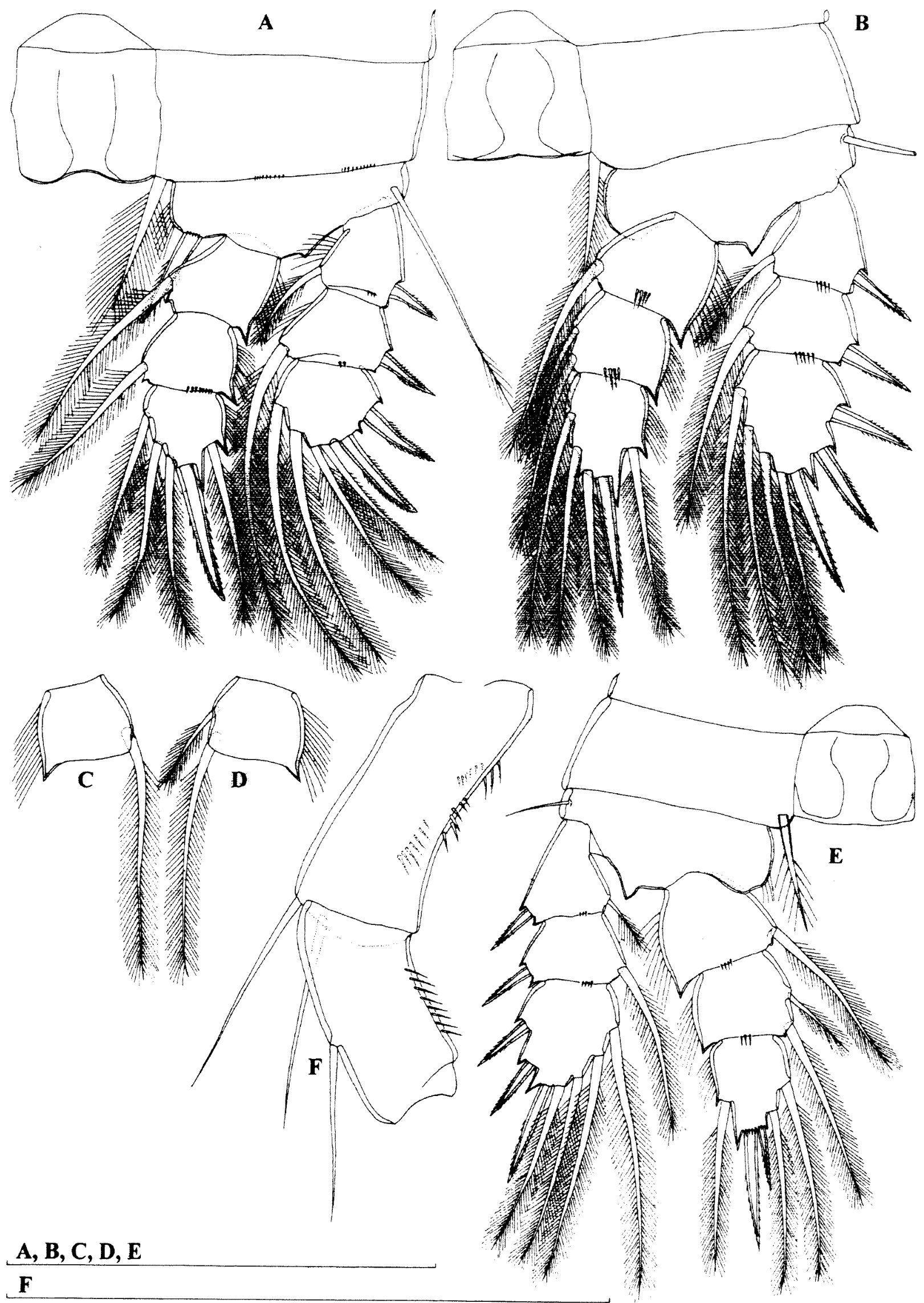

Figure 39 Diacyclops einslei De Laurentiis, Pesce and Humphreys 1999, female $(0.498 \mathrm{~mm})$ from locality 1 (WAM C34080): A, first swimming leg; B, third swimming leg; $C$, second endopodal segment of left second swimming leg; D, second endopodal segment of right second swimming leg; $E$, fourth swimming leg; $F$, antenna, proximal part. Scales $=0.1 \mathrm{~mm}$. 
segment armed with one smooth seta at middle, ornamented with longitudinal short row of long spinules along external margin. Second endopodal segment about 1.8 times as long as wide, ornamented with longitudinal row of spinules along external margin, armed with six smooth setae three lateral, two subapical; one subapical seta somewhat longer and much stronger than any other seta on that segment). Third endopodal segment 2.2 times as long as wide, armed with seven smooth apical setae and ornamented as previous segment.

Labrum (Figure 38E) trapezoidal and relatively large, ornamented with two rows of about 10 slender spinules on ventral surface. Cutting edge slightly concave, with 14 large and more or less sharp teeth between produced, serrated lateral corners.

Mandibula with small and not clearly distinct palp, armed with two very long, bipinnate setae and one short, smooth, seta on distal end. Coxal gnathobase cutting edge with only six verv strong teeth (innermost strongest and complex) and outermost pinnate seta, which much longer than short seta on palp.

Maxillula (Figure $40 C$ ) composed of well developed praecoxa and two-segmented palp. Arthrite of praecoxa with four strong and smooth apical spines; only one distinct, others completely fused to praecoxa. Praecoxa armed with five elements along inner margin, longest one plumose. Palp with distinct endopod, which bearing three pinnate apical setae, and armed laterally with one exopodal smooth seta and apically with two smooth slender setae and one robust, strongly bipinnate spine. Palp somewhat shorter than arthrite of praecoxa

Maxilla (Figure 40B) unornamented and fivesegmented but praecoxa fused to coxa on posterior surface. Proximal endite of praecoxa well developed, about as long as wide, armed with two pinnate setae; distal endite small, unarmed. Proximal endite of coxa with one short, bipinnate seta; distal endite highly mobile, elongate and armed apically with two setae (proximal seta bipinnate and strong but equally as long as distal smooth one). Basis expanded into robust smooth claw, armed with two setae; strong seta much longer than claw, strongly unipinnate; other seta minute. Endopod two-segmented; proximal segment armed with two robust setae, one unipinnate, other smooth; distal segment very small, ammed with one robust, unipinnate, apical seta and wo slender and smooth subapical ones. longest seta on distal endopodal segment somewhat shorter than strong seta on basis.

Maxilliped four-segmented, composed of syncoxa, basis and two-segmented endopod. Sincoxa 1.5 times as long as wide, unomamented and armed with three pinnate setae; middle seta strongest, slightly longer than most distal one and about 1.4 times as long as most proximal seta. Basis 1.2 times as long as wide, ornamented with single arched row of long spinules at middle, armed with two bipinnate, subequal setae. First endopodal segment unornamented and armed with one strong, pinnate seta; this seta longest and strongest on maxilliped. Second endopodal segment very small, unornamented but armed with three setae; innermost seta bipinnate, about as long as middle, smooth one and twice as long as outermost seta. All pinnate setae with very long pinnules.

All swimming legs with three-segmented exopod and endopod (Figure 39A, B, C, D, E and 40D, F, G). Armature formula of swimming legs as follows (legend: inner/outer spine or seta; inner/terminal/ outer):

\begin{tabular}{lcccccc} 
& \multicolumn{3}{c}{ Exopod } & \multicolumn{3}{c}{ Endopod } \\
Segments & 1 & 2 & 3 & 1 & 2 & 3 \\
Firstleg & $1 / 1$ & $1 / 1$ & $2 / 2 / 2$ & $1 / 0$ & $1 / 0$ & $2 / 2 / 1$ \\
Second leg & $1 / 1$ & $1 / 1$ & $3 / 2 / 2$ & $1 / 0$ & $1(2) / 0$ & $2 / 2 / 1$ \\
Third leg & $1 / 1$ & $1 / 1$ & $3 / 2 / 2$ & $1 / 0$ & $2 / 0$ & $2 / 2 / 1$ \\
Fourth leg & $1 / 1$ & $1 / 1$ & $3 / 2 / 2$ & $1 / 0$ & $2 / 0$ & $2 / 2 / 1$
\end{tabular}

Last exopodal segment spine formula: 2.3 .3 .3 Intercoxal sclerites of all swimming legs unornamented, with smooth and bilobate distal margin. All coxae unornamented (except for two short rows of minute spinules along posterior margin of first leg) but armed with plumose seta at inner distal corner. Spine inserted at inner, slightly protruded corner of basis of first leg reaches one third of second endopodal segment's length (Figure 39A). All setae slender and plumose. Majority of first and second endopodal and exopodal segments with very short row of spinules along posterior margin; all endopodal segments with row of hairs along outer margin; hairs also present along inner margin of basis and first exopodal segment of first swimming leg. Apical spine on third endopodal segment of first swimming leg very robust, about 1.8 times as long as segment (Figure 39A). Apical spine on third endopodal segment of second and third leg about 1.4 times as long as segment (Figure $39 B$ ). Second and third leg without any significant difference. Third endopodal segment of fourth swimming leg about 1.2 times as long as wide; outer apical spine about 1.9 times as long as inner one and 1.3 times as long as segment (Figure 39E).

Fifth leg (Figure $38 \mathrm{C}$ ) relatively small, twosegmented, unormamented and inserted clearly ventrally. Basal segment about 1.6 times as wide as long, armed with lateral uniplumose seta inserted on very short setophore. Distal segment much narrower, about twice as long as wide, armed with apical setae and subapical, inner spine; apical seta three times as long as segment, pinnate distally, reaching middle of genital double somite; subapical spine about 1.3 times as long as segment, bipinnate. sixth leg distinct, more or less semicircular, 


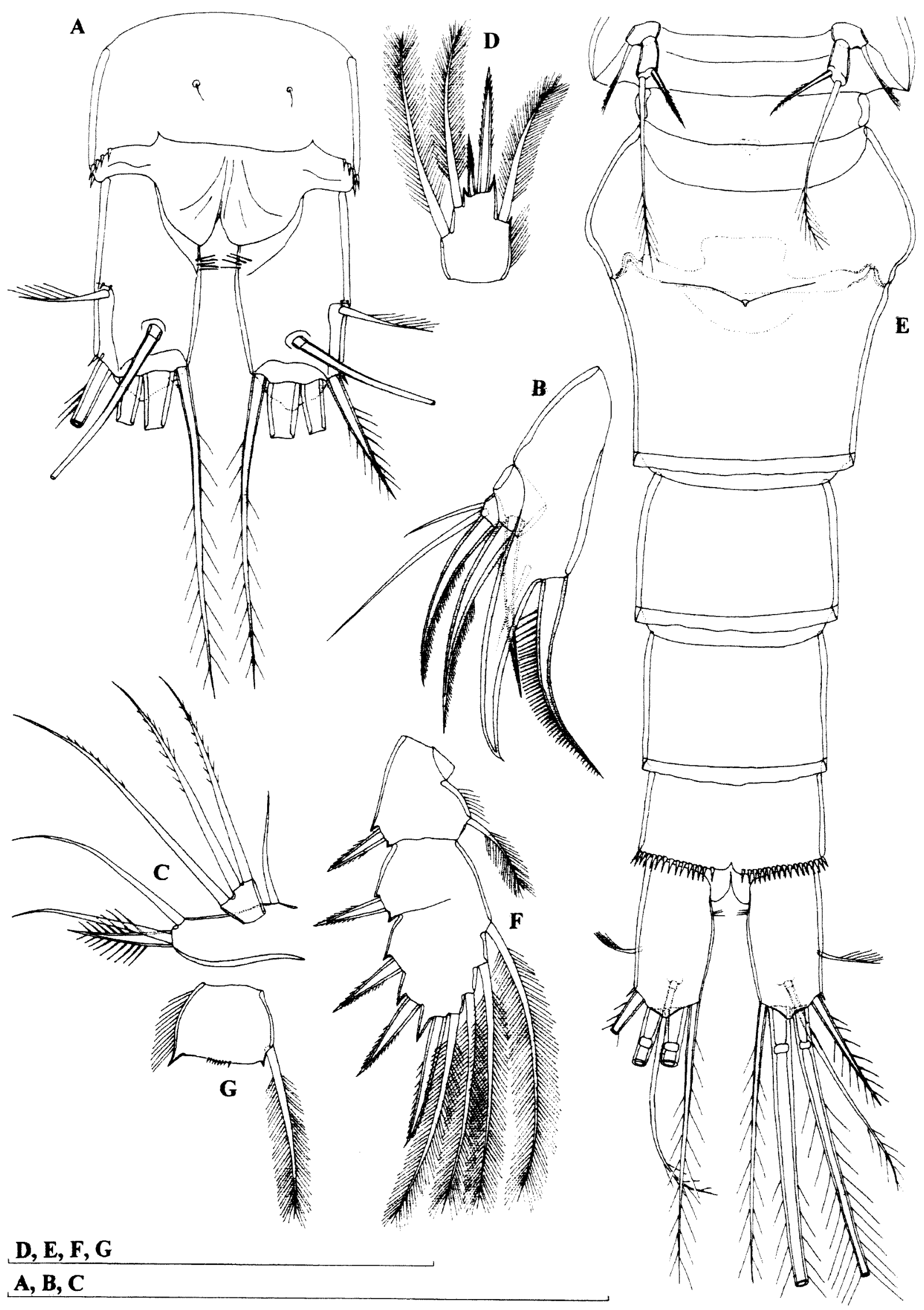

Figure 40 Diacyclops einslei De Laurentiis, Pesce and Humphreys 1999, A-C, female (0.498 mm) from locality 1 (WAM C34080); D-G, female $(0.581 \mathrm{~mm}$ ) from locality 2 (WAM C34081): A, anal somite and caudal rami, dorsal view; B, basis and endopod of maxilla; C, maxillular palp; D, third endopodal segment of fourth swimming leg; $E$, urosome, ventral view; F, exopod of third swimming leg; $G$, second endopodal segment of second swimming leg. Scales $=0.1 \mathrm{~mm}$. 


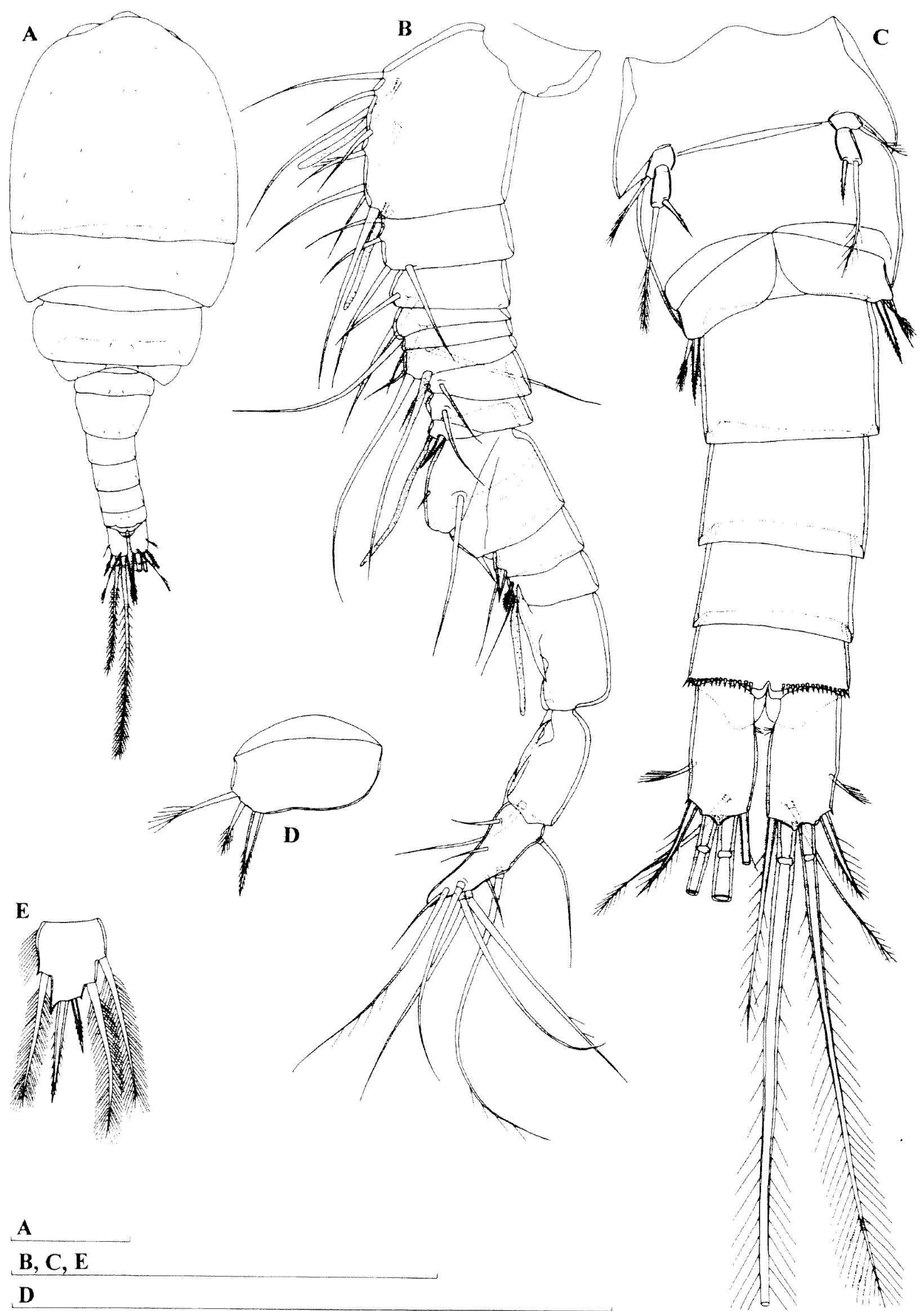

Figure 41 Diacyclops einslei De Laurentiis, Pesce and Humphrevs 1999 , male $(0.452 \mathrm{~mm})$ from locality 4 (WAM C34083): A, habitus, dorsal view; B, antennula; C, urosome, ventral view; D, sixth leg; $\mathrm{E}$, third endopodal segment of fourth swimming leg. Scale $=0.1 \mathrm{~mm}$. 
cuticular plate, armed with two almost equally long minute smooth spines and one bipinnate and much longer seta; median spine distinct, other one completely fused to leg.

Male. Habitus (Figure $41 \mathrm{~A}$ ) relatively robust, with prosome/urosome ratio almost two and greatest width at posterior end of cephalothorax. Body length/width ratio about 2.4; cephalothorax about three times as wide as genital somite.

Cephalothorax (Figure 41A) about as long as its greatest width, represents $42 \%$ of body length. Ornamentation of prosomites, colour and nauplius eye similar to those of female. Hyaline fringe of fifth pedigerous somite smooth, as well as those of other urosomites. Fifth pedigerous somite, as well as genital somite, ornamented with two dorsal sensilla; next three somites without any ornamentation.

Genital somite more than 1.7 times as wide as long (dorsal view). Anal somite and anal sinus similar to those of female.

Caudal rami (Figure 41C) about 1.9 times as long as wide, parallel, with very small space between them. Armature and ornamentation similar to female.

Antennula (Figure 41B) slightly longer than cephalothorax, 15-segmented, unornamented, digeniculate, with geniculations between eighth and ninth and between thirteenth and fourteenth segments. Two aesthetascs present on first, one on eighth and one on twelfth segment. Setal formula: 8.4.2.2.1.2.2.2.2.2.1.2.0.1.11. One seta on eighth, ninth, tenth, eleventh and twelfth segments very short, spiniform; all other setae slender and all setae, except one seta first and three setae on fifteenth segments, smooth. Only five setae on fifteenth and one on fourteenth segment articulating on basal part.

Antenna, labrum, mandibula, maxillula, maxilla, maxilliped and swimming legs similar to female. Third endopodal segment of fourth swimming leg (Figure 41E) about 1.2 times as long as wide, with outer apical spine more slender in female. Fifth leg also very similar to female.

Sixth leg (Figure 41C, D) distinct large plate, almost semicircular, unornamented and armed with one bipinnate spine and two plumose setae. Outermost seta about 0.8 times as long as spine and 1.2 times as long as middle seta.

\section{Variability}

Body length of females ranges from $0.477 \mathrm{~mm}$ to $0.604 \mathrm{~mm}(0.527 \mathrm{~mm}$ average; $\mathrm{n}=8)$, while in males it ranges from $0.446 \mathrm{~mm}$ to $0.452 \mathrm{~mm}(0.448 \mathrm{~mm}$ average; $n=3$ ). Second endopodal segment of the second swimming leg can be armed with one (Figure $39 \mathrm{C}$ and $40 \mathrm{G}$ ) or two setae on the inner margin. The seminal receptacle form may vary (Figure $38 \mathrm{~B}$ and $40 \mathrm{E}$ ). One female from locality 2 has an abnormal exopod of the third swimming leg, with partly fused second and third segments, and the inner seta on the second segment absent (Figure 40F). The third endopodal segment of the fourth swimming leg may be with or without an apical row of spinules (Figure 39E and 40D).

\section{Discussion}

De Laurentiis et al. (1999) described this species from a single bore in the Millstream aquifer. I have found it at four additional localities, all of them also within the Millstream aquifer. This suggests the species may be restricted to the Millstream calcrete, the second largest calcrete body in the Pilbara. At locality $4, D$. einslei was found together with $D$. humphreysi s. str. Diacyclops einslei differs from all the species described or redescribed in this monograph by the very short caudal rami and by the presence of two setae on the second endopodal segment on the third swimming leg. It shares with $D$. scanloni sp. nov, the armature of the first exopodal segments of all legs, although these two species are not very close. Diacyclops einslei is morphologically very similar to $D$. reidae De Laurentiis, Pesce and Humphreys, 1999, although they can be distinguished by their mouthparts.

\section{Diacyclops reidae De Laurentiis, Pesce and Humphreys, 1999}

\section{Synonymy}

Diacyclops reidae sp. nov. - De Laurentiis et al., 1999: 250, Figures 22-40.

\section{Discussion}

This species was described by De Laurentiis et al. (1999) from three bores from the Millstream aquifer in the Pilbara. It is very similar to $D$. einslei De Laurentiis, Pesce and Humphreys, 1999, a species described in the same publication, also from the Millstream aquifer. The differences between the two were well emphasised by De Laurentiis et al. (1999), so I will not repeat them here. However, the nature of the differences between the two species (mostly ornamentation and possibly some abnormalities of the labrum) makes it possible (although not very probable) that De Laurentiis et al. (1999) based their description of $D$. reidae on an aberrant specimen. But, their description was based on more than one animal, so I keep here $D$. reidae as a valid species. However, if the two species prove to be synonymous, normally $D$. reidae would have priority over $D$. einslei, because the former was described on the page 250 and the latter on the page 253 of the same publication. But, if $D$. reidae was described from an aberrant specimen (or specimens), then $D$. einslei could take priority. I have decided to await more material, as the 
sampling of stygofauna in the Pilbara region continues, before commenting more confidently on these two species and examining their type material.

\section{Diacyclops scanloni sp. nov.}

Figures $42-46$

\section{Material Examined}

\section{Holotype}

Females (WAM C34085), Australia, Pilbara, Ord Ranges, bore GNHSLK1664, 17 November 2002, leg. J. Cocking and M. Scanlon (CALM), 20'20'20'S $119^{\circ} 07^{\prime} 26^{\prime \prime} \mathrm{E}$ : dissected on two slides

\section{Allotype}

Male (WAM C34086), Australia, Pilbara, Ord Ranges, bore GNHSLK1664, 17 November 2002, leg. J. Cocking and M. Scanlon (CALM), 20'20'20'S $119^{\circ} 07^{\prime} 26^{\prime \prime} \mathrm{E}$ : dissected on two slides

\section{Other material}

1) Australia, Pilbara, West Strelley, bore MBSLK400A, 17 November 2002, leg. J. Cocking and M. Scanlon (CALM), 20 36'10'S 119 07'24'E : 21 males +30 females + nine copepodids in alcohol (WAM C34087)

2) Australia, Pilbara, Mulga Downs Station, Ebathacalby Well, 2 September 2000, leg. W.F. Humphreys (BES: 8440), 22 $14^{\prime} 58^{\prime \prime} \mathrm{S} 118^{\circ} 44^{\prime} 52^{\prime \prime} \mathrm{E}$ : three males + two females + four copepodids in alcohol (WAM C34088)

3) Australia, Pilbara, Mulga Downs Station, Brown Well, 3 September 2000, leg. W.F. Humphreys (BES: 8463), 22 12'54"S $118^{\circ} 31^{\prime} 05^{\prime \prime} \mathrm{E}$ : one male in alcohol (WAM C34089)

4) Australia, Pilbara, Mulga Downs Station, Calamina Well, 3 September 2000, leg. W.F.

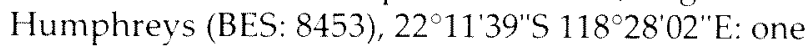
male + four copepodids in alcohol (WAM C34090)

5) Australia, Pilbara, Hamersley Station, Barnett Well, 29 September 1997, leg. W.F. Humphreys and S.M. Eberhard (BES: 4861), 22 36 $00^{\prime \prime S} 117^{\circ} 46^{\prime} 15^{\prime \prime} \mathrm{E}$ : one female in alcohol (WAM C34091)

6) Australia, Pilbara, Roy Hill Station, Battle Hill Well, 8 September 2000, leg. W.F. Humphreys (BES: 8506 and 8509 ), $22^{\circ} 44^{\prime} 28^{\prime \prime S} 120^{\circ} 07^{\prime} 37^{\prime \prime} \mathrm{E}$ : one male in alcohol (WAM C34092)

\section{Description}

Female (holotype). Body length, excluding caudal setae, $0.474 \mathrm{~mm}$. Habitus (Figure $42 \mathrm{~A}$ ) very robust, with prosome/urosome ratio almost 2.1 and greatest width at posterior end of cephalothorax. Body length/width ratio about 2.3; cephalothorax 2.4 times as wide as genital double somite. Free pedigerous somites without pronounced lateral expansions. Preserved specimen colourless. Nauplius eye not visible. Rostrum well developed, membranous and furnished with two large sensilla.

Cephalothorax (Figure 42A) about 1.1 times as long as its greatest width; represents $49 \%$ of total body length. Surface of cephalic shield with several large sensilla; no other ornamentation visible. Hyaline fringes of prosomites narrow and smooth. All free pedigerous somites ornamented dorsally with few sensilla. More or less sclerotized joint (as pseudosomite) present between prosome and urosome, as well as between fifth pedigerous somite and genital double somite. Fifth pedigerous somite with smooth fringe dorsally and ventrally, ornamented only with two dorsal sensilla.

Genital double somite (Figure 42B) about 0.8 times as long as wide, ornamented at middle with two dorsal sensilla. Hyaline fringe of genital double and two subsequent somites smooth both ventrally and dorsally. Copulatory pore small, ovoid, positioned just anterior of double somite midlength; copulatory duct relatively long, rigidly sclerotized. Seminal receptacle relatively large, clearly divided into anterior and posterior expansions, about as wide as long (ventral view), representing $48 \%$ of double somite width and $64 \%$ of its length; anterior expansion larger and wider than posterior one. Most lateral parts of oviducts rigidly sclerotized, with two loops; part of oviduct closest to receptacle membranous, relatively wide. Ovipores situated somewhat dorsolaterally, at 2/5 of double somite's length, covered by reduced sixth legs, which bearing two minute spines and one pinnate seta. Third and fourth urosomites without any visible ornamentation. Anal somite with smooth, broad, very short and slightly convex anal operculum (Figure 43B), which represents 51\% of somite's width and not reaching posterior margin of somite; ornamented with two large sensilla dorsally and with short transverse row of minute spinules on posterior margin ventrally (Figure 43B). Anal sinus widely opened, without visible ornamentation.

Caudal rami (Figure $42 \mathrm{~B}$ and $43 \mathrm{~B}$ ) almost three times as long as wide, parallel, with space between them slightly less than half of ramus' width; without transverse row of elongated spinules dorsally inside proximal inner recess and ornamented only with several spinules at base of lateral and outermost apical setae. Dorsal seta about 3.3 times as long as ramus and even somewhat longer than outer principal apical seta, inserted at $5 / 6$ of ramus length, uniarticulate at base and plumose distally. Lateral seta arising somewhat dorsolaterally at $3 / 5$ of ramus length, uniplumose and slightly longer than ramus' width. Outermost apical seta stout, spiniform, about 0.6 times as long as ramus, bipinnate. Innermost apical seta also bipinnate but more slender and about 1.8 times as long as outermost one. Principal apical setae 


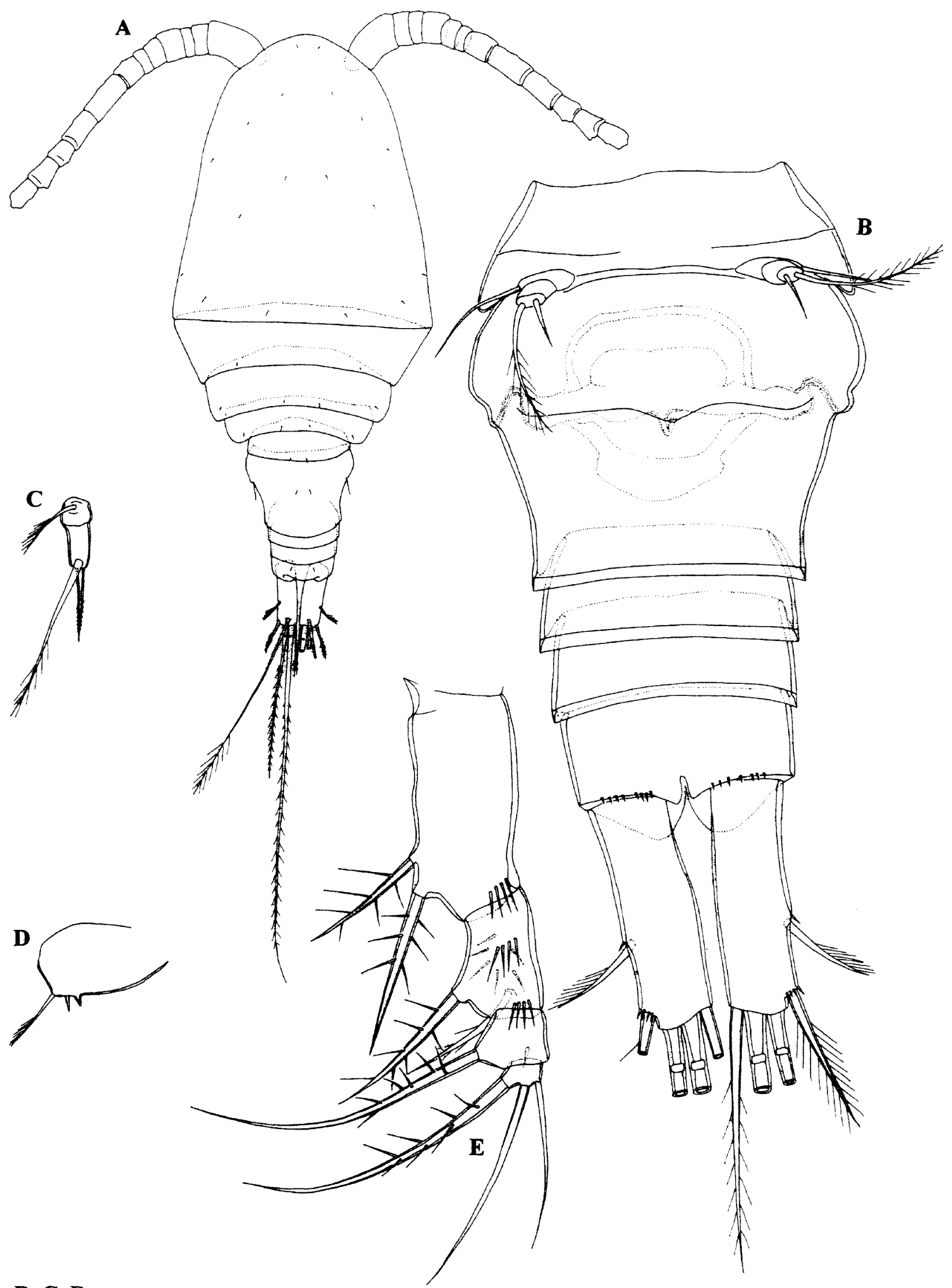

B, C, D

E

A

Figure 42 Diacyclops scanloni sp. nov., holotype (female): A, habitus, dorsal view; B, urosome, ventral view; C, fifth leg, lateral view; $D$, sixth leg; E, maxilliped. Scales $=0.1 \mathrm{~mm}$. 


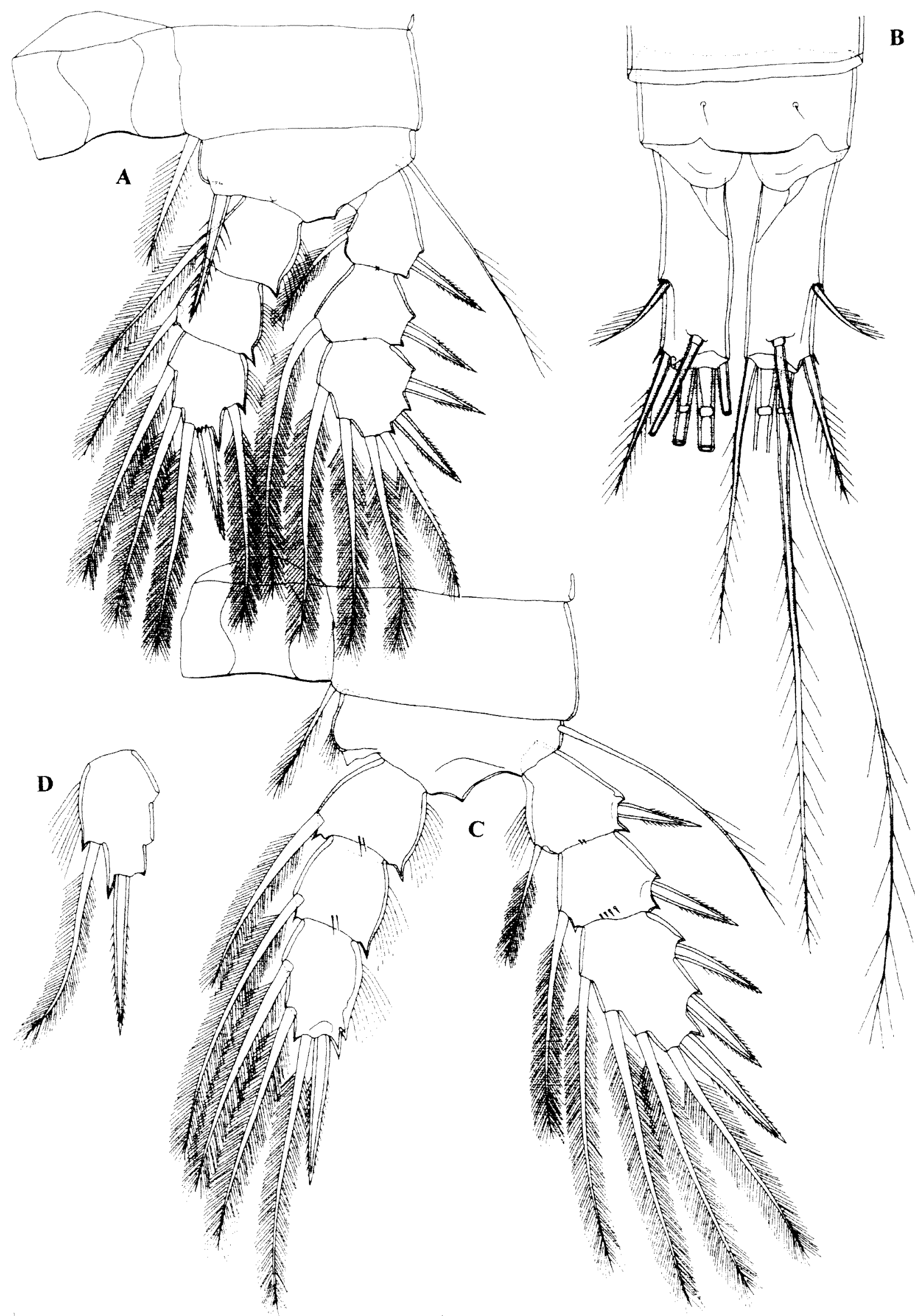

Figure 43 Diacyclops scanloni sp. nov., holotype (female): A, first swimming leg; B, anal somite and caudal rami, dorsal view; $C$, third swimming leg; $D$, third endopodal segment of third swimming leg. Scale $=0.1 \mathrm{~mm}$. 
plumose and with breaking planes; inner seta about 2.3 times as long as outer one, 0.6 times as long as body.

Antennula (Figure 44A) very long, almost reaching posterior end of cephalothorax, 12segmented, ornamented with very short transverse row of spinules on first segment, with one slender aesthetasc on ninth segment and setal formula: 8.4.2.6.3.2.2.3.2.2.3.8. No setae with breaking plane or articulating on basal part. One seta on sixth segment spiniform and very short; all other setae slender and most setae smooth, only four setae on twelfth and one seta on tenth segment pinnate distally. Length ratio of antennular segments, from proximal end and along caudal margins, $1: 0.3: 0.2$ : $0.5: 0.4: 0.3: 0.6: 1.1: 1: 0.6: 0.7: 0.8$.

Antenna (Figure $45 \mathrm{C}$ ) five-segmented, comprising very small and unornamented coxa, basis and threesegmented endopod; all endopodal segments of about same length; basis somewhat longer, about 2.4 times as long as wide, ornamented with few spinules near outer margin proximally, armed with two smooth setae at distal inner corner (inner one longer); seta representing exopod absent. First endopodal segment armed with one smooth seta at middle, ornamented with longitudinal row of slender spinules along external margin. Second endopodal segment about 2.1 times as long as wide, ornamented with longitudinal row of spinules along external margin distally, armed with six smooth setae (four lateral, two subapical; one subapical seta much longer and stronger than any other seta on that segment ). Third endopodal segment three times as long as wide, armed with seven smooth apical setae and ornamented as previous two segments.

Labrum trapezoidal, unornamented and relatively large. Cutting edge slightly concave, with 14 large and more or less sharp teeth between produced, pointed lateral corners.

Mandibula (Figure 45D) with small and not clearly distinct palp, armed with two very long, plumose setae and one short, smooth seta on distal end. Coxal gnathobase cutting edge with seven very strong, smooth teeth (innermost strongest and complex; others simple), three cuticular spinules at base of third and fourth teeth and outermost pinnate seta, which longer than short seta on palp.

Maxillula composed of well developed praecoxa and two-segmented palp. Arthrite of praecoxa with four strong and smooth apical spines; only one distinct, others completely fused to praecoxa. Praecoxa armed with five armature elements along inner margin, longest one plumose. Palp with distinct endopod, which bearing three smooth apical setae, and armed laterally with one exopodal smooth seta and apically with two smooth slender setae and one robust, strongly bipinnate spine. Palp clearly shorter than arthrite of praecoxa.
Maxilla (Figure 44C) unornamented and fivesegmented but praecoxa fused to coxa on posterior surface. Proximal endite of praecoxa well developed, about 1.7 times as long as wide, armed with two equally long, bipinnate setae; distal endite small, unarmed. Proximal endite of coxa with one stout, bipinnate seta; distal endite highly mobile, elongate and armed apically with two pinnate setae (proximal seta stronger and 1.1 times as long as distal one). Basis expanded into robust unipinnate claw, armed with two smooth setae; proximal seta as long as claw; distal seta slender, 0.5 times as long as claw. Endopod two-segmented; proximal segment armed with two robust, pinnate setae; distal segment very small, armed with one robust, pinnate, apical seta and two slender and smooth subapical setae. Longest seta on distal endopodal segment somewhat longer than strong seta on basis.

Maxilliped (Figure 42E) four-segmented, composed of syncoxa, basis and two-segmented endopod. Syncoxa about 2.4 times as long as wide, ornamented with short row of spinules near posterior margin and armed with two pinnate setae; distal seta about 1.3 times as long as proximal one. Basis 1.4 times as long as wide, ornamented one arched row of long spinules at middle and two transverse rows on opposite side, one at middle, other near posterior margin; armed with two bipinnate, subequal setae. First endopodal segment ornamented with single spinule near posterior margin and armed with one strong, pinnate seta; this seta longest and strongest on maxilliped. Second endopodal segment very small, unornamented but armed with three setae; innermost seta bipinnate, about 1.3 times as long as middle, smooth one and 1.8 times as long as outermost seta. All pinnate setae with very long pinnules.

All swimming legs with three-segmented exopod and endopod (Figure 43A, C, D and 44B). Armature formula of swimming legs as follows (legend: inner/ outer spine or seta; inner/terminal/outer):

\begin{tabular}{lcccccc} 
& \multicolumn{3}{c}{ Exopod } & \multicolumn{3}{c}{ Endopod } \\
Segments & 1 & 2 & 3 & 1 & 2 & 3 \\
First leg & $1 / 1$ & $1 / 1$ & $2 / 2 / 2$ & $1 / 0$ & $1 / 0$ & $2 / 2 / 1$ \\
Second leg & $1 / 1$ & $1 / 1$ & $3 / 2 / 2$ & $1 / 0$ & $1 / 0$ & $2 / 2 / 1$ \\
Third leg & $1 / 1$ & $1 / 1$ & $3 / 2 / 2$ & $1 / 0$ & $1 / 0$ & $2 / 2 / 1$ \\
Fourth leg & $1 / 1$ & $1 / 1$ & $3 / 2 / 2$ & $1 / 0$ & $2 / 0$ & $2 / 2 / 1$
\end{tabular}

Last exopodal segment spine formula: 2.3.3.3. Intercoxal sclerites of all swimming legs unornamented, with smooth and bilobate distal margin. All coxae unornamented and armed with plumose seta at inner distal corner. Basis of each leg also unornamented but armed with slender lateral seta on outer margin. Spine at inner corner of basis of first leg stout, reaching $3 / 4$ of second endopodal segment (Figure 43A). All setae slender and plumose, outer apical seta on third exopodal segment of first leg pinnate along outer margin, 


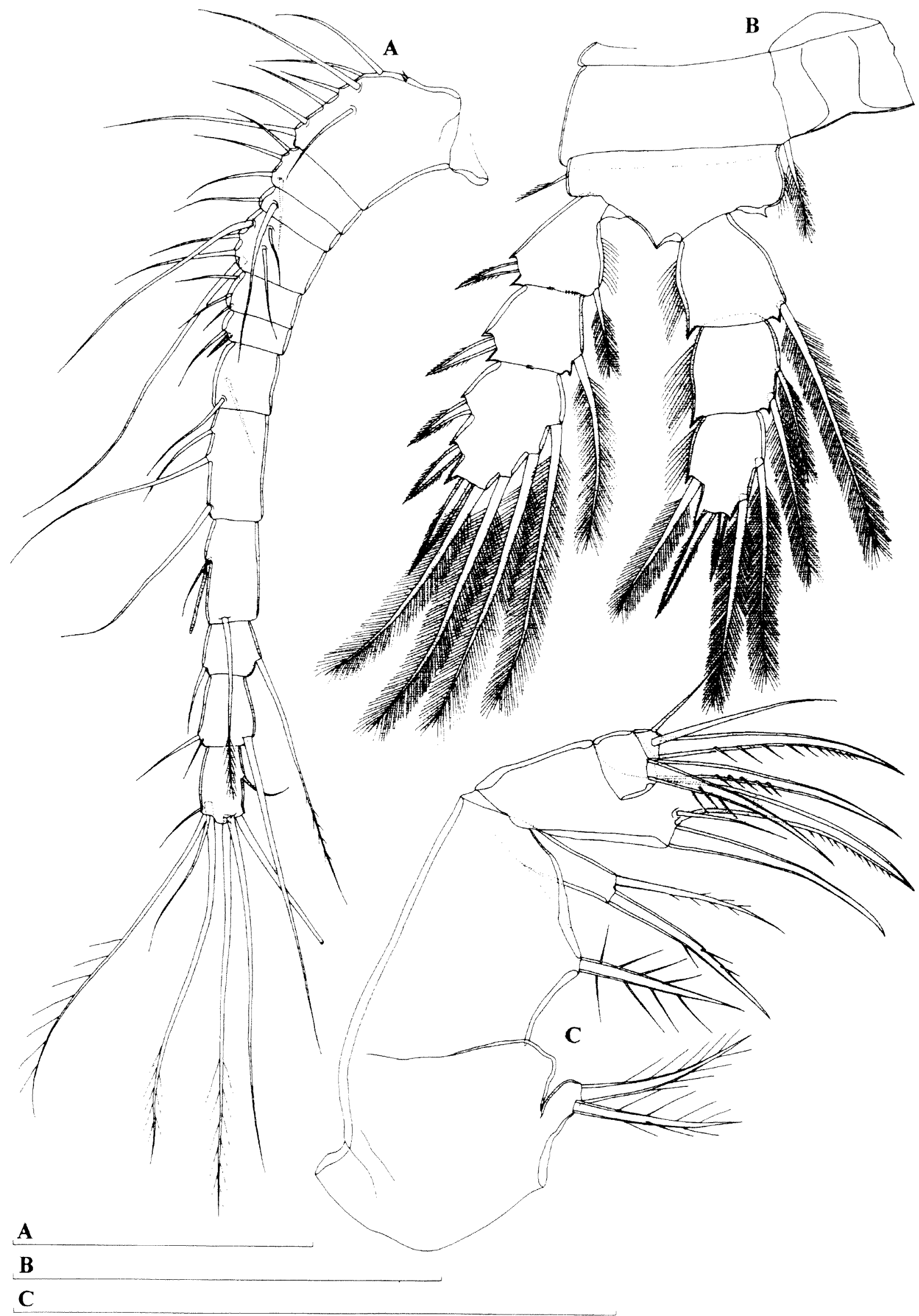

Figure 44 Diacyclops scanloni sp. nov., holotype (female): A, antennula; B, fourth swimming leg; C, maxilla. Scales = $0.1 \mathrm{~mm}$. 
plumose along inner one. All endopodal segments with row of hairs along outer margin; hairs also present along inner margin of first exopodal segment of each swimming leg. Apical spine on third endopodal segment of first swimming leg robust, about 1.3 times as long as segment (Figure 43A). Apical spine on third endopodal segment of second and third leg also1.3 times longer than segment; second and third leg without any important difference; one endopod of third swimming leg abnormal, without outer seta (Figure $43 \mathrm{C}$ ), while other one normally built (Figure 43D). Third endopodal segment of fourth swimming leg about 1.4 times as long as wide; armed apically with two strong spines; outer apical spine about 1.7 times as long as inner one and almost 1.2 times as long as segment (Figure 44B).

Fifth leg (Figure 42B, C) relatively small, twosegmented, unornamented and inserted clearly ventrally. Basal segment about 1.7 times as wide as long, armed with lateral uniplumose seta inserted on short setophore. Distal segment much narrower, almost twice as long as wide, armed with apical seta and subapical, inner spine; apical seta 2.6 times as long as segment, pinnate distally, reaching middle of genital double somite in length (Figure 42B); subapical spine about 1.3 times as long as segment.

Sixth leg (Figure 42D) distinct, more or less semicircular, cuticular plate, armed with two almost equally long minute smooth spines and one unipinnate, much longer seta; median spine distinct, other one completely fused to leg.

Male (allotype). Body length, excluding caudal setae, $0.448 \mathrm{~mm}$. Habitus (Figure $45 \mathrm{~A}$ ) relatively robust, with prosome/urosome ratio more than two and greatest width at posterior end of cephalothorax. Body length/width ratio about 2.4; cephalothorax 2.3 times as wide as genital somite.

Cephalothorax (Figure 45A) somewhat longer than its greatest width, represents $46 \%$ of body length. Ornamentation of prosomites, colour and nauplius eye similar to those of female. Hyaline fringe of fifth pedigerous somite smooth, as well as those of other urosomites. Fifth pedigerous somite, as well as genital somite, ornamented with two dorsal sensilla; next three urosomites without any ornamentation.

Genital somite (Figure 45B and 46B) about twice as wide as long (dorsal view), with two spermatophores completely formed inside. Anal somite and anal sinus similar to those of female.

Caudal rami (Figure 45B and 46B) parallel and about 2.8 times as long as wide. Armature and ornamentation similar to female, although dorsal seta slightly shorter than outer principal apical seta.

Antennula (Figure 46A) longer than cephalothorax, 15-segmented, unornamented, digeniculate, with geniculations between seventh and eighth and thirteenth and fourteenth segments. Three aesthetascs present on first segment, one on eight and one on twelfth segment. Setal formula: 8.4.2.3.1.2.1.2.2.2.1.2.0.1.11. One seta on ninth, tenth, eleventh and twelfth segments very short, spiniform; all other setae slender and all setae, except for three on fifteenth segment, smooth. Only three setae on fifteenth segment articulating on basal part.

Antenna, labrum, mandibula, maxillula, maxilla, maxilliped and swimming legs similar to female. Third endopodal segment of fourth swimming leg (Figure 46D) about 1.4 times as long as wide; outer apical spine 1.5 times as long as inner one and 1.2 times as long as segment.

Fifth leg (Figure 46B, E) very similar to female.

Sixth leg (Figure 46B, C) distinct, large cuticular plate, unornamented and armed with one bipinnate spine and two bipinnate setae. Outermost seta about 1.8 times as long as spine and 2.1 times as long as middle seta. Spine on sixth leg longer and stouter than that on fifth leg.

\section{Variability}

Body length of females ranges from $0.474 \mathrm{~mm}$ to $0.712 \mathrm{~mm}(0.61 \mathrm{~mm}$ average; $\mathrm{n}=8)$, while in males it ranges from $0.448 \mathrm{~mm}$ to $0.546 \mathrm{~mm}(0.496 \mathrm{~mm}$ average; $n=7)$. The outer seta on the third endopodal segment of one third leg is absent(Figure $43 \mathrm{C}$ ), but the opposite leg has normal setation (Figure 43D). No other type of variability was observed.

\section{Etymology}

The species is named in honour of Mike Scanlon from the Department of Conservation and Land Management (CALM), who was one of the collectors of the type material and of most of the material studied here. The name is a noun in the genitive singular.

\section{Discussion}

Five out of the seven localities in which $D$. scanloni sp. nov. was found are wells, which may suggest its stygophilic rather than stygobitic nature. In localities 1 and 6 it was found sympatrically with D. cockingi sp. nov., while in locality 2 it was found with $D$. humphreysi s. str. All three species differ sufficiently to remove any doubt about their specific status, furthermore only reproductively isolated populations could sustain these differences sympatrically. The sympatric occurrence suggests some sort of ecological specialisation, although very little is known about their ecology. Diacyclops scanloni differs from both $D$. humphreysi and $D$. cockingi by the armature of the swimming legs, as well as by the extraordinarily long dorsal caudal setae. Dorsal setae similar to those of $D$. scanloni 


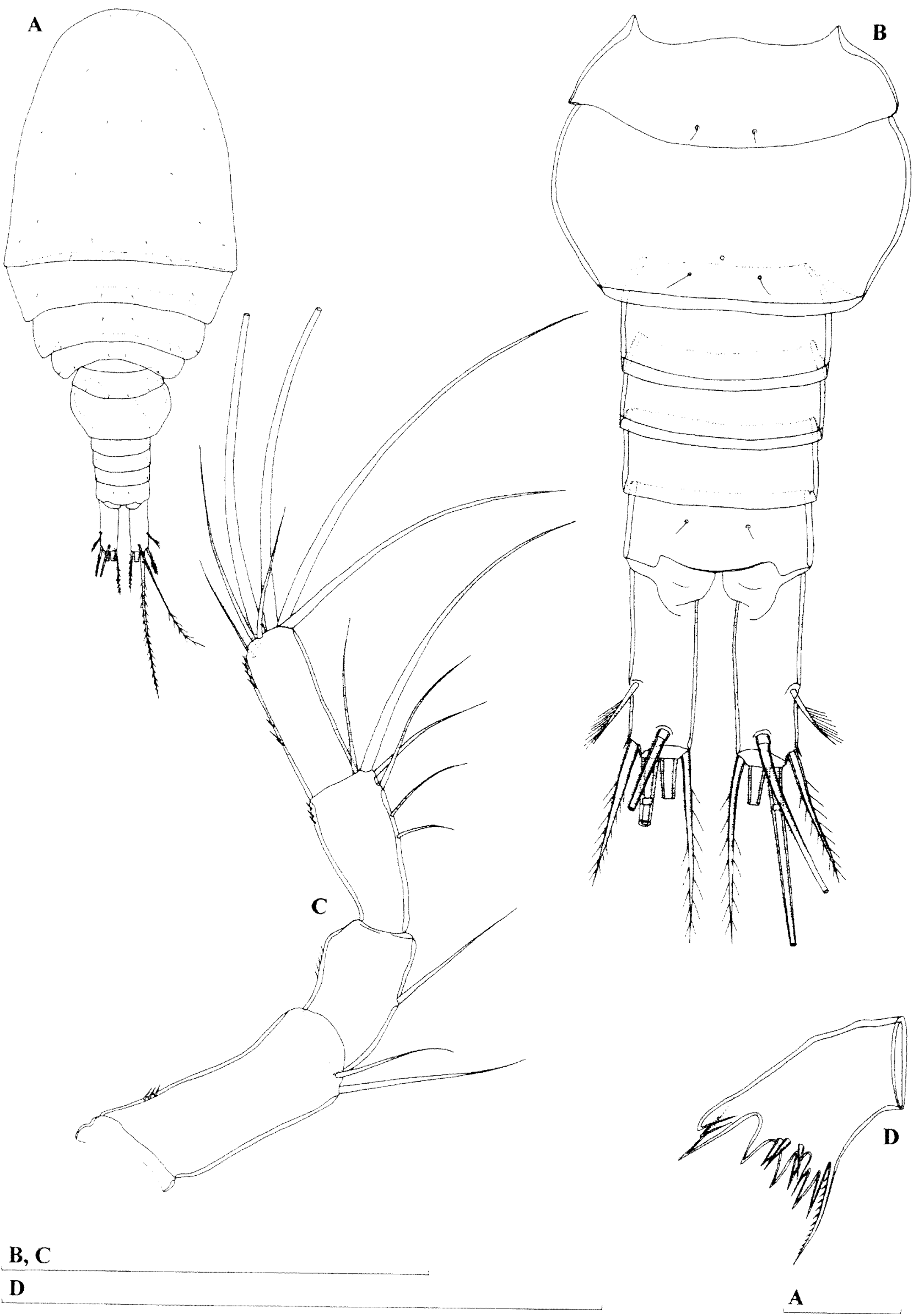

Figure 45 Diacyclops scanlonisp. nov, A and B, allotype (male); C and D, holotype (female): A, habitus, dorsal view; $B$, urosome, dorsal view; C, antenna; D, mandibula, cutting edge of coxa. Scales $=0.1 \mathrm{~mm}$. 

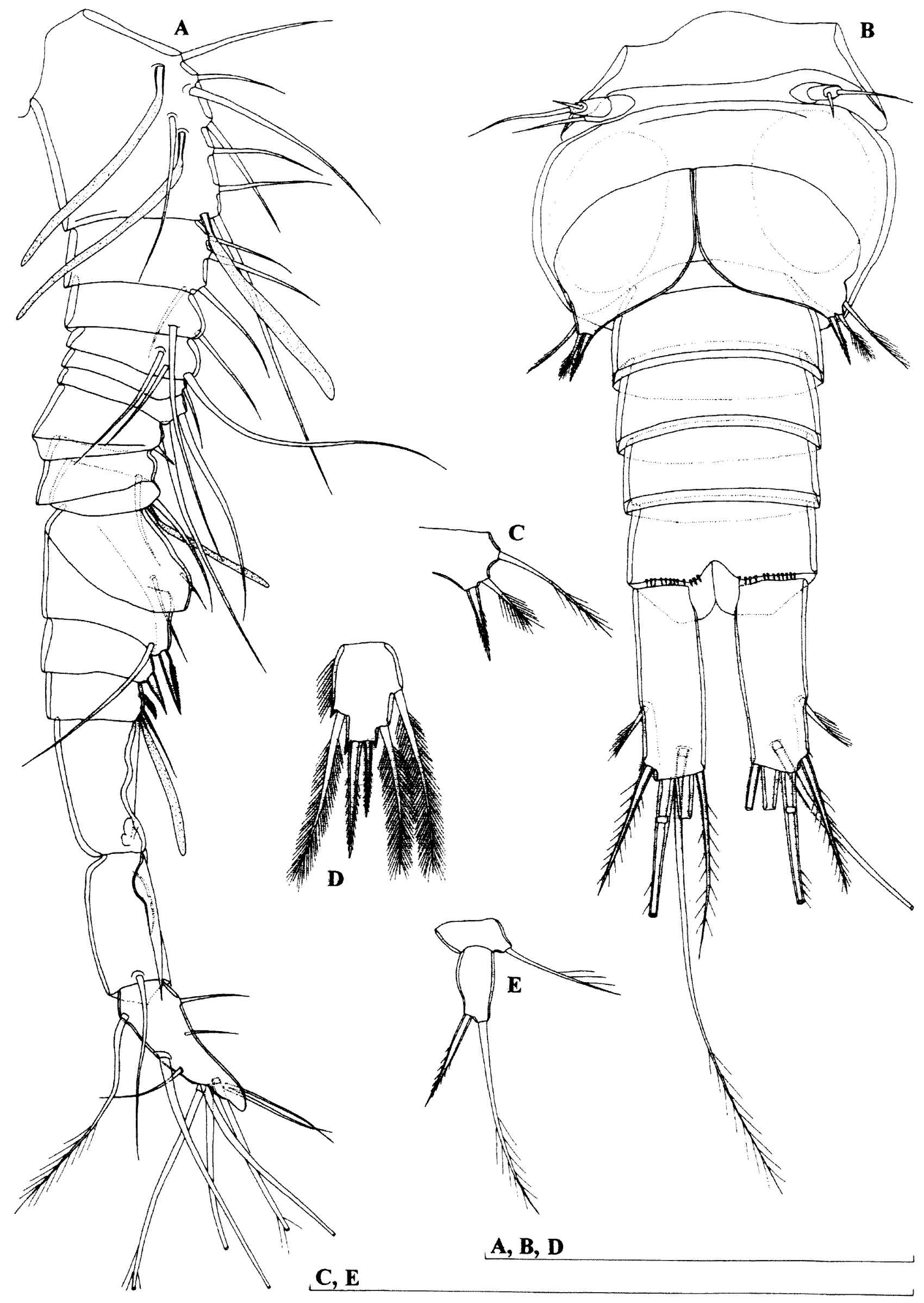

Figure 46 Diacyclops scanloni sp. nov., allotype (male): A, antennula; B, urosome, ventral view; C, sixth leg; D, third endopodal segment of fourth swimming leg; $E$, fifth leg. Scales $=0.1 \mathrm{~mm}$. 
can only be found in D. sobeprolatus sp. nov; differences between these two species were outlined in the Discussion section for the latter species.

The known Diacyclops species and subspecies in Australia now number nine and below is a key to aid in their identification. The key is based mainly on the morphology of the female.

1. Antennula 11-or 12-segmented 2

Antennula 17-segmented

D. bisetosus (Rehberg, 1880)

2. Antennula 12 -segmented 3

- Antennula 11-segmented D. cryonastes Morton, 1985

3. First exopodal segments of swimming legs without inner seta ..6

Same segments with inner seta 4

4. Dorsal caudal seta much shorter than outer principal apical one. 5

- Both setae equally long ..... D. scanloni sp. nov.

5. Labrum with very convex cutting edge.... .............. D. reidae De Laurentiis, Pesce and Humphreys, 1999

- Labrum with slightly convex cutting edge ....... .............. D. einslei De Laurentiis, Pesce and Humphreys, 1999

6. Dorsal caudal seta much shorter than outer principal apical one. 7

- Both setae equally long D. sobeprolatus sp. nov

7. Dorsal caudal seta much longer than innermost apical one 8

- Both setae equally long ..... D. cockingisp. nov.

8. Third endopodal segment of fourth leg with two apical spines

.... D. humphreysi humphreysi Pesce and De Laurentiis, 1996

- Same segment with single apical spine

Diacyclops humphreysi unispinosus sp. nov.

\section{Genus Metacyclops Kiefer, 1927}

\section{Metacyclops mortoni Pesce, De Laurentiis and Humphreys, 1996}

\section{Synonymy}

Metacyclops mortoni sp. nov. - Pesce et al, 1996a: 68, Figures 1-15.

Metacyclops mortoni Pesce, De Laurentiis and Humphreys, 1996 - De Laurentiis et al, 1999: 255.

\section{Discussion}

Although I have not found any specimens of Metacyclops mortoni Pesce, De Laurentiis and Humphreys, 1996, this species was reported from the Pilbara region by Pesce et al. (1996a) and De Laurentiis et al. (1999). All the localities are near the coast and the only additional published one is from the Cape Range peninsula (see map in Karanovic 2004 b). Some unpublished data suggest its presence further north, as it was found by Stuart Halse (pers. comm.) at Brett's Spring and Mandora Marsh (inland from Eighty-mile Beach). This species, with its spine formula 3.4.4.2, occupies a unique position in the genus and cannot be regarded as a close relative of any other Australian Metacyclops.

\section{Metacyclops pilbaricus Karanovic, 2004}

\section{Synonymy}

Metacyclops pilbaricus sp. nov. - Karanovic, 2004b: 203, Figures 3 and 29-44.

\section{Discussion}

Metacyclops pilbaricus was described from a single bore near Newman by Karanovic (2004b). It belongs to the "trispinosus"-group and is closely related to $M$. kimberleyi, a species also described by Karanovic (2004b). Unfortunately only females of $M$. pilbaricus were reported and I have not found any additional specimens of this rare species. Hopefully, further sampling in the Pilbara region will result in more specimens.

\section{Genus Apocyclops Lindberg, 1942}

\section{Apocyclops dengizicus (Lepeschkin, 1900)}

\section{Synonymy}

Cyclops diaphanus var. dengizica n.var. Lepeschkin, 1900: 26, Figures 1, 17, 19, 21, 25 and 26 (fide Kiefer, 1949).

Cyclops buxtoni n.sp. - Gumey, 1921: 84, Figures a, $b, c, d$ and $e$

Cyclops (Metacyclops) dimorphus n.sp. - Kiefer, 1934a: 271, Figures 5 and 6.

Cyclops dimorphus Kiefer - Yeatman, 1944: 72, Figures 133 and 134; Yeatman, 1963: 206, Figures $47-51$

Cyclops (Microcyclops) dimorphus Kiefer Johnson, 1953: 190, Figures 1-18.

Cyclops dengizicus (Lepeschkin) - Kiefer, 1928b: 396.

Cyclops (Metacyclops) dengizicus (Lepeschkin) Kiefer, 1936: 296, Figures 71-77. 
Metacyclops dengizicus (Lepeschkin) - Kiefer, 1949. 73, Figures 7-13.

Microcylops dengizicus (Lepeschkin) - Rylov, 1948: 275, Figure 66; Fernando and Ponyi, 1981: 119, Figures 13-16.

Cyclops (Apocyclops) dengizicus (Lepeschkin) Lindberg, 1942: 140.

Apocyclops dengizicus (Lepeschkin) - Kiefer, 1967: 300, Figures 21-25; Monchenko, 1974: 378, Figure 136; Alvarez Valderhang and Kewalramani, 1979: 1, Figures 1-4; Dussart and Defaye, 1985: 114; Pesce et al., 1996a: 75; Karanovic, 2004a: 100, Figures 43-45.

\section{Material Examined}

Australia, Pilbara, Robe River, bore G70730101, 14 November 2002, leg. J. Cocking and M. Scanlon (CALM), 21 ${ }^{\circ} 34^{\prime} 32^{\prime \prime S} 115^{\circ} 52^{\prime} 58^{\prime \prime} \mathrm{E}$ : one female in alcohol (WAM C34093)

\section{Discussion}

This stygoxene and almost cosmopolitan species was redescribed recently by Reid et al. (2002) from the United States, Monchenko (2003) from Ukraine, and Karanovic (2004a) from Australia. It has been recorded many times in Australia and is a widespread, commonly encountered species in surface waters (see Halse et al. 1996, 1998, 2000a, b, 2002a). In the Murchison region it was found in three out of 164 groundwater samples (Karanovic 2004a).

\section{Genus Fierscyclops Karanovic, 2004}

\section{Subgenus Pilbaracyclops subgen. nov.}

\section{Diagnosis}

Moderately large to large Cyclopinae, with robust habitus and greatest width at midlength of cephalothorax. Hyaline fringe of prosomites narrow and smooth. Genital double somite large, wider than long, with very large and clearly divided seminal receptacle. Anal operculum short and convex. Caudal rami about twice as long as wide, with large sensillum laterally in female; dorsal seta longer than ramus, while innermost and outermost setae shorter; principal apical setae with or without breaking planes. Antenulla 11-segmented in female and 16-segmented in male. Antenna foursegmented, armed with six elements on second endopodal segment; seta representing exopod absent. Labrum with slightly concave cutting edge, with 14 or 15 sharp teeth between produced and pointed lateral corners. Mandibula with two long and one short seta on reduced palp. Maxillula with distinct endopod, armed with three setae. Maxilla five-segmented, with reduced ornamentation of basal claw (two two four strong spinules).
Maxilliped four-segmented, with armature formula 2.2.1.2. All swimming legs with two-segmented exopods and endopods and with smooth intercoxal sclerites. Second exopodal segment spine formula 3.3.3.3(2) and setal formula 5.5.5.5. Basis of first swimming leg with short short inner spine. First exopodal segments of first and fourth legs without inner seta; those of second and third leg with inner seta. Second endopodal segment of first leg with two setae along inner margin; those of other swimming legs with three setae. Second endopodal segment of fourth leg armed apically with inner seta and outer spine. Fifth leg with basal segment fused to somite; basal seta inserted laterally, strong and pinnate. Distal segment of fifth leg about as long as wide, placed at lateral corner of somite and oriented posteriorly (forming $45^{\circ}$ angle with body axis), armed with apical outer seta and inner spine; spine strong, about twice as long as segment and only slightly shorter than seta. Male sixth leg armed with innermost spine and two setae (outermost longer than middle one).

\section{Type species}

Fierscyclops (Pilbaracyclops) supersensus sp. nov.

\section{Other species}

Fierscyclops (Pilbaracyclops) frustratio sp. nov.

\section{Etymology}

The subgenus name is derived from the region Pilbara (Western Australia), where it was collected, prefixed to the existing generic name Cyclops. Gender masculine.

Fierscyclops (Pilbaracyclops) supersensus sp. nov Figures 47-51

\section{Material Examined}

\section{Holotype}

Male (WAM C34094), Australia, Pilbara, Newman Borefield, large bore W78, 23 July 1997, leg. W.F. Humphreys and S.M. Eberhard (BES: 4835), $23^{\circ} 19^{\prime} 45^{\prime \prime} \mathrm{S} 119^{\circ} 51^{\prime} 15^{\prime \prime} \mathrm{E}$ : dissected on two slides

\section{Paratypes}

Australia, Pilbara, Newman Borefield, large bore W78, 23 July 1997, leg. W.F. Humphreys and S.M. Eberhard (BES: 4835), 2319'45"S 119 51'15"E: two males in alcohol (WAM C34095)

\section{Other material}

1) Australia, Pilbara, Ore Body 23, about $4.5 \mathrm{~km}$ north of Ophthalmia Dam, bore W079, sample 55.2, February 2001, leg. G. Humphreys, J. Bradbury and K. Armstrong (BES: 5592), 2319'46"S 11950'36"E: one female dissected on one slide (WAM C34096) 
2) Australia, Pilbara, Ore Body 23, about $4.5 \mathrm{~km}$ north of Ophthalmia Dam, bore T401, sample 25.2, February 2001, leg. G. Humphrevs, J Bradbury and K. Armstrong (BES: 5580), $23^{\prime} 18^{\prime} 01^{\prime \prime} \mathrm{S} 119^{\circ} 51^{\prime} 42^{\prime \prime} \mathrm{E}$ : two males + one copepodid (one male dissected on one slide (WAM C34097); others in alcohol (WAM (34098))

\section{Description}

Male (holotype). Body length, excluding caudal setae, $0.904 \mathrm{~mm}$. Habitus (Figure $47 \mathrm{~A}$ ) relatively robust, with prosome/urosome ratio 2.1 and greatest width at midlength of cephalothorax. Body length/width ratio about 2.8 ; cephalothorax 2.4 times as wide as genital somite. Free pedigerous somites without pronounced lateral expansions. Colour of preserved specimen yellowish. Nauplius eye not visible. Rostrum well developed, membranous, broadly rounded and furnished with two large sensilla.

Cephalothorax (Figure 47 A) about as long as its greatest width; represents $34 \%$ of total body length. Surface of cephalic shield with several large sensilla; no other ornamentation visible. Hyaline fringe of prosomites narrow and smooth. All free pedigerous somites ornamented dorsally with few sensilla. More or less sclerotized joint (as pseudosomite) present between prosome and urosome. Fifth pedigerous somite with smooth fringe dorsally and ventrally, ornamented only with four dorsal sensilla.

Genital somite (Figure $47 \mathrm{~A}, \mathrm{C}$ ) about 0.7 times as long as wide, ornamented with two large dorsal sensilla. Hyaline fringe of genital and three subsequent somites smooth both ventrally and dorsally. Third, fourth and fifth urosomites without any visible ornamentation; third somite about 1.5 times as long as fourth and even 2.6 times as long as fifth. Anal somite about as long as third urosomal one, with smooth, broad, very short and convex anal operculum (Figure 48B), which represents $61 \%$ of somite's width and not reaching posterior margin of somite; ornamented with two large sensilla dorsally and with transverse row of spinules on posterior margin (Figure 47C). Anal sinus widely opened, without visible ornamentation.

Caudal rami (Figure $47 \mathrm{C}$ and $48 \mathrm{~B}$ ) 2.3 times as long as wide, parallel, with space between them about one half of ramus' width; ornamented only with several spinules at base of lateral and outermost apical setae; distal margin ventrally without cuticular tube pore. Dorsal seta about twice as long as ramus, inserted at $4 / 5$ of ramus length, uniarticulate at base and unipinnate distally. Lateral seta arising somewhat dorsolaterally just posteriorly of ramus midlength, uniplumose and slightly longer than ramus' width. Outermost apical seta stout, spiniform, about 0.7 times as long as ramus, bipinnate. Innermost apical seta also bipinnate but more slender and about 1.2 times as long as outermost one. Principal apical setae plumose and without breaking plane; inner seta about 1.2 times as long as outer one, 0.3 times as long as body.

Antennula (Figure 47D) longer than cephalothorax, 16-segmented, unornamented, digeniculate, with geniculations between seventh and eighth and fourteenth and fifteenth segments. Seven aesthetascs present on first, one on fourth, one on ninth and one on sixteenth segment; all aesthetascs long, smooth and slender. Setal formula: 9.4.1.2.2.1.1.2.1.2.2.0.0.2.1.8. One seta on ninth, tenth, eleventh segment, as well as two setae on fourteenth segment very short, spiniform; all other setae slender and all setae, except spiniform seta on eleventh segment, smooth. Only four setae on sixteenth segment articulating on basal part; most apical seta on this segment fused basally with aesthetasc.

Antenna (Figure 48E) four-segmented, comprising coxobasis and three-segmented endopod; all endopodal segments of about same length, coxobasis somewhat longer. Coxobasis about 2.4 times as long as wide, unornamented but armed with two smooth setae at distal inner corner; seta representing exopod absent. First endopodal segment armed with one smooth seta at middle, ornamented with longitudinal row of spinules along external margin. Second endopodal segment about twice as long as wide, ornamented with longitudinal row of spinules along external margin, armed with six smooth setae (four lateral, two subapical; one subapical seta somewhat longer and much stronger than any other seta on that segment). Third endopodal segment 2.7 times as long as wide, armed with seven smooth apical setae and ornamented as previous segment.

Labrum (Figure 48A) trapezoidal, ornamented with two diagonal rows of long spinules on ventral surface, each containing 13 spinules. Cutting edge slightly convex, with 15 large and more or less sharp teeth between produced, pointed lateral corners.

Mandibula (Figure 48F and 50B) with small but clearly distinct palp, armed with two very long, plumose setae and one short, smooth seta on distal end. Coxal gnathobase cutting edge with eight very strong teeth (innermost strongest and complex; second and fourth from inner side also complex, others simple teeth) and outermost pinnate seta, which slightly longer than short seta on palp.

Maxillula (Figure 50A, C) composed of well developed praecoxa and two-segmented palp. Arthrite of praecoxa with four strong and smooth apical spines; only one distinct, others completely fused to praecoxa. Praecoxa armed with seven armature elements along inner margin, longest one plumose (Figure 50C). Palp with distinct endopod, 


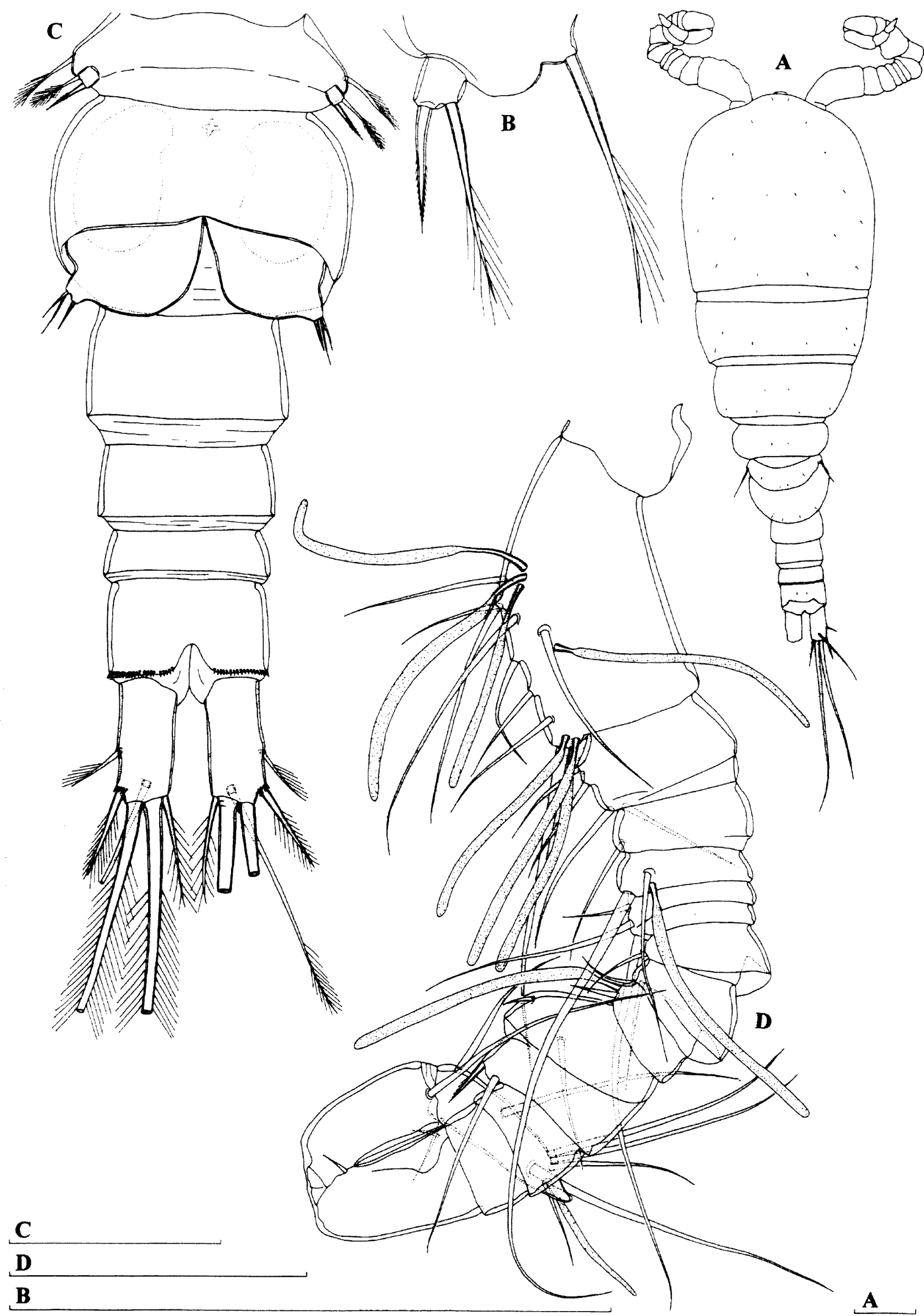

Figure 47 Fierscyclops (Pilbaracyclops) supersensus sp. nov., holotype (male): A, habitus, dorsal view; B, left fifth leg, lateral view; $C$, urosome, ventral view; $D$, antennula. Scales $=0.1 \mathrm{~mm}$. 


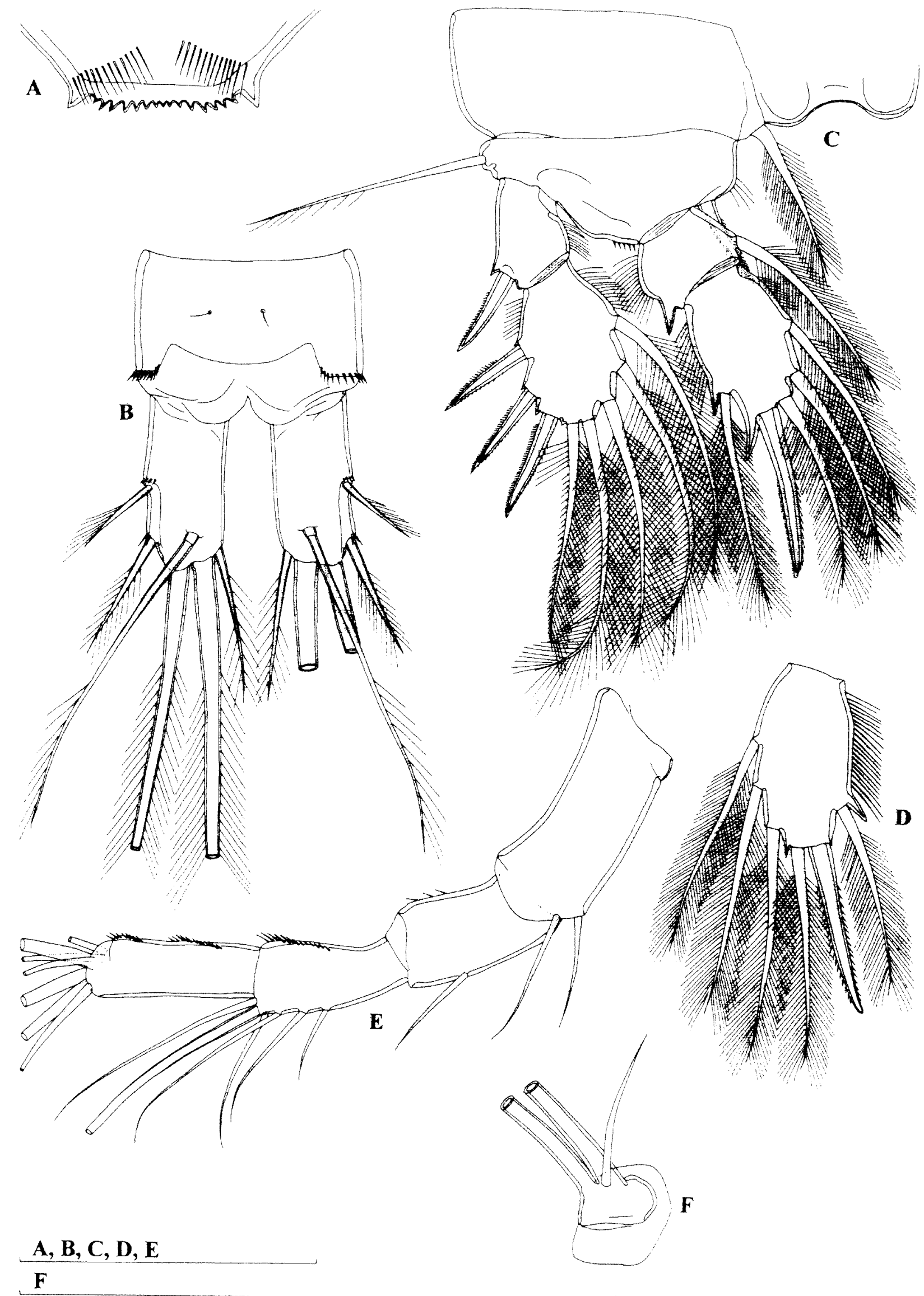

Figure 48 Fierscyclops (Pilbaracyclops) supersensus sp. nov., holotype (male): A, labrum; B, anal somite and caudal rami, dorsal view; C, first swimming leg; D, second endopodal segment of second swimming leg; $E$, antenna; F, mandibular palp. Scales $=0.1 \mathrm{~mm}$. 
which bearing three pinnate setae (two apical and one lateral), and armed laterally with one exopodal smooth seta and apically with two smooth slender setae and one robust, strongly bipinnate spine (Figure 50A). Palp slightly shorter than arthrite of praecoxa.

Maxilla (Figure 49E) unornamented and fivesegmented but praecoxa fused to coxa on posterior surface and also partly on anterior surface. Proximal endite of praecoxa well developed, about as long as wide, armed with two equally long, bipinnate setae; distal endite small, unarmed. Proximal endite of coxa with one short, smooth seta; distal endite highly mobile, elongate and armed apically with two smooth setae (proximal seta 1.7 times as long as distal one). Basis expanded into robust claw, ornamented with bunch of three robust spinules at middle and armed with two smooth setae; proximal seta strong about as long as claw; other seta slender, 0.5 times as long as claw. Endopod two-segmented; proximal segment armed with two robust, smooth setae (longer one as long as strong seta on basis; other one half as long); distal segment very small, armed with one robust apical seta and two slender subapical setae (all three smooth). Longest seta on distal endopodal segment about as long as strong seta on basis.

Maxilliped (Figure 50D) four-segmented, composed of syncoxa, basis and two-segmented endopod. Syncoxa strong, about twice as long as wide, unornamented and armed with two setae; distal seta pinnate, about twice as long as proximal one. Basis slender, 2.6 times as long as wide, ornamented with arched row of short spinules at middle and few spinules at distal outer corner, armed with two pinnate, subequal setae. First endopodal segment ornamented with few spinules and armed with one strong, unipinnate seta; this seta longest and strongest on maxilliped. Second endopodal segment very small, unornamented but armed with two smooth setae; inner seta much stronger and about 1.9 times as long as outer one.

All swimming legs with two-segmented exopod and endopod (Figure 48C, D and 49C, D). Armature formula of swimming legs as follows (legend: inner/ outer spine or seta; inner/terminal/outer):

\begin{tabular}{lcccc} 
& \multicolumn{2}{c}{ Exopod } & \multicolumn{2}{c}{ Endopod } \\
Segments & 1 & 2 & 1 & 2 \\
First leg & $0 / 1$ & $3 / 2 / 3$ & $1 / 0$ & $2 / 2 / 1$ \\
Second leg & $1 / 1$ & $4 / 2 / 2$ & $1 / 0$ & $3 / 2 / 1$ \\
Third leg & $1 / 1$ & $4 / 2 / 2$ & $1 / 0$ & $3 / 2 / 1$ \\
Fourth leg & $0 / 1$ & $3 / 2 / 2$ & $1 / 0$ & $3 / 2 / 1$
\end{tabular}

Last exopodal segment spine formula: 3.3.3.3. Intercoxal sclerites of all swimming legs unornamented, with smooth and bilobate distal margin. All coxae unornamented and armed with plumose seta at inner distal corner. Basis of each leg also unornamented (except few spinules and hairs on basis of first leg), armed with slender lateral seta on outer margin. Spine at inner corner of basis of first leg stout, reaching $1 / 5$ of second endopodal segment (Figure 48C). All setae slender and plumose, outer apical seta on second exopodal segment of first leg pinnate along outer margin, plumose along inner one. All endopodal segments with row of hairs along outer margin; hairs also present along inner margin of all exopodal segments, as well as along outer margin of second exopodal segment of each swimming leg. Apical spine on second endopodal segment of first swimming leg very robust, about 1.2 times as long as segment (Figure 48C). Apical spine on second endopodal segment of second and third leg about as long as segment; second (Figure 48D) and third leg (Figure 49C) without any important difference. Second endopodal segment of fourth swimming leg about 1.9 times as long as wide; armed apically with inner seta and outer spine; apical seta 2.2 times as long as spine and almost 1.6 times as long as segment (Figure 49D).

Fifth leg (Figure 47B, C and 49A) with basal segment completely fused to somite, without remnant of ancestral separation visible in dorsal view; outer basal seta inserted laterally on somite and unipinnate distally. Distal segment about as long as wide, armed apically with outer seta and inner spine; without any ornamentation. Apical seta bipinnate at distal end, short, about 3.9 times as long as segment, 1.2 times as long as spine and about 0.74 times as long as basal seta. Spine on distal segment bipinnate, very strong and 2.5 times as long as segment.

Sixth leg (Figure $47 \mathrm{C}$ and 49B) distinct, large cuticular plate, unornamented and armed with one bipinnate spine and two setae. Outermost seta unipnnate, about 1.4 times as long as spine and 1.5 times as long as middle bipinnate seta. Spine on sixth leg shorter than that on fifth leg.

Female. Habitus relatively robust, with prosome/ urosome ratio more than 2.3 and greatest width at middle of cephalothorax. Body length/width ratio about 2.6; cephalothorax twice as wide as genital double somite.

Cephalothorax somewhat longer than its greatest width, represents $36 \%$ of body length. Ornamentation of prosomites, colour and nauplius eye similar to those of male. Hyaline fringe of fifth pedigerous somite smooth, as well as those of other urosomites. Fifth pedigerous somite ornamented only with two dorsal sensilla.

Genital double somite (Figure 51A) somewhat wider than long, ornamented at middle with two dorsal sensilla and cuticular pore in between, as well as with two sensilla and one pore near posterior margin. Hyaline fringe of genital double and two subsequent somites smooth both ventrally and dorsally. Copulatory pore small, ovoid, positioned at $2 / 5$ of double somite's length; 


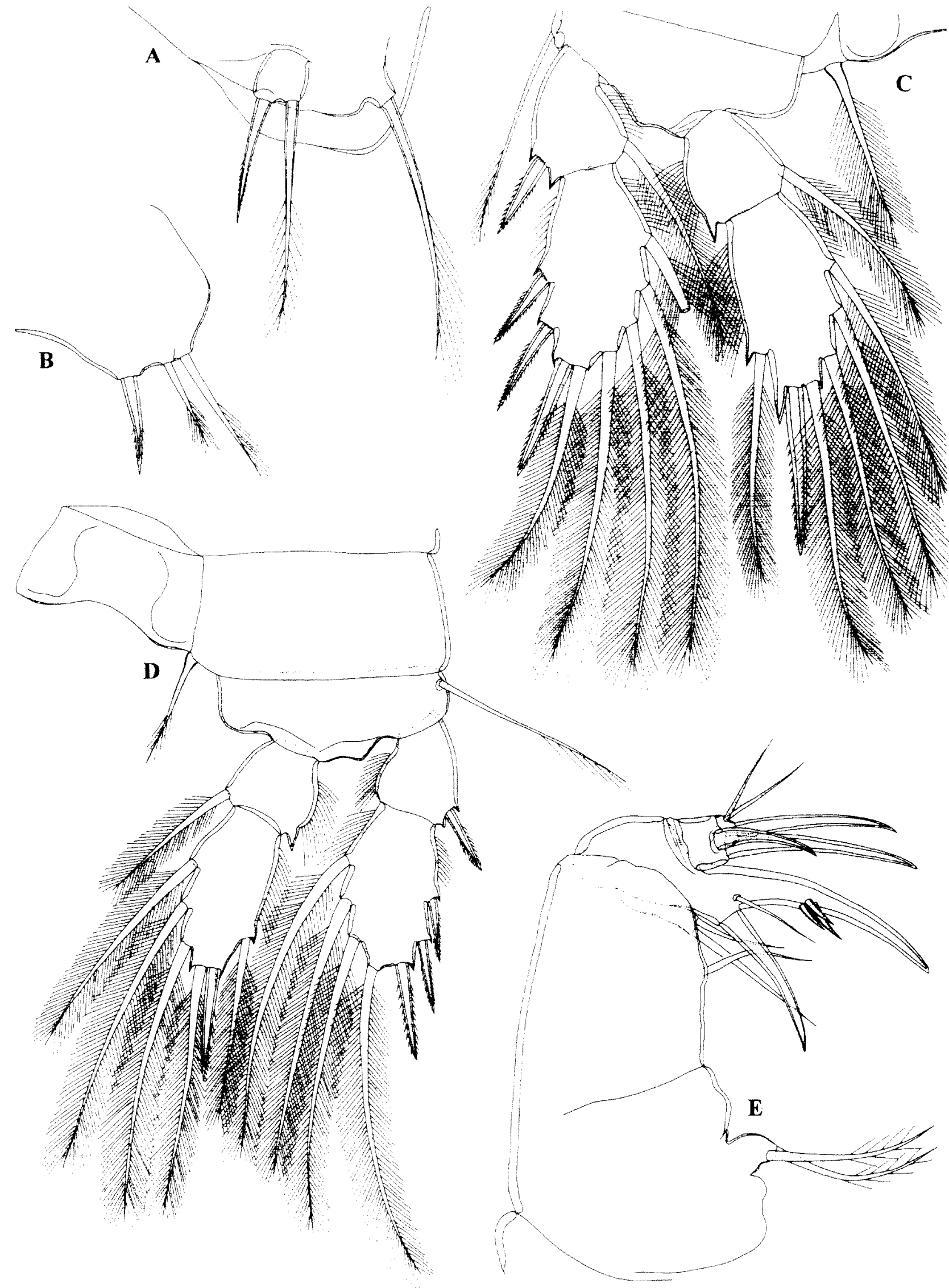

C, D, E

A, B

Figure 49 Fierscyclops (Pilbaracyclops) supersensus sp. now. holotype (male): A, left fifth leg, ventrolateral view; B. left sixth leg, lateral view; C. third swimming leg; D. fourth swimming leg; E, maxilla. Scales $=0.1 \mathrm{~mm}$. 
copulatory duct relatively long and narrow, rigidly sclerotized. Seminal receptacle very large and clearly divided into two expansions (mushroomlike), about 0.9 times as wide as long (ventral view), representing $62 \%$ of double somite width and $75 \%$ of its length; anterior expansion much shorter and somewhat wider than posterior one. Oviducts not rigidly sclerotized. Ovipores situated somewhat dorsolaterally, at $2 / 5$ of double somite's length, covered by reduced sixth legs, which bear two minute spines and one short seta.

Third urosomite (Figure 51A) ornamented dorsally near posterior margin with two sensilla and one cuticular pore in between; this somite about 1.4 times as long as fourth urosomal one, which unornamented.

Anal somite with smooth, broad, very short and slightly convex anal operculum, which represents $63 \%$ of somite's width and not reaching posterior margin of somite; ornamented with two large sensilla dorsally and with transverse row of spinules along posterior margin. Anal sinus widely open, without visible ornamentation.

Caudal rami (Figure 51A, E) parallel and about 2.4 times as long as wide. Armature and ornamentation similar to male (although dorsal seta slightly longer), except characteristic dorsolateral setule, inserted just anterior to lateral seta (Figure 51E).

Antennula (Figure 51D) reaching $2 / 3$ of cephalothorax, 11-segmented, unornamented, with one slender aesthetasc on seventh, eighth and eleventh segments and setal formula: 8.4.6.2.1.2.2.2.2.3.7. No setae with breaking planes and only one seta on sixth segment articulating on basal part. One seta on fifth segment spiniform and very short; all other setae slender and most setae smooth, only eight setae $(21 \%)$ pinnate distally. Length ratio of antennular segments, from proximal end and along caudal margins, $1: 0.3: 0.5: 0.3: 0.2$ : $0.5: 0.8: 0.8: 0.4: 0.5: 0.5$.

Antenna, labrum, mandibula, maxillula, maxilla (Figure 51B), maxilliped and swimming legs similar to male. Second exopodal segment of fourth swimming leg (Figure 51C) armed with five setae and three spines. Fifth leg (Figure $51 \mathrm{~A}$ ) very similar to male.

Sixth leg distinct, more or less semicircular, cuticular plate, armed with two smooth spines and one smooth, much longer seta; median spine distinct, other one completely fused to leg and much larger.

\section{Variability}

Body length of males ranges from $0.752 \mathrm{~mm}$ to $0.904 \mathrm{~mm}(0.855 \mathrm{~mm}$ average; $\mathrm{n}=4)$, while only one adult female was collected. The second exopodal segment of the fourth swimming leg of the holotype has only four setae (Figure 49D), while all the other specimens have a normal exopod, with five setae on the second segment (Figure 50F and 51C). Basis of the maxilla may be ornamented with three (Figure $49 \mathrm{E}$ and $51 \mathrm{~B}$ ) or only two (Figure 50E) strong spinules. A male from locality 2 has an abnormal first swimming leg exopod, armed with six setae on the second segment (Figure 50I), while the opposite leg has only five setae. The same specimen has the fifth leg with somewhat shorter outer apical seta than in holotype (Figure 50G).

\section{Etymology}

The specific name is composed of the Latin adverb "super" (meaning "over, above") and the Latin noun "sensus" (meaning "feeling, sensation"). It refers to numerous aesthetascs on the male antennula and should be treated as a noun in apposition.

\section{Discussion}

The genus Fierscyclops was established by Karanovic (2004a) to accommodate a single species from the Murchison region: Metacyclops fiersi De Laurentiis, Pesce and Humphreys, 2001. It shows close similarities with the cosmopolitan genera Apocyclops Lindberg, 1942 and Metacyclops Kiefer, 1927 (both of which have representatives in Australia) and also with another endemic Australian genus, Meridiecyclops Fiers, 2001. The latter genus was described by Fiers (2001) to accommodate two species, also previously known as members of Metacyclops. It can be distinguished from other Cyclopinae genera by the peculiar structures on the fourth leg basis and genital double somite but, most importantly, by the modification of the maxilla in male. None of these autapomorphies could be found in Fierscyclops (s. str.) fiersi or in two new species from the Pilbara.

The two new species from the Pilbara region can be distinguished by a number of morphological characters but their close relationship is evident from the following four synapomorphies: absence of the antennal exopod and reduced armature of the second endopodal segment; reduced armature of the maxilliped; reduced (and very strong) ornamentation of the maxillar basis; and reduced armature of the second endopodal segment of first, second and third swimming legs. All these characters distinguish the two new species from Fierscyclops (s. str.) fiersi, along with the apical armature of the second endopodal segment of the fourth leg, which could easily be a plesiomorphy. On the other hand, all three taxa share some very important morphological characters, such as a very similar shape of the fifth leg, three outer spines on the second and third swimming legs and a large sensillum laterally on the caudal ramus in the female. It is very clear that they have a close phylogenetic relationship but the two new species 


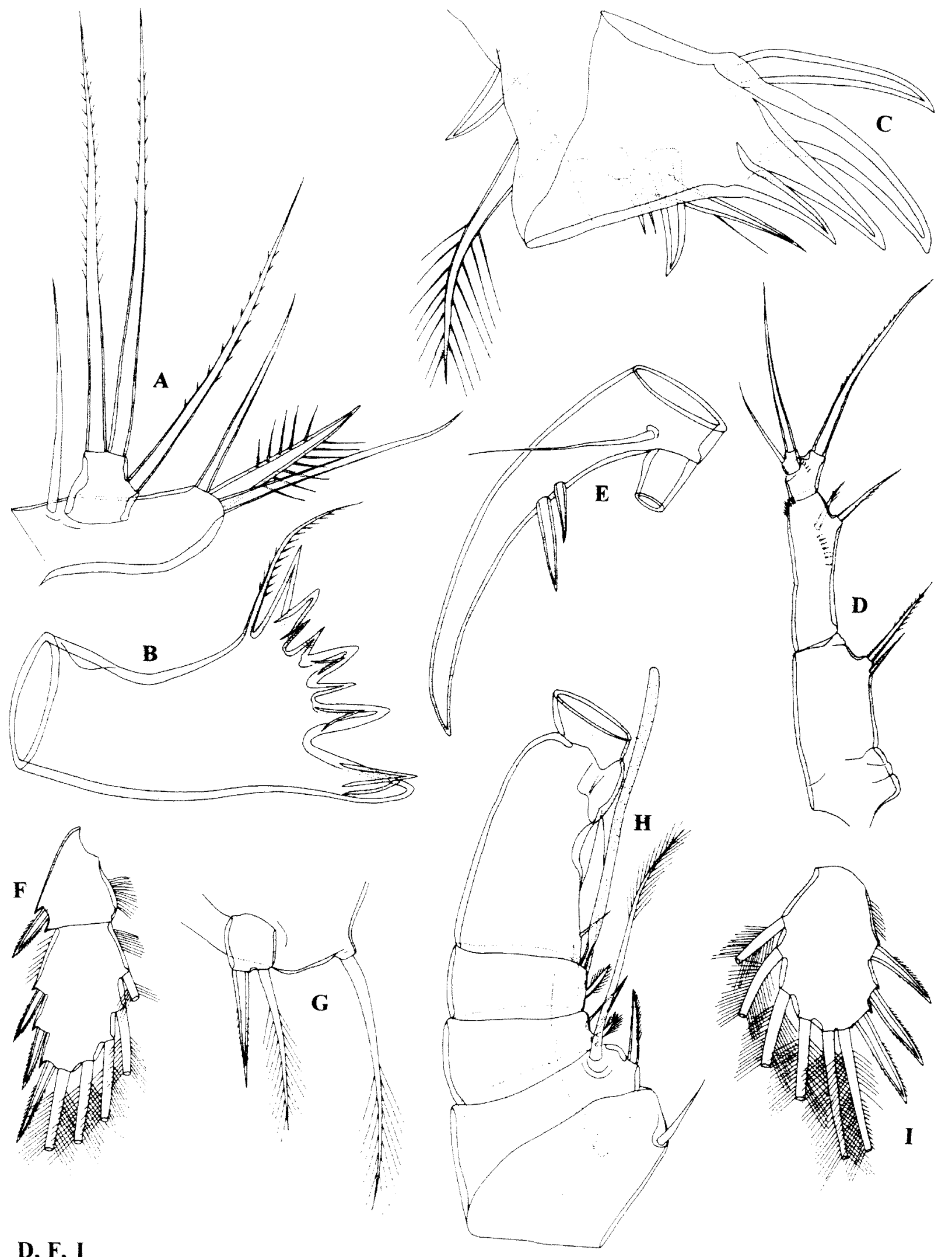

\section{H}

\section{$\mathrm{A}, \mathrm{B}, \mathrm{C}, \mathrm{E}, \mathrm{G}$}

Figure 50 Fierscyclops (Pilbaracyclops) supersensus sp. nov., A-D, holotype (male); E-I, male (0.752 mm) from locality 2 (WAM C34097): A, maxillular palp; B, mandibula, coxal gnathobase; C, praecoxa of maxillula; D, maxilliped; $E$, distal end of maxillar basis; $F$, exopod of fourth swimming leg; $G$, fifth leg; $H$, antennula, middle part; 1 , anormal second exopodal segment of first swimming leg. Scales $=0.1 \mathrm{~mm}$. 


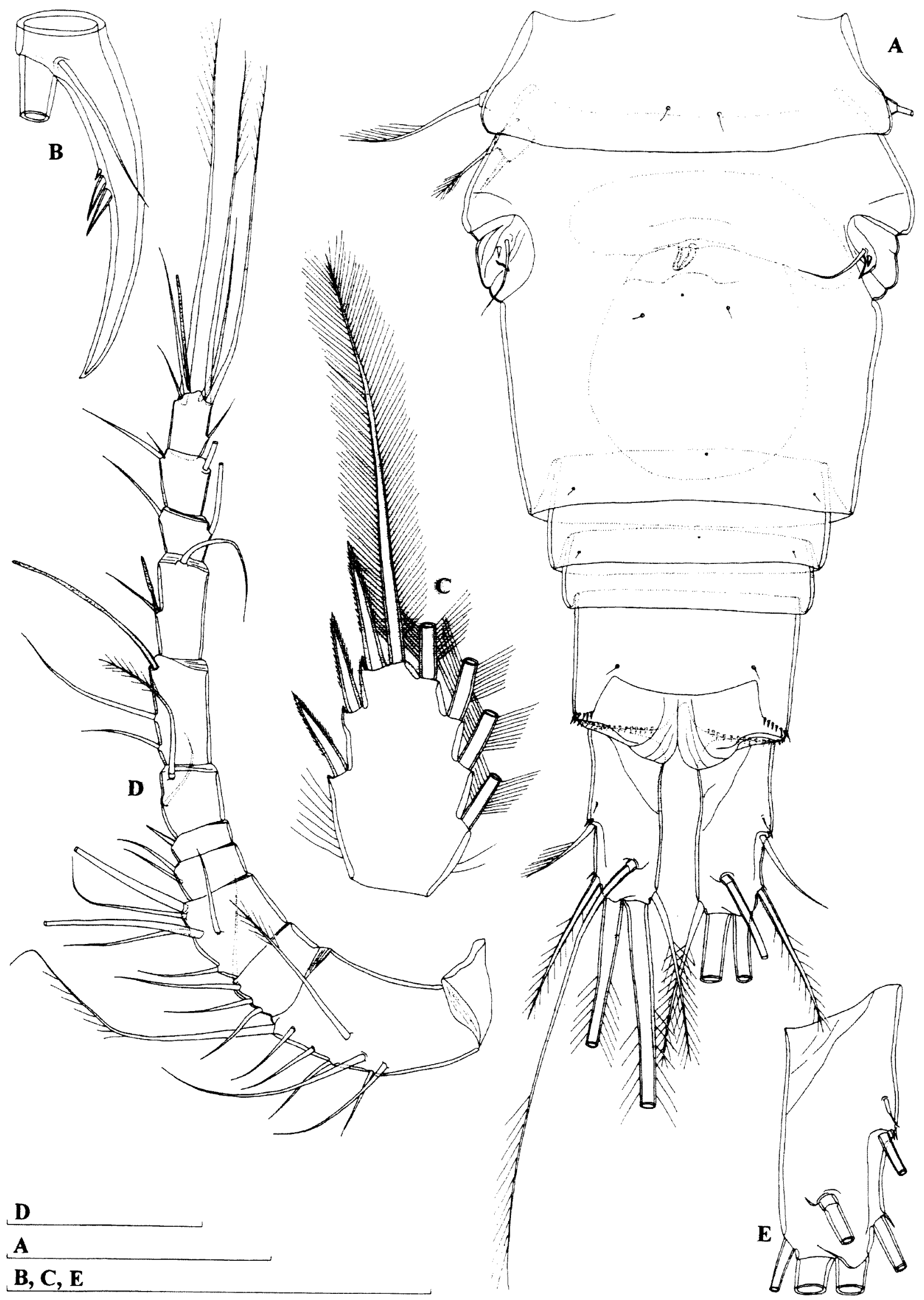

Figure 51 Fierscyclops (Pilbaracyclops) supersensus sp. nov., female $(0.8 \mathrm{~mm}$ ) from locality 1 (WAM C34096): A urosome, dorsal view; B, distal end of maxillar basis; C, second exopodal segment of fourth swimming leg; $D$, antennula; $\mathrm{E}$, right caudal ramus, dorsal view. Scales $=0.1 \mathrm{~mm}$. 
could not be included in the genus Fierscrclops s. str. without substantially enlarging its diagnosis. I decided to separate them into Pilbaracyclops subgen. nov. (rather than a new genus), as majority of their characters are apomorphies. With further investigations of Australian subterranean and surface waters it is reasonable to expect more species from this complex with plesiomorphic characters, which will slowly fill the gap between the two subgenera. However, the subgenera will always be easily distinguishable by the apical armature of the second endopodal segment of the fourth leg, a handy character, the true function of which remains to be discovered.

Fierscyclops (I.) supersensus sp. nov, was found only in three bores in the surveved area and its colour and relatively large size may suggest a stygophilic rather than stygobitic ecology. However, its main autapomorphy (unusually high number of aesthetascs on the first antennular segment) is something that would normally be considered as a stygomorphy (see Humphreys 2000b). Only further sampling from both surface and subterranean waters of this region will elucidate the true affinity of the species.

\section{Fierscyclops (Pilbaracyclops) frustratio sp. nov.} Figures 52-55

\section{Material Examined}

\section{Holotype}

Male (WAM C34099), Australia, Lake Disappointment, Ilgarari Creek, Bulloo Downs Station, Yanneri Well, 7 September 2000, leg. W.F. Humphreys (BES: 8491), 24 26'23"S 119 45'27"E: dissected on two slides

\section{Description}

Male (holotype). Body length, excluding caudal setae, $0.579 \mathrm{~mm}$. Habitus (Figure $52 \mathrm{~A}$ ) relatively robust, with prosome/urosome ratio 2.2 and greatest width at midlength of cephalothorax. Body length/width ratio about 2.8; cephalothorax 1.7 times as wide as genital somite. Free pedigerous somites without pronounced lateral expansions. Colour of preserved specimen yellowish. Nauplius eye not visible. Rostrum well developed, membranous, very broad and furnished with two large sensilla.

Cephalothorax (Figure 52A) about 1.1 times as long as its greatest width; represents $40 \%$ of total body length. Surface of cephalic shield with several large sensilla; no other ornamentation visible. Hyaline fringe of prosomites narrow and smooth. All free pedigerous somites ornamented dorsally with few sensilla and first somite additionally with three cuticular pores. More or less sclerotized joint (as pseudosomite) present between prosome and urosome. Fifth pedigerous somite with smooth fringe dorsally and ventrally, ornamented only with two dorsal and two lateral sensilla (Figure 52A, B).

Genital somite (Figure 52A, B and 53A) about 0.6 times as long as wide, ornamented with two large dorsal sensilla. Hyaline fringe of genital and subsequent somite smooth ventrally but serrated dorsally; fourth and fifth urosomites with hyaline fringe smooth both ventrally and dorsally. Third, fourth and fifth urosomites without any visible ornamentation; third somite about 1.3 times as long as fourth one and 1.9 times as long as fifth urosomite. Anal somite about as long as third unrosomal one, with smooth, broad, very short and convex anal operculum, which represents $55 \%$ of somite's width and not reaching posterior margin of somite; ornamented with two large sensilla dorsally and with transverse row of spinules on posterior margin (Figure 53A). Anal sinus widely opened, without visible ornamentation.

Caudal rami (Figure 52B and 53A) about twice as long as wide, slightly divergent, with space between them about one half of ramus' width; ornamented only with several spinules at base of lateral and outermost apical setae; distal margin ventrally with cuticular tube pore.. Dorsal seta about twice as long as ramus, inserted at $2 / 3$ of ramus length, uniarticulate at base and pinnate distally. Lateral seta arising just posteriorly of ramus midlength, uniplumose and slightly shorter than ramus' width. Outermost apical seta stout, spiniform, about as long as ramus, bipinnate. Innermost apical seta also bipinnate but more slender and about 0.6 times as long as outermost one. Principal apical setae plumose and with breaking plane; inner seta about 1.6 times as long as outer one, 0.5 times as long as body.

Antennula (Figure $53 \mathrm{C}$ and $54 \mathrm{~B}$ ) longer than cephalothorax, 16-segmented, unornamented, digeniculate, with geniculations between seventh and eighth and fourteenth and fifteenth segments. Three aesthetascs present on first, one on fourth, one on ninth, one on thirteenth and one on sixteenth segment; all aesthetascs long, smooth and slender. Setal formula: 8.4 .1 .2 .1 .2 .1 .1 .1 .2 .2 .2 .2 .1 .1 .8 . One seta on ninth, tenth and eleventh segment, two on twelfth and seta on fourteenth segment very short, spiniform; all other setae slender and all setae smooth, except spiniform setae on eleventh, twelfth and thirteenth segments. Only four setae on sixteenth segment and seta on fifteenth segment articulating on basal part; most apical seta on sixteenth segment fused basally with aesthetasc. Fourteenth and fifteenth segment with geniculation blades, each with cuticular pore at middle.

Antenna four-segmented, comprising coxobasis and three-segmented endopod; all endopodal segments of about same length, coxobasis somewhat longer. Coxobasis about 2.5 times as long 


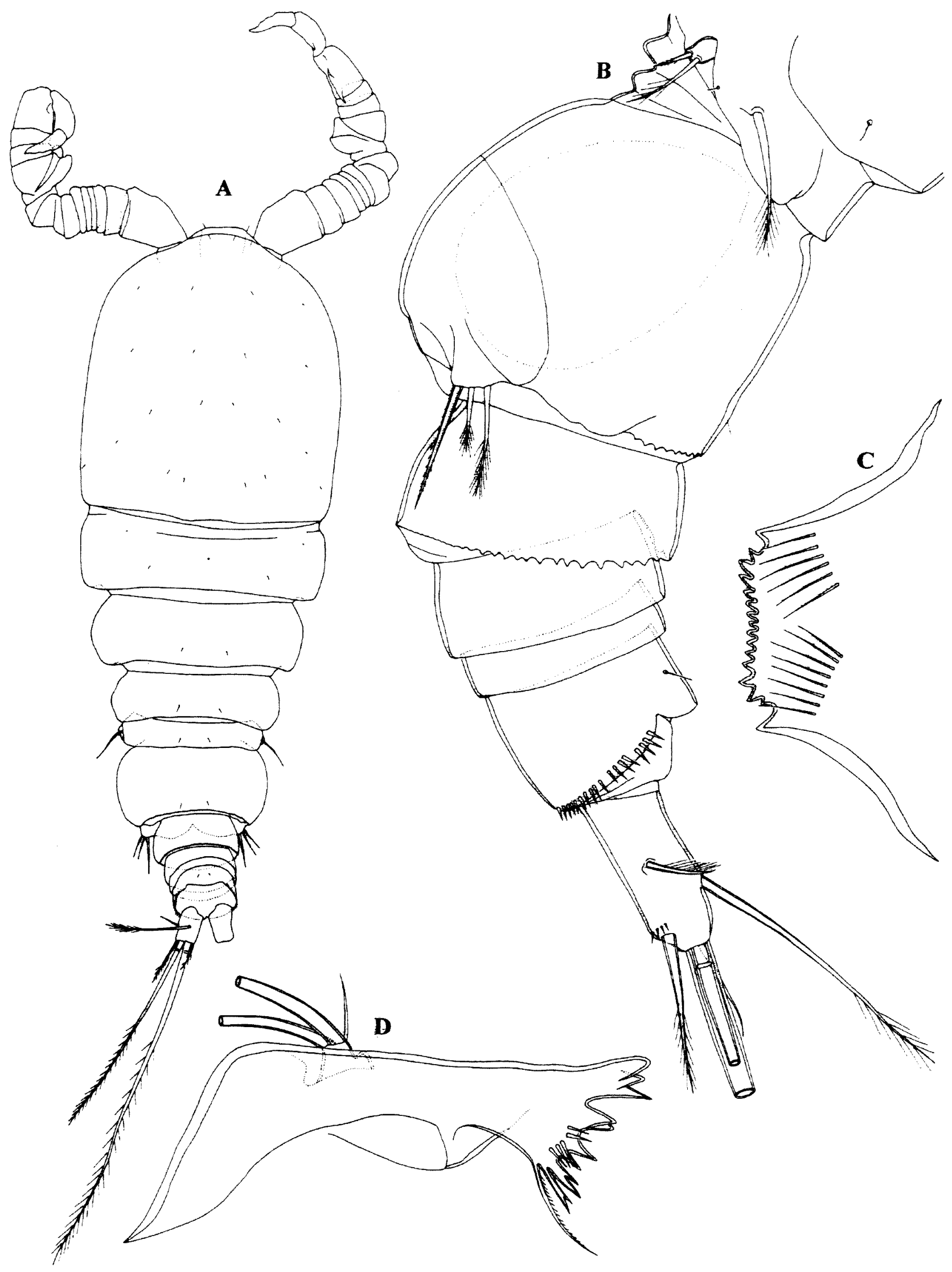

B

C, D

A

Figure 52 Fierscyclops (Pilbaracyclops) frustratio sp. nov., holotype (male): A, habitus, dorsal view; B, urosome, lateral view; C, labrum; $D$, mandibula. Scales $=0.1 \mathrm{~mm}$. 


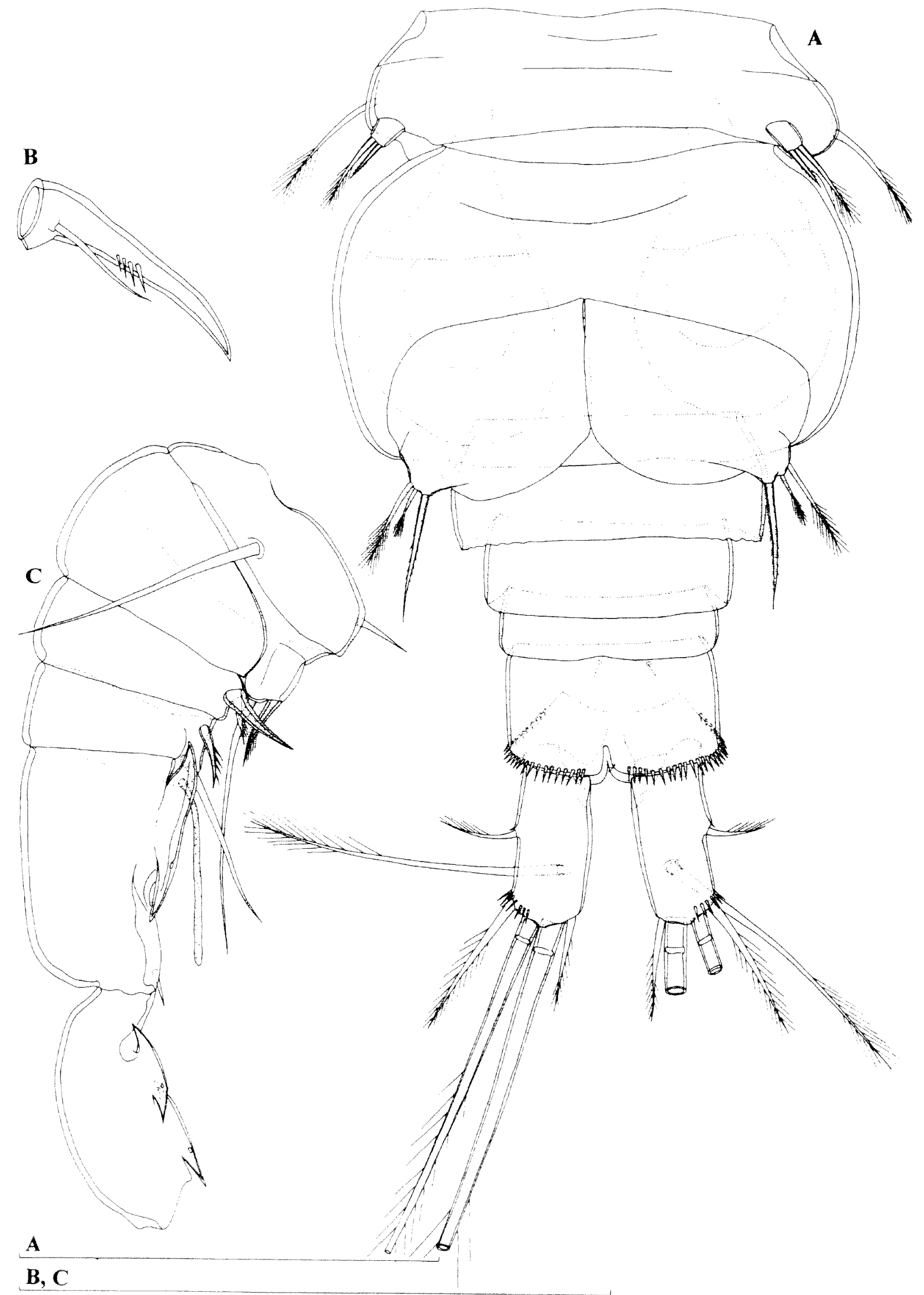

Figure 53 Fierscyclops (Pilbaracyclops) frustratio sp. nov, holotype (male): A, urosome, ventral view; B, distal part of maxillar basis; $C$, antennula, middle part. Scales $=0.1 \mathrm{~mm}$. 
as wide, unornamented but armed with two smooth setae at distal inner corner; seta representing exopod absent. First endopodal segment armed with one smooth seta at middle, ornamented with longitudinal row of spinules along external margin. Second endopodal segment about twice as long as wide, ornamented with longitudinal row of spinules along external margin, armed with six smooth setae (four lateral, two subapical; one subapical seta somewhat longer and much stronger than any other seta on this segment). Third endopodal segment 2.8 times as long as wide, armed with seven smooth apical setae and ornamented as previous segment.

Labrum (Figure 52C) trapezoidal, ornamented with two diagonal rows of long spinules (six to eight) on ventral surface. Cutting edge slightly concave, with 14 large and more or less sharp teeth between produced, pointed lateral corners.

Mandibula (Figure 52D) with small but clearly distinct palp, armed with two very long, plumose setae and one short, smooth seta on distal end. Coxal gnathobase cutting edge with six very strong teeth (innermost strongest and complex; second and fourth from inner side also complex, others simple), five spinules and outermost pinnate seta, which slightly longer than short seta on palp.

Maxillula composed of well developed praecoxa and two-segmented palp. Arthrite of praecoxa with four strong and smooth apical spines; only one distinct, others completely fused to praecoxa. Praecoxa armed with seven armature elements along inner margin, longest one plumose. Palp with distinct endopod, bearing three pinnate setae (two apical and one lateral), and armed laterally with one exopodal smooth seta and apically with two smooth slender setae and one robust, strongly bipinnate spine. Palp slightly shorter than arthrite of praecoxa.

Maxilla (Figure 53B) unornamented and fivesegmented but praecoxa fused to coxa on posterior surface and also partly on anterior surface. Proximal endite of praecoxa well developed, about as long as wide, armed with two equally long, bipinnate setae; distal endite small, unarmed. Proximal endite of coxa with one short, smooth seta; distal endite highly mobile, elongate and armed apically with two smooth setae (proximal seta 1.5 times as long as distal one). Basis expanded into robust claw, ornamented with short row of four robust spinules at middle and armed with two smooth setae; proximal seta strong about as long as claw; other seta slender, 0.5 times as long as claw. Endopod two-segmented; proximal segment armed with two robust, smooth setae (longer one as long as strong seta on basis; other one half as long); distal segment very small, armed with one robust apical seta and two slender subapical setae (all three smooth). Longest seta on distal endopodal segment about as long as strong seta on basis.
Maxilliped (Figure 54C) four-segmented, composed of syncoxa, basis and two-segmented endopod. Syncoxa strong, about twice as long as wide, ornamented with few spinules along outer margin and armed with two pinnate setae; distal seta about 1.7 times as long as proximal one. Basis not very slender, 1.2 times as long as wide, ornamented with arched row of long spinules at middle and transverse row of spinules near distal outer corner, armed with two pinnate setae. First endopodal segment unornamented but armed with one strong, bipinnate seta; this seta longest and strongest on maxilliped. Second endopodal segment very small, unornamented but armed with two setae; inner seta much stronger, bipinnate and about 1.9 times as long as outer, smooth one. All pinnate setae on maxilliped with long pinnules.

All swimming legs with two-segmented exopod and endopod (Figure 54A and 55A, B). Armature formula of swimming legs as follows (legend: inner/ outer spine or seta; inner/terminal/outer):

\begin{tabular}{lcccc} 
& \multicolumn{2}{c}{ Exopod } & \multicolumn{2}{c}{ Endopod } \\
Segments & 1 & 2 & 1 & 2 \\
First leg & $0 / 1$ & $3 / 2 / 3$ & $1 / 0$ & $2 / 2 / 1$ \\
Second leg & $1 / 1$ & $4 / 2 / 2$ & $1 / 0$ & $3 / 2 / 1$ \\
Third leg & $1 / 1$ & $4 / 2 / 2$ & $1 / 0$ & $3 / 2 / 1$ \\
Fourth leg & $0 / 1$ & $4 / 2 / 1$ & $1 / 0$ & $3 / 2 / 1$
\end{tabular}

Last exopodal segment spine formula: 3.3.3.2. Intercoxal sclerites of all swimming legs unornamented, with smooth and bilobate distal margin. All coxae ornamented with one or more rows of spinules and armed with plumose seta at inner distal corner. Basis of each leg unornamented (except two short rows on basis of first leg), armed with slender lateral seta on outer margin. Spine at inner corner of basis of first leg not very stout, reaching $1 / 5$ of second endopodal segment (Figure $54 \mathrm{~A}$ ). All setae slender and plumose. All endopodal segments with row of hairs along outer margin; hairs also present along inner margins of all exopodal segments. First exopodal and endopodal segment of each leg (except exopod of first leg) with posterior row of large spinules. Apical spine on second endopodal segment of first swimming leg very robust, curved and about 1.3 times as long as segment (Figure 54A). Apical spine on second endopodal segment of second and third leg slightly shorter than segment; second and third leg (Figure $55 \mathrm{~A})$ without any important difference. Second endopodal segment of fourth swimming leg about 1.7 times as long as wide; armed apically with inner seta and outer spine; apical seta 2.1 times as long as spine and almost 1.6 times as long as segment (Figure 55B).

Fifth leg (Figure 52B and 53A) with basal segment completely fused to somite, without remnant of ancestral separation visible in dorsal view; outer basal seta inserted laterally on somite and pinnate distally. Distal segment about as long as wide, 


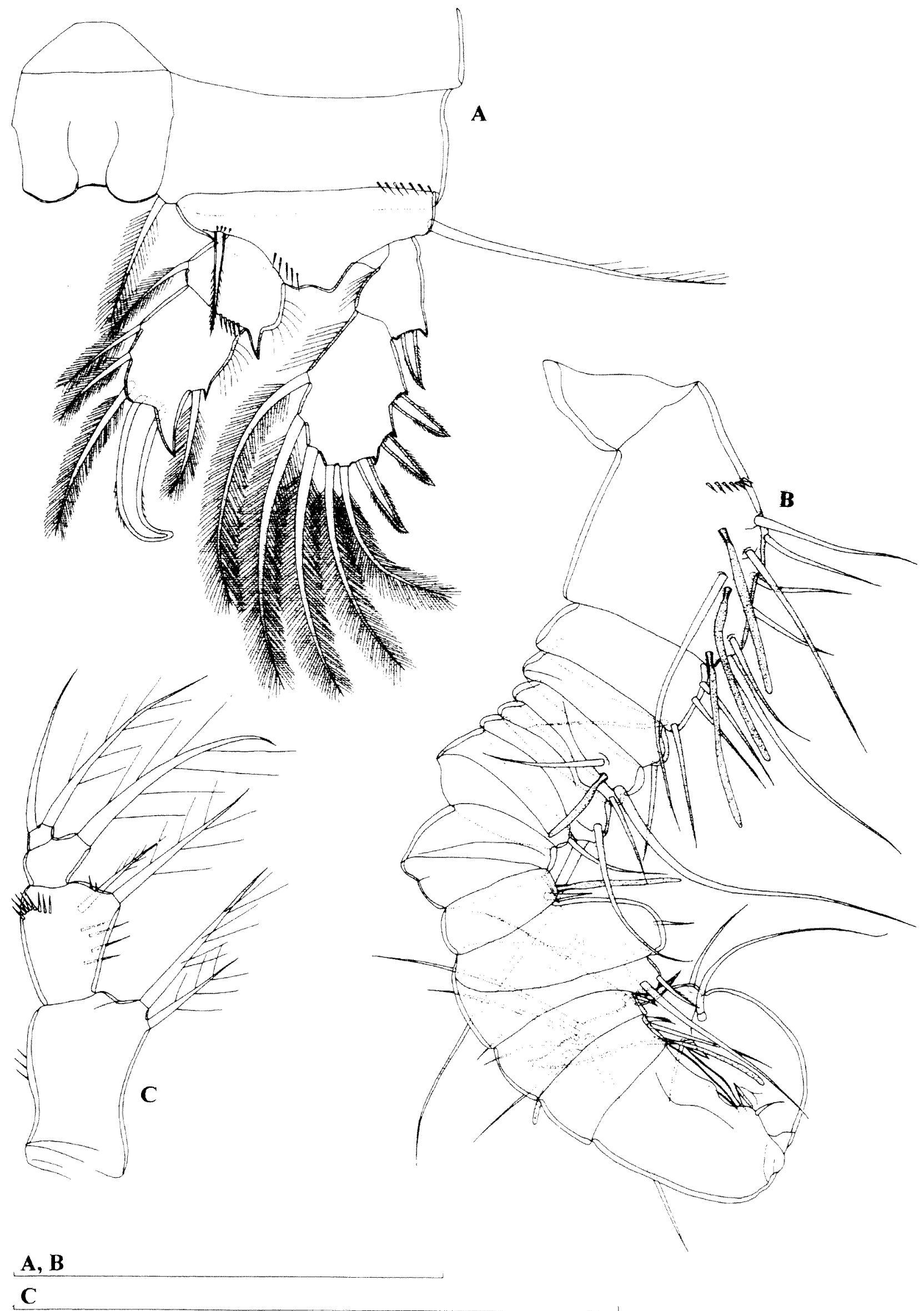

Figure 54 Fierscyclops (Pibaracyclops) frustratio sp. now, holotype (male): A, first swimming leg; B, antennula; C, maxilliped. Scales $=0.1 \mathrm{~mm}$. 


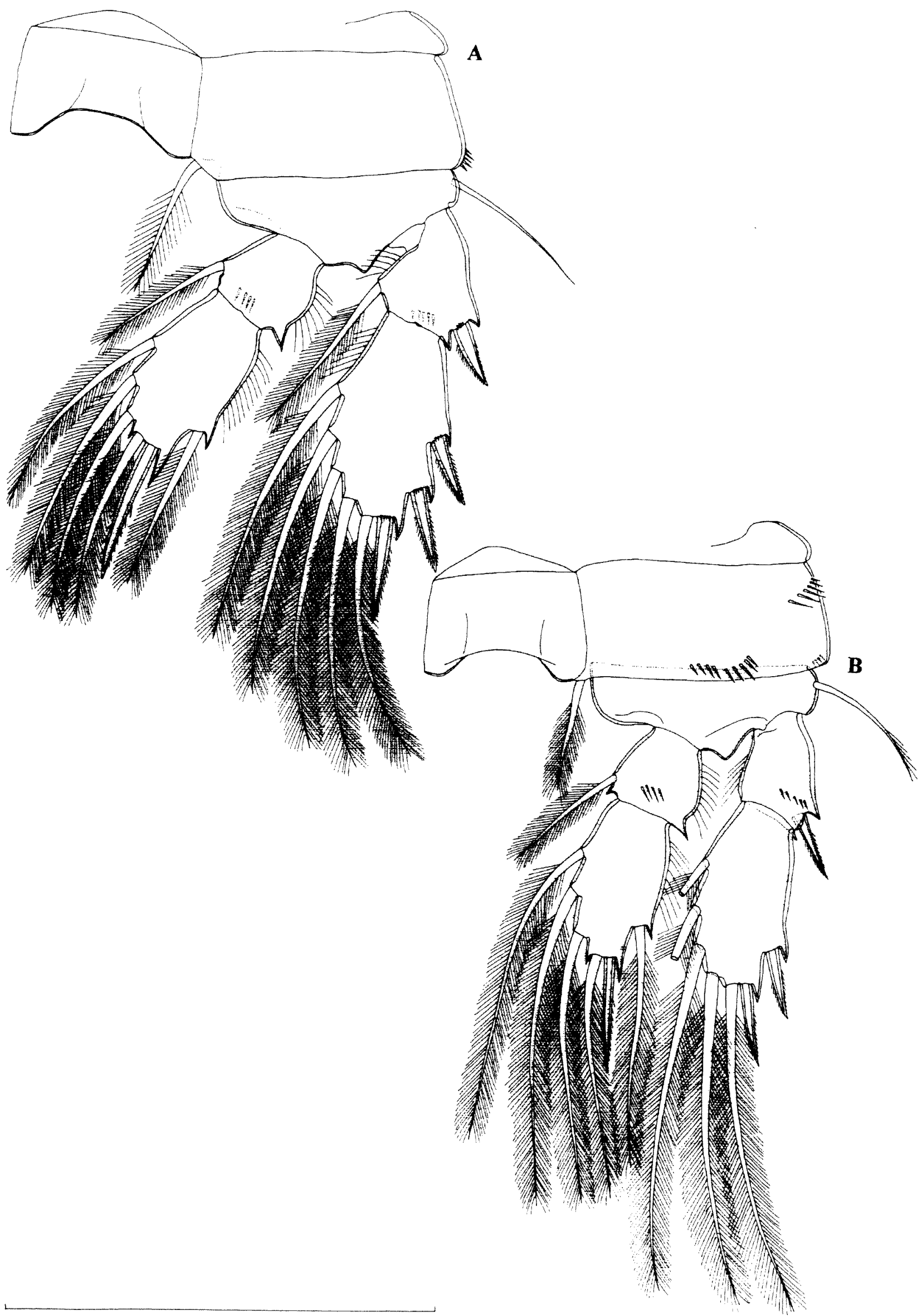

Figure 55 Fierscyclops (Pilbaracyclops) frustratio sp. nov., holotype (male): A, third swimming leg; B, fourth swimming leg. Scale $=0.1 \mathrm{~mm}$. 
armed with apical outer seta and apical inner spine; without any ornamentation. Apical seta on distal segment bipinnate at distal end, short, about 2.6 times as long as segment, almost twice as long as spine and about 0.8 times as long as basal seta. Spine on distal segment bipinnate, strong and 1.4 times as long as segment.

Sixth leg (Figure 52B and 53A) distinct, large cuticular plate, unomamented and armed with one bipinnate spine and two plumose setae. Outermost seta about 0.85 times as long as spine and 1.7 times as long as middle seta. Spine on sixth leg much longer than that on fifth leg.

Female. Unknown.

\section{Etymology}

The species is named after the Latin noun "frustratio", meaning "disappointment" and referring to the Lake Disappointment aquifer, where it was found. The name is a noun in apposition.

\section{Discussion}

Fierscyclops (Pilbaracyclops) frustratio sp. nov. differs from $F$. $(P)$ supersensus sp. nov. by its smaller size, more robust habitus, larger genital somite, shorter innermost apical caudal setae, less ornamented labrum, less slender maxilliped, shorter apical spine of the fifth leg, only two outer spines on the second exopodal segment of the fourth swimming leg and different number of aesthetascs on the first antennular segment in male (three in the former species and seven in the latter). Other small differences include ornamentation of some appendages but are not emphasised here because the variability is poorly known for $F .(P)$ supersensus and only one male of $F$. (P) frustratio was collected.

\section{Genus Microcyclops Claus, 1893}

\section{Microcyclops varicans (Sars, 1863)}

\section{Synonymy}

Cyclops varicans n.sp. - Sars, 1863: 252.

Cyclops varicans Sars - Sars, 1921: 54, plate 33; Henry, 1923: 562; Kiefer, 1929b: 27, Figures 2426.

Cyclops (Diacyclops) varicans Sars - Pesta, 1928: 119, Figure 101

Crclops (Microcyclops) varicans Sars - Kiefer, 1929a: 66, Figures 24a and 24b; Kiefer, 1933: 567. Figures 96 and 97; Kiefer, 1934b: 162, Figures 104 and 105; Stephanides, 1948: 50, Figures 184 187.

Microcyclops varicans (Sars) - Wilson, 1932: 326 ,
Figure 194; Rylov, 1948: 267, Figure 62; Lindberg, 1953: 6; Kiefer, 1960a: 45; Dussart, 1969: 180, Figure 89; Einsle, 1971: 48, Figure 16; Kiefer, 1978: 216; Dussart, 1981: 152, Figures 1012; Dussart and Frutos, 1985: 310, Figures 28-30; Defaye, 1988: 132, Figures 87-89; Dussart and Defaye, 1985: 102; Reid, 1992: 249, Figures $8 \mathrm{c}$ and 9c; Gaviria, 1998: 558; Hudson et al., 1998:16; Karanovic, 2004a: 121, Figure 51.

Microcyclops varicans varicans (Sars) - DamianGeorgescu, 1963: 162, Figure 83; Reid, 1985: 140, Figures 298-300.

Microcyclops (Microcyclops) varicans (Sars) Kiefer, 1938a: 57, Figures 39-41; Ito, 1954: 402, Figures 154-162; Ito, 1957: 18, Figures 49-52; Shen et al., 1979: 375, Figures 221-222.

Microcyclops (Microcyclops) varicans varicans (Sars) - Monchenko, 1974: 360, Figures 130-131.

Microcylops varicans var. rubellus (Lilleborg) Rylov, 1948: 269, Figures 63/3-63/10.

Microcyclops (Microcyclops) varicans f. rubellus (Lilljeborg) - Monchenko, 1974: 365, Figure 132.

Microcyclops varicans rubellus (Lilljeborg) Petkovski, 1955a: 84, Figures 35-39; DamianGeorgescu, 1963: 164, Figure 85; Plesa, 1981: 28, Figures 41 and 42; Dussart and Defaye, 1985: 104.

Microcyclops rubellus (Lilljeborg) - Kiefer, 1960a: 45, Figures 118-120; Dussart, 1969: 182, Figure 90; Kiefer, 1978: 216; Reid, 1992: 245, Figures 89; Gaviria, 1998: 558; Hudson et al., 1998: 15.

Microcyclops (Microcyclops) rubellus (Lilljeborg) Shen et al., 1979: 377, Figure 223.

Microcyclops varicans $f$. dojrensis n.f. - Petkovski, 1954: 20, Figures 23-27.

Cyclops subaequalis nov. spec. - Kiefer, 1928a: 558, Figures 39-40.

Microcyclops varicans subequalis (Kiefer) - Kiefer, 1956: 260, Figures 83-85; Dussart and Defaye, 1985: 104; Reid, 1985: 140, Figure 301.

\section{Material Examined}

1) Australia, Pilbara, Newman, bore W6, 13 November 1998, Leg. S.M. Eberhard (BES: 3580), $23^{\circ} 20^{\prime} \mathrm{S} 119^{\circ} 50^{\prime} \mathrm{E}$ : one copepodid in alcohol (WAM C34100)

2) Australia, Pilbara, Mulga Downs Station, Maddina Well, 3 September 2000, leg. W.F. Humphreys (BES: 8450), 22'1304'S 118 39'34'E: one damaged male in alcohol (WAM C34101)

3) Australia, Pilbara, Coolawanyah, bore COW1, 12 April 2003, leg. J. Cocking and M. Scanlon

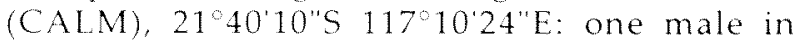
alcohol (WAM C34102) 
4) Australia, Pilbara, Lake Disappointment, Ilgarari Creek, Bulloo Downs Station, No 37 Government Well, 7 September 2000, leg. W.F.

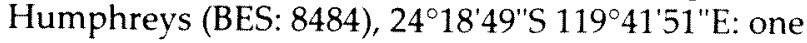
female in alcohol (WAM C34103)

5) Australia, Pilbara, Weeli Wolli Spring, surface pool, 16 November 1998, leg. S.M. Eberhard (BES: 3601 and 3608$), 22^{\circ} 55^{\prime} \mathrm{S} 119^{\circ} 11^{\prime} \mathrm{E}$ : one male + five females (one ovigerous) in alcohol (WAM C34104)

6) Australia, Pilbara, Newman, bore F3, 13 November 1998, leg. S.M. Eberhard (BES: 3583), $23^{\circ} 20^{\prime} \mathrm{S} 119^{\circ} 50^{\prime} \mathrm{E}$ : one male + one female + 24 copepodids (one copepodid dissected on one slide (WAM C34105); others in alcohol (WAM C34106))

7) Australia, Pilbara, Mulga Downs Station, Mamamoonah Well, 2 September 2000, leg. W.F. Humphreys (BES: 8442), 22 ${ }^{\circ} 07^{\prime} 28^{\prime \prime S} 118^{\circ} 17^{\prime} 16^{\prime \prime E}$ : one female + one copepodid in alcohol (WAM C34107)

8) Australia, Pilbara, Mulga Downs Station, Ebathacalby Well, 2 September 2000, leg. W.F. Humphreys (BES: 8440), 22 $2^{\circ} 14^{\prime} 58^{\prime \prime} \mathrm{S} 118^{\circ} 44^{\prime} 52^{\prime \prime} \mathrm{E}$ : one female in alcohol (WAM C34108)

9) Australia, Pilbara, Mulga Downs Station, Brown Well, 3 September 2000, leg. W.F. Humphreys (BES: 8463), 22 $12^{\prime} 54^{\prime \prime S} 118^{\circ} 31^{\prime} 05^{\prime \prime} \mathrm{E}$ : two males + two females + two copepodids in alcohol (WAM C34109)

10) Australia, Pilbara, Hamersley Range, Munjina Creek, 5 September 2000, leg. W.F. Humphreys (BES: 8473 and 8479): one male + six copepodids in alcohol (WAM C34110)

11) Australia, Pilbara, Hamersley Station, Barnett Well, 29 September 1997, leg. W.F. Humphreys and

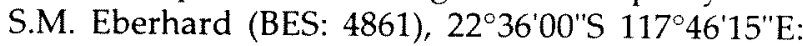
two males in alcohol (WAM C34111)

12) Australia, Pilbara, Coolawanyuah Station, Weelumurra Well, 29 July 1997, leg. W.F. Humphreys and S.M. Eberhard (BES: 4867), $22^{\circ} 05^{\prime} 52^{\prime \prime S} 117^{\circ} 42^{\prime} 11^{\prime \prime E}$ : seven males + four copepodids in alcohol (WAM C34112)

13) Australia, Pilbara, Mount Florence Station, V15 Well, 4 September 2000, leg. W.F. Humphreys (BES: 8465$), 22^{\circ} 04^{\prime} 45^{\prime \prime} \mathrm{S} 118^{\circ} 06^{\prime} 18^{\prime \prime} \mathrm{E}$ : five females in alcohol (WAM C34113)

14) Australia, Pilbara, Fortescue River road bridge, Bou-Rouch pump samples 2, 9, 10, four and 6, 5 August 1997, leg. W.F. Humphreys and S.M. Eberhard (BES: 1037, 4963, 4975, 4980 and 4998), $21^{\circ} 17^{\prime} 52^{\prime \prime S} 116^{\circ} 08^{\prime} 23^{\prime \prime} \mathrm{E}$ : one copepodid in alcohol (WAM C34114)

\section{Discussion}

This cosmopolitan species was recorded and partly redescribed from two subterranean localities in the Murchison region (Karanovic 2004a). In the Pilbara region it is more frequent, probably because subterranean waters here are of less increased salinity. It is a stygophile element in the copepod fauna of the Pilbara region, and recorded a number of times in Western Australian surface waters (Halse et al. 1996, 1998, 2000b, 2002b).

\section{Genus Allocyclops Kiefer, 1932}

\section{Subgenus Psammocyclops Kiefer, 1955}

\section{Allocyclops (Psammocyclops) consensus Karanovic, 2003}

\section{Synonymy}

Allocyclops (Psammocyclops) consensus n.sp. Karanovic, 2003: 142, Figures 1-15.

\section{Discussion}

Only one female of this interesting species was collected and described from Barrow Island, as the first representative of the genus Allocyclops Kiefer, 1932 in Australia (Karanovic 2003). Unfortunately, I have not found any additional material so far. The genus Allocyclops has representatives on all continents except Antarctica (Karanovic 2001b, 2003, Tomikawa et al. 2005) but all 14 species are very rare. The subgenus Psammocyclops Kiefer, 1955 shows clear Gondwana connections, as its representatives are distributed in South America, Africa, Madagascar and Australia. It is still unknown on the Indian subcontinent but the subterranean freshwaters there still await serious investigation (Ranga Reddy 2001, Karanovic and Pesce 2001, Karanovic and Ranga Reddy 2004a, 2004b).

\section{Order Harpacticoida Sars, 1903}

Family Ectinosomatidae Sars, 1903

Genus Pseudectinosoma Kunz, 1935

Pseudectinosoma galassiae sp. nov. Figures 56 and 57

\section{Material Examined}

\section{Holotype}

Female (WAM C34115), Australia, Pilbara, Robe River, bore G70730101, 14 November 2002, leg. J. Cocking and M. Scanlon (CALM), 21 $34^{\prime} 32^{\prime \prime S}$ $115^{\circ} 52^{\prime} 58^{\prime \prime} \mathrm{E}$ : dissected on one slide

\section{Allotype}

Male (WAM C34116), Australia, Pilbara, Robe River, bore G70730101, 14 November 2002, leg. J. Cocking and M. Scanlon (CALM), 21 $34^{\prime} 32^{\prime \prime S}$ $115^{\circ} 52^{\prime} 58^{\prime \prime} \mathrm{E}$ : dissected on one slide

\section{Paratypes}

Australia, Pilbara, Robe River, bore G70730101, 14 November 2002, leg. J. Cocking and M. Scanlon 
(CALM), 21 34'32"S 115'52'58'E: two males + one female + four copepodids (one male dissected on one slide (WAM C34117); one male on slide in toto (WAM C34118); others in alcohol (WAM C34119))

\section{Other material}

1) Australia, Pilbara, Robe River, bore G70730104, post-purge, 14 November 2002, leg. J. Cocking and M. Scanlon (CALM), 21 34'53'S 115'52'14"E: one female dissected on one slide (WAM C34120)

2) Australia, Pilbara, Robe River, bore G70730104, pre-purge, 14 November 2002, leg. J. Cocking and M. Scanlon (CALM), 21'34'53"S 114 52'14"E: one female in alcohol (WAM C34121)

3) Australia, Pilbara, Robe River, bore G70730102, 4 April 2003, leg. J. Cocking and M. Scanlon (CALM), $21^{\circ} 34^{\prime} 53^{\prime \prime} \mathrm{S} 115^{\circ} 52^{\prime} 14^{\prime \prime} \mathrm{E}$ : one female in alcohol (WAM C34122)

\section{Description}

Female (holotype). Total body length, measured from tip of rostrum to posterior tip of caudal rami acuminate lappets (excluding caudal setae), 0.25 $\mathrm{mm}$. Preserved specimen colourless. Nauplius eye absent. Habitus (Figure 56A, B) fusiform and robust, without distinct demarcation between prosome and urosome; prosome/urosome ratio 1.25; greatest width at posterior end of cephalothorax. Body length/width ratio about 3.4; cephalothorax 1.7 times as wide as genital double somite. Free pedigerous somites without pronounced lateral expansions or dorsally. Integument strongly chitinized. Rostrum hyaline, reaching $2 / 3$ of second antennular segment, fused at base with cephalothorax.

Cephalothorax about 1.2 times as long as wide; represents $36 \%$ of total body length (Figure $56 \mathrm{~A}, \mathrm{~B}$ ). Surface of cephalic shield with scattered small sensilla and cuticular pores; tergites of first three free pedigerous somites ornamented with several sensilla and pores. Hyaline fringe of all prosomites narrow and smooth. Fifth pedigerous somite (first urosomal) ornamented with four dorsal sensilla and two dorsolateral pores (one on each side); hyaline fringe sharply serrated dorsally and laterally, smooth ventrolaterally.

Genital double somite (Figure 56A, B and 57B) about 0.7 times as long as wide (dorsal view), without suture or any other trace of subdivision, ornamented with two sensilla dorsally near posterior margin, two cuticular pores laterally at middle and two pores ventrally near copulatory pore; hyaline fringe sharply serrated both ventrally and dorsally. Copulatory pore small, ovoid, situated at $1 / 3$ of double somite's length. Copulatory duct narrow and short, not rigidly scletotized; seminal receptacle not clearly visible. Fused sixth legs forming simple genital operculum, without any armature or ornamentation (Figure
$57 B)$. Third urosomite ornamented only with two dorsal sensilla near posterior margin; hyaline fringe sharply serrated both ventrally and dorsally.

Preanal somite without any ornamentation, with sharply serrated fringe ventrally (Figure 57B); hind margin clearly bulging posteriorly in dorsal region, forming finely serrated, broadly convex and short pseudoperculum (Figure 56B). Anal somite medially cleft, without anal operculum; ornamented with two large sensilla and two pores dorsally, two cuticular pores laterally (one on each side) and transverse row of spinules on posterior margin ventrally (Figure 56A and 57B, F). Anal sinus widely opened, without visible ornamentation.

Caudal rami (Figure 56A, B and 57B, F) short, 1.7 times as long as greatest width, almost triangular and divergent, with space between them about one ramus width; unornamentated and armed with five smooth setae (one lateral, one dorsal and three apical); posterior margin of rami terminating dorsally and ventrally as acuminate lappets of about same length, dorsal lappet broader. Dorsal seta without visible articulation at base, positioned close to inner margin and 0.6 times as long as ramus including dorsal lappet and only slightly longer and more slender than lateral seta. Inner apical seta not covered by lappets ventrally and only slightly dorsally, 1.3 times as long as ramus. Principal apical setae with breaking planes and with basal part completely covered by lappets, both dorsally and ventrally; middle apical seta strongest, about 1.6 times as long as outer apical seta and 0.6 times as long as body.

Antennula (Figure 56C) very short, approximately 0.3 times as long as cephalothorax, five-segmented. Second and fifth segments with parts of ancestral suture still visible (ancestral antennula was probably seven-segmented). Second segment with long aesthetasc subapically, which reaching beyond posterior tip of antennula slightly more than length of fifth segment. Much smaller and shorter aesthetasc on fifth segment apically, almost 1.9 times as long as segment. Setal formula: 1.11.1.2.2. No setae with breaking plane or articulating on basal part and all setae smooth. Length ratio of antennular segments, from proximal end, $1: 1.6$ : $0.8: 1: 1.3$.

Antenna (Figure 56D) longer than antennula, comprising coxa, basis, two-segmented endopod and two-segmented exopod. Coxa very short, without any ornamentation. Basis largest segment, about 2.2 times as long as wide, unarmed and unornamented. First endopodal segment also without ornamentation and armature, about 2.3 times as long as wide and 0.9 times as long as basis. Second endopodal segment ornamented with one surface frill subdistally and two long spinules on inner margin proximally; armature consists of two 


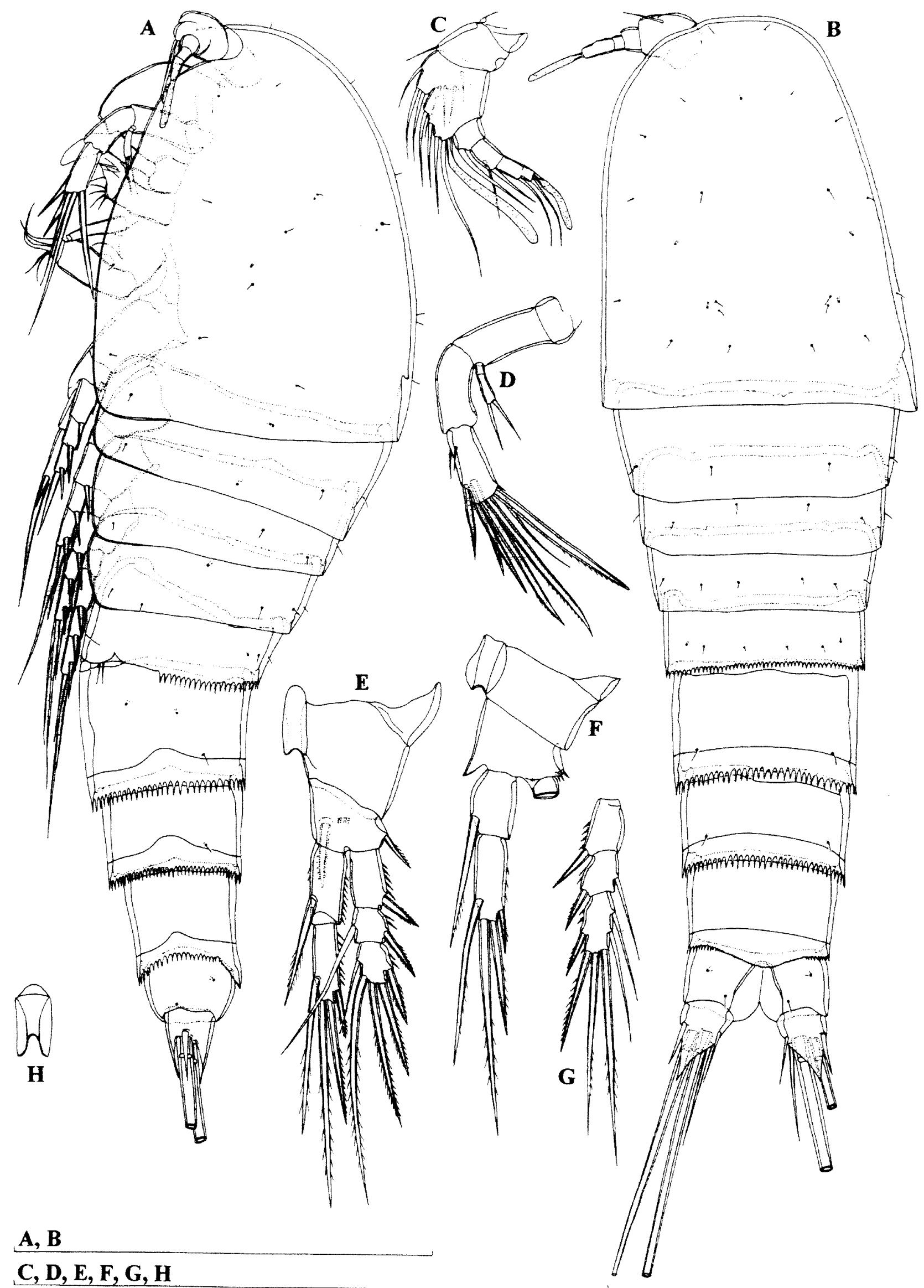

Figure 56 Pseudectinosoma galassiae sp. nov, holotype (female): A, habitus, lateral view; B, habitus, dorsal view; C, antennula; D, antenna; E, first swimming leg; F, second swimming leg, without exopod; $G$, exopod of second swimming leg; $\mathrm{H}$, intercoxal sclerite of third swimming leg. Scales $=0.1 \mathrm{~mm}$. 
lateral spines and five apical setae; one apical seta slender, while other four very robust and spiniform, three of them unipinnate distally. First exopodal segment minute, unornamented and unarmed, about 1.5 times as long as wide. Second exopodal segment almost three times as long as wide and three times as long as first segment; unornamented and armed with two apical smooth setae, which about 1.3 times as long as segment.

Labrum (Figure 56A) large, rigidly sclerotized, rhomboidal, strongly bulging but without any beak visible in lateral view.

Mandibula (Figure $57 \mathrm{C}$ ) with broad cutting edge of coxa, armed with two very strong teeth ventrally, one unipinnate seta dorsally and many pointed small teeth in between. Basis squarish plate, unornamented, about 2.3 times as long as wide, armed with three smooth setae along inner margin. Endopod one-segmented, also unornamented, about twice as long as wide, armed with one lateral and three apical smooth setae; all setae of about same length. Exopod very small but distinct segment, armed with one lateral and two apical smooth setae.

Maxillula with large praecoxa, arthrite highly mobile, armed apically with four unguiform smooth spines, laterally without ornamentation or armature. Coxa, basis and endopod completely fused; coxa-basis armed with four slender setae along inner margin; endopod armed with one lateral and three apical setae. Exopod onesegmented, very small, armed with two apical setae. All setae on maxillula smooth.

Maxilla (Figure 57D) composed of syncoxa, basis and four-segmented endopod. Syncoxa with three endites; most proximal and middle endites, rudimentary, armed with one short seta each; most distal endite large, highly mobile, about three times as long as wide, armed apically with two long and smooth setae. Basis as large as syncoxa, armed with two lateral and two subapical smooth setae. First and second endopodal segment armed with one strong, spiniform, unguiform and unipinnate seta each; third and forth segment armed with one smooth and slender seta each. No ornamentation visible on maxilla.

Maxilliped (Figure 57E) slender, not prehensile, three-segmented, composed of coxobasis and twosegmented endopod. Coxobasis unornamented and unarmed, about 1.5 times as long as wide. First endopodal segment largest one, unarmed but ornamented with longitudinal row of large spinules, 1.8 times as long as wide and 1.4 times as long as coxobasis. Second endopodal segment smaller than coxobasis, unornamented and armed with three pinnate setae; apical seta longest

All swimming legs with three-segmented exopod and two-segmented endopod (Figure 56E, F, G, H and $57 \mathrm{~A}$ ). Armature formula of swimming legs as follows (legend: inner/outer spine or seta; inner/ terminal/outer):

\begin{tabular}{|c|c|c|c|c|c|}
\hline \multirow[b]{2}{*}{ Segments } & \multicolumn{3}{|c|}{ Exopod } & \multicolumn{2}{|c|}{ Endopod } \\
\hline & 1 & 2 & 3 & 1 & 2 \\
\hline First leg & $0 / 1$ & $1 / 1$ & $1 / 2 / 2$ & $1 / 0$ & $1 / 2 / 1$ \\
\hline Second leg & $0 / 1$ & $1 / 1$ & $2 / 2 / 2$ & $1 / 0$ & $1 / 2 / 1$ \\
\hline Third leg & $0 / 1$ & $1 / 1$ & $2 / 2 / 2$ & $1 / 0$ & $1 / 2 / 1$ \\
\hline Fourth leg & $0 / 1$ & $1 / 1$ & $1 / 2 / 2$ & $1 / 0$ & $1 / 2 / 1$ \\
\hline
\end{tabular}

Intercoxal sclerites of all swimming legs smooth, narrow, shorter than coxa and with concave distal margin. Praecoxae and coxae of all legs unomamented and unarmed, protected laterally by tergites of prosomites. Basis of first swimming leg armed with one strong spine on inner distal corner and one spine on outer margin; ornamented with one row of large spinules near base of inner spine. Basis of other swimming legs without spine on outer margin, which ornamented with few spinules; its inner distal corner produced posteriorly as spiniform process. Endopod of first swimming leg slightly longer than exopod, while endopods of all other legs slightly shorter. Majority of endopodal and exopodal segments ornamented with row of spinules along outer margin. First endopodal segment of first leg about as long as second one, while first endopodal segment of other swimming legs somewhat shorter. Armature of exopods and endopods very stout, mostly pinnate.

Fifth legs (Figure 57B) completely fused to somite, with only short demarcation line; baseoendopod and exopod completely fused and reduced to simple semicircular lamellar plate; not protruding beyond posterior edge of somite, unornamented and armed with two smooth seate; outer seta 1.6 times as long as inner one.

Sixth legs (Figure 57B) completely fused into very small, broad and short but distinct cuticular plate covering gonopore. Sixth legs without armature or ornamentation.

Male (allotype). Body length, excluding caudal setae, $0.235 \mathrm{~mm}$. Habitus, ornamentation of prosomites, colour and nauplius eye similar to female. Hyaline fringe of all prosomites smooth; that of urosomites (except anal one) sharply serrated. Fifth pedigerous somite with two large ventrolateral cuticular pores.

Genital somite 2.5 as wide as long. Single, completely formed, longitudinally-placed spermatophore (Figure 57G) visible inside first two urosomites. Anal somite similar to female, although ventral posterior row of spinules missing.

Caudal rami (Figure 57G) about 1.3 times as long as wide; ventral lappets smaller and shorter than in female. Armature and ornamentation similar to female but inner apical seta longer and positioned more ventrally.

Antennula (Figure 57H) seven-segmented, strongly geniculate, with insertions of some setae hardly visible. Apical aesthetasc smaller than in female. 

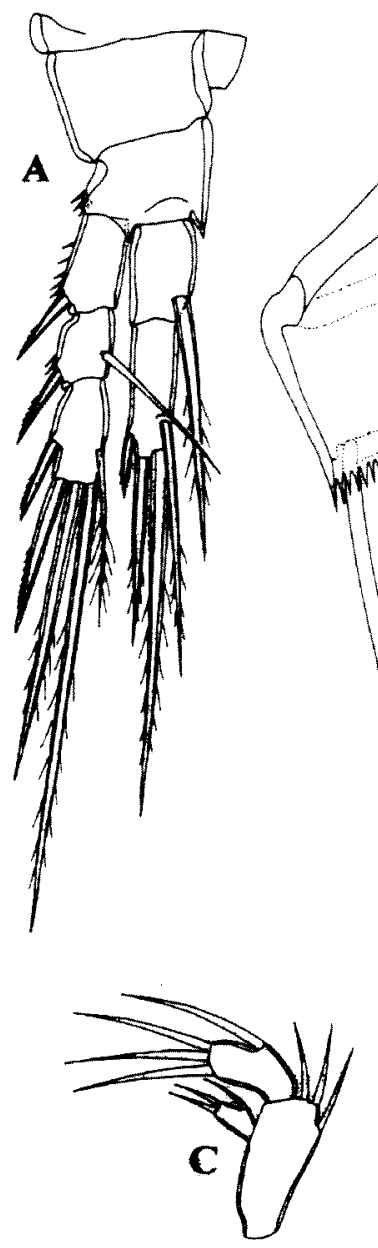

\section{B}
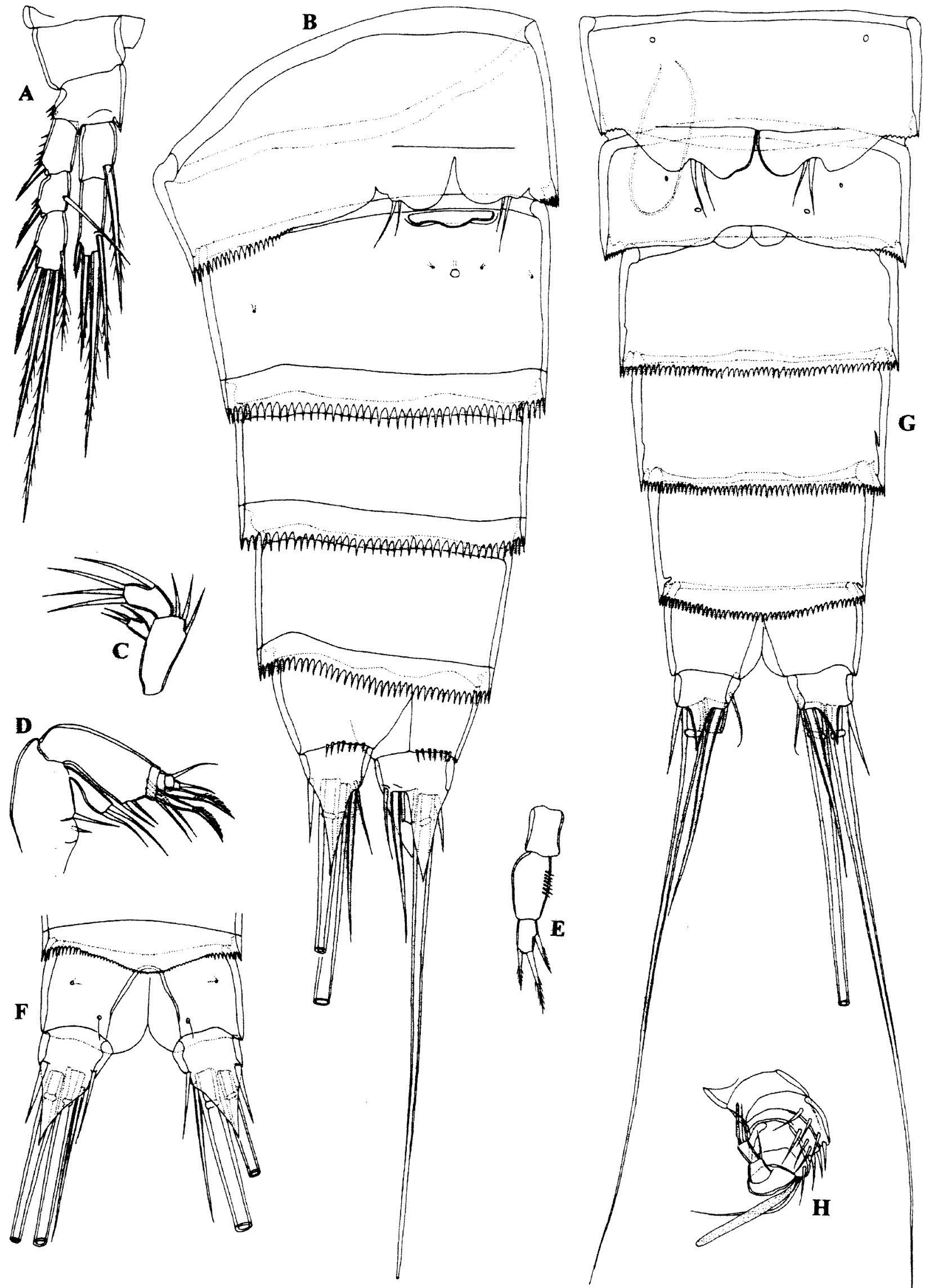

$\mathbf{G}$
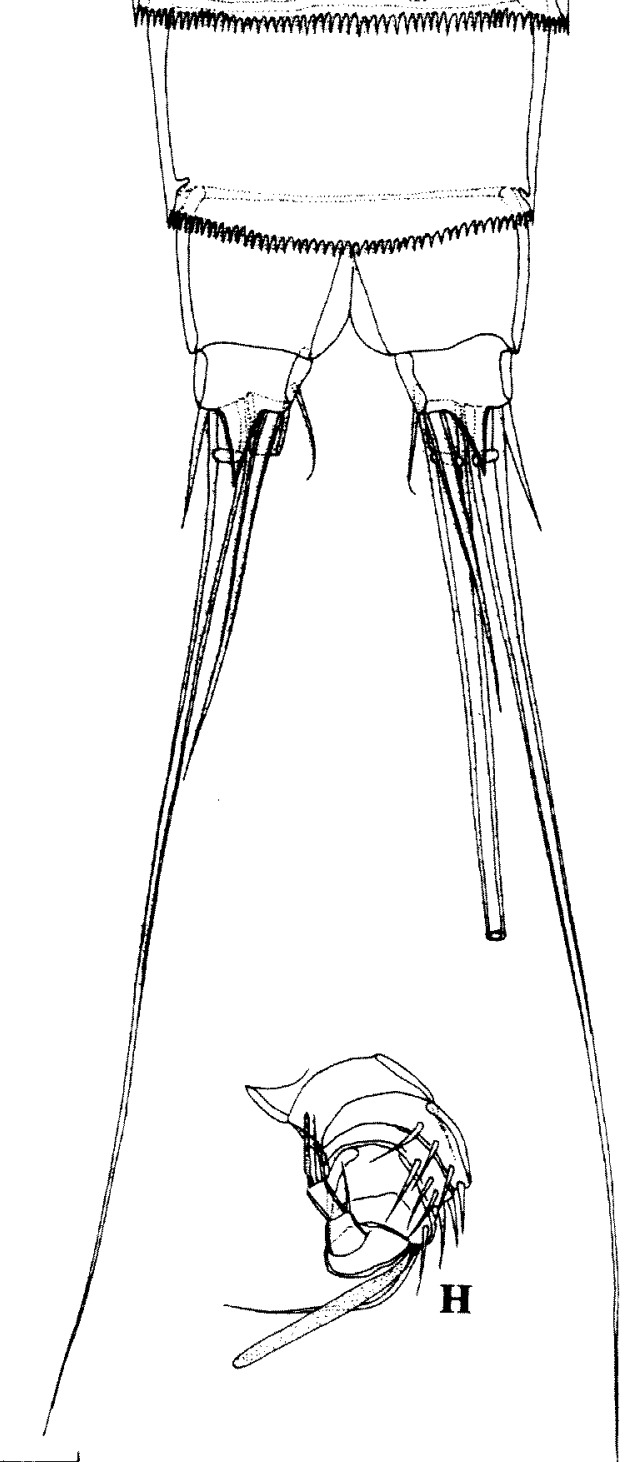

Figure 57 Pseudectinosoma galassiae sp. nov., A-F, holotype (female); $\mathrm{G}$ and $\mathrm{H}$, allotype (male): A, fourth swimming leg; B, urosome, ventrolateral view; $C$, mandibular palp; D, maxilla; E, maxilliped; $F$, anal somite and caudal rami, dorsal view; $\mathrm{G}$, urosome, ventral view; $\mathrm{H}$, antennula. Scale $=0.1 \mathrm{~mm}$. 
Antenna, labrum, mandibula, maxillula, maxilla, maxilliped and swimming legs similar to female.

Fifth legs (Figure $57 \mathrm{G}$ ) similar to female but less fused to each other, as well as to somite, and also more protruding posteriorly; two smooth setae inserted between two lobes with outer seta only 1.2 times as long as inner one.

Sixth legs (Figure 57G) minute but distinct semicircular plates, without any armature or ornamentation.

\section{Variability}

Body length of females ranges from $0.238 \mathrm{~mm}$ to $0.265 \mathrm{~mm}(0.248 \mathrm{~mm}$ average; $\mathrm{n}=4)$, while in males it ranges from $0.209 \mathrm{~mm}$ to $0.242 \mathrm{~mm}(0.228 \mathrm{~mm}$ average; $n=3$ ). No other type of variability was observed.

\section{Etymology}

This species is named in honour of Dr Diana M.P. Galassi from the University of L'Aquila (Italy), as recognition of her important work on the taxonomy and phylogeny of the genus Pseudectinosoma. The name is a noun in the genitive singular.

\section{Discussion}

The family Ectinosomatidae Sars, 1904 presently encompasses about 233 species and subspecies, classified into 20 valid genera (Karanovic and Pesce 2001). Only the genera Rangabradya Karanovic and Pesce, 2001 and Pseudectinosoma Kunz, 1935 are predominantly freshwater; all of the others are marine genera, some of which contain a few freshwater species (Galassi et al. 1999a, Karanovic and Pesce 2001). Lang (1965) noted two distinct lines of evolution within the family: one of which comprises genera with a rectangular cephalothorax and linear body shape, and the other with a cephalothorax gradually attenuated anteriorly and fusiform body shape.

At present, the genus Pseudectinosoma includes six species: $P$. galassiae sp. nov. from Western Australia; P. janineae Galassi, Dole-Olivier and De Laurentiis, 1999 from France (Galassi et al. 1999); $P$. kunzi Galassi, 1997 from Italy (Galassi 1997), P. minor Kunz, 1935 from Germany (Kunz 1935, Schäfer 1936, Kunz 1974); P. reductum Galassi and De Laurentiis, 1977 from Italy (Galassi and De Laurentiis 1997); and $P$. vandeli (Rouch, 1969) from France (Rouch 1969). The record of $P$. minor from salt marshes in New Jersey (United States) by Coull (1977) is doubtful, as is that by Heip et al. (1983) and Huys et al. (1996) from the North Sea (see Galassi et al. 1999a).

Several Australian species of harpacticoids and cyclopoids have been squeezed into one of the European genera, mostly as a temporary solution. However, that is not the case with Pseudectinosoma galassiae sp. nov. This species not only fits perfectly in the genus but also has exactly the same fifth leg as $P$. janineae and $P$. vandeli, although it can be distinguished from both by the different armature formula of the swimming legs. In fact, $P$. galassiae has a unique armature formula of the swimming legs in the genus (see Galassi et al. 1999a). It also differs from $P$. janineae by having only one lateral seta on the caudal rami (vs. two in $P$. janineae), fivesegmented antennula (vs. four-segmented), unarmed first exopodal segment of the antenna (single seta in $P$. janineae), and reduced armature of all mouth appendages. Although published descriptions and illustrations of $P$. vandeli are not complete (Rouch 1969), they are adequate enough to suggest a close relationship with $P$. galassiae. Both species have similar antennula, antenna and mouth appendages and the most similar armature formula of the swimming legs. However, $P$. vandeli is readily distinguishable from the new species by the much larger and more armed endopod of the mandibula, longer exopodal setae on the antenna, presence of two lateral setae on the caudal rami and presence of single inner seta on the third exopodal segment of the second and third swimming legs (vs. two in $P$. galassiae). One can discern several other differences between the two but with limited information on the extent of individual variation in $P$. vandeli, these differences should perhaps not be overly stressed. Other species of Pseudectinosoma have a different shape of the fifth leg, which is more reduced in $P$. kunzi and $P$. reductum and more complex in $P$. minor. Because the latter species can be found in brackish waters, the theory about the marine origin of Pseudectinosoma (see Kunz 1974, Galassi et al. 1999a, 1999b) is, in my opinion, well supported. The timing of the origin could well be as early as the Jurassic and certainly by the Middle Cretaceous (Galassi et al. 1999b). At that time the plate that is now Western Australia, formed the eastern shore of the Greater Tethys (Howarth 1980, Yager and Humphreys 1996).

\section{Family Diosaccidae Sars, 1906}

\section{Genus Schizopera Sars, 1905}

\section{Schizopera roberiverensis sp. nov. Figures 58-62}

\section{Material Examined}

\section{Holotype}

Female (WAM C34123), Australia, Pilbara, Robe River, bore G70730104, post-purge, 14 November 2002, leg. J. Cocking and M. Scanlon (CALM), $21^{\circ} 34^{\prime} 53^{\prime \prime} \mathrm{S} 115^{\circ} 52^{\prime} 14^{\prime \prime} \mathrm{E}$ : dissected on two slides

\section{Paratypes}

Australia, Pilbara, Robe River, bore G70730104, 
post-purge, 14 November 2002, leg. J. Cocking and M. Scanlon (CALM), 21 34'53"S 115 52'14"E: two females + one copepodid (one female (HA 225) dissected by Jane McRae (WAM C34124); others in alcohol (WAM C34125))

\section{Other material}

1) Australia, Pilbara, Paraburdoo Town Borefield, bore TPB2-1, 22 November 2002, leg. J. Cocking and

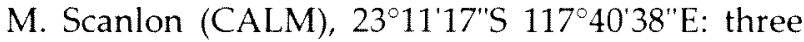
males + four females + six copepodids (one male and one female dissected on one slide each (WAM C34126 and C34127); others in alcohol (WAM C34128))

2) Australia, Pilbara, Robe River, bore G70730101, 4 April 2003, leg. J. Cocking and M. Scanlon (CALM), 21 34 32'S 115 52'58'E: one copepodid in alcohol (WAM C34129)

3) Australia, Pilbara, Robe River, bore G70730102, 4 April 2003, leg. J. Cocking and M. Scanlon (CALM), 21 ${ }^{\circ} 34^{\prime} 53^{\prime \prime S} 115^{\circ} 52^{\prime} 14^{\prime \prime} \mathrm{E}$ : three males + one female in alcohol (WAM C34130)

4) Australia, Pilbara, Robe River, Yarraloola Station, bore PANNASLK4, 5 April 2003, leg. J. Cocking and M. Scanlon (CALM), 21 $37^{\prime} 59^{\prime \prime S}$ $115^{\circ} 57^{\prime} 41^{\prime \prime} \mathrm{E}$ : two males + three females + two copepodids in alcohol (WAM C34131)

\section{Description}

Female (holotype). Total body length, measured from tip of rostrum to posterior margin of caudal rami (excluding caudal setae), $0.41 \mathrm{~mm}$. Colour of preserved specimen yellowish. Nauplius eye not visible. Habitus (Figure 58B, C) cylindrical, slender, without distinct demarcation between prosome and urosome; prosome/urosome ratio 1.05 ; greatest width at posterior end of cephalothorax. Body length/width ratio about 4.9 ; cephalothorax 1.28 times as wide as genital double somite. Free pedigerous somites without pronounced lateral expansions or dorsally. Integument relatively strongly chitinized. Whole body (except appendages) and caudal rami, beside other ornamentation, with dense cover of minute spinules (Figure 59A). Rostrum (Figure 58C) long, reaching $2 / 3$ of second antennular segment, linguiform, with blunt tip, about 1.8 times as long as wide and clearly demarcated at base; ornamented with two sensilla dorsolaterally.

Cephalothorax (without rostrum) about 1.4 times as long as wide; represents $28 \%$ of total body length. Surface of cephalic shield and tergites of first three free pedigerous somites with numerous large sensilla, (Figure 59C). Hyaline fringe of first and second free prosomites narrow and smooth; that of third free prosomite finely serrated dorsally, with smooth interruption medially. Fifth pedigerous somite (first urosomal) ornamented with four dorsal large sensilla and two lateral sensilla (one on each side), as well as with two cuticular pores ventrolaterally (one on each side); hyaline fringe sharply serrated.

Genital double somite (Figure 58A, C and 59A) about 0.9 times as long as wide (ventral view), without visible suture; ornamented with four sensilla dorsally: two at midlength, two near posterior margin; hyaline fringe sharply serrated both ventrally and dorsally. Female genital complex typical for genus: single copulatory pore partly covered by epicopulatory bulb (which serves also as copulatory duct), two small seminal receptacles placed inside large, paired, genital apertures; apertures with two ventral gonopores, each covered by reduced sixth leg (Figure 58A). Epicopulatory bulb large, elongated, about 2.1 times as long as wide. Seminal receptacles very small, ovoid, not reaching distal margin of sixth leg, about 0.6 times as long as epicopulatory bulb. Third urosomite ornamented with two dorsal and two lateral sensilla near posterior margin; hyaline fringe serrated. Preanal somite without any ornamentation (except for dense cover of small spinules - which cover whole body); hind margin clearly bulging posteriorly in dorsal region, forming very sharply serrated pseudoperculum (Figure 59D). Anal somite with convex and very short anal operculum (ornamented with transverse row of spinules along posterior margin); ornamented with two large sensilla dorsally, two lateral cuticular pores, two ventral pores and transverse row of large spinules along posterior margin (Figure 58A and 59A, D). Anal sinus widely opened and smooth; represents $60 \%$ of somite's width.

Caudal rami (Figure 58A and 59A, D) 1.8 times as long as greatest width, cylindrical, slightly divergent, with little space between them; ornamentated with two ventral cuticular pores and transverse row of spinules along posterior margin; armed with six armature elements (two lateral, one dorsal and three apical). Dorsal seta short, about 0.9 times as long as ramus, inserted at $3 / 4$ of ramus length, biarticulate at base and smooth. Lateral proximal spine arising at $3 / 5$ of ramus length, 0.54 times as long as ramus. Lateral distal seta very slender, smooth, arising slightly ventrolaterally at $4 / 5$ of ramus length, about 0.8 times as long as ramus. Inner apical seta smooth, 0.4 times as long as ramus. Principal apical setae with breaking planes; middle apical seta strongest, bipinnate at distal end, about 2.5 times as long as unipinntate outer apical seta and 0.6 times as long as body length.

Antennula (Figure 60G) eight-segmented, approximately 0.8 times as long as cephalothorax, with slender aesthetasc on eighth segment and large aesthetasc on fourth segment, which reaching slightly beyond tip of appendage; setal formula: 1.8.6.2.2.3.4.6. Only two lateral setae on eighth 


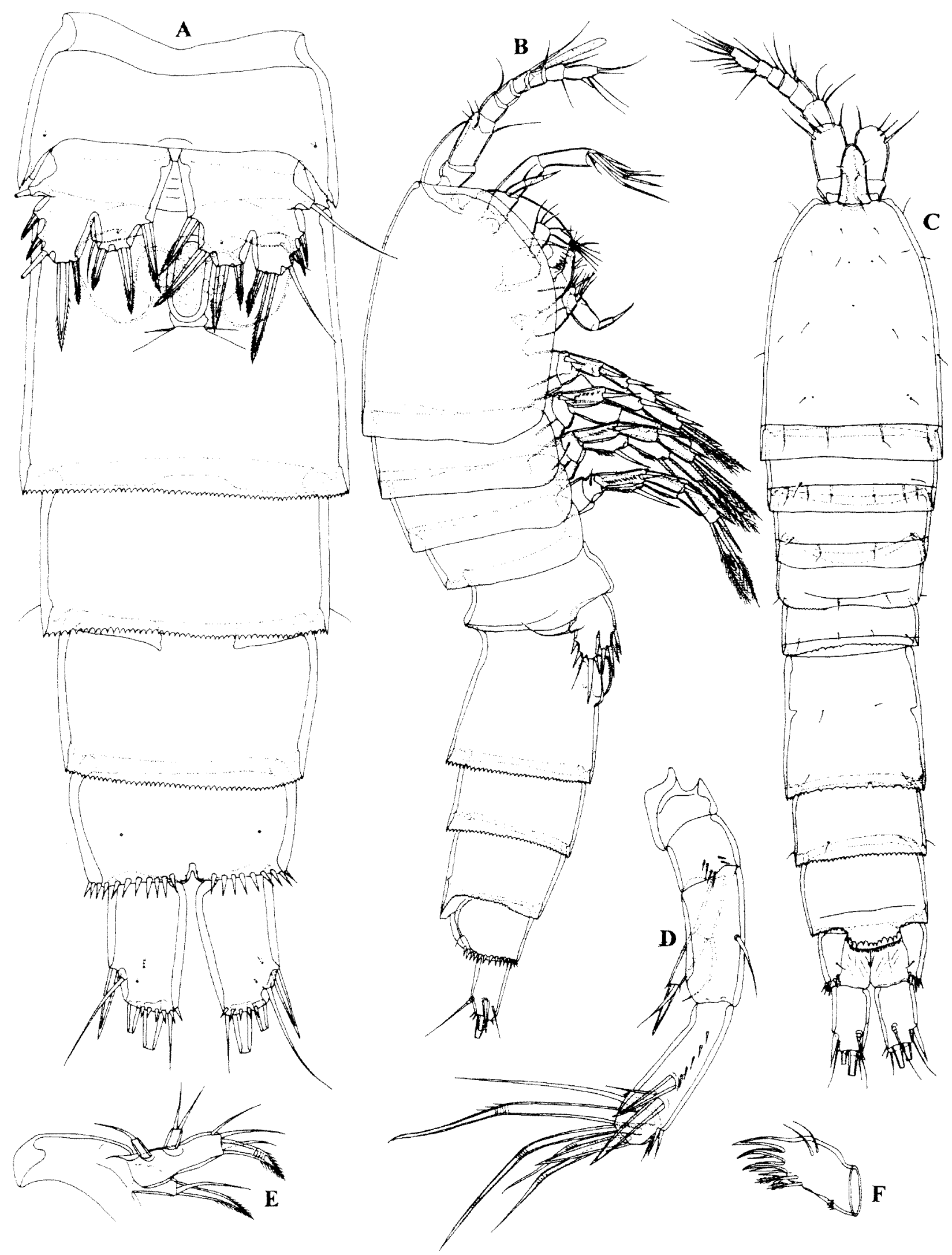

A

D, E, F

B, C

Figure 58 Schizopera roberiverensis sp. nov., holotype (female): A, urosome, ventral view; B, habitus, lateral view; C, habitus, dorsal view; D, antenna; E, maxillula, without arthrite of praecoxa; F, arthrite of maxillular praecoxa. Scales $=0.1 \mathrm{~mm}$. 


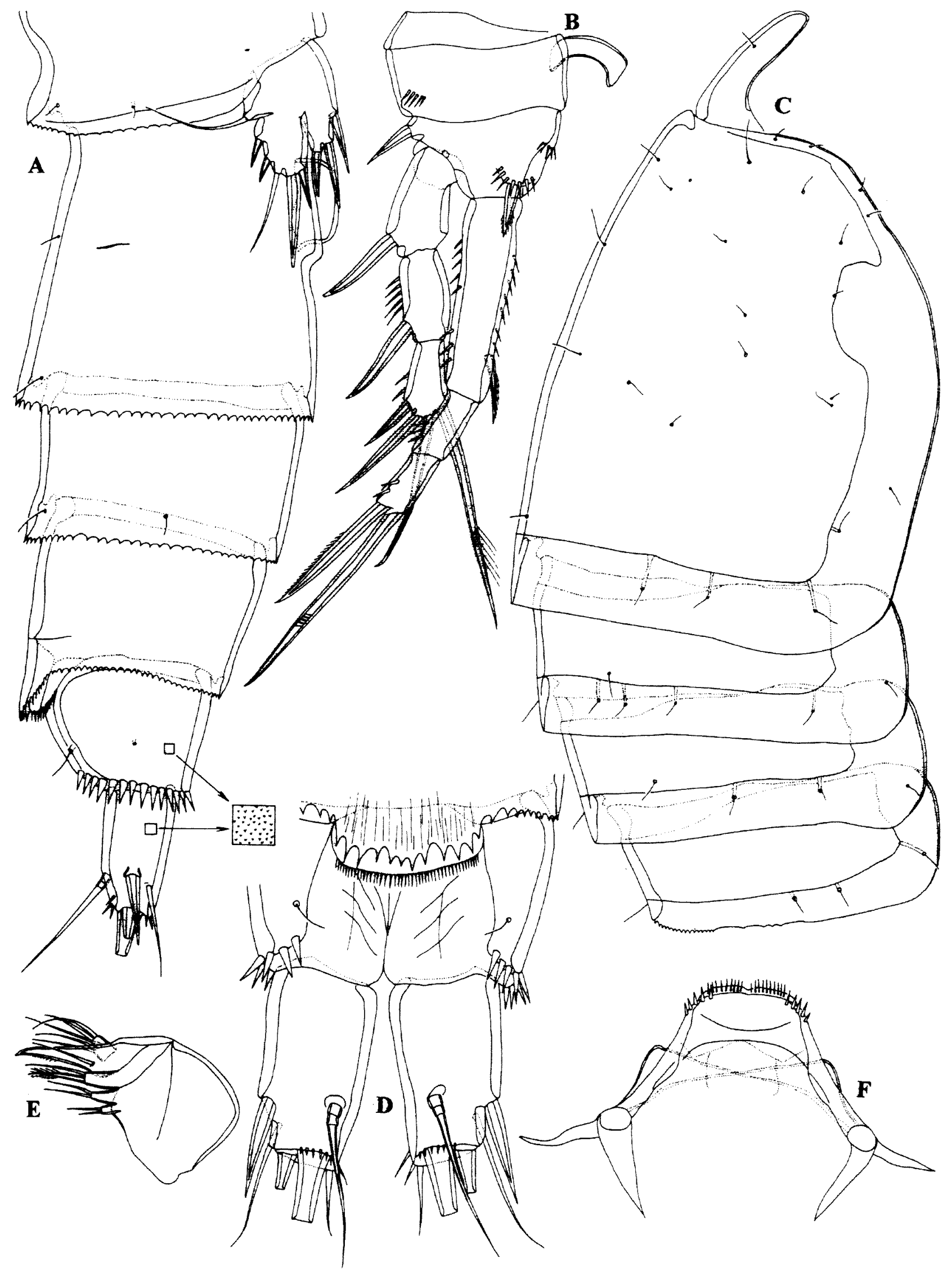

\section{A, C \\ B, D, E, F}

Figure 59 Schizopera roberiverensis sp. nov., holotype (female): A, urosome, lateral view; B, first swimming leg; C, prosome, lateral view; $\mathrm{D}$, anal somite and caudal rami, dorsal view; $\mathrm{E}$, maxilla; $\mathrm{F}$, labrum. Scales $=0.1 \mathrm{~mm}$. 
segment and one on seventh segment articulating on basal part. All setae smooth. Length ratio of antennular segments, from proximal end, $1: 1.3$ : $0.6: 0.8: 0.5: 0.6: 0.5: 1$.

Antenna (Figure 58D) comprising coxa, basis, two-segmented endopod and two-segmented exopod. Coxa very short, without any ornamentation. Basis also short, about as long as wide, ornamented with several spinules near inner margin. First endopodal segment 2.1 times as long as wide and 2.3 times as long as basis, without any ornamentation, armed with one smooth lateral seta at middle. Second endopodal segment longer and more slender than first, with one surface frill subdistally; lateral armature consists of two smooth spines flanking small seta; apical armature consisting of one slender smooth seta, one smooth spine and four geniculate setae, longest one bearing spinules around geniculation and fused basally to another slender seta. Ornamentation of second endopodal segment consists of longitudinal row of small spinules along anterior margin, diagonal row of large spinules between lateral and apical armature elements and diagonal row of small spinules along subdistal frill. Both exopodal segments of about same length; first segment armed with one smooth subapical seta, unornamented; second segment armed apically with one smooth seta and one smooth spine of about same length, ornamented with transverse subterminal row of spinules.

Labrum (Figure 59F) large, rigidly sclerotized, with rounded cutting edge, ornamented apically and subapically with many spinules; lateral spinules stronger than middle ones.

Mandibula (Figure 60H) with narrow cutting edge of coxa, armed with many blunt teeth and with one smooth seta. Basis squarish plate, about 1.9 times as long as wide, armed with three setae along inner margin (two smooth, one unipinnate). Endopod one-segmented, about 2.8 times as long as wide, armed with two lateral and five apical smooth setae. Exopod very small but distinct segment, armed with single smooth apical seta.

Maxillula (Figure 58E, F) with large praecoxa, arthrite highly mobile, armed apically with six strong smooth spines and two pinnate setae, laterally with two slender smooth setae and ornamented with short row of spinules on middle of arthrite (Figure 58F). Coxa small, armed with two setae on inner margin; proximal seta slender and smooth, distal seta very strong, spiniform and bipinnate. Basis furnished with one strong, curved, spine and three setae on inner margin. Endopod one-segmented, small, about 1.6 times as long as wide, armed with two apical smooth and equally long setae. Exopod also distinct and very small segment, armed with single smooth apical seta.

Maxilla (Figure 59E) composed of syncoxa, basis and two-segmented endopod. Syncoxa with three endites, each armed with two subequal setae. Basis armed with one apical, claw-like, spine (completely fused with basis) and one slender lateral seta. Each endopodal segment armed with two smooth and slender setae. No ornamentation visible on maxilla.

Maxilliped (Figure 60F) prehensile, threesegmented, composed of coxobasis and twosegmented endopod. Coxobasis ornamented with longitudinal row of large spinules, armed with three setae on inner margin (two bipinnate, one smooth). First endopodal segment about 2.6 times as long as wide, ornamented with longitudinal row of very large spinules on proximal part; armed with one lateral and one subapical smooth seta. Second endopodal segment armed with one claw-like apical spine and one slender and shorter subapical seta.

All swimming legs with three-segmented exopod and endopod (Figure 59B and 60A, B, C). Armature formula of swimming legs as follows (legend: inner/ outer spine or seta; inner/terminal/outer):

\begin{tabular}{|c|c|c|c|c|c|c|}
\hline \multirow[b]{2}{*}{ Segments } & \multicolumn{3}{|c|}{ Exopod } & \multicolumn{3}{|c|}{ Endopod } \\
\hline & 1 & 2 & 3 & 1 & 2 & 3 \\
\hline First leg & $0 / 1$ & $0 / 1$ & $1 / 1 / 2$ & $1 / 0$ & $0 / 0$ & $0 / 1$ \\
\hline Second leg & $0 / 1$ & $0 / 1$ & $0 / 2 / 2$ & $0 / 0$ & $1 / 0$ & \\
\hline Thi & $0 / 1$ & $0 / 1$ & $0 / 2 / 2$ & $1 / 0$ & $1 / 0$ & \\
\hline Fourth leg & $0 / 1$ & $0 / 1$ & $0 / 2 / 2$ & $1 / 0$ & $0 / 0$ & \\
\hline
\end{tabular}

Intercoxal sclerites of all swimming legs smooth; that of first leg small, with concave distal margin; those of other legs large, with distal margins protruded into two more or less sharp processes. Coxae of all legs, except third one, ornamented with short row of spinules near distal outer corner, unarmed. Basis of first swimming leg armed with one strong spine on inner distal corner and one spine on outer margin; ornamented with one row of large spinules at base of inner spine and with short row of shorter spinules on inner margin. Basis of second leg with spine on outer margin; that of third and fourth legs with slender seta. First endopodal segment of first swimming leg almost as long as entire exopod (Figure 59B), about 3.7 times as long as wide. Third endopodal segment of first leg with two geniculate armature elements, and third exopodal. Endopod and exopod of second, third and fourth swimming legs of about same length; inner distal margin of first and second segment with finely serrated surface frill. All exopods and endopods ornamented with spinules or hairs on both inner and outer margins.

Fifth leg (Figure 58A and 60D) biramous but exopod mostly fused to baseoendopod on inner side, on both frontal and caudal surfaces. Baseoendopod with outer basal smooth seta arising from relatively short setophore, without ornamentation at its base. Endopodal lobe trapezoidal, extending almost to posterior margin of exopod, ornamented with small cuticular pore 


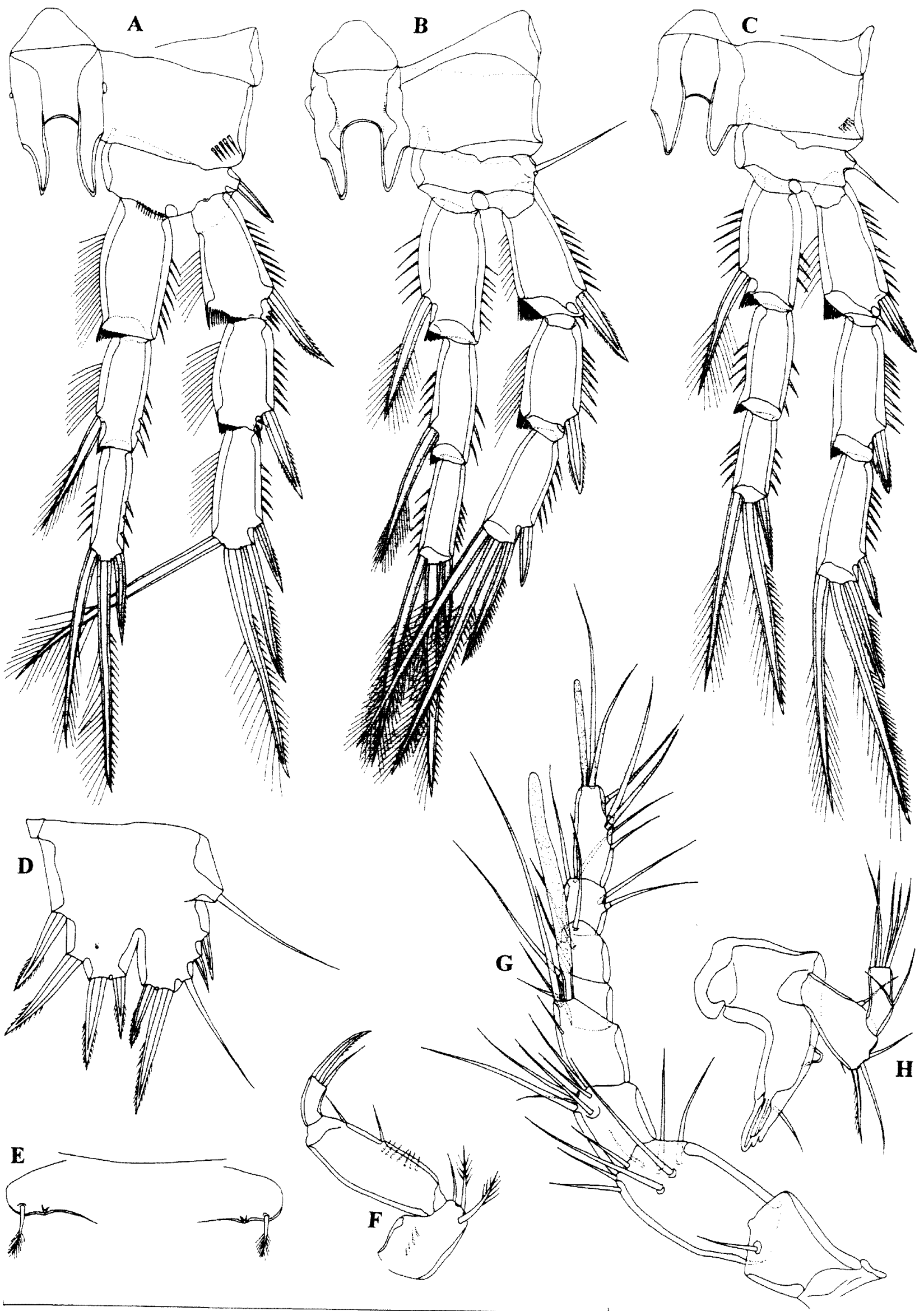

Figure 60 Schizopera roberiverensis sp. nov., holotype (female): A, second swimming leg; B, third swimming leg; C, fourth swimming leg; $D$, fifth leg; $E$, sixth legs; F, maxilliped; $G$, antennula; $H$, mandibula. Scale $=0.1 \mathrm{~mm}$. 


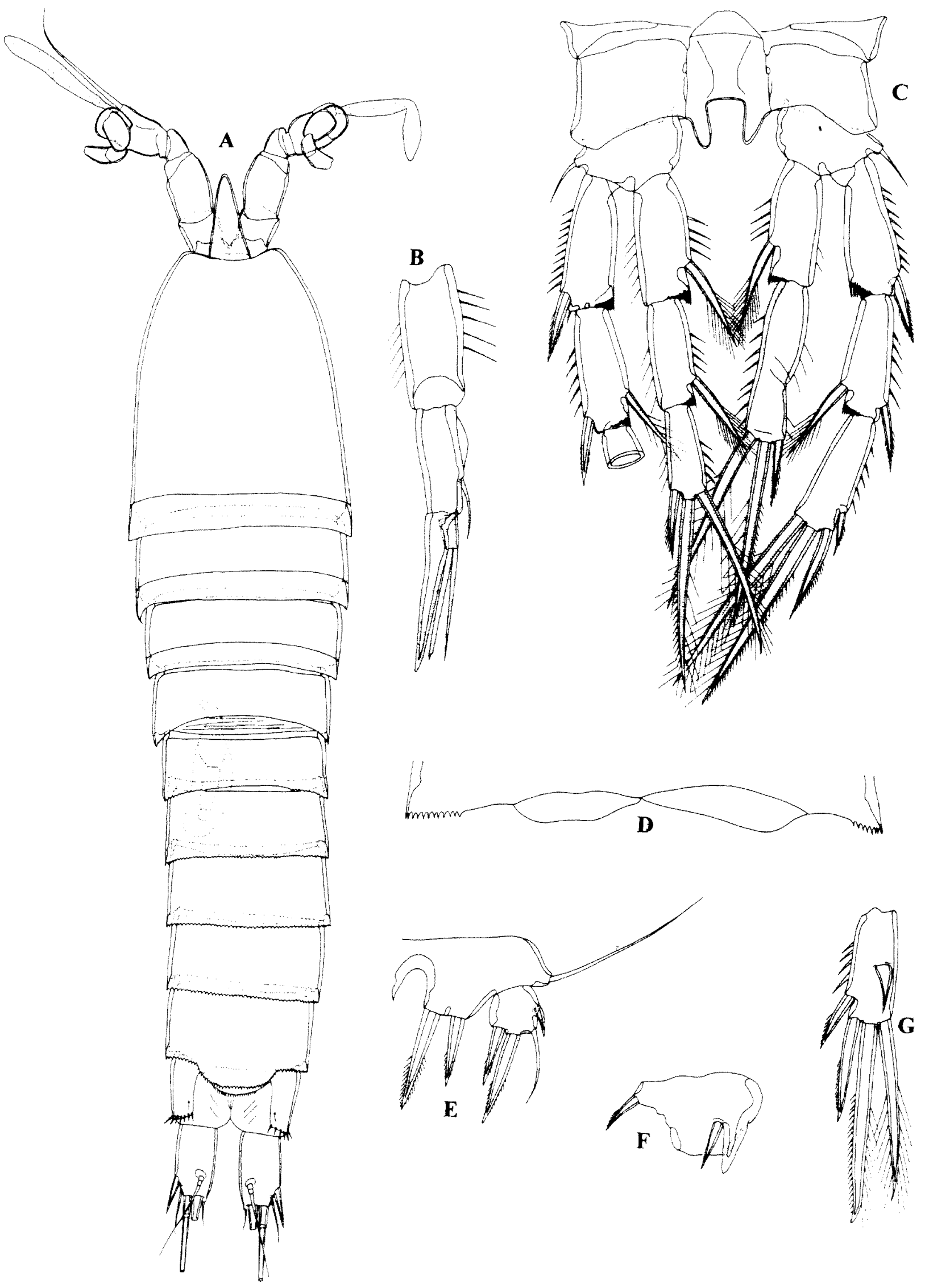

\section{B, C, D, E, F, G}

Figure 61 Schizopera roberiverensis sp. nov., A, male $(0.381 \mathrm{~mm}$ ) from locality 1 (WAM C34128); B-G, male (0.35 mm) from locality 1 (WAM 34126): A, habitus, dorsal view; B, endopod of second swimming leg; C, fourth swimming legs; D, sixth legs; E, fifth leg; F, basis of first swimming leg; $G$, third exopodal segment of third swimming leg. Scales $=0.1 \mathrm{~mm}$. 
and armed with three or four very stout, spiniform, elements. Exopod subquadrangular, about 1.3 times as long as maximum width, unornamented but armed with five armature elements; two innermost strong and bipinnate, middle one smooth and slender, two outermost short, stout and smooth; length ratio of exopodal armature elements, from inner side, $1: 1.9: 1.9: 0.6: 0.7$.

Sixth leg (Figure 60E) indistinct, very small cuticular plate, covering gonopore, armed with one very small spine and one plumose and slender setae.

Male. Habitus (Figure 61A) cylindrical, slender, similar to female; prosome/urosome ratio 1.18 and greatest width at posterior end of cephalothorax. Body length/width ratio about 4.6; cephalothorax 1.4 times as wide as genital somite. Ornamentation of prosomites, colour and nauplius eye similar to female. Hyaline fringe of all prosomites smooth and those of all urosomal somites (except anal one) sharply serrated. Rostrum (Figure 61A) long, reaching midlength of second antennular segment, linguiform, with almost sharp tip, about twice as long as wide and clearly demarcated at base; ornamented with two sensilla dorsolaterally.

Cephalothorax (without rostrum) about 1.3 times as long as wide; represents $27 \%$ of total body length, excluding caudal setae.

Genital somite twice as wide as long. Single, completely formed, longitudinally-placed spermatophore (Figure 61A) visible inside first two urosomites. Preanal and anal somites similar to female.

Caudal rami about 1.86 times as long as wide, cylindrical, parallel, with space between them slightly more than half of ramus' width. Armature and ornamentation similar to female, although dorsal seta relatively longer.

Antennula as long as cephalothorax, also basically eight-segmented (although distal part of third segment is distinct lobe bearing two apical setae) strongly geniculate, with geniculation visible between fifth and sixth segment. Aesthetascs as in female, on fourth and eighth segment; first one longer and stronger. First, second, seventh and eighth segments similar to female. Setal formula: 1.8.8.8.2.0.4.6. All setae smooth and just two setae on seventh segment and four setae on eighth segment articulating on basal part. Only one seta on fourth segment transformed into spiniform armature element, all other setae slender.

Antenna, labrum, mandibula, maxillula, maxilla, maxilliped, exopod and endopod of first swimming leg, exopod of second leg and endopod of third leg similar to female.

First swimming leg (Figure 61F) with modified basis, inner margin of which very rigidly sclerotized, with spiniform, smooth process distally.
Inner spine on basis singnificantly smaller than in female, without spinules at its base, as long as spiniform process.

Second swimming leg (Figure 61B) with transformed endopodal second and third segments. Second segment with part of inner margin protruded into rounded indistinct lobe, without ornamentation on its surface; inner seta shorter than in female, smooth and slender. Third segment completely modified; two ancestral apical setae transformed into smooth, spiniform armature elements of about same length; outer one stronger. Ancestral outer spine completely fused to somite, transformed into very strong and smooth thorn, which longer than ancestral apical elements. As result of these transformations, third segment medially cleft.

Third swimming leg (Figure 61G) with very characteristic spine on inner margin of third exopodal segment. This spine swollen at basal part, with very sharp tip, not reaching beyond distal margin of third segment. First and second exopodal segments of third leg similar to female.

Fifth legs (Figure 61E) with basally fused baseoendopods, without cuticular pores or any other ornamentation. Endopodal lobe trapezoidal, extending to middle of exopod length, armed with two very strong apical spines; inner spine about 1.5 times as long as outer one. Exopod about as long as its maximum width, armed with four armature elements; innermost short element missing, others similar to female; length ratio of exopodal armature elements, from inner side, $1: 1.6: 1.3: 0.5$.

Sixth legs (Figure 61D) distinct, pair of small and short, cuticular plates, without any armature or ornamentation; left plate wider and larger than right one.

\section{Variability}

Body length of females ranges from $0.338 \mathrm{~mm}$ to $0.469 \mathrm{~mm}(0.416 \mathrm{~mm}$ average; $\mathrm{n}=7)$, while in males it ranges from $0.331 \mathrm{~mm}$ to $0.392 \mathrm{~mm}(0.358$ $\mathrm{mm}$ average; $\mathrm{n}=5$ ). The holotype female has four armature elements on the baseoendopod of the left fifth leg (Figure 58A and 60D) and only three on the baseoendopod of the right fifth leg (Figure $58 \mathrm{~A}$ ). An aberrant female from locality 1 has many differences when compared with the holotype, including an aberrant exopod of the first swimming leg (Figure 62B), inner seta present on the second exopodal segment of the second swimming leg (Figure 62C), the same thing on the third leg, plus asymmetrical endopods (Figure 62D), an exopod of the fifth leg with only four armature elements (Figure 62F), and the pseudoperculum less serrated. One male from locality 1 has asymmetrical endopods of the fourth swimming leg, one of them being abnormal (Figure 61C). 


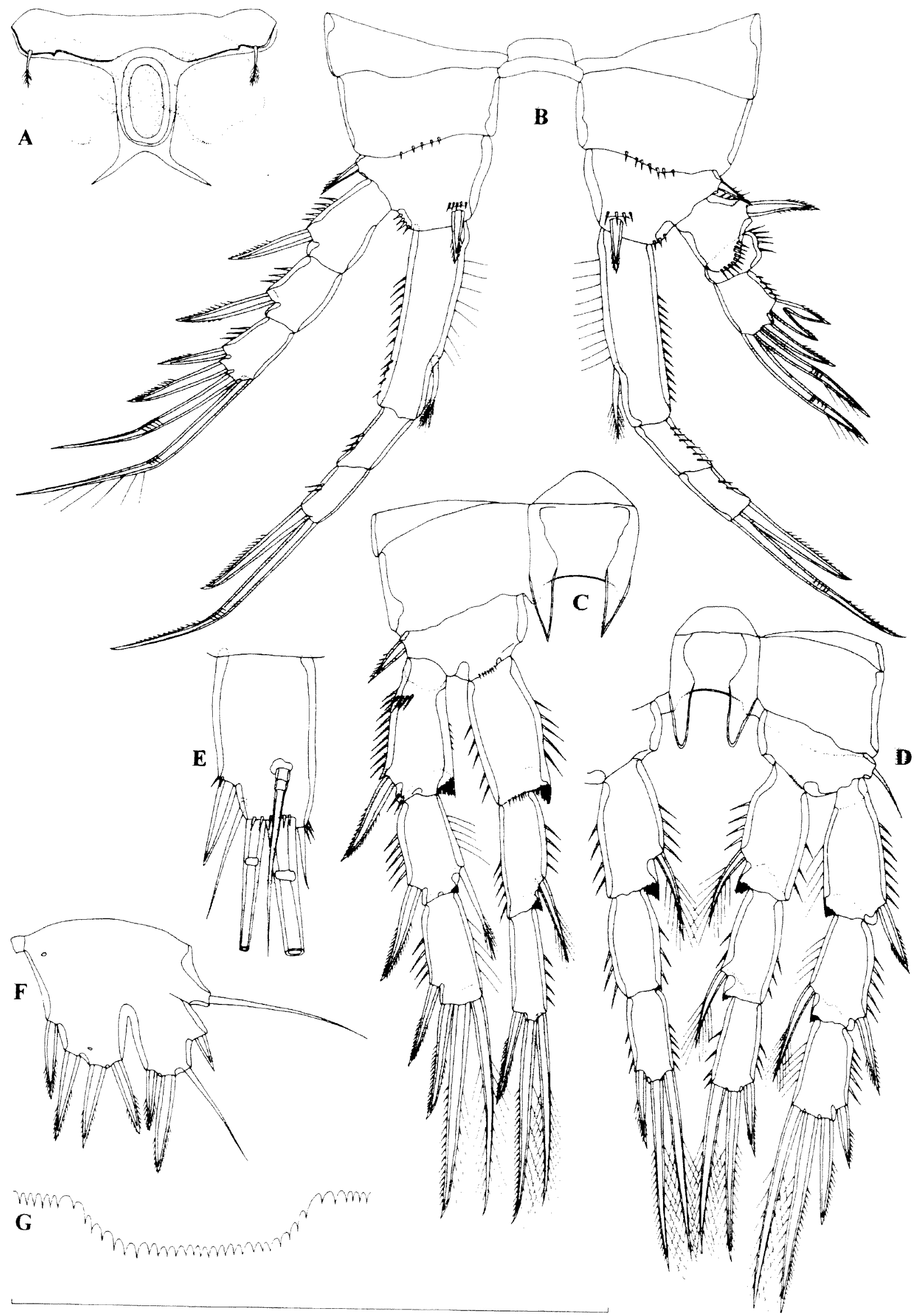

Figure 62 Schizopera roberiverensis sp. nov., aberant female $(0.465 \mathrm{~mm})$ from localilty 11 (WAM C34127): A, genital field; B, first swimming legs; C, second swimming leg; D, third swimming legs; E, left caudal ramus, dorsal view; F, fifth leg; $G$, pseudo-operculum. Scale $=0.1 \mathrm{~mm}$. 


\section{Etymology}

The new species is named after the type locality, Robe River.

\section{Discussion}

In my previous monograph (Karanovic 2004a) five new species of Schizopera Sars, 1905 were described from the Murchison region: $S$. austindownsi Karanovic, 2004, S. depotspringsi Karanovic, 2004, S. jundeei Karanovic, 2004, S. oldcuei Karanovic, 2004 and S. uramurdahi Karanovic, 2004. All of them are closely related species, which probably originated from an ancient common ancestor. The two new species from the Pilbara region are also members of the same flock, having a distinct basis of the antenna and very similar swimming legs. Another large but morphologically distinct, freshwater flock is known from Lake Tanganyika (Sars 1909, Gurney 1928, Lang 1948, Rouch and Chappuis 1960), although this flock will probably be separated into a new genus in the future (Karanovic 2004a). The genus Schizopera presently encompasses about 75 species and subspecies, mostly inhabiting marine littoral, estuaries, coastal lagoons and interstitial waters of beaches around the world.

Schizopera roberiverensis sp. nov. can be distinguished from all the other Australian species by the very elongated epicopulatory bulb and coarsely serrated large pseudoperculum (Figures $58 \mathrm{~A}$ and 59D). Other autapomorphies are all reductions and they include: innermost apical seta on the third endopodal segment of first leg absent; only three setae on the third endopodal segment of second and third leg; second exopodal and endopodal segments of the fourth leg without inner seta; and very short armature elements of the fifth leg. This species could be distinguished from the five Murchison representatives also by the absence of large spinules on the inner margin of the caudal rami and reduced armature of the mandibula and maxillula, which are synapomorphies with $S$. weelumurra sp. nov. The male of $S$. roberiverensis, unlike other Australian Schizopera species, lacks the inner seta on the third endopodal segment of the second leg (Figure 61B) (males of S. oldcuei and S. weelumurra are still unknown).

\section{Schizopera weelumurra sp. nov.} Figures 63 and 64

\section{Material Examined}

\section{Holotype}

Female (WAM C34132), Australia, Pilbara, Coolawanyah Station, Weelumurra Well, 29 July 1997, leg. W.F. Humphreys and S.M. Eberhard (BES: 4867), $22^{\circ} 05^{\prime} 52^{\prime \prime} \mathrm{S} 117^{\circ} 42^{\prime} 11^{\prime \prime} \mathrm{E}$ : dissected on two slides

\section{Description}

Female (holotype). Total body length, measured from tip of rostrum to posterior margin of caudal rami (excluding caudal setae), $0.396 \mathrm{~mm}$. Colour of preserved specimen light brown. Nauplius eye not visible. Habitus cylindrical, slender, without distinct demarcation between prosome and urosome; prosome/urosome ratio 1.1; greatest width at posterior end of cephalothorax. Body length/width ratio about 4.6 ; cephalothorax 1.25 times as wide as genital double somite. Free pedigerous somites without pronounced lateral expansions or dorsally. Integument relatively strongly chitinized. Whole body (except appendages) and caudal rami, beside other ornamentation, with a dense cover of minute spinules. Rostrum (Figure 63B) long, reaching $2 / 3$ of second antennular segment, linguiform, with blunt tip, about 1.9 times as long as wide and clearly demarcated at base; ornamented with two sensilla dorsolaterally.

Cephalothorax (without rostrum) about 1.3 times as long as wide; represents $29 \%$ of total body length. Surface of cephalic shield and tergites of three free pedigerous somites with numerous large sensilla, as well as. Hyaline fringe of first and second free prosomites narrow and smooth; that of third free prosomite finely serrated dorsally. Fifth pedigerous somite (first urosomal) ornamented with four dorsal large sensilla and two lateral sensilla (one on each side); hyaline fringe sharply serrated dorsally.

Genital double somite (Figure 63A) about 0.8 times as long as wide (ventral view), without visible suture; ornamented with two sensilla laterally and four sensilla dorsally: two at midlength, two near posterior margin; hyaline fringe sharply serrated both ventrally and dorsally. Female genital complex with single copulatory pore partly covered by epicopulatory bulb, two small seminal receptacles placed inside large, paired, genital apertures; apertures with two ventral gonopores, each covered by reduced sixth leg. Epicopulatory bulb large, ovoid, about 1.5 times as long as wide. Seminal receptacles very small, kidney-like, not reaching distal margin of sixth leg, about 0.5 times as long as epicopulatory bulb. Third urosomite ornamented with two dorsal and two lateral sensilla near posterior margin; hyaline fringe serrated. Preanal somite without any ornamentation (except for dense cover of small spinules over whole body); hind margin clearly bulging posteriorly in dorsal region, forming finely serrated pseudoperculum (Figure 64E). Anal somite with convex and very short anal operculum (ornamented with transverse row of minute spinules along posterior margin); ornamented with two large sensilla dorsally, two lateral cuticular pores, two ventral pores and transverse row of large spinules along posterior 


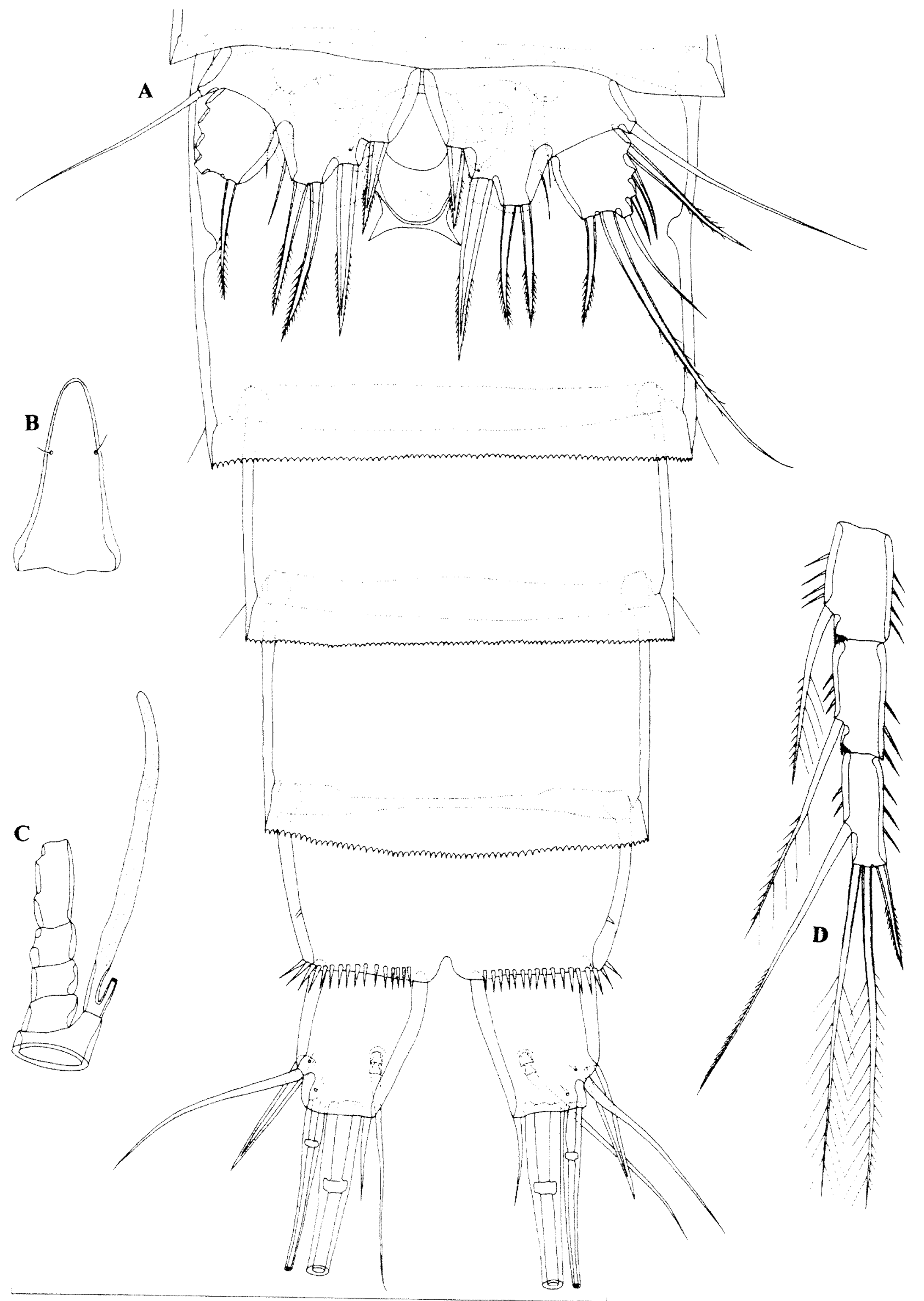

Figure 63 Schizopera weelumurra sp. nov., holotype (female): A, urosome, ventral view; B, rostrum, dorsal view; C, antennula, distal part without armature; $D$, endopod of third swimming leg. Scale $=0.1 \mathrm{~mm}$. 


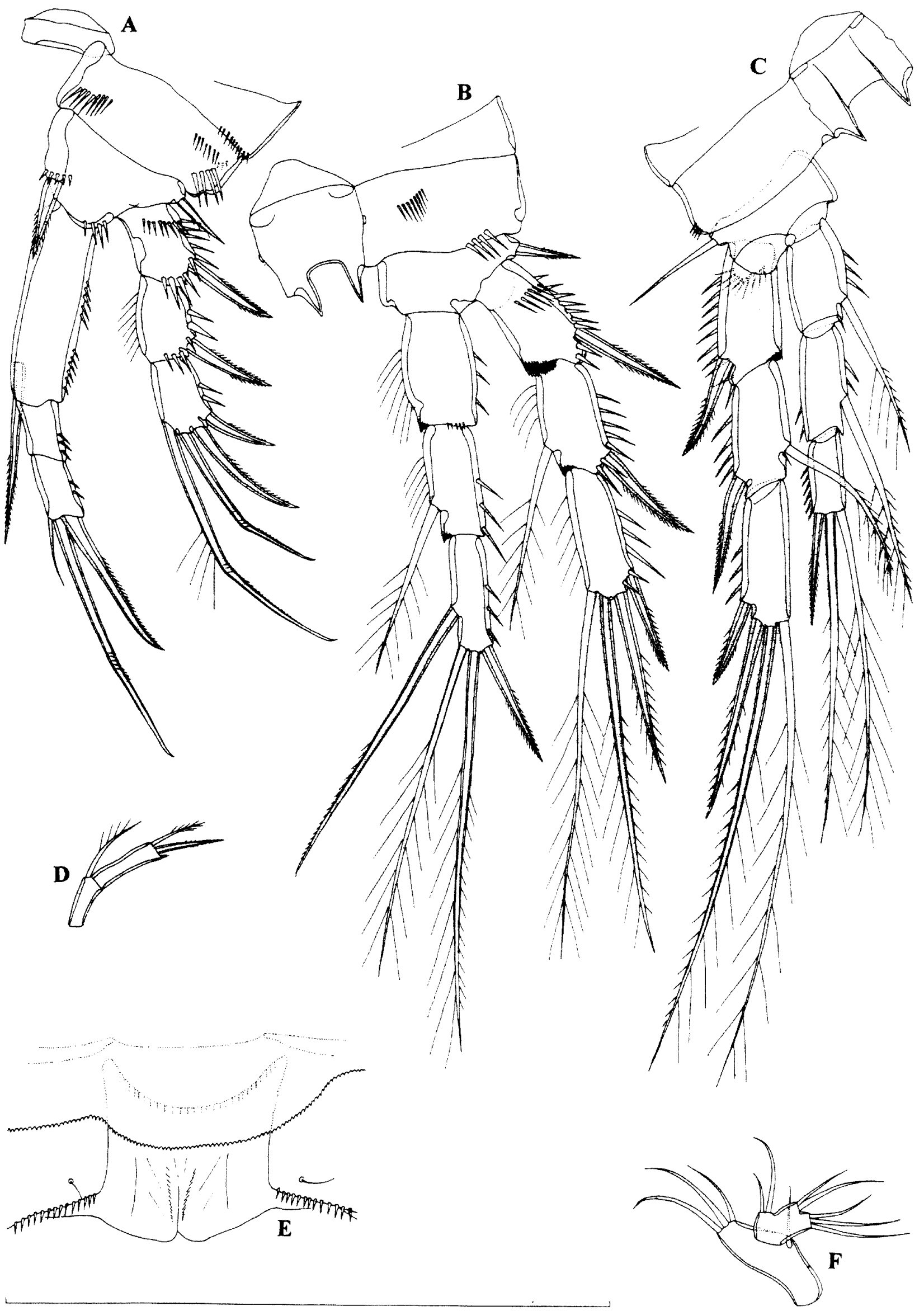

Figure 64 Schizopera weelumurra sp. nov., holotype (female): A, first swimming leg; B, second swimming leg; C, fourth swimming leg; D, exopod of antenna; $E$, anal sinus with pseudo-operculum, dorsal view; F, mandibular palp. Scale $=0.1 \mathrm{~mm}$. 
margin (Figure 63A and 64E). Anal sinus widely opened and ornamented with two longitudinal rows of minute spinules, represents $40 \%$ of somite's width.

Caudal rami (Figure 63A) 1.2 times as long as greatest width, short, cylindrical, slightly divergent, with space between them less than half of one ramus' width; ornamentated only with two ventral cuticular pores; no transverse row of spinules along posterior margin; armed with six armature elements (two lateral, one dorsal and three apical). Dorsal seta about 1.7 times as long as ramus, inserted at $3 / 5$ of ramus length, biarticulate at base and smooth. Lateral proximal spine also arising at $3 / 5$ of ramus length, as long as ramus. Lateral distal seta slender, smooth, arising slightly ventrolaterally at $3 / 4$ of ramus length, about 1.5 times as long as ramus. Inner apical seta smooth, 0.6 times as long as ramus. Principal apical setae with breaking plane; middle apical seta strongest, bipinnate at distal end, about 2.5 times as long as unipinnate outer apical seta and 0.7 times as long as body length.

Antennula (Figure 63C) eight-segmented, approximately 0.8 times as long as cephalothorax, with slender aesthetasc on eighth segment and much bigger aesthetasc on fourth segment, which reaching beyond tip of appendage for length of last three segments; setal formula: 1.8.6.2.2.3.4.6. Only two lateral setae on eighth segment and one on seventh segment articulating on basal part. All setae smooth. Length ratio of antennular segments, from proximal end, $1: 1.3: 0.6: 0.8: 0.6: 0.4: 0.5: 1$.

Antenna (Figure 64D) comprising coxa, basis, two-segmented endopod and two-segmented exopod. Coxa very short, without any ornamentation. Basis also short, about as long as wide, ornamented with several spinules near inner margin. First endopodal segment twice times as long as wide and 2.5 times as long as basis, without any ornamentation, armed with one smooth lateral seta at middle. Second endopodal segment longer and more slender than first endopodal, with one surface frill subdistally; lateral armature consists of two smooth spines flanking small seta; apical armature consisting of one slender smooth seta, one smooth spine and four geniculate setae, longest one bearing spinules around geniculation and fused basally to another slender seta. Ornamentation of second endopodal segment consists of longitudinal row of small spinules along anterior margin, diagonal row of large spinules between lateral and apical armature elements and diagonal row of small spinules along subdistal frill. First exopodal segment armed with one unipinnate subapical seta, unornamented; second segment about 1.3 times as long as first one, armed apically with one bipinnate, slender seta and one bipinnate spine of about same length, ornamented with transverse subterminal row of spinules.
Labrum large, rigidly sclerotized, with rounded cutting edge, mamented apically and subapically with many spinules; lateral spinules stronger than middle ones.

Mandibula (Figure 64F) with narrow cutting edge of coxa, armed vith many blunt teeth and with one smooth seta. Basis elongated plate, about 2.6 times as long as wide, armed with three smooth setae along inner margin. Endopod one-segmented, about 1.5 times as long as wide, armed with two lateral and five apical smooth setae. Exopod completely fused to basis, armed with single smooth apical seta.

Maxillula with large praecoxa, arthrite of which highly mobile, armed apically with six strong smooth spines and two pinnate setae, laterally with two slender smooth setae and ornamented with short row of spinules on middle of arthrite. Coxa small, armed with two setae on inner margin; proximal seta slender and smooth, distal seta very strong, spiniform and bipinnate. Basis furnished with one strong, curved, spine and three setae on inner margin. Endopod one-segmented, small, about 1.6 times as long as wide, armed with two apical smooth and equally long setae. Exopod also distinct and very small segment, armed with single smooth apical seta.

Maxilla composed of syncoxa, basis and twosegmented endopod. Syncoxa with three endites, each armed with two subequal setae. Basis armed with one apical, claw-like, spine (which completely fused with basis) and one slender lateral seta. Each endopodal segment armed with two smooth and slender setae. No ornamentation visible on maxilla.

Maxilliped prehensile, three-segmented, composed of coxobasis and two-segmented endopod. Coxobasis ornamented with longitudinal row of large spinules, armed with three setae on inner margin (two bipinnate, one smooth). First endopodal segment about 2.5 times as long as wide, ornamented with longitudinal row of very large spinules on proximal part; armed with one lateral and one subapical smooth seta. Second endopodal segment armed with one claw-like apical spine and one slender and shorter subapical seta.

All swimming legs with three-segmented exopod and endopod (Figure 63D and 64A, B, C). Armature formula of swimming legs as follows (legend: inner/ outer spine or seta; inner/terminal/outer):

\begin{tabular}{lcccccc} 
& \multicolumn{3}{c}{ Exopod } & \multicolumn{3}{c}{ Endopod } \\
Segments & 1 & 2 & 3 & 1 & 2 & 3 \\
First leg & $0 / 1$ & $0 / 1$ & $1 / 1 / 2$ & $1 / 0$ & $0 / 0$ & $1 / 1 / 1$ \\
Second leg & $0 / 1$ & $1 / 1$ & $0 / 2 / 2$ & $0 / 0$ & $1 / 0$ & $1 / 2 / 1$ \\
Third leg & $0 / 1$ & $1 / 1$ & $0 / 2 / 2$ & $1 / 0$ & $1 / 0$ & $1 / 2 / 1$ \\
Fourth leg & $0 / 1$ & $1 / 1$ & $0 / 2 / 2$ & $1 / 0$ & $1 / 0$ & $0 / 2 / 1$
\end{tabular}

Intercoxal sclerites of all swimming legs smooth; that of first leg small, with concave distal margin; that of other legs large, with distal margin protruded into two sharp processes. Coxae of all 
legs, ornamented with short row of spinules near distal outer corner, unarmed; coxa of second leg with additional row of spinules at middle; coxa of first leg with several additional rows of spinules. Basis of first swimming leg armed with one strong spine on inner distal corner and one spine on outer margin; ornamented with one row of large spinules at base of inner spine and with short row of longer spinules on posterior margin. Basis of second leg with spine on outer margin; those of third and fourth legs with slender seta; all unornamented. First endopodal segment of first swimming leg shorter than exopod (Figure 64), about 3.3 times as long as wide. Third endopodal and third exopodal segment of first leg with two geniculate armature elements. Endopod and exopod of second and third swimming legs of about same length, endopod of fourth leg somewhat shorter; inner distal margin of first and second segment with finely serrated surface frill. Majority of exopodal and endopodal segments ornamented with spinules or hairs on both inner and outer margins.

Fifth leg (Figure 63A) clearly biramous. Baseoendopod with outer basal smooth seta arising from relatively short setophore, without ornamentation at base. Endopodal lobe almost triangular, extending to $2 / 3$ of exopod in length, ornamented with small cuticular pore and armed with four stout, spiniform, elements; two inner elements more robust; length ratio of endopodal armature elements, from inner side, $1: 2.2: 1.5: 1.5$. Exopod subquadrangular, about as long as maximum width, unornamented and armed with six armature elements; two innermost strong and bipinnate, third one smooth and slender, fourth and fifth short, stout and smooth and outermost strong and bipinnate; length ratio of exopodal armature elements, from inner side, $1: 2.9: 1.2: 0.5: 0.6: 1.5$.

Sixth leg (Figure 63A) indistinct, very small cuticular plate, covering gonopore, armed with one very small spine and two smooth and slender setae; inner seta about 1.5 times as long as outer one.

Male. Unknown.

\section{Etymology}

The new species is named after the type locality, Weelumurra Well. The name is a noun in apposition.

\section{Discussion}

Schizopera weelumurra sp. nov. is readily distinguishable from its six Australian congeners by its very short caudal rami. It differs from $S$. roberiverensis sp. nov. additionally in a number of morphological characters, including the armature formula of the swimming legs, distinct exopod of the fifth leg which is armed with six elements, finely serrated pseudoperculum and a different shape of the epicopulatory bulb and seminal receptacle.
However, both species share a reduced ornamentation of the caudal rami and armature of mouth appendages. As it looks now, $S$. weelumurra occupies an intermediate position between the more primitive Murchison species (S. austindownsi, $S$. depotspringsi, S. jundeei, S. oldcuei, S. uramurdahi; see Karanovic 2004a) and S. roberiverensis, which shows the greatest number of reductions. Although these reductions are usually interpreted as stygomorphies, the colour of both new species from the Pilbara suggest a stygophilic, rather than stygobitic, ecology. As discussed in Karanovic (2004a), it seems that the presence of Schizopera species in the subterranean waters of Western Australia is a relatively recent event, i.e. a consequence of climatic changes in the Quaternary, because they are represented by closely related species and have a clear marine origin. They are probably more diverse in the Murchison region than in the Pilbara because the saline groundwaters of the former region are more similar to their ancestral habitat. Only further investigations of surface waters of both the Pilbara and Murchison regions will be able to answer which of the Schizopera species are stygobites and which stygophiles.

Besides seven Australian representatives, six other species of the genus Schizopera have a more or less distinct basis of the antenna, although they differ by a number of important morphological characters (Karanovic 2004a, p. 155). To further help distinguish the different Australian species, a key is provided below to aid in their identification, based mostly on females. The record of $S$. clandestina (Klie, 1924) by Halse et al. (2002a) needs to be verified, as this species was listed without any drawings, descriptions or comments. Therefore, this species is not included into the key.

1. Caudal rami without large spinules along inner margin .

- Caudal rami with large spinules along inner margin and dorsally

2. Third endopodal segment of first, second and third leg without inner seta

S. roberiverensis sp. nov.

- Same segment with inner seta

S. weelumurra sp. nov.

3. Exopod of fifth leg with five armature elements

Exopon

- Same segment with six elements ....................... 5

4. Caudal rami more than four times as long as wide. S. jundeei Karanovic, 2004

- Caudal rami less than twice as long as wide .... S. depotspringsi Karanovic, 2004

5. Outermost apical seta on caudal rami much longer than ramus 
Same seta about as long as ramus

S. oldcuei Karanovic, 2004

6. Caudal rami more than twice as long as wide S. uramurdahi Karanovic, 2004

Caudal rami less than 1.5 times as long as wide S. austindownsi Karanovic, 2004

\section{Family Tetragonicipitidae Lang, 1944}

\section{Genus Phyllopodopsyllus T. Scott, 1906}

\section{Phyllopodopsyllus wellsi Karanovic, Pesce and Humphreys, 2001 \\ Figure 65}

\section{Synonymy}

Phyllopodopsyllus wellsi sp. nov. - Karanovic et al., 2001: 334, Figures 1-19.

\section{Material Examined}

Australia, Pilbara, Barrow Island, bore MW18, 11 August 2002, leg. G. Humphreys (BIOTA) $20^{\circ} 46^{\prime} 47^{\prime \prime S} 115^{\circ} 28^{\circ} 06^{\prime \prime} \mathrm{E}$ : one female (HA 215) dissected on one slide by Jane McRae (WAM C34133)

\section{Supplementary description}

Maxillula (Figure $65 \mathrm{~F}$ ) with large praecoxa, arthrite of which not mobile, armed apically with five strong spines (one smooth; others unipinnate along concave margin), laterally with two slender smooth setae on anterior surface and dorsally with four setae (longest one pinnate distally); unornamented. Coxa small, armed with three smooth setae on inner margin; one seta very strong and spiniform, other two slender. Basis twice as long as coxa and slightly longer than arthrite of praecoxa, furnished with four strong setae apically (on inner margin) and with three slender smooth setae laterally. Endopod one-segmented, small, about 2.3 times as long as wide, armed with three apical and one lateral smooth and equally long setae. Exopod also one-segmented and small, 1.6 times as long as wide, armed with three smooth apical setae

Maxilla (Figure 65J) composed of syncoxa, basis and two-segmented endopod. Syncoxa ovoid, unornamented, with four endites; most proximal endite with two bipinnate setae, one fused basally to endite; second endite armed with single bipinnate seta; third endite largest, armed with three setae (one unipinnate); most distal endite with two setae, one smooth, one with two long pinnules. Basis also unornamented but armed with one apical, claw-like, spine (completely fused with basis) and one smooth lateral seta. Each endopodal segment armed with two smooth setae; outer apical seta on second segment geniculate.

\section{Variability}

A single female from Barrow Island differs from the type material by a much longer principal apical seta on the caudal rami (Figure 65B) and by only one apical seta on the third exopodal segment of the fourth leg (Figure 65C). The second endopodal segment of the third swimming leg with three (Figure 65B) or two setae was already reported as a variability in the Cape Range population (Karanovic et al., 2001). Other important morphological characters are the same as in the type material, including the armature of the endopods of the second (Figure $65 \mathrm{~A}$ ) and fourth (Figure 65D) swimming legs, fifth leg (65G), antenna (Figure 65H) and antennula (Figure 65I).

\section{Discussion}

This species was described from two bores in Cape Range by Karanovic et al. (2001), so the record from Barrow Island extends its known distribution northwards. Unfortunately, only one female was collected and studied here, so nothing could be said with certainty about the status of the Barrow Island population. The differences between this specimen and the Cape Range population (as outlined in the Variability section) are reflection of either an aberrant specimen or geographical variability between the two populations. The former possibility seems more probable to me. As the maxillula and maxilla were not properly presented in the original description, they are redescribed here.

\section{Phyllopodopsyllus thiebaudi Petkovski, 1955}

Figures 66-68

\section{Synonymy}

Phyllopodopsyllus thiebaudi n. sp. - Petkovski, 1955b: 130, Figures 14-20.

Phyllopodopsyllus thiebaudi Petkovski - Petkovski 1957: 9; Vervoort, 1964: 286; Lang, 1965: 387; Coull, 1969: 29; Apostolov, 1972: 236, Figures 193-199; Apostolov, 1973b: 99b; Coull, 1973: 17; Kunz, 1984: 39; Apostolov and Marinov, 1988: 259, Figures 103/1a-e, 142/3; Bodin, 1997: 146.

Phyllopodopsyllus thiebaudi thiebaudi Petkovski Karanovic et al., 2001: 342.

Phyllopodopsyllus cf. thiebaudi Petkovski - Wells and McKenzie, 1973: 137, Figure 2e-h.

Paraphyllopodopsyllus intermedius n. sp. - Noodt 1955: 97, Figures 49-66. 


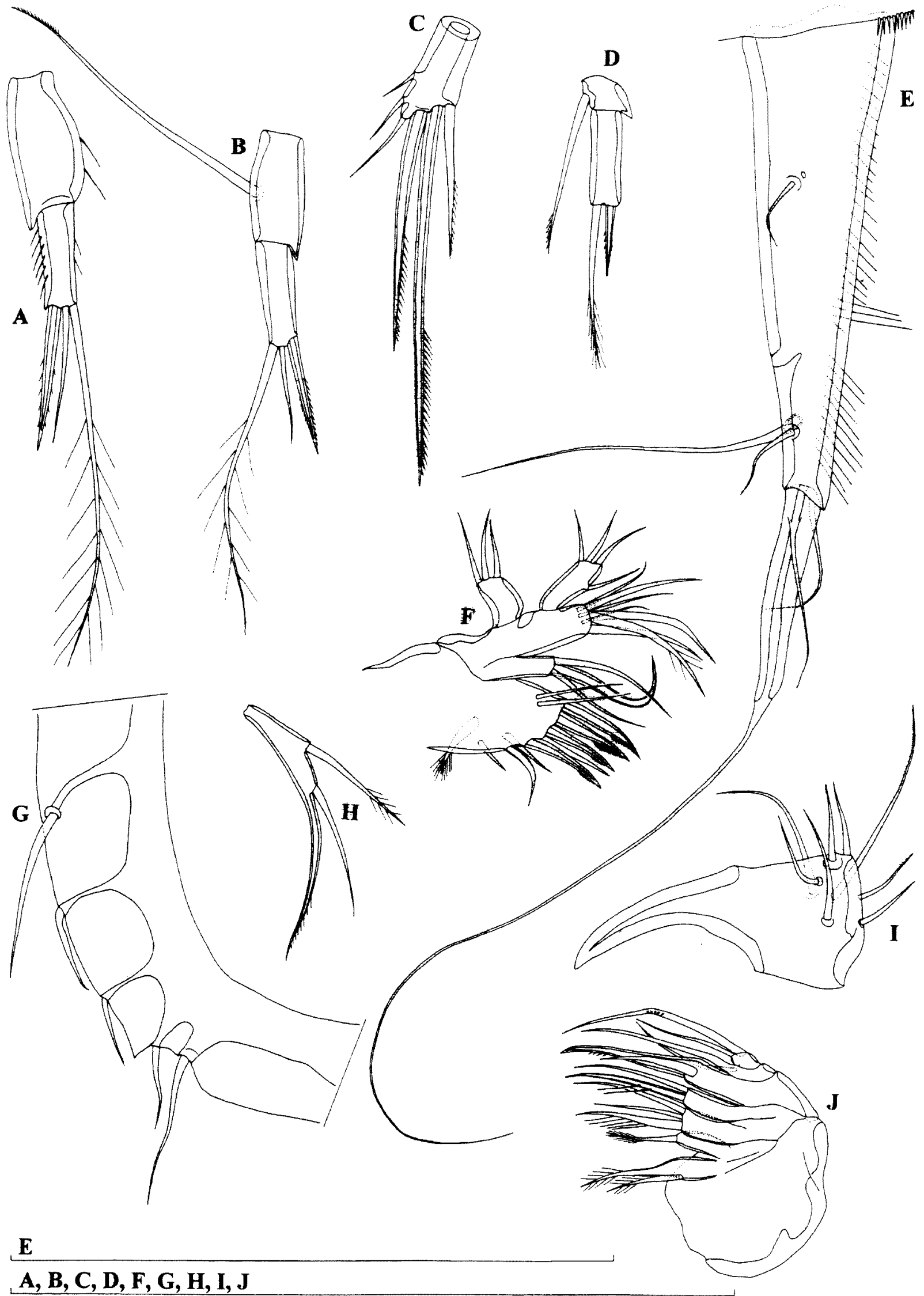

Figure 65 Phyllopodopsyllus wellsi Karanovic, Pesce and Humphreys 2001, female from Barrow Island (WAM C34133): A, endopod of second swimming leg; B, endopod of third swimming leg; $C$, third exopodal segment of fourth swimming leg; $D$, endopod of fourth swimming leg; $E$, right caudal ramus, ventrolateral view; F, maxillula; $\mathrm{G}$, distal outer corner of fifth leg; $\mathrm{H}$, exopod of antenna; $\mathrm{I}$, second segment of antennula; J, maxilla. Scales $=0.1 \mathrm{~mm}$. 
Phyllopodopsyllus intermedius Noodt - Lang, 1965: 387; Fiers, 1986: 110

Phyllopodopsyllus pirgos n. sp. - Apostolov, 1969: 117, Figures 8-15.

Phyllopodopsyllus pirgos Apostolov - Apostolov, 1972: 235.

[non] Phyllopodopsyllus thiebaudi santacruzensis nov. subspec. - Mielke, 1989: 135, Figures 25-30.

\section{Material Examined}

1) Australia, Pilbara, Barrow Island, bore MW17, 10 August 2002, leg. G. Humphreys (BIOTA) 20 46'S 115 28' $\mathrm{E}$ : one female (HA 214) dissected by Jane McRae on one slide (WAM C34134) + one copepodid (HA 216) dissected by Jane McRae on one slide (WAM C34135)

2) Australia, Pilbara, Barrow Island, bore AMW20, 10 August 2002, leg. G. Humphreys (BIOTA): one female (HA 213) dissected on one slide by Jane McRae (WAM C34136)

\section{Supplementary description}

Female. Rostrum (Figure 67C) ornamented only with pair of dorsal sensilla, linguiform, about 1.4 times as long as greatest width and clearly demarcated at base. Surface of cephalic shield (Figure 67B) with many sensilla and cuticular pores, as well as tergites of three free pedigerous somites; hyaline fringes narrow and finely serrated dorsally, smooth laterally

Genital double somite (Figure 66C) with arched suture on ventral surface, marked by rigid internal sclerotized ridge. Single copulatory pore relatively wide, situated at $2 / 3$ of double somite's length, at interruption of internal ridge. Copulatory duct narrow and short, rigidly sclerotized. Seminal receptacles very small, ovoid. Paired genital apertures with two ventral gonopores, each covered by reduced sixth leg. Small, tongue-like spermatophore attached to genital pore.

Hyaline fringes of fifth pedigerous and genitaldouble somites serrated dorsally and laterally, smooth ventrally; those of third and fourth urosomites serrated both ventrally and dorsally. Anal somite with convex and very short anal operculum (which omamented with transverse row of minute spinules along posterior margin and represents $42 \%$ of somite's width); ornamented with two large sensilla dorsally and transverse row of large spinules along posterior margin (Figure 66 A) Anal sinus widely opened and ornamented with two diagonal rows of fine spinules on each side laterally.

Caudal rami (Figure 66 A) about 1.5 times as long as greatest width, with characteristically swollen, complex proximal part and cylindrical and simple distal part, with small space between them; ornamentated with two ventral cuticular pores, one dorsal and one lateral row of spinules at middle and transverse row of spinules along posterior margin ventrally; armed with six armature elements (two lateral, one dorsal and three apical). Dorsal seta short, about 0.5 times as long as ramus, inserted close to posterior margin, biarticulate at base and smooth. Lateral proximal seta slender and smooth, arising at middle of ramus length, 0.4 times as long as ramus, with short setula close to its base. Lateral distal seta slender, smooth, arising close to posterior margin, about 0.3 times as long as ramus. Inner apical seta slender and smooth, moved ventrally, 0.54 times as long as ramus. Principal apical setae without breaking planes, fused to each other basally; middle apical seta strongest; outer apical seta slender and smooth, about as long as ramus.

Antennula (Figure 67C) nine-segmented, approximately 0.8 times as long as cephalothorax, with slender aesthetasc on ninth segment and much bigger aesthetasc on fourth segment, which reaching beyond tip of appendage for length of last segment; setal formula: 1.9.6.4.2.4.2.2.7. Only four lateral setae on eighth segment and one on seventh segment articulating on basal part. All setae smooth. Length ratio of antennular segments, from proximal end and along posterior surface, $1: 0.3: 0.3: 0.3$ : $0.2: 0.2: 0.15: 0.1: 0.5$. Second segment without unguiform process, with smooth and straight posterior margin.

Antenna (Figure 68D) comprising coxa, basis, two-segmented endopod and one-segmented exopod. Coxa very short, without any ornamentation. Basis well developed, about 2.4 times as long as wide, ornamented with several spinules on distal inner corner and unarmed. First endopodal segment 2.8 times as long as wide and slightly longer than basis, without any ornamentation or armature. Second endopodal segment longer and more slender than first, ornamented with two surface frills (one at middle, other subdistally) and longitudinal row of spinules along anterior margin; lateral armature consists of two smooth spines flanking slender smooth seta; apical armature consisting of two slender smooth setae, one smooth spine and four geniculate setae, longest one fused basally to another slender seta. Exopod slender. unornamented and armed with three pinnate elements, of which apical one strongest and basally fused to segment.

Mandibula (Figure 67D) with broad cutting edge of coxa, armed with three complex ventral teeth, one unipinnate, slender, dorsal seta and seven simple sharp teeth in between. Basis squarish plate, about 2.3 times as long as wide, armed with three pinnate setae along inner margin and ornamented with several rows of very long spinules. Endopod 


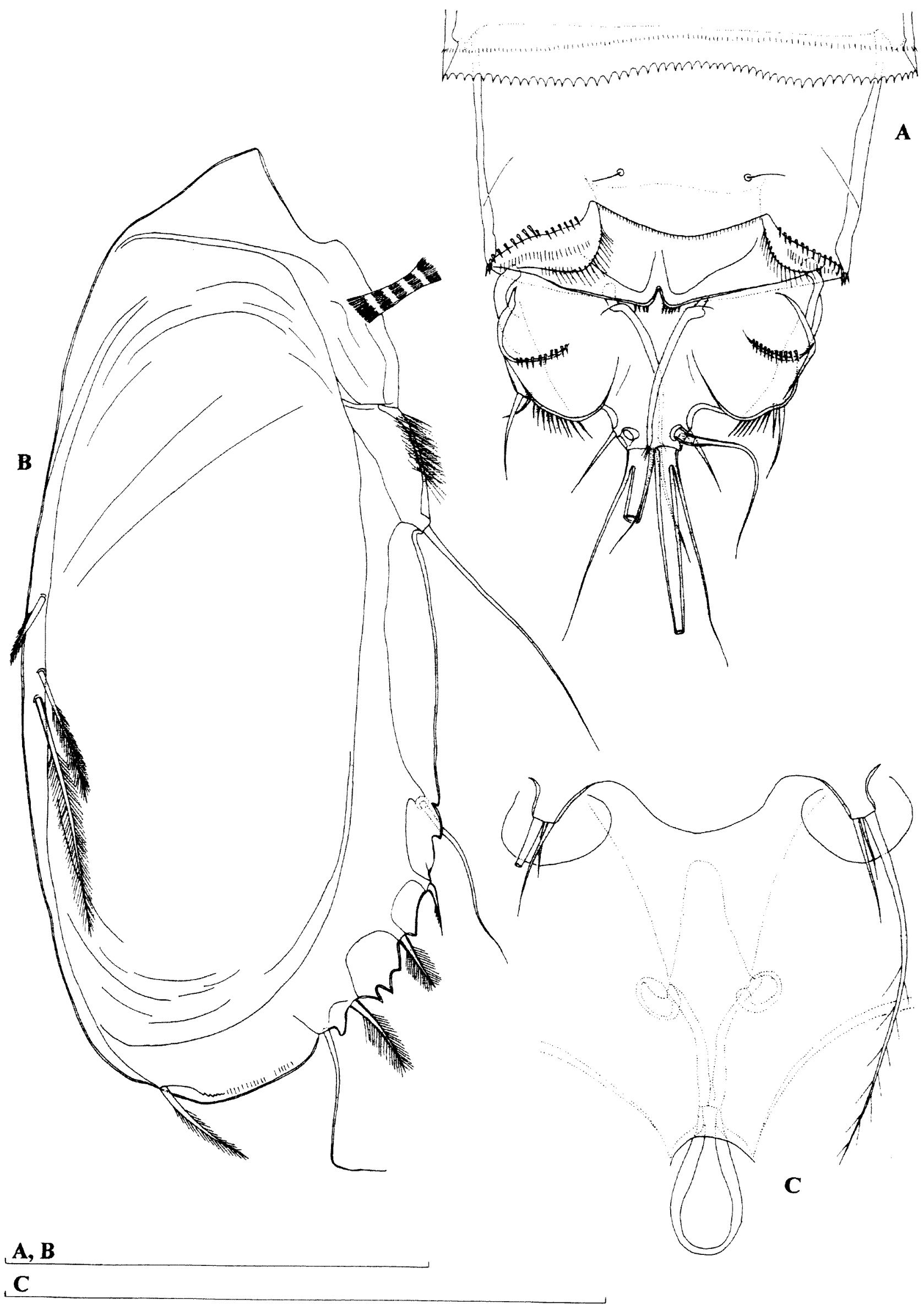

Figure 66 Phyllopodopsyllus thiebaudi Petkovski 1955, female from locality 1 (WAM C34134): A, anal somite and caudal rami, dorsal view; $B$, right fifth leg, internal (posterior) view; $C$, genital field. Scales $=0.1 \mathrm{~mm}$. 


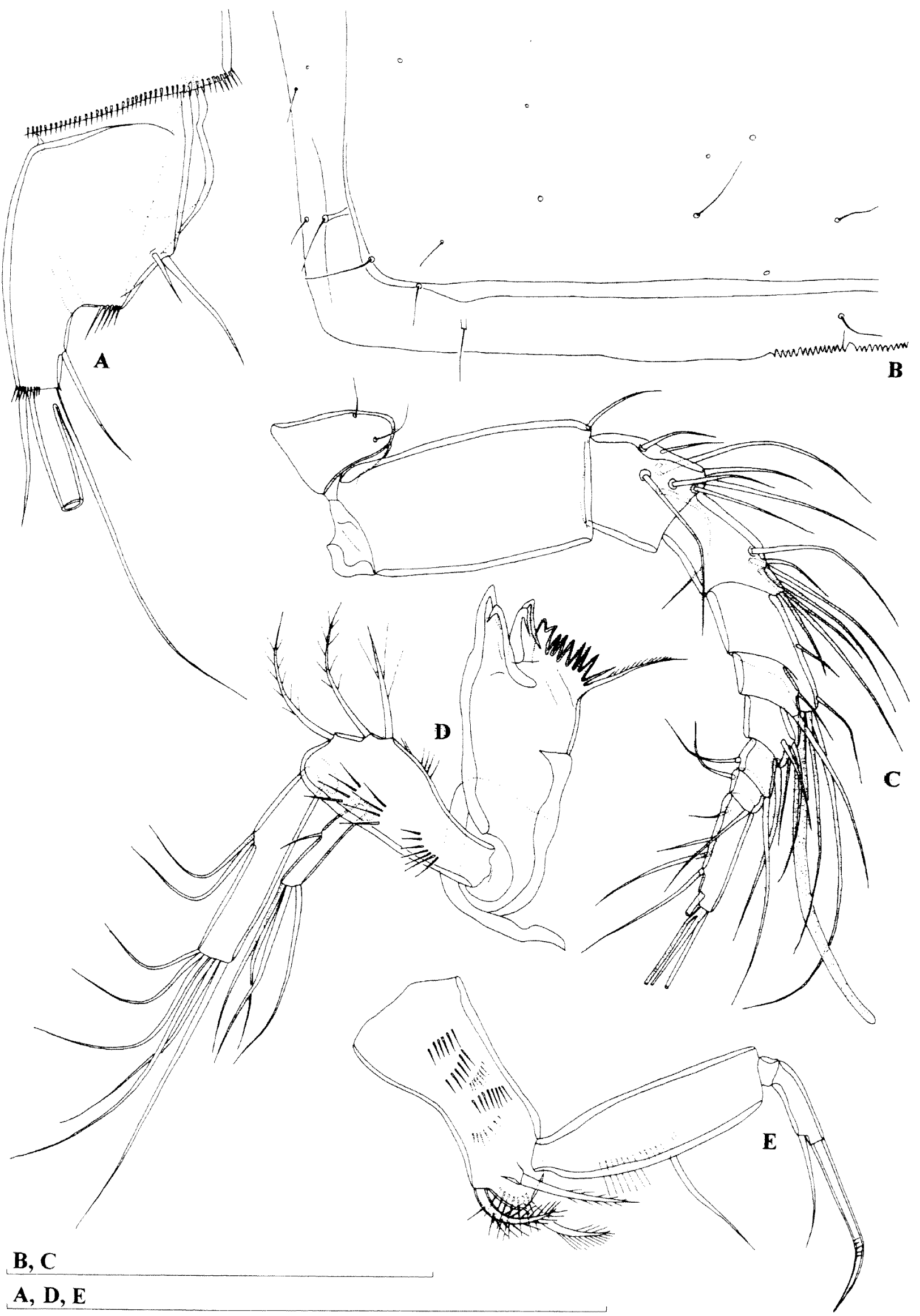

Figure 67 Phyllopodopsyllus thiebaudi Petkovski 1955, A, female from locality 2 (WAM C34136); B-E, female from locality 1 (WAM C34134): A, left caudal ramus, ventral view; B, cephalic shield, left posterior corner; C, rostrum and antennula; $\mathrm{D}$, mandibula; $\mathrm{E}$, maxilliped. Scales $=0.1 \mathrm{~mm}$. 


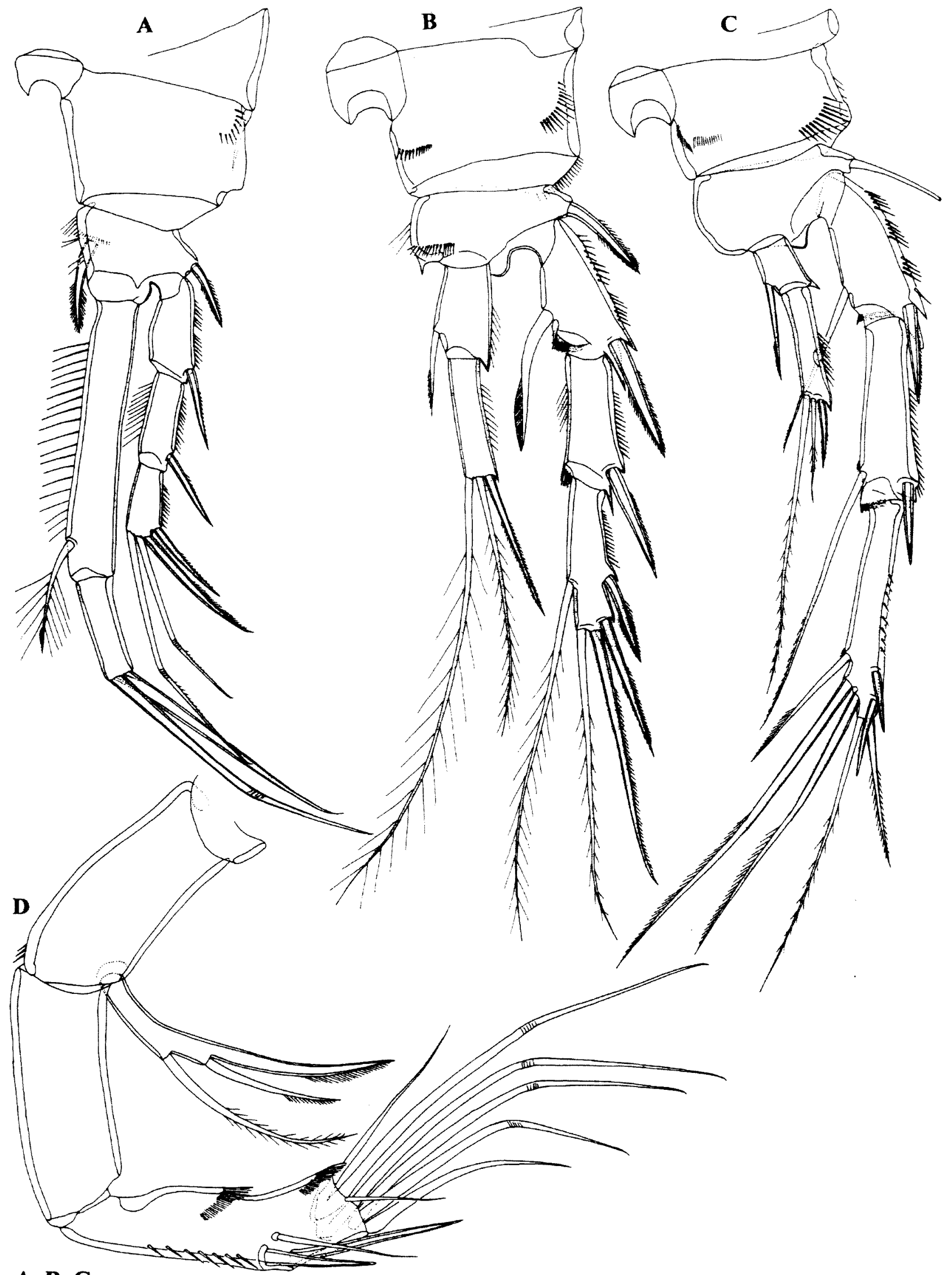

\section{$\mathrm{A}, \mathrm{B}, \mathrm{C}$}

D

Figure 68 Phyllopodopsyllus thiebaudi Petkovski 1955, female from locality 1 (WAM C34134): A, first swimming leg; $B$, second swimming leg; $C$, fourth swimming leg; $D$, antenna. Scales $=0.1 \mathrm{~mm}$. 
one-segmented, as long as basis and about 5.2 times as long as wide, armed with two lateral and six apical smooth setae. Exopod approximately half as long as endopod, about 5.6 times as long as wide, armed with one lateral and four apical smooth setae.

Maxilliped (Figure 67E) prehensile, threesegmented, composed of coxobasis and twosegmented endopod. Coxobasis ornamented with several transverse rows of large spinules, armed with three pinnate setae on inner margin. First endopodal segment about 3.3 times as long as wide, ornamented with longitudinal row of long spinules on proximal part; armed with one lateral smooth seta. Second endopodal segment armed with one claw-like apical spine and one slender and shorter subapical seta

All swimming legs with three-segmented exopod and two-segmented endopod (Figure 68A, B, C). Armature formula of swimming legs as follows (legend: inner/outer spine or seta; inner/terminal/ outer)

\begin{tabular}{|c|c|c|c|c|c|}
\hline \multirow[b]{2}{*}{ Segments } & \multicolumn{3}{|c|}{ Exopod } & \multicolumn{2}{|c|}{ Endopod } \\
\hline & 1 & 2 & 3 & 1 & 2 \\
\hline First leg & $0 / 1$ & $0 / 1$ & $0 / 2 / 2$ & $1 / 0$ & $0 / 2 / 0$ \\
\hline Second leg & $1 / 1$ & $0 / 1$ & $1 / 2 / 2$ & $1 / 0$ & $0 / 3 / 0$ \\
\hline Third leg & $1 / 1$ & $0 / 1$ & $1 / 2 / 2$ & $1 / 0$ & $0 / 3 / 0$ \\
\hline Fourth leg & $1 / 1$ & $1 / 1$ & $3 / 2 / 2$ & $1 / 0$ & $0 / 3 / 0$ \\
\hline
\end{tabular}

Intercoxal sclerites of all swimming legs smooth and concave distal margin. Coxae of all legs ornamented with one or more short rows of spinules and unarmed. Basis of first swimming leg armed with one strong spine on inner margin and one spine on outer margin; ornamented with one row of large spinules at base of inner spine. Basis of second leg with spine on outer margin; those of third and fourth legs with slender seta. First endopodal segment of first swimming leg slightly longer than entire exopod (Figure 68A), about 5.7 times as long as wide. Third endopodal and third exopodal segment of first leg with two geniculate armature elements, Endopods and exopods of second and third swimming legs of about same length as first two exopodal segments, that of fourth leg reaching midlength of second exopodal segment; inner distal margin of first and second exopodal segments with finely serrated surface frill. All exopodal and most endopodal segments ornamented with row of spinules along outer margin; some segments with spinules also along inner margin.

Fifth leg (Figure 66B) typically foliaceous, with completely fused baseoendopod and exopod but with chitinous suture marking original separation; ornamented with short field of hair-like spinules between base and epipodal slender seta. Former baseoendopod armed with three slender and plumose setae, most distal longest. Former exopod armed with six setae; most proximal and fifth seta smooth and slender, others pinnate or plumose; second seta from proximal end characteristically curved posteriorly.

Sixth leg (Figure 66C) indistinct, very small cuticular plate, covering gonopore, armed with three slender setae; outermost seta bipinnate, about 5.7 times as long as middle smooth seta and 3.4 times as long as innermost smooth seta.

\section{Discussion}

Phyllopodopsyllus thiebaudi was described from interstitial habitats of the Adriatic Sea by Petkovski (1955b) in January. Later the same year, Noodt (1955) described $P$. intermedius from interstitial habitats of the French side of the Bay of Biscay, naturally unaware of the Petkovski's publication. The latter species was synonymized with the former by Lang (1965) and this has been accepted by all modern taxonomists (see, for example, Coull 1973, Kunz 1984, Bodin 1997, Karanovic et al. 2001) except Fiers (1986). Phyllopodopsyllus thiebaudi was consequently recorded from numerous localities in the Mediterranean Sea, Atlantic and Indian Ocean (see Synonymy). Mielke (1989) described a new subspecies from the Pacific Ocean, $P$. thiebaudi santacruzensis, from interstitial habitats of the Galapagos Islands. As the main difference between his subspecies and the nominotypical one, Mielke (1989) emphasised the different armature of the male fifth leg exopod (with four elements in P.t. santacruzensis, vs. five elements in $P$. t. thiebaudi). As I have a few specimens from the Adriatic Sea in my private collection (from near the type locality; unpublished data), I compared them with the material from Barrow Island. The only difference between the two is the slightly narrower posterior part of the caudal rami in the Barrow Island population. All the other morphological details are the same in both populations, including the general shape and armature of the caudal rami (Figure 66A), ornamentation of the cephalothorax (Figure 67B), shape of the genital field (Figure 66C), antennula (Figure 67C), antenna (Figure 68D), mandibula (Figure 67D), first swimming leg (Figure 68A), second leg (Figure 68B), fourth leg (Figure 68C) and fifth leg (Figure 66B). As some of these characters have never been described in great detail for the nominotypical subspecies (as opposed to a very detailed description of $P$. $t$. santacruzensis) I give here a supplementary description, based on the Australian population. The shape of the first swimming leg (Figure 68A) should be added to the list of differences between $P$. t. thiebaudi and P. t. santacruzensis, which has a much more robust endopod in the latter subspecies (see Mielke 1989). 
Family Ameiridae Monard, 1927

\section{Genus Parapseudoleptomesochra Lang, 1965}

\section{Parapseudoleptomesochra tureei sp. nov. \\ Figures 69-72}

\section{Material Examined}

\section{Holotype}

Female (WAM C34137), Australia, Pilbara, Turee Creek, bore PFO9-4, 23 November 2002, leg. J. Cocking and M. Scanlon (CALM), 23 $22^{\prime} 07^{\prime \prime S}$ $117^{\circ} 57^{\prime} 36^{\prime \prime} E$ : dissected on two slides

\section{Allotype}

Male (WAM C34138), Australia, Pilbara, Turee Creek, bore PFO9-4, 23 November 2002, leg. J. Cocking and M. Scanlon (CALM), 23 22'07"S $117^{\circ} 57^{\prime} 36^{\prime \prime} \mathrm{E}$ : dissected on two slides

\section{Paratypes}

Australia, Pilbara, Turee Creek, bore PFO9-4, 23 November 2002, leg. J. Cocking and M. Scanlon (CALM), 23⒉ $22^{\prime} 07^{\prime \prime S} 117^{\circ} 57^{\prime} 36^{\prime \prime} \mathrm{E}$ : one male + three females (one female dissected on one slide (WAM C34139); others in alcohol (WAM C34140)

\section{Description}

Female (holotype). Total body length, measured from tip of rostrum to posterior margin of caudal rami (excluding caudal setae), $0.585 \mathrm{~mm}$. Preserved specimen colourless. Nauplius eye absent. Habitus (Figure 69C) fusiform, slender, without distinct demarcation between prosome and urosome; prosome/urosome ratio 1.4 and greatest width at posterior end of cephalothorax. Body length/width ratio about 4.1; cephalothorax 1.6 times as wide as genital double somite. Free pedigerous somites without pronounced lateral expansions or dorsally. Integument not strongly chitinized; two cuticular windows on proximal part of genital double somite laterally (one on each side). Rostrum small, membranous, ovoid, reaching just beyond proximal margin of first antennular segment, about as long as wide and demarcated at base; ornamented with two dorsal sensilla.

Cephalothorax almost triangular in dorsal view, about 1.1 times as long as wide; represents $27 \%$ of total body length. Surface of cephalic shield ornameted with many large sensilla, as well as tergites of three free pedigerous somites. Some sensilla or cuticular pores on cephalothorax and free pedigerous somites not visible, because specimen covered by many ciliates and small bits of organic material. Hyaline fringes of all prosomites smooth. Fifth pedigerous (first urosomal) somite ornamented with six dorsal and four lateral sensilla (two on each side); hyaline fringe finely serrated dorsolaterally.
Genital double somite (Figure 69A, C and 70C) as long as wide (ventral view), with suture visible dorsolaterally and furnished with row of small spinules and one cuticular pore laterally, as well two sensilla dorsally; additionally ornamented with posterior row of spinules (which interrupted by much smaller spinules ventrally) along with eight large sensilla (two dorsal, two ventral and two on each side laterally); hyaline fringe finely serrated both ventrally and dorsally; proximal part of double somite with one large cuticular window on each side laterally. Female genital complex with single ovoid copulatory pore, rigidly sclerotized conical copulatory duct and two large ovoid seminal receptacles. Single large genital aperture covered by fused reduced sixth legs (Figure 69A); represents 44 $\%$ of somite width. Third urosomite also ornamented with posterior interrupted row of spinules along with eight large sensilla; hyaline fringe also finely serrated both dorsally and ventrally. Preanal somite ornamented just with posterior uninterrupted row of spinules; hyaline fringe finely serrated both dorsally and ventrally. Anal somite (Figure 69A and 70A, C) ornamented with pair of large dorsal sensilla, two ventral cuticular pores and transverse row of large spinules along posterior margin, dorsal ones longer than ventral. Anal operculum convex, not reaching posterior end of anal somite, represents $44 \%$ of somite's width, ornamented with 11 strong spinules near posterior margin. Anal sinus ornamented with one transverse and two diagonal rows of minute spinules.

Caudal rami (Figure 69A and 70A) short, slightly shorter than greatest width (ventral view), parallel, with space between them more than one ramus width; armed with six armature elements (two lateral, one dorsal and three apical). Ornamentation consists of one short setula at base of proximal lateral seta, two spinules at base of distal lateral seta, two spinules at base of dorsal seta and posterior row of few large spinules ventrally. Dorsal seta relatively long, inserted on tip of short bulb, near posterior margin, about 3.1 times as long as caudal ramus, biarticulate at base and smooth. Proximal lateral seta about 0.4 times as long as dorsal seta, arising dorsolaterally at $3 / 4$ of ramus length. Distal lateral seta about 0.9 times as long as dorsal one and twice as long as proximal one, smooth. Inner apical seta also smooth, almost as long as distal lateral seta and about 2.5 times as long as ramus. Middle apical seta strongest, with breaking plane, pinnate at distal end, about 1.7 times as long as outer apical seta and 0.4 times as long as total body length. Outer apical seta also with breaking plane and pinnate at distal end.

Antennula (Figure 69E) eight-segmented, approximately 1.1 times as long as cephalothorax, with long aesthetasc on fourth segment, which reaches beyond tip of appendage for length of last 


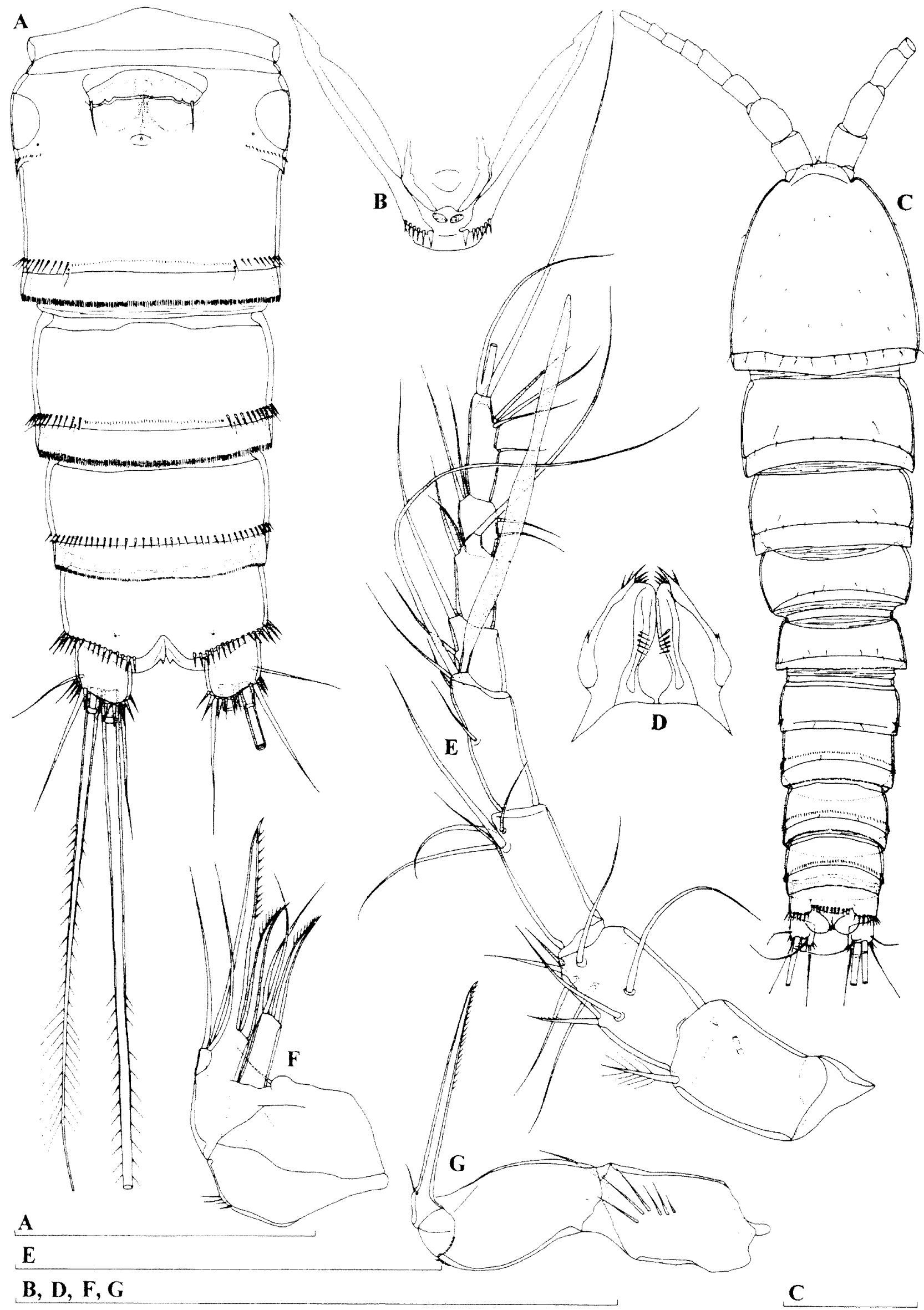

Figure 69 Parapseudoleptomesochra tureei sp. nov., holotype (female): A, abdomen, ventral view; B, labrum; C, habitus, dorsal view; $D$, paragnaths; $E$, antennula; $F$, maxilla; $G$, maxilliped. Scales $=0.1 \mathrm{~mm}$. 
segment; setal formula: 1.8.5.4.2.3.4.7. Only seta on first segment and one seta on second segment pinnate, all other setae smooth. Only two setae on seventh segment and two lateral setae on eighth segment articulating on basal part. All setae without breaking plane. Two apical setae on eighth segment fused basally. First segment ornamented with cuticular tube pore on anterior surface; other segments without any ornamentation. Length ratio of antennular segments, from proximal end, $1: 1: 1$ $: 1: 0.5: 0.7: 0.4: 0.8$.

Antenna (Figure 70B) slender, composed of coxa, basis, two-segmented endopod and one-segmented exopod. Coxa very short, unornamented. Basis about 1.5 times as long as wide, ornamented with two short rows of long spinules on outer margin, unarmed. First endopodal segment about 2.3 times as long as wide, unornamented and unarmed. Second endopodal segment with two surface frills subdistally, armed laterally with two spines flanking thin seta; apical armature consisting of five geniculate setae, longest one close but not fused basally to additional smaller seta, bearing proximal tuft of fine setules and unipinnate distally; ornamentation consists of long spinules along anterior surface. Exopod one-segmented, almost cylindrical, ornamented with longitudinal row of spinules along posterior surface, armed with three apical strong setae.

Labrum (Figure 69B) large compared with cephalothorax, almost triangular, rigidly sclerotized, with very short and slightly concave cutting edge, ornamented subapically with two rows of strong spinules. Two ovoid fields of gustatory papillae visible on dorsal (posterior) surface.

Paragnaths (Figure 69D) ellipsoid, about twice as long as wide, with group of spinules of different length apically, few spinules laterally, as well as group of five large spinules on proximal inner part of each lobe.

Mandibula (Figure 70F) with narrow cutting edge of elongated coxa, armed with three coarse teeth ventrally, one unipinnate seta dorsally and many small teeth in between (one tooth at middle stronger and longer than others). Palp uniramous, comprising basis and one-segmented endopod. Basis slender, unarmed and unornamented, about twice as long as wide. Endopod also slender and unornamented, about 0.7 times as long as basis and about 3.1 times as long as wide; armed with five slender and smooth setae apically.

Maxillula (Figure 70E) with large praecoxa, arthrite rectangular, ornamented with short transverse row of spinules on anterior surface; armed with two anterior surface setae, two lateral and four apical elements (probably three spines and one strong seta). Coxal endite armed with one curved and stout, unipinnate seta and two smooth, slender setae. Basis shorter than coxal endite, armed with five smooth setae apically and subapically. Endopod represented by minute segment, armed with two apical smooth setae of about same length.

Maxilla (Figure 69F) with two endites on syncoxa; proximal endite minute, ornamented with one smooth seta; distal endite well developed, highly mobile, armed with one curved pinnate spine and two smooth subequal setae, which about 1.3 times as long as spine. Basis drawn out into long claw, with much shorter spiniform and curved seta at base. Endopod represented by minute segment, armed with two smooth subequal apical setae.

Maxilliped (Figure 69G) with stout syncoxa, ornamented with arched row of very long spinules and armed with one smooth seta subapically. Basis about twice as long as wide and somewhat longer than syncoxa, ornamented with row of minute spinules subapically and unarmed. Endopod represented by long curved claw, which ornamented with row of spinules along concave side distally, accompanied at base by thin smooth seta.

All swimming legs with three-segmented exopod and endopod (Figure 70D and 71A, B, C). Armature formula of swimming legs as follows (legend: inner/ outer spine or seta; inner/terminal/outer):

\begin{tabular}{lcccccc} 
& \multicolumn{3}{c}{ Exopod } & \multicolumn{3}{c}{ Endopod } \\
Segments & 1 & 2 & 3 & 1 & 2 & 3 \\
First leg & $0 / 1$ & $1 / 1$ & $0 / 2 / 3$ & $1 / 0$ & $0 / 0$ & $1 / 1 / 1$ \\
Second leg & $0 / 1$ & $1 / 1$ & $1 / 2 / 3$ & $1 / 0$ & $1 / 0$ & $1 / 1 / 1$ \\
Third leg & $0 / 1$ & $1 / 1$ & $1 / 2 / 2$ & $1 / 0$ & $1 / 0$ & $2 / 1 / 1$ \\
Fourth leg & $0 / 1$ & $1 / 1$ & $2 / 2 / 2$ & $1 / 0$ & $1 / 0$ & $2 / 1 / 1$
\end{tabular}

Intercoxal sclerites of all swimming legs with concave distal margin; that of second leg (Figure $71 \mathrm{~A}$ ) ornamented with two arched rows of spinules near distal margin; others without any surface ornamentation. Praecoxa with short row of long spinules along outer posterior margin and coxa with row of spinules near outer margin in all swimming legs; coxa of first swimming leg with additional long row of spinules near distal margin. Basis ornamented with very long spinules on outer margin and with row of spinules along posterior margin, between endopod and exopod; armed with outer spine on first and second swimming legs and with outer smooth seta on third and fourth legs; basis of first leg with short and sout spine on inner distal corner and two spinules at its base. Exopods and endopods of all swimming legs ornamented with long spinules along outer margin and some segments also with spinules along inner and distal margin. First exopodal segment of all legs slightly shorter or as long as second exopodal segment. First endopodal segment of first swimming leg (Figure 70D) stout, about 2.8 times as long as wide, somewhat shorter than all three exopodal segments together. Endopods of second and third swimming legs (Figure $71 \mathrm{~A}, \mathrm{~B}$ ) reaching middle of third exopodal segment in length; while endopod of 


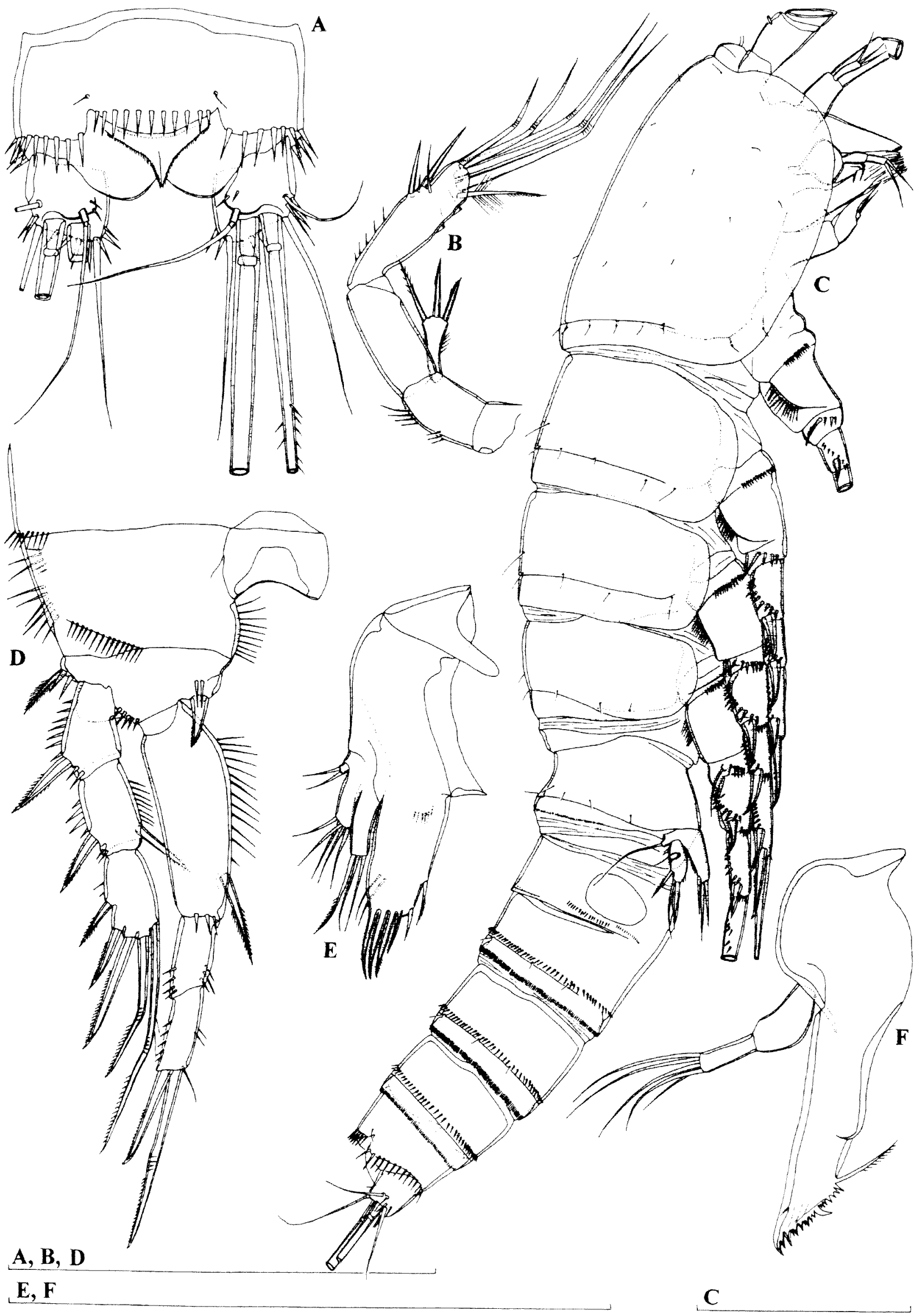

Figure 70 Parapseudoleptomesochra tureei sp. nov, holotype (female): A, anal somite and caudal rami, dorsal view; B, antenna; $C$, habitus, lateral view; D, first swimming leg; $E$, maxillula; $F$, mandibula. Scales $=0.1 \mathrm{~mm}$. 


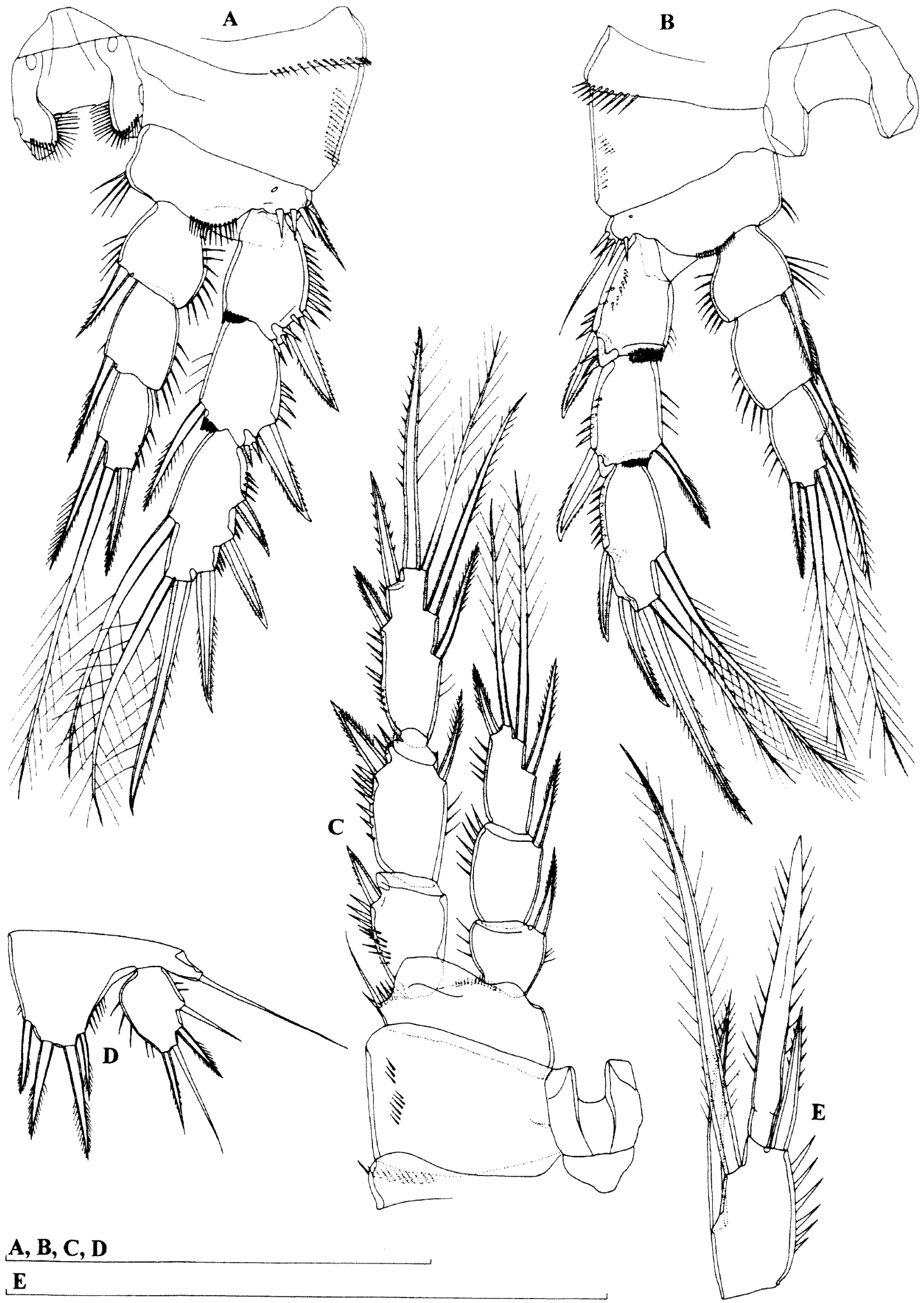

Figure 71 Parapseudoleptomesochra tureei sp. nov, A-D, holotype (female): E, paratype female (0.496 mm; WAM C34139): A, second swimming leg; B, third swimming leg; C, fourth swimming leg; D, fifth leg; E, third endopodal segment of third swimming leg. Scales $=0.1 \mathrm{~mm}$. 
fourth swimming leg (Figure 71C) as long as first two exopodal segments. All setae on exopods and endopods (except minute inner seta on third endopodal segment of first leg) very strong and many spiniform.

Fifth leg (Figure 71D) biramous, baseoendopods not fused. Baseoendopod with outer basal seta long and smooth, arising from long setophore. Endopodal lobe relatively narrow, convex, extending almost to posterior margin of exopod in length, ornamented with spinules both along inner and outer margin; armed with four stout, short bipinnate setae, with length ratio (from inner side) $1: 1.4: 1.6: 0.9$. Exopod ovoid, about 1.5 times as long as maximum width, ornamented with few slender spinules along inner and outer margin and armed with four setae; innermost seta pinnate and strong, as well as third seta from inner side, other two setae smooth and slender. Length ratio of four exopodal setae, from inner side, $1: 1.4: 0.8: 0.8$.

Sixth legs (Figure 69A) completely fused, indistinct, forming simple operculum covering single gonopore, without any ornamentation, each armed with single smooth and thin seta.

Male (allotype). Body length, excluding caudal setae, $0.412 \mathrm{~mm}$. Habitus, ornamentation of prosomites, rostrum, colour and nauplius eye similar to female. Hyaline fringe of all prosomites smooth.

Genital somite twice as wide as long, without spermatophore visible inside and with one large cuticular window on each side laterally (Figure $72 \mathrm{~A}$ ). Urosomites ornamentation similar to female, although posterior row of spines not interrupted ventrally.

Caudal rami (Figure 72A) about 0.85 times as long as wide. Armature and ornamentation similar to female, just two additional cuticular pores present ventrally and innermost apical seta somewhat longer than distal lateral one.

Antennula (Figure 72B) long and slender, tensegmented, strongly geniculate, with geniculation between seventh and eighth segment; ornamented with short row of spinules and cuticular tube pore on first segment. Very long aesthetasc on apical acrothek of fifth segment (homologueue to aesthetasc on fourth segment in female); very slender aesthetasc on tenth segment apically. First two and last two segments similar to female. Setal formula: 1.10.6.18.2.3.1.4.6. Majority of setae smooth and slender; seta on first and one seta on second segment pinnate; two setae on fifth, one on sixth and two on seventh segment very short and spiniform. Only three lateral setae on tenth segment and two setae on ninth segment articulating on basal part. No setae with breaking plane. One apical seta on tenth segment fused basally with slender aesthetasc.

Antenna, labrum, paragnaths, mandibula, maxillula, maxilla, maxilliped, second swimming leg and fourth swimming leg similar to female.
First swimming leg (Figure 72E) with spatulashaped and smooth modified inner spine on basis.

Third swimming leg (Figure $72 \mathrm{C}$ ) with apical seta on third endopodal segment very short and smooth; other details similar to female.

Fifth legs (Figure 72D) with baseoenopods not fused. Baseoendopod with outer basal seta long, smooth, arising from long setophore. Endopodal lobe broad, concave, not extending to middle of exopod, unornamented and armed with two stout bipinnate spines; inner spine about 1.6 times as long as outer one. Exopod small, ovoid, about 1.3 times as long as maximum width, ornamented with few spinules along inner margin and armed similarly to female; length ratio of four exopodal setae, from inner side, $1: 2.2: 1: 2$.

Sixth legs (Figure 72A, D) narrowly fused basally but distinct from somite, each armed with two smooth setae; inner seta slightly shorter than outer one.

\section{Variability}

Body length of females ranges from $0.485 \mathrm{~mm}$ to $0.585 \mathrm{~mm}(0.53 \mathrm{~mm}$ average; $\mathrm{n}=4)$, while only one male $(0.375 \mathrm{~mm})$, besides the allotype, was collected. One paratype female has an abnormal third endopodal segment of the third swimming leg (Figure 71E), with the apical armature element modified. No other type of variability was observed.

\section{Etymology}

The new species is named after the type locality, Turee Creek. The name is a noun in the genitive singular

\section{Discussion}

The first representatives of Parapseudoleptomesochra Lang, 1965 from Australia were described as new species from subterranean waters of the Murchison region by Karanovic (2004a) and they are: $P$. karamani and $P$. rouchi. In the same publication a key to 28 species and subspecies of this genus was presented, in which the new species from the Pilbara would key out as P. incerta (Chappuis, 1933). Parapseudoleptomesochra tureei sp. nov. and $P$. incerta share the same armature formula of the exopods of the swimming legs (with the relatively rare six element armature of the third exopodal segment of the second leg) and short caudal rami, but can be distinguished by the different armature formula of the endopods of all swimming legs. Parapseudoleptomesochra incerta was incompletely described (as a subspecies of Nitokra lacustris (Schmankevitch, 1875)) by Chappuis (1933) from the Curac 0 Island (Netherland Antilles) based on a single female, so many morphological characters could not be compared with the new species. 


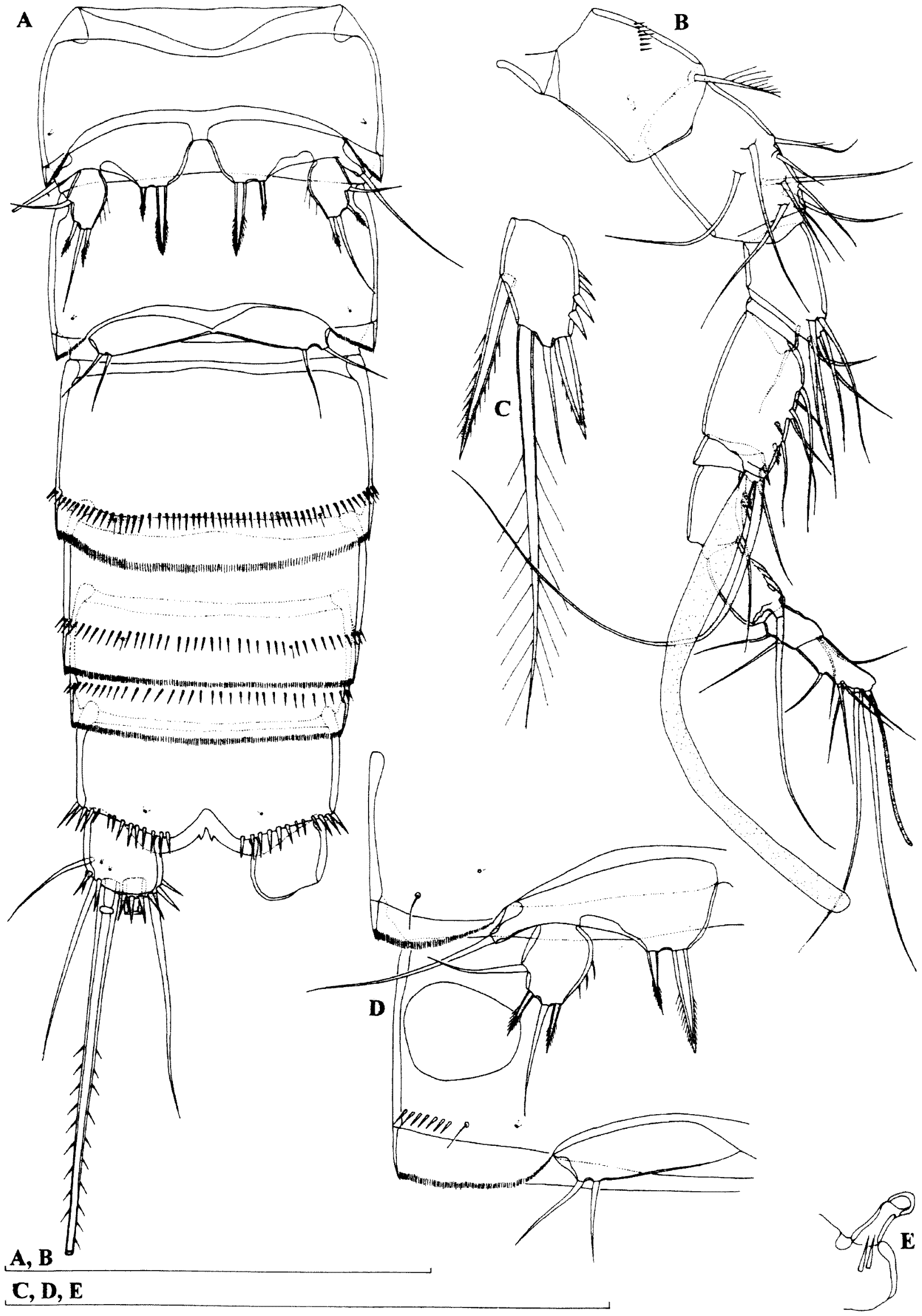

Figure 72 Parapseudoleptomesochra tureei sp. nov., allotype (male): A, urosome; B, antennula; C, third endopodal segment of third swimming leg; D, fifth and sixth leg; E, modified spine on basis of first swimming leg Scales $=0.1 \mathrm{~mm}$. 
However, they can be separated by the exopod of the fifth leg (armed with six setae in $P$. incerta and four setae in $P$. tureel) and the ornamentation of the anal operculum (with six spines in $P$. incerta and 11 in $P$. tureei). Besides $P$. incerta and $P$. tureei only $P$. dubia Kunz, 1975 has an exopod of the second leg armed with six elements on the third segment. The latter species, described from a single female by Kunz (1975) from South Africa, also has short caudal rami and a similar anal operculum but differs in the armature formula of the swimming legs and the fifth leg as well. All other species of Parapseudoleptomesochra differ even more from $P$. tureei, including the two Australian representatives. Their independent and ancient invasion of the subterranean waters of Western Australia seems very likely. All three Australian species have a different armature formula of all swimming legs and the fifth leg and a different shape and ornamentation of the urosomites and caudal rami, as well as other differences in ornamentation and proportions. Parapseudoleptomesochra tureei also has two setae on the male sixth leg (a plesiomorphic state in the genus), while a sixth leg with a single seta is a synapomorphy of the two Murchison species. A female fifth leg with four armature elements on both the exopod and the endopod is found in $P$. tureei and also the following four species: P. ommeyyadensis Rouch, 1986 from Spain (Rouch 1986b); P. pristina Wells, 1967 from Inhaca Island (Mozambique) (Wells 1967); P. syriaca Cottarelli, Puccetti and Saporito, 1985 from Syria (Cottarelli et al. 1985); and P. mielkei Karanovic, 2004 from Venezuela (Mielke 1995, Karanovic 2004a). As all these species differ from each other markedly, the similar state of the fifth leg must be a convergence. Lateral cuticular windows on the genital double somite in the female (Figures 69A and $70 \mathrm{C}$ ) and genital somite in the male (Figure $72 \mathrm{D})$, as well as a tube pore on the first antennular segment (Figures $69 \mathrm{E}$ and $72 \mathrm{~B}$ ) seem to be autapomorphies of the new species, although a great number of Parapseudoleptomesochra species have been incompletely described and these characters may have been overlooked. One undescribed species (Karanovic, in preparation) from south-west Western Australia has a similar pore on the antennula, although not cuticular windows. This species shares the greatest number of morphological characters with $P$. tureei, although it is geographically more distant than $P$. karamani and $P$. rouchi from the Murchison (Karanovic 2004a)

\section{Genus Biameiropsis gen. nov.}

\section{Diagnosis}

Moderately large Ameiridae, with cylindrical habitus and without distinct demarcation between prosome and urosome. Rostrum small, rectangular or almost triangular. Surface of dorsal shield covering cephalotorax ornamented with few large sensilla, as well as tergites of three free pedigerous somites; urosomites ornamented with sensilla, posterior rows of large spinules and several rows of minute spinules; hyaline fringes of all prosomites smooth, those of urosomites finely serrated. Genital double somite with suture visible ventrolaterally. Anal somite cleft medially; anal operculum very short, slightly convex, ornamented with numerous small spinules. Caudal rami from 0.6 to 1.5 times as long as wide, with complete armature; innermost apical and distal lateral setae of about same length, longer than ramus or dorsal seta. Antennula eightsegmented in female, longer than cephalothorax; first segment about as long as second. Antenna composed of coxa, basis, two-segmented endopod and one segmented exopod; basis with or without inner seta; exopod armed with three setae. Mandibula with narrow cutting edge on elongated coxa and biramuous palp, comprising large basis, one-segmented endopod and one-segmented exopod. Maxillula with one-segmented and minute exopod and endopod; endopod basally not demarcated; exopod very slender. Maxilla with two endites on syncoxa; endopod minute and basally fused to elongated basis. Maxilliped threesegmented; syncoxa and endopod armed with single seta each, basis unarmed. All swimming legs with three-segmented exopods and endopods and with three outer spines on third exopodal segment; first exopodal segments about as long as second ones; first endopodal segment of first leg somewhat longer than entire exopod, while endopods of other legs shorter than exopods. First exopodal segment of swimming legs with or without inner seta; third exopodal segment of second and fourth leg with seven elements, that of third leg with eight elements; third endopodal segment of second and fourth leg with five elements, that of third leg with four to six elements. No sexual dimorphism in swimming legs. Fifth leg in female with four or five elements on baseoendopod and five elements on exopod; same leg in male with three and five or six elements respectively. Male sixth leg with three elements; antennula 11-segmented and not strongly geniculate and first swimming leg with modified inner basal spine.

\section{Type species}

Biameiropsis barrowisp. nov.

\section{Other species}

Biameiropsis abbreviata (Sars, 1911) comb. nov (syn. Ameiropsis abbreviata Sars, 1911)

\section{Etymology}

The generic name is composed of the initials of 
the type locality (Barrow Island), prefixed to the existing generic name, Ameiropsis. The prefix also suggests the current number of species in the new genus, while Ameiropsis is morphologically the closest to the new genus. Gender feminine.

\section{Biameiropsis barrowensis sp. nov. Figures $73-76$ and 111}

\section{Material Examined}

\section{Holotype}

Female (WAM C34141), Australia, Pilbara, Barrow Island, bore MW13/SB31, 22 October 1998, leg. W.F. Humphreys and S.M. Eberhard (BES: 3399), $20^{\circ} 46^{\prime} 51^{\prime \prime S} 115^{\circ} 28^{\prime} 01^{\prime \prime E}$ : dissected on one slide

\section{Paratypes}

Australia, Pilbara, Barrow Island, bore MW13/ SB31, 22 October 1998, leg. W.F. Humphreys and

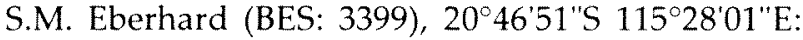
nine females (one dissected on one slide (WAM C34142); one on slide in toto (WAM C34143); others in alcohol (WAM C34144))

\section{Topotypes}

Australia, Pilbara, Barrow Island, bore MW13, 23 October 1998, leg. W.F. Humphreys and S.M. Eberhard (BES: 3425), 20 46'51'S 115'28'01"E: one male dissected on one slide (WAM C34145)+ four females in alcohol (WAM C34146)

\section{Other material}

1) Australia, Pilbara, Barrow Island, bore MW13, 10 August 2002, leg. G. Humphreys (BIOTA) $20^{\circ} 46^{\prime} \mathrm{S} 115^{\circ} 28^{\prime} \mathrm{E}$ : one female (HA 212) dissected by Jane McRae on one slide (WAM C34147)

2) Australia, Pilbara, Barrow Island, bore MW18, 11 August 2002, leg. G. Humphreys (BIOTA) $20^{\circ} 46^{\prime} 47^{\prime \prime} \mathrm{S} 115^{\circ} 28^{\prime} 06^{\prime \prime} \mathrm{E}$ : one female (HA 211) dissected by Jane McRae on one slide (WAM C34148)

\section{Description}

Female (holotype). Total body length, measured from tip of rostrum to posterior margin of caudal rami (excluding caudal setae), $0.61 \mathrm{~mm}$. Preserved specimen colourless. Nauplius eye absent. Habitus (Figure 73B) cylindrical and slender, without distinct demarcation between prosome and urosome; prosome as long as urosome and greatest width at posterior end of cephalothorax and second pedigerous (first free) somite, which of same width. Body length/width ratio about 4.2 ; cephalothorax 1.3 times as wide as genital double somite. Free pedigerous somites without pronounced lateral expansions or dorsally. Integument not strongly chitinized. Rostrum (Figure 74E) small, membranous, rectangular, reaching first quarter of first antennular segment, about 1.3 times as long as wide and not demarcated at base; ornamented with two dorsal sensilla at anterior lateral corners.

Cephalothorax about as long as wide; represents $24 \%$ of total body length. Surface of cephalic shield and tergites of first three free pedigerous somites ornamented with few very large sensilla,. Hyaline fringes of all prosomites smooth.

All urosomites with serrated hyaline fringes and with several parallel rows of very minute spinules, in addition to ornamentation described below. Genital double somite (Figure 73A, C) about 0.9 times as long as wide (ventral view), with suture visible ventrolaterally and with internal chitinous rib marking original segmentation dorsally and laterally; ventrolateral part of suture ornamented with row of spinules and one sensilla on each side one interrupted row of small spinules and four sensilla dorsally near chitinous rib; posterior row of spinules uninterrupted but ventral spinules much stronger than dorsal ones, accompanied with six sensilla (two dorsal, two lateral and two ventral). Genital complex (Figure 73C) with single broad copulatory pore, not sclerotized and conical copulatory duct, and small seminal receptacles fused medially. Single genital aperture covered by simple operculum formed from fused reduced sixth legs; represents $47 \%$ of double somite width. Third urosomite ornamented only with posterior uninterrupted row of spinules (ventral ones strongest) along with eight sensilla (two dorsal, two ventral, and four lateral). Preanal somite (fourth urosomal) without any sansillae, ornamented only with posterior ventral row of small spinules. Anal somite (Figure 73A, C) distinctly cleft medially ornamented with pair of large dorsal sensilla, two ventral cuticular pores at anterior part, two short ventral rows of small spinules at middle and transverse row of small spinules along posterior margin. Anal operculum (Figure 73A) very short slightly convex, reaching middle of anal somite, represents $48 \%$ of somite's width, ornamented with row of numerous small spinules along posterior margin. Anal sinus widely opened, smooth.

Caudal rami (Figure 73A, C) very short, 0.6 times as long as greatest width (ventral view), slightly divergent, with space between them somewhat more than one ramus width; armed with six armature elements (two lateral, one dorsal and three apical). Ornamentation consists of strong setula and two small spinules at base of proximal lateral seta, two strong spinules at base of distal lateral seta and two spinules on posterior margin ventrally, at base of inner apical seta. Dorsal seta relatively short, inserted on tip of short bulb, near posterior margin, about 2.6 times as long as caudal ramus, uniarticulate at base and smooth. Proximal lateral seta about 0.8 times as long as dorsal seta, 


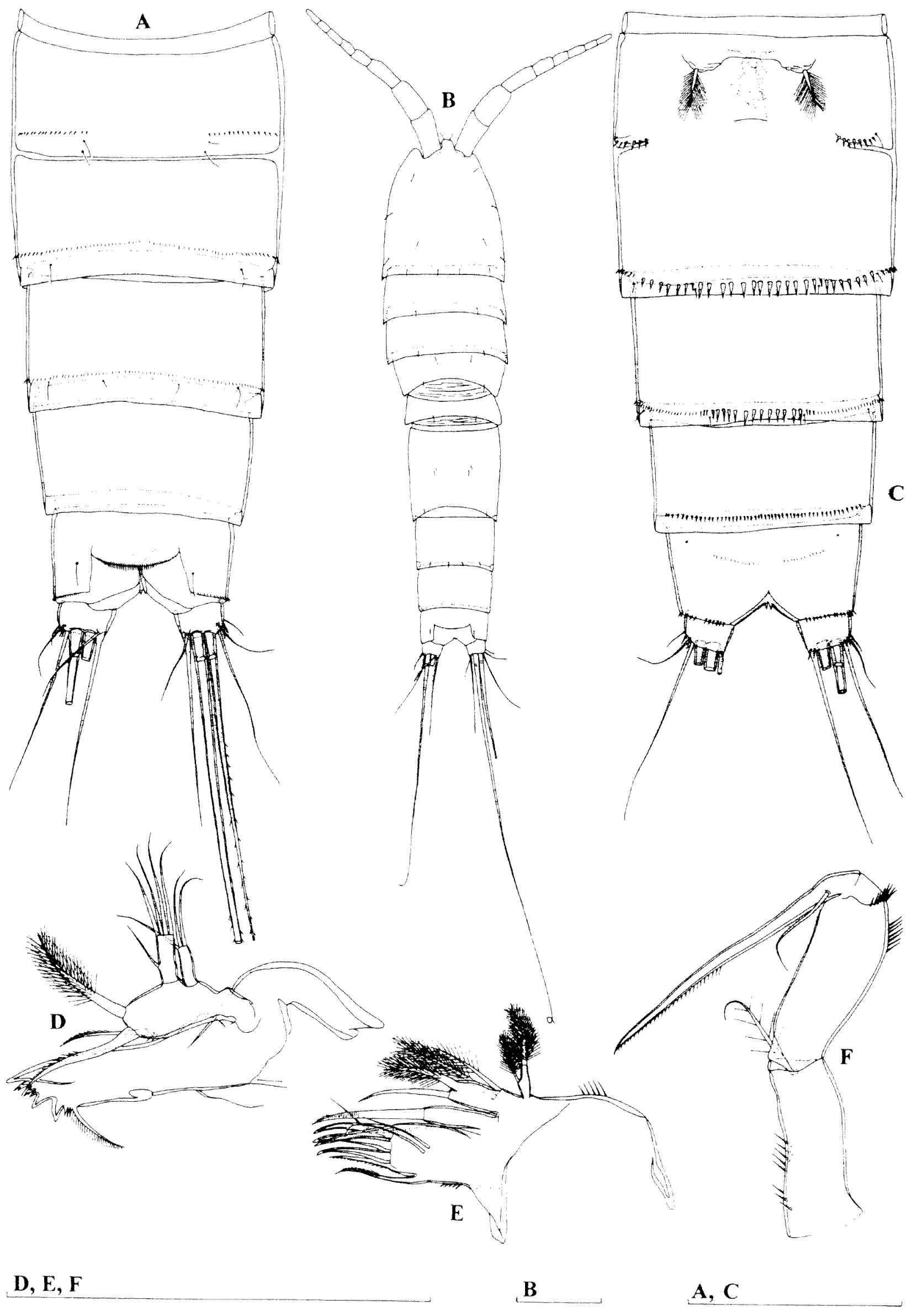

Figure 73 Biameiropsis barroni gen et sp. now, holotype (female): A, abdomen, dorsal view; B, habitus, dorsal view; $C$, abdomen, ventral view; D, mandibula; $E$, maxillula; F, maxilliped. Scales $=0.1 \mathrm{~mm}$. 


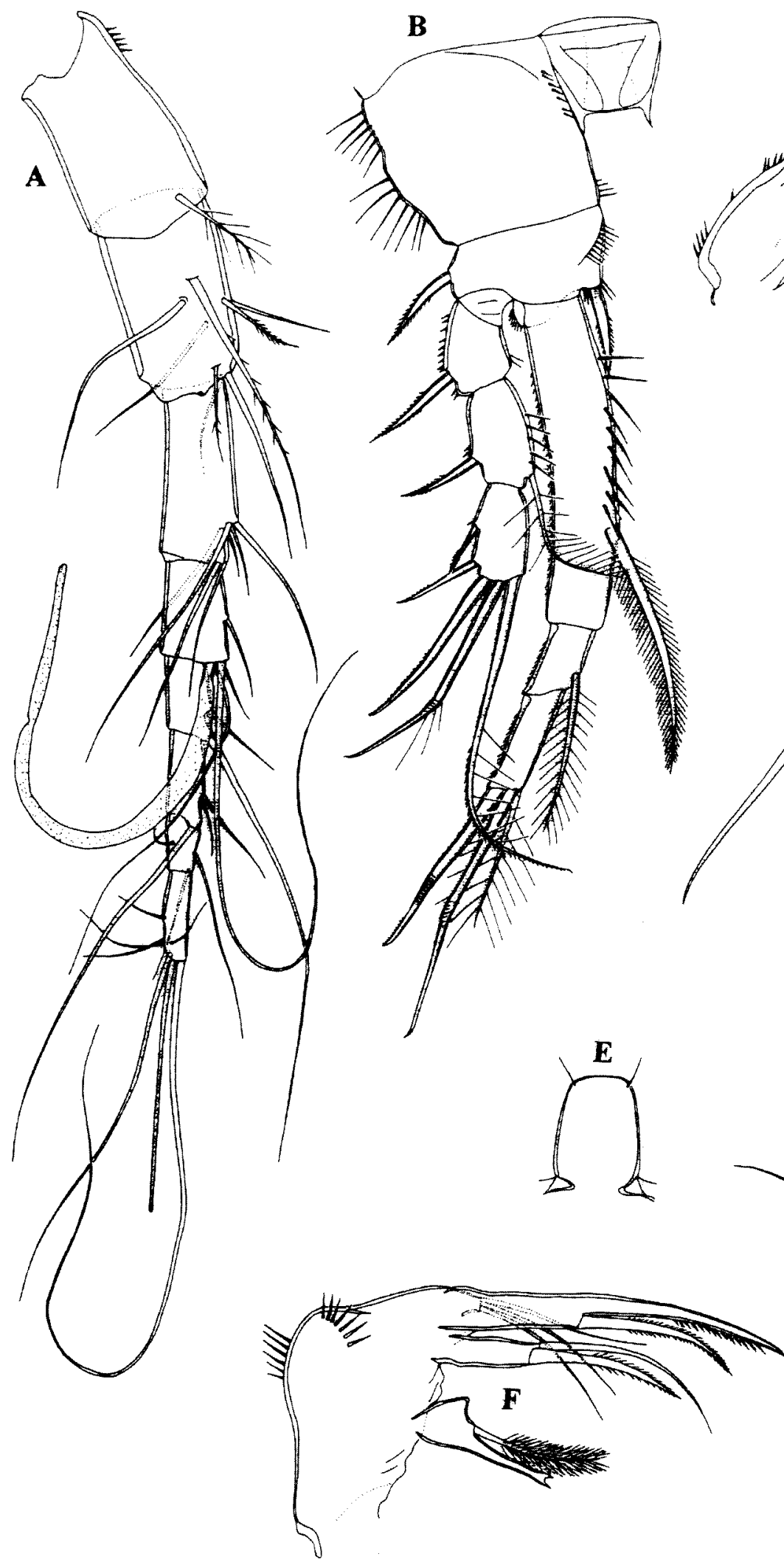

\section{C, D, E, F, G}

A, B

Figure 74 Biameiropsis barrowi gen. et sp. nov., holotype (female): A, antennula; B, first swimming leg; C, paragnaths; $D$, antenna; $E$, rostrum, dorsal view; $F$, maxilla; $G$, fifth leg. Scales $=0.1 \mathrm{~mm}$. 
originating dorsolaterally at $2 / 3$ of ramus length. Distal lateral seta about 2.7 times as long as proximal one, smooth, arising near posterior margin. Inner apical seta long, smooth, partly fused to ramus, about 1.13 times as long as distal lateral seta. Middle apical seta strongest, with breaking plane, bipinnate at distal end, about 1.6 times as long as outer apical seta, and 0.75 times as long as body. Outer apical seta also pinnate and with breaking plane, about as long as abdomen and caudal rami together.

Antennula (Figure 74A) eight-segmented, approximately 1.5 times as long as cephalothorax, with long aesthetasc on fourth segment, reaching beyond tip of appendage for more than length of last three segments, and one very slender aesthetasc on eighth segments apically; setal formula: 1.8.7.3.2.3.3.7. Only seta on first and three setae on second segment pinnate, all other setae smooth. No setae articulating on basal part or fused to each other, and all setae without breaking plane. First segment ornamented with short row of spinules on anterior surface proximally. Length ratio of antennular segments, from proximal end, $1: 0.9$ : $0.8: 0.5: 0.3: 0.4: 0.25: 0.4$.

Antenna (Figure 74D) slender, its apical armature elements protecting cephalothorax shield ventrolaterally, composed of coxa, basis, twosegmented endopod, and one-segmented exopod. Coxa very short, unornamented. Basis about 1.3 times as long as wide, unornamented and armed with single smooth setae on inner margin distally. First endopodal segment about 2.2 times as long as wide, unornamented and unarmed. Second endopodal segment about 1.3 times as long as first one, with surface frill subdistally, armed laterally with two spines flanking thin seta; apical armature consisting of five very strong and geniculate setae, longest one fused basally to additonal smaller and slender seta; ornamentation consists of few small spinules along anterior surface. Exopod onesegmented, cylindrical, about 3.5 times as long as wide, unornamented but armed with two apical and one lateral strong setae; all setae bipinnate and of about same length.

Labrum relatively large compared with cephalothorax, trapezoidal, rigidly sclerotized, with broad and almost straight cutting edge, ornamented apically with many hair-like spinules, and subapically with two rows of strong spinules. Two ovoid fields of gustatory papillae present on dorsal (posterior) surface

Paragnaths (Figure 74C) ovoid, fused basally forming trapezoidal labium, ornamented with many minute spinules on median lobe apically and with two short rows of large spinules along outer margin, as well as single spinule between these rows; distal outer corners produced posteriorly as spiniform process on both paragnaths.
Mandibula (Figure 73D) with narrow cutting edge on elongated coxa, armature of which clearly divided into two parts, ventral and dorsal; ventral part consists of two coarse teeth with several small teeth between them; dorsal part consists of one coarse tooth, one unipinnate dorsalmost seta and two smaller teeth between them. Palp biramous, comprising large basis, one-segmented endopod, and one-segmented exopod. Basis rectangular, about twice as long as wide, ornamented with two spinules near inner margin proximally and armed with three strong setae along inner margin; proximal two setae unipinnate and curved, most distal seta flaccid and densely plumose. Endopod small and slender, rectangular, unornamented, about as long as basis width, and about 2.5 times as long as wide; armed with four smooth setae apically and one smaller smooth seta laterally (at 2/5 of inner margin). Exopod also rectangular and small, about 0.8 times as long as endopod and about three times as long as wide; armed with three smooth apical setae and unornamented.

Maxillula (Figure 73E) with large praecoxa, arthrite rectangular, ornamented with row of spinules basally, armed with two anterior surface setae, two lateral unipinnate elements and four apical smooth and very strong elements. Outer distal corner of praecoxa armed with short row of very large spinules. Coxal endite armed with one curved pinnate spine and one smooth and short seta. Basis shorter than coxal endite, armed with one smooth and one flaccid and densely plumose seta on inner margin; plumose seta fused basally with basis. Endopod represented by minute segment, basally not demarcated, armed with two apical setae; inner seta flaccid and densely plumose, outer one normally plumose. Exopod small and very slender segment, about 2.8 times as long as wide, unornamented, and armed with two facid and densely plumose setae (one apical, one lateral).

Maxilla (Figure 74F) with two endites on syncoxa; proximal endite short, with distal margin transformed into keel, armed with distal flaccid and densely plumose seta and with proximal armature element, fused basally to endite and concavely terminated; distal endite rectangular, slender, armed with proximal pinnate and curved spine and with distal smooth and long seta. Basis drawn out into long claw, with somewhat shorter spiniform and curved seta at base. Endopod represented by minute, basally fused, segment, armed with two smooth subequal apical setae. Outer distal margin of maxilla ornamented with two rows of very large spinules.

Maxilliped (Figure 73F) with long syncoxa, about 2.5 times as long as wide, ornamented with two groups of strong spinules along inner margin and armed with one plumose seta subapically. Basis somewhat longer than syncoxa, about 2.5 times as 


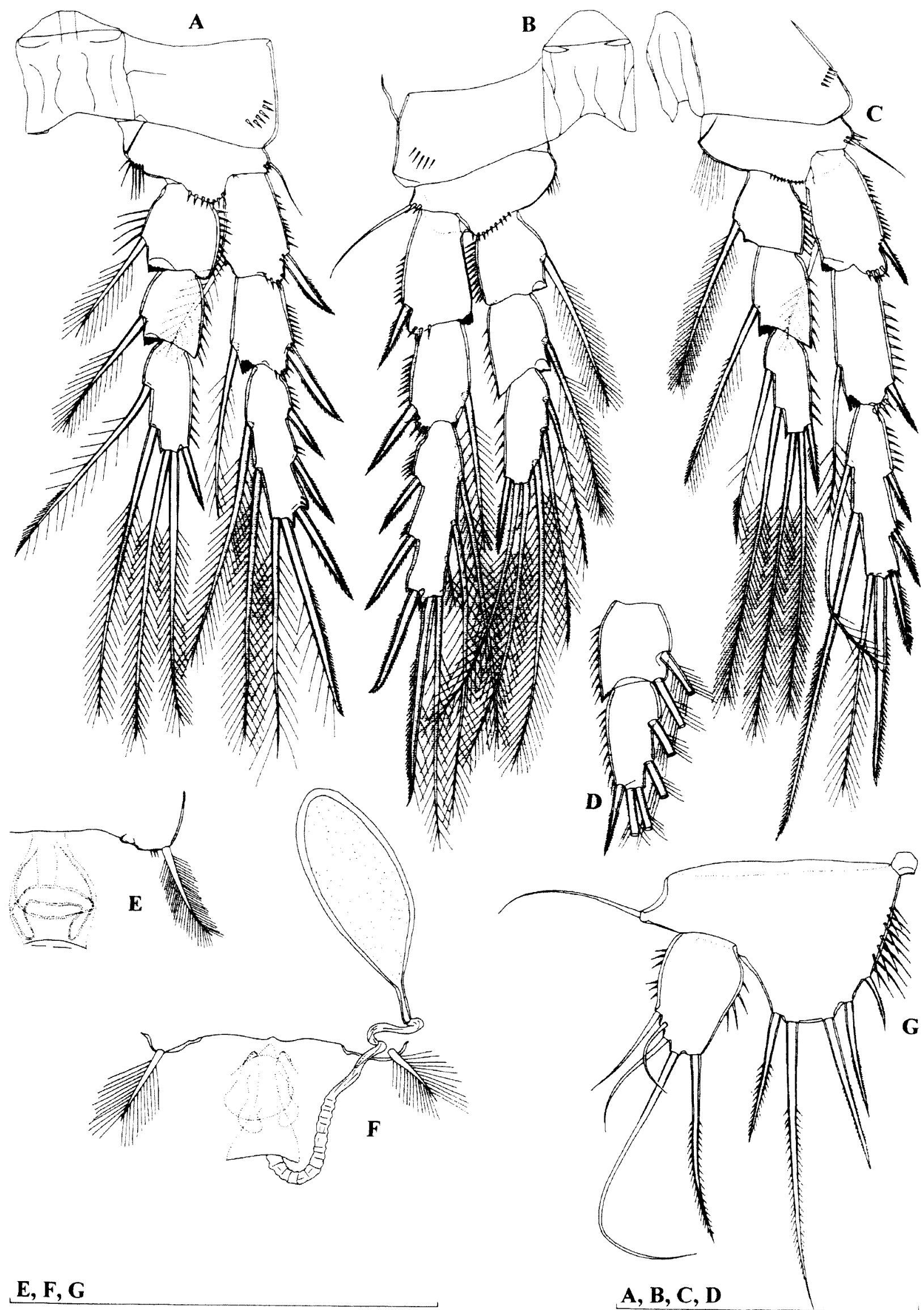

Figure 75 Biameiropsis barrowi gen. et sp. nov., A-C, holotype (female); D and E, female from locality 2 (WAM C34148); $F$ and $G$, paratype female (0.594 mm: WAM C34142): $A$, second swimming leg; $B$, third swimming leg; C, fourth swimming leg; D, second and third endopodal segments of anormal third swimming leg; $E$, genital field; F, genital field, with sparmatophore attached; G, fifth leg. Scales $=0.1 \mathrm{~mm}$. 
long as wide, unarmed but ornamented with two short rows of large spinules at distal outer region (one longitudinal and one transverse). Endopod represented by long curved claw, about 1.5 times as long as basis, ornamented with row of spinules along concave side distally, accompanied at its base by slender smooth seta.

All swimming legs with three-segmented exopod and endopod (Figure $74 \mathrm{~B}$ and $75 \mathrm{~A}, \mathrm{~B}, \mathrm{C}$ ). Armature formula of swimming legs as follows (legend: inner) outer spine or seta; inner/terminal/outer):

\begin{tabular}{lcccccc} 
& \multicolumn{3}{c}{ Exopod } & \multicolumn{3}{c}{ Endopod } \\
Segments & 1 & 2 & 3 & 1 & 2 & 3 \\
First leg & $0 / 1$ & $1 / 1$ & $0 / 2 / 3$ & $1 / 0$ & $1 / 0$ & $1 / 1 / 1$ \\
Second leg & $1 / 1$ & $1 / 1$ & $2 / 2 / 3$ & $1 / 0$ & $1 / 0$ & $2 / 2 / 1$ \\
Third leg & $0 / 1$ & $1 / 1$ & $3 / 2 / 3$ & $1 / 0$ & $1 / 0$ & $3 / 2 / 1$ \\
Fourth leg & $1 / 1$ & $1 / 1$ & $2 / 2 / 3$ & $1 / 0$ & $1 / 0$ & $2 / 2 / 1$
\end{tabular}

Intercoxal sclerites of all swimming legs with concave distal margin, without any surface ornamentation. Coxa unarmed and ornamented with several large spinules near outer margin in all swimming legs; coxa of first swimming leg with additional spinules along inner margin. Basis ornamented with short row of spinules along distal anterior margin, as well as with several spinules on inner margin (hairs on fourth leg) and with few spinules on outer margin (except in first leg), armed with outer spine on first swimming leg, and with outer smooth and short seta on second, third, and fourth legs; basis of first leg with stout spine on inner distal corner. Exopod and endopod of all swimming legs ornamented with long spinules along outer margins, and exopodal segments also with spinules along distal margin. First exopodal segment in all legs about as long as second one. First endopodal segment of first swimming leg (Figure 74B) about 4.7 times as long as wide, slightly longer than all exopodal segments together. Endopod of second swimming leg (Figure 75A) reaching middle of third exopodal segment; endopod of third leg (Figure $75 \mathrm{~B}$ ) reaching $1 / 3$ of third exopodal segment; while endopod of fourth swimming leg (Figure 75C) slightly longer than first two exopodal segments. Most proximal spine on outer margin of third exopodal segment of first leg much smaller than others. Outer apical armature element on third exopodal segment of second, third and fourth leg pinnate along outer margin, while plumose along inner margin. Distal inner seta on third exopodal segment of fourth leg very strong, spiniform and longest one.

Fifth leg (Figure 74G) biramous, large, with minute intercoxal sclerite visible. Baseoendopod with outer basal smooth seta long, arising from relatively short setophore. Endopodal lobe wide, trapezoidal, extending to middle of exopod, ornamented with very long spinules along inner margin and armed with five stout bipinnate setae. Length ratio of endopodal setae, from outer side, 1 :
$2.2: 1.2: 0.9: 0.4$. Exopod ovoid, about 1.5 times as long as maximum width, ornamented with few large spinules both along outer and inner margin and armed with five setae. Innermost seta bipinnate, all other setae smooth. Length ratio of exopodal setae, from inner side, $1: 1.6: 0.6: 0.4$ : 0.5 . Fourth exopodal seta from inner side moved to ventral surface.

Sixth legs (Figure 73C) completely fused, basally indistinct, very small cuticular plates, forming simple operculum covering single gonopore, each armed with one plumose and short seta.

Male (topotype). Body length, excluding caudal setae, $0.448 \mathrm{~mm}$. Habitus, ornamentation of prosomites, colour, and nauplius eye similar to female. Hyaline fringes of all prosomites smooth, those of urosomites finely serrated both dorsally and ventrally. Single small, completely formed, diagonally-placed, spermatophore (Figure 76B) visible inside genital somite. Urosomites (Figure 76A) ornamentation simlar to female. Anal somite (Figure 76A, D, H) ornamented with pair of dosal large sensilla, two lateral rows of small spinules at anterior half, transverse row of spinules along posterior margin and several short rows of very minute spinules. Anal operculum similar to female but somewhat more convex and additionally ornamented with minute spinules along posterior margin.

Caudal rami (Figure $76 \mathrm{~A}, \mathrm{D}, \mathrm{H}$ ) very short, 0.5 times as long as greatest width (ventral view), slightly divergent, with space between them somewhat more than one ramus width. Armature and ornamentation similar to female, except proximal lateral seta somewhat stronger and longer.

Antennula (Figure $76 \mathrm{C}$ ) very long and slender, 11 -segmented, not strongly geniculate, with geniculation visible between eighth and ninth segment; first segment longest. Very long aesthetasc on apical acrothek of sixth segment (homologue to aesthetasc on fourth segment in female); eleventh segment with very slender aesthetasc apically; very small aesthetasc on fourth segment. Setal formula: 1.1.8.5.0.6.1.4.1.2.7. All setae smooth, except for one spiniform seta on eighth segment and plumose seta on first segment. No setae with breaking plane or articulating on basal part.

Antenna (Figure 76E), labrum, paragnaths, mandibula, maxillula, maxilla, maxilliped, second swimming leg, third swimming leg, and fourth swimming leg similar to female.

First swimming leg (Figure 76G) with modified inner spine on basis, which hooked and smooth, complex.

Fifth legs (Figure 76B, F) with fused baseoenopods but distinct from somite. Endopodal lobe trapezoidal, unornamented, extending to middle of exopodal length, armed with three armature elemnts, outermost smooth and small, 


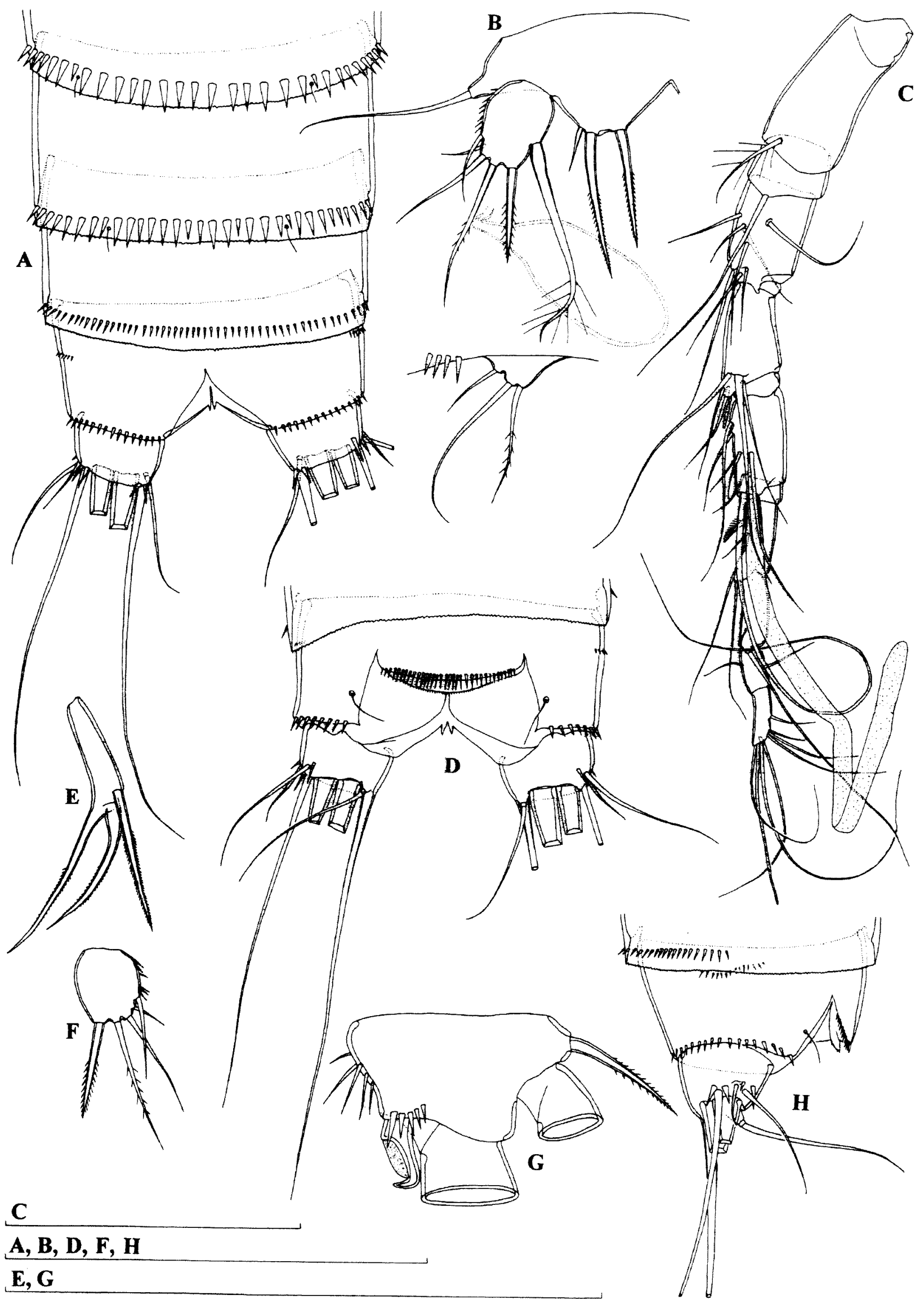

Figure 76 Biameiropsis barrowi gen. et sp. nov., topotype male (0.448 mm; WAM C34145): A, abdomen, ventral view; $B$, right fifth and sixth legs, ventral view; $C$, antennula; $D$, anal somite and caudal rami, dorsal view; $E$, exopod of antenna; F, exopod of right fifth leg; $G$, basis of first swimming leg; $H$, anal somite and left caudal ramus, lateral view. Scales $=0.1 \mathrm{~mm}$. 
other two bipinnate and strong; length ratio of endopodal armature elements, from outer side, 1 : 3.2 : 2.6. Exopod ovoid, about 1.3 times as long as wide, ornamented with spinules along outer margin, armed with five setae on left leg, while on right leg with additional very strong and long seta on inner margin; length ratio of exopodal setae on left leg, from inner side, $1: 1.4: 1.1: 0.4: 0.9$. Three outer setae on exopod smooth, other two (or three) pinnate.

Sixth leg (Figure 76B) simple triangular cuticular plate, unomamented but armed with three setae; innermost seta pinnate, other two smooth; length ratio of setae, from inner side, $1: 1.4: 0.4$.

\section{Variability}

Body length of females ranges from $0.519 \mathrm{~mm}$ to $0.665 \mathrm{~mm}(0.591 \mathrm{~mm}$ average; $\mathrm{n}=13)$, while only one male was collected. Small differences are noted in the shape of the seminal receptacle (Figure $73 \mathrm{C}$ and $75 \mathrm{E}, \mathrm{F}$ ) and ornamentation of the female fifth leg (Figure $74 \mathrm{G}$ and $75 \mathrm{G}$ ). The female from locality 2 has an abnormal endopod of the third swimming leg (Figure 75D), with most proximal seta of the third segment moved to the second segment. Also the male fifth legs are asymmetrical (Figure 76B, F), with the innermost armature element missing on the left leg.

\section{Etymology}

The new species is named after the type locality, Barrow Island. The name is a noun in the genitive singular.

\section{Discussion}

In keys to genera of the family Ameiridae by Lang (1965), Petkovski (1976) and most recently Boxshall and Halsey (2004), the new genus would key out as Ameiropsis Sars, 1907. The latter genus was first rejected by Lang $(1935,1936)$ and then reinstated by Lang (1944, 1948). Lang (1948) provided a key to seven species recognised by him as valid, and placed two species within this genus as incertae sedis. One of these, A. ariana Monard, 1928, was transferred to the newly established genus Ameiropsyllus by Bodin (1977), while the other one, A. robinsoni Gurney, 1927, remains incertae sedis. Only two new species of Ameiropsis have been described since Lang's (1948) revision: A. australis Kunz, 1975 from the littoral of South Africa (Kunz 1975) and A. reducta Apostolov, 1973 from the Black Sea (Apostolov 1973a, Apostolov and Marinov 1988). Although, the family Ameiridae is notorious for its numerous ill-defined genera and the fine-level systematics are considered a nightmare by many workers (Conroy-Dalton and Huys 1996, 1998), the genus Ameiropsis has stayed rather compact and well-defined. However, one of the nine species currently recognised as members of this marine genus, stands well apart from the rest because of its one-segmented exopod on the antenna. This species was described by Sars (1911) from Norway as Ameiropsis abbreviata, from a single female and it has never been reported again. This reduction would normally be regarded as a reflection of evolution within the genus if the Australian representative, with a similarly reduced exopod, did not have a plesiomorphic armature of the antennular basis (with inner seta present). All other members of Ameiropsis have an unarmed basis of the antenna as a clear synapomorphy, although their exopod is plesiomorphic. This can only mean that the two species, now in the genus Biameiropsis, shared the same ancestor with Ameiropsis and are not examples of intrageneric evolution. This is the main reason $I$ have erected a new genus. It should be mentioned here that a plesiomorphic exopod of antenna is also present in two genera separated from Ameiropsis: Ameiropsyllus Bodin, 1977 and Pseudoameiropsis Pallares, 1982. They both differ from Biameiropsis in a number of other characters (see Bodin 1977, Pallares 1982) and contain two and one species, respectively (Bodin 1997). I would agree with Conroy-Dalton and Huys (1996) that "the detailed morphology of the antennary exopod differs considerably among ameirids and it is clear that its usefulness in elucidating relationships has been grossly underestimated in the past".

Biameiropsis barrowensis sp. nov., although clearly a subterranean species, differs from $B$. abbreviata by a number of plesiomorphic features, including the armature of the second, third, fourth and fifth leg and also the armature of the basis of antenna (armed with single seta in the former species vs. unarmed in the latter). They can be additionally distinguished by the shape of the caudal rami, which are much more elongated in $B$. abbreviata. Unfortunately, many details can not be compared (especially mouth parts) because they are not given in the original description of this species. That, along with the greater number of plesiomorphic features, is why I designate $B$. barrowensis as the type species of the genus.

\section{Genus Archinitocrella gen. nov.}

\section{Diagnosis}

Moderately large Ameiridae, with cylindrical habitus and without distinct demarcation between prosome and urosome. Integument not strongly chitinized and hyaline fringes of all somites smooth. Rostrum small, ovoid. Surface of cephalic shield and tergites of free pedigerous somites ornamented with numerous very large sensilla. Genital double somite with suture visible only laterally, with wide copulatory pore and sclerotized conical copulatory duct; single aperture covered by fused sixth legs, 
without any armature or ornamentation. Anal operculum convex, short, ornamented with numerous spinules along posterior margin. Caudal rami about as long as wide, slightly divergent; dorsal seta longer than any lateral seta; innermost apical seta about as long as ramus; principal apical setae with breaking planes. Antennula in female eightsegmented, slender, much longer than cephalothorax. Antennula in male ten-segmented, not strongly geniculate. Antenna composed of coxa, basis, two-segmented endopod and one-segmented exopod; exopod armed with two setae. Labrum large, with short cutting edge. Mandibula with narrow cutting edge and uniramous, two-segmented palp; basis unarmed, endopod with four apical setae. Maxillula with endopod almost completely fused to basis, armed with single seta. Maxilla with single endite on syncoxa; endopod minute but distinct segment. Maxilliped three-segmented, unarmed. All swimming legs with three-segmented exopod; endopod of first and second legs also threesegmented, while that of third and fourth leg twosegmented; all exopodal segments of about same length; third exopodal segment of first leg with three outer spines, those of other legs with two outer spines; first endopodal segment of first leg about as long as first two exopodal segments. Basis of first leg in male with inner spine untransformed. Inner apical seta on second endopodal segment of third leg in male shorter than in female, spiniform. Fifth leg in female biramous; baseoendopods not fused, each armed with single large spine on broad and convex endopodal lobe; exopod ovoid, about 1.8 times as long as wide, armed with three slender elements. Fifth leg in male with baseoendopods unarmed and fused medially; exopods asymmetrical but also armed with three elements. Sixth legs in male narrowly fused basally but distinct from somite, each armed with single smooth element.

\section{Type and only species}

Archinitocrella newmanensis sp. nov.

\section{Etymology}

The generic name is composed of the Greek prefix "archi-" (meaning "old") and the existing generic name, Nitocrella. Gender feminine.

\section{Archinitocrella newmanensis sp. nov.} Figures $77-81$ and $112 \mathrm{~A}-\mathrm{B}$

\section{Material Examined}

\section{Holotype}

Female (WAM C34149), Australia, Pilbara, Newman Borefield, bore WB23/1, 22 July 1997, leg. W.F. Humphreys and S.M. Eberhard (BES: 4803), $23^{\circ} 19^{\prime} 30^{\prime \prime} \mathrm{S} 119^{\circ} 50^{\prime} 51^{\prime \prime} \mathrm{E}$ : dissected on two slides
Paratypes

Australia, Pilbara, Newman Borefield, bore WB23/1, 22 July 1997, leg. W.F. Humphreys and S.M. Eberhard (BES: 4803), 2319'30'S 119 50'51"E: two females (one dissected on one slide (WAM C34150), one in alcohol (WAM C34151))

\section{Other material}

1) Australia, Pilbara, Production Bore K31, bore W260, 4 October 2002, leg. J. Cocking and M. Scanlon (CALM), 23⒈ $31^{\prime \prime S} 119^{\circ} 52^{\prime} 12^{\prime \prime E}$ : one female (HA 220) dissected on one slide by Jane McRae (WAM C34152)

2) Australia, Pilbara, Newman Borefield, bore W236, 22 July 1997, leg. W.F. Humphreys and S.M.

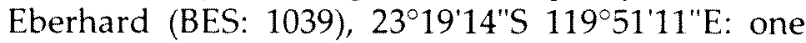
male + two females in alcohol (WAM C34153)

3) Australia, Pilbara, Newman Borefield, monitoring bore for pump K27, 23 July 1997, leg. W.F. Humphreys and S.M. Eberhard (BES: 1040), $23^{\circ} 19^{\prime} 45^{\prime \prime S} 119^{\circ} 51^{\prime} 27^{\prime \prime} \mathrm{E}$ : one female in alcohol (WAM C34154)

4) Australia, Pilbara, Newman Borefield, bore W77, 23 July 1997, leg. W.F. Humphreys and S.M. Eberhard (BES: 4831), $23^{\circ} 19^{\prime} 30^{\prime \prime S} 119^{\circ} 50^{\prime} 51^{\prime \prime E}$ : two females + one copepodid in alcohol (WAM C34155)

5) Australia, Pilbara, GNH near Newman Airport, bore W28, 4 October 2002, leg. J. Cocking and M. Scanlon (CALM), 23⒉ $4^{\prime} 12^{\prime \prime S} 119^{\circ} 47^{\prime} 45^{\prime \prime} \mathrm{E}$ : one male dissected on two slides (WAM C34156) + two females dissected by Jane McRae on one slide each (WAM C34157 and C34158)

6) Australia, Pilbara, Production Bore K31, bore W260, 10 April 2003, leg. J. Cocking and M. Scanlon (CALM), 2317'31'S 119 52'12"E: three males + 10 females + one copepodid in alcohol (WAM C34159)

7) Australia, Pilbara, Production Bore K31, bore W260, 4 October 2002, leg. J. Cocking and M. Scanlon (CALM), 2317'31'S 119 52'12"E: 15 males + 61 females ( 5 ovigerous) +22 copepodids in alcohol (WAM C34160)

8) Australia, Pilbara, Newman, bore W135, 20 November 1998, leg. S.M. Eberhard (BES: 6380), $23^{\circ} 17^{\prime} \mathrm{S} 119^{\circ} 52^{\prime} \mathrm{E}$ : nine males +19 females (one ovigerous) +13 copepodids (one female dissected on one slide (WAM C34161); others in alcohol (WAM C34162))

9) Australia, Pilbara, Newman, bore W222, 20 November 1998, leg. S.M. Eberhard (BES: 6391), $23^{\circ} 20^{\prime} \mathrm{S} 119^{\circ} 51^{\prime} \mathrm{E}$ : four males + one female in alcohol (WAM C34163)

10) Australia, Pilbara, Hardey River Borefield, bore HRO28, 27 July 1997, leg. W.F. Humphreys and S.M. Eberhard (BES: 4851), 22.43'01"S $117^{\circ} 30^{\prime} 59^{\prime \prime} \mathrm{E}$ : one female in alcohol (WAM C34164)

\section{Description}

Female (holotype). Total body length, measured from tip of rostrum to posterior margin of caudal 


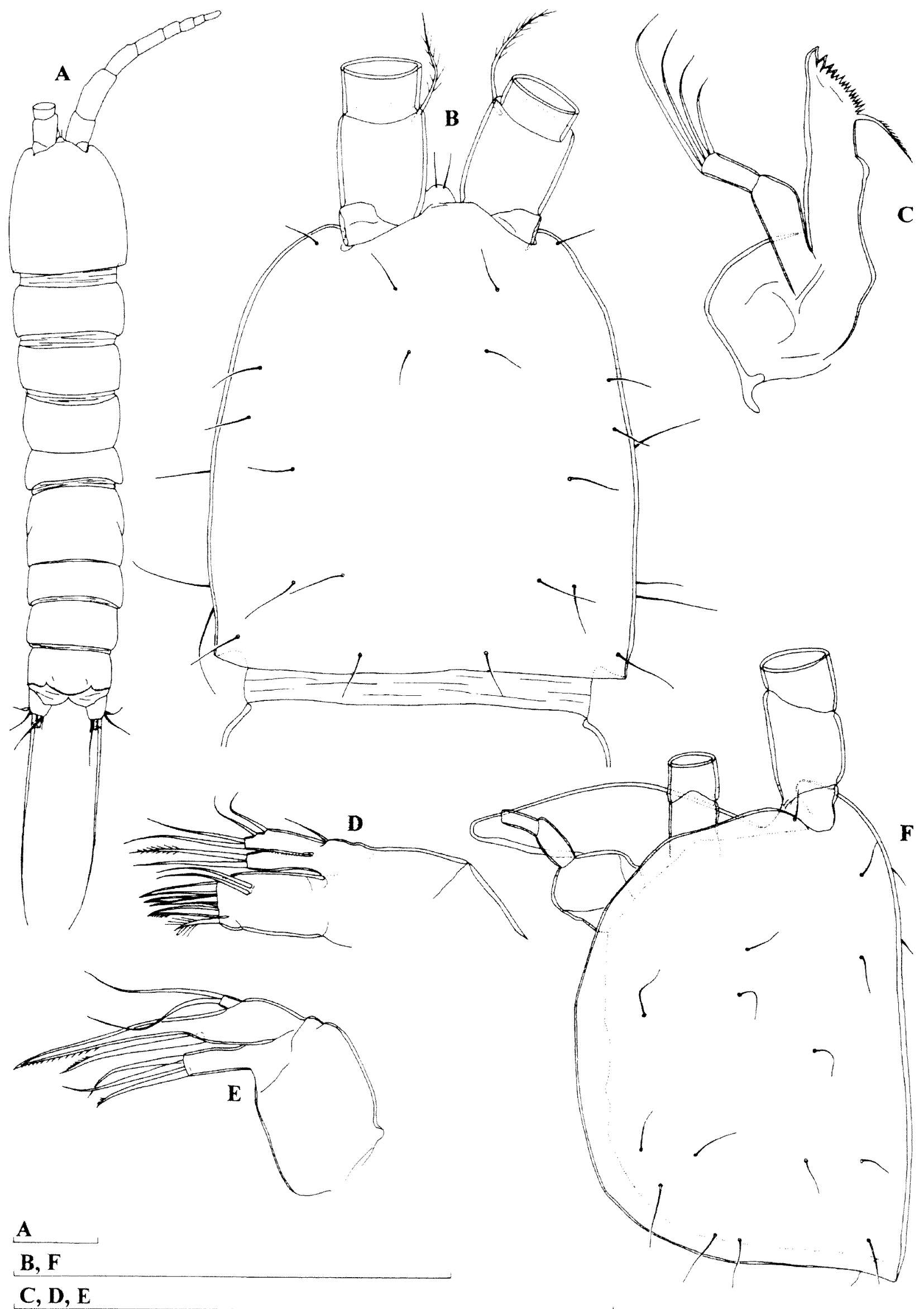

Figure 77 Archinitocrella newmanensis gen. et sp. nov., holotype (female): A, habitus, dorsal view; B, cephalothorax, dorsal view; C, mandibula; D, maxillula; E, maxilla; F, cephalothorax, lateral view. Scales $=0.1 \mathrm{~mm}$. 
rami (excluding caudal setae), $0.477 \mathrm{~mm}$. Preserved specimen colourless. Nauplius eye absent. Habitus (Figure 77A) cylindrical, slender, without distinct demarcation between prosome and urosome; prosome/urosome ratio 1.2 and greatest width at posterior end of cephalothorax. Body length/width ratio about 4.1; cephalothorax 1.2 times as wide as genital double somite. Free pedigerous somites without pronounced lateral expansions or dorsally. Integument not strongly chitinized and no cuticular windows visible. Rostrum small, membranous, ovoid, reaching just beyond proximal margin of first antennular segment, about as long as wide and not demarcated at base; ornamented with two dorsal sensilla.

Cephalothorax (Figure 77B, F) slightly conical in dorsal view, about 1.1 times as long as wide; represents $22 \%$ of total body length. Surface of cephalic shield and tergites of three free pedigerous somites ornamented with many very large sensilla. Hyaline fringes of all somites smooth. Fifth pedigerous (first urosomal) somite ornamented with four dorsal sensilla.

Genital double somite (Figure 78A) 0.8 times as long as wide (ventral view), with suture visible only laterally; ornamented with four large sensilla dorsally (two at middle, two near posterior margin) and with two sensilla ventrally near posterior margin. Female genital complex with single wide copulatory pore, sclerotized conical copulatory duct and two large semicircular seminal receptacles. Single large genital aperture covered by fused reduced sixth legs; represents $49 \%$ of somite width. Third urosomite also ornamented with two ventral and two dorsal large sensilla near posterior margin. Preanal somite ornamented only with posterior uninterrupted row of small spinules; no sensilla on this somite. Anal somite (Figure 78A, D) ornamented with pair of large dorsal sensilla, one transverse row of minute spinules at middle ventrally and transverse row of larger spinules along posterior margin, dorsal ones shorter than ventral. Anal operculum convex, not reaching posterior end of anal somite, represents $51 \%$ of somite's width, ornamented with row of 44 spinules near posterior margin. Anal sinus unornamented, widely opened.

Caudal rami (Figure 78A, C, D) short, as long as greatest width (ventral view), slightly divergent, with space between them more than one ramus width, conical; armed with six armature elements (two lateral, one dorsal and three apical). Ornamentation consists of one long setula at base of proximal lateral seta, two spinules at base of distal lateral seta, few spinules at base of dorsal seta, two ventral cuticular pores and posterior row of few spinules ventrally, near inner margin. Dorsal seta relatively long, inserted near posterior margin, about twice as long as caudal ramus, biarticulate at base and smooth. Proximal lateral seta about 0.5 times as long as dorsal seta, arising slightly dorsolaterally at $3 / 4$ of ramus length. Distal lateral seta arising ventrolaterally, at $4 / 5$ of ramus length, about 0.8 times as long as dorsal one and 1.4 times as long as proximal one, smooth. Inner apical seta small, also smooth, about 0.7 times as long as ramus. Middle apical seta strongest, with breaking plane, pinnate at distal end, about 1.5 times as long as outer apical seta and almost 0.6 times as long as total body length. Outer apical seta also with breaking plane and pinnate at distal end.

Antennula (Figure 79A) eight-segmented, slender, approximately 1.6 times as long as cephalothorax, with slender and long aesthetasc on fourth segment, which reaches beyond tip of appendage for more than length of last four segments together; setal formula: 199.6.3.2.3.4.7. Only seta on first segment pinnate, all other setae smooth. No setae articulating on basal part and all setae without breaking planes. Two apical setae on eighth segment fused basally. First segment ornamented with few spinules on anterior surface proximally; other segments without any ornamentation. Length ratio of antennular segments, from proximal end, 1 $: 2.1: 1.1: 1.2: 0.7: 0.7: 0.5: 0.8$.

Antenna (Figure 79E) composed of coxa, basis, two-segmented endopod and one-segmented exopod. Coxa very short, unornamented. Basis about 1.4 times as long as wide, ornamented with two short rows of long spinules at outer distal corner, unarmed. First endopodal segment about 1.9 times as long as wide, unornamented and unarmed. Second endopodal segment longest, 1.6 times as long as first endopodal and three times as long as wide, armed laterally with two smooth spines flanking thin seta; apical armature consisting of five geniculate setae, longest one fused basally to additional smaller seta, bearing proximal tuft of fine setules; ornamentation consists of one spinule on anterior surface. Exopod one-segmented, cylindrical, unornamented and armed with two apical pinnate setae; inner one almost twice as long as outer one.

Labrum (Figure 78E) large compared with cephalothorax, trapezoidal, rigidly sclerotized, with very short and slightly concave cutting edge, ornamented subapically with two rows of strong spinules with many minute spinules in between, apically. No fields of gustatory papillae visible on dorsal (posterior) surface.

Paragnaths ellipsoid, about twice as long as wide, with group of spinules of different length apically, few spinules laterally, as well as group of five large spinules on proximal inner part of each lobe.

Mandibula (Figure $77 \mathrm{C}$ ) with narrow cutting edge on elongated coxa, armed with three coarse teeth ventrally, one unipinnate seta dorsally and many small teeth in between. Palp uniramous, comprising 


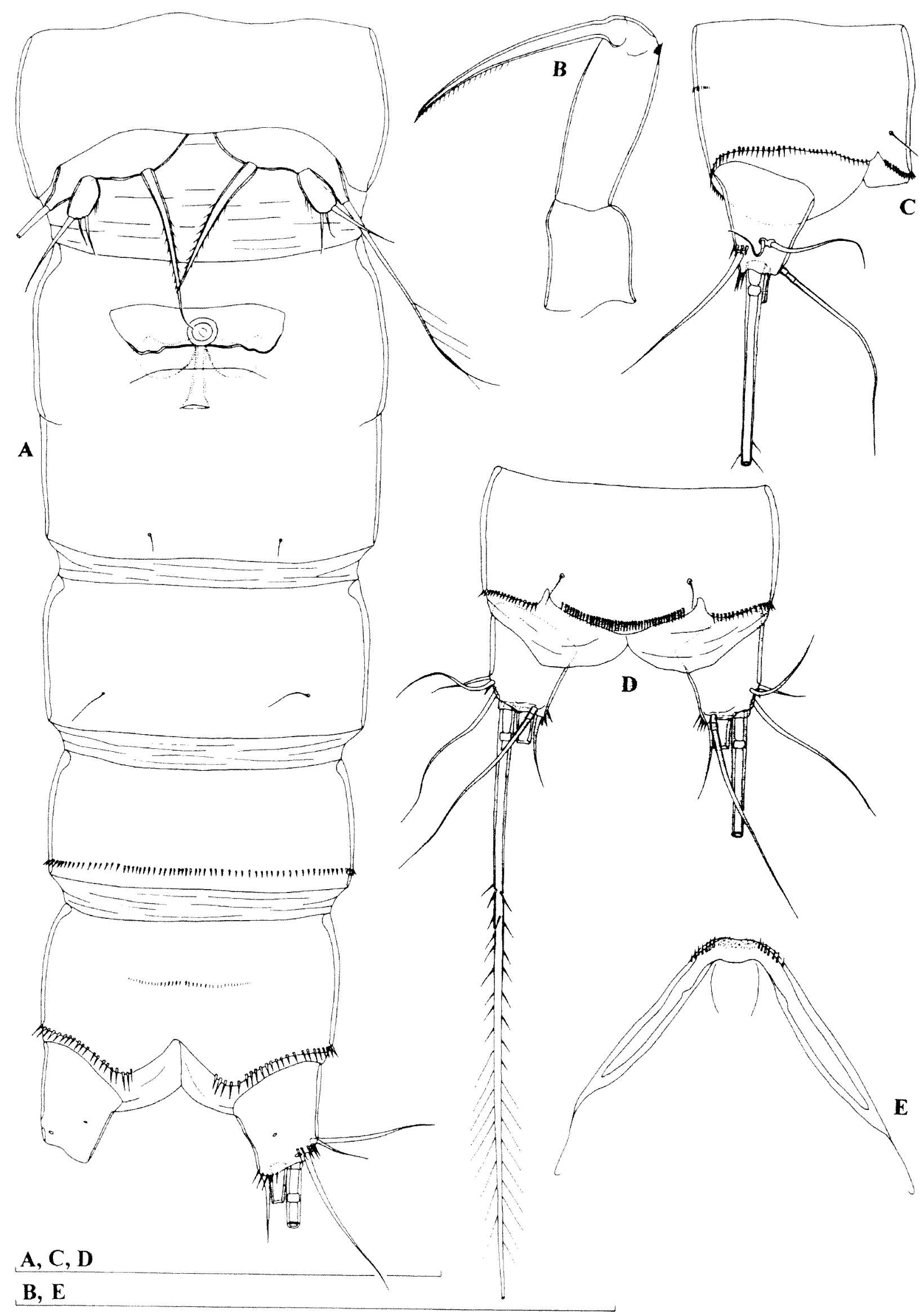

Figure 78 Archinitocrella newmanensis gen, et sp. nov, holotype (female): A, urosome, ventral view; B, maxilliped; C, anal somite and left caudal ramus, lateral view; $D$, anal somite and caudal rami, dorsal view; $E$, labrum. Scales $=0.1 \mathrm{~mm}$. 


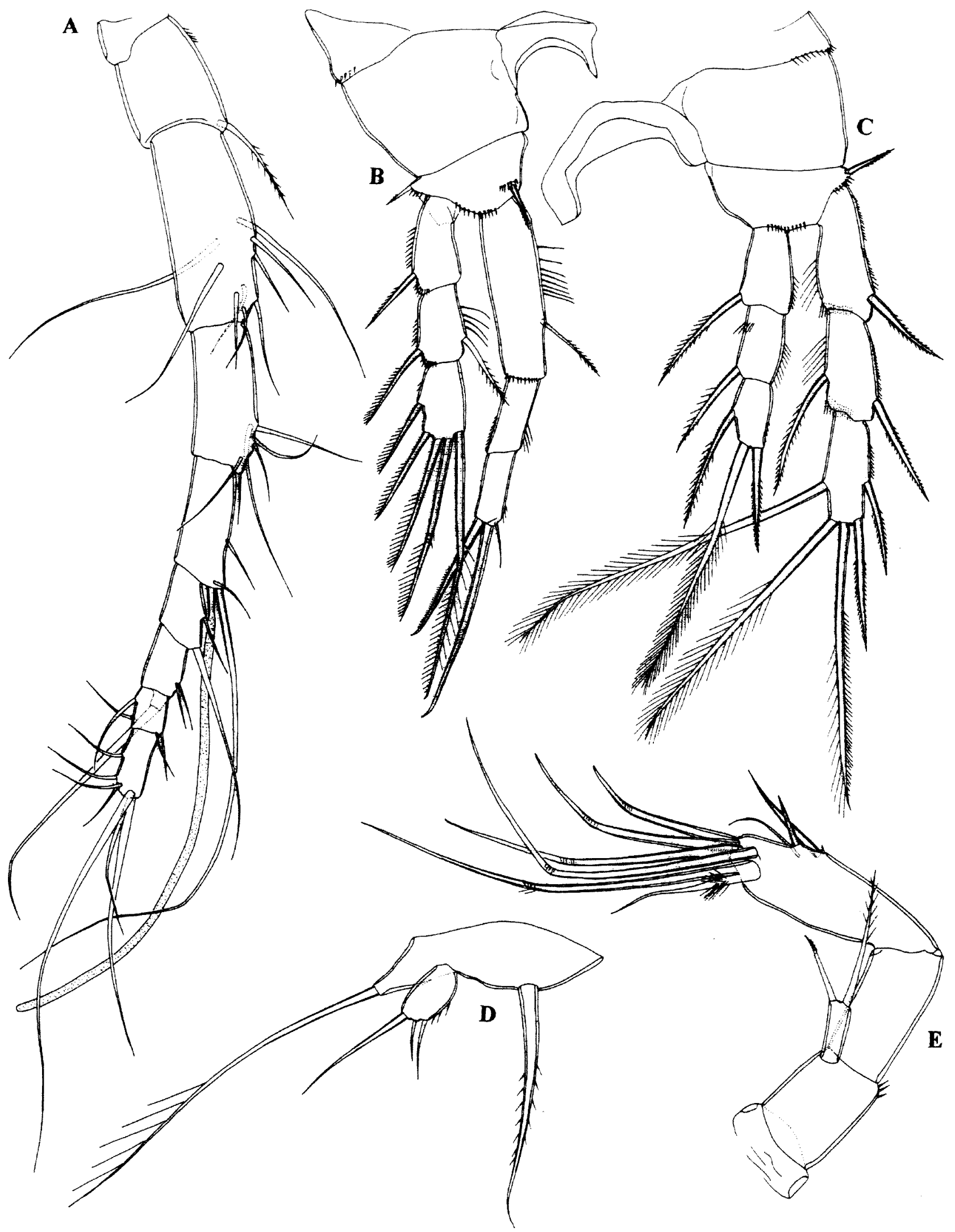

\section{A, B, C \\ D, E}

Figure 79 Archinitocrella newmanensis gen. et sp. nov., holotype (female): A, antennula; B, first swimming leg; C, second swimming leg; $D$, fifth leg; $E$, antenna. Scales $=0.1 \mathrm{~mm}$. 
basis and one-segmented endopod. Basis slender, unarmed and unornamented, more than twice as long as wide. Endopod also slender and unornamented, about 0.5 times as long as basis and about 2.4 times as long as wide; armed with four slender and smooth setae apically, outermost one longest, innermost one shortest.

Maxillula (Figure 77D) with large praecoxa, arthrite rectangular, movable, unornamented; armed with two smooth setae on anterior surface and five apical elements (probably four spines and one dorsal seta). Coxal endite armed with one pinnate and one smooth seta, of about same length. Basis as long as coxal endite, armed with four smooth setae apically and subapically. Endopod minute segment, almost completely fused to basis, armed with single smooth apical seta.

Maxilla (Figure 77E) with proximal endite of syncoxa completely reduced; distal endite well developed, highly mobile, armed with one curved pinnate spine and two smooth subequal setae, which somewhat longer than spine. Basis drawn out into long claw, with much shorter spiniform and curved seta at base. Endopod represented by minute segment, armed with two smooth subequal apical setae.

Maxilliped (Figure 78B) with short syncoxa, which unornamented and unarmed, slightly longer than wide. Basis more than twice as long as wide and somewhat longer than syncoxa, ornamented with row of minute spinules subapically and unarmed. Endopod represented by long curved claw, ornamented with row of spinules along concave side distally; without thin seta at base.

All swimming legs with three-segmented exopod; endopod of first and second leg also threesegmented (Figure 79B, C), while that of third and fourth leg two-segmented (Figure $80 \mathrm{~A}, \mathrm{~B}$ ). Armature formula of swimming legs as follows (legend: inner/outer spine or seta; inner/terminal/ outer):

\begin{tabular}{|c|c|c|c|c|c|c|}
\hline \multirow[b]{2}{*}{ Segments } & \multicolumn{3}{|c|}{ Exopod } & \multicolumn{3}{|c|}{ Endopod } \\
\hline & 1 & 2 & 3 & 1 & 2 & 3 \\
\hline First leg & $0 / 1$ & $1 / 1$ & $0 / 2 / 3$ & $1 / 0$ & $0 / 0$ & $1 / 1 / 1$ \\
\hline Second leg & $0 / 1$ & $1 / 1$ & $1 / 2 / 2$ & $1 / 0$ & $1 / 0$ & $1 / 1 / 1$ \\
\hline Third leg & $0 / 1$ & $1 / 1$ & $1 / 2 / 2$ & $1 / 0$ & $2 / 1 / 1$ & - \\
\hline Fourth leg & $0 / 1$ & $1 / 1$ & $2 / 2 / 2$ & $1 / 0$ & $2 / 1 / 0$ & - \\
\hline
\end{tabular}

Intercoxal sclerites of all swimming legs with concave distal margin and without any surface omamentation. Praecoxa with short row of long spinules along outer posterior margin; coxa of third swimming leg with two short row of spinules near outer margin, other coxae unornamented and all coxae unarmed. Basis ornamented with spinules near outer margin and with row of spinules along posterior margin, between endopod and exopod; armed with outer bipinnate spine on first and second swimming legs and with outer smooth seta on third and fourth legs; basis of first leg with short spine at inner distal corner and row of spinules at its base. Most exopodal and endopodal segments ornamented with spinules along outer margin and some segments also with spinules along inner and distal margins. First exopodal segment of all legs slightly longer than second exopodal segment. First endopodal segment of first swimming leg (Figure 79B) stout, about 3.3 times as long as wide, about as long as first two exopodal segments together. Endopod of second swimming leg (Figure 79C) reaching middle of third exopodal segment; while endopod of third and fourth swimming legs (Figure $80 \mathrm{~A}, \mathrm{~B})$ shorter than first two exopodal segments. All setae on exopods and endopods (except minute inner seta on third endopodal segment of first leg) strong and many spiniform.

Fifth leg (Figure 78A and 79D) biramous, baseoendopods not fused. Baseoendopod with outer basal seta long and unipinnate, arising from long setophore. Endopodal lobe very broad, only slightly convex, extending to first third of exopod, unornamented but armed with single, very stout and bipinnate seta, which 3.7 times as long as exopod and almost 0.7 times as long as outer basal seta. Exopod ovoid, small, about 1.8 times as long as maximum width, ornamented with few slender spinules along inner margin and armed with three slender and smooth setae; length ratio of exopodal setae, from inner side, $1: 0.7: 2.2$. Longest seta on exopod much shorter than endopodal seta.

Sixth legs (Figure 78A) completely fused, indistinct, forming simple operculum covering single gonopore, without any ornamentation or armature.

Male. Habitus, ornamentation of prosomites, rostrum, colour and nauplius eye similar to female. Hyaline fringe of all somites smooth.

Genital somite more than twice as wide as long, with small spermatophore visible inside (Figure 81A). Urosomites ornamentation similar to female, although anal somite without middle row of spinules ventrally but additionaly ornamented with two cuticular pores posteriorly.

Caudal rami (Figure 81A) about as long as wide. Armature and ornamentation similar to female, but two ventral cuticular pores absent and innermost apical seta somewhat longer and more slender than in female.

Antennula (Figure 81B) long and slender, tensegmented, not strongly geniculate, with geniculation between seventh and eighth segment, unornamented. Very long aesthetasc on apical acrothek of fifth segment (homologue to aesthetasc on fourth segment in female); one small aesthetasc on sixth segment. First two and last two segments similar to female. Setal formula: 1.10.7.2.7.1.3.1.4.8. Majority of setae smooth and slender; seta on first segment pinnate; two setae on fifth, one on sixth and one on seventh segment very short and 

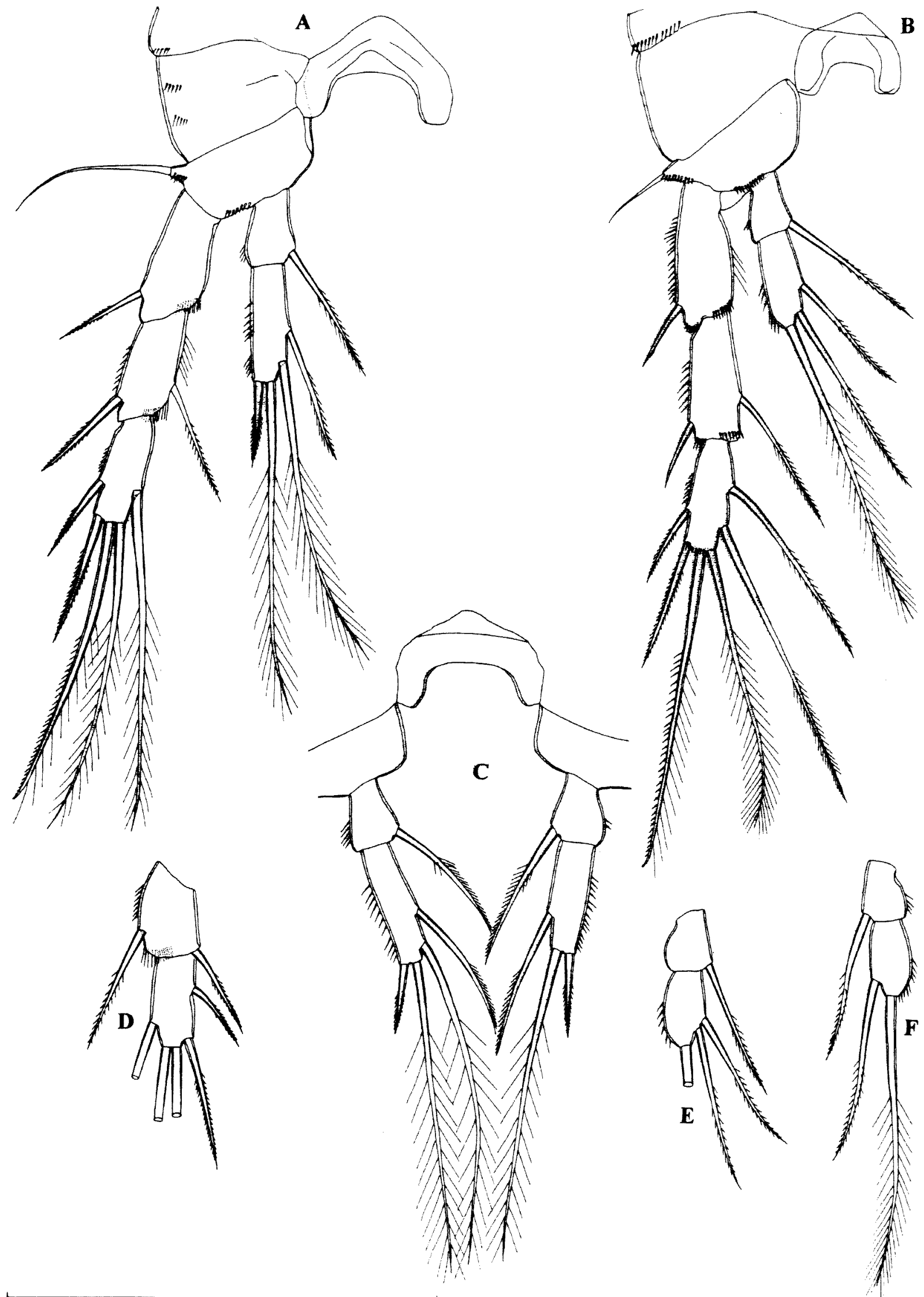

Figure 80 Archinitocrella newmanensis gen. et sp. nov., A and B, holotype (female); $\mathrm{C}$, female $(0.465 \mathrm{~mm})$ from locality 8 (WAM C34161); D-F, paratype female (0.458 mm; WAM C34150): A, third swimming leg; B, fourth swimming leg; $C$, endopods and intercoxal sclerite of third swimming leg; D, second and third exopodal segments of third swimming leg; $\mathrm{E}$, endopod of right swimming leg; $\mathrm{F}$, endopod of left swimming leg. Scale $=0.1 \mathrm{~mm}$. 
spiniform. Only three lateral setae on tenth segment, seta on eighth segment and one seta on second segment articulating on basal part. No setae with breaking planes.

Antenna, labrum, paragnaths, mandibula, maxillula, maxilla, maxilliped, second swimming leg and fourth swimming leg similar to female.

First swimming leg (Figure 81C) also similar to female, without significantly modified inner spine on basis.

Third swimming leg (Figure 81D) with apical seta on third endopodal segment much shorter and with small pinnules (instead of being plumose); other details similar to female.

Fifth legs (Figure 81A) with baseoenopods fused medially but distinct from somite. Baseoendopod with outer basal seta long, smooth, arising from long setophore. Endopodal lobe broad, almost straight, unornamented and unarmed. Exopod small, pentagonal, about 1.2 times as long as maximum width, unornamented and armed similarly to female on right leg, while innermost seta on left leg very long, strong and plumose distally.

Sixth legs (Figure 81A) narrowly fused basally but distinct from somite, each armed with one smooth seta; left leg larger than right one.

\section{Variability}

Body length of females ranges from $0.404 \mathrm{~mm}$ to $0.482 \mathrm{~mm}(0.462 \mathrm{~mm}$ average; $\mathrm{n}=8)$, while in males it ranges from $0.404 \mathrm{~mm}$ to $0.438 \mathrm{~mm}(0.421 \mathrm{~mm}$ average; $\mathrm{n}=5$ ). One female from locality 8 has asymmetrical endopods of the third swimming leg (Figure $80 \mathrm{C}$ ), with only three armature elements on the second segment of one endopod but the normal four elements on the opposite endopod. One paratype female has asymmetrical endopods of the fourth swimming leg (Figure $80 \mathrm{E}, \mathrm{F}$ ), as well as an abnormal exopod of the third swimming leg (Figure 80D). Exopods of the fith leg in the male are also asymmetrical (Figure $81 \mathrm{~A}$ ), the left one having much stronger innermost armature element than the right one.

\section{Etymology}

The new species is named after the type locality, Newman Borefield.

\section{Discussion}

Archinitocrella gen. nov has a segmentation of the swimming legs that is unique in the family Ameiridae, with the endopod of the first and second legs three-segmented and that of the third and fourth legs two-segmented. Another very important generic character is the untransformed inner basal spine of the first swimming leg in male (Figure $81 \mathrm{C}$ ). The modification of this spine in male Ameiridae is one of the most important family autapomorphies, so its state in Archinitocrella would, at the first glance, suggest an erroneous systematic position in this family. The only other Ameiridae genus with unmodified inner basal spine is Psammonitocrella, which was proposed by Rouch (1992) to accommodate two interstitial species collected in the hyporheic zone of an intermittent desert stream in Arizona (United States). Its familial placement was questioned by Martinez Arbizu and Moura (1994), who removed the genus from Ameiridae and regarded it as the sistergroup of the family Parastenocarididae. Lee and Huys (2002) proposed to relocate Psammonitocrella to the Ameiridae, based on their opinion that the absence of a sexually dimorphic inner basal spine is a paedomorphic feature and an autapomorphy in the genus. Reid et al. (2003) and Karanovic (2004a) accepted their view.

Archinitocrella gen. nov. and Psammonitocrella are not closely related and an unmodified inner basal spine is the only relevant shared character, i.e. it is an obvious convergence. Psammonitocrella differs from the new genus by a number of stygomorphies, including the segmentation and armature of all swimming legs and fifth leg as well. Psammonitocrella has separate genital and first abdominal somites in the adult female (another paedomorphic feature) but also a plesiomorphic exopod of the antenna (with all three armature elements present) and very long caudal rami (Rouch 1992), which all distinguish this genus from Archinitocrella. The new genus belongs to that evolutionary line of Ameiridae that encompasses the genera Nitocrellopsis Galassi, De Laurentiis and Dole-Olivier, 1999, Pseudoleptomesochrella Lang, 1965 and Nitocrella Chappuis, 1923. None of the known endemic Australian Ameiridae genera (see Lee and Huys 2002, Karanovic 2004a), or those described in this monograph, is closely related to Archinitocrella, which further supports my view of a very ancient origin of the freshwater Ameiridae. That, combined with the numerous stygomorphies and convergences, is making the job of evaluating distinct evolutionary lineages within this family very difficult. The primary taxonomic subdivisions in freshwater Ameiridae have traditionally been based on swimming legs segmentation (Lang 1948, 1965, Petkovski 1976), an approach characterised as simplistic by Lee and Huys (2002) and Reid et al. (2003) and certainly creating many unnatural genera. However, lack of information about many morphological details in the published descriptions and uncertainty about the extent of the diversity of this family in many parts of the world, presents a problem when trying to establish natural phylogenetic groups. On the positive side, as a result of a great morphological plasticity in the 


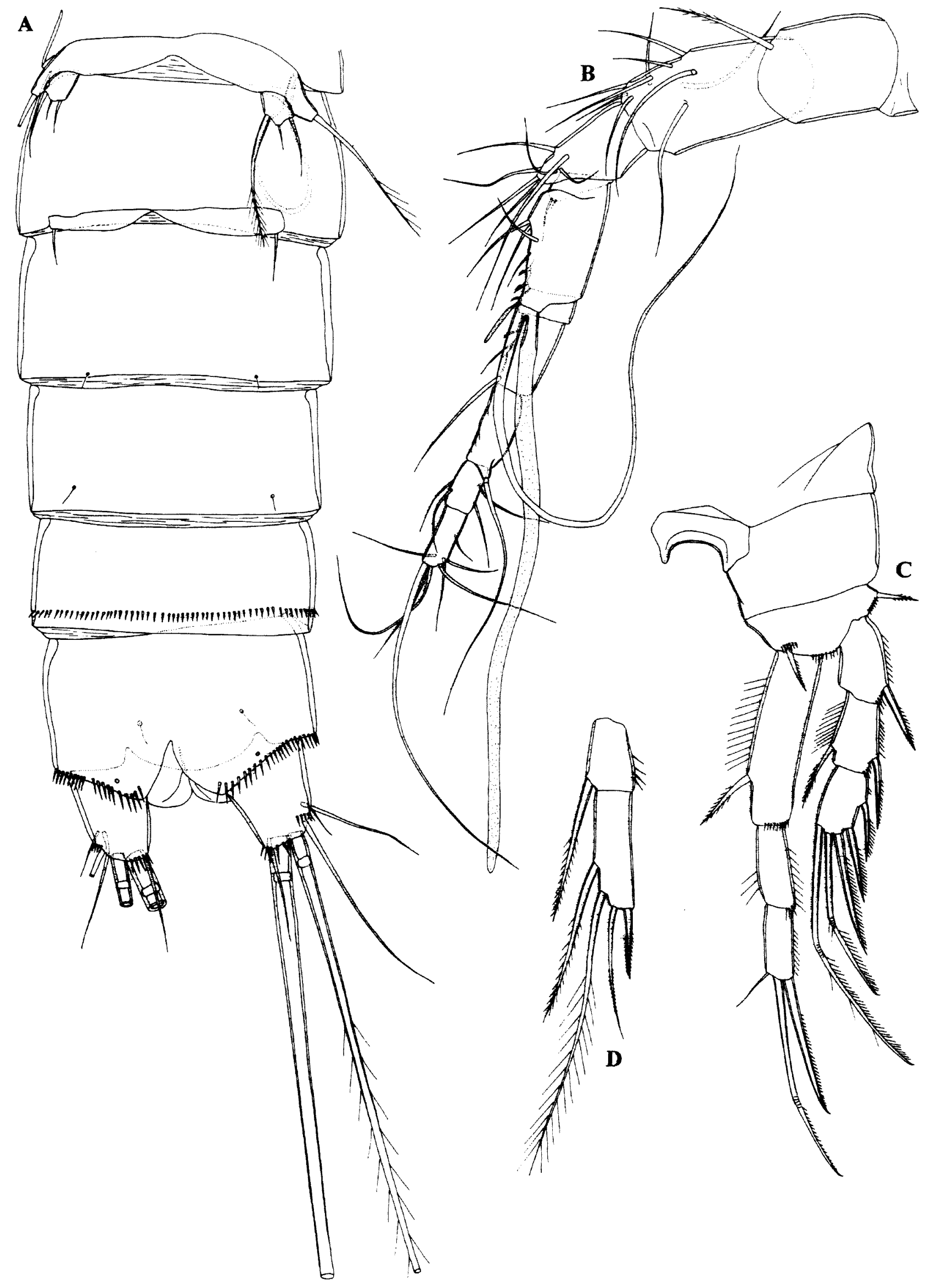

Figure 81 Archinitocrella newmanensis gen. et sp. nov., male (0.404 mm) from locality 5 (WAM C34256): A, urosome, ventral view; $B$, antennula; $C$, first swimming leg; $D$, endopod of third swimming leg. $S c a l e=0.1 \mathrm{~mm}$. 
majority of characters traditionally used in the taxonomy of this family, we have far less synonyms at the species level.

Reid et al. (2003) suggested the potential importance of the fifth leg shape for the systematic groupings at the generic level in the Ameiridae. However, the fifth leg cannot be used with the same confidence here as in some other copepod families. This appendage in Archinitocrella has only one strong element on the endopodal lobe in the female and three slender elements on the small exopod (Figure 79D). Superficially similar female fifth legs (with only one endopodal element) can be found in three, closely related with each other, Caucasian species of Nitocrella ( $N$. jankowskajae, $N$. monchenkoi and $N$. kirgizica), described by Borutzky (1972); two littoral species of Parevansula from Mozambique ( $P$. reductiforma and $P$. secunda) described in the new genus Philoleptomesochra by Wells (1967), which was later synonymized; Nitocrella unispinosus Shen and Tai, 1973 from China (see Shen et al. 1979); and also in at least some specimens of two Australian species, described in two different genera by Karanovic (2004a) (Nitocrella obesa and Haifameira pori). However, none of these taxa have such a broad endopodal lobe and such a strong element on it as Archinitocrella and the numerous other morphological differences suggest there is no close relationship between the other species and the new genus. In this example, the shape of the fifth leg is a good indicator of a close relationship between the three Caucasian and one Chinese Nitocrella species (where it is not just superficially similar and where other morphological characters also support close relationship) but it is only superficially similar in the Australian Nitocrella obesa and other abovementioned cases, where the number of armature elements on the female fifth leg endopodal lobe is convergent in different genera or a result of parallelism.

\section{Genus Abnitocrella gen. nov.}

\section{Diagnosis}

Moderately large Ameiridae, with cylindrical habitus and without distinct demarcation between prosome and urosome. Rostrum minute, not demarcated at base. Hyaline fringe of all prosomites smooth. Genital double somite without any suture visible; copulatory pore small and ovoid; copulatory duct well sclerotized and seminal receptacles ovoid; single genital aperture covered by fused and unarmed sixth legs. Anal operculum broad, convex ornamented with posterior row of numerous spinules. Caudal rami from 1.3 to 3.4 times as long as wide, with pronounced apical ventral rounded shelf and complete armature; dorsal seta biarticulate at base and longer than lateral or innermost apical setae. Antennula eightsegmented, with long aesthetasc on fourth segment; first segment as long as or shorter than second. Antenna composed of coxa, basis, two-segmented endopod and one-segmented exopod; exopod very small, armed with one or two elements. Labrum large, trapezoidal, with broad and well ornamented cutting edge. Mandibula with narrow cutting edge and uniramous palp; basis unarmed and unornamented, about twice as long as wide; endopod much smaller than basis, armed apically with five smooth setae. Maxillular endopod present or absent. Maxilla with only one endite on syncoxa, which armed with three apical elements; basis drawn out into long claw, with one spiniform seta at its base; endopod minute but distinct segment, armed with two slender setae. Maxilliped three segmented, unarmed or armed with one element on syncoxa and one on endopod. All swimming legs with three-segmented exopod; endopod of first leg also three-segmented, that of other legs twosegmented; first exopodal segments of all legs without inner setae and third exopodal segments of all legs with two outer spines; first endopodal segment of first leg shorter than exopod. Fifth leg fused to somite, represented by small setophore bearing outer basal seta; and in female with one or two additional setae of unclear origin (probably exopodal). Male sixth leg absent. Male antennula ten-segmented, not strongly geniculate. First swimming leg in male with significanlty modified inner basal spine. Second endopodal segment of third leg in male with inner apical element shorter than in female and more spiniform. Spermatophore very small.

\section{Type species}

Abnitocrella halsei sp. nov.

\section{Other species \\ Abnitocrella eberhardi sp. nov.}

\section{Etymology}

The genus name is composed of the Latin preposition "ab" (meaning "from") and the existing generic name Nitocrella. Gender feminine.

\section{Abnitocrella halsei sp. nov.}

Figures 82-85

\section{Material Examined}

\section{Holotype}

Female (WAM C34165), Australia, Pilbara, Paraburdoo Town Borefield, bore PTO-11, 9 April 2003, leg. J. Cocking and M. Scanlon (CALM), $23^{\circ} 11^{\prime} 18^{\prime \prime} \mathrm{S} 117^{\circ} 40^{\circ} 03^{\prime \prime} \mathrm{E}$ : dissected on two slides 
Allotype

Male (WAM C34166), Australia, Pilbara, Paraburdoo Town Borefield, bore PTO-11, 9 April 2003, leg. J. Cocking and M. Scanlon (CALM), $23^{\circ} 11^{\prime} 18^{\prime \prime} \mathrm{S} 117^{\circ} 40^{\prime} 03^{\prime \prime} \mathrm{E}$ : dissected on one slide

\section{Paratypes}

Australia, Pilbara, Paraburdoo Town Borefield, bore PTO-11, 9 April 2003, leg. J. Cocking and M.

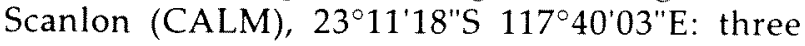
males + two females + one copepodid (one male and one female dissected on one slide each (WAM C34167 and C34226); others in alcohol (WAM C34168))

\section{Other material}

Australia, Pilbara, Fortescue 3A, bore G 70830104, 14 November 2002, leg. J. Cocking and M. Scanlon (CALM), $21^{\circ} 12^{\prime} 57^{\prime \prime S} 116^{\circ} 02^{\prime} 32^{\prime \prime} \mathrm{E}$ : one female + one copepodid dissected on one slide each by Jane McRae (HA 223 and 224), in very poor condition (WAM C34169 and C34170)

\section{Description}

Female (holotype). Total body length, measured from tip of rostrum to posterior margin of caudal rami (excluding caudal setae), $0.477 \mathrm{~mm}$. Preserved specimen colourless. Nauplius eye absent. Habitus (Figure 82A) cylindrical, not very slender, without distinct demarcation between prosome and urosome; prosome/urosome ratio 1.1 and greatest width at posterior end of cephalothorax. Body length/width ratio about 4.1 ; cephalothorax 1.4 times as wide as genital double somite. Free pedigerous somites without pronounced lateral expansions or dorsally; thoracic, as well as abdominal, somites connected by well developed arthrodial membranes. Pleural areas of cephalothorax and first three free pedigerous somites not well developed; cephalic appendages and coxae of swimming legs clearly exposed in lateral view (Figure 82A). Integument very weakly chitinized and no cuticular windows visible. Rostrum minute, membranous, almost triangular in dorsal view, reaching just beyond proximal margin of first antennular segment, about as long as wide and not demarcated at base; ornamented with two dorsal sensilla.

Cephalothorax (Figure $82 \mathrm{~A}$ and $83 \mathrm{C}$ ) slightly conical from dorsal view, about 1.1 times as long as wide; represents $25 \%$ of total body length. Surface of cephalic shield and tergites of first three free pedigerous somites ornameted with many very large sensilla. Hyaline fringe of all somites smooth. Fifth pedigerous (first urosomal) somite ornamented with four dorsal sensilla.

Genital double somite (Figure 83A) 0.7 times as long as wide (ventral view), without any suture visible; ornamented only with two cuticular pores ventrally and two sensilla dorsally. Female genital complex with single minute and ovoid copulatory pore, well sclerotized and cylindrical copulatory duct and two large ovoid seminal receptacles. Single large genital aperture covered by fused reduced sixth legs, represents $39 \%$ of somite width. Third urosomite ornamented with two ventral short rows of small spinules posteriorly, as well as with two dorsal large sensilla near posterior margin. Preanal somite short, ornamented with posterior uninterrupted row of small spinules ventrally; no sensilla on this somite. Anal somite (Figure 83A) ornamented with pair of large dorsal sensilla, one transverse complex row of minute spinules at middle ventrally and transverse row of larger spinules along posterior margin, dorsal ones shorter than ventral. Anal operculum (Figure 83F) convex, almost reaching posterior end of anal somite, represents $55 \%$ of somite's width, ornamented with row of 33 spinules near posterior margin. Anal sinus unornamented, widely opened .

Caudal rami (Figure 83A) 1.3 times as long as greatest width (ventral view), slightly conical and divergent, with space between them more than one ramus width; armed with six elements (two lateral, one dorsal and three apical). Ornamentation consists of one long setula at base of proximal lateral seta, two spinules at base of distal lateral seta, few spinules at base of dorsal seta and single spinule at base of innermost apical seta ventrally. Dorsal seta relatively short, inserted at $3 / 4$ of ramus length, about 1.3 times as long as ramus, biarticulate at base and smooth. Proximal lateral seta about 0.8 times as long as dorsal seta, arising at $2 / 3$ of ramus length. Distal lateral seta arising ventrolaterally, at $4 / 5$ of ramus length, about 0.8 times as long as dorsal one and 0.9 times as long as proximal one, smooth. Inner apical seta slender, also smooth, about 1.2 times as long as ramus. Middle apical seta strongest, with breaking plane, pinnate at distal end, about 1.5 times as long as outer apical seta and almost 0.4 times as long as total body length. Outer apical seta also with breaking plane and pinnate at distal end.

Antennula (Figure 82D) eight-segmented, slender, approximately 1.2 times as long as cephalothorax, with long aesthetasc on fourth segment, which reaches beyond tip of appendage for more than length of last three segments together; setal formula: 1.9.6.3.2.2.4.7. All setae slender and smooth. Only one lateral seta on eighth segment articulating on basal part and no setae with breaking plane. Two apical setae on eighth segment fused basally. First segment relatively large, ornamented with short transverse row of spinules on anterior surface at middle; other segments without any ornamentation. Length ratio of antennular segments, from proximal end, $1: 1: 0.7$ : $0.9: 0.4: 0.7: 0.4: 0.6$. 


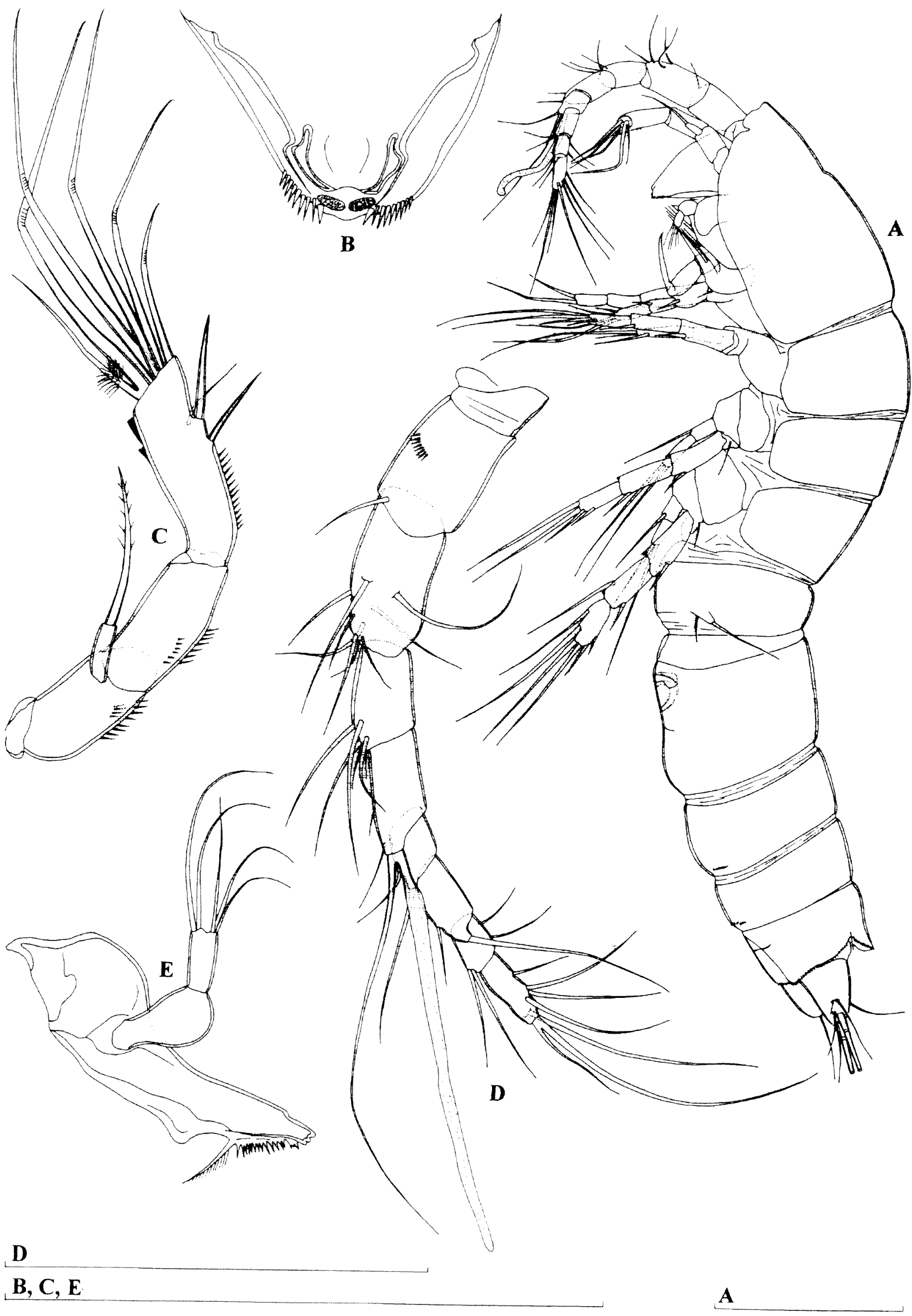

Figure 82 Abnitocrella halsei gen. et sp. nov., holotype (female): A, habitus, lateral view; B, labrum; C, antenna; D, antennula; $E$, mandibula. Scales $=0.1 \mathrm{~mm}$. 


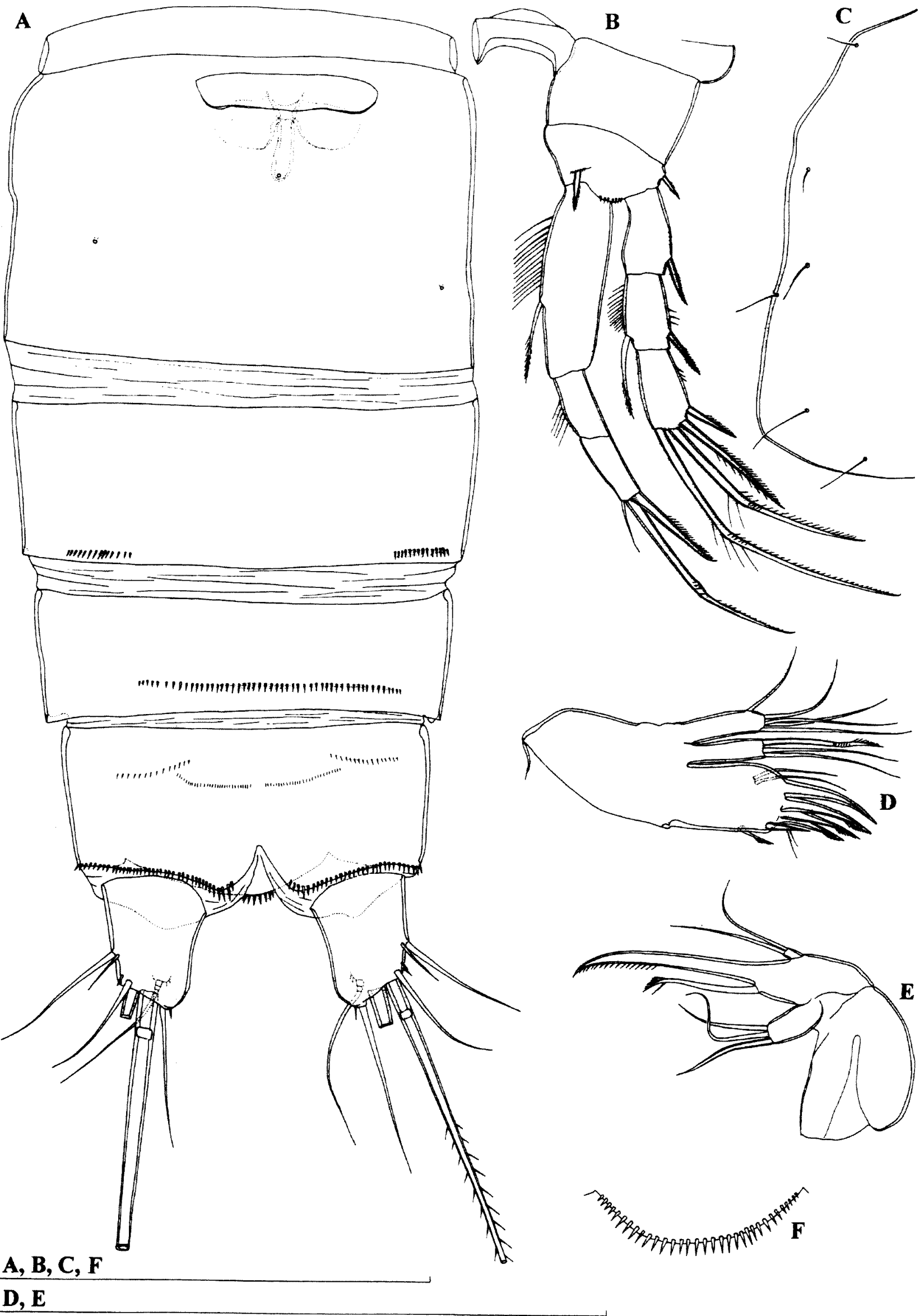

Figure 83 Abnitocrella halsei gen. et sp. nov., holotype (female): A, abdomen, ventral view; B, first swimming leg; C, cephalic shield, left lateral margin; D, maxillula; $E$, maxilla; $F$, anal operculum. Scales $=0.1 \mathrm{~mm}$. 
Antenna (Figure 82C) composed of coxa, basis, two-segmented endopod and one-segmented exopod. Coxa very short, unomamented. Basis about 1.9 times as long as wide, ornamented with two rows of spinules along outer margin. First endopodal segment about 2.3 times as long as wide, ornamented similarly to basis and unarmed. Second endopodal segment longest, 1.3 times as long as first and 3.5 times as long as wide, armed laterally with two smooth spines flanking thin seta; apical armature consisting of five geniculate setae, longest one fused basally to additional smaller seta, bearing proximal tuft of fine setules; ornamentation consists of row of spinules on anterior surface. Exopod onesegmented, cylindrical and small, unornamented and armed with single apical pinnate seta, which 2.7 times as long as segment.

Labrum (Figure 82B) large compared with cephalothorax, trapezoidal, rigidly sclerotized, with broad and concave cutting edge, which ornamented subapically with two rows of strong spinules. Two ovoid fields of gustatory papillae visible on dorsal (posterior) surface.

Mandibula (Figure 82E) with narrow cutting edge on elongated coxa, armed with three coarse teeth ventrally, one unipinnate seta dorsally and numerous small teeth in between. Palp uniramous, comprising basis and one-segmented endopod. Basis with bulging inner margin distally, unarmed and unornamented, almost twice as long as wide. Endopod slender and unornamented, about 0.6 times as long as basis and about 2.3 times as long as wide; armed with five slender and smooth setae apically, outermost one longest, innermost one shortest.

Maxillula (Figure 83D) with large praecoxa, arthrite of which rectangular, not movable, unornamented; armed with two smooth setae on anterior surface, two setae on dorsal surface and four apical elements (probably three spines and one dorsal seta). Coxal endite armed with one pinnate and curved seta and two smooth setae of about same length, longer than curved one. Basis as long as coxal endite, armed with five smooth setae apically and subapically. Endopod absent.

Maxilla (Figure 83E) with proximal endite on syncoxa completely reduced; distal endite well developed, highly mobile, armed with one curved smooth spine and two smooth subequal setae, somewhat longer than spine. Basis drawn out into long claw, with much shorter spiniform and curved seta at base. Endopod represented by minute segment, armed with two smooth subequal apical setae.

Maxilliped with large syncoxa, unornamented and unarmed and almost twice as long as wide. Basis 2.8 times as long as wide and 1.4 times longer than syncoxa, unornamented and unarmed. Endopod represented by long curved claw, which ornamented with row of spinules along concave side distally; without thin seta at base.

All swimming legs with three-segmented exopod; endopod of first leg also three-segmented (Figure $83 \mathrm{~B}$ ), while those of other legs two-segmented (Figure $84 \mathrm{~A}, \mathrm{~B}, \mathrm{C}$ ). Armature formula of swimming legs as follows (legend: inner/outer spine or seta; inner/terminal/outer):

\begin{tabular}{|c|c|c|c|c|c|c|}
\hline & \multicolumn{3}{|c|}{ Exopod } & \multicolumn{3}{|c|}{ Endopod } \\
\hline Segments & 1 & 2 & 3 & 1 & 2 & 3 \\
\hline First leg & $0 / 1$ & $1 / 1$ & $0 / 2 / 2$ & $1 / 0$ & $0 / 0$ & $1 / 1$ \\
\hline Second leg & $0 / 1$ & $1 / 1$ & $0 / 2 / 2$ & $1 / 0$ & $2 / 1 / 1$ & - \\
\hline Third & $0 / 1$ & $1 / 1$ & $0 / 2 / 2$ & $1 / 0$ & $2 / 1 / 0$ & \\
\hline Fourth leg & $0 / 1$ & $1 / 1$ & $2 / 2 / 2$ & $1 / 0$ & $0 / 1 / 0$ & - \\
\hline
\end{tabular}

Intercoxal sclerites of all swimming legs with concave distal margin and without any surface ornamentation. Praecoxae and coxae also unornamented (except few spinules on coxa of second leg near inner distal corner and few spinules on coxa of third leg on outer distal corner) and unarmed. Basis of third leg ornamented with few spinules near outer margin; basis of first and second leg with row of spinules along posterior margin, between endopod and exopod; basis of fourth leg unomamented; armed with outer bipinnate spine on first and second swimming legs and with outer smooth seta on third and fourth legs; basis of first leg with short spine at inner distal corner and row of spinules at its base. Most exopodal and endopodal segments ornamented with spinules along outer margin and some segments also with spinules along inner and distal margin. First exopodal segment of all legs about as long as second exopodal segment. First endopodal segment of first swimming leg (Figure 83B) stout, about three times as long as wide, somewhat longer than first two exopodal segments together. Endopod of second swimming leg (Figure 84A) slightly shorter than first two exopodal segments together; endopod of third leg (Figure $84 \mathrm{~B}$ ) reaching middle of second exopodal segment in length; while endopod of fourth swimming leg (Figure 84C) as long as first exopodal segment. All setae on exopods and endopods (except minute inner seta on third endopodal segment of first leg) strong and many spiniform.

Fifth leg (Figure $82 \mathrm{~A}$ ) fused to somite; represented by small setophore bearing outer basal seta and only one additional seta with unclear origin (it could be either exopodal or baseoendopodal). Both setae smooth and outer basal seta about 2.5 times as long as other one.

Sixth legs (Figure 83A) completely fused, indistinct, forming simple operculum covering single gonopore, without any ornamentation or armature

Male (allotype). Body length, exluding caudal setae, $0.419 \mathrm{~mm}$. Habitus, ornamentation of prosomites, rostrum (Figure 851), colour and 


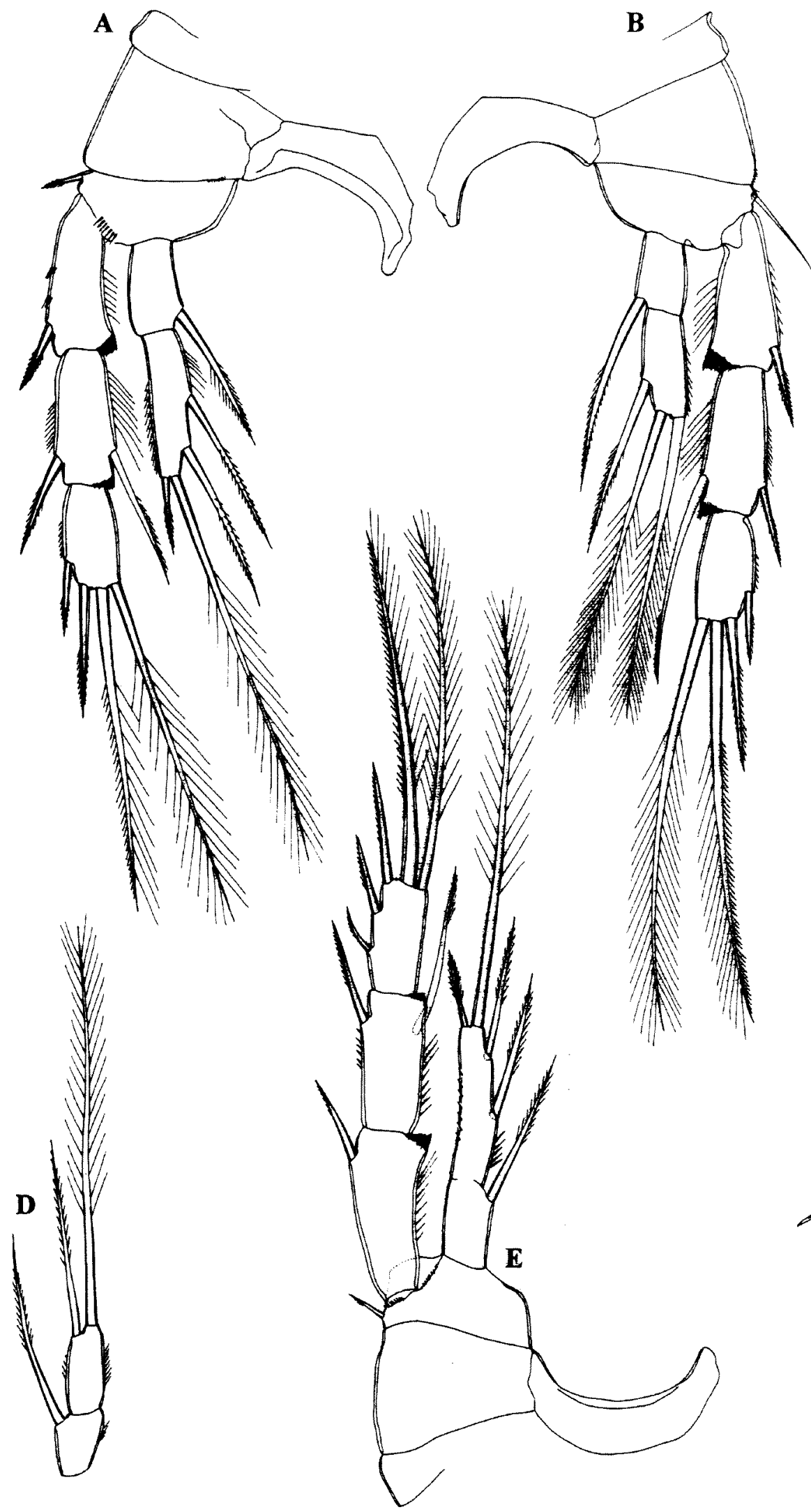

\section{$A, B, C, D, E$}

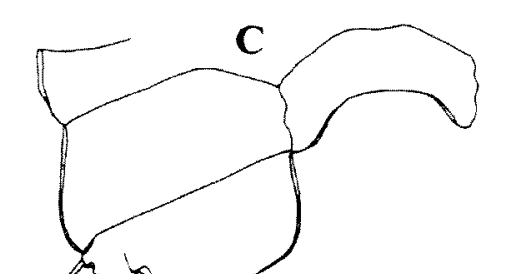

F

Figure 84 Abnitocrella halsei gen. et sp. nov., A-C, holotype (female); D-F, paratype female (0.477 mm; WAM C34226): A, second swimming leg; $B$, third swimming leg; $C$, fourth swimming leg; $D$, endopod of fourth swimming leg; E, second swimming leg; F, maxilliped. Scales $=0.1 \mathrm{~mm}$. 
nauplius eye similar to female. Hyaline fringe of all somites smooth.

Genital somite (Figure 85A) more than 2.6 times as wide as long, with small and longitudinally placed spermatophore visible inside (Figure $85 \mathrm{H}$ ). Urosomites ornamentation similar to female in dorsal view but different in ventral view: genital somite unornamented; third and fourth urosomal somites each with pair of long sensilla near posterior margin; preanal somite with pair of sensilla and uninterrupted row of spinules in between; anal somite similar to female, but with two additional cuticular pores ventrally

Caudal rami (Figure 85A) more conical than in female, about as long as wide. Armature and ornamentation similar to female, but with few more spinules at base of innermost apical seta.

Antennula (Figure 85E) long and slender, tensegmented, unornamented, not strongly geniculate, with geniculation between seventh and eighth segment. Very long aesthetasc on apical acrothek of fifth segment (homologue to aesthetasc on fourth segment in female); one smaller and slender aesthetasc on eighth segment apically. Only first two segments similar to female. Setal formula: 1.8.6.2.7.2.2.1.4.7. Majority of setae smooth and slender; seta on first segment pinnate; two setae on fifth, one on sixth and one on seventh segment very short and spiniform and also pinnate. Only three lateral setae on tenth and two setae on eighth segment articulating on basal part. No setae with breaking plane.

Antenna, labrum, mandibula, maxillula, maxilla, maxilliped, second swimming leg (Figure 85D) similar to female.

First swimming leg (Figure 85B) with significantly modified inner spine on basis, which broad, smooth and roundly bilobate distally.

Third swimming leg (Figure $85 \mathrm{C}$ ) with apical seta on third endopodal segment somewhat shorter and pinnate (instead of being plumose); other details similar to female.

Fourth swimming leg (Figure 85F) with two armature elements on second endopodal segment.

Fifth legs (Figure 85A) completely fused to somite, represented only by small setophore bearing outer smooth basal seta

Sixth legs (Figure 85A) absent.

\section{Variability}

Body length of females ranges from $0.446 \mathrm{~mm}$ to $0.477 \mathrm{~mm}(0.461 \mathrm{~mm}$ average; $\mathrm{n}=4)$, while in males it ranges from $0.415 \mathrm{~mm}$ to $0.44 \mathrm{~mm}(0.424 \mathrm{~mm}$ average; $n=3$ ). One paratype female has an abnormal second swimming leg (Figure $84 \mathrm{E}$ ), with three outer spines on the third exopodal segment and with endopodal segments partly fused. The same specimen has two armature elements on the second endopodal segment of the fourth swimming leg (Figure 84D). No other type of variability was observed.

\section{Etymology}

The species is named in honour of Dr Stuart A. Halse from the Department of Conservation and Land Management in Perth, who entrusted to me all the copepod material collected during the Pilbara Survey and who also led this project from the beginning. The name is a noun in the genitive singular.

\section{Discussion}

In the key to the genera of Ameiridae by Boxshall and Halsey (2004), which is mostly based on the swimming legs segmentation, both members of the new genus would key out as Nitocrella Chappuis, 1923. The latter genus was established by Chappuis (1923) to accommodate one new species from Serbia, Nitocrella hirta. In the subsequent years many authors, including Chappuis himself, have taken the conservative approach in utilising the genus as a taxonomic repository, which blurred its boundaries in a remarkable way. It was Lang (1965) who first tried to narrow the generic boundaries of Nitocrella and removed all species displaying threesegmented endopods of second, third and fourth legs to a new genus Parapseudoleptomesochra and created a second genus, Pseudoleptomesochrella, to accommodate all Nitocrella species characterised by two-segmented endopods of second, third and fourth leg and the presence of an inner seta on the first exopodal segment of all swimming legs. Even under its revised taxonomic concept the genus Nitocrella continued to accumulate a large number of new species, which prompted Petkovski (1976) to subdivide the genus even further. He separated two new genera (Stygonitocrella and Nitocrellopsis) but did not designate type species for them. This made both generic names unavailable until recently, when Galassi et al. (1999) and Reid et al. (2003) fixed type species and made the names available with their authorship. Another new genus (Neonitocrella) from the Nitocrella-complex was established by Karanovic (2004a), to accommodate one new Australian subterranean species, $N$. aboriginesi.

Abnitocrella gen. nov. can be distinguished from Nitocrella by its extremely reduced fifth legs, both in female and male, by the reduced armature of the antennal exopod and by a complete loss of the sixth leg in the male. Although the reductions displayed by the two new species could be interpreted merely as a reflection of the evolution within the genus Nitocrella, the fact that they are achieved in a similar way in two morphologically not very close species suggests a phylogenetic importance of these reductions. The majority of Nitocrella species (including the type species) have an antennal 


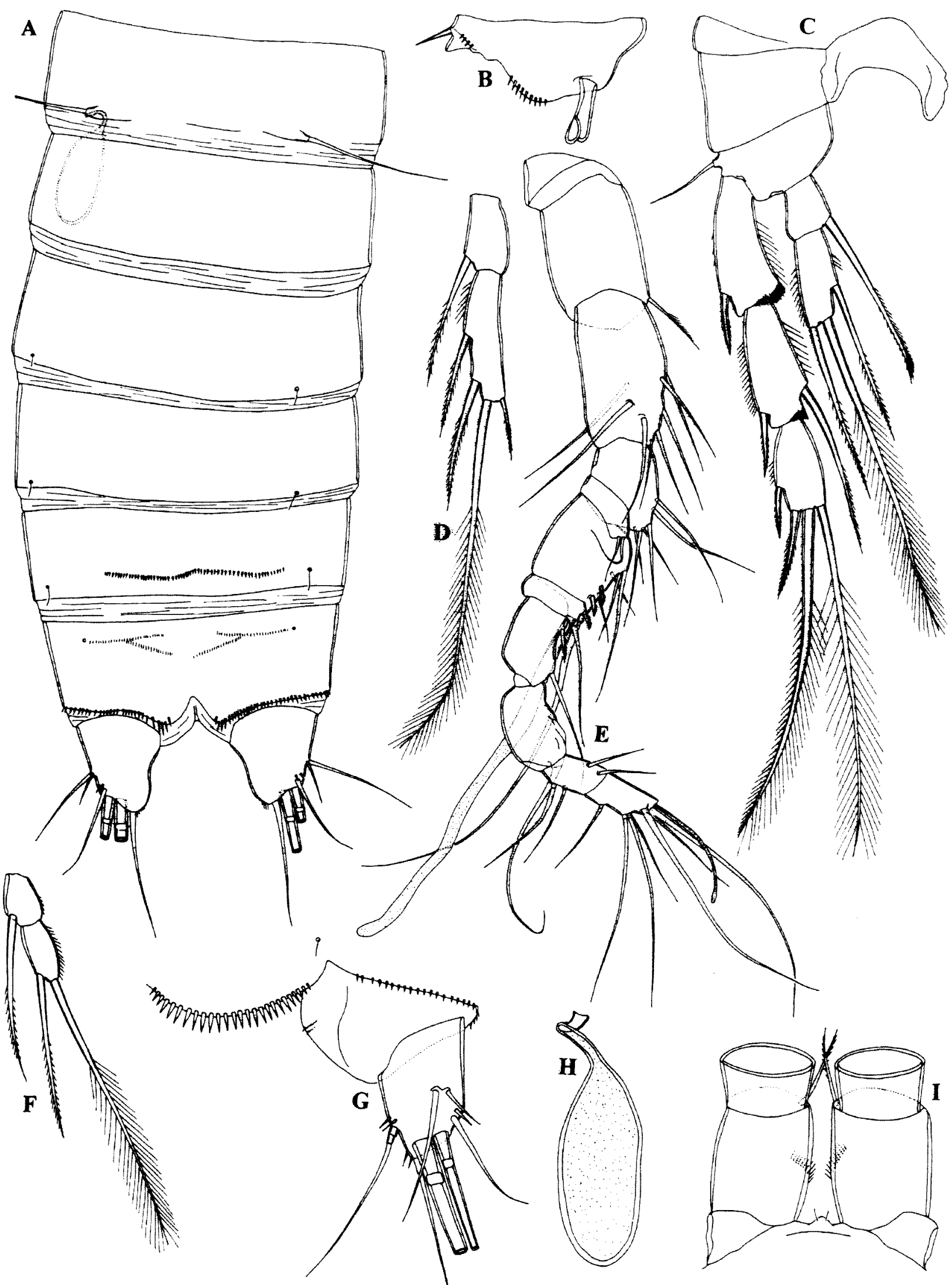

C, D, E, F, G, I

\section{$\mathbf{B}, \mathbf{H}$}

Figure 85 Abnitocrella halsei gen. et sp. nov., allotype (male): A, urosome, ventral view; B, basis of first swimming leg; $C$, third swimming leg; D, secoond swimming leg; E, antennula; F, endopod of fourth swimming leg; $G$, anal operculum and right furcal ramus, dorsal view; $H$, spermatophore; I, rostral region, dorsal view. Scales $=0.1 \mathrm{~mm}$. 
exopod with three setae, fifth legs two-segmented and a male sixth leg with at least one or two armature elements. The genus is present in Australia with three subterranean species, all of them from the Murchison region (Karanovic 2004a). Only one species with similarly reduced fifth legs in the female is currently regarded as a member of Nitocrella, $N$. africana Chappuis, 1955. This species, described from the interstitial habitats of Lake Tanganyika (Chappuis 1955) and never recorded again, shows a number of differences when compared to Abnitocrella (including a plesiomorphic antennal exopod, much more reduced armature of the swimming legs and shape of the fifth leg in the male) and could not be included into the new genus. Unfortunately, the original description of $N$. africana is fragmentary and many characters cannot be compared with the two Australian representatives. The species may represent a distinct genus but, in view of the complete lack of information on the mouth appendages and other important morphological characters, it should be placed as species incerate sedis in Nitocrella. A very reduced fifth leg is found in another endemic Australian genus, Inermipes Lee and Huys, 2002, although here with a clearly distinct exopod in both sexes (Lee and Huys, 2002). Inermipes shares with Abnitocrella a reduced armature of the antennal exopod and mouth appendages but can be distinguished by a different segmentation of the swimming legs and is more closely related to Stygonitocrella than to Nitocrella. Unfortunately, much as plesiomorphic character states are of no significance in determining evolutionary affinity, extreme reductive apomorphies present similar problems. For example, all we can say about the maxillipeds in Abnitocrella halsei and Inermipes humphreysi Lee and Huys, 2002 is that they lack any armature. These two species additionally share a very similar (again extremely reduced) exopod of the antenna, unlike the other representative of the genus Abnitocrella (see below), and one could question their systematic positions. However, I believe that the segmentation of the swimming legs and the shape of the fifth leg provide much more reliable characters than the previously mentioned maxilliped and antennal exopod.

The only other genus of Ameiridae with a similarly reduced fifth leg is Psammonitocrella Rouch, and especially P. longifurcata Rouch, 1992. As I have already discussed this genus (see the Discussion section for Archinitocrella gen. nov.), here I will mention only the main characters that differentiate it from Abnitocrella: exopod of antenna with three armature elements, first swimming leg in male without transformed inner basal spine, endopod of the fourth leg completely (or almost completely) reduced, and separate genital and first abdominal somites in the adult female (see Rouch 1992). This, together with a very reduced armature of the swimming legs, strongly suggests a paedomorphic origin of Psammonitocrella, as suggested by Lee and Huys (2002), possibly from an Abnitocrella-like ancestor. Finally, I should mention Nitocrellopsis intermedia (Chappuis, 1937), an Ameiridae with a similarly reduced fifth leg in the female, although it is distinct from the somite. This species was described from Macedonia by Chappuis (1937) and differs from Abnitocrella in numerous characters (see also Dussart 1967), including the fifth leg shape, which seems to be only superficially similar in the two taxa.

\section{Abnitocrella eberhardi sp. nov.}

Figures $86-88$ and $112 \mathrm{C}-\mathrm{F}$

\section{Material Examined}

\section{Holotype}

Female (WAM C34171), Australia, Pilbara, Mulga Downs Station, Calamina Well, 3 September 2000, leg. W.F. Humphreys (BES: 8455), 22¹'39"S $118^{\circ} 28^{\prime} 02^{\prime \prime} \mathrm{E}$ : dissected on two slides

\section{Paratypes}

Australia, Pilbara, Mulga Downs Station, Calamina Well, 3 September 2000, leg. W.F.

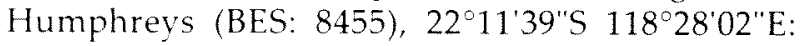
three females (one dissected on one slide (WAM C34172); others in alcohol (WAM C34173))

\section{Topotype}

Australia, Pilbara, Mulga Downs Station, Calamina Well, second sample, 3 September 2000 , leg. W.F. Humphreys (BES: 8453), 22 11'39"S $118^{\circ} 28^{\prime} 02^{\prime \prime} \mathrm{E}$ : one female in alcohol (WAM C34176)

\section{Other material}

1) Australia, Pilbara, Mulga Downs Station, Salt Well, 5 September 2000, leg. W.F. Humphreys (BES: $8476), 22^{\circ} 17^{\prime} 42^{\prime \prime S} 118^{\circ} 47^{\prime} 22^{\prime \prime} \mathrm{E}$ : one female in alcohol (WAM C34174)

2) Australia, Pilbara, Mulga Downs Station, Ebathacalby Well, 2 September 2000, leg. W.F. Humphreys (BES: 8440 ), 22 $2^{\circ} 14^{\prime} 58^{\prime \prime S} 118^{\circ} 44^{\prime} 52^{\prime \prime} \mathrm{E}$ : three females in alcohol (WAM C34175)

3) Australia, Pilbara, Fortescue Valley, Ebathacalby Well, $25 \mathrm{July}$ 1997, leg. W.F. Humphreys and S.M. Eberhard (BES: 4848 and 5648), 22 1459"S $118^{\circ} 44^{\prime} 51^{\prime \prime} \mathrm{E}$ : one female in alcohol (WAM C34177)

\section{Description}

Female (holotype). Total body length, measured from tip of rostrum to posterior margin of caudal 


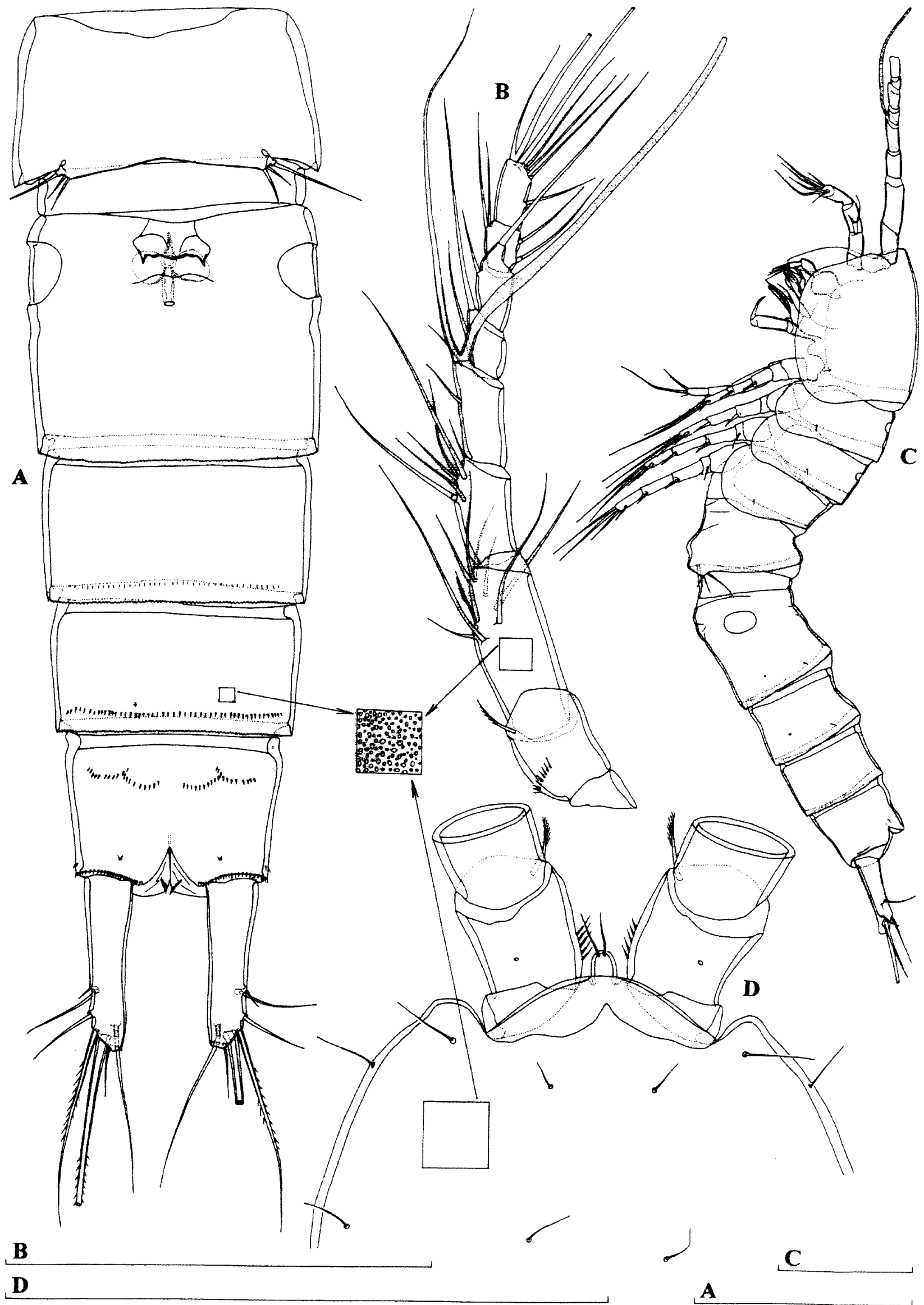

Figure 86 Abnitocrella eberhardi gen. et sp. nov., holotype (female): A, urosome, ventral view; B, antennula; C, habitus, lateral view; D, anterior part of cephalothorax, dorsal view. Scales $=0.1 \mathrm{~mm}$. 
rami (excluding caudal setae), $0.521 \mathrm{~mm}$. Preserved specimen colourless. Nauplius eye absent. Habitus (Figure $86 \mathrm{C}$ and $87 \mathrm{~A}$ ) cylindrical and slender, without distinct demarcation between prosome and urosome; prosome/urosome ratio 0.7 and greatest width at posterior end of cephalothorax. Body length/width ratio about 5.5; cephalothorax 1.1 times as wide as genital double somite. Free pedigerous somites without pronounced lateral expansions or dorsally; thoracic, as well as abdominal, somites connected by well developed arthrodial membranes. Pleural areas of cephalothorax and first three free pedigerous somites well developed; cephalic appendages and coxae of swimming legs not exposed in lateral view (Figure 86C). Integument not strongly chitinized but much stronger than in previous species. One dorsal cuticular window on second and third pedigerous somites (first and second free) and two lateral windows on proximal part of genital double somite (one on each side). Whole body, including caudal rami and all appendages covered by numerous small cuticular pits; only cuticular windows and arthrodial membranes not covered by them. More or less sclerotized joint (as pseudosomite) present between fifth pedigerous and genital double somite. Rostrum minute, well sclerotized, lunguiform in dorsal view, reaching $1 / 4$ of first antennular segment, about 1.2 times as long as wide and not demarcated at base; ornamented with two dorsal sensilla, which longer than rostrum itself.

Cephalothorax (Figure 86D and 87D) almost rectangular in dorsal view, about 1.2 times as long as wide; represents $22 \%$ of total body length. Surface of cephalic shield and tergites of first three free pedigerous somites ornameted with many large sensilla. Hyaline fringes of cephalothorax and anal somite smooth; those of all other somites finely serrated. Fifth pedigerous (first urosomal) somite ornamented with four dorsal sensilla.

Genital double somite (Figure 86A) 0.85 times as long as wide (ventral view), without any suture visible; ornamented with two cuticular pores laterally (one on each side) and four sensilla dorsally (two at middle, two near posterior margin). Female genital complex (Figure $88 \mathrm{~K}$ ) with single large and ovoid copulatory pore, well sclerotized and cylindrical copulatory duct and two ovoid seminal receptacles. Single, not very large, genital aperture covered by fused reduced sixth legs, represents $27 \%$ of somite width. Third urosomite ornamented with two cuticular pores laterally, as well as with two dorsal large sensilla near posterior margin. Preanal somite short, ornamented with posterior uninterrupted row of small spinules ventrally; no sensilla on this somite. Anal somite (Figure 86A and 87F) ornamented with pair of large dorsal sensilla, pair of ventral cuticular pores, one transverse complex row of minute spinules at $1 / 3$ of somite length ventrally and transverse row of larger spinules along posterior margin, dorsal ones shorter than ventral; additional short row of small spinules laterally, close to and parallel with that along posterior margin. Anal operculum (Figure 87F) slightly convex, not reaching posterior end of anal somite, represents $53 \%$ of somite's width, ornamented with row of 45 minute spinules near posterior margin. Anal sinus ornamented with two diagonal rows of minute spinules, widely opened and filled with small bits of organic material.

Caudal rami (Figure $86 \mathrm{~A}$ and $87 \mathrm{~A}, \mathrm{~F}$ ) very long, 3.4 times as long as greatest width (ventral view), cylindrical, parallel, with space between them almost 1.5 times of one ramus width; armed with six elements (two lateral, one dorsal and three apical). Ornamentation consists of one short setula at base of proximal lateral seta, few minute spinules at base of distal lateral seta, few spinules at base of dorsal seta and two spinules at base of innermost apical seta ventrally. Dorsal seta relatively short, inserted at $5 / 6$ of ramus length, about as long as ramus, biarticulate at base and smooth. Proximal lateral seta about 0.5 times as long as dorsal seta, arising somewhat dorsolaterally at $2 / 3$ of ramus length. Distal lateral seta arising at $4 / 5$ of ramus length, about 0.4 times as long as dorsal one and 0.8 times as long as proximal one, smooth. Inner apical seta short and slender, also smooth, about 0.3 times as long as ramus. Middle apical seta strongest, without breaking plane, pinnate at distal end, about 3.4 times as long as outer apical seta and almost 0.4 times as long as total body length. Outer apical seta also without breaking plane and pinnate at distal end.

Antennula (Figure 86B) eight-segmented, slender, approximately 1.3 times as long as cephalothorax, with long and slender aesthetasc on fourth segment, which reaches beyond tip of appendage almost for length of last four segments together; setal formula: 1.9.6.3.2.2.4.7. All setae slender and most setae smooth; only seta on first and one seta on second segment unipinnate. Three lateral seta on eighth, two on seventh and one on third segment articulating on basal part; no setae with breaking plane. Two apical setae on eighth segment fused basally. First segment relatively short, ornamented with transverse row of spinules on anterior surface; other segments without any ornamentation. Length ratio of antennular segments, from proximal end, 1 $2: 0.9: 1: 0.6: 1: 0.5: 0.7$.

Antenna (Figure 87E) composed of coxa, basis, two-segmented endopod and one-segmented exopod. Coxa very short, unornamented. Basis about 1.6 times as long as wide, unornamented and unarmed. First endopodal segment about 1.8 times as long as wide and 1.2 times as long as basis, also unornamented and unarmed. Second endopodal 


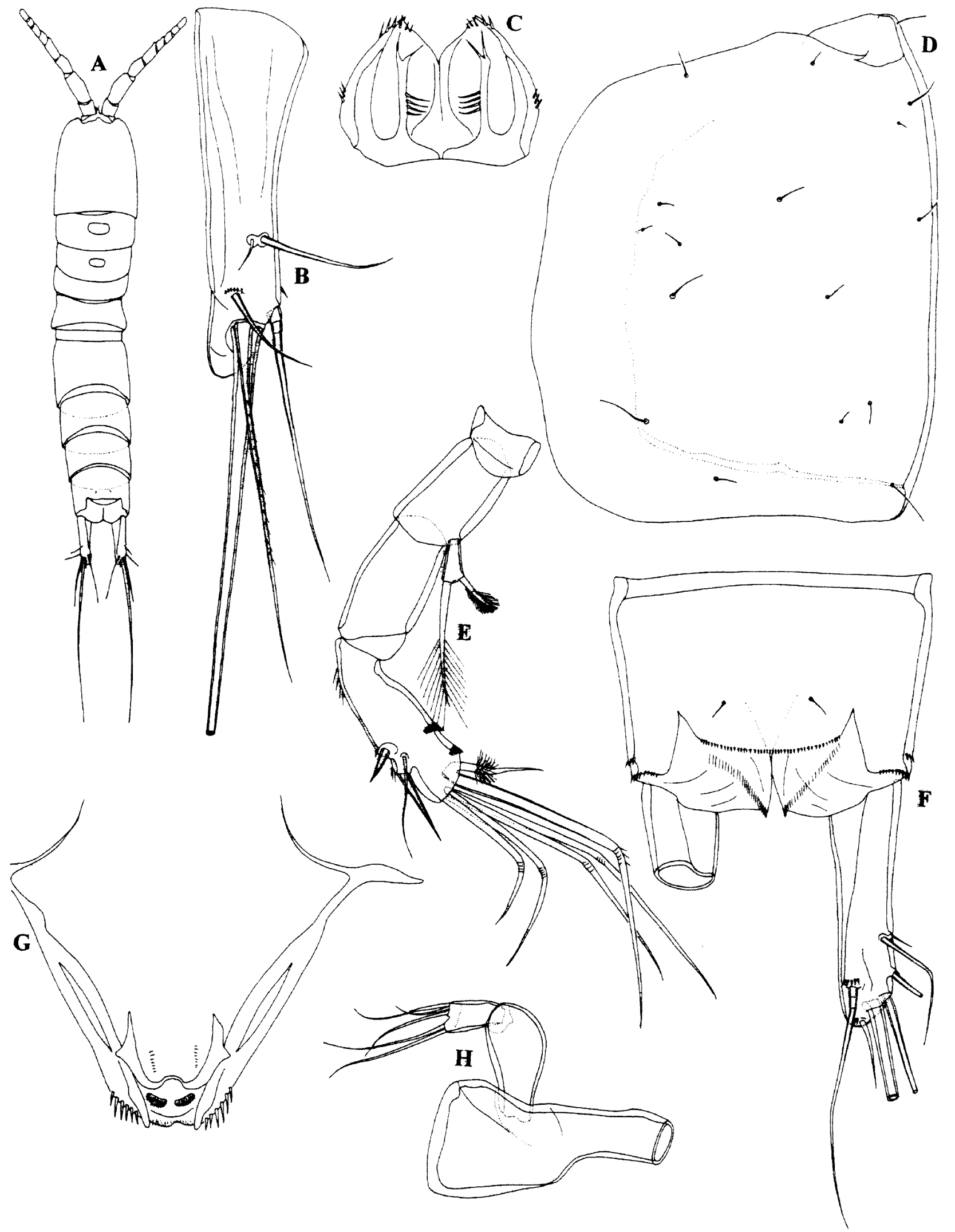

D, F

\section{$\mathbf{B}, \mathbf{C}, \mathbf{E}, \mathbf{G}, \mathbf{H}$}

A

Figure 87 Abnitocrella eberhardi gen. et sp. nov, holotype (female): A, habitus, dorsal view; B, left caudal ramus, lateral view; $C$, paragnaths; D, cephalic shield, lateral view; $\mathrm{E}$, antenna; $\mathrm{F}$, anal somite and caudal rami, dorsal view; $\mathrm{G}$, labrum; H, mandibula, without cutting edge. Scales $=0.1 \mathrm{~mm}$. 
segment longest, 1.5 times as long as first and 3.1 times as long as wide, armed laterally with two smooth spines flanking thin seta; apical armature consisting of five geniculate setae, longest one fused basally to additional smaller seta, bearing proximal tuft of fine setules; ornamentation consists of row of spinules on anterior surface and with two surface frills subdistally. Exopod one-segmented, cylindrical and small, about 2.1 times as long as wide, unornamented and armed with two apical plumose setae; outer seta 2.7 times as long as inner one, which slightly longer than segment.

Labrum (Figure $87 \mathrm{G}$ ) large compared with cephalothorax, trapezoidal, rigidly sclerotized, with broad and concave cutting edge, which ornamented subapically with two rows of strong spinules and with numerous minute spinules between two spiniform precesses; additionally ornamented with two longitudinal rows of minute spinules. Two ovoid fields of gustatory papillae visible on dorsal (posterior) surface.

Paragnaths (Figure $87 \mathrm{C}$ ) ovoid, fused basally forming trapezoidal labium, ornamented with numerous minute spinules apically and with two short rows of spinules along outer margin; longitudinal row of four large spinules at middle; distal outer corner produced posteriorly as spiniform process on both paragnaths.

Mandibula (Figure 87H and 88J) with narrow cutting edge on elongated coxa, armed with two coarse teeth ventrally, one unipinnate seta dorsally and numerous small teeth in between; one tooth at middle longer than others. Palp uniramous, comprising basis and one-segmented endopod. Basis with bulging inner margin distally, unarmed and unornamented, almost twice as long as wide. Endopod also unornamented, about 0.5 times as long as basis and about 1.8 times as long as wide; armed with five slender and smooth setae apically.

Maxillula (Figure 88G) with large praecoxa, arthrite rectangular, movable and unornamented; armed with two smooth setae on anterior surface, two setae on dorsal surface and four apical elements (probably three spines and one dorsal seta). Coxal endite armed with one pinnate and curved seta and two smooth setae of about same length, shorter than curved one. Basis slightly shorter than coxal endite, armed with five smooth setae apically and subapically. Endopod minute but distinct, segment; armed with two apical smooth setae of about same length

Maxilla (Figure 88H) with proximal endite on syncoxa completely reduced; distal endite well developed, highly mobile, armed with one curved pinnate spine and two smooth subequal setae, 1.8 times as long as spine. Basis drawn out into long claw, with much shorter spiniform and curved seta at base. Endopod represented by minute segment, armed with two smooth subequal apical setae.
Maxilliped (Figure 88E) with large syncoxa, which unornamented and armed with single seta subdistally, about twice as long as wide. Basis 2.4 times as long as wide and 1.3 times longer than syncoxa, unornamented and unarmed. Endopod represented by long curved claw, ornamented with row of spinules along concave side distally and armed with thin seta at base.

All swimming legs with three-segmented exopod; endopod of first leg also three-segmented (Figure $88 \mathrm{~A})$, while those of other legs two-segmented (Figure 88B, C, D). Armature formula of swimming legs as follows (legend: inner/outer spine or seta; inner/terminal/outer):

\begin{tabular}{|c|c|c|c|c|c|c|}
\hline \multirow[b]{2}{*}{ Segments } & \multicolumn{3}{|c|}{ Exopod } & \multicolumn{3}{|c|}{ Endopod } \\
\hline & 1 & 2 & 3 & 1 & 2 & 3 \\
\hline First leg & $0 / 1$ & $1 / 1$ & $0 / 2 / 2$ & $1 / 0$ & $0 / 0$ & $1 / 1 / 1$ \\
\hline econd leg & $0 / 1$ & $1 / 1$ & $1 / 2 / 2$ & $1 / 0$ & $1 / 1 / 1$ & - \\
\hline $\operatorname{leg}$ & $0 / 1$ & $1 / 1$ & $1 / 2 / 2$ & $1 / 0$ & $2 / 1 / 1$ & - \\
\hline ourth leg & $0 / 1$ & $1 / 1$ & $2 / 2 / 2$ & $1 / 0$ & $1 / 1 / 1$ & - \\
\hline
\end{tabular}

Intercoxal sclerites of all swimming legs with concave distal margin; that of first, third and fourth legs without any surface ornamentation; sclerite of second leg with two rows of long spinules distally. Praecoxae and coxae of all swimming legs unornamented and unarmed. Basis ornamented with few spinules near outer margin (except on first leg, which unornamented) and with row of spinules along posterior margin, between endopod and exopod; armed with outer outer smooth seta on third and fourth legs but without armature on outer margin of first and second leg; basis of first leg with short spine at inner distal corner. Most exopodal and endopodal segments ornamented with spinules along outer margin and some segments also with spinules along inner and distal margin. First exopodal segment of all legs slightly shorter than second segment. First endopodal segment of first swimming leg (Figure $88 \mathrm{~A}$ ) relatively short, about 2.7 times as long as wide, somewhat shorter than first two exopodal segments together. Endopod of second swimming leg (Figure 88B) as long as first two exopodal segments together; endopod of third (Figure $88 \mathrm{C}$ ) and fourth swimming legs (Figure $88 \mathrm{D})$ shorter than first two exopodal segments. All setae on exopods and endopods (except minute inner seta on third endopodal segment of first leg) strong and many spiniform. Exopod of second swimming leg very similar to exopod of third leg.

Fifth leg (Figure 88F) fused to somite; represented by small setophore bearing outer basal seta and two additional setae without clear origin (they could be either exopodal or baseoendopodal, or one of each). All setae smooth; outer basal seta about 3.1 times as long as middle seta and 2.3 times as long as innermost seta.

Sixth legs (Figure 88K) completely fused, indistinct, forming simple operculum covering single gonopore, without any ornamentation but 


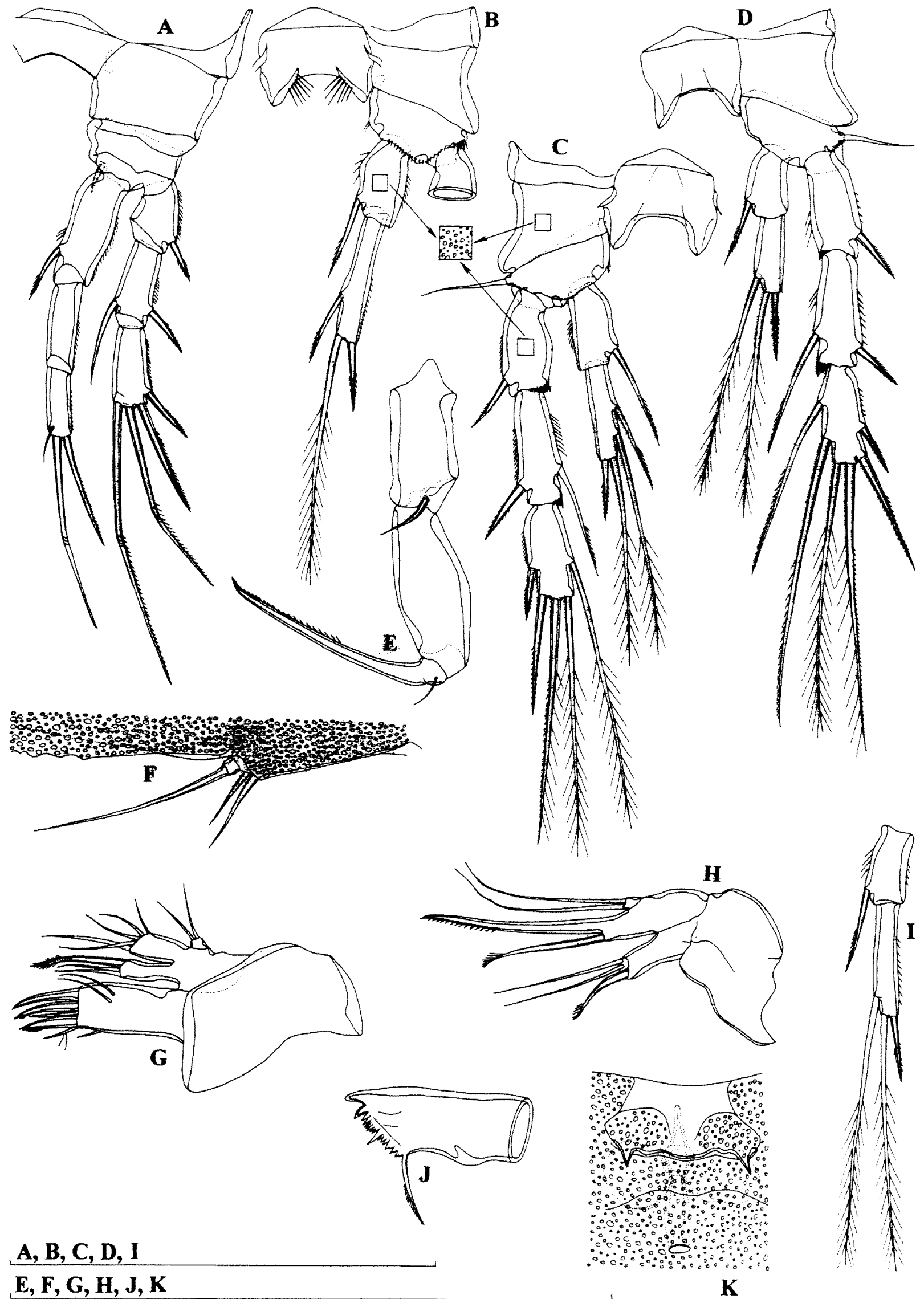

Figure 88 Abnitocrella eberhardi gen. et sp. nov., A-H and J-K, holotype (female); I, paratype female $(0.524 \mathrm{~mm}$; WAM C34172): A, first swimming leg; B, second swimming leg, without exopod; C, third swimming leg; D, fourth swimming leg; $E$, maxilliped; $F$, fifth leg; $G$, maxillula; $H$, maxilla; $I$, endopod of third swimming leg; $\mathrm{J}$, cutting edge of mandibula; $\mathrm{K}$, genital field. Scales $=0.1 \mathrm{~mm}$. 
armed with two minute spines fused basally to operculum.

Male. Unknown.

\section{Variability}

Body length of females ranges from $0.5 \mathrm{~mm}$ to $0.531 \mathrm{~mm}(0.519 \mathrm{~mm}$ average; $n=4)$, while no males were collected. One paratype female has only three armature elements on the second endopodal segment of the third swimming leg (Figure 88I). No other type of variability was observed.

\section{Etymology}

The species is named in honour of Dr Stefan M. Eberhard from the Department of Conservation and Land Management in Perth, who is part of the Pilbara Survey team working on stygofauna.

\section{Discussion}

Abnitocrella eberhardi sp. nov. differs from $A$. halsei in a number of characters, most of which are plesiomorphic in the former species, including the armature of the antennal exopod, maxillula, maxilliped, exopod of the second swimming leg, third swimming leg, endopod of the fourth swimming leg and fifth leg. On the other hand, the absence of an external basal spine on first and second leg, armature of the second leg endopod and the caudal rami shape are all apomorphic features of A. eberhardi. Cuticular windows on the first and second free prosomites and the genital somite, present in $A$. eberhardi, could well be hardly visible in $A$. halsei, due to the very thin integument of this species. The distinctive pattern of external integumental ornamentation of $A$. eberhardi also was not recorded in $A$. halsei, which may be an additional distinguishing character between the two. Such a great number of differences between the two currently known species of Abnitocrella suggest a relatively long evolutionary history of this genus and, possibly, some more representatives in Australian (or even ex-Gondwana) subterranean waters. Considering the minute proportion of subterranean waters in Australia that have been investigated and the richness of the freshwater Ameiridae here, we may be just at the beginning of understanding the evolutionary history of this group of copepods

\section{Genus Stygonitocrella Reid, Hunt and Stanley, 2003}

\section{Stygonitocrella trispinosa sp. nov.} Figures $89-93$ and 113

\section{Material Examined}

\section{Holotype}

Female (WAM C34178), Australia, Pilbara, De
Grey Station, bore GNHSLK1696, 17 November 2002, leg. J. Cocking and M. Scanlon (CALM), $20^{\circ} 18^{\prime} 59^{\prime \prime} \mathrm{S} 119^{\circ} 25^{\prime} 35^{\prime \prime} \mathrm{E}$ : dissected on two slides

\section{Allotype}

Male (WAM C34179), Australia, Pilbara, De Grey Station, bore GNHSLK1696, 17 November 2002, leg. J. Cocking and M. Scanlon (CALM), 20 18'59"S $119^{\circ} 25^{\circ} 35^{\prime \prime} \mathrm{E}$ : dissected on two slides

\section{Paratypes}

Australia, Pilbara, De Grey Station, bore GNHSLK1696, 17 November 2002, leg. J. Cocking and M. Scanlon (CALM), 20 18'59'S 119 25'35"E: three males (one dissected on one slide (WAM C34180); others in alcohol (WAM C34181))

\section{Other material}

1) Australia, Pilbara, Carlindi Creek, bore MBSLK388A, 17 November 2002, leg. J. Cocking and M. Scanlon (CALM), 20 58 $14^{\prime \prime S} 117^{\circ} 05^{\prime} 30^{\prime \prime} \mathrm{E}$ : six males + seven females + three copepodids (one female dissected on one slide (WAM C34182); others in alcohol (WAM C34183))

2) Australia, Pilbara, West Strelley, bore MBSLK400A, 17 November 2002, leg. J. Cocking and M. Scanlon (CALM), 20 36 $10^{\prime \prime S} 119^{\circ} 07^{\prime} 24^{\prime \prime} E$ : three males + nine females + five copepodids in alcohol (WAM C34184)

3) Australia, Pilbara, Yule River, bore GNHSLK1448, 18 November 2002, leg. J. Cocking and M. Scanlon (CALM), 21 36 11'S 118 48'52"E: two males + one female in alcohol (WAM C34185)

\section{Description}

Female (holotype). Total body length, measured from tip of rostrum to posterior margin of caudal rami (excluding caudal setae), $0.495 \mathrm{~mm}$. Preserved specimen colourless. Nauplius eye absent. Habitus (Figure 89A, B) cylindrical, slender, without distinct demarcation between prosome and urosome; prosome/urosome ratio 0.9 and greatest width at posterior end of cephalothorax. Body length/width ratio about 4.9 ; cephalothorax 1.2 times as wide as genital double somite. Free pedigerous somites without pronounced lateral expansions or dorsally. Integument not strongly chitinized and second and third pedigerous somites (first and second free) with one large dorsal cuticular window each. Rostrum very small, membranous, ovoid, reaching just beyond proximal margin of first antennular segment, about as long as wide and not demarcated at base; ornamented with two dorsal sensilla.

Cephalothorax (Figure 89A, B) almost triangular in dorsal view, about as long as wide; represents $20 \%$ of total body length. Surface of cephalic shield and tergites of first three free pedigerous somites ornameted with numerous large sensilla. Hyaline 


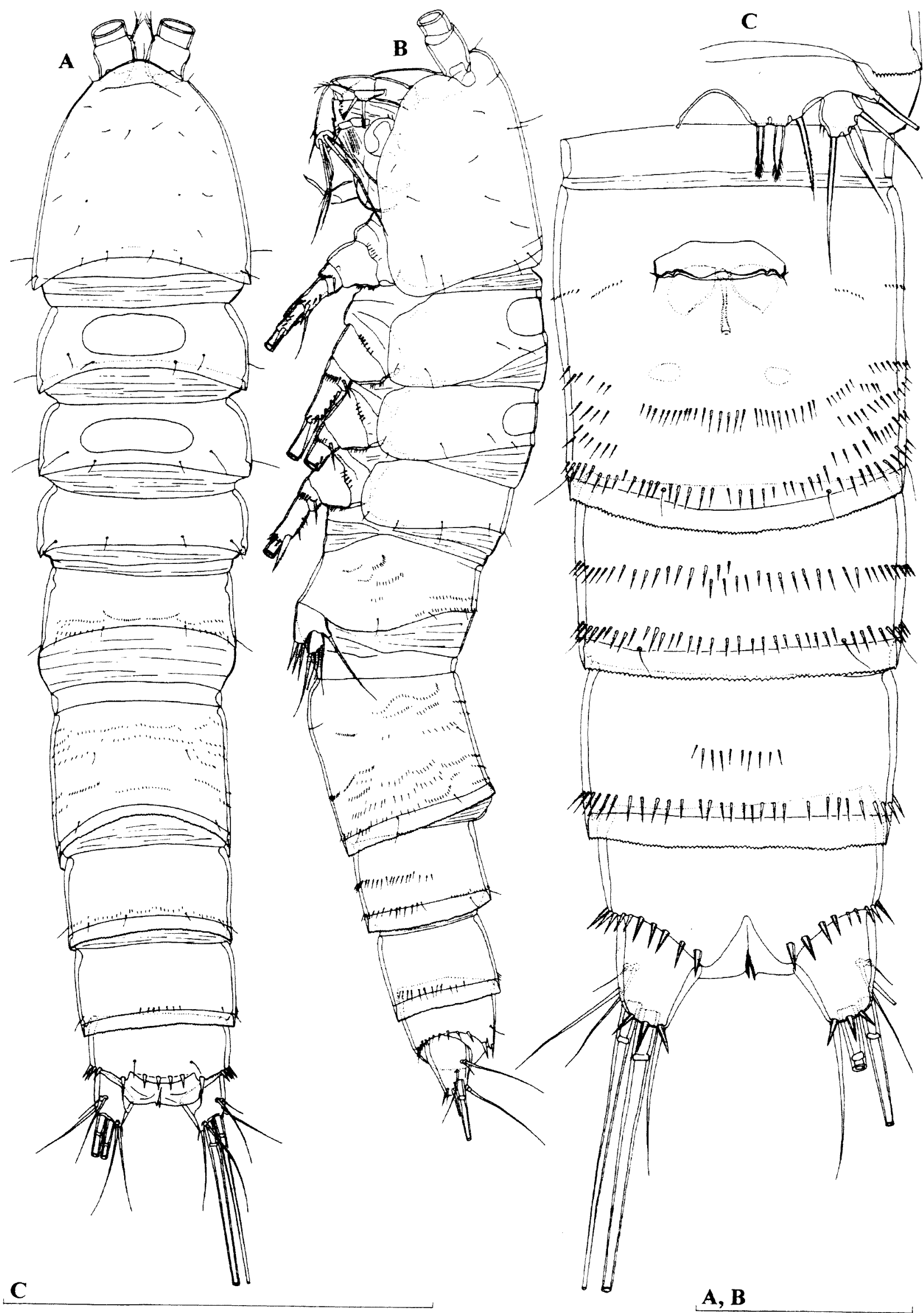

Figure 89 Stygonitocrella trispinosa sp. nov, holotype (female): A, habitus, dorsal view; B, habitus, lateral view; C, urosome, ventral view. Scale $=0.1 \mathrm{~mm}$. 
fringe of all prosomites narrow and smooth. Fifth pedigerous (first urosomal) somite ornamented with four dorsal sensilla posteriorly, two lateral sensilla (one on each side) and several arched and transverse rows of small spinules dorsally and laterally; hyaline fringe smooth dorsally and finely serrated laterally.

Genital double somite (Figure 89A, B, C) as long as wide (ventral view), without visible suture; ornamented with four large sensilla dorsally (two at middle, two near posterior margin), two sensilla ventrally and four laterally (two on each side) near posterior margin, as well with many transverse rows of larger or smaller spinules on all sides. Hyaline fringe finely serrated both ventrally and dorsally. Female genital complex with single small copulatory pore, sclerotized narrow copulatory duct and two small semicircular seminal receptacles. Single small genital aperture covered by fused reduced sixth legs, represents $38 \%$ of somite width. Third urosomite ornamented with eight large sensilla near posterior margin (four dorsal, two lateral and two ventral), with single posterior row of minute spinules dorsally and with two parallel rows of large spinules ventrally; hyaline fringe serrated. Preanal somite also with finely serrated hyaline fringe dorsally and ventrally, ornamented with short posterior row of small spinules dorsally and with two parallel rows of larger spinules ventrally (anterior short and posterior long); no sensilla on this somite. Anal somite (Figure $89 \mathrm{C}$ and $90 \mathrm{~A}$ ) ornamented with pair of large dorsal sensilla and transverse row of very large and stout spinules along posterior margin, one on each corner near anal operculum exceptionally strong. Anal operculum convex, not reaching posterior end of anal somite, represents $45 \%$ of somite's width, ornamented with four strong spinules near posterior margin. Anal sinus ornamented with two rows of minute spinules, widely opened

Caudal rami (Figure $89 \mathrm{C}$ and $90 \mathrm{~A}$ ) short, as long as greatest width (ventral view), conical, slightly divergent, with space between them about one ramus width, with small chitinous ridge dorsally; armed with six armature elements (two lateral, one dorsal and three apical). Ornamentation consists of one long setula at base of proximal lateral seta and posterior row of three large spinules ventrally. Dorsal seta inserted near posterior margin closer to inner margin, about 2.5 times as long as caudal ramus, biarticulate at its base and smooth. Proximal lateral seta about 0.7 times as long as dorsal one, arising somewhat dorsolaterally at middle of ramus length. Distal lateral seta arising at $5 / 6$ of ramus length, about as long as proximal one, smooth. Inner apical seta well developed, also smooth, about 1.4 times as long as ramus. Middle apical seta strongest, with breaking plane, smooth, about 2.7 times as long as outer apical seta and almost 0.7 times as long as body. Outer apical seta also with breaking plane and smooth.

Antennula (Figure 90B) eight-segmented, slender, approximately 1.2 times as long as cephalothorax, with long aesthetasc on fourth segment, which reaches beyond tip of appendage for more than length of last three segments together, as well as with much smaller aesthetasc on eighth segment apically; setal formula: 1.8.6.3.2.2.4.7. Only seta on first segment pinnate, all other setae smooth. Only four setae on eighth segment articulating on basal part and all setae without breaking plane. One apical seta on eighth segment fused basally to aesthetasc. First segment ornamented with short row of spinules on anterior surface at middle; other segments without any ornamentation. Length ratio of antennular segments, from proximal end, $1: 1.7$ : $1.3: 1.1: 0.6: 1: 0.4: 0.8$.

Antenna (Figure 90C) composed of coxa, basis, two-segmented endopod and one-segmented exopod. Coxa very short, unornamented. Basis about 1.6 times as long as wide, ornamented with row of long spinules along outer margin distally, unarmed. First endopodal segment about 1.9 times as long as wide, unornamented and unarmed. Second endopodal segment longest, 1.4 times as long as first and 3.3 times as long as wide, armed laterally with two smooth spines flanking thin seta; apical armature consisting of five geniculate setae, longest one fused basally to additional smaller seta, bearing proximal tuft of fine setules; ornamentation consists of few spinules along anterior surface. Exopod one-segmented, 0.7 times as long as basis and 2.5 times as long as wide, unomamented but armed with three pinnate setae; innermost seta 1.6 times as long as other two (which of about same length) and almost 1.5 times as long as exopod.

Labrum (Figure 91F) not very large compared with cephalothorax, trapezoidal, rigidly sclerotized, with relatively broad and almost straight cutting edge, ornamented subapically with two rows of strong spinules and one row of smaller spinules in between, apically. No fields of gustatory papillae visible on dorsal (posterior) surface.

Mandibula (Figure 90E) with broad cutting edge on elongated coxa, armed with three coarse teeth ventrally, one unipinnate seta dorsally and numerous small teeth in between. Palp uniramous, comprising basis and one-segmented endopod Basis slender, unarmed and unornamented, more than twice as long as wide. Endopod also slender and unornamented, about 0.7 times as long as basis and about 1.9 times as long as wide; armed with five slender and smooth setae apically, outermost one longest, innermost one shortest.

Maxillula (Figure 90F) with large praecoxa, arthrite rectangular, not movable, unornamented; armed with two smooth setae on anterior surface, 


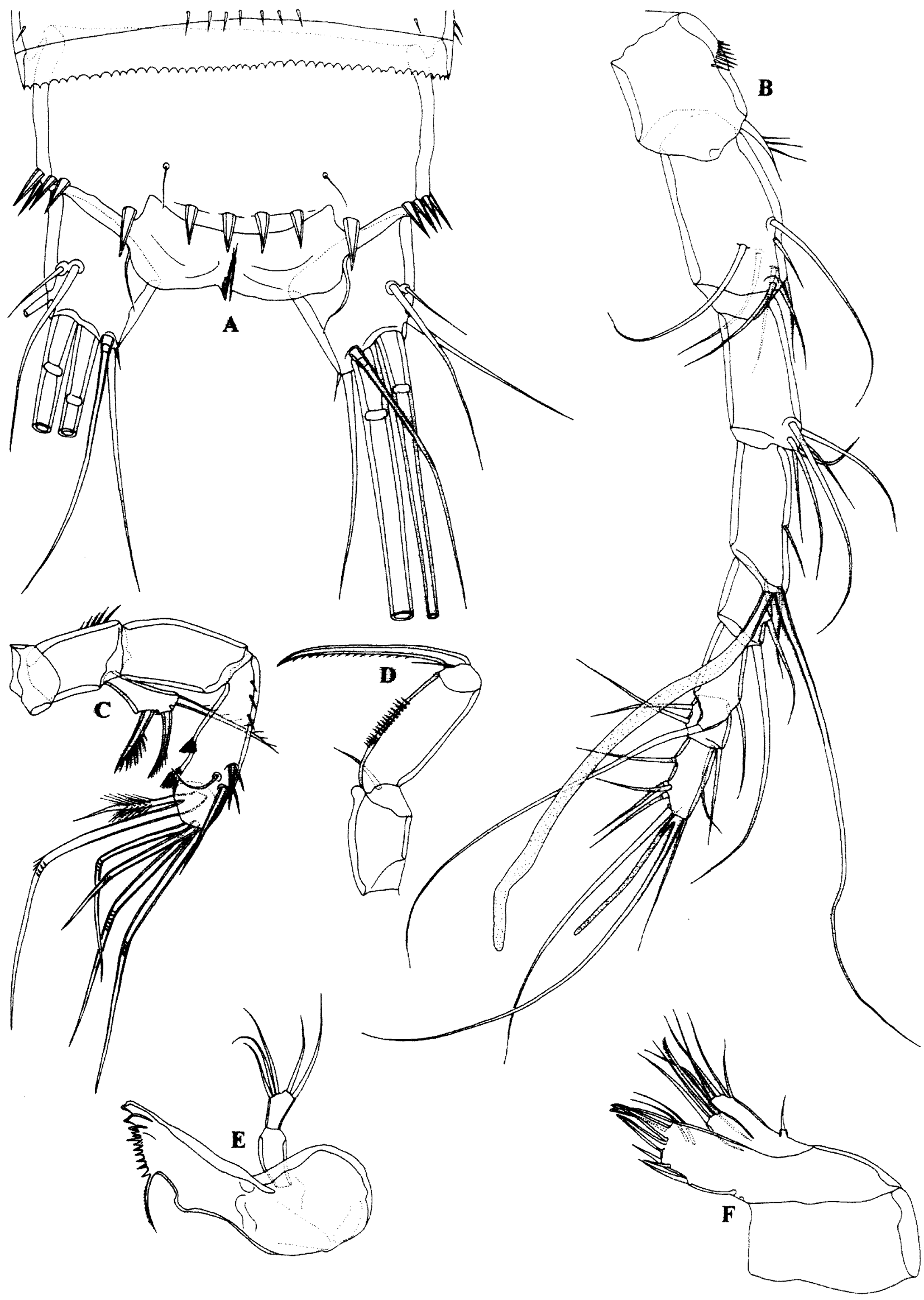

Figure 90 Stygonitocrella trispinosa sp. nov., holotype (female): A, anal somite and caudal rami, dorsal view; B, antennula; $C$, antenna; D, maxilliped; $E$, mandibula; F, maxillula. Scale $=0.1 \mathrm{~mm}$. 


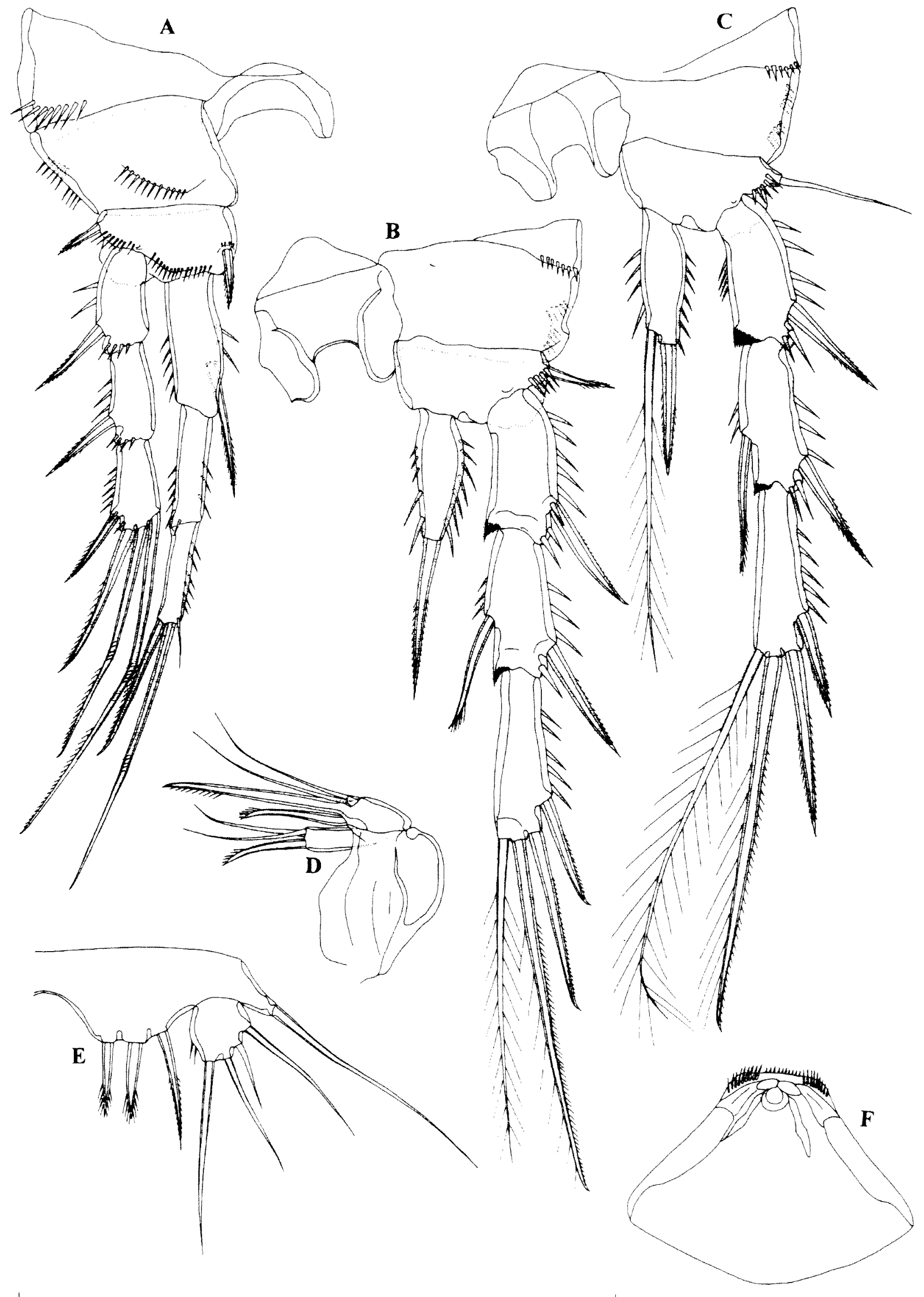

Figure 91 Stygonitocrella trispinosa sp, nov, holotype (female): A, first swimming leg; B, second swimming leg; C, third swimming leg; D, maxilla; E, left fifth leg; F, labrum. Scale $=0.1 \mathrm{~mm}$. 
two setae on dorsal margin and four apical elements (probably three spines and one dorsal seta). Coxal endite armed with one pinnate and two smooth setae, all of about same length. Basis somewhat longer than coxal endite, armed with five smooth setae apically and subapically. Endopod minute segment, basally fused to basis, armed with single smooth apical seta.

Maxilla (Figure 91D) with proximal endite on syncoxa completely reduced; distal endite well developed, highly mobile, armed with one curved pinnate spine and two smooth subequal setae, which 1.4 times as long as spine. Basis drawn out into long claw, with much shorter spiniform and curved seta at base. Endopod represented by minute segment, armed with two smooth subequal, long apical setae.

Maxilliped (Figure 90D) with well developed syncoxa, which unornamented and armed with single smooth seta subapically, 1.8 times as long as wide. Basis almost three times as long as wide and almost 1.5 times as long as syncoxa, ornamented with row of large spinules along inner margin and unarmed. Endopod represented by long curved claw, ornamented with row of spinules along concave side distally; with thin seta at base.

All swimming legs with three-segmented exopod; endopod of first leg also three-segmented (Figure 91A), endopod of other swimming legs onesegmented (Figure 91B, C and 92A). Armature formula of swimming legs as follows (legend: inner/ outer spine or seta; inner/terminal/outer):

\begin{tabular}{lcccccc} 
& \multicolumn{3}{c}{ Exopod } & \multicolumn{3}{c}{ Endopod } \\
Segments & 1 & 2 & 3 & 1 & 2 & 3 \\
First leg & $0 / 1$ & $0 / 1$ & $0 / 2 / 2$ & $1 / 0$ & $0 / 0$ & $1 / 1 / 1$ \\
Second leg & $0 / 1$ & $1 / 1$ & $0 / 2 / 2$ & $0 / 1 / 0$ & - & - \\
Third leg & $0 / 1$ & $1 / 1$ & $0 / 2 / 2$ & $1 / 1 / 0$ & - & - \\
Fourth leg & $0 / 1$ & $1 / 1$ & $1 / 2 / 2$ & $0 / 1 / 0$ & - & -
\end{tabular}

Intercoxal sclerites of all swimming legs with concave distal margin and without any surface ornamentation. Praecoxa with row of long spinules along outer posterior margin; coxae of all swimming legs with two short rows of spinules near outer margin and unarmed, coxa of first leg with additional diagonal row of spinules. Basis of all legs ornamented with spinules near outer margin and that of first leg additionally with row of spinules along posterior margin; armed with outer bipinnate spine on first and second swimming legs and with outer smooth seta on third and fourth legs; basis of first leg with stout spine on inner distal corner and row of spinules at its base. All exopodal and endopodal segments ornamented with strong spinules along outer margin and some segments also with spinules along inner and distal margin. First exopodal segment of all legs about as long as second exopodal segment. First endopodal segment of first swimming leg (Figure 91 A) not very large, about 2.7 times as long as wide and reaching slightly beyond midlength of second exopodal segment. Endopod of other swimming legs about as long as first exopodal segment (that of fourth leg somewhat shorter). All setae on exopods and endopods (except minute inner seta on third endopodal segment of first leg) strong and many spiniform.

Fifth leg (Figure 91E) biramous but baseoendopods fused medially. Baseoendopod with outer basal seta long and smooth, arising from long setophore. Endopodal lobe very broad, convex, extending to middle of exopod, unornamented but armed with three very stout and bipinnate elements; outermost element longest and most slender, about 1.3 times as long as middle and innermost one (which of about same length) and almost 1.9 times as long as exopod. Exopod ovoid, small, about as long as maximum width, ornamented with two slender spinules on inner margin and armed with four slender and smooth setae; length ratio of exopodal setae, from inner side, $1: 0.7: 0.4: 0.8$. Longest seta on exopod 1.6 times as long as outermost endopodal armature element.

Sixth legs (Figure 89C) completely fused, indistinct, forming simple operculum covering single gonopore, without any ornamentation but armed with two minute smooth setae.

Male (allotype). Body length, excluding caudal setae, $0.419 \mathrm{~mm}$. Habitus (Figure 92D), ornamentation of prosomites, rostrum, colour and nauplius eye similar to female. Hyaline fringe of all prosomites smooth; second and third pedigerous somite with dorsal cuticular window, as in female.

Genital somite more than twice as wide as long. Single, longitudinally placed spermatophore inside fifth pedigerous and genital somite (Figure 92D). Urosomites ornamentation similar to female, although preanal somite with uninterrupted posterior row of spinules dorsally (although those in middle much longer; Figure 93A) and anal somite with additional ventral row of spinules at middle (Figure 93B).

Caudal rami (Figure 93A, B) about as long as wide. Armature and ornamentation similar to female, just one additional cuticular pore present dorsally and one spinule at base of distal lateral seta.

Antennula (Figure 92E) long and slender, tensegmented, not strongly geniculate, with geniculation between seventh and eighth segment, unornamented. Very long and broad aesthetasc on apical acrothek of fifth segment (homologue to aesthetasc on fourth segment in female); one smaller aesthetasc on tenth segment. First two and last two segments similar to female. Setal formula: 1.9.4.2.6.0.2.1.4.6. Majority of setae smooth and slender; seta on first segment and proximal seta on seventh segment pinnate, all other setae smooth; 


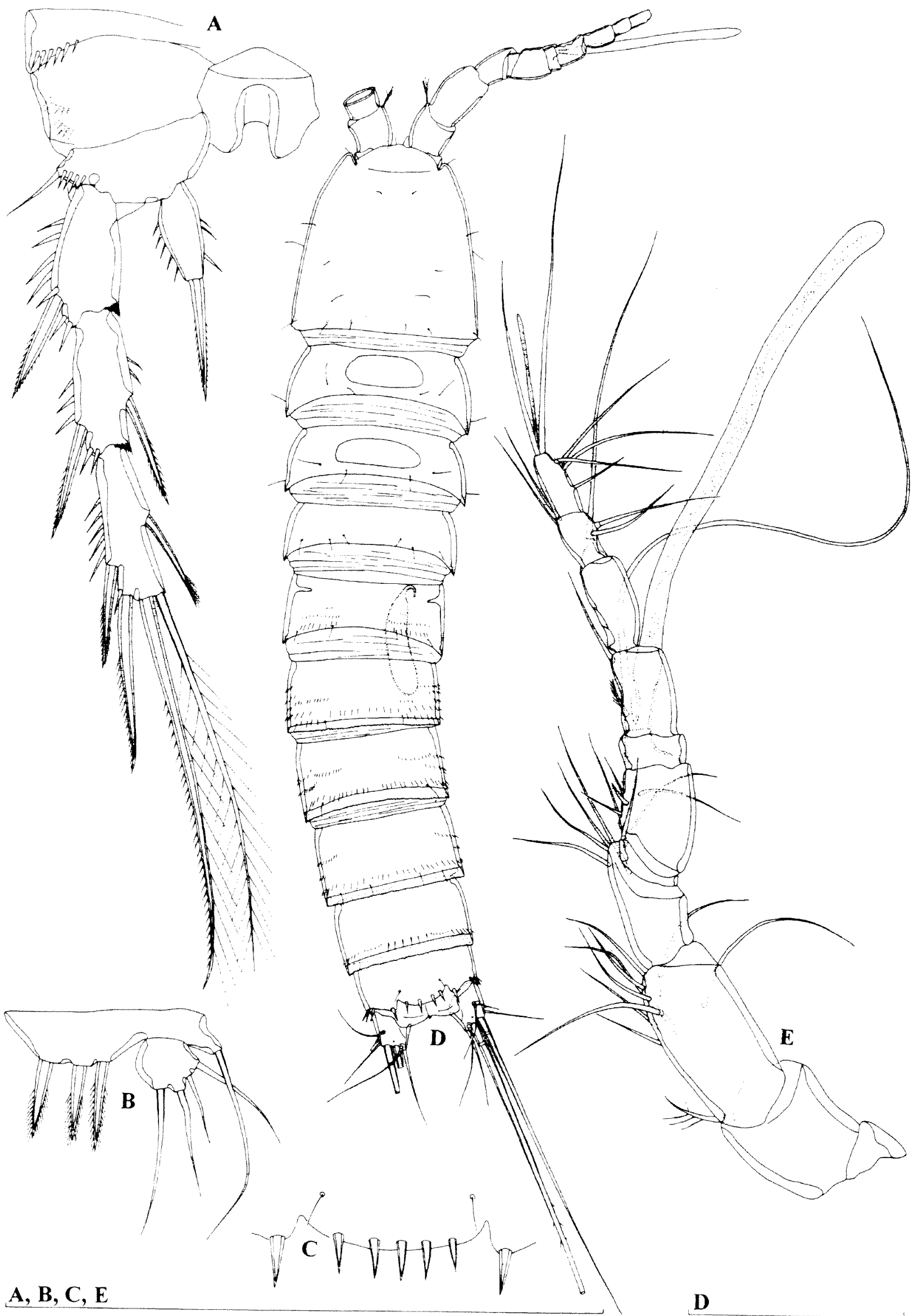

Figure 92 Stygonitocrella trispinosa sp. nov. A, holotype (female); B and C, female $(0.483 \mathrm{~mm}$ ) from locality 1 (WAM C34182); D and E, allotype (male): A, fourth swimming leg; B, fifth leg; $C$, anal operculum; $D$, habitus, dorsal view; $\mathrm{E}$, antennula. Scales $=0.1 \mathrm{~mm}$. 


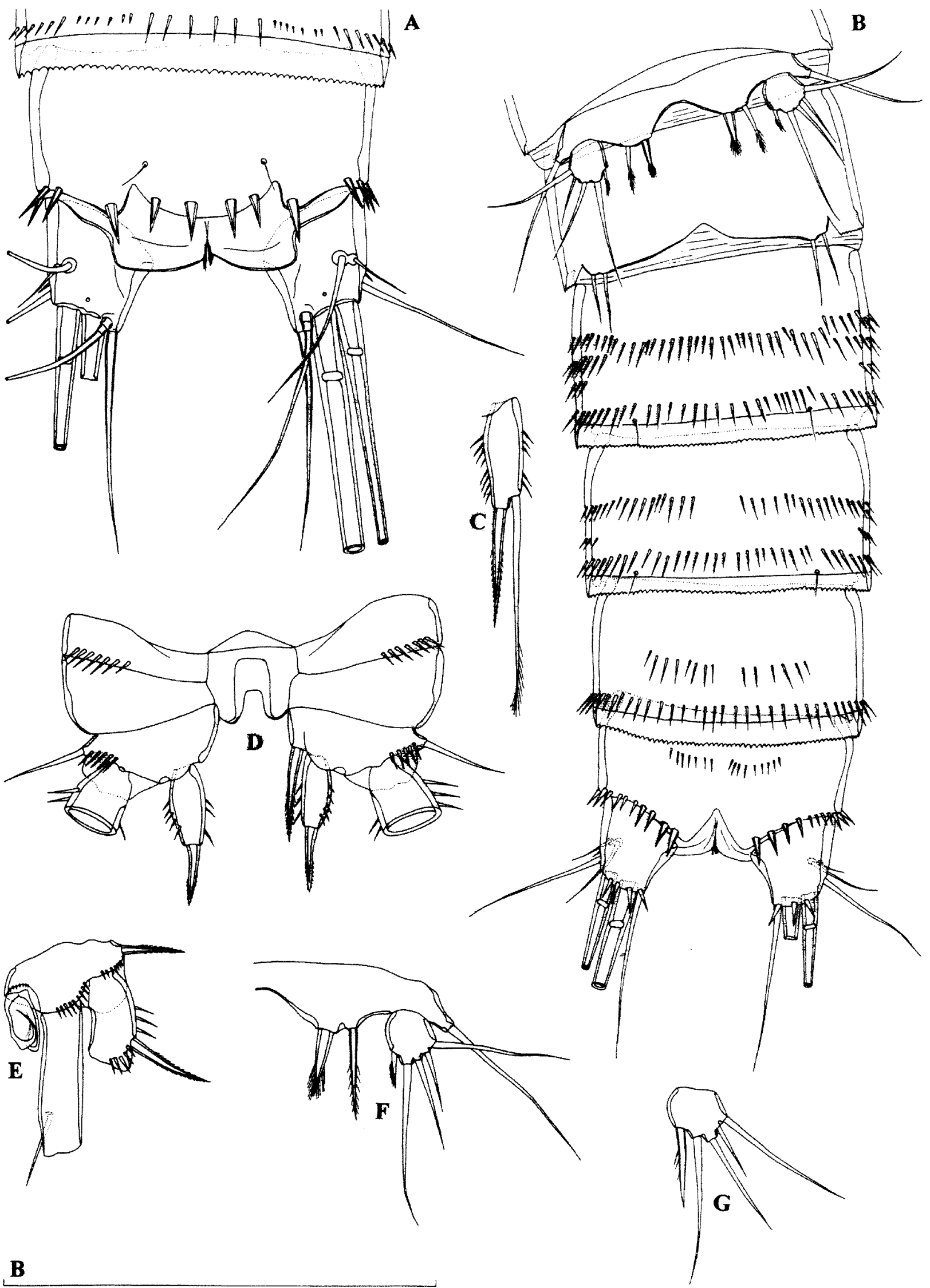

$A, C, D, E, F, G$

Figure 93 Stygonitocrella trispinosa sp. nov., A-F, allotype (male); G, paratype male (0.403 mm; WAM C34180): A, anal somite and caudal rami, dorsal view; B, urosome, ventral view; C, endopod of third swimming leg; D, fourth swimming legs, without exopods; E, basis and first endopodal and exopodal segments of first swimming leg; F, left fifth leg; G, exopod of left fifth leg. Scales $=0.1 \mathrm{~mm}$. 
only one seta on fifth segment and one on seventh segment very short and spiniform. Just two lateral setae on tenth segment and one seta on ninth segment articulating on basal part. No setae with breaking plane.

Antenna, labrum, mandibula, maxillula, maxilla, maxilliped, second swimming leg and fourth swimming leg (Figure 93D) similar to female.

First swimming leg (Figure 93E) with significantly modified inner spine on basis, which smooth, bilobate at distal end and very large.

Third swimming leg (Figure 93C) with inner seta on endopod somewhat shorter and with fewer and smaller pinnules; other details similar to female.

Fifth legs (Figure 93F) with baseoenopods fused medially but distinct from somite. Baseoendopod with outer basal seta long, smooth, arising from long setophore. Endopodal lobe relatively narrow, almost straight, unornamented and armed with two elements; outer armature element more slender and 1.4 times as long as inner one. Exopod small, ovoid, about 1.2 times as long as maximum width, unornamented and armed similarly to female but with additional small and pinnate seta on inner margin, which shorter than exopod; length ratio of exopodal seta, from inner side, $1: 4.3: 2.5: 1.6: 3.8$

Sixth legs (Figure 93B) narrowly fused basally and also indistinct from somite, each armed with two smooth setae; inner seta about 1.2 times as long as outer one.

\section{Variability}

Body length of females ranges from $0.416 \mathrm{~mm}$ to $0.528 \mathrm{~mm}(0.464 \mathrm{~mm}$ average; $\mathrm{n}=8)$, while in males it ranges from $0.342 \mathrm{~mm}$ to $0.446 \mathrm{~mm}(0.402 \mathrm{~mm}$ average; $n=8$ ). One female from locality 1 has a much stouter outermost armature element on the endopodal lobe of the fifth leg (Figure 92B), as well as five strong spinules on the anal operculum (Figure 92C). The allotype has asymmetrical bases of the fourth swimming leg (Figure 93D), with an atavistic spine on the inner margin of one leg. One paratype male has a much stronger innermost armature element on the exopod of the fifth leg (Figure 93G) than the allotype.

\section{Etymology}

The specific name refers to the armature of the fifth leg baseoendopod in the female, which consists of three spiniform elements. It is an adjective agreeing in gender with the feminine generic name.

\section{Discussion}

Petkovksi (1976) revised the genus Nitocrella Chappuis, 1924 and proposed the erection of a new genus Stygonitocrella for species with reduced segmentation of the swimming legs endopods (with the endopod of the fourth leg one-segmented and those of the second and third leg one- or two- segmented). He also compiled a key to the nine species recognised by him as valid at the time but did not designate a type species. Reid et al. (2003) designate Stygonitocrella montana (Noodt, 1965) as the type species of Stygonitocrella, making the name available with their authorship, and revised the generic diagnosis. They recognised 11 species as valid members of the genus and placed Stygonitocrella orghidani (Petkovski, 1973) as incertae sedis. Lee and Huys (2002) provided a table of known characters of appendages for Stygonitocrella species, along with three other closely related genera. Although they considered Stygonitocrella as an "unnatural genus" and claimed that the members could be grouped into several discrete lineages, each with a typical leg setation pattern and a restricted geographical distribution, they emphasised that formal recognition of these lineages is presently impossible because of the lack of detail provided by most descriptions and the fact that many of them are based on few specimens or only one sex. Species of Stygonitocrella are known from freshwater subterranean habitats in Europe, Central Asia, Cuba, Argentina and the United States. The three species described herein constitute the first record of the genus in Australia. As all three have endopod of the second, third and fourth legs one-segmented, they fit well within the generic diagnosis as revised by Reid et al. (2003). In fact their armature formula of swimming legs is so similar to Stygonitocrella ljovuschkini, described by Borutzky (1967) from Caucasus, that a close phylogenetical relationship between them seems very likely. Similar armature of the fifth and sixth legs, both in female and male, and the genital somite in female fused to the first abdominal one are the characters that further support their close relationship. However, $S$. ljovuschkini can be readily distinguished from the three Australian representatives by the absence of an inner seta on the second exopodal segment of the first leg (vs. present in all three Australian species) and the absence of inner setae on the third exopodal segment of the fourth swimming leg (vs. one or two inner setae in Australian species). All other species of Stygonitocrella differ morphologically much more from the Australian representatives. All three species described herein share a number of important morphological characters (armature formula of swimming legs, shape of the genital double somite in female, caudal rami shape and relatively similar mouth appendages), so I presume their very close phylogenetical relationship and relatively recent origin. This assumption is further supported by their allopatric distribution.

Stygonitocrella trispinosa sp. nov. can be distinguished from the two Australian congeners by two large dorsal cuticular windows on the first 
and second free prosomites, and the strongly ornamented urosome, as well as by the armature of the fifth leg baseoendopod in female. It differs additionally from each species separately, by a number of minute morphological characters (mostly details in ornamentation) but also by some more important ones: it differs from S. unispinosa by the armature of the maxilliped, dorsal ornamentation of the anal somite and by the shape of the inner basal spine on the first leg in the male; and from $S$. bispinosa by the armature of the third exopodal segment of the fourth leg. It should be also mentioned here that $S$. trispinosa has the widest distribution in the Pilbara, basically from De Grey River to Fortescue River. The other two species are restricted to a single river aquifer each.

Stygonitocrella trispinosa is the second reported species of Stygonitocrella with integumental windows on the free prosomites, the first one being S. sequoyahi, described by Reid et al. (2003) from Oklahoma (United States). However, the latter species has two lateral windows on each of three free prosomites and also differs from the former species by a number of important morphological characters, including the segmentation of the swimming legs, armature of mouth appendages and caudal rami shape. Any closer relationship between the two seems unlikely, which further supports Lee and Huys' (2002) view of the polyphyletic nature of Stygonitocrella. However, I do agree with Reid et al. (2003) that "for now it seems best to maintain the simple general concept of Stygonitocrella as proposed by Petkovski (1976), pending recollection and redescription of several of the species that are presently assigned to this genus". I also hope that the new members from Australia and elsewhere will shed a new light on the importance of different morphological characters. Besides the three new species described here, I have another two new species from Australia (Karanovic, in preparation): one from the Kimberley region in Western Australia and the other one from Pioneer Valley in Queensland.

Stygonitocrella unispinosa sp. nov. Figures $94-97$ and $114 \mathrm{~A}-\mathrm{C}$

\section{Material Examined}

\section{Holotype}

Female (WAM C34186), Australia, Pilbara, Robe River, bore G70730104, post-purge, 14 November 2002, leg. J. Cocking and M. Scanlon (CALM), $21^{\circ} 34^{\prime} 53^{\prime \prime} \mathrm{S} 115^{\circ} 52^{\prime} 14^{\prime \prime} \mathrm{E}$ : dissected on one slide

\section{Allotype}

Male (WAM C34187), Australia, Pilbara, Robe River, bore G70730104, post-purge, 14 November
2002, leg. J. Cocking and M. Scanlon (CALM), $21^{\circ} 34^{\prime} 53^{\prime \prime S} 115^{\circ} 52^{\prime} 14^{\prime \prime E}$ : dissected on one slide

\section{Paratypes}

Australia, Pilbara, Robe River, bore G70730104, post-purge, 14 November 2002, leg. J. Cocking and M. Scanlon (CALM), 21 $34^{\prime} 53^{\prime \prime S} 115^{\circ} 52^{\prime} 14^{\prime \prime} \mathrm{E}$ : one male + six females + one copepodid (one female dissected on one slide (WAM C34188); one female (HA 226) dissected by Jane McRae on one slide (WAM C34189); others in alcohol (WAM C34190))

\section{Topotypes}

1) Australia, Pilbara, Robe River, bore G70730104, pre-purge, 14 November 2002, leg. J. Cocking and M. Scanlon (CALM), 21 34'53"S 114 $52^{\prime} 14^{\prime \prime} E$ : one male + one female in alcohol (WAM C34191)

2) Australia, Pilbara, Robe River, bore G70730104, post-purge II, 14 November 2002, leg. J. Cocking and M. Scanlon (CALM), 21 $34^{\prime} 53^{\prime \prime S} 114^{\circ} 52^{\prime} 14 " \mathrm{E}$ : one copepodid in alcohol (WAM C34192)

\section{Other material}

1) Australia, Pilbara, Robe River, bore G70730101, 14 November 2002, leg. J. Cocking and M. Scanlon (CALM), 21 ${ }^{\circ} 34^{\prime} 32^{\prime \prime} \mathrm{S} 115^{\circ} 52^{\prime} 58^{\prime \prime} \mathrm{E}$ : two males + three females + two copepodids in alcohol (WAM C34193)

2) Australia, Pilbara, Robe River, Yarraloola Station, bore PANNASLK4, 5 April 2003, leg. J. Cocking and M. Scanlon (CALM), 21 $37^{\circ} 59^{\prime \prime} S$ $115^{\circ} 57^{\prime} 41^{\prime \prime} \mathrm{E}$ : two females + two copepodids in alcohol (WAM C34194)

\section{Description}

Female (holotype). Total body length, measured from tip of rostrum to posterior margin of caudal rami (excluding caudal setae), $0.353 \mathrm{~mm}$. Preserved specimen colourless. Nauplius eye absent. Habitus (Figure 94A and 95A) cylindrical, slender, without distinct demarcation between prosome and urosome; prosome/urosome ratio 0.96 and greatest width at third pedigerous somite (second free). Body length/width ratio about 4.7; cephalothorax as wide as genital double somite. Free pedigerous somites without pronounced lateral expansions or dorsally. Integument weakly chitinized and no cuticular windows visible. Pleural areas of cephalothorax and first three free pedigerous somites not well developed; cephalic appendages and coxae of swimming legs clearly exposed in lateral view (Figure 95A). More or less sclerotized joint (as pseudosomite) present between fifth pedigerous and genital double somite. Rostrum minute, membranous, ovoid, reaching just beyond proximal margin of first antennular segment, about as long as wide and not demarcated at base; ornamented with two dorsal sensilla. 

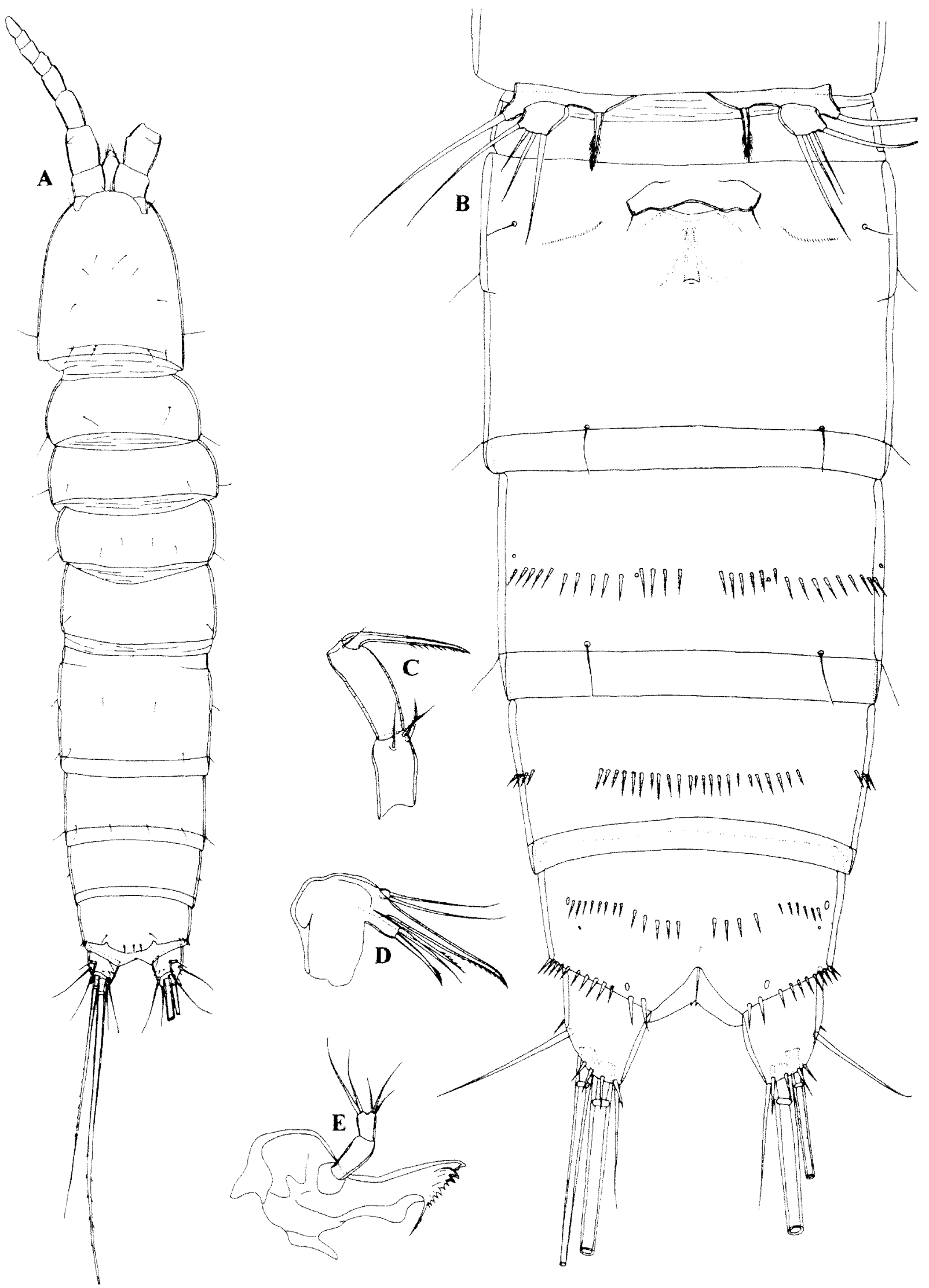

\section{$\mathrm{B}, \mathrm{C}, \mathrm{D}, \mathrm{E}$}

A

Figure 94 Stygonitocrella unispinosa sp. now, holotype (female): A, habitus, dorsal view; B, urosome, ventral view; C, maxilliped; D, maxilla; E, mandibula. Scales $=0.1 \mathrm{~mm}$. 
Cephalothorax (Figure 94A and 95A) almost rectangular from dorsal view, about 1.1 times as long as wide; represents $20 \%$ of total body length. Surface of cephalic shield and tergites of three free pedigerous somites ornameted with several very large sensilla. Hyaline fringe of all somites smooth. Fifth pedigerous (first urosomal) somite ornamented only with two lateral sensilla on each side.

Genital double somite (Figure 94B) 0.7 times as long as wide (ventral view), with very short suture visible laterally; ornamented with four large sensilla dorsally, four sensilla and two pores laterally (two sensilla and one pore on each side) and four sensilla ventrally (one each side proximally, two near posterior margin), as well as with two short ventral rows of minute spinules, near genital complex. Female genital complex with single small copulatory pore, sclerotized and narrow copulatory duct and two ovoid seminal receptacles. Single small genital aperture covered by fused reduced sixth legs, represents $33 \%$ of somite width. Third urosomite ornamented with eight large sensilla near posterior margin (four dorsal, two lateral and two ventral) and with slightly interrupted row of large spinules (along with four cuticular pores) at middle ventrally. Preanal somite ornamented only with interrupted ventrolateral row of large spinules at middle, along with two lateral cuticular pores (one on each side); no sensilla on this somite. Anal somite (Figure 94B and 95B) ornamented with pair of large dorsal sensilla, three large ventral cuticular pores, transverse row of large spinules along posterior margin ventrolaterelly and with slightly interrupted ventral row of spinules at midlength. Anal operculum convex, not reaching posterior end of anal somite, represents $42 \%$ of somite's width, ornamented with three spinules near posterior margin. Anal sinus unornamented, widely opened .

Caudal rami (Figure 94B and 95B) short, slightly divergent, slightly shorter than greatest width (ventral view), conical, with small chitinous ridge dorsally, with space between them about one ramus width; armed with six armature elements (two lateral, one dorsal and three apical). Ornamentation consists of one long setula at base of proximal lateral seta, one cuticular pore dorsally, one spinule at base of distal lateral seta, two spinules at base of dorsal seta and posterior row of four large spinules ventrally. Dorsal seta inserted near posterior margin very close to inner margin, about 1.8 times as long as caudal ramus, biarticulate at base and smooth.Proximal lateral seta about 1.2 times as long as dorsal one, arising dorsolaterally at middle of ramus length. Distal lateral seta arising at $3 / 4$ of ramus length, slightly shorter than dorsal seta, smooth. Inner apical seta well developed, also smooth, about 1.6 times as long as ramus. Middle apical seta strongest, with breaking plane, weakly pinnate distally, about twice as long as outer apical seta and more than 0.6 times as long as body. Outer apical seta also with breaking plane and pinnate.

Antennula (Figure 95D) eight-segmented, unornamented, approximately 1.2 times as long as cephalothorax, with long and broad aesthetasc on fourth segment, which reaches beyond tip of appendage almost for length of last four segments together, as well as with much smaller aesthetasc on eighth segment apically; setal formula: 1.8.6.3.2.2.4.8. Only seta on first segment pinnate, all other setae smooth. Only two setae on eighth and two setae on seventh segment articulating on basal part and all setae without breaking plane. One apical seta on eighth segment fused basally to aesthetasc. Length ratio of antennular segments, from proximal end, $1: 1.5: 1: 0.8: 0.5: 0.9: 0.4: 0.7$.

Antenna (Figure 95C) composed of coxa, basis, two-segmented endopod and one-segmented exopod. Coxa very short, unornamented. Basis about 1.6 times as long as wide, unornamented and unarmed. First endopodal segment about 1.7 times as long as wide, somewhat longer than basis, also unornamented and unarmed. Second endopodal segment longest, 1.6 times as long as first and three times as long as wide, with two surface frills on posterior surface, armed laterally with two smooth spines flanking thin seta; apical armature consisting of five geniculate setae, longest one fused basally to additional smaller seta, bearing proximal tuft of fine setules; ornamentation consists of few spinules along anterior surface. Exopod 0.7 times as long as basis and 2.3 times as long as wide, unornamented and armed with three pinnate setae; innermost seta 1.4 times as long as other two (which of about same length) and also 1.4 times as long as exopod.

Labrum (Figure 95F) large compared with cephalothorax, trapezoidal, rigidly sclerotized, with very broad and almost straight cutting edge, ornamented subapically with two short rows of spinules. Two ovoid fields of gustatory papillae visible on dorsal (posterior) surface.

Mandibula (Figure 94E) with broad cutting edge on elongated coxa, armed with three coarse teeth ventrally, one unipinnate seta dorsally and several small teeth in between. Palp uniramous, comprising basis and one-segmented endopod. Basis slender, unarmed and unornamented, twice as long as wide. Endopod also unornamented, about 0.5 times as long as basis and about 1.4 times as long as wide; armed with five slender and smooth setae apically, outermost one longest, innermost one shortest.

Maxillula (Figure 95E) with large praecoxa, arthrite rectangular, not movable, unornamented; armed with two smooth setae on anterior surface, two setae on dorsal margin and four apical elements (probably three spines and one dorsal seta). Coxal endite small, reaching half length of coxal arthrite, armed with one pinnate and two 


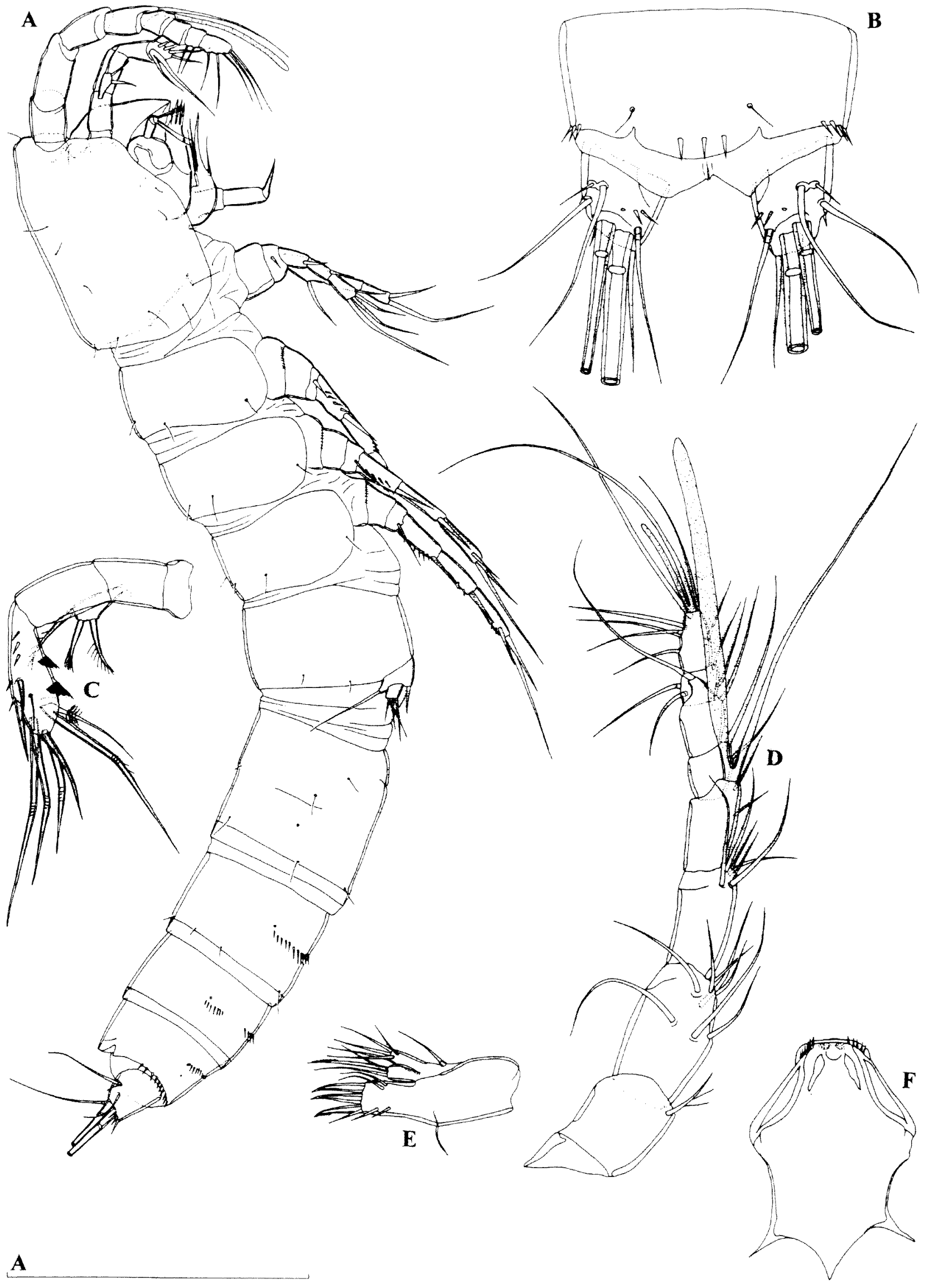

B, C, D, E, F

Figure 95 Stygonitocrella unispinosa sp. nov, holotype (female): A, habitus, lateral view; B, anal somite and caudal rami, dorsal view; $C$, antenna; $D$, antennula; $E$, maxillula; $F$, labrum. Scales $=0.1 \mathrm{~mm}$ 

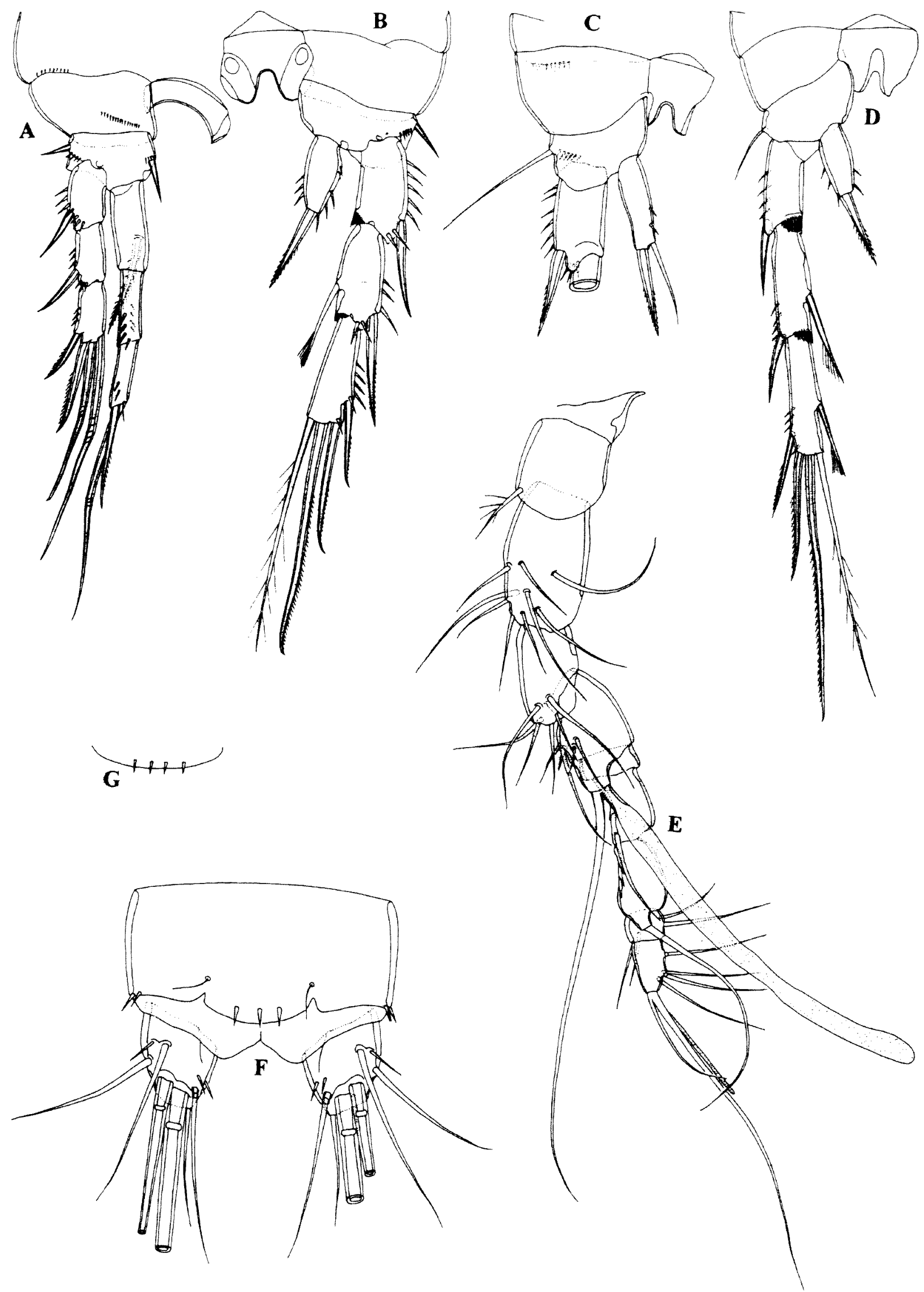

Figure 96 Stygonitocrella unispinosa sp. nov., A-D, holotype (female); E and F, allotype (male); G, paratype female (WAM C34189): A, first swimming leg; B, second swiming leg; $C$, third swimming leg, without second and third exopodal segments; D, fourth swimming leg; E, antennula; F, anal somite and caudal rami, dorsal view. Scale $=0.1 \mathrm{~mm}$. 
smooth setae, all of about same length. Basis somewhat longer than coxal endite, armed with five smooth setae apically and subapically. Endopod minute but distinct segment, armed with single smooth apical seta.

Maxilla (Figure 94D) with proximal endite on suncoxa completely reduced; distal endite well developed, highly mobile, armed with one curved pinnate spine and one smooth seta, slightly longer than spine. Basis drawn out into long claw, with shorter spiniform and curved seta at its base. Endopod represented by minute segment, armed with two smooth subequal, long apical setae.

Maxilliped (Figure 94C) with well developed syncoxa, unomamented but armed with three smooth seta subapically; 1.9 times as long as wide. Basis almost 2.4 times as long as wide and 1.2 times as long as syncoxa, unornamented. Endopod represented by long curved claw, omamented with row of spinules along concave side distally; with thin seta at base?

All swimming legs with three-segmented exopod; endopod of first leg also three-segmented (Figure $96 \mathrm{~A})$, endopods of other swimming legs onesegmented (Figure 96B, C, D). Armature formula of swimming legs as follows (legend: inner/outer spine or seta; inner/terminal/outer):

\begin{tabular}{lcccccc} 
& \multicolumn{3}{c}{ Exopod } & \multicolumn{3}{c}{ Endopod } \\
Segments & 1 & 2 & 3 & 1 & 2 & 3 \\
First leg & $0 / 1$ & $0 / 1$ & $0 / 2 / 2$ & $1 / 0$ & $0 / 0$ & $1 / 1 / 1$ \\
Second leg & $0 / 1$ & $1 / 1$ & $0 / 2 / 2$ & $0 / 1 / 0$ & - & - \\
Third leg & $0 / 1$ & $1 / 1$ & $0 / 2 / 2$ & $1 / 1 / 0$ & - & - \\
Fourth leg & $0 / 1$ & $1 / 1$ & $1 / 2 / 2$ & $0 / 1 / 0$ & - & -
\end{tabular}

Intercoxal sclerites of all swimming legs with concave distal margin and without any surface ornamentation. Praecoxa of first and third leg with row of spinules along outer posterior margin, that of second and fourth legs unornamented; coxa of first leg with diagonal row of spinules, while coxae of all other swimming legs unornamented. Basis of all legs ornamented with spinules near outer margin; armed with outer smooth spine on first and second swimming legs and with outer smooth seta on third and fourth legs; basis of first leg with stout spine on inner distal corner and row of spinules at its base. All exopodal and endopodal segments ornamented with strong spinules along outer margin and some segments also with spinules along inner and distal margin. First exopodal segment of all legs about as long as second exopodal segment. First endopodal segment of first swimming leg (Figure 96A) not very large, about 2.5 times as long as wide and reaching slightly beyond midlength of second exopodal segment. Endopod of other swimming legs about as long as first exopodal segment (that of fourth leg somewhat shorter). All setae on exopods and endopods (except minute inner seta on third endopodal segment of first leg and inner seta on third leg endopod) strong and many spiniform.

Fifth leg (Figure 94B) biramous, baseoendopods not fused medially. Baseoendopod with outer basal seta long and smooth, arising from long setophore. Endopodal lobe verv small, only slightly convex, not extending bevond proximal margin of exopod in length, unornamented and armed with single very stout and bipinnate armature element, which 1.7 times as long as exopod. Exopod quadriform, small, about 0.8 times as long as maximum width, unomamented and armed with four slender and smooth setae; length ratio of exopodal setae, from inner side, $1: 0.7: 0.4: 1.4$. Longest seta on exopod 2.6 times as long as endopodal armature element.

Sixth legs (Figure 94B) completely fused, indistinct, forming simple operculum covering single gonopore, without any ornamentation but armed with two minute smooth setae.

Male (allotype). Body length, excluding caudal setae, $0.346 \mathrm{~mm}$. Habitus (Figure 97D), ornamentation of prosomites, rostrum, colour and nauplius eve similar to female. Hyaline fringe of all somites smooth.

Genital somite more than twice as wide as long. Single, longitudinally placed, large spermatophore inside fifth pedigerous and genital somites (Figure 97D). Urosomites ornamentation similar to female, except that third urosomite additionally ornamented with interrupted ventral row of spinules and two cuticular pores at middle and preanal somite with two large cuticular pores ventrally proximally (Figure 97A). Anal operculum with three spinules (Figure 96F), as in female.

Caudal rami (Figure $96 \mathrm{~F}$ and $97 \mathrm{~A}$ ) about 0.8 times as long as wide. Armature and ornamentation similar to female, but dorsal cuticular pore absent and ventral posterior margin with three, instead of four, spinules.

Antemula (Figure 96E) long and slender, tensegmented, not strongly geniculate, with geniculation between seventh and eighth segment, unornamented. Very long and broad aesthetasc on apical acrothek of fifth segment (homologue to aesthetasc on fourth segment in female); one smaller aesthetasc on tenth segment. First two and last two segments similar to female. Setal formula: 1.9.5.1.6.0.1.1.4.6. Majority of setae smooth and slender; only seta on first segment pinnate, all other setae smooth; only one seta on fifth segment very short and spiniform. Only four lateral setae on tenth and one seta on ninth segment articulating on basal part. No setae with breaking plane.

Antenna, labrum, mandibula, maxillula, maxilla, maxilliped, second swimming leg (Figure 97E), third swimming leg (Figure 97F) and fourth swimming leg similar to female.

First swimming leg (Figure 97B, C) with significantly modified inner spine on basis, which 


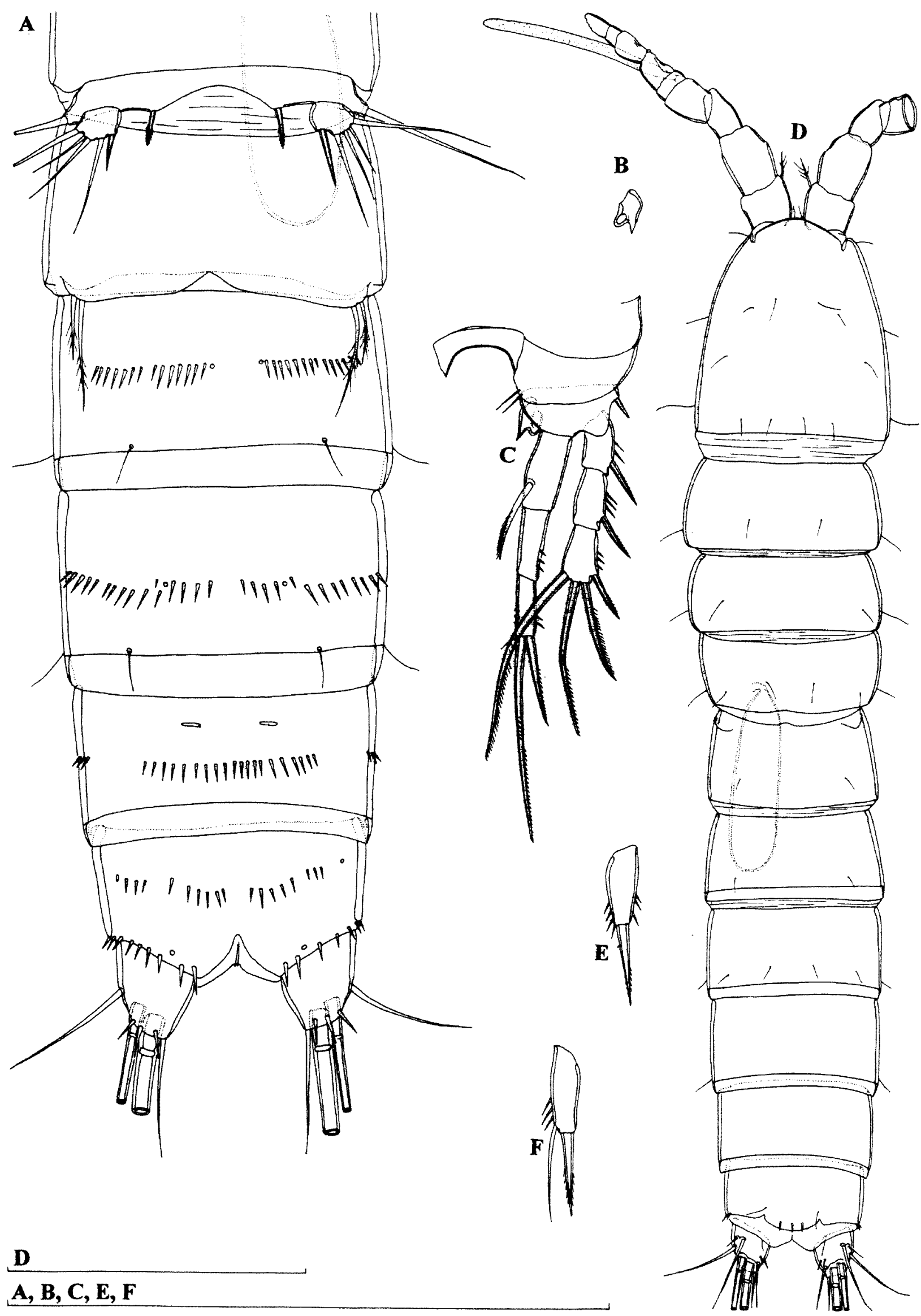

Figure 97 Stygonitocrella unispinosa sp. nov., allotype (male): A, urosome, ventral view; B, transformed spine on inner margin of first swimming leg basis; C, first swimming leg; D, habitus, dorsal view; E, endopod of second swimming leg; $F$, endopod of third swimming leg. Scales $=0.1 \mathrm{~mm}$. 
smooth and bilobate at distal end and very large; inner lobe pointed, outer blunt.

Fifth legs (Figure 97A) with baseoenopods fused medially but distinct from somite. Baseoendopod and endopodal lobe similar to female. Exopod small, ovoid, about 0.8 times as long as maximum width, unornamented and armed similarly to female but with additional stout and smooth seta on inner margin, which shorter on right leg than on left one; length ratio of exopodal seta on left leg, from inner side, $1: 1.7: 1.3: 0.9: 2.4$

Sixth legs (Figure 97A) narrowly fused basally and indistinct from somite, each armed with two pinnate setae; inner seta about 1.7 times as long as outer one.

\section{Variability}

Body length of females ranges from $0.304 \mathrm{~mm}$ to $0.353 \mathrm{~mm}$ ( $0.33 \mathrm{~mm}$ average; $\mathrm{n}=7$ ), while in males it ranges from $0.277 \mathrm{~mm}$ to $0.346 \mathrm{~mm}(0.316 \mathrm{~mm}$ average; $n=4$ ). One paratype female has four spinules on the anal operculum (Figure 96G). The exopods of the allotype's fifth leg are also slightly asymmetrical (Figure 97A). No other type of variability was observed.

\section{Etymology}

The specific name refers to the armature of the fifth leg baseoendopod in the female, which consists of a single spiniform element. It is an adjective agreeing in gender with the feminine generic name.

\section{Discussion}

It seems that the only autapomorphy of $S$. unispinosa sp. nov. is its reduced armature of the fifth leg baseoendopod, which consists of a single strong spine in both female and male. Another character that easily distinguishes this species from both Australian congeners is the plesiomorphic armature of the maxilliped, with three elements on the first segment. Stygonitocrella unispinosa seems to be restricted to the Robe River aquifer, which means it lives between $S$. trispinosa sp. nov. to the north-east and $S$. bispinosa sp. nov. to the southwest. The lack of gradual north-south change in the morphological characters of these three taxa further supports their specific status. Aproximately equal distribution of plesiomorphic and apomorphic characters in each species rules out the possibility that any of the species is an ancestor to the other one, and suggests they originated from the same ancestor at about the same time. It should also be mentioned here that no other species of Stygonitocrella is known with a single endopodal spine on the fifth leg but that many species have this appendage even more reduced. Although the shape of the fifth leg may be a very good character at the specific level, its importance at the generic level is rather limited in this group of freshwater Ameiridae, contrary to the suggestion of Reid et al. (2003). The three Australian species are a very good example of that.

\section{Stygonitocrella bispinosa sp. nov. Figures $98-100$ and $114 \mathrm{D}-\mathrm{F}$}

\section{Material Examined}

Holotype

Female (WAM C34195), Australia, Pilbara, Cane River Borefield, bore CR7/97, 5 April 2003, leg. J. Cocking and M. Scanlon (CALM), 21 41'46"S $115^{\circ} 22^{\prime} 22^{\prime \prime} \mathrm{E}$ : dissected on two slides

\section{Allotype}

Male (WAM C34196), Australia, Pilbara, Cane River Borefield, bore CR7/97, 5 April 2003, leg. J. Cocking and M. Scanlon (CALM), 21 $41^{\prime} 46^{\prime \prime S}$ $115^{\circ} 22^{\prime 2} 2^{\prime \prime} \mathrm{E}$ : dissected on two slides

\section{Paratypes}

Australia, Pilbara, Cane River Borefield, bore CR7/97, 5 April 2003, leg. J. Cocking and M. Scanlon (CALM), $21^{\circ} 41^{\prime} 46^{\prime \prime S} 115^{\circ} 22^{\prime} 22^{\prime \prime} \mathrm{E}$ : four males + four females (one male (WAM C34197) and two females (WAM C34198 and C34199) dissected on one slide each; others in alcohol (WAM C34200)

\section{Description}

Female (holotype). Total body length, measured from tip of rostrum to posterior margin of caudal rami (excluding caudal setae), $0.393 \mathrm{~mm}$. Colour of preserved specimen yellowish. Nauplius eye not visible. Habitus (Figure 98D) cylindrical, slender, without distinct demarcation between prosome and urosome; prosome/urosome ratio about 1.0 and greatest width at second pedigerous (first free) somite. Body length/width ratio about 5.4; cephalothorax 1.1 times as wide as genital double somite. Free pedigerous somites without pronounced lateral expansions or dorsally. Integument weakly chitinized but cephalothorax with small dorsal cuticular window in anterior part. Pleural areas of cephalothorax and first three free pedigerous somites not well developed; cephalic appendages and coxae of swimming legs clearly exposed in lateral view. More or less sclerotized joint (as pseudosomite) present between fifth pedigerous and genital double somite (Figure 98A). Rostrum very small, membranous, ovoid, reaching just beyond proximal margin of first antennular segment, about as long as wide and not demarcated at base; ornamented with two dorsal sensilla.

Cephalothorax (Figure 98D) almost rectangular in dorsal view, about 1.3 times as long as wide; represents $22 \%$ of total body length. Surface of 
cephalic shield and tergites of three free pedigerous somites ornameted with many large sensilla. Hyaline fringe of all prosomites narrow and smooth. Fifth pedigerous (first urosomal) somite ornamented with two large dorsal sensilla and one cuticular pore in between; hyaline fringe smooth dorsally and laterally.

Genital double somite (Figure 98A) about 0.8 times as long as wide (ventral view), without visible suture; ornamented with four large sensilla dorsally (two at middle, two near posterior margin), two sensilla ventrally and four laterally (two on each side) near posterior margin. Hyaline fringe finely serrated both ventrally and dorsally. Female genital complex with single small copulatory pore, sclerotized narrow and short copulatory duct and two small semicircular seminal receptacles. Single small genital aperture covered by fused reduced sixth legs, represents $33 \%$ of somite width. Third urosomite ornamented with eight large sensilla near posterior margin (four dorsal, two lateral and two ventral) and with two short and parallel rows of spinules ventrally, anterior row accompanied by two cuticular pores, posterior one widely interrupted at middle; hyaline fringe finely serrated. Preanal somite also with finely serrated hyaline fringe dorsally and ventrally, without any ornamentation. Anal somite (Figure 98A, E, F) ornamented with pair of large dorsal sensilla, with two ventral and two lateral cuticular pores and with transverse row of very large and stout spinules along posterior margin dorsolaterally (one on each corner near anal operculum exceptionally strong), as well as with two large spinules ventrally, at base of caudal rami. Anal operculum convex, not reaching posterior end of anal somite, represents $43 \%$ of somite's width, ornamented with six strong spinules near posterior margin. Anal sinus unornamented and widely opened.

Caudal rami (Figure 98A, E, F) short, slightly divergent, as long as greatest width (ventral view), conical, with space between them more than one ramus width; armed with six armature elements (two lateral, one dorsal and three apical). Ornamentation consists of one long setula at base of proximal lateral seta, one dorsal cuticular pore, two minute spinules at base of distal lateral seta, one large spinule at base of dorsal seta and posterior row of two large spinules ventrally. Dorsal seta inserted near posterior margin, very close to inner margin, about 2.3 times as long as caudal ramus, biarticulate at base and smooth. Proximal lateral seta about as long as dorsal one, arising almost dorsally at middle of ramus length. Distal lateral seta arising at $2 / 3$ of ramus length, about 0.7 times as long as proximal one, smooth. Inner apical seta well developed, also smooth, about 1.5 times as long as ramus. Middle apical seta strongest, with breaking plane, smooth, about twice as long as outer apical seta and almost 0.5 times as long as body. Outer apical seta also with breaking plane and smooth.

Antennula (Figure 99E) approximately 1.2 times as long as cephalothorax, eight-segmented, stout and unomamented, with long aesthetasc on fourth segment, which reaches beyond tip of appendage for less than length of last three segments together, as well as with much smaller and more slender aesthetasc on eighth segment apically; setal formula: 1.8.5.3.2.2.4.7. Only seta on first segment pinnate, all other setae smooth. Only four setae on eighth segment articulating on basal part and all setae without breaking plane. One apical seta on eighth segment fused basally to aesthetasc. Length ratio of antennular segments, from proximal end, 1 $: 1.9: 1.2: 1.2: 0.8: 1: 0.5: 0.6$

Antenna (Figure 99F) composed of coxa, basis, two-segmented endopod and one-segmented exopod. Coxa very short, unornamented. Basis about 1.5 times as long as wide, ornamented with row of long spinules along outer margin distally, unarmed. First endopodal segment about 1.9 times as long as wide, unornamented and unarmed. Second endopodal segment longest, 1.5 times as long as first and 3.1 times as long as wide, armed laterally with two smooth spines flanking thin seta; apical armature consisting of five geniculate setae, longest one with few pinnules along convex margin and fused basally to additional smaller seta, bearing proximal tuft of fine setules; ornamentation consists of few spinules along anterior surface proximmally and two surface frills on posterior surface. Exopod trapezoidal, 0.7 times as long as basis and 1.5 times as long as wide, unornamented but armed with three pinnate setae; innermost seta 1.6 times as long as other two (which of about same length) and almost twice as long as exopod.

Labrum not very large compared with cephalothorax, trapezoidal, rigidly sclerotized, with relatively broad and almost straight cutting edge, ornamented subapically with two rows of strong spinules and one row of smaller spinules in between, apically. No fields of gustatory papillae visible on dorsal (posterior) surface.

Paragnaths ellipsoid (Figure 98C), about 1.7 times as long as wide, with group of four large spinules on proximal inner part of each lobe and with pointed and serrated tips.

Mandibula (Figure 99G) with broad cutting edge on elongated coxa, armed with three coarse teeth ventrally, one unipinnate seta dorsally and numerous small teeth in between. Palp uniramous, comprising basis and one-segmented endopod. Basis slender, unarmed and unornamented, about twice as long as wide. Endopod also slender and unornamented, about 0.7 times as long as basis and about 1.9 times as long as wide; armed with five slender and smooth setae apically. 


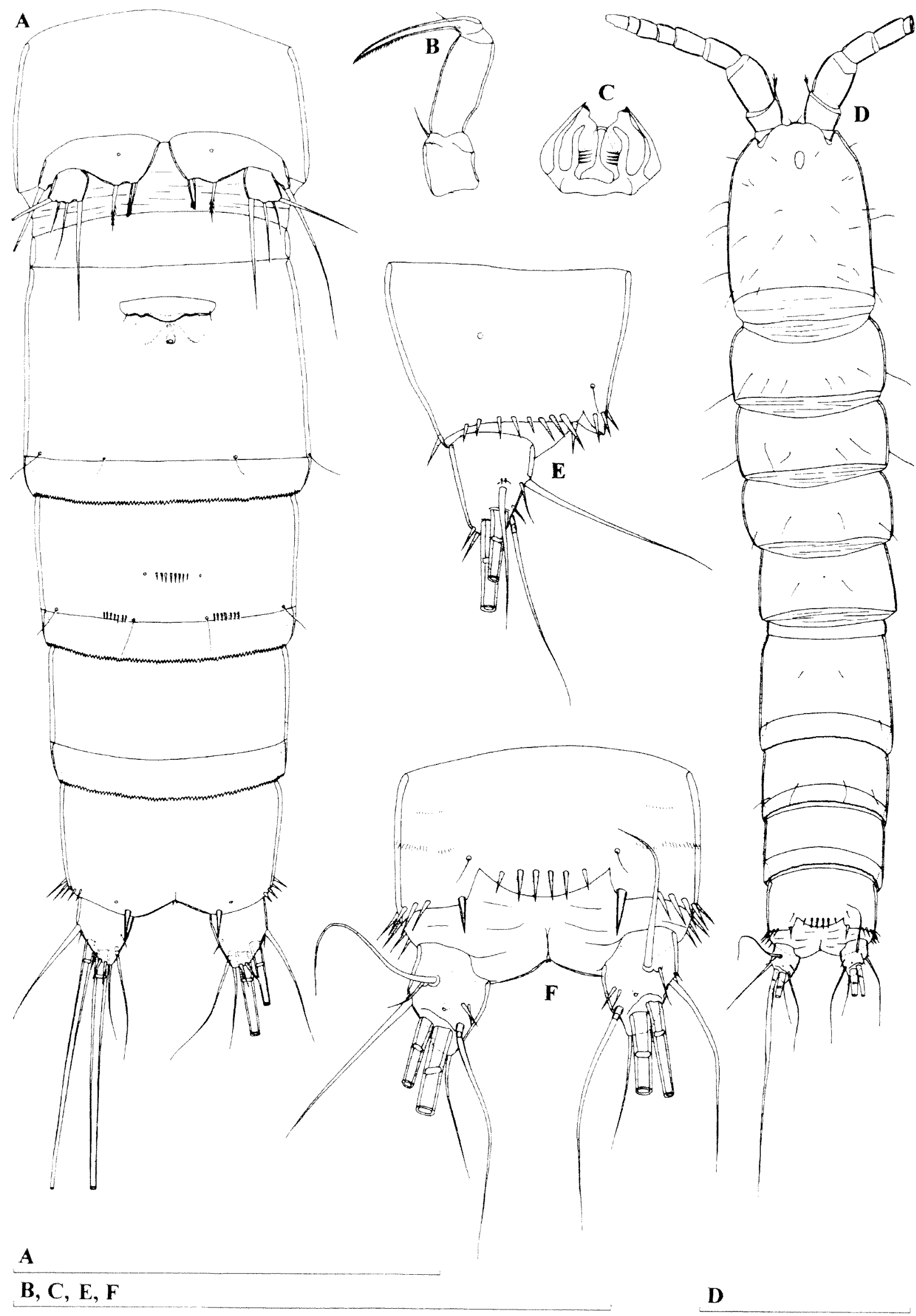

Figure 98 Stggonitocrella bispinosasp. nor, holotype (female): A, urosome, ventral view; B, maxilliped; C, paragnaths; D, habitus, dorsal view; $E$, anal somite and left caudal ramus, lateral view; $F$, anal somite and caudal rami, dorsal view. Scales $=0.1 \mathrm{~mm}$. 


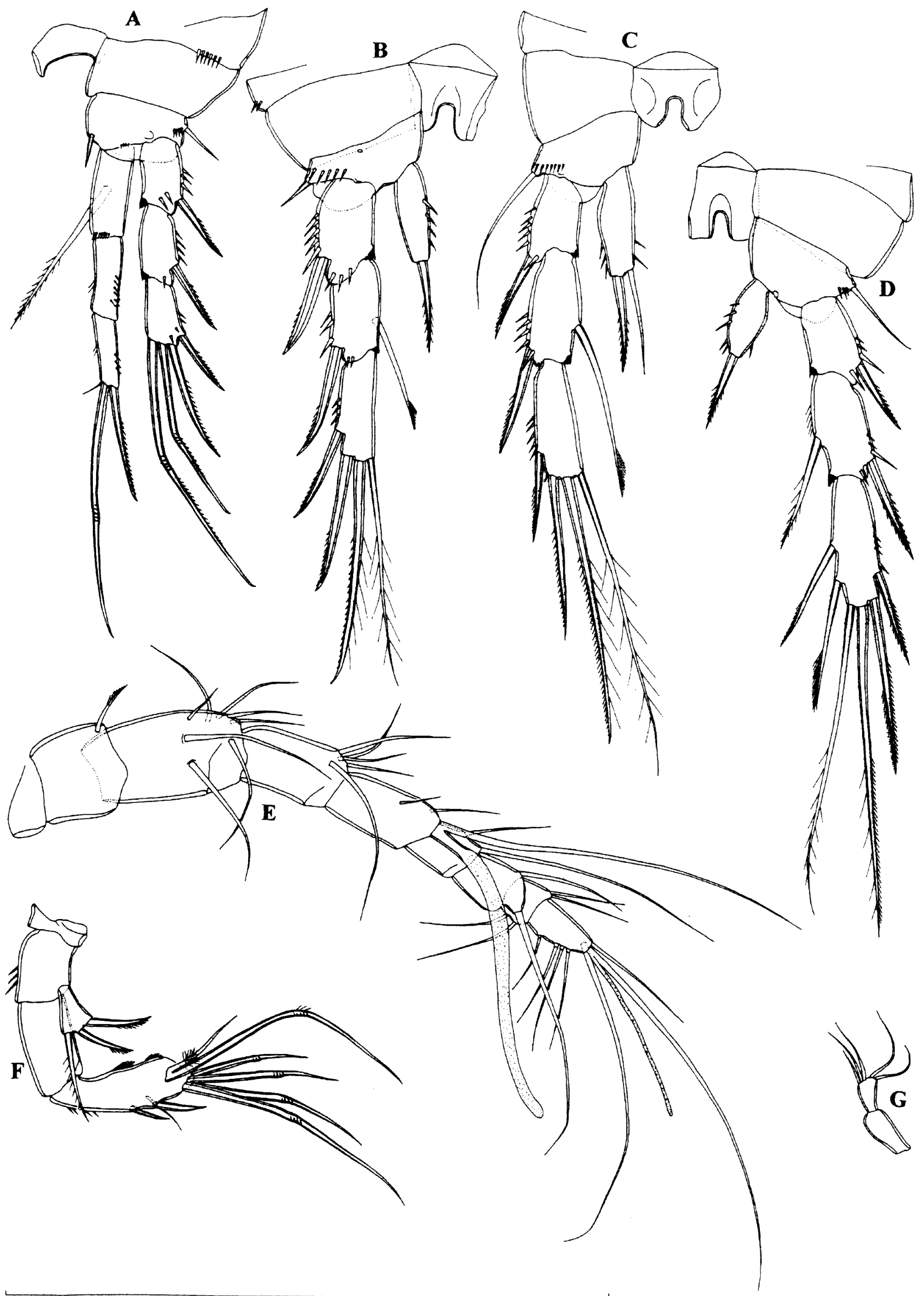

Figure 99 Stygonitocrella bispinosa sp. nov., holotype (female): A, first swimming leg; B, second swimming leg; C, third swimming leg; D, fourth swimming leg; $E$, antennula; $F$, antenna; $G$, mandibular palp. Scale $=0.1 \mathrm{~mm}$. 
Maxillula with large praecoxa, arthrite rectangular, not movable, unomamented; armed with two smooth setae on anterior surface, two setae on dorsal margin and four apical elements (probably three spines and one dorsal seta). Coxal endite armed with one pinnate and two smooth setae, all of about same length. Basis somewhat longer than coxal endite, armed with five smooth setae apically and subapically. Endopod minute but distinct segment, armed with single smooth apical seta.

Maxilla with proximal endite on syncoxa completely reduced; distal endite well developed, highly mobile, armed with one curved pinnate spine and two smooth subequal setae, which somewhat longer than spine. Basis drawn out into long claw, with much shorter spiniform and curved seta at base. Endopod represented by minute segment, armed with two smooth subequal, long apical setae.

Maxilliped (Figure 98B) with short syncoxa, unornamented but armed with single smooth seta subapically, 1.2 times as long as wide. Basis 2.5 times as long as wide and almost 1.9 times as long as syncoxa, also unornamented. Endopod represented by long curved claw, ornamented with row of spinules along concave side distally; with thin seta at base.

All swimming legs with three-segmented exopod; endopod of first leg also three-segmented (Figure 99A), endopod of other swimming legs onesegmented (Figure 99B, C, D). Armature formula of swimming legs as follows (legend: inner/outer spine or seta; inner/terminal/outer):

\begin{tabular}{lcccccc} 
& \multicolumn{3}{c}{ Exopod } & \multicolumn{3}{c}{ Endopod } \\
Segments & 1 & 2 & 3 & 1 & 2 & 3 \\
First leg & $0 / 1$ & $0 / 1$ & $0 / 2 / 2$ & $1 / 0$ & $0 / 0$ & $1 / 1 / 1$ \\
Second leg & $0 / 1$ & $1 / 1$ & $0 / 2 / 2$ & $0 / 1 / 0$ & - & - \\
Third leg & $0 / 1$ & $1 / 1$ & $0 / 2 / 2$ & $1 / 1 / 0$ & - & - \\
Fourth leg & $0 / 1$ & $1 / 1$ & $2 / 2 / 2$ & $0 / 1 / 0$ & - & -
\end{tabular}

Intercoxal sclerites of all swimming legs with concave distal margin and without any surface ornamentation. Praecoxa of first and second leg with row of long spinules along outer posterior margin, that of third and fourth legs unornamented; coxae of all swimming legs smooth. Basis of all legs ornamented with spinules near outer margin and that of first leg additionally with short row of minute spinules along posterior margin; armed with outer smooth spine on first and second swimming legs and with outer smooth seta on third and fourth legs; basis of first leg with small and smooth spine at inner distal corner. All exopodal and endopodal segments ornamented with strong spinules along outer margin and some segments also with spinules along inner and distal margin. First exopodal segment of all legs about as long as second exopodal segment. First endopodal segment of first swimming leg (Figure 99A) not very large, about 2.5 times as long as wide and hardly reaching midlength of second exopodal segment. Endopod of other swimming legs about as long as first exopodal segment. All setae on exopods and endopods (except minute inner seta on third endopodal segment of first leg) strong and many spiniform.

Fifth leg (Figure 91E) biramous, baseoendopods not fused medially. Baseoendopod with outer basal seta long and smooth, arising from long setophore. Endopodal lobe very broad, convex, extending to middle of exopod, ornamented with single cuticular pore and armed with two bipinnate elements; outer armature element more slender and 1.3 times as long as inner one. Exopod quadriform, small, about as long as maximum width, unornamented but armed with four slender and smooth setae; length ratio of exopodal setae, from inner side, $1: 0.5: 0.3$ : 0.8 . Longest seta on exopod 2.7 times as long as outer endopodal armature element.

Sixth legs (Figure 98A) completely fused, indistinct, forming simple operculum covering single gonopore, without any ornamentation and armed with single minute smooth setae, which smaller than any sensillum on genital double somite.

Male (allotype). Body length, excluding caudal setae, $0.357 \mathrm{~mm}$. Habitus, ornamentation of prosomites, rostrum, colour and nauplius eye similar to female. Hyaline fringe of all prosomites smooth; cephalothorax with dorsal cuticular window, as in female.

Genital somite more than twice as wide as long. Single, longitudinally placed spermatophore inside fifth pedigerous and genital somites (Figure 100D). Urosomites ornamentation similar to female, although fourth urosomite without posterior row of spinules ventrally. Anal operculum with six spinules (Figure 100E).

Caudal rami (Figure 100D) about as long as wide. Armature and ornamentation similar to female but dorsal seta somewhat shorter than in female.

Antennula long and slender, ten-segmented, not strongly geniculate, with geniculation between seventh and eighth segment, unornamented. Very long and broad aesthetasc on apical acrothek of fifth segment (homologue of aesthetasc on fourth segment in female); one smaller aesthetasc on eighth segment. First two and last two segments similar to female. Setal formula: 1.9.4.2.6.0.2.1.4.6. Majority of setae smooth and slender; seta on first segment and proximal seta on seventh segment pinnate, all other setae smooth; only one seta on fifth and one on seventh segment very short and spiniform. Only two lateral setae on tenth and one seta on ninth segment articulating on basal part. No setae with breaking plane

Antenna, labrum, mandibula, maxillula, maxilla, maxilliped, second swimming leg, third swimming leg and fourth swimming leg similar to female. 


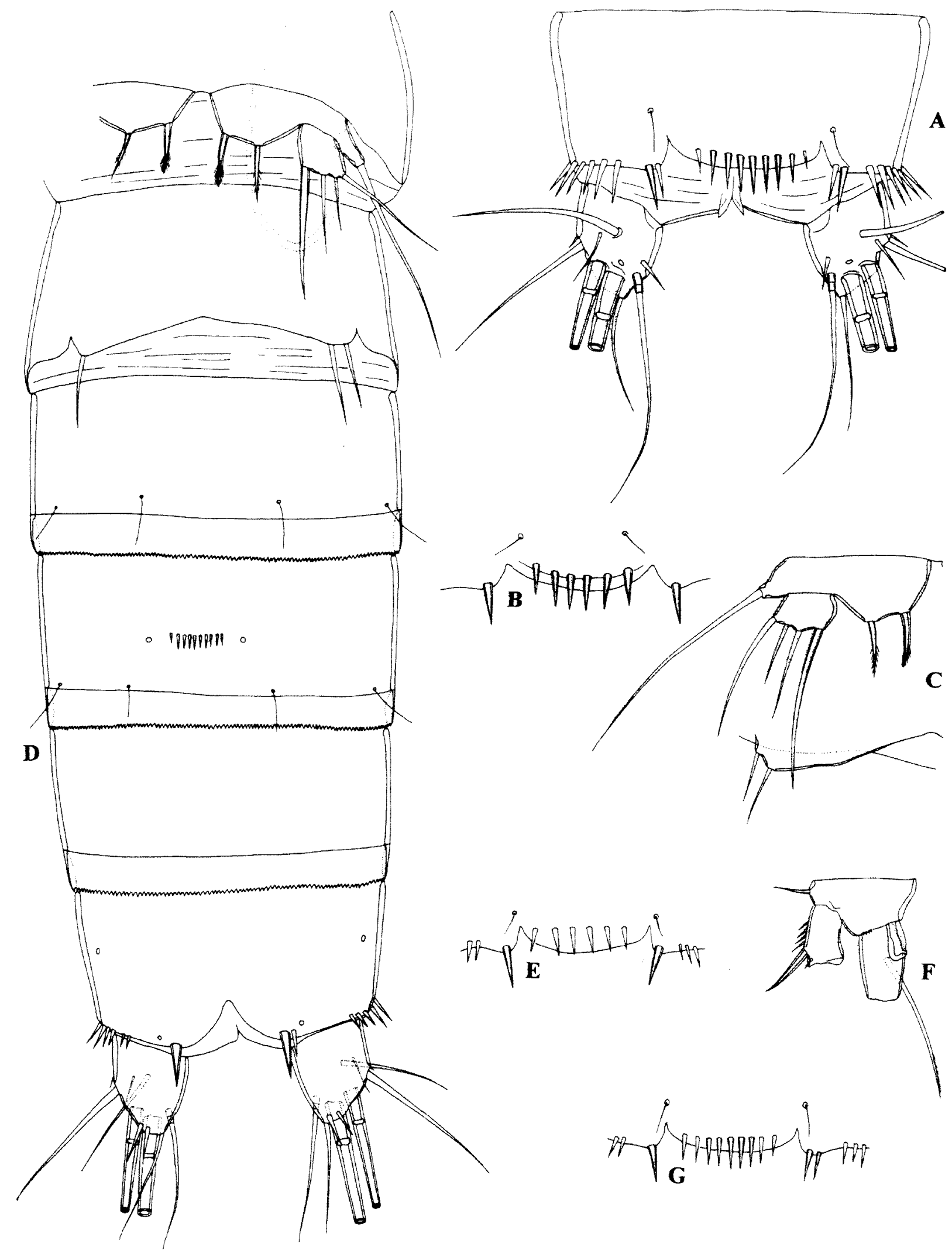

Figure 100 Stygonitocrella bispinosa sp. nov., A, paratype female $(0.358 \mathrm{~mm}$; WAM C34198); B, paratype female (0.385 mm; WAM C34199); $C$ and G, paratype male $(0.35 \mathrm{~mm}$; WAM C34197); D-F, allotype (male): A, anal somite and caudal rami, dorsal view; $\mathrm{B}$, anal operculum; $\mathrm{C}$, fifth and sixth legs; $\mathrm{D}$, urosome, ventral view; E, anal operculum; F, basis and first endopodal and exopodal segments of first swimming leg; $G$, anal operculum. Scale $=0.1 \mathrm{~mm}$. 
First swimming leg (Figure 100F) with significantly modified inner spine on basis, which smooth, unilobate, strongly chitinized and relatively large.

Fifth legs (Figure 100D) with baseoenopods not fused medially and distinct from somite. Baseoendopod with outer basal seta long, smooth, arising from long setophore. Endopodal lobe relatively broad, unornamented and similarly armed as in female; outer armature element only slightly longer than inner one. Exopod also very similar to female

Sixth legs (Figure 100D) narrowly fused basally and indistinct from somite; right leg armed with single smooth seta, left one armed with two smooth setae (inner seta about 1.2 times as long as outer one).

\section{Variability}

Body length of females ranges from $0.346 \mathrm{~mm}$ to $0.393 \mathrm{~mm}(0.372 \mathrm{~mm}$ average; $\mathrm{n}=5)$, while in males it ranges from $0.338 \mathrm{~mm}$ to $0.37 \mathrm{~mm}(0.351 \mathrm{~mm}$ average; $n=5$ ). The number of spinules on the anal operculum can vary between six and nine and also the comer near anal operculum can be furnished with one or two spinules (Figure $98 \mathrm{~F}$ and $100 \mathrm{~A}, \mathrm{~B}$, E, G). No other type of variability was observed.

\section{Etymology}

The specific name refers to the armature of the fifth leg baseoendopod in female, which consists of two spiniform elements. It is an adjective agreeing in gender with the feminine generic name.

\section{Discussion}

Besides having a unique armature of the female fifth leg baseoendopod, S. bispinosa sp. nov. can be easily distinguished from both $S$. trispinosa and $S$. unispinosa by the plesiomorphic armature of the third exopodal segment of the fourth swimming leg (with two inner setae). A single small dorsal integumental window on the cephalothorax was also not observed in the other two species. Another autapomorphy of $S$. bispinosa is the reduced armature of the fifth leg exopod in the male. This species seems to be restricted geographically to the Cane River aquifer.

As the number of species has increased from nine to 14, since the last generic key by Petkovski (1976), below I present a new key to aid in their identification. Here, I also include S. orghidani (Petkorski, 1973), although I agree with Lee and Huys (2002) and Reid et al. (2003) that this species should be treated as incertae sedis in the genus Stygonitocrella. Stygonitocrella insularis (Miura 1962), which was listed in Petkovski's (1976) kev, was transferred by Lee and Huys (2002) into a newly described genus Neonitocrella.
1. Exopod of fifth leg present ............................. 2

- This segment absent

S. orghidani (Petkovski, 1973)

2. Third exopodal segment of third and fourth leg with two outer spines 3

Same segment with single outer spine

S. sequoyahi Reid et al., 2003

3. Endopod of second and third legs onesegmented

One or both of these segments two-segmented

4. Endopod of second and third legs twosegmented

Endopod of third leg in female one-segmented, of second leg two-segmented

5. Exopod of fifth leg in female with three setae.. S. tianschanica (Borutzky, 1972)

- Same segment with two setae S. pseudotianschanica (̌́tirba, 1973)

6. Second endopodal segment of third leg with one seta

Same segment with two setae ....................... 8

7. Second endopodal segment of second leg with one seta .............. S. montana (Noodt, 1965)

Same segment with two setae

S. djirgalanica (Borutzky, 1978)

8. Second endopodal segment of second leg with one seta

- Same segment with two setae

S. karamani (Petkovski, 1959)

9. Baseoendopod of fifth leg in female with two setae S. petkovski Pesce, 1985

- Same segment with three setae.

S. colchica Borutzky and MichailovaNeikova, 1970

10. Endopod of third leg with two setae 12

- Same segment with single seta 11

11. Baseoendopod of fifth leg in male unarmed ... S. guadalfensis Rouch, 1985

Same segment with two or three setae

S. dubia (Chappuis, 1937)

12. Third exopodal segment of fourth leg with one or two inner setae

Same segment without inner setae S. ljovuschkini (Borutzky, 1967)

13. Third exopodal segment of fourth leg with single inner seta 14

- Same segment with two inner setae S. bispinosa sp. nov 
14. Baseoendopod of fifth leg in female with three setae $S$. bispinosa sp. nov.

- Same segment with single armature element ... S. unispinosa sp. nov.

\section{Genus Inermipes Lee and Huys, 2002}

\section{Inermipes humphreysi Lee and Huys, 2002}

\section{Synonymy}

Inermipes humphreysi sp. nov. - Lee and Huys, 2002: 40, Figures 1-5.

\section{Discussion}

Lee and Huys (2002) described this genus and species from several bores on Barrow Island. Unfortunately, I do not have any additional material of this species. The very close relationship between Inermipes and Stygonitocrella was discussed in detail by Lee and Huys (2002). Very similar segmentation and armature of the swimming leg endopods between the former and the three Australian Stygonitocrella representatives suggests that the genus Inermipes could have been derived from Stygonitocrella, rather than from a Neonitocrella-like ancestor, as speculated by Lee and Huys (2002).

\section{Family Parastenocarididae Chappuis, 1940}

Genus Parastenocaris Kessler, 1913

Parastenocaris jane sp. nov.

Figures $101-104$ and $115 \mathrm{~A}-\mathrm{C}$

\section{Material Examined}

\section{Holotype}

Male (WAM C34201), Australia, Pilbara, Paraburdoo Town Borefield, bore TPB2-1, 22 November 2002, leg. J. Cocking and M. Scanlon (CALM), $23^{\circ} 11^{\prime} 17^{\prime \prime S} 117^{\circ} 40^{\prime} 38^{\prime \prime} \mathrm{E}$ : dissected on one slide

\section{Allotype}

Female (WAM C34202), Australia, Pilbara, Paraburdoo Town Borefield, bore TPB2-1, 22 November 2002, leg. J. Cocking and M. Scanlon (CALM), $23^{\circ} 11^{\prime} 17^{\prime \prime S} 117^{\circ} 40^{\prime} 38^{\prime \prime} \mathrm{E}$ : dissected on one slide

\section{Paratypes}

Australia, Pilbara, Paraburdoo Town Borefield, bore TPB2-1, 22 November 2002, leg. J. Cocking and

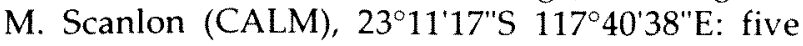
males + one female + one copepodid (one male on slide in toto (WAM C34203); others in alcohol (WAM C34204)

\section{Other material}

1) Australia, Pilbara, Turee Creek, bore PFO11-3, 8 April 2003, leg. J. Cocking and M. Scanlon (CALM), 23 $3^{\circ} 9^{\prime} 27^{\prime \prime} S 117^{\circ} 44^{\prime} 46^{\prime \prime} \mathrm{E}$ : one copepodid in alcohol (WAM C34205)

2) Australia, Pilbara, GNH near Newman Airport, bore W28, 4 October 2002, leg. J. Cocking and M.

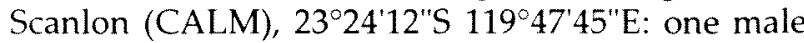
+ one female (male dissected on one slide (WAM C34206); female in alcohol (WAM C34207))

3) Australia, Pilbara, Railway near OB 25, bore W13, 4 October 2002, leg. J. Cocking and M. Scanlon

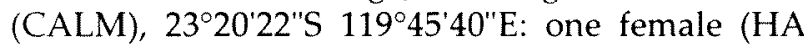
218) dissected by Jane McRae on one slide (WAM C34208)

4) Australia, Pilbara, Homestead Creek, bore 96HDM09, 7 April 2003, leg. J. Cocking and M. Scanlon (CALM), 22 $12^{\circ} 20^{\prime \prime S} 117^{\circ} 09^{\prime} 01^{\prime \prime E}$ : one female on slide in toto (WAM C34209)

5) Australia, Pilbara, SW of OB 23 (Ore Body 23, about $4.5 \mathrm{~km}$ north of Ophthalmia Dam), bore W234, 10 April 2003, leg. J. Cocking and M. Scanlon (CALM), 2319'02"S 119 51'01"E: five males + one female (one male dissected on one slide (WAM C34210); female on slide in toto (WAM C34211); others in alcohol (WAM C34212))

6) Australia, Pilbara, SW of OB 23(Ore Body 23, about $4.5 \mathrm{~km}$ north of Ophthalmia Dam), bore 23-4, 4 April 2002, leg. J. Cocking and M. Scanlon (CALM), 2319'02"S 119 51'01"E: nine males + four females + two copepodids in alcohol (WAM C34213)

7) Australia, Pilbara, W of OB 23 (Ore Body 23, about $4.5 \mathrm{~km}$ north of Ophthalmia Dam), bore W270, 4 October 2002, leg. J. Cocking and M.

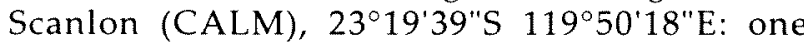
female in alcohol (WAM C34214)

8) Australia, Pilbara, Cane River Borefield, bore CR7/97, 5 April 2003, leg. J. Cocking and M. Scanlon (CALM), $21^{\circ} 41^{\prime} 46^{\prime \prime} S 115^{\circ} 22^{\prime} 22^{\prime \prime} \mathrm{E}$ : four copepodids in alcohol (WAM C34215)

\section{Description}

Holotype (male). Total body length, measured from tip of rostrum to posterior margin of caudal rami (excluding caudal setae), $0.501 \mathrm{~mm}$. Preserved specimen colourless. Nauplius eye absent. Habitus (Figure 101A, F) cylindrical and very slender, without any demarcation between prosome and urosome; prosome/urosome ratio 0.7 ; greatest width at fourth pedigerous (third free) somite but very hard to locate. Body length/width ratio about 8.4; cephalothorax 1.15 times as wide as genital somite. Free pedigerous somites without any expansions laterally or dorsally; thoracic, as well as abdominal, somites connected by well developed arthrodial membranes. Integument not very strongly chitinized; simple large dorsal integumental window on genital and next three 


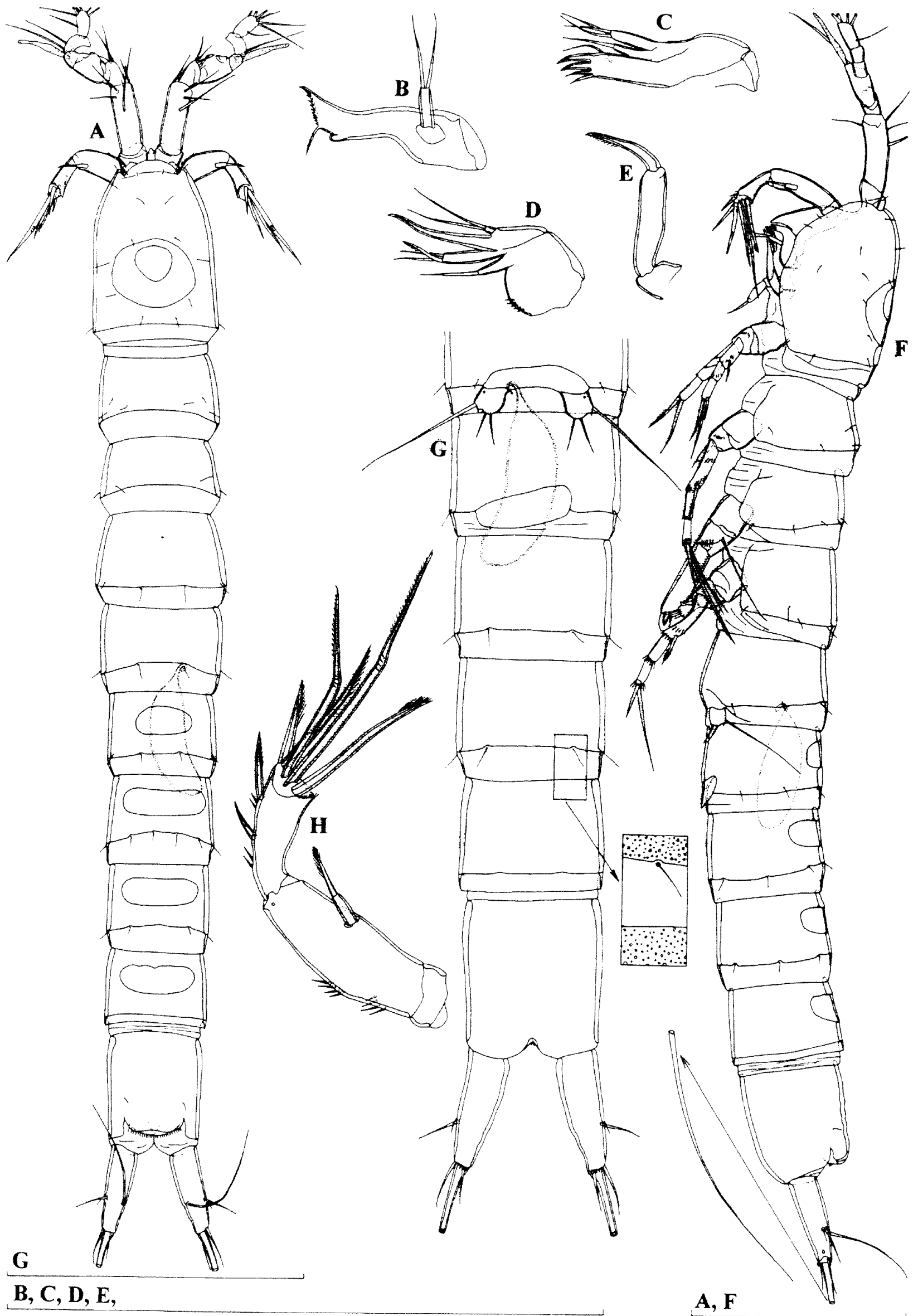

Figure 101 Parastenocaris jane sp. nov., holotype (male): A, habitus, dorsal view; B, mandibula; C, maxillula; D, maxilla; $E$, maxilliped; $F$, habitus, lateral view; $G$, urosome, ventral view; $H$, antenna. Scales $=0.1 \mathrm{~mm}$. 
urosomites, cephalothorax with double dorsal window posteriorly (smaller window with thinner integument inside bigger one). Pleural areas of cephalothorax and free pedigerous somites not well developed; cephalic appendages and coxae of swimming legs clearly exposed in lateral view. Whole body, including caudal rami, covered by numerous small cuticular pits; only appendages, cuticular windows and arthrodial membranes not covered by them. Rostrum small, membranous, ornamented with two large dorsal sensilla, linguiform, almost reaching distal margin of first antennular segment, about twice as long as wide.

Cephalothorax (Figure 101A) about 1.4 times as long as wide; representing $16 \%$ of total body length. Surface of cephalic shield and tergites of free pedigerous somites ornamented with several large sensilla. Hyaline fringe of all somites smooth.

Genital somite (Figure 101 A, F) ornamented with two sensilla dorsally and four sensilla laterally (two on each side), about 1.4 times as wide as long, with single, large, completely formed and longitudinally placed spermatophore (Figure 101G) visible inside. Third urosomite ornamented with four dorsal, four lateral and two ventral sensilla posteriorly. Fourth somite with two dorsal, four lateral (two on each side) and two ventral sensilla. Fifth urosomal (preanal) somite without any visible ornamentation, except for small cuticular pits that cover whole body. Anal somite ornamented with pair of large dorsal sensilla and one transverse row of spinules on inner side of anal operculum. Anal operculum (Figure 102A) well developed, with somewhat concave and smooth distal margin, not reaching posterior end of anal somite, representing $63 \%$ of somite's width. Anal sinus widely opened, with smooth ventral side and row of spinules on dorsal side (below anal operculum).

Caudal rami (Figure $101 \mathrm{G}$ and $102 \mathrm{~A}, \mathrm{E}$ ) about 2.9 times as long as greatest width (dorsal view), cylindrical (slightly narrowing towards distal end), divergent, with space between them more than one ramus width; armed with six armature elements (two lateral, one dorsal and three apical). Ornamentation consists of large cuticular pore laterally close to posterior margin and row of small spinules along posterior margin ventrally. Dorsal seta relatively long, inserted somewhat closer to inner margin at about $3 / 5$ of ramus length, about 1.3 times as long as caudal ramus, biarticulate at base and smooth. Lateral setae thin and smooth, inserted close to each other also at $3 / 5$ of ramus length. Proximal lateral seta placed more dorsally, about 2.8 times as long as distal minute one, and about 0.4 times as long as ramus. Inner apical seta small, smooth, inserted more ventrally, about 0.3 times as long as ramus. Middle apical seta strongest, without breaking plane, also smooth, about nine times as long as outer apical seta and 0.3 times as long as whole body. Outer apical seta small, also without breaking plane and smooth, about 0.5 times as long as ramus.

Antennula (Figure 102C) approximately as long as cephalothorax, eight-segmented, prehensile and strongly geniculate, unornamented. Proximal anterior corner of fifth segment and distal anterior corner of seventh segment protrude as strong spiniform processes, forming powerful pincers. Broad aesthetasc on fourth segment reaching tip of appendage. Much shorter apical aesthetasc on eighth segment. Setal formula: 0.6.4.2.4.0.0.8. All setae slender and almost all (except most proximal seta on second segment) smooth. Only one seta on second segment and one on third articulating on basal part; one apical seta fused basally with apical aesthetasc.

Antenna (Figure 101H) relatively stout and long, composed of coxa, allobasis, one-segmented endopod, and one-segmented exopod. Coxa very short, unornamented. Allobasis about 2.8 times as long as wide, unarmed, ornamented with two short rows of large spinules along anterior surface and one cuticular pore near distal margin. Endopod about three times as long as wide, with surface frill subdistally, ornamented with few large spinules along anterior surface, armed laterally with two spines (proximal smooth and distal unipinnate) and apically with five strong and pinnate elements (two geniculate). Exopod minute, cylindrical, about 2.6 times as long as wide, unornamented but armed with single pinnate apical seta, about 1.6 times as long as segment.

Mandibula (Figure 101B) with narrow cutting edge on elongated coxa, armed with one coarse tooth ventrally, one unipinnate seta dorsally, and several smaller teeth in between. Palp onesegmented, cylindrical, about 2.8 times as long as wide, unornamented and armed apically with two smooth and subequal setae.

Maxillula (Figure 101C) with relatively small praecoxa, arthrite rectangular, long, unornamented but armed with one slender anterior surface setae and four apical elements (probably three spines and one strong seta). Coxal endite armed with one smooth seta apically, about 1.2 times as long as endite. Basis longer than coxal endite, armed with three apical smooth setae of about same length. Endopod and exopod absent.

Maxilla (Figure 101D) with row of spinules and two endites on syncoxa; proximal one armed apically with single smooth seta; distal endite twice as long as proximal one, armed apically with two smooth and one strong unipinnate seta. Basis drawn out into strong and smooth claw, without seta at base. Endopod represented by minute but distinct segment, armed with two smooth subequal apical setae

Maxilliped (Figure 101E) with unornamented 


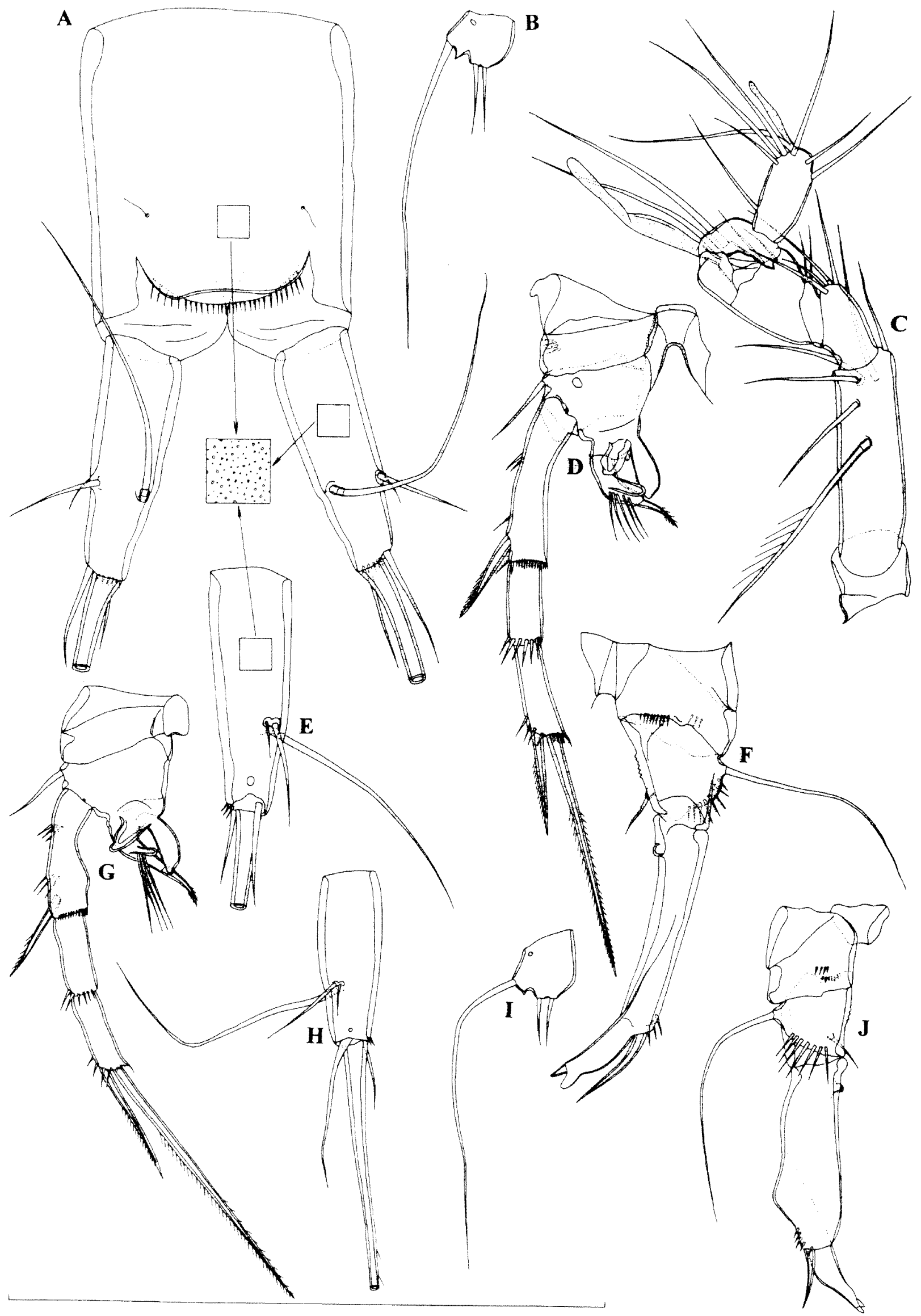

Figure 102 Parastenocaris jane sp. nov, A-F, holotype (male); G-J, male (0.382 mm) from locality 2 (WAM C34206): A, anal somite and caudal rami, dorsal view; B, fifth leg; $C$, antennula; D, fourth swimming leg; $E$, left caudal ramus, lateral view; $F$, third swimming leg; $G$, fourth swimming leg; $H$, right caudal ramus, lateral view; $I$, fifth leg; , third swimming leg. Scale $=0.1 \mathrm{~mm}$. 
short syncoxa; basis about 3.8 times as long as wide, unornamented and unarmed; endopod represented by short curved claw, ornamented with row of spinules along concave side distally, about 0.8 times as long as basis.

First swimming leg with smooth coxa and intercoxal sclerite. Basis ornamented with few large spinules at base of outer spine and few spinules along distal margin, between endopod and exopod. Exopod three-segmented, armed with one outer spine on first segment and four elements on third segment (two outer spines and two apical geniculate setae); ornamented with few large spinules along outer margin on all segments. Endopod two-segmented, about as long as exopod; first segment reaching slightly beyond distal margin of second exopodal segment, about 3.6 times as long as wide, unarmed, ornamented with large spinules along outer and inner margin; second segment armed apically with long geniculate seta and much shorter spine.

Second swimming leg with smooth coxa and intercoxal sclerite; basis unarmed, ornamented with row of spinules on outer margin. Exopod threesegmented, ornamented with large spinules along outer margin, and with hyaline frills on each segment distally on inner side; first segment armed with single outer spine; second segment unarmed; third segment armed with three long elements (probably outer spine and two apical setae), innermost one about as long as exopod. Endopod one-segmented, linguiform, about 4.4 times as long as wide, reaching middle of first exopodal segment, ornamented with several spinules along apical margin, armed apically with one smooth seta, about 0.7 times as long as segment.

Third swimming leg (Figure 102F) with smooth praecoxa and intercoxal sclerite. Coxa ornamented with short row of spinules along distal margin, on both anterior and posterior surface. Basis robust, armed with long outer seta and ornamented with diagonal row of large spinules close to outer margin; inner margin bluntly serrated at middle. Endopod minute segment, basally fused to basis, unornamented and armed apically with smooth seta, 4.6 times as long as segment. Exopod with both segments fused; ancestral proximal segment about 3.5 times as long as wide, with chitinous bulb on proximal part of inner margin and three long spinules near distal outer corner, armed subapically with strong, smooth and curved spine, reaching distal margin of apophysis; ancestral distal segment (apophysis) much smaller, oriented inward, unornamented but armed with minute spine apically, which forms pincers with produced and blunt outer apical corner.

Fourth swimming leg (Figure 102D) with smooth parecoxa, intercoxal sclerite and basis; coxa with few spinules near outer margin; basis armed with slender and smooth outer seta, inner-distal corner of basis produced into two large, heavily sclerotized, linguiform and blunt structures, longer one almost as long as endopod. Exopod threesegmented, ornamented with few large spinules along outer margin, and first and third segment with hyaline frills distally on inner side; first segment with concave inner margin, armed with single outer spine; second segment unarmed; third segment armed with outer spine and very long and strong apical seta. Endopod one-segmented, about 0.4 times as long as first exopodal segment, clawlike, curved inwards, armed with single pinnate apical seta and ornamented with longitudinal row of five very long and slender spinules; middle part of endopod produced as separate smooth lobe, reaching distal margin of segment. Endopod and basal claws resembling powerful pincers.

Fifth leg (Figure 102B) simple quadriform cuticular plate, ornamented with single large cuticular pore basally and armed with three smooth setae along distal margin; outermost seta (ancestral basal one) longest, about 4.5 times as long as other two subequal setae. Distal margin between outermost and other two setae produced posteriorly as small spiniform process. Fifth legs distinct at base (Figure 101G) with space between them slightly les than two legs width.

Sixth legs (Figure 101G) completely fused, forming single, smooth, large operculum covering gonopore, which represents $55 \%$ of genital somite width.

Female (allotype). Body length, excluding caudal setae, $0.39 \mathrm{~mm}$. Habitus (Figure 103A), ornamentation of prosomites, colour and nauplius eye similar to male.

Genital double somite (Figure 103A, D and 104B) about as long as wide (ventral view), without any trace of subdivision except for two ancestral integumental windows being partly fused into single large and complex one; ornamented with six posterior sensilla (two dorsal, two ventral and two lateral) and two large dorsal sensilla anteriorly. Genital complex (Figure 104B) occupying anterior ventral half of genital double somite; genital aperture paired, each closed off by small, unarmed operculum derived from vestigial sixth leg; median copulatory pore located anteriorly between genital apertures; seminal receptacles elongated, small; copulatory duct very short and well sclerotized. Third and fourth (preanal) somites similar to male. Anal somite ornamented additionally with two venatral pores (Figure 103E) and two lateral ones (one on each side; Figure 103D).

Caudal rami (Figure 103E, D and 104C) similar to male but slightly shorter and with middle and outermost apical setae unipinnate.

Antennula (Figure 104A) seven-segmented, unornamented, approximately as long as 


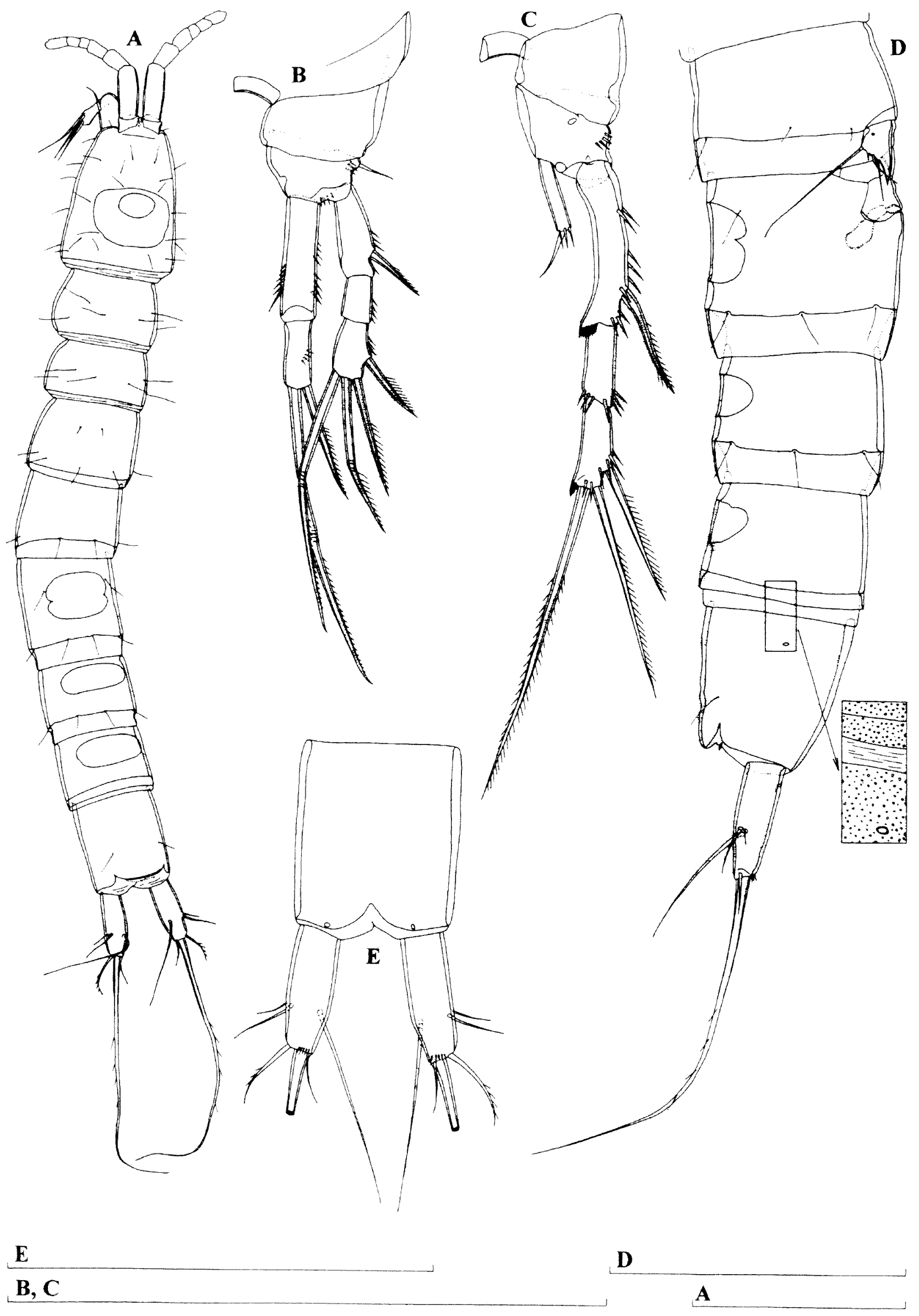

Figure 103 Parastenocaris jane sp. nov., allotype (female): A, habitus, dorsal view; B, first swimming leg; C, second swimming leg; D, urosome, lateral view; $E$, anal somite and caudal rami, ventral view. Scales $=0.1 \mathrm{~mm}$. 
cephalothorax, with broad aesthetasc on fourth segment, reaching tip of appendage and more slender apical aesthetasc on seventh segment, which fused basally to apical seta; setal formula: 0.4.5.2.1.0.9. Most proximal seta on second segment unipinnate and articulating on basal part, all other setae smooth and without articulation or breaking plane. Length ratio of antennular segments, from proximal end, $1: 2.5: 1.5: 1.5: 0.8$ $: 0.7: 1.4$

Antenna, mandibula, maxillula, maxilla, maxilliped, first swimming leg (Figure 103B) and second swimming leg (Figure 103C) similar to male.

Third swimming leg (Figure 104F) with smooth intercoxal sclerite and coxa; basis ornamented with large cuticular pore proximally and row of spinules near outer margin, armed with very long and smooth outer seta about as long as exopod. Exopod two-segmented, ornamented with large spinules along outer margin, both segments with hyaline frills distally on inner side; first segment armed with single outer spine; second with outer spine and apical strong seta. Endopod one-segmented, with ancestral apical spine completely fused to segment but still bipinnate; reaching $2 / 3$ of first exopodal segment.

Fourth swimming leg (Figure 104E) without spiniform processes on basis. Endopod onesegmented, ornamented with four large spinules at base of ancestral apical spine, which fused to segment and bipinnate. Exopod similar to male.

Fifth leg (Figure 104D) simple triangular cuticular plate, about twice as long as wide; ornamentation and armature similar to male but inner distal corner produced posteriorly into sharp and smooth, clawlike process, half as long as innermost and middle seta. Fifth legs separated medially, with space between them less than one leg width.

Sixth leg (Figure 104B) small cuticular plate, covering gonopore, unornamented and unarmed.

\section{Variability}

Body length of males ranges from $0.374 \mathrm{~mm}$ to $0.501 \mathrm{~mm}(0.426 \mathrm{~mm}$ average; $\mathrm{n}=10)$, while in females it ranges from $0.356 \mathrm{~mm}$ to $0.492 \mathrm{~mm}(0.424$ $\mathrm{mm}$ average; $\mathrm{n}=4$ ). Small differences are noted in the apperance of the male third (Figure $102 \mathrm{~F}, \mathrm{~J}$ ) and fourth (Figure 102D, G) swimming legs but they are more the result of different positions of these three dimensional structures. The male from locality 2 has a somewhat longer outer apical seta on the caudal rami (Figure 102H) than the holotype. The female from locality 2 has a somewhat different endopod of the fourth swimming leg (Figure 104H) than the allotype, as well as a much narrower fifth leg (Figure 104G), which is also ornamented with two spinules on the produced inner distal corner. The female from locality 5 has the principal apical seta on the caudal rami very short and swollen proximally (Figure 104I). No other type of variability was observed.

\section{Etymology}

The species is named in honour of Jane McRae from the Department of Conservation and Land Management in Perth, in recognition of her contribution to understanding the composition and distribution of the copepod fauna of Western Australia. The name is a noun in apposition.

\section{Discussion}

The family Parastenocarididae Chappuis, 1940 is almost exclusively freshwater in distribution (Boxshall and Jaume 2000) and has six well recognised genera: Parastenocaris Kessler, 1913; Forficatocaris Jakobi, 1969; Paraforficatocaris Jakobi, 1972; Potamocaris Dussart, 1979; Murunducaris Reid, 1994; and Simplicaris Galassi and De Laurentiis, 2004. Currently, the genus Parastenocaris contains around 220 species and subspecies (Galassi and Laurentiis 2004). Representatives of this genus are distributed over all continents, although, interestingly they have never been recorded in New Zealand (Huys and Boxshall 1991). Although the phylogenetic relationships within the genus are still uncertain (Martínez Arbizu 1997), the system of eight phyletic groups proposed by Lang (1948) seems to be the most appropriate at this time, although it requires knowledge of males, and many species are still known only from females. The taxonomic impediments surrounding the genus Parastenocaris were recently discussed by Galassi and De Laurentiis (2004) and Karanovic (2005). Typical Parastenocaris habitats are only fragmentarily investigated on most continents, including Australia (Karanovic 2004a). Future genetic investigations of similar morphological forms (considered now as one species) may even double the final number of species. The assumption made by Boxshall and Jaume (2000) "that tectonic events have shaped modern distributions more than subsequent dispersal events" of Parastenocaris is very probable. Thus all Australian species fit well into the existing groups of species originally defined by Lang (1948).

Three species of Parastenocaris have been described so far from Australia. Schminke (1981) reported "four species belonging to three genera" of Parastenocarididae from Australia but unfortunately they all remain undescribed and unnamed. Unpublished data of S. Halse (pers. comm.) suggest the presence of this genus at Mandora Marsh, just north of the Pilbara. Parastenocaris solitaria Karanovic, 2004, was described from the Murchison region, but only from females, so its affinities have not been properly evaluated (Karanovic 2004a). Recently, I 


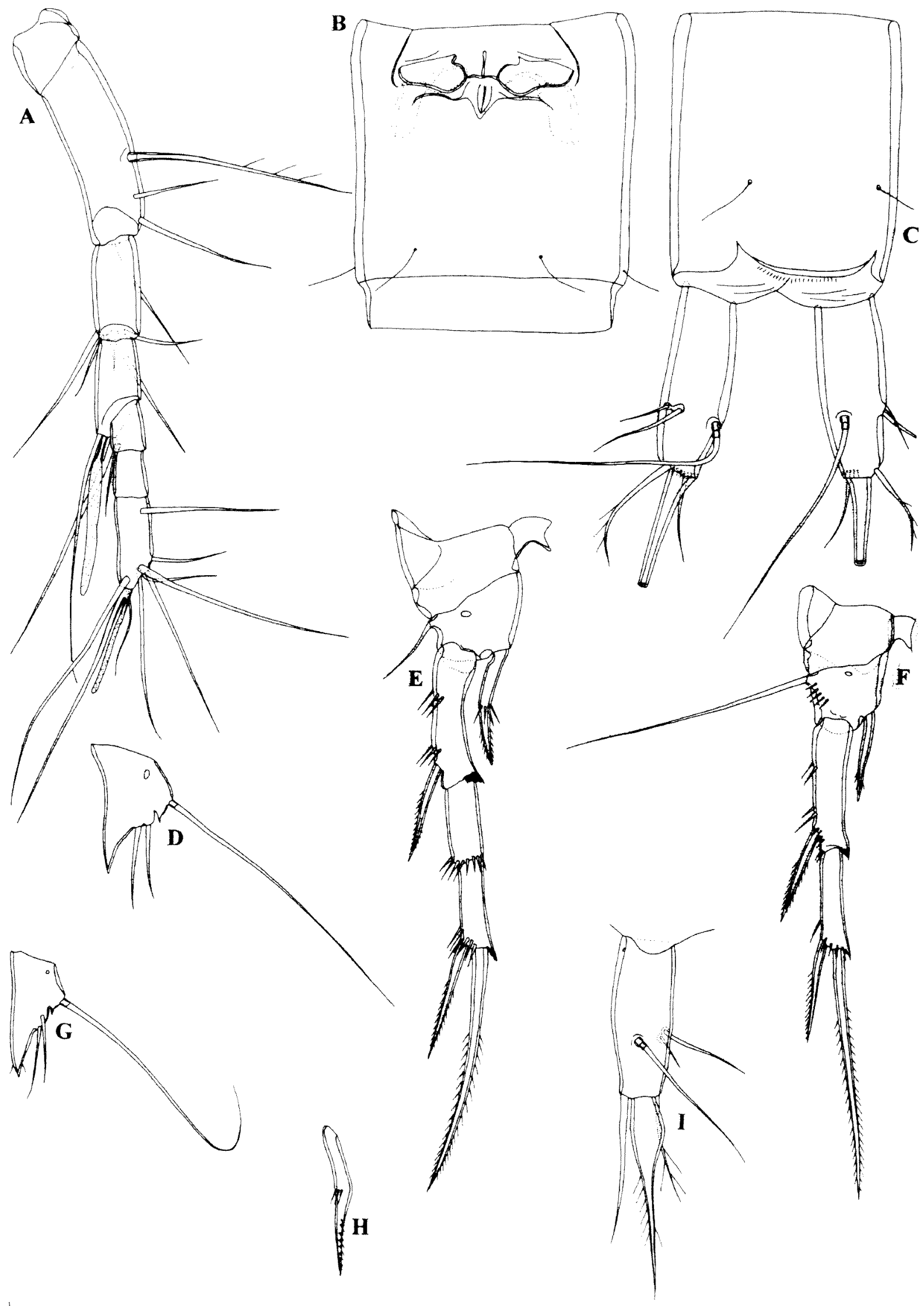

Figure 104 Parastenocaris jane sp. nov, A-F, allotype (female); $\mathrm{G}$ and $\mathrm{H}$, female $(0.39 \mathrm{~mm}$ ) from locality 2 (WAM C34207); I, female $(0.356 \mathrm{~mm}$ ) from locality 5 (WAM C34211): A, antennula; B, genital double somite, ventral view; $C$, anal somite and caudal rami, dorsal view; $D$, fifth leg; $E$, fourth swimming leg; $F$, third swimming leg; $G$, fifth leg; $H$, endopod of fourth swimming leg; I, right caudal ramus, semidorsal (inner dorsal) view. Scale $=0.1 \mathrm{~mm}$. 
have described another two new Australian species of Parastenocaris, luckily based on both females and males (Karanovic 2005): P. eberhardi Karanovic, 2005 and $P$. kimberleyensis Karanovic, 2005. The former species is morphologically very similar to $P$. solitaria, which helped to establish its affinities (in the "minuta"-group), while the latter belongs to the "brevipes"-group of species.

Parastenocaris jane sp. nov. also belongs to the "brevipes"-group of species (having the characteristic endopodal complex of the male fourth leg; the long distally serrate endopod of the female fourth leg; the tapering caudal ramus with dorsal and lateral setae inserted around midlength; the sixth legs in the male fused into a single operculum; and the bilobate fifth leg in the female), which was defined by Lang (1948) and named after the type species of the genus. Besides $P$. brevipes, which is the only member of the genus with a Holarctic distribution (see Lang 1948, Reid 1995), 17 species have been described so far in this group: five of them from Sri Lanka by Enckell (1970) [P. brincki, $P$. irenae, $P$. lanceolata, $P$. noodti and $P$. singhalensis]; four from the United States by Pennak (1939), Borutzky (1952), Whitman (1984) and Reid (1991a) [P. starretti, P. wilsoni, P. texana and $P$. palmerae respectively]; three from Japan by Miura (1962, 1969) and Kikuchi (1970) [P. oshimaensis, $P$. biwae and $P$. hinumaensis respectivelyl; two from India by Ranga Reddy (2001) [P. gayatri and P. savita]; one from China by Shen and Tai (1973) [P. longipoda]; one from Sumatra by Chappuis (1931) [P. feuerborni]; and one from the Kimberley Region in Western Australia by Karanovic (2005) [P. kimberleyensis]. Parastenocaris biwae, $P$. starretti and $P$. wilsoni were synonymized with $P$. brevipes by Reid (1995), who also recognised the possible origin of the brevipes- group in tropical Asia. Parastenocaris texana, because of the incomplete original description, was placed as incertae sedis by Karanovic (2005). Reid (1995) expressed doubts about the position of her $P$. palmerae in the "brevipes"-group but there are currently no strong reasons to exclude this species. Galassi and De Laurentiis (2004) also included $P$. longicaudis Chappuis, 1931 and $P$. arctica Bortutzky, 1952 in this group, although they are known only as females and their status could not be verified (see Lang 1948, Borutzky 1952). Karanovic (2005) compiled a key to 14 valid species in the "brevipes"-group, which was based solely on the morphology of males, since females of $P$. brincki, $P$. lanceolata and $P$. singhalensis are still unknown. In that key $P$. jane sp. nov. would key out somewhere between $P$. feuerborni and $P$. kimberleyensis. However, it can be distinguished from both species by the shape of the male fourth leg endopod (which is armed apically with a spiniform element) and also by a different shape of the third leg in the male. Additionally $P$. jane differs from $P$. kimberleyensis (see Karanovic 2005) by a number of characters, including the presence of cuticular windows, ornamentation of the integument, and the shape of the inner basal processes on the fourth leg in the male. Unfortunately, the description of $P$. feuerborni is incomplete (see Chappuis 1931, Lang 1948), so many morphological details could not be compared. The pattern of integumental windows found in $P$. jane is probably among the most primitive ones and is found in many species of the "brevipes"-group, as well as in Simplicaris lathaea Galassi and De Laurentiis, 2004 for example. The presence of the "brevipes"-group in northern parts of Western Australia may suggest their relatively recent arrival, if the hypothesis of the origin of this group being in tropical Asia is correct (Reid 1995).

\section{Family Canthocamptidae Sars, 1906}

Genus Elaphoidella Chappuis, 1929

Elaphoidella humphreysi sp. nov. Figures $105-108$ and $115 \mathrm{D}-\mathrm{F}$

\section{Material Examined}

\section{Holotype}

Female (WAM C34216), Australia, Pilbara, Ord Ranges, bore GNHSLK1664, 17 November 2002, leg. J. Cocking and M. Scanlon (CALM), 20'20'20'S $119^{\circ} 07^{\prime} 26^{\prime \prime} \mathrm{E}$ : dissected on one slide

\section{Allotype}

Male (WAM C34217), Australia, Pilbara, Ord Ranges, bore GNHSLK1664, 17 November 2002, leg. J. Cocking and M. Scanlon (CALM), 20'20'20"S $119^{\circ} 07^{\prime 2} 6^{\prime \prime} \mathrm{E}$ : dissected on two slides

\section{Other material}

1) Australia, Pilbara, West Strelley, bore MBSLK400A, 17 November 2002, leg. J. Cocking and M. Scanlon (CALM), 20 36'10"S 119 $07^{\circ} 24^{\prime \prime} \mathrm{E}$ : 12 males +13 females + eight copepodids (one male and one female dissected on one slide each (WAM C34218 and C34219); others in alcohol (WAM C34220))

2) Australia, Pilbara, Yule River, bore GNHSLK1448, 18 November 2002, leg. J. Cocking and M. Scanlon (CALM), 21 $36^{\prime} 11^{\prime \prime S} 118^{\circ} 48^{\prime} 52^{\prime \prime} \mathrm{E}: 17$ males +20 females +13 copepodids in alcohol (WAM C34221)

3) Australia, Pilbara, Tabba Tabba Creek, bore GNHSLK1648A, 16 November 2002, leg. J. Cocking and M. Scanlon (CALM), 20'22'14"S 118 56'58'E: 32 males +47 females +14 copepodids (one female dissected on one slide (WAM C34222); others in alcohol (WAM C34223)) 
4) Australia, Pilbara, Robe River, Yarraloola Station, bore PANNASLK4, 5 April 2003, leg. J. Cocking and M. Scanlon (CALM), 21.37'59"S 115 57 41"E: two females + one copepodid (one female dissected on one slide (WAM C34224); others in alcohol (WAM C34225))

\section{Description}

Female (holotype). Total body length, measured from tip of rostrum to posterior margin of caudal rami (excluding caudal setae), $0.0 .537 \mathrm{~mm}$. Colour of preserved specimen light brown. Nauplius eye not visible. Habitus (Figure 105A) spindle-shaped and robust but without distinct demarcation between prosome and urosome; prosome/urosome ratio 1.0 and greatest width at posterior end of cephalothorax and at second pedigerous (first free) somite, which equally wide. Body length/width ratio about 3.8 ; cephalothorax 1.4 times as wide as genital double somite. Free pedigerous somites without pronounced lateral expansions or dorsally. Integument strongly chitinized, without integumental windows; thoracic, as well as abdominal, somites connected by relatively short arthrodial membranes. Pleural areas of cephalothorax and first three free pedigerous somites not well developed; cephalic appendages and coxae of swimming legs clearly exposed in lateral view (Figure 105B). Rostrum very small, not well chitinized, linguiform, reaching first third of first antennular segment, about as long as wide and not demarcated at base; ornamented with two dorsal sensilla, which about as long as rostrum.

Cephalothorax (Figure 105A, B) slightly shorter than wide from dorsal view, gradually tapering anteriorly; represents $25 \%$ of total body length. Surface of cephalic shield and tergites of first three free pedigerous somites ornamented with many sensilla of different length (some very large), Hyaline fringe of all prosomites narrow and smooth. Fifth pedigerous (first urosomal) somite also with smooth hyaline fringe, ornamented with four dorsal sensilla posteriorly.

Genital double somite (Figure 105C) about 0.8 times as long as wide (ventral view), without any trace of subdivision, ornamented with posterior uninterrupted row of spinules both ventrally and dorsally, two arched and two transverse rows of spinules near genital complex, two cuticular pores near copulatory pore, short dorsal row of minute spinules at middle and six posterior large sensilla (two dorsal, two ventral and two lateral). Genital complex (Figure 106E) with single large copulatory pore, situated at $4 / 5$ of double somite length; copulatory duct rigidly sclerotized, gradually tapering anteriorly, very wide and long; seminal receptacles very small and ovoid, rigidly sclerotized. Genital aperture covered by small operculum formed by fused reduced sixth legs, which represents $27 \%$ of somite width. Third urosomite ornamented with posterior uninterrupted row of strong spinules both dorsally and ventrally, with additional parallel row of small spinules ventrally and two rows dorsally and with eight large posterior sensilla (two dorsal, four ventral and two lateral). Preanal somite without any sensilla, ornamented with posterior uninterrupted row of large spinules (those in midventral much shorter) and three dorsal and one ventral row of minute spinules, parallel to posterior row (Figure $105 \mathrm{~A}, \mathrm{C})$. Anal somite ornamented with pair of dorsal sensilla, two lateral cuticular pores on each side, two lateral arched rows of spinules, two interrupted rows of spinules ventrally and four rows dorsally. Anal operculum (Figure 106A), ornamented with row of 29 spinules along posterior margin, not reaching posterior end of anal somite, represents $46 \%$ of somite's width. Anal sinus with row of spinules along dorsal wall, below and parallel to anal operculum (Figure 105D).

Caudal rami (Figure 105C, D and 106A) short, 0.9 times as long as greatest width (ventral view), dorsoventrally depressed (broad in dorsal or ventral view but relatively slender in lateral view), slightly divergent, with space between them less than one ramus width; armed with six elements (three lateral, one dorsal and three apical). Dorsal chitinous ridge only present at base of dorsal seta. Ornamentation consists of one setule at base of proximal lateral seta, two small cuticular pores ventrally close to anterior margin, two large cuticular pores laterally close to posterior margin, several large spinules along inner margin and posterior ventral row of small spinules. Dorsal seta long, inserted at $4 / 5$ of ramus length, about 2.7 times as long as caudal ramus, biarticulate at base and smooth. Proximal lateral seta 0.8 times as long as ramus, arising laterally at $2 / 5$ of ramus length, smooth. Distal lateral seta about as long as proximal one, arising somewhat ventrolaterally at middle of ramus, also smooth. Inner and outer apical setae of about same length and strength, unipinnate, without breaking plane, about 1.8 times as long as ramus. Middle apical seta strongest, also without breaking plane, bipinnate at distal end, about 4.8 times as long as outer apical seta and 0.5 times as long as whole body.

Antennula (Figure 106B) 8-segmented, unornamented, approximately as long as cephalothorax, with relatively short aesthetasc on fourth segment, not reaching beyond tip of appendage and slender and somewhat shorter apical aesthetasc on eighth segment; setal formula: 1.9.5.2.1.3.2.7. All setae smooth, slender and without breaking plane. Only one seta on seventh and four setae on eighth segment articulating on basal part. Length ratio of antennular segments, from proximal end, $1: 1.5: 1: 0.8: 0.5: 0.5: 0.5: 1$. 


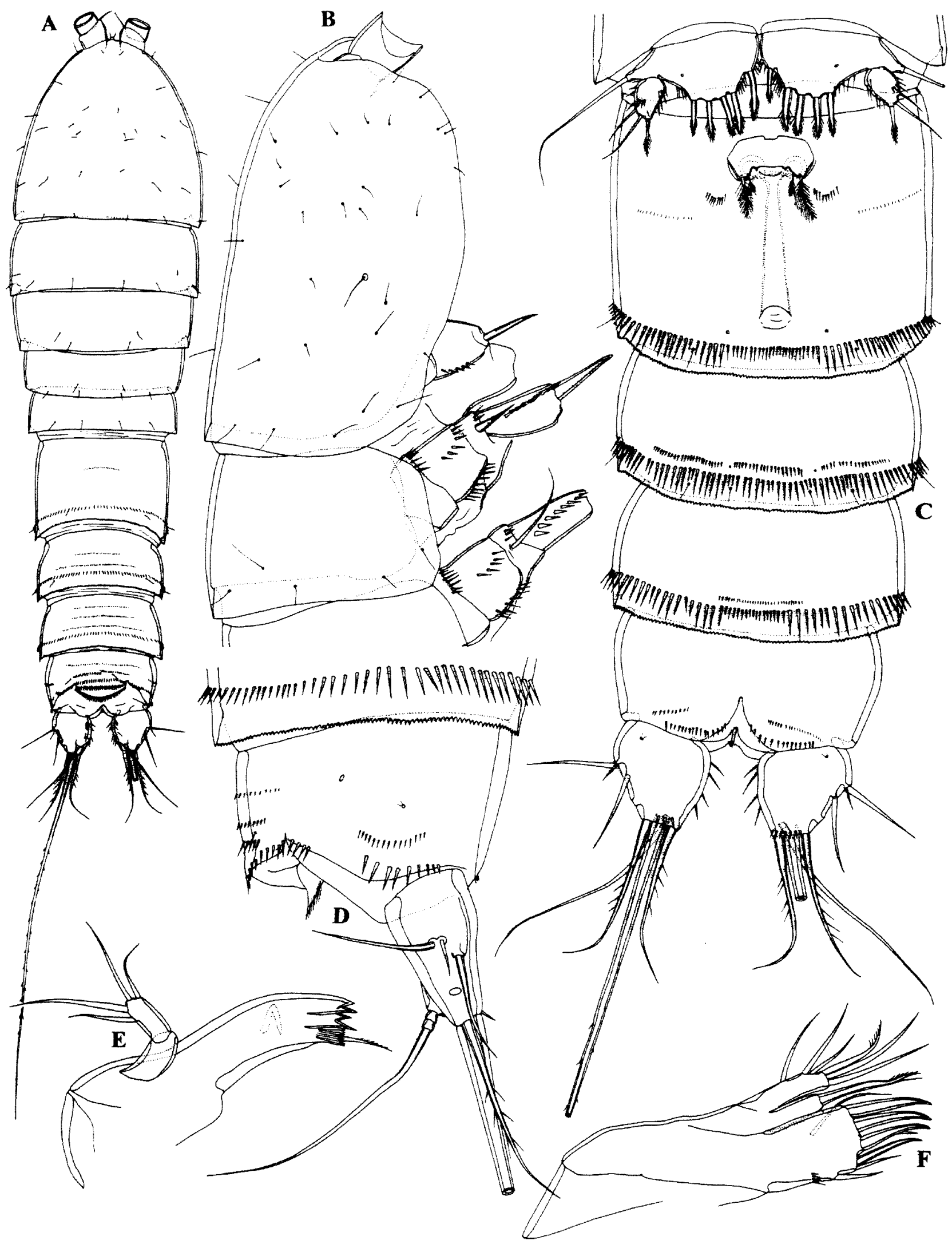

D

B, C

\section{E, F}

Figure 105 Elaphoidella humphreysi sp. nov., holotype (female): A, habitus, dorsal view; B, prosome, lateral view; C, urosome, ventral view; $D$, anal somite and right caudal ramus, lateral view; $E$, mandibula; $F$, maxillula. Scales $=0.1 \mathrm{~mm}$. 


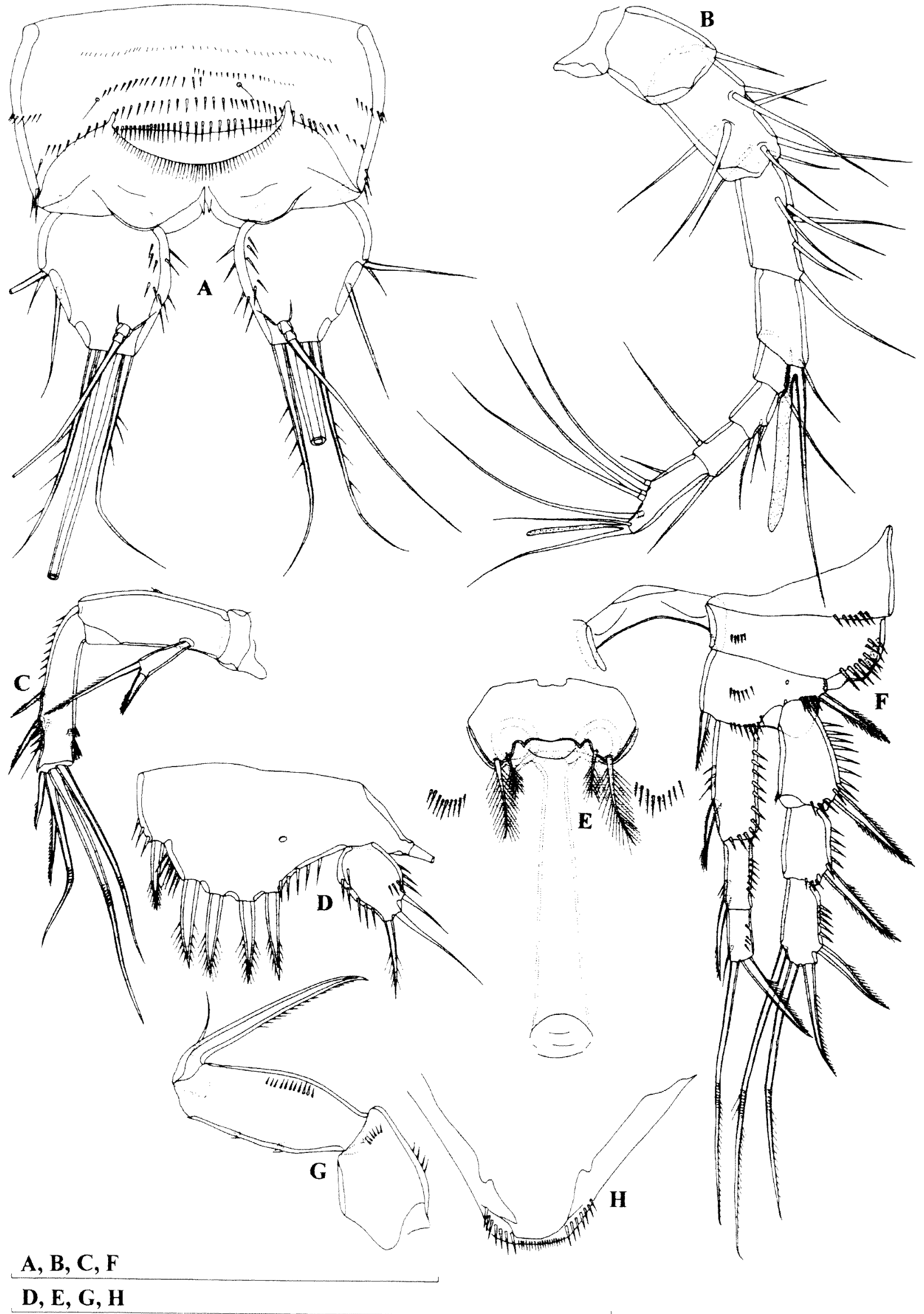

Figure 106 Elaphoidella humphreysi sp. nov., holotype (female): A, anal somite and caudal rami, dorsal view; B, antennula; C, antenna; D, left fifth leg; $E$, genital field; F, first swimming leg; $G$, maxilliped; $H$, labrum. Scales $=0.1 \mathrm{~mm}$. 
Antenna (Figure 106C) short, composed of coxa, allobasis, one-segmented endopod and onesegmented exopod. Coxa very short, unornamented. Allobasis about 2.8 times as long as wide, ornamented with few spinules on anterior surface at middle, unarmed. Endopod about 4.6 times as long as wide and somewhat longer than allobasis, ornamented with row of large spinules along anterior surface and with two surface frills subdistally on posterior surface; armed laterally with two unipinnate spines flancking thin seta and apically with four strong elements (three smooth and geniculate, one unipinnate). Exopod cylindrical, slender, unornamented but armed with two pinnate apical elements; inner element more slender, about 2.3 times as long as outer spiniform one and 1.9 times as long as exopod.

Labrum (Figure 106 H) not very large compared with cephalothorax, with trapezoidal free part, rigidly sclerotized, with broad and almost straight cutting edge, ornamented apically with many minute spinules and subapically with two short rows of seven strong spinules. Gustatory papillae not visible on dorsal (posterior) surface.

Mandibula (Figure 105E) with narrow cutting edge on elongated coxa, armed with two coarse teeth ventrally, one unipinnate seta dorsally and numerous smaller teeth in between; large spiniform process on distal dorsal margin of coxa. Palp uniramous, comprising basis and one-segmented endopod. Basis slender, about twice as long as wide, unornamented and unarmed. Endopod also slender and unornamented, slightly shorter than basis and about 2.3 times as long as wide; armed with four slender and smooth setae apically and subapically.

Maxillula (Figure 105F) with large praecoxa, arthrite rectangular, short, ornamented with few spinules basally, armed with single smooth anterior surface seta, two lateral elements and five apical elements (probably three spines and two strong setae). Coxal endite armed with single curved and pinnate apical spine. Basis longer than coxal endite, armed with three smooth lateral setae and three apical setae (one pinnate and two smooth). Endopod and exopod absent.

Maxilla (Figure 107D) with two similar mobile endites on syncoxa; proximal armed with one unipinnate and one smooth element of about same length; distal endite armed with three elements of similar length (one pinnate and strong, two smooth and slender). Syncoxa without visible ornamentation. Basis drawn out into strong claw, with two smooth setae at its base (one on anterior, one on posterior surface). Endopod represented by minute but distinct segment, armed with two smooth apical setae.

Maxilliped (Figure 106G) with short and unarmed syncoxa, ornamented with two short rows of spinules. Basis also unarmed, about 2.5 times as long as wide and 1.5 times as long as syncoxa, ornamented withone longitudinal row of spinules near inner margin and two short transverse rows on outer margin. Endopod represented by long curved claw, which ornamented with row of spinules along concave side distally and accompanied at its base by thin smooth seta.

All swimming legs with three-segmented exopod. Endopod of first swimming leg also threesegmented (Figure 106F), endopod of other swimming legs two-segmented (Figure 107A, B, C), although endopods of second and third leg with parts of ancestral segmentation visible as suture on inner margin of second segment. Armature formula of swimming legs as follows (legend: inner/outer spine or seta; inner/terminal/outer):

\begin{tabular}{|c|c|c|c|c|c|c|}
\hline \multirow[b]{2}{*}{ Segments } & \multicolumn{3}{|c|}{ Exopod } & \multicolumn{3}{|c|}{ Endopod } \\
\hline & 1 & 2 & 3 & 1 & 2 & 3 \\
\hline First leg & $0 / 1$ & $0 / 1$ & $0 / 2 / 2$ & $1 / 0$ & $1 / 0$ & $1 / 1 / 1$ \\
\hline Second leg & $0 / 1$ & $1 / 1$ & $1 / 2 / 2$ & $1 / 0$ & $1 / 1 / 1$ & - \\
\hline Third leg & $0 / 1$ & $1 / 1$ & $1 / 2 / 2$ & $1 / 0$ & $2 / 1 / 1$ & - \\
\hline Fourth leg & $0 / 1$ & $1 / 1$ & $1 / 2 / 2$ & $1 / 0$ & $1 / 1 / 1$ & - \\
\hline
\end{tabular}

Intercoxal sclerites of all swimming legs very broad and short, with concave distal margin and without any surface ornamentation. Praecoxa ornamented with short row of large spinules along posterior margin. Coxa ornamented with few short rows of very large spinules near outer margin and unarmed; coxa of first swimming leg ornamented with additional short row of spinules close to inner margin. Basis with cuticular pore at base of exopod, ornamented with few spinules along posterior margin and armed with bipinnate outer spine on first and second swimming legs and with outer smooth seta on third and fourth legs; basis of first leg with long spine at inner distal corner, reaching $2 / 5$ of first endopodal segment. Exopod and endopod of all swimming legs ornamented with very long spinules along outer margins and on some segments also along inner and distal margins. First and second exopodal segment of all legs of about same length, with distal outer corner not produced posteriorly as spiniform process. First endopodal segment of first swimming leg (Figure $106 \mathrm{~F}$ ) about 2.6 times as long as wide, reaching middle of second exopodal segment. Endopod of second (Figure 107A) and third swimming leg (Figure 107B) somewhat longer than first two exopodal segments; while endopod of fourth swimming leg (Figure 107C) hardly reaching middle of second exopodal segment. Two setae on third exopodal segment of first swimming leg, as well as one seta on third endopodal segment, geniculate. All other setae not modified and relatively strong, most of them pinnate or plumose, at least at distal end. All spines very strong and pinnate compared to segments.

Fifth leg (Figure 106D) biramous, clearly distinct, 


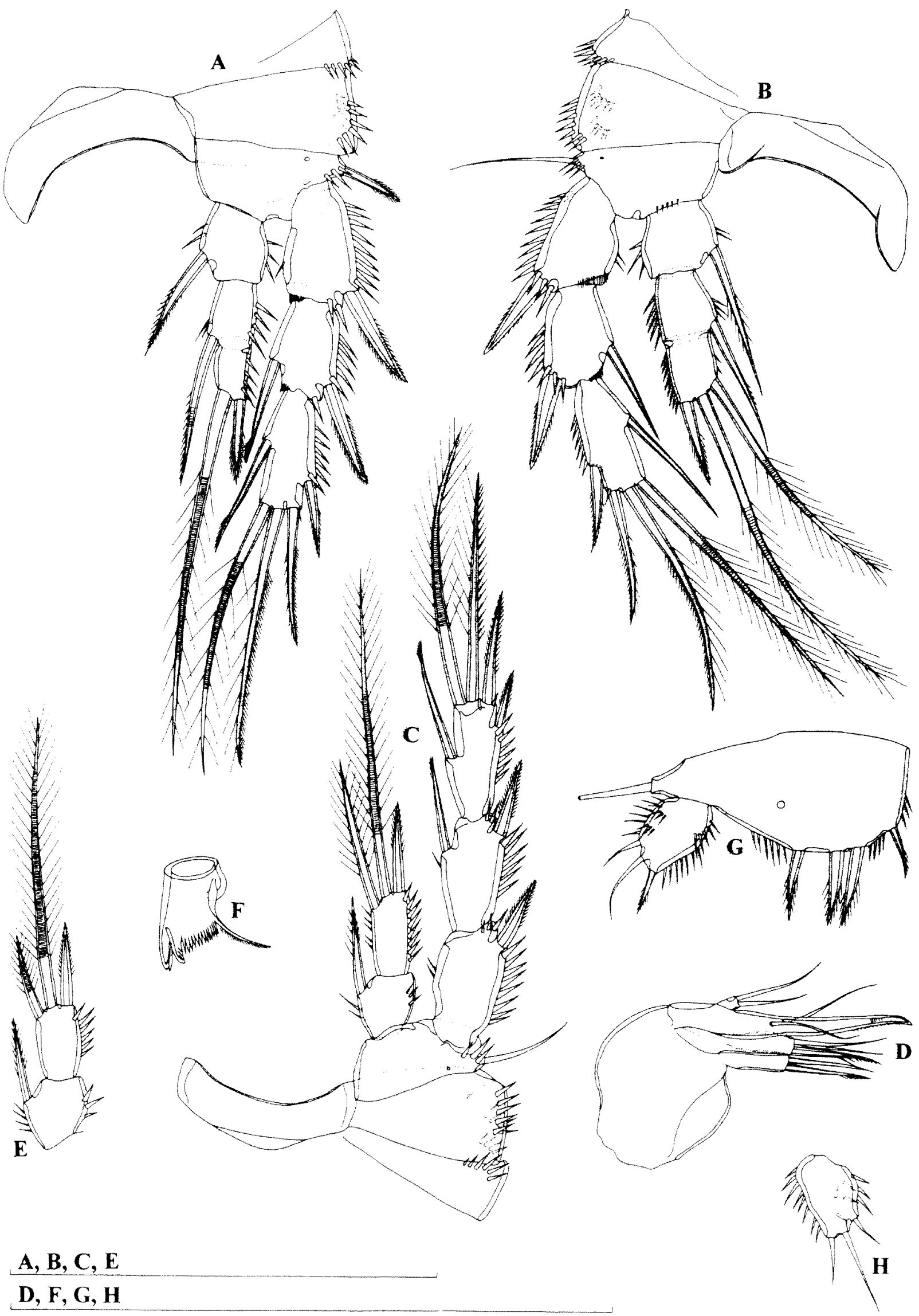

Figure 107 Elaphoidella humphreysi sp. nov. A-D, holotype (female): E, F and $\mathrm{H}$, female $(0.546 \mathrm{~mm})$ from locality 1 (WAM C34219); G, female (0.478 mm) from locality 4 (WAM C34224): A, second swimming leg; $B$, third swimming leg; $C$, fourth swimming leg; D, maxilla; E, endopod of fourth swimming leg; F, cutting edge of mandibula; $G$, right fifth leg; $H$, exopod of left fifth leg. Scales $=0.1 \mathrm{~mm}$ 
with little space between legs. Baseoendopod with outer basal seta very long, smooth, arising from relatively long setophore. Endopodal lobe very broad and convex, not extending to middle of exopod, ornamented with long spinules along both inner and outer margins and armed with five very stout, spiniform, bipinnate and subequal elements. Exopod ovoid, about 1.4 times as long as maximum width and armed with three setae; innermost seta strong and bipinnate, other two smooth and slender. Length ratio of exopodal setae (from inner side), $1: 1.4: 0.8$; length ratio of setae on endopodal lobe (also from inner side), $1: 1.3: 1.2: 1.2: 1.3$.

Sixth legs (Figure 106E) fused, very small cuticular plates, forming simple operculum covering single gonopore, each armed with two plumose thin setae; outer seta about twice as long as inner one.

Male (allotype). Body length, excluding caudal setae, $0.583 \mathrm{~mm}$. Habitus, ornamentation of prosomites, colour and nauplius eye similar to female. Hyaline fringe of all prosomites smooth. Fifth pedigerous (first urosomal) somite also with smooth hyaline fringe, ornamented only with two dorsal and two lateral (one on each side) sensilla.

Genital somite about twice as wide as long, ornamented with two dorsal sensilla and two parallel dorsolateral rows of spinules. Single small, completely formed and longitudinally-placed spermatophore (Figure 108A) visible inside genital somite. Third and fourth urosomites ornamented with two dorsal sensilla, two cuticular pores ventrally, uninterrupted posterior row of large spinules and one or two short parallel rows of minute spinules on ventral and dorsal surface. Fifth urosomal (preanal) somite ornamented just with posterior row of large spinules and two additional rows of minute spinules. Anal somite (last urosomal) similar to female but with larger ventral spinules along posterior margin (Figure 108A).

Caudal rami (Figure 108A, E) about 1.1 times as long as wide (ventral view), slightly divergent, with space between them about one ramus width. Chitinous ridge at base of dorsal seta absent. Armature and ornamentation similar to female.

Antennula (Figure 108B, C) very strong, about as long as cephalothorax, unornamented, strongly geniculate, basically eight-segmented but fourth segment with distinct spiniform lobe proximally, armed with strong spine, two smooth seta and one spiniform process and almost looks like additional segment. Sixth segment with complicated cuticular structures, unarmed and unornamented. Seventh segment very short, also unarmed and unornamented. Geniculation visible between fourth and fifth and fifth and sixth segments. Relatively long aesthetasc on subapical acrothek of fourth segment and slender aesthetasc apically on eighth segment, fused basally to apical seta. First two segments similar to female. Setal formula: 1.9.7.7.3.0.0.9. All setae smooth. Only six setae on eighth segment articulating on basal part.

Antenna, labrum, mandibula, maxillula, maxilla, maxilliped, first swimming leg and fourth swimming leg similar to female.

Second swimming leg (Figure 108F) without inner apical spine on second endopodal segment but with large cuticular pore instead. Exopod similar to female.

Third swimming leg (Figure 108G) with endopod characteristically modified, unornamented, threesegmented; first segment armed with strong and short spine on inner margin; second with inner margin characteristically drawn out and modified as long spiniform process, about 1.2 times as long as entire endopod, with sharply pointed tip; third endopodal segment armed with two pinnate seta, apical one about 1.7 times as long as subapical inner one; outer subapical spine missing. Second exopodal segment of third leg (Figure 108H) with outer distal corner produced as spiniform smooth process.

Fifth legs (Figure 108A, I) with fused baseoenopods but distinct from somite. Endopodal lobe almost straight, smooth, ornamented only with cuticular pore and unarmed. Exopod ovoid, about 1.8 times as long as maximum width, ornamented with large spinules on both inner and outer margin, armed with three setae; length ratio of exopodal setae (from inner side), $1: 0.8: 0.6$. Only innermost seta pinnate, others smooth; innermost seta 0.7 times as long as exopod, while outermost seta hardly any longer than spinules.

Sixth legs (Figure 108A) fused to each other and fused to somite; simple cuticular plates, each armed with two short setae and unornamented; outer seta pinnate and about 2.5 times as long as inner smooth one.

\section{Variability}

Body length of females ranges from $0.478 \mathrm{~mm}$ to $0.567 \mathrm{~mm}(0.532 \mathrm{~mm}$ average; $\mathrm{n}=10)$, while in males it ranges from $0.431 \mathrm{~mm}$ to $0.583 \mathrm{~mm}(0.532$ $\mathrm{mm}$ average; $\mathrm{n}=7$ ). The strength and relative length of armature elements on the exopod of the fifth leg can vary somewhat, both in the female (Figure $106 \mathrm{D}$ and $107 \mathrm{G}, \mathrm{H}$ ) and male (Figure 108I, J). One female from locality 4 has only four armature elements on the endopodal lobe of the fifth leg (Figure 107G). One female from locality 1 has a somewhat shorter inner armature element on the second endopodal segment of the fourth swimming leg (Figure 107E) than the holotype.

\section{Etymology}

The species is named in honour of Dr William F. Humphreys from the Western Australian Museum in Perth, who entrusted to me all the copepod 


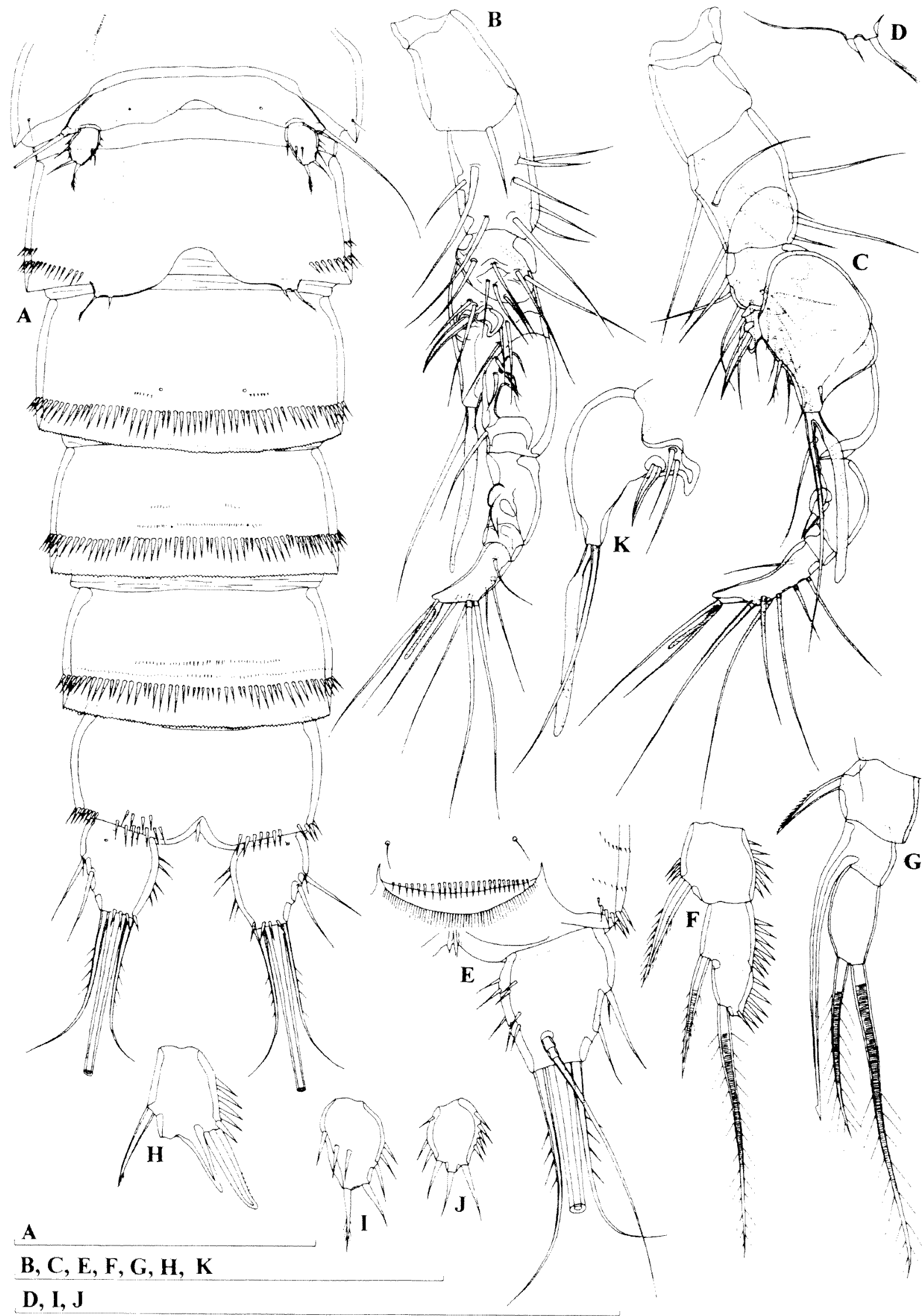

Figure 108 Elaphoidella humphrersi sp. now. A-I, allotype (male); J and K, male (0.537 mm) from locality 1 (WAM C34218): A, urosome, ventral view; $B$, antennula, anterior view; $C$, antennula, dorsal view; $D$, sixth leg; $E$, anal operculum and right caudal ramus, dorsal view; F, endopod of second swimming leg; G, endopod of third swimming leg; $H$, second exopodal segment of third swimming leg; 1 exopod of left fifth leg; ], exopod of right fifth leg; $\mathrm{K}$, antennula, detail. Scales $=0.1 \mathrm{~mm}$. 
material from the Pilbara, collected during his various field trips and projects. The name is a noun in the genitive singular.

\section{Discussion}

Elaphoidella Chappuis, 1929 is the largest canthocamptid genus and, with just over two hundred described freshwater species and subspecies (Karanovic 2001a), is (after Parastenocaris Kessler, 1913) the second largest and widespread copepod genus. Although very specious, Elaphoidella is relatively homogeneous and attempts to split it up into different genera (Apostolov 1985), or to return it to the subgeneric status (Hammond 1988) of the genus Canthocamptus Westwood, 1836 have been unsuccessful (Reid 1990, Reid and Ishida 1993, Karanovic 1998, 2001a). Presently the majority of copepodologists support the generic status of Elaphoidella, as well as its separation into 11 species groups, created by Lang (1948) and supplemented by Petkovski and Brancelj (1988). Some of these groups will probably be elevated to the generic level in a future revision of the genus, although incomplete descriptions of many species will make this an enormous task.

Surprisingly, only two widely distributed Elaphoidella species have been confirmed so far from Australia (see Hammond 1987): E bidens Schmeil, 1894 and E. grandidieri Guerne and Richard, 1893. The former species was reported by Hammond (1987) from numerous surface water localities in Queensland, New South Wales, Victoria and South Australia, while the latter was only found in tropical norhern Queensland. I found a large parthenogenetic population of $E$. grandidieri in Pioneer Valley in Queensland (unpublished data) and am convinced that this species and the genus Elaphoidella in general are recent arrivals in Australia. The closely related and endemic genus Australocamptus Karanovic, 2004 is much more diversified here and along with three species described from the Murchison region (Karanovic 2004a) we have material (Karanovic, Halse and McRae in preparation) of six new surface water species from south-west Western Australia, as well as one new subterranean species from the Kimberley Region in Western Australia and one from Pioneer Valley in Queensland. Elaphoidella humphreysi sp. nov. is the first endemic and subterranean Australian representative and can be distinguished from both $E$. bidens and $E$. grandidieri by a number of morphological characters, including the armature of the antennal exopod, basis of mandibula, swimming legs and fifth legs in both male and female. In an unusual way $E$. humphreysi combines a number of rare generic characters, although its only autapomorphy is the reduced armature of the antennal exopod, with only two elements (other Elaphoidella species have three or four elements on that segment). More than four armature elements on the baseoendopod of the female fifth leg is found only in $E$. humphreysi, E. aberrans Chappuis, 1954 from Madagascar (Chappuis 1954) and E. birsteini Borutzky, 1948 from the Caucasus (Borutzky 1948). The latter two species differ from the new one in the shape of the caudal rami, as well as in the armature formula of the swimming legs. It should be mentioned here that $E$. tenuicaudis (Herrick, 1884) has been reported with five elements on the baseoendopod of the female fifth leg but this species was so inadequately described that it was placed as species incerta by Lang (1948). Another rare characteristic of $E$. humphreysi is an armed sixth leg in the male, which has been recorded in only three other Elaphoidella species: $E$. arambourgi Chappuis, 1935, E. hyalina Chappuis, 1932 and E. stammeri Chappuis, 1936. Unfortunately, many species in this genus were described and are still known only as females, so this character may be more common. The majority of Elaphoidella species, unlike E. humphreysi, have an inner seta on the second endopodal segment of first leg, as well as two inner setae on the third exopodal segment of the fourth leg in female. However, these characters are not as rare in the genus as those mentioned above. The second endopodal segment of the first leg without an inner seta is a character also found in E. calypsonis Chappuis and Rouch, 1959; E. cavicola Shen and Tai, 1965; E. dubia Kiefer, 1931; E. labani Löffler, 1973; E. longiseta Chappuis, 1932; E. miurai Chappuis, 1955; E. romanica Kilhavý, 1969; E. siolii Kiefer, 1967; E. striblingi (Reid, 1990); and also in some populations of $E$. elaphoides (Chappuis, 1923) from Italy (see Pesce 1980). A third exopodal segment of the fourth leg in female with less than two inner setae is found in a number of species, including E. apostolovi (Pesce and De Laurentiis, 1984); E. coiffaiti Chappuis and Kiefer, 1952; E. damasi Chappuis, 1938; E. longifurcata Chappuis and Kiefer, 1952; E. mauro Chappuis, 1956; E. nuragica Galassi and Pesce, 1986; and E. silverii Pesce, 1985.

Because of the shape of the antennal exopod $E$. humphreysi would key out in Lang's (1948) key as Epactophanes Mrazek, 1893, although this genus has quite a different form of the male third leg, as well as a different female genital field. I believe that the reduced armature of this segment is a result of intrageneric evolution, rather that anything else, because this character is very variable in some canthocamptids within the same population of one species and sometimes even on a single specimen (see Karanovic 1999a). The recently described canthocamptid genus Lessinocamptus Stoch, 1997 also includes members with two or three armature 
elements on the exopod of the antenna (Stoch 1997).

The following characters place $E$. humphreysi unmistakably into the genus Elaphoidella: antenna with an allobasis; shape of the genital field and sixth leg in the female; armature of the mouth appendages (mandibula with an endopod); only two outer spines on the third exopodal segment of all swimming legs; two-segmented endopod of second, third and fourth legs; reduced armature of the female fifth leg; shape of the modified male third leg; unarmed baseoendopod of the fifth leg in the male. The new species does not have any close relatives among living Elaphoidella species and can only be tentatively included into the first ("similis")-group of species of Lang (1948). Superficially similar caudal rami are found in Sardinian E. nuragica Pesce and Galassi, 1986 but this species differs from $E$. humphreysi in many characters (see Galassi and Pesce 1987).

\section{GENERAL DISCUSSION}

The Pilbara region has proved to have a rich copepod stygofauna, with 41 species and subspecies, classified into 24 genera, seven families and two orders. Five genera, two subgenera, 22 species and one subspecies described in this monograph are new to science.

Of the 41 species and subspecies (note that the hybrid population between two subspecies of Diacyclops humphreysi Pesce and De Laurentiis, 1996 is not treated as a taxon although it has been listed separately in the text), five species $(12 \%)$ have a cosmopolitan or almost cosmopolitan distribution: Tropocyclops prasinus (Fischer, 1860), Ectocyclops phaleratus (Koch, 1838), Apocyclops dengizicus (Lepeschkin, 1900), Microcyclops varicans (Sars, 1863) and Phyllopodopsyllus thiebaudi Petkovski, 1955. The last mentioned species is marine, mostly inhabiting the interstitial of sandy beaches, while the other four are tolerant and ecologically euryvalent species that occur in a wide range of freshwater habitats. Two other species listed in the monograph have a relatively wide distribution: Thermocyclops aberanns Lindberg, 1952 is known from Cambodia, Malaysia, Java and now from the Pilbara region, while Mesocyclops darwini Dussart and Fernando, 1988 is known from New Guinea and northern parts of Australia (Western Australia, Northern Territory and Queensland). Mesocyclops brooksi Pesce, De Laurentiis and Humphreys, 1996 and Mesocyclops notius Kiefer, 1981 are widely distributed Australian species and Diacyclops humphreysi humphreysi Pesce and De Laurentiis, 1996 is known from Western Australia. For more details and relevant references one should refer to the Discussion section for each species. All the abovementioned species are stygoxene (or at most stygophile) elements of the copepod stygofauna in the Pilbara region. The remaining 31 species and subspecies $(76 \%)$ from the area surveyed are endemic and most probably stygobitic (although it is possible that Mesocyclops holynskaesp. nov. is a stygoxene element). It should be mentioned here that two endemic species (Metacyclops mortoni Pesce, De Laurentiis and Humphreys, 1996 and Phyllopodopsyllus wellsi Karanovic, Pesce and Humphreys, 2001) were also recorded for the neighbouring Cape Range peninsula, an area zoogeographically inseparable from the Pilbara (as far as subterranean fauna is concerned). A single newly described subspecies, Diacyclops humphreysi unispinosus ssp. nov., is restricted to Barrow Island, off the Pilbara coast. One subgenus (Pilbaracyclops subgen. nov.) and four genera (Orbuscyclops gen. nov., Archinitocrella gen. nov., Abnitocrella gen. nov. and Inermipes Lee and Huys, 2002) appear to be endemic to the region.

A very long process of accumulation is likely to be one of the main reasons for such a rich fauna of subterranean copepods, as this part of Australia has been emergent, and hence a freshwater system, since the Precambrian (Beard 1998). It is very probable that the first colonisers started to populate subterranean waters of the Pilbara, just after the Permo-Carboniferous glaciation (see Karanovic 2004a), which spread throughout much of the Gondwana supercontinent. During the PermoCarboniferous glaciation ice covered the entire Australian plate for a long time (Playford 2003), probably wiping out all surface (Frakes 1999) and subterranean life. Representatives of the genera Allocyclops Kiefer, 1932 and Parastenocaris Kessler, 1913 may have invaded the subterranean waters of the Pilbara as early as the Jurassic, because these cosmopolitan genera have no marine relatives and no modern pathways between different continents, making it likely their present distribution is the result of continental drift. Dramatic and frequent changes in global climate during the Quaternary Period (Frakes 1999, Marwick 2002) may have contributed tremendously to the present structure of the subterranean copepod fauna of the Pilbara, forcing many species to take underground refuge as surface waters dried and encouraging further speciation and therefore leaving many obviously young stygobionts. Species from the genera Diacyclops Kiefer, 1927, Schizopera Sars, 1905 and Stygonitocrella Reid, Hunt and Stanley, 2003, for example, are very close morphologically and phylogenetically and thus probably very young.

Although the majority of species from the Pilbara have a clear freshwater origin, no less than 16 species (39\%) are marine derived, with their close relatives still flourishing in the marine environment, both in benthic and meiofaunal communities. Some of them are quite recent colonisers, like the 

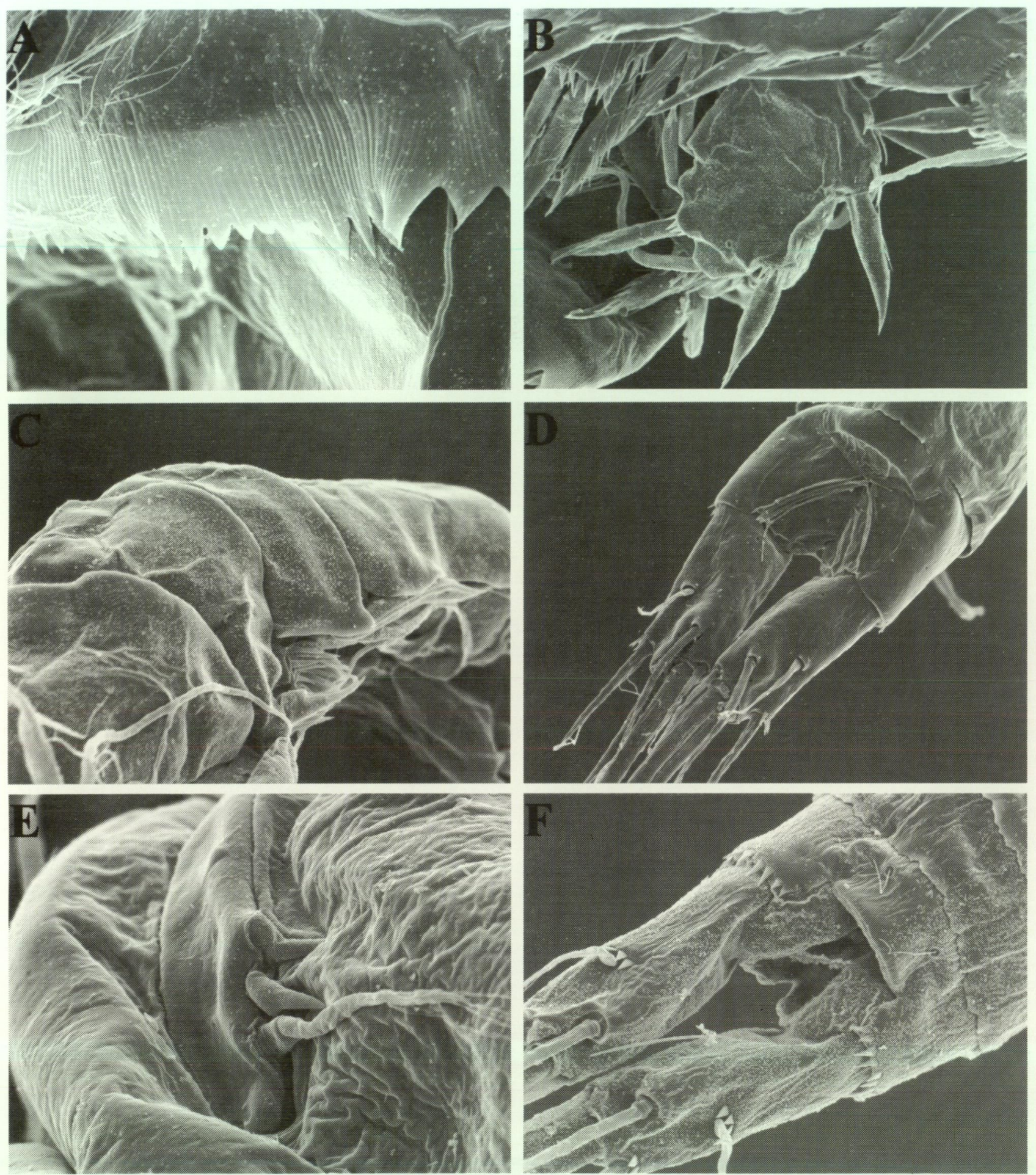

Figure 109 Scanning electron micrographs of some copepods from Pilbara: A, Halicyclops (Rochacyclops) calm sp. nov. (female), hyaline fringe of the genital double somite, ventral view; B, H. (R.) calm sp. nov. (male), exopod of the left sixth leg, anterior surface; C, H. (R.) calm sp. nov. (male), detail of the antennula, dorsal view; D, Tropocyclops prasinus (Fischer, 1860) (female), anal somite and caudal rami, dorsal view; E, T. prasinus (Fischer, 1860) (female), ovipore with the reuced sixth leg, lateral view; Diacyclops humphreysi unispinosus ssp. nov. (male), anal somite and caudal rami, dorsal view.

representatives of the genera Halicyclops Norman, 1903, Schizopera Sars, 1905 and Phyllopodopsyllus T. Scott, 1906. Each of these three genera has more than 70 taxa inhabiting the marine littoral, estuaries, coastal lagoons, anchialine caves and interstitial waters of beaches around the world, with only a small proportion of freshwater representatives (Karanovic et al. 2001, Karanovic 2004a). Also the genus Biameiropsis gen. nov., although presently accommodating only two species, probably had its centre of diversity in the marine environment. The other five Ameiridae Monard, 1927 genera 

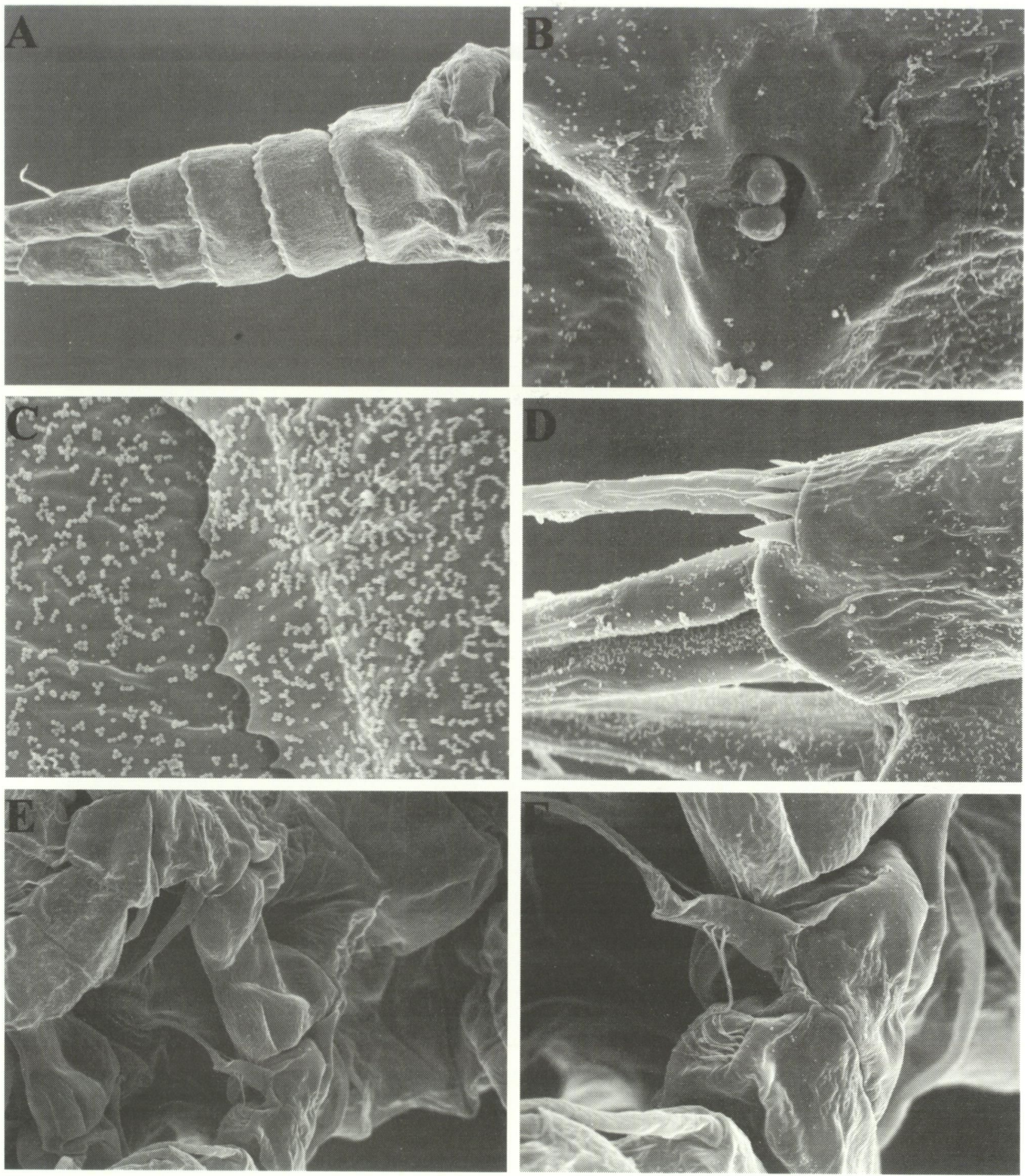

Figure 110 Scanning electron micrographs of Diacyclops humphreysi unispinosus ssp. nov. (female): A, abdomen, ventral view; $B$, copulatory pore; $C$, hyaline fringe of the genital double somite; D, posterior end of the right caudal ramus, ventral view; E, first swimming leg with the intercoxal sclerite in the middle, aterior surface; F, inner margin of the basis of the first swimming leg and coxal seta.

(Parapseudoleptomesochra Lang, 1965; Archinitocrella gen. nov., Abnitocrella gen. nov., Stygonitocrella Reid, Hunt and Stanley, 2003 and Inermipes Lee and Huys, 2002) are assumed to be marine crawlouts, because their close relatives live in the sea but their present distribution is consistent with the hypothesis that movement of tectonic plates was the vicariant event. It is likely that these genera were already present in coastal subterranean waters by the Middle Cretaceous and possibly even as early as the Jurassic (Yager and Humphreys 1996, Humphreys 2000a). At that time the plate that is now Western Australia formed the eastern shore of the Greater Tethys (Howarth 1980). The characters of the first Australian representative of the genus Pseudectinosoma Kunz, 1935, P. galassiae sp. nov., 

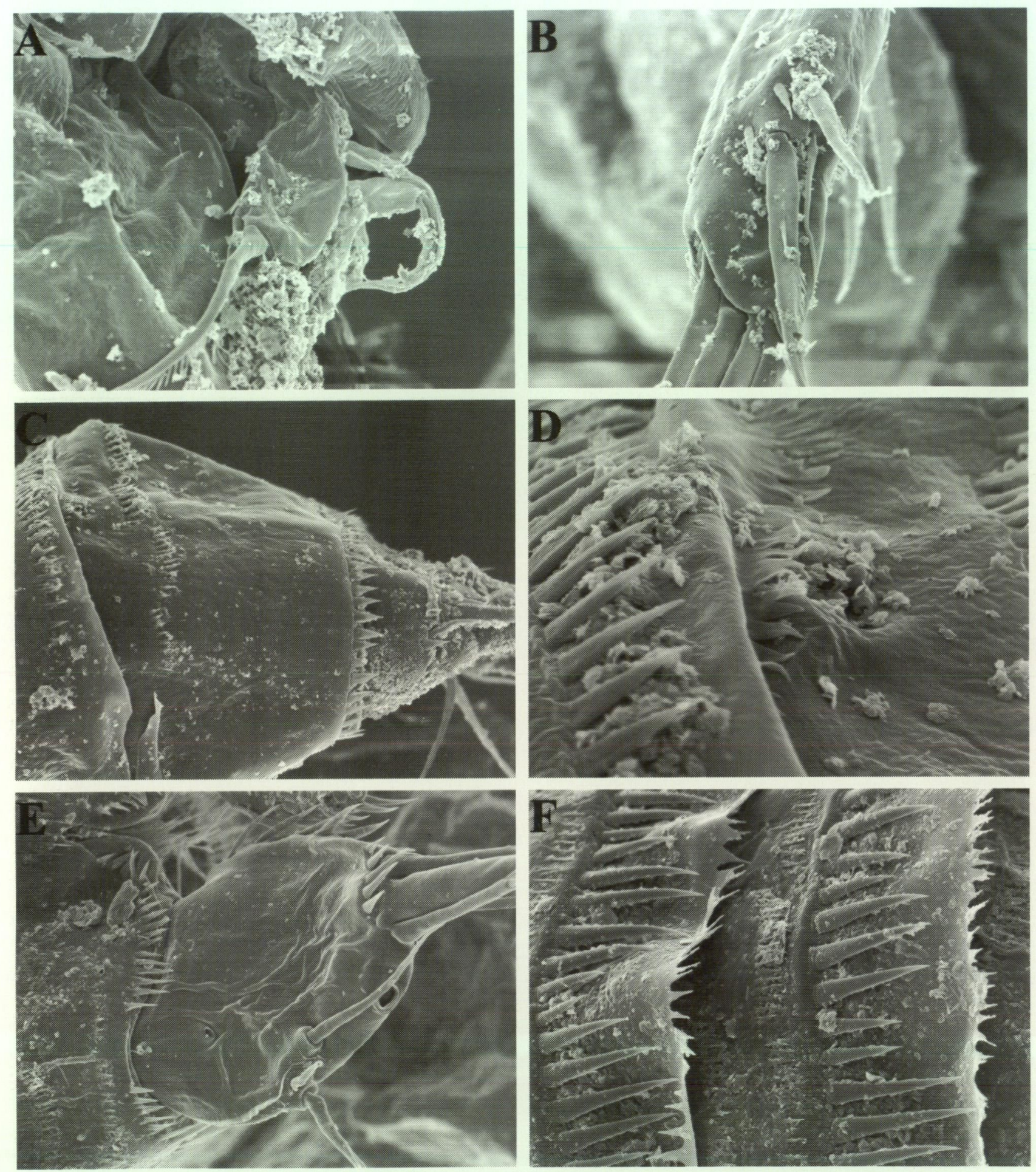

Figure 111 Scanning electron micrographs of Biameiropsis barrowi gen. et sp. nov. (female): A, left mandibular palp, ventral view; B, distal tip of antenna, lateral view; C, anal somite and right caudal ramus, lateral view; D, detail of the hyaline fringe of the preanal somite; ventrolateral view; E, right caudal ramus, ventral view; F, hyaline fringes of the third and fourth (preanal) somites, detail, ventral view.

strongly suggests a Tethyan origin of this genus as well. The Tethyan connection of many other crustacean taxa has been already recognised by Holthuis (1960), Humphreys and Adams (1991), Poore and Humphreys (1992), Bruce and Humphreys (1993), Yager and Humphreys (1996) and Jaume and Humphreys (2001).

A prominent zoogeographical feature of the
Pilbara copepods with a freshwater origin is the Eastern Gondwana connection. The "alticola"group of the genus Diacyclops Kiefer, 1927 (which contains all Diacyclops species from the Pilbara; see the Discussion section for Diacyclops humphreysi humphreysi Pesce and De Laurentiis, 1996 in this monograph), the "trispinosus"-group of the genus Metacyclos Kiefer, 1927 (see Karanovic 2004b) and 

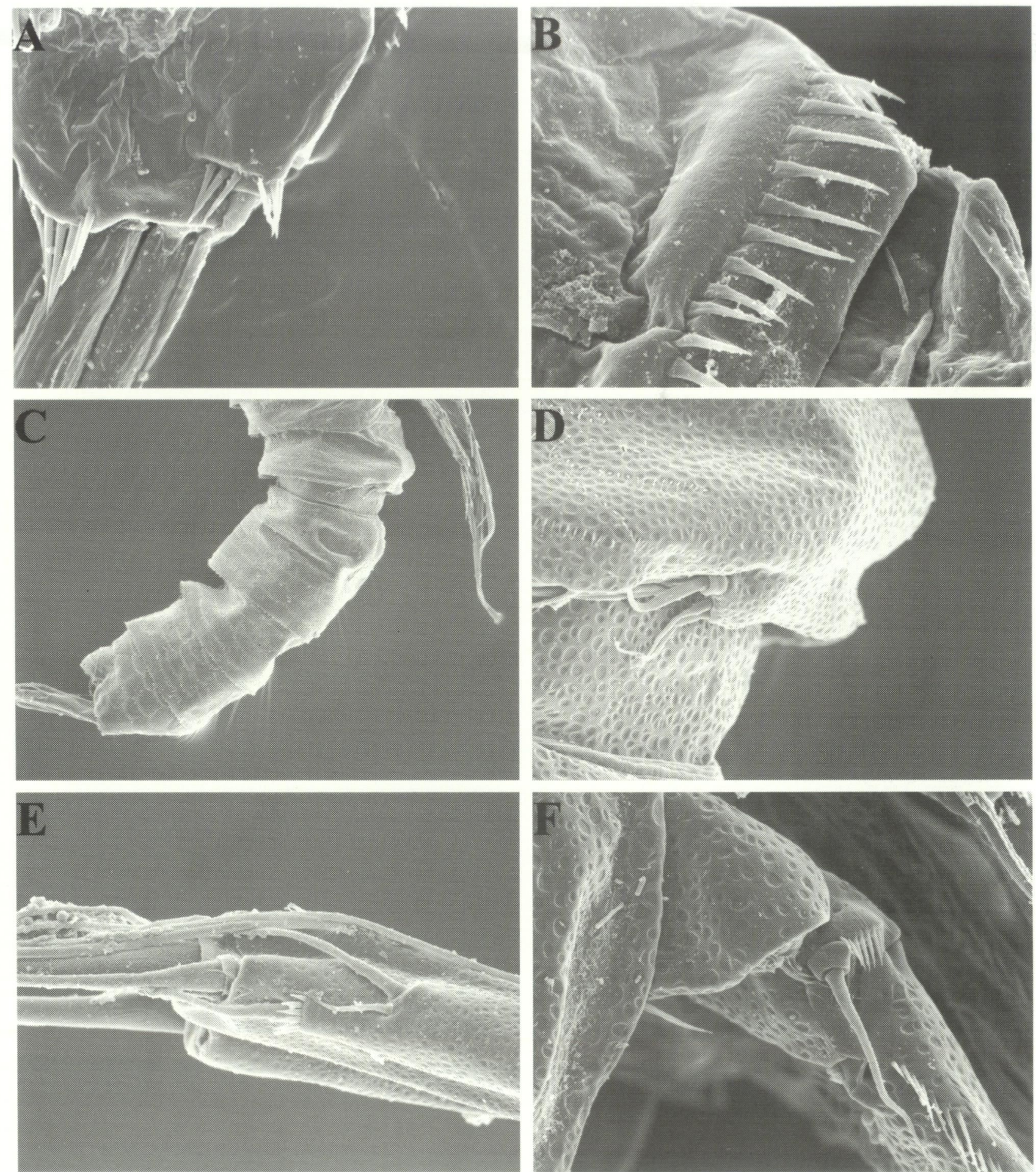

Figure 112 Scanning electron micrographs of some copepods from Pilbara: A, Archinitocrella newmani gen. et sp. nov. (male), left caudal ramus, ventral view; B, A. newmani gen. et sp. nov. (female), hyaline fringe of the preanal somite, lateral view; C, Abnitocrella eberhardi gen. et sp. nov. (female), urosome, lateral view; D, A. eberhardi gen. et sp. nov. (female), right fifth leg, lateral view; E, $A$. eberhardi gen. et sp. nov. (female), posterior part of the right caudal ramus, lateral view; F, A. eberhardi gen. et sp. nov. (female), coxa, basis and first exopodal segment of the right fourth swimming leg, lateral lview.

the subgenus Psammocyclops Kiefer, 1955 (see Karanovic 2003) all have relatively clear Eastern Gondwana connections. The genus Australoeucyclops gen. nov. has its representatives in Australia, New Zealand and Indonesia, while Orbuscyclops gen. nov. and Fierscyclops Karanovic,
2004 are endemic Australian genera. Other freshwater genera from this region are all cosmopolitan or nearly cosmopolitan (Tropocyclops Kiefer, 1927; Ectocyclops Brady, 1904, Thermocyclops Kiefer, 1937; Mesocyclops Sars, 1914; Apocyclops Lindberg, 1942; Microcyclops 

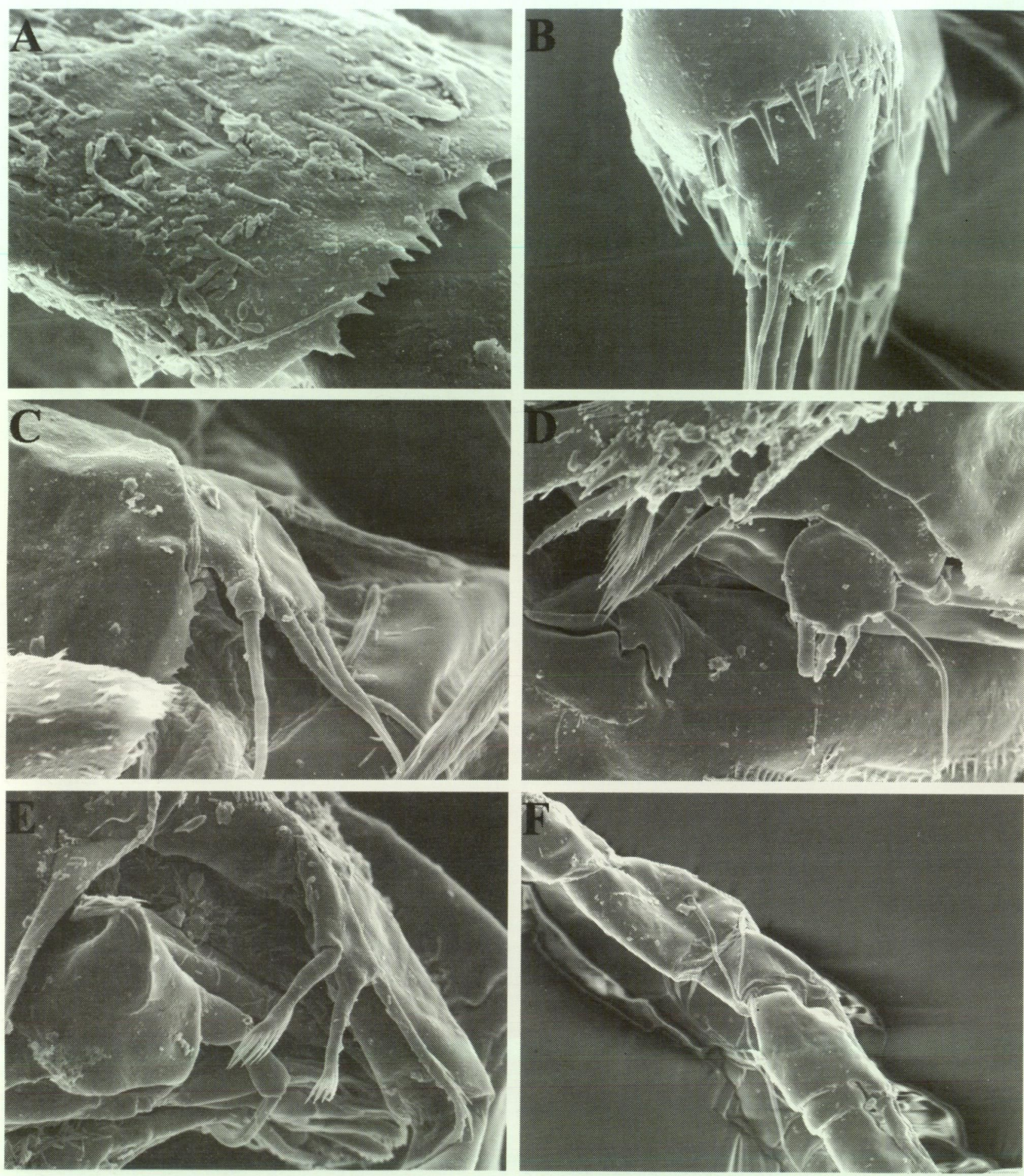

Figure 113 Scanning electron micrographs of Stygonitocrella trispinosa sp. nov.: A, female, posterior part of the genital double somite, lateral view; B, female, anal somite and rigth çaudal ramus, lateral view; C, female, rigth fifth leg, lateral view; D, female, left fifth and sixth legs, ventral view (anterior surface); E, female, exopod of the rigth antenna and some mouth parts, lateral view; F, male, part of the left antennula, lateral view.

Claus, 1893; Parastenocaris Kessler, 1913; and Elaphoidella Chappuis, 1929).

A majority of the copepod species from the Pilbara was collected as small to very small numbers of individuals. Based on the qualitative investigations made and only subterranean waters sampled, little can be said of their population densities, habitat preference and species dominance. However, the most common species in my samples was Diacyclops humphreysi Pesce and De Laurentiis, 1996, found in 66 out of 160 samples $(41 \%)$. The next most common species were Halicyclops (Rochacyclops) rochai De Laurentiis, Pesce and Humphreys, 1999 (found in 20 samples), 

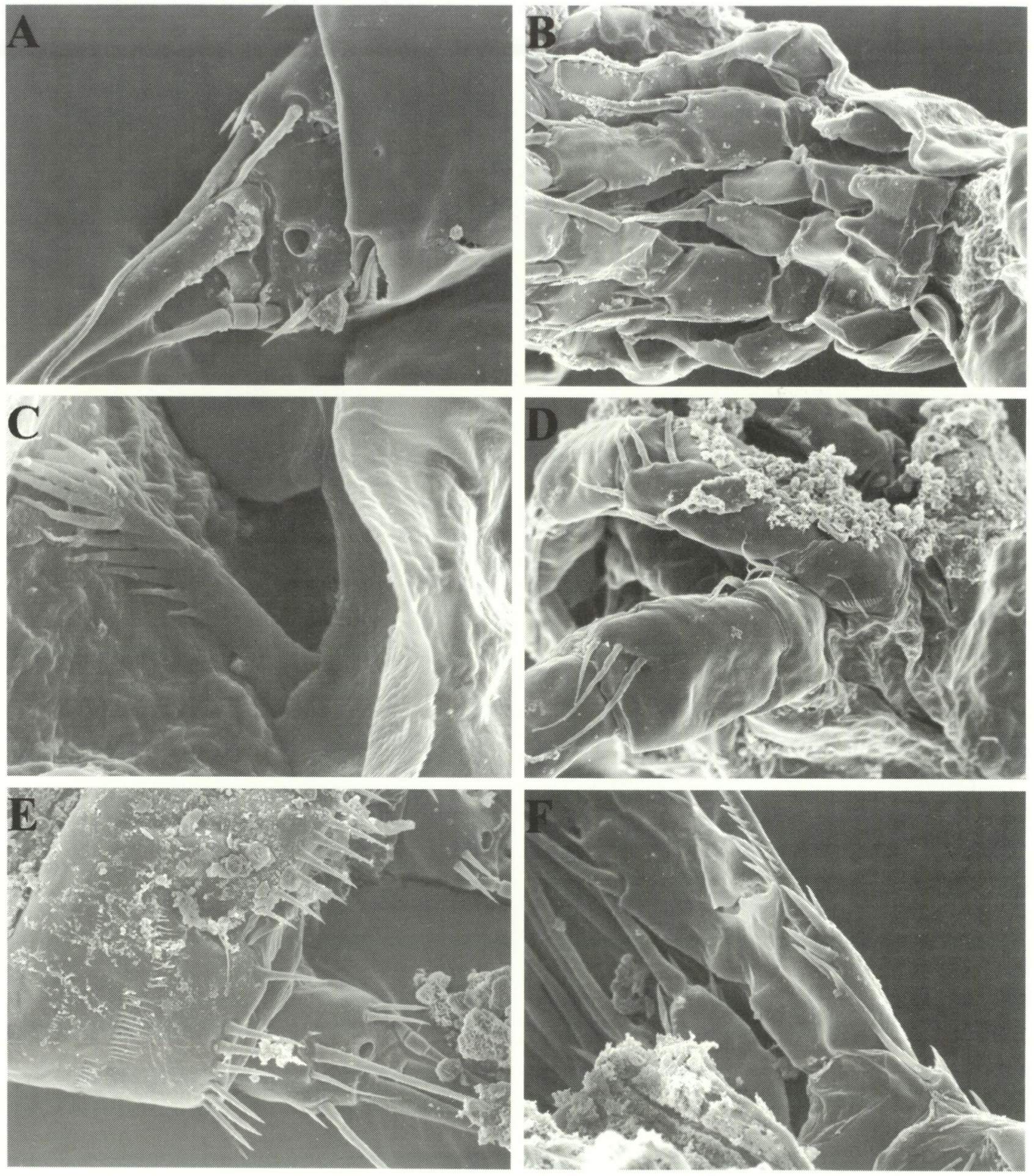

Figure 114 Scanning electron micrographs of some copepods from Pilbara: A, Stygonitocrella unispinosa sp. nov. (female), left caudal ramus, dorsal view; B, S. unispinosa sp. nov. (female), fourth swimming legs, posterior surface; C, S. unispinosa sp. nov. (female), baseoendopodal spine of the fifth leg; D, Stygonitocrella bispinosa sp. nov. (female), first two segment of the antennulae, dorsal view; E, S. bispinosa sp. nov. (female), anal somite and laft caudal ramus, dorsal view; F, S. bispinosa sp. nov. (male), fourth swimming leg, posterior surface.

Diacyclops cockingi sp. nov. (17 samples) and Microcyclops varicans (Sars, 1863) (found in 14 samples). The fact that the cyclopoids were more common than the harpacticoids may reflect sampling techniques used. It is likely that net hauls preferentially collected cyclopoids from the water columns of bores and wells, rather than the harpacticoids more likely to be associated with bore walls and sediments. Very small spaces in interstitial habitats are practically undisturbed when using haul-nets. The most common harpacticoid in the area surveyed was 

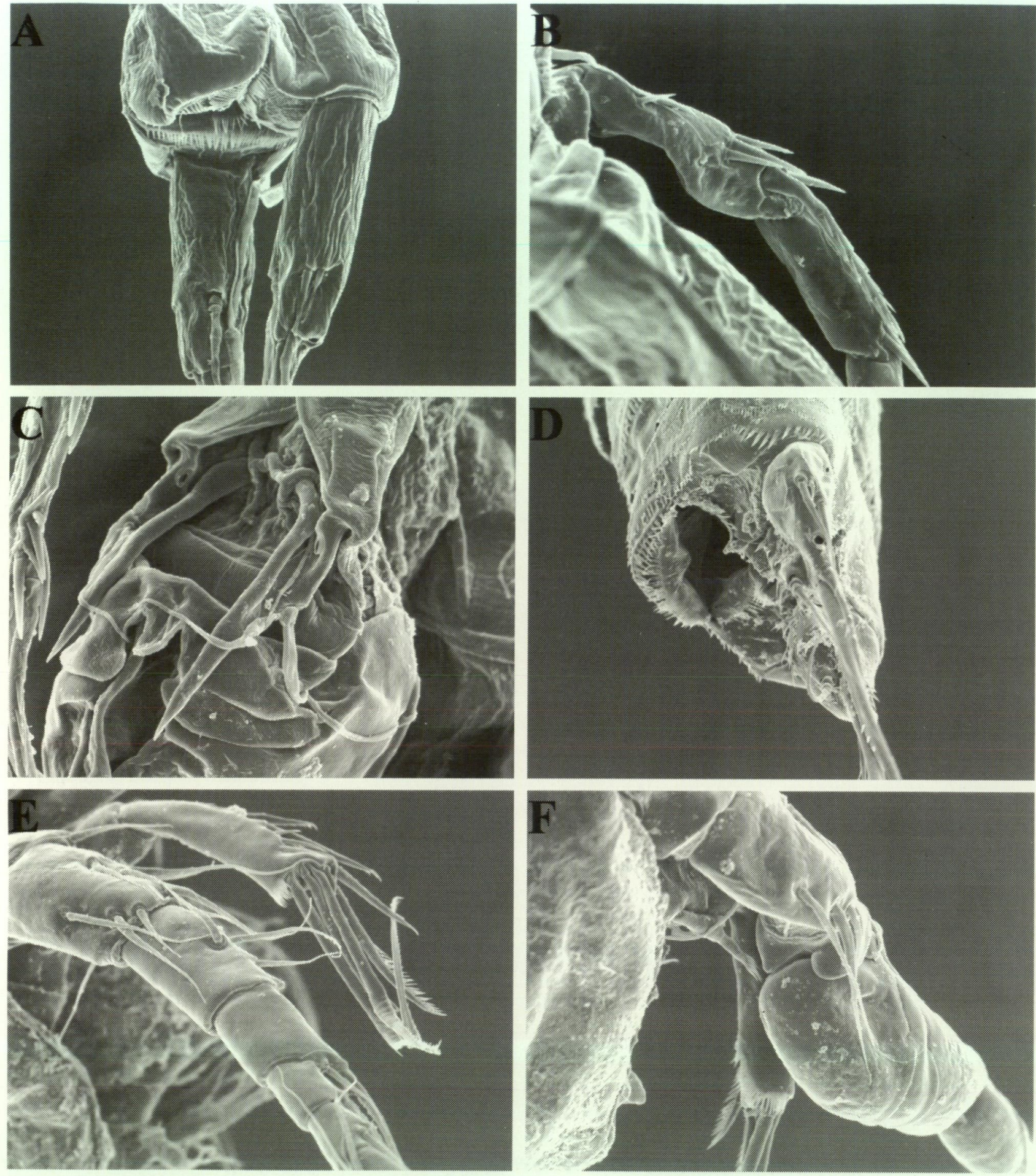

Figure 115 Scanning electron micrographs of some copepods from Pilbara: A, Parastenocaris jane sp. nov. (male), anal somite and caudal rami, dorsocaudal view; B, P. jane sp. nov. (male), basis and exopod of the fourth swimming leg, lateral view; C, $P$. jane sp. nov. (female), fifth legs, ventral view (anterior surface); D, Elaphoidella humphreysi sp. nov. (female), anal sinus and caudal rami, posterior view; E, E. humphreysi sp. nov. (female), antennula and antenna, lateral view; F, E. humphreysi sp. nov. (male), antennula and antenna, dorsal view.

Archinitocrella newmani gen. et sp. nov. (present in 11 out of 160 samples), closely followed by Parastenocaris jane sp. nov. (found in 9 samples).

The Pilbara is the second Western Australian region where I have had a chance to work on subterranean copepods in a survey like manner.
The first was the neighbouring Murchison region, just south from the Pilbara (Karanovic 2004a). Not surprisingly, many new taxa were described from the Murchison and some species had a very restricted distribution, although none seemed to be restricted to a single calcrete body. Predominance 


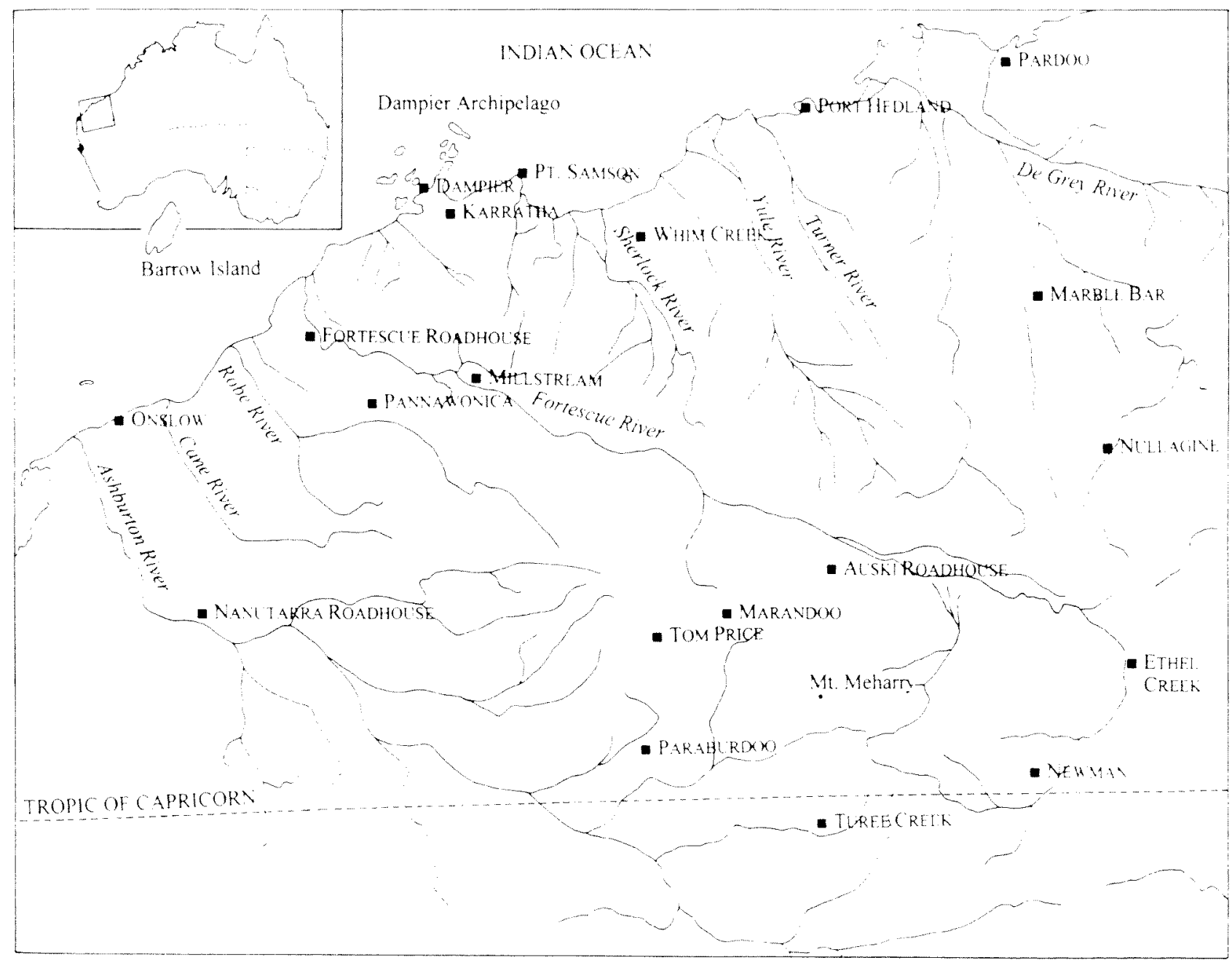

Figure 116 Map of the Pilbara region. Inset, location of the Pilbara in Australia.

of species from the genera Halicyclops Norman, 1903 and Schizopera Sars, 1905 reflected the higher salinity subterranean waters in this verv arid region, but some ancient freshwater stygobionts (from the genera Goniocyclops Kiefer, 1955 and Nitocrella Chappuis, 1923, for example) also occurred. Some new species were widespread in the Murchison and I speculated (Karanovic 2004a) that "this unusually high endemism will probably be reduced when subterranean waters of other Australian regions are investigated". However, not a single species endemic to the Murchison was found in the Pilbara and those that occur in both regions are widespread Australian (like Mesocrclops brooksi Pesce, De Laurentiis and Humphreys, 1996) or cosmopolitan species (Apocrclops dengizicus (Lepeschkin, 1900) and Microcyclops baricans (Sars, 1863) for example). There are also differences in the copepod genera of the Pilbara and Murchison: two Halicyclops Norman, 1903 species from the Pilbara belong to a different subgenus; small cyclopoids are represented by Allocyclops Kiefer, 1932 and Orbuscyclops gen. nov. in the Pilbara and by Goniociclops Kiefer, 1955 in the Murchison; not a single member of Australocamptus Karanovic, 2004 was found in the Pilbara; and instead of Nitocrella Chappuis, 1923 the Pilbara has Stygonitocrella Reid, Hunt and Stanley, 2003. Even when species look superficially similar they are really not. For example members of the genus Metacyclops Kiefer, 1927(see Karanovic 2004b): M. mortoni Pesce, De Laurentiis and Humphreys, 1996 was never found in the Murchison and M. pilbaricus Karanovic, 2004, although a member of the same species-group as two Murchison representatives ( $M$. laurentiisae Karanovic, 2004 and M. pilanus Karanovic, 2004) is really more closely related to a species from the Kimberley (M. Kimberleri Karanovic, 2004). Even the two Parastenocaris Chappuis, 1933 species in the Pilbara and Murchison are from two different groups and Parapseudoleptomesochra tureei sp. nov is more closely related to a species from Margaret River than to its two Murchison congeners ( $P$. Karamani Karanovic, 2004 and $P$. rouchi Karanovic, 2004). Surprising differences between the subteranean faunas of these two regions are not restricted to copepods: diving beetles are absent from Pilbara altogether and the 
composition of ostracod faunas is also very different (Watts and Humphreys 2003, Karanovic and Marmonier 2003).

Examination of limited collections from other parts of Australia (Kimberley and Margaret River in Western Australia and Pioneer Valley in Queensland (mostly unpublished data, except for Karanovic 2004b and Karanovic 2005)) shows each of these three regions has stronger connections to either the Pilbara or Murchison than these neighbouring regions have to each other. For example, the genus Australocamptus Karanovic, 2004 is present in the Murchison, Kimberley, Pioneer Valley and the Western Australian wheatbelt region, but not in the Pilbara. Stygonitocrella Petkovski, 1976 is present in the Pilbara, Kimberley and Pioneer Valley, but not in the Murchison. Goniocyclops Kiefer, 1955 was found in the Murchison, Kimberley and Pioneer Valley, but not in the Pilbara. Australoeucyclops gen. nov. was found in Pilbara and Margaret River and so on. The only real connection between the Murchison and Pilbara seems to be the genus Schizopera Sars, 1905, with five and two species respectively. What could cause such strong differences between these neighbouring stygofaunas is hard to say, especially because the regions are part of the same Precambrian plate that has never been submerged (Bird and Chivas 1988, Beard 1998), have similar arid climates (Beard 1975, 1976) and do not appear to have a long lasting barrier between them. It almost seems that they once were on two opposite ends of an ancient Australian continent, which was subsequently curved in a form of doughnut; the only problem with this "theory" is the lack of evidence (the result of such an event would not be much smaller than the Himalayas are today and Australia is a pretty flat continent, with some central parts even below the sea level).

I tentatively propose here a "pulsating desert hypothesis" that may account for some of the observed differences between the Pilbara and Murchison stygofaunas. This hypothesis assumes that the Tropic of Capricorn was a long-term barrier between the two regions. It is almost a general knowledge now that there have been past episodes of very severe aridity in Australia (Beard 1975, Fox 1999, Frakes 1999, Marwick 2002). During these arid phases the real desert would have spread westwards from the central part of the continent, perhaps wiping out most of the stygofauna and forcing the rest to retreat, first towards the coast and then either northwards or southwards. During the periods of increased humidity the regions would be repopulated and two different faunas would meet around the Tropic of Capricorn. Then another cycle would begin and these faunas really did not have a chance to develop any stronger connections. The Cape Range peninsula has very similar copepods to Pilbara, as it lies north of this parallel.

It should be mentioned that the diversity of the three main freshwater harpacticoid families (Canthocamptidae Sars, 1906, Parastenocarididae Chappuis, 1933 and Ameiridae Monard, 1927) is quite different in Australian subterranean waters from elsewhere (although only Europe can be considered well investigated). In Western Australia Ameiridae are the most diverse family and Canthocamptidae and Parastenocarididae are represented with only a few species, and that is the only other common feature of the Pilbara and Murchison. In European subterranean waters Canthocamptidae are the most diverse family, followed by Parastenocarididae and Ameiridae (see Dussart 1967, Kiefer 1978, Rouch 1986a, Dussart and Defaye 1990). Differences in family dominance and diversity may reflect a different colonisation history of the subterranean freshwater habitats in parts of the former Gondwana and in the Northern Hemisphere (see also Karanovic and Ranga Reddy 2004a).

\section{ACKNOWLEDGEMENTS}

This study was financially supported by the Department of Conservation and Land Management (as part of the Pilbara Region Biological Survey). The Department also provided the majority of the material used in this monograph. Other material was kindly entrusted to me by Dr William F. Humphreys (Western Australian Museum). Thanks are extended to the Western Australian Museum for kindly granting me the status of Research Associate; although working in a shed (due to the current relocation of the Museum) could hardly be called a privilege. I am very grateful to Dr Stuart Halse (CALM) for his valuable comments on an early draft of this monograph, and to Dr John B.J. Wells (Victoria University of Wellington) for his very prompt, extensive and excellent reviewer's report.

\section{REFERENCES}

Alvarez Valderhaug, V. (1979). Larval development of Apocyclops dengizicus Lepeshkin (Copepoda). Crustaceana 36: 1-8.

Apostolov, A. (1972). Catalogue des Copépodes harpacticoides marins de la Mer Noire. Zoologischer Anzeiger, Leipzig 188: 202-254.

Apostolov, A. (1973a). Apport vers l'études d'Harpacticoides Pontiques habitant les algues marines. Zoologischer Anzeiger, Leipzig 191: 263-281.

Apostolov, A. (1973b). Sur divers Harpacticoides (Copépodes) de la Mer Noire. Zoologischer Anzeiger, Leipzig 190: 88-109. 
Apostolov, M.A. and Marinov, T.M. (1988). Copepoda, Harpacticoida (morski harpaktikoidi). Fauna na Bulgaria, 18: pp. 1-384, Sofia.

Baribwegure, D., Defaye, D. and Mirabdullayev, I. (2000). Redescription and new rank of Thermocyclops tchadensis Dussart et Gras, 1966 (Copepoda: Cyclopoida). Annales Zoologici Warszawa 50: 627631.

Beard, J.S. (1975). Vegetation survey of Western Australia, Pilbara. University of Western Australia Press, Perth.

Beard, J.S. (1976). Vegetation survey of Western Australia, Murchison. University of Western Australia Press, Perth.

Beard, J.S. (1998). Position and developmental history of the central watershed of the Western Shield, Western Australia. Journal of the Royal Society of Western Australia 81: 157-164.

Bird, M.I. and Chivas, A.R. (1988). Oxygen isotope dating of the Australian regolith. Nature 33: 513-516.

Bodin, P. (1977). Copépodes Harpacticoides marins des environs de la Rochelle, 5. Espèces nouvelles ou incertaines. Vie et Milieu 27: 311-357.

Borutzky, E.V. (1948). Copepoda Harpacticoida pescher Kavkaza. Byulleten Moskovskogo Obschestva Ispytatelei Prirody (nov. ser.) 53: 3-12.

Borutzky, E.V. (1952). Harpacticoida presnyh vod. Fauna SSSR, Rakoobraznye 3 (4): pp. 1-424, Moscow-St Petersburg.

Borutzky, E.V. (1967). Biospeologica Sovietica 32, O rode Nitocrella Chappuis (Copepoda, Harpacticoida). Byulleten Moskovskogo Obschestva Ispytatelei Prirody (nov. ser.) 72: 32-39.

Borutzky, E.V. (1972). Copepoda Harpacticoida from subterranean water of the shore of Issyk-kul and Southern Kisilkum. Fauna Gruntovyh vod Srednei Azii, Trudy Zoologicheskogo Instituta Akademiia Nauk SSSR, Leningrad 51: 98-119. [in Russian]

Boxshall, G.A. and Halsey, S.H. (2004). An introduction to copepod diversity. The Ray Society, London.

Boxshall, G.A. and Jaume, D. (2000). Making waves: the repeated colonization of freshwater by copepod crustaceans. Advances in Ecological Research 31: 6179.

Brehm, V. (1953). Contributions to the freshwater microfauna of Tasmania. Papers and Proceedings of the Royal Society of Tasmania 87: 33-62.

Bruce, N.L. and Humphreys, W.F. (1993). Haptolana pholeta sp. nov., the first subterranean flabelliferan isopod crustacean (Cirolanidae) from Australia. Invertebrate Taxonomy 7: 875-884.

Burbidge, A.H., Harvey, M.S. and McKenzie, N.L. (eds.) (2000). Biodiversity of the Southern Carnavon Basin, Western Asutralia. Records of the Western Australian Museum Supplement 61: 1-602.

Chappuis, P.A. (1924). Descriptions préliminaires de Copépodes nouveaux de Serbie. Buletinul Societatii de Stiinte din Cluj, Romania 2: 27-45.

Chappuis, P.A. (1931). Copepoda Harpacticoida der Deutschen Limnologischen Sunda-Expedition. Archiv für Hydrobiologie Supplement 8: 512-584.
Chappuis, P.A. (1933). Zoologische Ergebnisse einer Reise nach Bonaire, Curaçao und Aruba im Jahre 1930, Süs- und Brackwasser-Copepoden von Bonaire Curaçao und Aruba, I. Harpacticoida. Zoologische Jahrbucher, Abteilung für Systematik, Okologie und Geographie der Tiere 64: 391-404.

Chappuis, P.A. (1937). Weitere subterrane Harpacticoiden aus Jugoslavien. Buletinul Societatii de Stiinte din Cluj, Romania 8: 503-532.

Chappuis, P.A. (1940). Die Harpacticoiden des Grundwassers des unteren Maintales. Archiv für Hydrobiologie 36: 286-305.

Chappuis, P.A. (1951). Copépodes de Tasmanie. Archives de Zoologie Experimentale et Generale 87: 104-115.

Chappuis, P.A. (1954). Recherches'sur la faune interstitielle des sédiments marins et d'eau douce a Madagascar, IV. Copépodes Harpacticoides psammiques de Madagascar. Mémoires de l'Institut Scientifique de Madagascar, Série A 9: 45-73.

Chappuis, P.A. (1955). Harpacticoides Psammiques du Lac Tanganika. Revue de Zoologie et de botanique africaines 51: 68-80.

Comita, G.W. (1951). Studies on Mexican copepods. Transactions of the American Microscopical Society 70: 367-379.

Conroy-Dalton, S. and Huys, R. (1997). Towards a revision of Ameira Boeck, 1865 (Harpacticoida, Ameiridae): re-examination of the $A$. tenella-group and the establishment of Filexilia gen. n. and Glabrameira gen. n. Zoologica Scripta 25: 317-339.

Conroy-Dalton, S. and Huys, R. (1998). Towards a revision of Ameira Boeck, 1865 (Harpacticoida, Ameiridae): reinstatement of Psammameira Noodt, 1952. Zoologica Scripta 27: 247-261.

Cottarelli, V., Puccetti, A.C. and Saporito, P.E. (1985). Una nuova Parapseudoleptomesochra di acque freatiche della Siria: Parapseudoleptomesochra syriaca n.sp. (Crustacea, Copepoda, Harpacticoida). Fragmenta Entomologica Roma 18: 1-9.

Coull, B.C. (1969). Phyllopodopsyllus hermani, a new species of harpacticoid copepod from Bermuda. Crustaceana 16: 27-32.

Coull, B.C. (1973). Harpacticoid copepods (Crustacea) of the family Tetragonicipitidae Lang: A review and revision, with keys to the genera and species. Proceedings of the Biological Society of Washington 86: 9-24.

Coull, B.C. (1977). Marine flora and fauna of the northeastern United States, Copepoda: Harpacticoida). NOAA Technical Report NHFS Circular 399: 1-48.

Cracraft, J. (1991). Patterns of diversification within continental biotas: hierarchical congruence among the areas of Australian vertebrates. Australian Systematic Botany 4: 211-227.

Crisp, M.D., West, J.G. and Linder, H.P. (1999). Biogeography of the terrestrial Flora. Flora of Australia (2nd end), Canberra 1: 321-368.

Damian-Georgescu, A. (1963). Copepoda, fam. Cyclopidae (forme de apã dulce). Fauna Republicii Populare Romaîne, Crustacea, 4(6): pp. 1-204, Bucharest. 
Danielopol, D.L., Baltanás, A. and Humphreys, W.F. (2000). Danielopolina kornickeri sp. n. (Ostracoda, Thaumatocypridoidea) from a Western Australian anchialine cave - morphology and evolution. Zoologica Scripta 29: 1-16.

Defaye, D. (1988). Contribution à la connaissance des Crustacés Copépodes d'Ethiopie. Hydrobiologia 164: 103-147.

Defaye, D., Dussart, B.H., Fernando, C.H. and Sarnita, A.S. (1987). On some species of the genus Thermocyclops (Crustacea, Copepoda) from the Oriental Region. Canadian Journal of Zoology 65: 3144-3153.

De Laurentiis, P., Pesce, G.L. and Halse, S.A. (1997). Discovery of the first representative of the genus Neocyclops Gurney in Australia, and description of Neocyclops (Neocyclops) petkovskii n.sp. (Copepoda, Halicyclopinae). Bulletin Zoölogisch Museum Universiteit van Amsterdam 16: 15-19.

De Laurentiis, P., Pesce, G.L. and Humphreys, W.F. (1999). Copepods from ground waters of Western Australia, IV. Cyclopoids from basin and craton aquifers (Crustacea: Copepoda: Cyclopidae). Records of the Western Australian Museum 19: 243-257.

Dussart, B. (1967). Les Copépodes des eaux continentales $d^{\prime}$ Europe Occidentale, 1. Calanoides et Harpacticoids. N. Boubée \& Cie, Paris.

Dussart, B.H. (1968). Contribution à l'étude des eaux douces de l'Ennedi. Bulletin de I'T.F.A.N. 30: 127-134.

Dussart, B. (1969). Les Copépodes des eaux continentales d'Europe Occidentale, 2. Cyclopoïdes et Biologie. N. Boubée \& Cie, Paris.

Dussart, B. (1981). Copépodes du bassin du Niger. Bulletin de I'I.F.A.N. 43: 135-169.

Dussart, B.H. (1982). Copépodes des Antilles françaises. Revue d'Hydrobiologie Tropicale 15: 313-324.

Dussart, B. and Defaye, D. (1985). Répertoire Mondial des Copépodes Cyclopoïdes. Centre National de la Recherche Scientifique, Bordeaux.

Dussart, B. and Defaye, D. (1990). Répertoire mondial des crustacés copépodes des eaux intérieures, III. Harpacticoïdes. Crustaceana, Supplement 16: 1-384.

Dussart, B.H. and Fernando, C.H. (1986). The Mesocyclops problem today. Proceedings of the Second International Conference on Copepoda, Ottawa, Canada; Syllogeus 58: 288-293.

Dussart, B.H. and Fernando, C.H. (1998). Sur quelques Mesocyclops (Crustacea, Copepoda). Hydrobiologia 157: 241-264.

Dussart, B.H. and Frutos, S.M. (1985). Sur quelques copépodes d'Argentine. Revue d'Hydrobiologie Tropicale 18: 305-314.

Einsle, U. (1970). Études morphlologiques sur des espéces de Thermocyclops (Crust. Cop.) d'Afrique et d'Europe. Cah. ORSTOM, série Hydrobiologie 4: 1338.

Einsle, U. (1971). Freilebende Copepoden. Resultats Scientifiques de $I^{\prime}$ Exploration Hydrobiologique du Basin du Lac Bangweolo et du Luapula 13: 1-74.

Enckell, P.H. (1970). Parastenocarididae (Copepoda Harpacticoida) from Ceylon. Arkiv för Zoologi 22: 545-556.
Fedchenko, A.P. (1875). Puteschestvie v Turkestan, Entomostraca. Zoogeographicheskiia Izsledovaniia, Moskva 2: 22-61.

Fernando, C.H. and Ponyi, J.E. (1981). The freeliving freshwater cyclopoid Copepoda (Crustacea) of Malaysia and Singapore. Hydrobiologia 78: 113-123.

Fiers, F. (1986). New and interesting copepods (Crustacea, Copepoda) from brackish waters of Laing Island (Northern Papua New Guinea). Bulletin de I'Institut Royal des Sciences Naturelles de Belgique, Biologie 56: 99-120.

Fiers, F. (2001). Meridiecyclops, gen. nov., a new cyclopid genus (Crustacea: Copepoda: Cyclopidae) from southern Australia. Invertebrate Taxonomy 15: 893908.

Fiers, F., Reid, J.W., Iliffe, T.M. and Suárez-Morales, E. (1996). New hypogean cyclopoid copepods (Crustacea) from the Yucatán Peninsula, Mexico. Contributions to Zoology 66: 65-102.

Fox, M.D. (1999). Present environmental influences on the Australian Flora. Flora of Australia (2nd edn) 1 : 205-249, Canberra.

Frakes, L.A. (1999). Evolution of Australian enviroments. Flora of Australia (2nd edn) 1: 163-203. (Canberra)

Galassi, D.M.P. (1997). The genus Pseudectinosoma Kunz, 1935: an update, and description of Pseudectinosoma kunzi sp. n. from Italy (Crustacea: Copepoda: Ectinosomatidae). Archiv für Hydrobiologie 139: 277-287.

Galassi, D.M.P. and De Laurentiis, P. (1997). Pseudectinosoma reductum, a new ectinosomatid harpacticoid from spring waters in Italy (Crustacea: Copepoda). Hydrobiologia 356: 81-86.

Galassi, D.M.P. and De Laurentiis, P. (2004). Towards a revision of the genus Parastenocaris Kessler, 1913: establishment of Simplicaris gen. nov. from groundwaters in central Italy and review of the $P$. brevipes-group (Copepoda, Harpacticoida, Parastenocarididae). Zoological Journal of the Linnean Society 140: 417-436.

Galassi, D.M.P., De Laurentiis, P. and Dole-Olivier, M.-J. (1999). Nitocrellopsis rouchi sp. n., a new ameirid harpacticoid from phreatic waters in France (Copepoda: Harpacticoida: Ameiridae). Hydrobiologia 412: 177-189.

Galassi, D.M.P., De Laurentiis, P. and Petitta, M. (1997) Il genere Pseudectinosoma Kunz (Crustacea, Copepoda, Ectinosomatidae) nei sistemi carsici dell'Appennino centrale e meridionale: Problematiche ecologiche e biogeografiche. In G. Belmonte, G. Ciccarese and L. Ruggiero, L. (eds) II carsismo dell'Area Mediterranea: Geologia Paleogeografia Biologia, pp. 115-127, Universitá di Lecce, Lecce.

Galassi, D.M.P., Dole-Olivier, M.-J. and De Laurentiis, P. (1999). Phylogeny and biogeography of the genus Pseudectinosoma, and description of $P$. janineae $\mathrm{sp}$. n. (Crustacea, Copepoda, Ectinosomatidae). Zoologica Scripta 28: 289-303.

Galassi, D.P. and Pesce, G.L. (1988). New localities of Elaphoidella nuragica Pesce and Galassi, with a description of the female (Copepoda Harpacticoida: Canthocamptidae). Bollettino del Museo Civico di Storia Naturale di Verona 14: 311-314. 
Gaviria, S. (1994). Los Copepodos (Arthropoda, Crustacea) de vida libre de las aguas continentales de Colombia. Revista de la Academia Colombiana de Ciencias Exactas, Físicas y Natural 19: 361-385.

Gaviria, S. (1998). Checklist and distribution of the freeliving copepods (Arthropoda: Crustacea) from Austria. Annalen des Naturhistorischen Museums in Wien, Serie B 100: 539-594.

Ghenne, V. and Fiers, F. (2000). On Mesocyclops iranicus Lindberg, 1936 (Copepoda: Cyclopoida) and the cyclopoid collection made by Knut Lindberg during his 1935 visit to Iran. Annales Zoologici Warszawa 50: 93-98.

Gourbault, N. and Lescher-Moutoué, F. (1979). Faune des eaux souterraines de Mojorque. Endins 5/6: 43-54.

Gurney, R. (1921). Freshwater Crustacea collected by Pr. P.A. Buxton in Mesopotamia and Persia. Journal of the Bombay natural History Society 27: 835-843.

Gurney, R. (1928). Some Copepoda from Tanganyika collected by Mr S.R.B. Pask. Proceedings of the Zoological Society of London Aar 1928: 317-332.

Halse, S.A., Cale, D.J., Jasinska, E.J. and Shiel, R.J. (2002a). Monitoring change in aquatic invertebrate biodiversity: sample size, faunal elements and analytical methods. Aquatic Ecology 36: 395-410.

Halse, S.A., Pearson, G.B., McRae, J.M. and Shiel, R.J. (2000a). Monitoring aquatic invertebrates and waterbirds at Toolibin and Walbyring Lakes in the Western Australian wheatbelt. Journal of the Royal Society of Western Australia 83: 17-28.

Halse, S.A., Scanlon, M.D. and Cocking, J.S. (2002b). Do springs provide a window to the groundwater fauna of the Australian arid zone? In D. Yinfoo (ed.), Balancing the groundwater budget: Proceedings of an International Groundwater Conference, Darwin 2002, pp. 1-12. International Association of Hydrogeologists, Darwin.

Halse, S.A., Shiel, R.J. and Pearson, G.B. (1996). Waterbirds and aquatic invertebrates of swamps on the Victoria-Bonaparte mudflat, northern Western Australia. Journal of the Royal Society of Western Australia 79: 217-224.

Halse, S.A., Shiel, R.J., Storey, A.W., Edward, D.H.D., Lansbury, I., Cale, D.J. and Harvey, M.S. (2000b). Aquatic invertebrates and waterbirds of wetlands and rivers of the southern Carnarvon Basin, Western Australia. Records of the Western Australian Museum Supplement 61: 217-265.

Halse, S.A., Shiel, R.J. and Williams, W.D. (1998). Aquatic invertebrates of Lake Gregory, northwestern Australia, in relation to salinity and ionic composition. Hydrobiologia 381: 15-29.

Hamond, R. (1987). Non-marine harpacticoid copepods of Australia, I. Canthocamptidae of the genus Canthocamptus Westwood s. lat. and Fibulacamptus, gen. nov., and including the description of a related new species of Canthocamptus from New Caledonia. Invertebrate Taxonomy 1: 1023-1247.

Heip, C., Herman, R. and Vincx, M. (1983). Subtidal meiofauna of the North Sea: a review. Biologisch Jahrboek 51: 116-170.

Henry, M. (1919). On some Australian freshwater
Copepoda and Ostracoda. Journal of the Royal Society of New South Wales 53: 29-48.

Henry, M. (1923). A monograph of the freshwater Entomostraca of New South Wales, part II, Copepoda. Proceedings of the linnean Society of New South Wales 47: 551-570.

Heberer, G. and Kiefer, F. (1932). Zur Kenntnis der Copepodenfauna der Sunda Inseln. Archiv für Naturgeschichte Berlin 1: 225-274.

Herbst, H.-V. (1986). Beschreibung des Thermocyclops hastatus antillensis $s$. ssp. mit einem Bestimmungsschlüssel für die Gattung Thermocyclops Kiefer, 1927. Bijdragen tot de Dierkunde 56: 165-180.

Holthuis, L.B. (1960). Two new species of atyid shrimps from subterranean waters in N.W. Australia (Decapoda: Natantia). Crustaceana 1: 47-57.

Holyńska, M. (2000). Revision of the Australasian species of the genus Mesocyclops Sars, 1914 (Copepoda: Cyclopidae). Annales Zoologici Warszawa 50: 363447.

Holyńska, M. and Brown, M. (2003). Three new species of Mesocyclops G. O. Sars, 1914 (Copepoda, Cyclopoida) from Australia and Burma, with comments on the Mesocyclops fauna of Australia. Crustaceana 75: 1301-1334.

Howarth, F.G. (1980). The zoogeography of specialized cave animals: a bioclimatic model. Evolution 34: 394 406.

Hudson, P.L., Reid, J.W., Lesko, L.T. and Selgeby, J.H. (1998). Cyclopoid and harpacticoid copepods of the Laurentian Great Lakes. Bulletin of the Ohio Biological Survey, new series 12: 1-50.

Humes, A.G. (1947). A new cyclopoid copepod from a Bornean crustacean. Transactions of the American Microscopical Society 66: 293-301.

Humphreys, W.F. (1993). Stygofauna in semi-arid tropical Western Australia: a Tethyan connection? Mémoires de Biospéologie 20: 111-116.

Humphreys, W.F. (1999). Relict stygofauna living in sea salt, karst and calcrete habitats in arid northwestern Australia contain many ancient lineages. In $\mathrm{W}$. Ponder and D. Lunney, (eds). The other 99\%, the conservation and biodiversity of Invertebrates. pp. 219-227. Transaction of the Royal Zoological Society of New South Wales, Mosman.

Humphreys, W.F. (2000a). Karst wetlands biodiversity and continuity through major climatic change: an example from arid tropical Western Australia. In B. Gopal, W.J. Junk and J.A. Davis, (eds). Biodiversity in wetlands: assessment, function and conservation, vol. 1. pp 227-258. Backhuys Publishers, Leiden.

Humphreys, W.F. (2000b). Background and glossary. In H. Wilkens, D.C. Culver and W.F. Humphreys, (eds). Ecosystems of the World, 30: Subterranean Ecosystems. pp. 3-14. Elsevier, Amsterdam.

Humphreys, W.F. (2001). Groundwater calcrete aquifers in the Australian arid zone: the context to an unfolding plethora of stygal biodiversity. Records of the Western Australian Museum Supplement 64: 6383.

Humphreys, W.F. and Adams, M. (1991). The 
subterranean aquatic fauna of the North West Cape peninsula, Western Australia. Records of the Western Australian Museum 15: 383-411.

Huys, R. and Boxshall, G.A. (1991). Copepod Evolution. The Ray Society, London.

Huys, R., Gee, J.M., Moore, C.G. and Hamond, R. (1996). Marine and Brackish Water Harpacticoid Copepods. In Barnes, R.S.K. and Crothers, J.H. (Eds). Synopses of the British Fauna (new ser.) 51, Field Studies Council, Shrewsbury.

ICZN (1999). Fourth edition. The International Trust for Zoological Nomenclature, London.

Ishida, T. (2002a). The second species of Ochridacyclops Kiefer, 1937 (Copepoda, Cyclopoida) from Japan. Biogeography 4: 19-23.

Ishida, T. (2002b). Illustrated Fauna of the freshwater cyclopoid copepods of Japan. Bulletin of the Biogeographical Society of Japan 57: 37-106.

Ito, T. (1954). Cyclopoida copepods of Japanese subterranean waters. Report of Faculty of Fisheries Prefectual University of Mie 1: 372-416.

Ito, T. (1957). Groundwater copepods from south-western Japan. Hydrobiologia 11: 1-28.

Jackson, M.J. (1977). Relict Early Caenozoic drainages in arid Western Australia. Zeitschrift für Geomorphologie 21: 379-400.

Jaume, D., Boxshall, G.A. and Humphreys, W.A. (2001). New stygobiont copepods (Calanoida; Misophrioida) from Bundera Sinkhole, an anchialine cenote in northwestern Australia. Zoological Journal of the linnean Society 133: 1-24.

Jaume, D. and Humphreys, W.F. (2001). A new genus of epacteriscid calanoid copepod from an anchialine sinkhole on northwestern Australia. Journal of Crustacean Biology 21: 157-169.

Johnson, M.W. (1953). The copepod Cyclops dimorphus Kiefer from the Salton Sea. American Midland Naturalist 49: 188-192.

Karanovic, I. and Marmonier, P. (2003). Three new genera and nine new species of the subfamily Candoninae (Crustacea, Ostracoda, Podocopida) from the Pilbara Region (Western Australia). Beaufortia 53: $1-51$.

Karanovic, T. (1998). Two interesting species of the genus Elaphoidella Chappuis, 1929 (Crustacea, Copepoda) from Balkan Peninsula. Mémoires de Biospéologie 25: 25-33.

Karanovic, T. (1999a). The taxonomic status of Attheyella (B.) wulmeri (Kerhervé, 1914) (Crustacea: Copepoda: Harpacticoida). Annales de Limnologie 35: 233-244.

Karanovic, T. (1999b). First record of Metacyclops stammeri Kiefer, 1938 from Balkan Peninsula (Crustacea, Copepoda). Spixiana 22: 193-198.

Karanovic, T. (2000). On Reidcyclops, new genus (Crustacea, Copepoda), with the first description of the male of Reidcyclops trajani (Reid and Strayer, 1994), new combination. Beaufortia 50: 79-88.

Karanovic, T. (2001a). Elaphoidella uva n.sp. (Crustacea, Copepoda) and two other interesting species of the genus Elaphoidella from Montenegro (SE Europe). Beaufortia 51: 57-74.

Karanovic, T. (2001b). Description of Allocyclops montenegrinus, spec. nov. and a revision of the genus Allocyclops Kiefer, 1932. Spixiana 24: 19-27.

Karanovic, T. (2003). First representative of the genus Allocyclops Kiefer, 1932 (Crustacea, Copepoda, Cyclopoida) from the Australian subterranean waters. Annales de Limnologie 39: 141-149.

Karanovic, T. (2004a). Subterranean Copepoda from arid Western Australia. Crustaceana Monographs 3: 1366.

Karanovic, T. (2004b). The genus Metacyclops Kiefer in Australia (Crustacea: Copepoda: Cyclopoida), with description of two new species. Records of the Western Australian Museum 22: 193-212.

Karanovic, T. (2005). Two new subterranean Parastenocarididae (Crustacea, Copepoda, Harpacticoida) from Western Australia. Records of the Western Australian Museum 22: 353-374.

Karanovic, T. and Pesce, G.L. (2001). A new genus and species of the family Ectinosomatidae (Crustacea: Copepoda: Harpacticoida) from the groundwaters of India. Annales de Limnologie 37: 281-292.

Karanovic, T., Pesce, G.L. and Humphreys, W.F. (2001). Copepods from ground waters of Western Australia, V. Phyllopodopsyllus wellsi sp. nov. (Crustacea: Copepoda: Harpacticoida) with a key to world species. Records of the Western Australian Museum 20: 333-344.

Karanovic, T. and Ranga Reddy, Y. (2004a). A new genus and species of the family Diosaccidae (Copepoda: Harpacticoida) from the groundwaters of India. Journal of Crustacean Biology 24: 246-260.

Karanovic, T. and Ranga Reddy, Y. (2004b). First record of Phyllognathopus bassoti Rouch, 1972 from India, with remarks on the family Phyllognathopodidae Gurney, 1932 (Crustacea, Copepoda, Harpacticoida). Annales de Limnologie 40: 121-132.

Karaytug, S. and Boxshall, G.A. (1996). The life cycle of Paracyclops fimbriatus (Fischer, 1853) (Copepoda, Cyclopoida). Bulletin of the Natural History Museum London, Zoology 62: 41-70.

Karaytug, S. and Boxshall, G.A. (1998a). Partial revision of Paracyclops Claus, 1893 (Copepoda, Cyclopoida, Cyclopidae) with descriptions of four new species. Bulletin of the Natural History Museum London, Zoology 64: 111-205.

Karaytug, S. and Boxshall, G.A. (1998b). The Paracyclops fimbriatus-complex (Copepoda, Cyclopoida): a revision. Zoosystema 20: 563-602.

Karaytug, S. and Boxshall, G.A. (1998c). The female antennules of Paracyclops (Cyclopoida: Cyclopidae): their significance for systematics. Journal of Marine Systems 15: 397-400.

Karaytug, S. and Boxshall, G.A. (1999). Antennules of the male of Paracyclops (Copepoda): functional significance and their importance in systematics. Journal of Crustacean Biology 19: 371-379.

Karaytug, S., Boxshall, G.A. and Ishida, T. (1996). A new species of Ochridacyclops (Kiefer, 1937) (Copepoda, Cyclopoida) from Japan. Hydrobiologia 332: 111-117.

Karaytug, S., Defaye, D. and Boxshall, G.A. (1998). Two new species of Paracyclops (Copepoda: Cyclopoida, Cyclopidae) from Africa. Hydrobiologia 382: 119-136. 
Kiefer, F. (1927). Versuch eines Systems der Cyclopiden. Zoologischer Anzeiger 73: 302-308.

Kiefer, F. (1928a). Crustacea I, Copepoda aquae dulcis. Faune des Colonies francaises 1: 535-570.

Kiefer, F. (1928b). Zur kenntnis der Mikrofauna von Britisch Indien. Records of the Indian Museum Calcuta 30: 387-398.

Kiefer, F. (1928c). 2. Beiträge zur Copepodenkunde (VIII). Zoologischer Anzeiger 76: 5-18.

Kiefer, F. (1929a). Crustacea Copepoda, 2. Cyclopoida Gnathostoma. Das Tierreich 53: 1-102.

Kiefer, F. (1929b). Zur Kenntnis einiger Artengruppen der Süßwasser-Cyclopiden. Zeitschrift für wissenschaftliche Zoologie 133: 1-56.

Kiefer, F. (1929c). Neue Ruderfußkrebse von den SundaInseln. Zoologischer Anzeiger 84: 46-49.

Kiefer, F. (1930a). Neue Ruderfußkrebse von den SundaInseln. Zoologischer Anzeiger 86: 185-189.

Kiefer, F. (1930b). Neue Cyclopiden von den SundaInseln. Zoologischer Anzeiger 89: 319-322.

Kiefer, F. (1931). Die Untergattung Tropocyclops der Gattung Eucyclops (Copepoda Cyclopoida). Zeitschrift für wissenschaftliche Zoologie 138: 487514.

Kiefer, F. (1932). Neue Süßwassercopepoden aus Jugoslawien. Zoologischer Anzeiger 101: 49-60.

Kiefer, F. (1933). Die freilebenden Copepoden der Binnengewässer von Insulinde. Archiv für Hydrobiologie Supplement 12: 519-621.

Kiefer, F. (1934a). Neue Ruderfuâkrebse aus Nordamerica. Zoologischer Anzeiger 107: 269-271.

Kiefer, F. (1934b). Die freilebenden Copepoden Südafrikas. Zoologischer Jahresbericht 65: 99-192.

Kiefer, F. (1937). Ein neuer Cyclopide (Crust. Copepoda) aus dem Ochridasee. Zoologischer Anzeiger 120: 137143.

Kiefer, F. (1938a). Freilebende Ruderfusskrebse (Crustacea Copepoda) von Formosa. Bulletin of the Biogeographical Society of Japan 8: 35-73.

Kiefer, F. (1938b). Ruderfußkrebse (Crust. Cop.) aus Mexico. Zoologischer Anzeiger 123: 274-280.

Kiefer, F. (1944). Freilebende Ruderfuâkrebse (Crust. Cop.) von einigen Inseln des Indischen Ozeans. Zoologischer Anzeiger 145: 79-88.

Kiefer, F. (1949). The Armstrong College Zoological Expedition to Siwa Oasis (Libyan Desert) 1935, Freilebende Ruderfuszkrebse (Crustacea Copepoda). Proceedings of the Egyptian Academy of Sciences 4: 62-112.

Kiefer, F. (1956). Freilebende Ruderfusskrebse (Crustacea Copepoda), I. Calanoida und Cyclopoida. In Gessner, $\mathrm{F}$ and Vareschi, V. (Eds), Ergebnisse der deutschen limnologischen Venezuela-Expedition 1952 1, pp. 233-268. Deutscher Verlag der Wissenschaften, Berlin.

Kiefer, F. (1960a). Ruderfusskrebse (Copepoden). Kosmos, Stuttgart.

Kiefer, F. (1960b). Psammobionte Ruderfuâkrebse (Crust. Cop.) aus dem Gebiet der Unterweser und von der Insel Helgoland. Zoologischer Anzeiger 165: 30-37.

Kiefer, F. (1962). Eine kleine Copepodenausbeute
(Crustacea Copepoda) aus der Republik Kongo. Bulletin de I'Institut de Recherches Scientifiques au Congo 1: 119-122.

Kiefer, F. (1967). Cyclopiden aus salzhaltigen Binnengewässern australiens (Copepoda). Crustaceana 12: 292-302.

Kiefer, F. (1969). Eine neue Paracyclops-Art (Crustacea Copepoda) aus Australien. Zoologischer Anzeiger 182: 91-94.

Kiefer, F. (1978). Copepoda non-parasitica. In J. Illies, (ed.), Limnofauna Europaea (2nd end), pp 209-225. Gustav Fischer Verlag and Swets \& Zeitlinger B.V., Stuttgart.

Kiefer, F. (1981). Beitrag zur Kenntnis von Morphologie, Taxonomie und geographischer Verbreitung von Mesocyclops leuckarti auctorum. Archiv für Hydrobiologie Supplementband 62: 148-190.

Kiefer, F. and Fryer, G. (1978). Das Zooplankton der Binnengewässer, 2. Teil. E. Schweizerbart'sche Verlagsbuchhandlung, Stuttgart.

Kikuchi, Y. (1970). A new species of Parastenocaris (Harpacticoida) from a sandy beach of the Lake Hinuma. Annotationes Zoologicae Japonenses 43: 170-173.

Knott, B. and Halse, S.A. (1999). Pilbarophreatoicus platyarthricus n.gen., n.sp. (Isopoda: Phreatoicidea: Amphisopidae) from the Pilbara region of Western Australia. Records of the Australian Museum 51: 33 42.

Kunz, H. (1935). Zur Oekologie der Copepoden Schleswig-Holsteins und der Kieler Bucht. Schriften des Naturwissenchaftlichen Vereins für SchleswingHolstein 21: 84-132.

Kunz, H. (1975). Copepoda Harpacticoidea aus dem Litoral des südlichen Afrika. Kieler Meeresforschungen 31: 179-212.

Kunz, H. (1984). Fünf Beiträge zur Kanntnis mariner Harpacticoida. Mitteilungen aus dem Zoologischen Museum der Universität Kiel 2: 1-56.

Lang, K. (1935). Undersökningar över Öresund, Untersuchungen aus dem Öresund 18, Ameira arenicola n. sp. (Copepoda, Harpacticoida) nebst Bemerkungen über die Gattung Ameira und ihr nahe stehene Gattungen. Acta Universitatis Lundensis (nov. ser.) 31: 1-12.

Lang, K. (1936). Beiträge zur Kenntnis der Harpacticiden, 6. Bemerkungen über die Familie der Ameiridae Monard. Zoologischer Anzeiger 114: 133-136.

Lang, K. (1944). Monographie der Harpacticiden (Vorläufige Mitteilung). Almquist and Wiksells Boktryckeri AB, Uppsala.

Lang, K. (1948). Monographie der Harpacticiden. Nordiska Bokhandeln A-B, Lund.

Lang, K. (1965). Copepoda Harpacticoida from the Californian Pacific coast. Kungl. Svenska Vetenskapsakademiens Handlingar 10: 1-560.

Lee, W. and Huys, R. (2002). A new genus of groundwater Ameiridae (Copepoda, Harpacticoida) from boreholes in Western Australia and the artificial status of Stygonitocrella Petkovski, 1976. Bulletin of the Natural History Museum, London (Zoology) 68: 39-50. 
Lewis, M.H. (1974). Paracyclops waiariki n.sp. (Copepoda: Cyclopoida) from thermal waters in Rotorua. New Zealand Journal of Marine and Freshwater Research 8: 275-281.

Lindberg, K. (1942). Cyclopides (Crustacés Copépodes) de l'Inde XIV-XVIII. Records of the Indian Museum in Calcuta 44: 139-190.

Lindberg, K. (1948). Deux Cyclopides (Crustacés Copépodes) nouveaux de l'Australie. Bulletin de la Societe Zoologique de France 73: 71-76.

Lindberg, K. (1952). Cyclopides (Crustacés Copépodes) du Royaume du Cambodge. Bulletin de Institut royal des Sciences naturelles de Belgique 28: 1-16.

Lindberg, K. (1953). Cyclopides (Crustacés Copépodes) de l'Australia. Lunds Universitets Årsskrift (n.f.) 49: $1-8$.

Lindberg, K. (1954). Cyclopides (Crustacés copépodes) d'îles du Pacifique Sud (Mélanésie et Micronésie) et de Bornéo. Kungl. Fysiografiska Sällskapets i Lund Förhandlingar 24: 1-14.

Löffler, H. (1968). Die Crustaceenfauna der Binnengewässer ostafrikanischer Hochberge. Hochgebirgsforschung 1: 107-170.

Marsh, C.D. (1910). A revision of the North American species of Cyclops. Transactions of the Wisconsis Academy of Sciences, Arts and Letters 16: 10671136.

Martinez Arbizu, P. and Moura, G. (1994). The phylogenetic position of the Cylindropsyllinae Sars (Copepoda, Harpacticoida) and the systematic status of the Leptopontiinae Lang. Zoologische Beiträge 35: $55-77$.

Marwick, B. (2002). Milly's Cave: Evidence for human occupation of the inland Pilbara during the Last Glacial Maximum. Tempus 7: 21-33.

Mazepova, G.F. (1950). K poznaniu fauny Cyclopoida oz. Baykal. Doklady Akademii Nauk SSSR 72: 809-812.

Mielke, W. (1989). Interstitielle Fauna von Galapagos, XXXVI. Tetragonicipitidae (Harpacticoida). Microfauna Marina 5: 95-172.

Mielke, W. (1995). Interstitial copepods (Crustacea) from the Caribbean coast of Venezuela. Microfauna Marina 10: $41-65$.

Miura, Y. (1962). Subterranean harpacticoid copepods of the Amami Group of the Ryukyu Islands. Annotationes Zoologicae Japonenses 35: 95-105.

Miura, Y. (1969). A new harpacticoid copepod from a sandy beach of Lake Biwa. Annotationes Zoologicae Japonenses 42: 40-44.

Monchenko, V.I. (1974). Schelepnoroti Ciklopopodibni Ciklopi (Cyclopidae). Fauna Ukraïni 27(3): pp. 1-452. (Kiev)

Monchenko, V.I. (1977a). On a strong modificated new copepod Colpocyclops dulcis gen. et sp. n. (Crustacea, Cyclopidae). Vestnik Zoologii 6 (1977): 25-32. [in Russian]

Monchenko, V.I. (1977b). Smirnoviella reducta gen. et sp. n. (Crustacea, Copepoda) from the Dniestr Estuary (Black Sea Basin). Zoologicheskii Zchurnal 61: 14021406. [in Russian]

Monchenko, V.I. (1978). Halicyclops longispinosus transference to the genus Colpocyclops (Crustacea,
Copepoda) and first description of its males. Vestnik Zoologii 5 (1978): 68-72. [in Russian]

Monchenko, V.I. (1982). Rod Smirnoviella (Crustacea, Cyclopidae) v Kaspiiskom more s opisaniem novogo vida. Vestnik Zoologii 3 (1982): 12-15.

Monchenko, V.I. (2000). Cryptic species in Diacyclops bicuspidatus (Copepoda: Cyclopoida): evidence from crossbreeding studies. Hydrobiologia 417: 101-107.

Monchenko, V.I. (2003). New north records, redescription and halopathy of Apocyclops dengizicus (Copepoda, Cyclopoida). Vestnik Zoologii 37: 79-84.

Monchenko, V.I. and Von Vaupel Klein, J.C. (1999). Oligomerization in Copepoda Cyclopoida as a kind of orthogenetic evolution in the Animal Kingdom. Crustaceana 72: 241-264.

Morton, D.W. (1985). Revision of the Australian Cyclopidae (Copepoda: Cyclopoida), I. Acanthocyclops Kiefer, Diacyclops Kiefer and Australocyclops, gen. nov. Australian Journal of Marine and Freshwater Research 36: 615-634.

Morton, D.W. (1990). Revision of the Australian Cyclopidae (Copepoda: Cyclopoida), II. Eucyclops Claus and Ectocyclops Brady. Australian Journal of Marine and Freshwater Research 41: 657-675.

Noodt, W. (1955). Harpacticiden (Crust. Cop.) aus dem Sandstrand der französischen Biscaya-Küste. Kieler Meeresforschungen 11: 86-109.

Pallares, R.E. (1982). Un nuevo genero para le familia Ameiridae (Copepoda, Harpacticoida). Contribución Científica del Centro de Investigación de Biología Marina (CIBIMA) Buenos Aires 199: 1-9.

Pennak, R.W. (1939). A new copepod from the sandy beaches of a Wisconsin lake. Transactions of the American Microscopic Society 58: 224-227.

Pesce, G.L. (1980). Ricerche faunistiche in aque freatiche delle Marche e stato attuale delle conoscenze sulla fauna interstiziale Italiana. Rivista di Idrobiologia 19: 547-591.

Pesce, G.L. (1994). The genus Diacyclops Kiefer in Italy: a taxonomic, ecological and biogeographical up-to-date review (Crustacea Copepoda Cyclopidae). Arthropoda Selecta 3: 13-19.

Pesce, G.L. (1996). Towards a revision of Cyclopinae copepods (Crustacea, Cyclopidae). Fragmenta Entomologica Roma 28: 189-200.

Pesce, G.L. and De Laurentiis, P. (1996). Copepods from ground waters of Western Australia, III. Diacyclops humphreysi n.sp. and comments on the Diacyclops crassicaudis complex (Copepoda, Cyclopidae). Crustaceana 69: 524-531.

Pesce, G.L., De Laurentiis, P. and Humphreys, W.F. (1996a). Copepods from ground waters of Western Australia, I. The genera Metacyclops, Mesocyclops, Microcyclops and Apocyclops (Crustacea: Copepoda: Cyclopidae). Records of the Western Australian Museum 18: 67-76.

Pesce, G.L., De Laurentiis, P. and Humphreys, W.F. (1996b). Copepods from ground waters of Western Australia, II. The genus Halicyclops (Crustacea: Copepoda: Cyclopidae). Records of the Western Australian Museum 18: 77-85.

Pesta, O. (1928). Die Tierwelt Deutschlands und der 
angrenzenden Meeresteile nach ihren Merkmalen und nach ihrer Lebensweise; Krebstiere oder Crustacea, 1. Ruderfüâer oder Copepoda (1. Calanoida, 2. Cyclopoida). Verlag von Gustav Fischer, Jena.

Petkovski, T. (1954). Beitrag zur Kenntnis der jugoslavischen Cyclopiden. Acta Musei Macedonici Scientiarum Naturalium 12(4): 1-31.

Petkovski, T.K. (1955a). IV Beitrag zur Kenntnis der Copepoden. Acta Musei Macedonici Scientiarum Naturalium 3(3): 71-104.

Petkovski, T.K. (1955b). Zweiter Beitrag zur Kenutnis der Harpacticiden-fauna unserer Meeresküste. Fragmenta Balcanica Musei Macedonici Scientiarum Naturalium 1(15): 125-139.

Petkovski, T.K. (1957). VI Beitrag zur Kenntnis der Grundwasser-copepoden unserer Meeresküste. Izdanija Institut de Pisciculture de la RP Macédonie 2(1): $1-16$.

Petkovski, T.K. (1969). Marine Harpacticoiden aus dem Küstensand von Bulgarien. Acta Musei Macedonici Scientiarum Naturalium 11(6): 111-129.

Petkovski, T.K. (1976). Drei neue Nitocrella-Arten von Cuba, zugleich eine Revision des Genus Nitocrella Chappuis (s. restr.) (Crustacea, Copepoda, Ameiridae). Acta Musei Macedonici Scientiarum Naturalium 15(1): 1-26.

Petkovski, T.K. (1985). Etude sur quelques Copepodes Harpacticoides du genre Elaphoidella Chappuis, 1929 de Bulgarie avec une révision du genre. Acta Musei Macedonici Scientiarum Naturalium 17(7): 133-164.

Petkovski, T.K. (1986a). Zur Taxonomie des Genus Mesocyclops G. O. Sars 1914 (Crustacea, Copepoda, Cyclopoida) in der Neotropis. Acta Musei Macedonici Scientiarum Naturalium 18(3): 47-79.

Petkovski, T.K. (1986b). Zur Taxonomie des Genus Neocyclops Gurney 1927 (Crustacea, Copepoda, Cyclopoida). Acta Musei Macedonici Scientiarum Naturalium 18(2): 27-46.

Petkovski, T.K. and Brancelj, A. (1988). Elaphoidella serbica n.sp., ein neuer Harpacticoide aus Ostserbien (Crustacea, Copepoda). Fragmenta Balcanica Musei Macedonici Scientiarum Naturalium 14(6): 47-58.

Pinder, A.M., Halse, S.A., McRae, J.M. and Shiel, R.J. (2004). Aquatic invertebrate assemblages of wetlands and rivers in the Wheatbelt region of Western Australia. Records of the Western Australian Museum Supplement 67: 7-37.

Playford, P. (2003). The Permo-Carboniferous glaciation of Gondwana: its impact on Western Australia. Western Wildlife 7: 1-5.

Pleşa, C. (1956). Contributii la fauna ciclopidelor (Crustacee Copepode) din Republica Popularã Romûnã. Analele Institutului de Cercetãri Piscicole 1: 363-372.

Pleşa, C. (1971). Contribution à la connaissance des Cyclopides (Crustacea, Copepoda) des grottes et des eaux interstitielles de Suisse. Revue Suisse de Zoologie 78: 833-850.

Pleşa, C. (1981). Cyclopides (Crustacea, Copepoda) de Cuba. Résultats des expeditions biospéologiques cubano-roumaines à Cuba (Editura Academiei Republicii Socialiste Romania) 3: 17-34.
Poore, G.C.B. and Humphreys, W.F. (1992). First record of Thermosbaenacea (Crustacea) from the Southern Hemisphere: a new species from a cave in tropical Western Australia. Invertebrate Taxonomy 6: 719725.

Poore, G.C.B. and Humphreys, W.F. (1998). The first record of the Spelaeogriphacea (Crustacea) from Australasia: a new genus and species from an aquifer in the arid Pilbara of Western Australia. Crustaceana 71: 721-742.

Pospisil, P. and Stoch, F. (1997). Rediscovery and redescription of Austriocyclops vindobonae Kiefer, 1964 (Copepoda, Cyclopoida) with remarks on the subfamily Eucyclopinae Kiefer. Crustaceana 70: 901910.

Ranga Reddy, Y. (2001). Discovery of Parastenocarididae (Copepoda, Harpacticoida) in India, with the description of three new species of Parastenocaris Kessler, 1913, from the River Krishna at Vijayawada. Crustaceana 74: 705-733.

Reid, J.W. (1985). Chave de identificação e lista de referências bibliográficas para as espécies continentais Sulamericanas de vida livre da ordem Cyclopoida (Crustacea, Copepoda). Boletim de Zoologia, Universidade de São Paulo 9: 17-143.

Reid, J.W. (1990). Canthocamptus (Elaphoidella) striblingi, new species (Copepoda: Harpacticoida) from Costa Rica. Proceedings of the Biological Society of Washington 103: 336-340.

Reid, J.W. (1991a). Diacyclops albus n.sp. and Parastenocaris palmerae n.sp. (Crustacea: Copepoda) from the meiofauna of a stream bed in Virginia, U.S.A. Canadian Journal of Zoology 69: 2893-2902.

Reid, J.W. (1991b). Some species of Tropocyclops (Crustacea, Copepoda) from Brazil, with a key to the American species. Bijdragen tot de Dierkunde 61: 315.

Reid, J.W. (1992). Copepoda (Crustacea) from fresh waters of the Florida Everglades, U.S.A., with a description of Eucyclops conrowae n. sp. Transactions of the American Microscopical Society 111: 229-254.

Reid, J.W. (1993a). New records and redescriptions of American species of Mesocyclops and of Diacyclops bernardi (Petkovski, 1986) (Copepoda: Cyclopoida). Bijdragen tot de Dierkunde 63: 173-191.

Reid, J.W. (1993b). Diacyclops virginianus, a new species of Cyclopoida (Crustacea: Copepoda) from Goose Creek, Virginia. The Maryland Naturalist 37: 36-45.

Reid, J.W. (1995). Redescription of Parastenocaris brevipes Kessler and description of a new species of Parastenocaris (Copepoda: Harpacticoida: Parastenocarididae) from the U.S.A. Canadian Journal of Zoology 73: 173-187.

Reid, J.W. (2002). First confirmed New World recod of Apocyclops dengizicus (Lepeshkin), with a key to the species of Apocyclops in North America and the Caribbean Region (Crustacea: Copepoda: Cyclopidae). Jeffersoniana 10 (2002): 1-25.

Reid, J.W. (2004). New records and new species of the genus Diacyclops (Crustacea; Copepoda) from subterranean habitats in southern Indiana, USA. Jeffersoniana 12 (2004): 1-65. 
Reid, J.W., Hunt, G.W. and Stanley, E.H. (2003). A new species of Stygonitocrella (Crustacea: Copepoda: Ameiridae), the first report of the genus in North America. Proceedings of the Biological Society of Washington 116: 996-1006.

Reid, J.W. and Ishida, T. (1993). New species and records of the genus Elaphoidella (Crustacea: Copepoda: Harpacticoida) from the United States. Proceedings of the Biological Society of Washington 106: 137-146.

Reid, J.W. and Janetzky, W. (1996). Colonization of jamaican bromeliads by Tropocyclops jamaicensis $n$. sp. (Crustacea: Copepoda: Cyclopoida). Invertebrate Biology 115: 305-320.

Reid, J.W. and Strayer, D.L. (1994). Diacyclops dimorphus, a new species of copepod from Florida, with comments on morphology of interstitial cyclopine cyclopoids. Journal of the North American Benthological Society 13: 250-265.

Rocha, C.E.F. (1995). Copepods of the genus Halicyclops (Cyclopidae) from Belize. Hydrobiologia 308: 1-11.

Rocha, C.E.F. and Iliffe, T.M. (1994). Troglocyclops janstocki, new genus, new species, a very primitive cyclopid (Copepoda: Cyclopoida) from an anchialine cave in the Bahamas. Hydrobiologia 292/293: 105-111.

Rocha, C.E.F., Iliffe, T.M., Reid, J.W. and Suárez-Morales, E. (1998). A new species of Halicyclops (Copepoda, Cyclopoida, Cyclopidae) from cenotes of the Yucatan peninsula, Mexico, with and identification key for the species of the genus from the Caribbean Region and adjacent areas. Sarsia 83: 387-399.

Rocha, C.E.F., Iliffe, T.M., Reid, J.W. and Suárez-Morales, E. (2000). Prehendocyclops, a new genus of the subfamily Halicyclopinae (Copepoda, Cyclopoida, Cyclopidae) from cenotes of the Yucatan Peninsula, Mexico. Sarsia 85: 119-140.

Rouch, R. (1969). Recherches sur les eaux souterraines, 6. Sigmatidium vandeli n. sp., Ectinosomidae des eaux souterraines continentales. Annales de Spéléologie 24: 421-429.

Rouch, R. (1986a). Copepoda: les Harpacticoïdes souterrains des eaux douces continentales. In $\mathrm{L}$. Botosaneanu, (ed.), Stygofauna Mundi, A faunistic, distributional and ecological synthesis of the World Fauna inhabiting subterraenan waters (including the marine interstitial), pp. 321-355. E.J. Brill / Dr. W. Backhuys, Leiden.

Rouch, R. (1986b). Quelques nouvelles Parapseudoleptomesochra Lang, 1965 (Harpacticoidea, Ameiridae) des eaux souterraines du sud de l'Espagne. Stygologia 2: 217-253.

Rouch, R. (1992). Un nouveau genre d'Ameiridae (Copepoda, Harpacticoida) dans le milieu hyporhéique d'un cours d'eau de l'Arizona. Stygologia 7: 149-157.

Rouch, R. and Chappuis, P.A. (1960). Sur quelques Copépodes Harpacticoides de lac Tanganyika. Revue de Zoologie et de Botanique Africaines 61: 283-286.

Rylov, V.M. (1948). Cyclopoida presnyh vod. Fauna SSSR, Rakoobraznye, 3(3): pp. 1-318. (Moscow Leningrad)

Sars, G.O. (1863). Oversigt af de indenlandske Ferskvandscopepoder. Forhandlinger i VidenskabsSelskabet i Christiana Aar 1862: 212-262.
Sars, G.O. (1896). On fresh-water Entomostraca from the neighbourhood of Sydney, partly raised from dried mud. Archiv für Mathematik og Naturvidenskab 18: $1-81$.

Sars, G.O. (1909). Zoological results of the third Tanganyika expedition, report on the Copepoda. Proceedings of the Zoological Society of London Aar 1909: 31-77.

Sars, G.O. (1911). Copepoda Harpacticoida, Parts 33 and 34, supplement (continued). An account of the Crustacea of Norway, Bergen Museum 5: pp. 397420.

Sars, G.O. (1921). Copepoda supplement, Parts 5 and 6 (Cyclopoida, continued). An account of the Crustacea of Norway, Bergen Museum 7: pp. 57-80.

Schäfer, H.W. (1936). Harpacticoiden aus dem Brackwasser der Insel Hiddensee. Zoologische Jahrbücher (Systematik) 8: 546-588.

Schminke, H.K. (1981). Perspectives in the study of the zoogeography of interstitial Crustacea: Bathynellacea (Syncarida) and Parastenocarididae (Copepoda). International Journal of Speleology 11: 83-89.

Shen, C.-J. and Tai, A.-Y. (1964). Description of new species of freshwater Copepoda from Kwangtung Province, South China. Acta Zootaxonomica Sinica 1: 367-396.

Shen, C.-J. and Tai, A.-Y. (1973). Preliminary analysis of the characteristics of the harpacticoid Copepoda fauna of China and description of some new species. Acta Zoologica Sinica 19: 365-384.

Shen, C.-J., Tai, A.-Y., Zhang, C.-Z., Li, Z.-Y., Song, D.-X., Song, Y.-Z. and Chen, G.-X. (1979). Fauna Sinica, Crustacea, Freshwater Copepoda. Șcience Press, Beijing. [in Chinese]

Šrámek-Hušek, R. (1953). Naši klanonožci. Èeskoslovenská Akademie Vì d: pp. 1-64. (Praha)

Šrámek-Hušek, R. (1957). K rozšírení a ekologii Tropocyclops prasinus na Moravì. Acta Societatus Zoologicae Bohemoslovenicae 21: 159-163.

Stephanides, T. (1948). A survey of the freshwater biology of Corfu and of other regions of Greece. Praktika toi Ellenikoi Udrobiologikoi Indtitoitoi, Athens 2: 1-263.

Stoch, F. (1997). A new genus and two new species of Canthocamptidae (Copepoda, Harpacticoida) from caves in northern Italy. Hydrobiologia 350: 49-61.

Stock, J.H. and Von Vaupel Klein, J.C. (1996). Mounting media revisited: the suitability of Reyne's fluid for small crustaceans. Crustaceana 69: 794-798.

Storr, G.M. (1984). Birds of the Pilbara region, Western Australia. Records of the Western Australian Museum Supplement 16: 1-63.

Strayer, D. (1988). New and rare copepods (Cyclopoida and Harpacticoida) from freshwater interstitial habitats in southeastern New York. Stygologia 4: 279291.

Tait, R.D., Shiel, R.J. and Koste, W. (1984). Structure and dynamics of zooplanton communities, Alligator Rivers Region, N.T., Australia. Hydrobiologia 113: 1-13.

Timms, B.V. and Morton, D.W. (1988). Crustacean zooplankton assemblages in freshwater of tropical Australia. Hydrobiologia 164: 161-169. 
Tomikawa, K., Ishida, T. and Mawatari, S.F. (2005). Allocyclops (Allocyclops) austronipponicus, a new species of cyclopoid copepod (Crustacea: Cyclopoida: Cyclopidae) from Okinawa Island, Japan. Species Diversity 10: 19-26.

Ueda, H., Ishida, T. and Imai J.-I. (1996). Planctonic cyclopoid copepods from small ponds in Kyushu, Japan, I. Subfamily Eucyclopinae with descriptions of micro-characters on appendages. Hydrobiologia 333: $45-56$.

Van de Graaff, W.J.E., Crowe, R.W.A., Bunting, J.A. and Jackson, M.J. (1977). Relict Early Cainozoic drainages in arid Western Australia. Zeitschrift für Geomorphologie 21: 379-400.

Van de Velde, I. (1984). Revision of the African species of the genus Mesocyclops Sars, 1914 (Copepoda: Cyclopidae). Hydrobiologia 109: 3-66.

Vervoort, W. (1964). Free-living Copepoda from Ifaluk Atoll in the Caroline Islands. Bulletin of the Smithsonian Institution, United States National Museum 236: 1-431.

Watts, C.H.S. and Humphreys, W.F. (2004). Twenty-five new Dytiscidae (Coleoptera) of the genera Tjirtudessus Watts and Humphreys, Nirripirti Watts and Humphreys and Bidessodes Regimbart, from underground waters in Australia. Records of the South Australian Museum 36: 135-187.

Wells, J.B.J. (1967). Littoral Copepoda (Crustacea) of Inhaca Island, Mozambique. Transactions of the Royal Society of Edinburgh 67: 189-358.
Wells, J.B.J. (1973). Report on a small collection of benthic copepods from marine and brackish waters of Aldabra, Indian Ocean. Crustaceana 25: 133-146.

Whitman, R.L. (1984). Parastenocaris texana, new species (Copepoda: Harpacticoida: Parastenocarididae) from an east Texas sandy stream with notes on its ecology. Journal of Crustacean Biology 4: 695-700.

Wilson, C.B. (1932). The copepods of the Woods Hole region, Massachusetts. Bulletin of the Smithsonian Institution, United States National Museum 158; Reprinted by Antiquariaat Junk, Netherlands: 1-431. (Lochem)

Wilson, G.D.F. and Ponder, W.F. (1992). Extraordinary new subterranean isopods (Peracarida: Crustacea) from the Kimberley region, Western Australia. Records of the Australian Museum 44: 279-298.

Yager, J. and Humphreys, W.F. (1996). Lesionectes exleyi, sp. nov., the first remipede crustacean recorded from Australia and the Indian Ocean, with a key to the world species. Invertebrate Taxonomy 10: 171-187.

Yeatman, H.C. (1944). American cyclopoid copepods of the viridis-vernalis group, including a description of Cyclops carolinianus n.sp. The American Midland Naturalist 32: 1-90.

Yeatman, H.C. (1963). Some redescriptions and new records of littoral copepods from the Woods Hole, Massachusetts Region. Transactions of the American Microscopical Society 82: 197-209.

Yeatman, H.C. (1983). Copepods from microhabitats in Fiji, Western Samoa, and Tonga. Micronesica 19: 5790. 